The effects of housing density and the trade-off between housing density and sprawl area on breeding birds and carabid beetles

By

Sara A. Gagné, B.Sc.

A thesis submitted to the Faculty of Graduate Studies and Research in partial fulfillment of the requirements for the degree of

Doctor of Philosophy

Department of Biology

Carleton University

Ottawa, Ontario

June 17, 2009

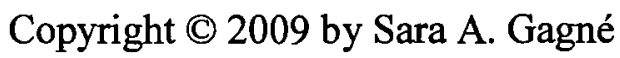




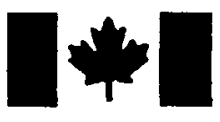

\section{Library and Archives} Canada

Published Heritage Branch

395 Wellington Street Ottawa ON K1A ON4 Canada
Bibliotheque et

Archives Canada

Direction du

Patrimoine de l'édition

395 , rue Wellington

Ottawa ON K1A ON4

Canada
Your file Votre reférence

ISBN: 978-0-494-60103-7

Our file Notre reférence

ISBN: 978-0-494-60103-7
NOTICE:

The author has granted a nonexclusive license allowing Library and Archives Canada to reproduce, publish, archive, preserve, conserve, communicate to the public by telecommunication or on the Internet, loan, distribute and sell theses worldwide, for commercial or noncommercial purposes, in microform, paper, electronic and/or any other formats.

The author retains copyright ownership and moral rights in this thesis. Neither the thesis nor substantial extracts from it may be printed or otherwise reproduced without the author's permission.
AVIS:

L'auteur a accordé une licence non exclusive permettant à la Bibliothèque et Archives Canada de reproduire, publier, archiver, sauvegarder, conserver, transmettre au public par télécommunication ou par l'Internet, prêter, distribuer et vendre des thèses partout dans le monde, à des fins commerciales ou autres, sur support microforme, papier, électronique et/ou autres formats.

L'auteur conserve la propriété du droit d'auteur et des droits moraux qui protège cette thèse. $\mathrm{Ni}$ la thèse ni des extraits substantiels de celle-ci ne doivent être imprimés ou autrement reproduits sans son autorisation.
In compliance with the Canadian Privacy Act some supporting forms may have been removed from this thesis.

While these forms may be included in the document page count, their removal does not represent any loss of content from the thesis.
Conformément à la loi canadienne sur la protection de la vie privée, quelques formulaires secondaires ont été enlevés de cette thèse.

Bien que ces formulaires aient inclus dans la pagination, il n'y aura aucun contenu manquant.

\section{Canadä}




\section{Abstract}

Given that urban populations are projected to increase well into the future, to be accompanied by rapid and dramatic changes to landscapes over broad spatial scales, an important question is how do we mitigate the impacts of this future growth on biodiversity? Specifically, how best can we accommodate a given human population in a given landscape to minimize its impacts on biodiversity? For a given human population, it is unclear whether the impacts on biodiversity are less where housing density is high and sprawl area is small or where housing density is low and sprawl area is large. In this thesis, I addressed the question 'at what housing density are the impacts of a given human population on biodiversity minimized?' using breeding birds (Chapter 1) and carabid beetles (Chapter 2). I empirically sampled both taxa in sites representing a gradient in housing density. I then estimated breeding bird and carabid beetle abundance and species richness in four hypothetical development scenarios representing the housing density/sprawl area trade-off: Undeveloped, Dispersed, Semi-compact and Compact. My results suggest that clustering development at a high housing density minimizes the impacts of a given human population on forest bird and forest beetle diversity. In Chapter 3, I used the empirical data I collected in the sites described above to determine if breeding bird responses to urbanization were indicative of those of carabid beetles. My results indicate that breeding birds and carabid beetles do not respond similarly to increasing housing density and I report novel patterns of response of the latter taxon to urbanization. The conservation implications of forest birds and forest beetles exhibiting high diversity in compact development are profound, particularly if all forest taxa share 
this response. If future development is compact rather than dispersed, the amount of habitat spared for forest taxa would potentially be enormous. Many questions in addition to those I addressed in this thesis remain to be answered in the field of urban ecology to further our understanding of the effects of urbanization and to identify the manner in which we may mitigate these effects on biological diversity. 


\section{Acknowledgements}

I especially thank Dr. Lenore Fahrig for her direction, advice and support over the last six years. Her steady guidance deftly pointed out the unlimited vistas that now lie before me in the realms of scientist, teacher, and writer. Henceforth, all my professional achievements and none of my shortcomings are due to her and my only hope is to, even for the briefest of moments, scale the heights upon which she resides and share the view.

My committee members, Dr. C. Scott Findlay and Dr. Pierre Mineau, also deserve my thanks. Both were kind enough to share their great knowledge with me and wait patiently, with flashlight in hand, as I fumbled through the often dark carverns of this thesis.

The last six years have provided me with the opportunity to interact with many kind, intelligent and creative people. Of note: Amanda Dam, Dr. Felix Eigenbrod, Leif Olson, Dr. Jochen Jaeger, Rachelle McGregor, Dr. Krista Ryall, Dr. Julie Brennan, Dr. Rebecca Tittler, Dan Bert, Dr. Raphaël Proulx, Dr. Mark Forbes, Dr. Andrew Simons, Dr. James Cheetham, Dr. Naomi Cappuccino, Dr. Kathy Lindsay, Dr. Charles Francis, Dr. Lutz Tischendorf, Dave Ladd, Neil Charbonneau, Adam Smith, Glenn Cunnington, Keith Munro, Trina Rytwinski, Patricia Summers, Ashley McClaren, Heather Coffey, and Adam Ford. Thanks for your support, friendship and all the laughs.

Those yet deserving of praise and gratitude include the staff of the Department of Biology, especially Marija Gojmerac, Anna Riethman-Gladish, Ed Bruggink, Dave Omond, Ian Babcock, Mike Weber, Joan Mallett, Joyce Cook, and Jussi Helava. You made my time at Carleton University all the more enjoyable. 
I also thank my parents, Paul and Shari Gagné, for their love and support. In all ways I am their daughter and find myself writing this because of them.

Finally, the last six years have given me not only a thesis but also the love of my life, Lucas Robertson. This thesis is dedicated to him, as is all that I do. 


\section{Table of contents}

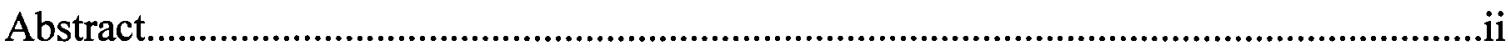

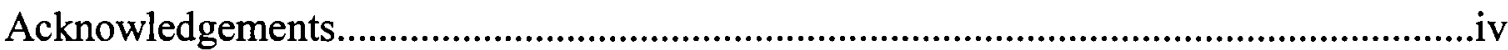

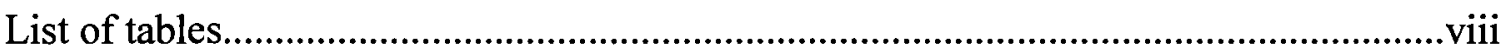

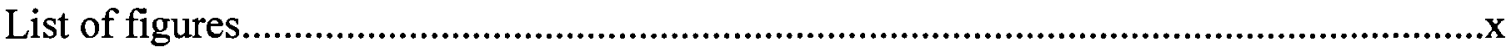

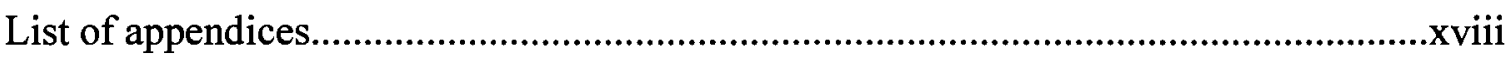

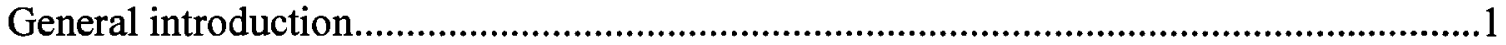

Chapter 1: The trade-off between housing density and sprawl area: minimizing impacts to forest breeding birds

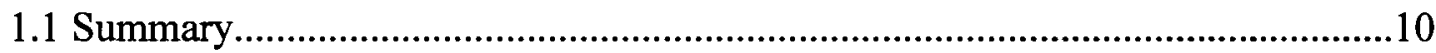

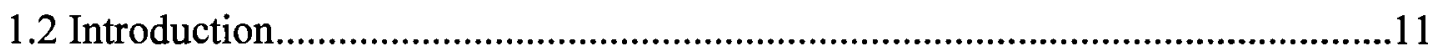

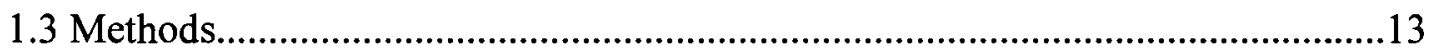

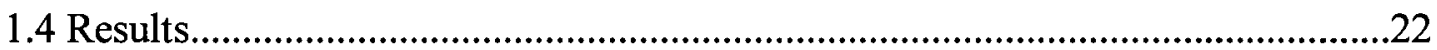

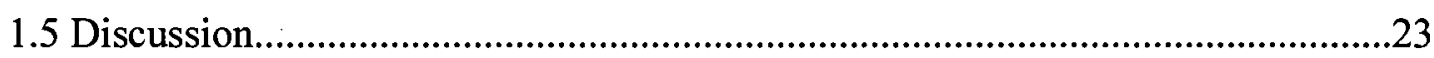

Chapter 2. The trade-off between housing density and sprawl area: minimizing impacts to carabid beetles (Coleoptera: Carabidae)

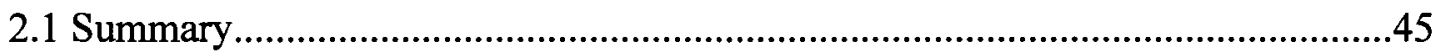

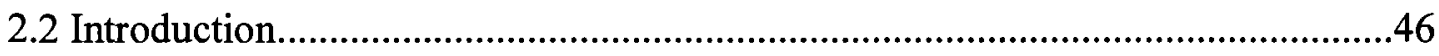

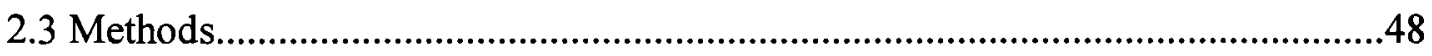

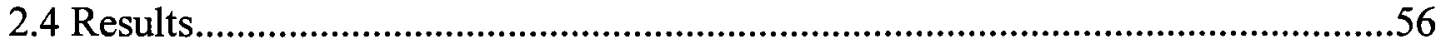

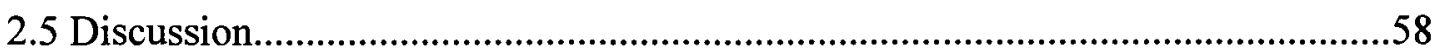

Chapter 3. Do birds and beetles show similar responses to urbanization? 


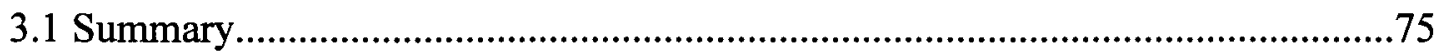

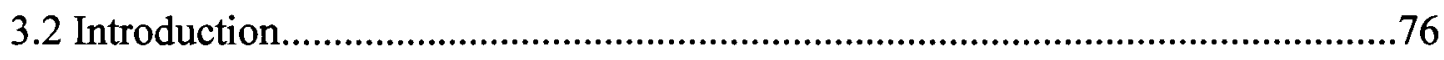

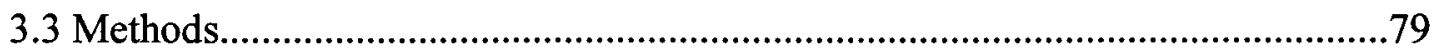

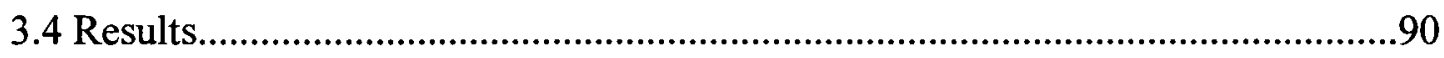

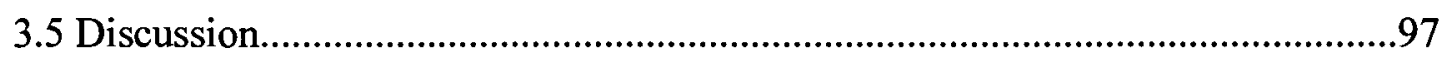

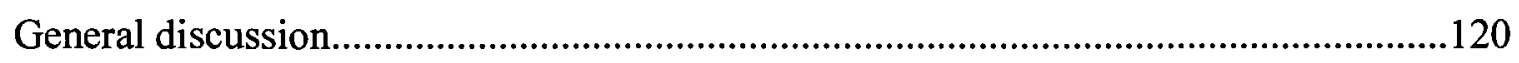

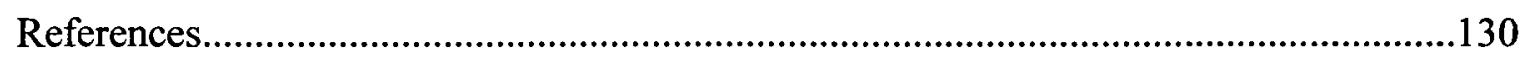

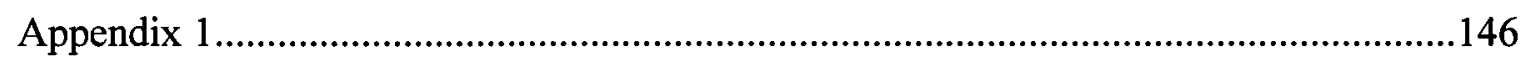

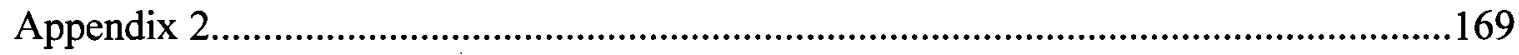

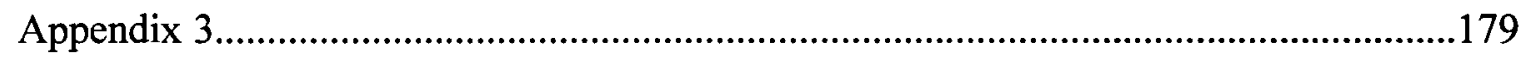

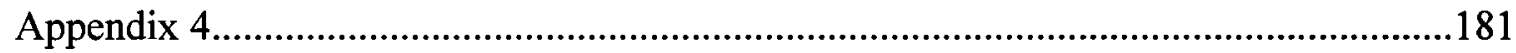

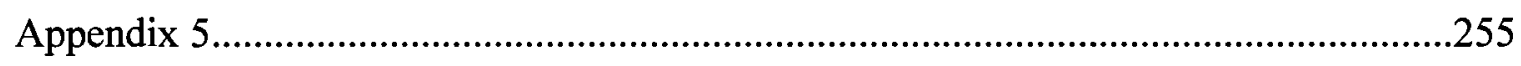

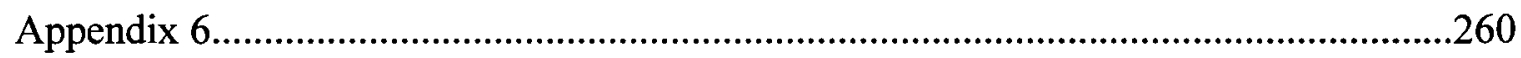

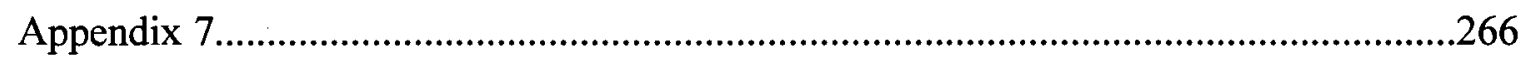

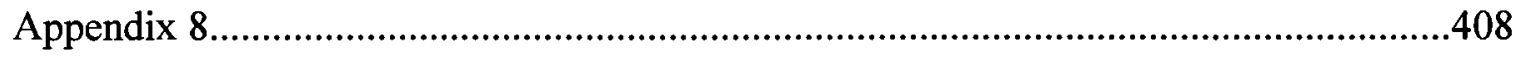

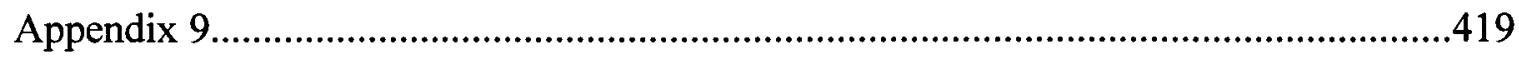




\section{List of tables}

Table 1.1. Forest bird abundance and species richness (mean $+/$ - SE) at $500 \mathrm{~m} \times 500 \mathrm{~m}$ bird survey sites in six housing categories (see 1.3 Methods for category definitions). Habitat affinities are described in Table 1.2.

Table 1.2. Forest bird species observed during point count surveys and their estimated abundances in development scenarios. Habitat affinities are based on information in Poole (2005): 'Forest interior' includes species that occur only in forest habitat, being most abundant in the forest interior and avoiding the forest edge; 'Forest edge' includes species that are most common in forest habitat but also occur in a wide range of other habitat types as well as species that occur both in the forest interior and edge. See Fig. 1.3 for descriptions of scenarios.

Table 2.1. Carabid beetle abundance and species richness (mean $+/-\mathrm{SE}$ ) at $500 \mathrm{~m}$ x 500 $\mathrm{m}$ beetle survey sites in six housing categories (see section 2.3 Methods for category definitions). The species included in each group are given in Appendix 5.

Table 3.1. The fit of three species-abundance distribution models to bird and carabid beetle community data collected at two spatial scales in seven categories of sites representing two predictor variables, housing density and neighboring housing density. Values are the percentage of best models $\left(\Delta \mathrm{AIC}_{\mathrm{c}}<2\right)$ that were geometric series, lognormal or broken stick. The number of models of each type over the total number of best models for each category and scale is given in parentheses. Increases or decreases in the prevalence of a model as housing density or neighboring housing 
density increase are indicated in bold type. F, Forested; E, Exurban; S, Suburban; U, Urban; EN, Exurban Neighbor; SN, Suburban Neighbor; UN, Urban Neighbor.

Table 3.2. Correlations (Kendall's $\tau$ ) between bird and carabid beetle variables describing community structure at two spatial scales in categories representing two predictor variables, housing density and neighboring housing density. No introduced bird species were counted in neighboring housing density categories. 


\section{List of figures}

Figure 1.1. The study area surrounding the cities of Ottawa, Ontario and Gatineau, Quebec, Canada. Inset depicts the location of the study area in eastern North America. Bird survey sites are $0.25 \mathrm{~km}^{2}$ areas indicated by symbols representing six housing categories: $\bullet$ Forested $\left(0\right.$ dwellings $\left./ \mathrm{km}^{2}\right)$, Exurban $(<56$ dwellings $\left./ \mathrm{km}^{2}\right)$, $\star$ Suburban (140-712 dwellings $\left./ \mathrm{km}^{2}\right)$, * Urban $(>1,244$ dwellings $/ \mathrm{km}^{2}$ ); and two categories of forested sites adjacent to developments of Suburban and Urban densities: - Suburban Neighbor, $\$$ Urban Neighbor. Dark gray lines indicate roads. Forest cover is in light gray.

Figure 1.2. Typical sites in which breeding birds were surveyed. All bird survey sites were $500 \mathrm{~m} \times 500 \mathrm{~m}$. Point count stations are shown as gray diamonds. (a) Example sites representing a range of housing densities; I surveyed four replicate sites of each type. (b) Example Suburban Neighbor site: the $500 \mathrm{~m}$ x $500 \mathrm{~m}$ forested bird survey site was adjacent to the same area of Suburban-density development. I surveyed three replicate Neighbor sites adjacent to each of the Suburban and Urban housing density levels.

Figure 1.3. Hypothetical development scenarios representing a gradient of increasing housing density and decreasing sprawl area. For a given forested area (the Undeveloped scenario), the same number of dwellings is depicted at three housing densities, Exurban, Suburban and Urban, resulting in dispersed, semi-compact and compact development patterns, respectively. Hatched areas represent forest habitat adjacent to development, typical of Neighbor sites. Drawings, including proportions 
of each cover type in each scenario, are not to scale. For example, the developed portion of the Semi-compact scenario was $6.18 \%$ of the total area of the scenario. Scenarios were $22.96 \mathrm{~km}^{2}$.

Figure 1.4. Illustration of the method for estimating the abundance of a typical forest bird species in a development scenario. Shown is the Semi-compact scenario (see Fig. 1.3; not to scale). Numbers represent the relative abundance of the species in each bird survey site, calculated from point count data. Three types of bird survey sites make up the Semi-compact scenario: Suburban, Forested and Suburban Neighbor. For each site area in the scenario, a relative abundance value was randomly chosen from the replicate bird survey sites in the appropriate housing category. To illustrate this, the developed portion of the scenario has been filled in with randomly chosen relative abundance values from the Suburban bird survey sites. For areas in the development scenario that are smaller than site areas, the relative abundance value was multiplied by the proportion of a site area represented. Finally, the randomly selected values for the entire Semi-compact scenario were summed to yield an estimate of the abundance of the forest bird species in the whole development scenario.

Figure 1.5. The estimated abundances of three bird groups in four hypothetical development scenarios: U, Undeveloped; D, Dispersed; SC, Semi-compact; C, Compact. (a) Forest birds. (b) Forest interior birds. (c) Forest edge birds. The species included in each group are given in Table 1.2. The lower edge of each box is the first 
quartile, the bold center line is the median and the upper edge is the third quartile of the distribution. Whiskers extend to the minimum and maximum values.

Figure 1.6. The estimated species richnesses of three bird groups in four hypothetical development scenarios: U, Undeveloped; D, Dispersed; SC, Semi-compact; C, Compact. (a) Forest birds. (b) Forest interior birds. (c) Forest edge birds. The species included in each group are given in Table 1.2. The lower edge of each box is the first quartile, the bold center line is the median and the upper edge is the third quartile of the distribution. Whiskers extend to the minimum and maximum values. Species richness estimates for the Undeveloped and Dispersed scenarios had zero variance. This is because all bird species counted in the four Forested survey sites (for the Undeveloped scenario) and the four Exurban survey sites (for the Dispersed scenario) were always estimated to be in at least one of the large number (91.83) of replicate site areas in these scenarios.

Figure 2.1. The study area surrounding the cities of Ottawa, Ontario and Gatineau, Quebec, Canada. Inset depicts the location of the study area in eastern North America. Beetle survey sites are $0.25 \mathrm{~km}^{2}$ areas indicated by symbols representing six housing categories: $\bullet$ Forested $\left(0\right.$ dwellings $\left./ \mathrm{km}^{2}\right),+$ Exurban $(<56$ dwellings $\left./ \mathrm{km}^{2}\right), \star$ Suburban (140-712 dwellings $\left./ \mathrm{km}^{2}\right)$, * Urban $(>1,244$ dwellings $/ \mathrm{km}^{2}$ ); and two categories of forested sites adjacent to developments of Suburban and Urban densities: Suburban Neighbor, $\checkmark$ Urban Neighbor. Dark gray lines indicate roads. Forest cover is in light gray.

Figure 2.2. Typical sites in which carabid beetles were surveyed. All beetle survey sites xii 
were $500 \mathrm{~m} \times 500 \mathrm{~m}$. Pit trapping stations are shown as light gray stars. (a) Example sites representing a range of housing densities; I surveyed four replicate sites of each type. (b) Example Suburban Neighbor site: the $500 \mathrm{~m}$ x $500 \mathrm{~m}$ forested beetle survey site was adjacent to at least $500 \mathrm{~m} \times 500 \mathrm{~m}$ of Suburban-density development. I surveyed three replicate Neighbor sites adjacent to each of the Suburban and Urban housing density levels.

Figure 2.3. Hypothetical development scenarios representing a gradient of increasing housing density and decreasing sprawl area. For a given forested area (the Undeveloped scenario), the same number of dwellings is depicted at three housing densities, Exurban, Suburban and Urban, resulting in dispersed, semi-compact and compact development patterns, respectively. Hatched areas represent forest habitat adjacent to development, typical of Neighbor sites. Drawings, including proportions of each cover type in each scenario, are not to scale. For example, the developed portion of the Semi-compact scenario was $6.18 \%$ of the total area of the scenario. Scenarios were $22.96 \mathrm{~km}^{2}$.

Figure 2.4. Illustration of the method for estimating the abundance of a carabid beetle species in a development scenario. Shown is the Semi-compact scenario (see Fig. 2.3; not to scale). Numbers represent the relative abundance of the species in each beetle survey site, calculated from pitfall trap data. Three types of beetle survey sites make up the Semi-compact scenario: Suburban, Forested and Suburban Neighbor. For each site area in the scenario, a relative abundance value was randomly chosen from the replicate beetle survey sites in the appropriate housing category. To 
illustrate this, the developed portion of the scenario has been filled in with randomly chosen relative abundance values from the Suburban beetle survey sites. For areas in the development scenario that are smaller than site areas, the relative abundance value was multiplied by the proportion of a site area represented. Finally, the randomly selected values for the entire Semi-compact scenario were summed to yield an estimate of the abundance of the carabid beetle species in the whole development scenario.

Figure 2.5. The estimated abundances of five carabid beetle groups in four hypothetical development scenarios: U, Undeveloped; D, Dispersed; SC, Semi-compact; C, Compact. (a) All beetles. (b) Forest beetles. (c) Open-habitat beetles. (d) Native beetles. (e) Introduced beetles. The species included in each group are given in Appendix 5. The lower edge of each box is the first quartile, the bold center line is the median and the upper edge is the third quartile of the distribution. Whiskers extend to the minimum and maximum values.

Figure 2.6. The estimated species richnesses of three carabid beetle groups in four hypothetical development scenarios: U, Undeveloped; D, Dispersed; SC, Semicompact; C, Compact. (a) All beetles. (b) Forest beetles. (c) Open-habitat beetles. The species included in each group are given in Appendix 5. The lower edge of each box is the first quartile, the bold center line is the median and the upper edge is the third quartile of the distribution. Whiskers extend to the minimum and maximum values. Species richness estimates for the Undeveloped and Dispersed scenarios had zero variance. This is because all beetle species collected in the four Forested survey 
sites (for the Undeveloped scenario) and the four Exurban survey sites (for the Dispersed scenario) were always estimated to be in at least one of the large number (91.83) of replicate site areas in these scenarios.

Figure 3.1. The study area surrounding the cities of Ottawa, Ontario and Gatineau, Quebec, Canada. Inset depicts the location of the study area in eastern North America. Sites are $0.25 \mathrm{~km}^{2}$ areas indicated by symbols representing four housing density categories: - Forested $\left(0 \mathrm{dwellings} / \mathrm{km}^{2}\right),+$ Exurban $\left(<56 \mathrm{dwellings} / \mathrm{km}^{2}\right)$, Suburban (140-712 dwellings $\left./ \mathrm{km}^{2}\right), *$ Urban ( $>1,244$ dwellings $\left./ \mathrm{km}^{2}\right)$; and three categories of forested sites adjacent to developments of Exurban, Suburban and Urban densities, respectively: $\boldsymbol{\Delta}$ Exurban Neighbor, a Suburban Neighbor, Urban Neighbor. Dark gray lines indicate roads. Forest cover is in light gray.

Figure 3.2. Typical sites in which breeding birds and carabid beetles were surveyed. Sites were $500 \mathrm{~m} \times 500 \mathrm{~m}$. Bird point count stations are depicted as light gray diamonds. Beetles were pitfall trapped at stations depicted by light gray diamonds and stars. (a) Example sites representing a range of housing densities; I surveyed four replicate sites of each type. (b) Example Suburban Neighbor site. The $500 \mathrm{~m} \mathrm{x}$ $500 \mathrm{~m}$ forested site, in which birds and beetles were surveyed, is adjacent to at least $500 \mathrm{~m} \times 500 \mathrm{~m}$ of Suburban-density development. I surveyed three replicate Neighbor sites adjacent to each of the Exurban, Suburban and Urban housing density levels.

Figure 3.3. The abundance (a) and species richness (b) of forest birds and carabid beetles 
and the abundance of introduced birds and carabid beetles (c) in Forested (F), Exurban (E), Suburban (S) and Urban (U) sites. Dark gray bars represent forest interior birds in (a) and (b) and introduced birds in (c). Light gray bars represent forest edge birds and open bars represent carabid beetles. Habitat affinities are described in the text. Different lowercase letters above bars indicate significant pairwise differences between site categories within each taxon and habitat affinity group.

Figure 3.4. The locations of bird (a) and carabid beetle (b) species scores from redundancy analyses with housing density as a predictor. The centroids of the Forested (F), Exurban (E), Suburban (S) and Urban (U) housing density categories are also shown.

Figure 3.5. The $k$-dominance curves of birds (a) and carabid beetles (b) at two spatial scales. Each curve represents the data collected at a single site or station. Forested sites and stations are shown in pale gray, Exurban sites and stations are shown in medium gray, Suburban sites and stations are shown in dark gray and Urban sites and stations are shown in very dark gray. A community is considered to exhibit a greater degree of dominance (by a single species) than another community if its $k$ dominance curve lies above and never intersects that of the other community.

Figure 3.6. Additive partitioning of bird and carabid beetle diversity in housing density (a) and neighboring housing density (b) categories. Dark gray bars are the average station species richness $\left(\alpha_{1}\right)$, light gray bars are the average species richness among stations $\left(\beta_{1}\right)$ and open bars are the average species richness among sites $\left(\beta_{2}\right)$. F, 
Forested; E, Exurban; S, Suburban; U, Urban; EN, Exurban Neighbor; SN, Suburban Neighbor; UN, Urban Neighbor.

Figure 3.7. Non-metric multidimensional scalings of bird and carabid beetle community data collected in Forested (F), Exurban (E), Suburban (S), Urban (U), Exurban Neighbor (EN), Suburban Neighbor (SN) and Urban Neighbor (UN) sites. The ordination of sites with respect to housing density is shown in (a) and with respect to neighboring housing density in (b).

Figure 3.8. The Kulczynski distance between pairs of Forested (F), Exurban (E), Suburban (S) and Urban (U) sites. The Kulczynski distance between two sites is calculated by summing species abundance minima and dividing this value by each site's total abundance. One minus the average of these two values is the distance between the two sites. Dark gray bars represent the distances between bird communities and open bars represent those between carabid beetle communities. Different lowercase letters above bars indicate significant pairwise differences between site categories for each taxon. 


\section{List of appendices}

Appendix 1. Forest breeding bird relative abundances in survey sites and stations.

Appendix 2. The estimated abundances of 39 forest bird species in four hypothetical development scenarios: U, Undeveloped; D, Dispersed; SC, Semi-compact; C, Compact. The lower edge of each box is the first quartile, the bold center line is the median and the upper edge is the third quartile of the distribution. Whiskers extend to the minimum and maximum values.

Appendix 3. The estimated abundances of open woodland birds, the American Crow Corvus brachyrhynchos, the Common Grackle Quiscalus quiscula and the Brownheaded Cowbird Molothrus ater in four hypothetical development scenarios: U, Undeveloped; D, Dispersed; SC, Semi-compact; C, Compact. Open woodland birds are species observed during point counts at bird survey sites that are adapted to open areas interspersed with large trees according to Poole (2005). The lower edge of each box is the first quartile, the bold center line is the median and the upper edge is the third quartile of the distribution. Whiskers extend to the minimum and maximum values.

Appendix 4. Carabid beetle relative abundances in survey sites and stations.

Appendix 5. Carabid beetle species collected during pitfall trapping and their estimated abundances in development scenarios. I classified beetles as 'native', 'introduced', 'forest' and 'open-habitat' species according to Lindroth (1961-1969). I defined forest species as those that occur primarily in forested or wooded habitat, and in some cases open country. I defined open-habitat species as those occurring in a xviii 
variety of open-habitat types (e.g., open woods, meadows, fields) including roadsides, gravel pits and cultivated ground. If the habitat affinity of a species was not recorded in Lindroth (1961-1969), I classified the species according to H. Goulet (Agriculture and Agri-Food Canada, pers. comm.) with two exceptions. The habitat affinity of Cicindela sexguttata was determined according to Schultz (1998) and the habitat affinity of Trichotichnus vulpeculus was determined according to Stanton et al. (2003) and Webster and Bousquet (2008).

Appendix 6. Native breeding bird and carabid beetle species classified as 'forest interior', 'forest edge', 'forest' or 'open-habitat' species. Introduced bird and beetle species are also listed.

Appendix 7. Breeding bird and carabid beetle relative abundances in sites and stations.

Appendix 8. Scatterplots of breeding bird and carabid beetle variables describing community structure.

Appendix 9. The locations of Suburban Neighbor $(\boldsymbol{m})$ and Urban Neighbor $(\checkmark)$ sites in the study area. Exurban Neighbor sites are represented by the symbol $\Delta$ and Forested sites are represented by the symbol $\bullet$. Dark gray lines indicate roads. Forest cover is in light gray. 


\section{General introduction}

Over the last 60 years, urbanization has become an important driver of land cover change in North America. The populations of modern cities, such as New York, grew rapidly in the $19^{\text {th }}$ century and the first three decades of the $20^{\text {th }}$ century as rural dwellers moved into city centers to take part in the new industrialized economy. The decades following the Great Depression and the Second World War were also characterized by a large shift in population in North America. In response to the high demand for affordable housing for returning veterans and their families, the U.S. Government created new housing programs accompanied by tax incentives and mortgage subsidies. The result was 1.2 million new housing starts every year from 1947 to 1964 in that country (Teaford 1993). Most of these new units were single-family homes built on agricultural or forested land surrounding older city centers. This trend has continued to the present, with the United States' suburban population increasing from a quarter of the total population in 1950 to just over one half in 2000 (Platt 2004). A similar trend, although at a smaller scale, has also occurred in Canada. Thus, over the last six decades, a large land area in North America has been transformed from forested and agricultural covers to residential land cover. Brown et al. (2005) estimated that nearly $25 \%$ of the land area of the conterminous United States is now covered by low-density residential development. Land cover change at this spatial scale has resulted in large amounts of habitat loss and fragmentation. For example, in the U.S. Midwest, $54 \%$ of forests are now within $5 \mathrm{~km}$ of settlements with $>8$ housing units $/ \mathrm{km}^{2}$ (Radeloff et al. 2005 
These patterns are reflected in Canada' capital city, Ottawa. Urban growth in Ottawa is characterized by its greenbelt, 20,000 hectares of federally owned land separating the older city center from suburban and rural areas. Between 1971 and 1996, the population and the number of dwellings inside the greenbelt increased by $16 \%$ and $63 \%$, respectively (City of Ottawa 2008). During the same period, in Ottawa's suburban centers and rural areas, populations and dwelling counts exploded, increasing by $327 \%$ and $429 \%$ respectively (City of Ottawa 2008). In addition, the housing density outside the greenbelt is just over half that inside the greenbelt ( 345 dwellings $/ \mathrm{km}^{2}$ outside compared to 568 dwellings $/ \mathrm{km}^{2}$ inside) (City of Ottawa 2008).

The growth of urban populations - those inhabiting areas with at least 1,000 inhabitants and a population density of at least 400 persons $/ \mathrm{km}^{2}$ (United Nations 2008) is projected to continue, although the majority of change will be in the developing rather than the developed world. The global human population is projected to reach 9.2 billion by $2050,70 \%$ of whom will live in urban areas (United Nations 2008). By 2050, the urban population in less developed regions of the world will have increased by $135 \%$, far surpassing the projected increase of $19 \%$ for more developed regions (United Nations 2008). In China and India, where global economic development is increasingly focused, urban populations will increase by $94 \%$ and $181 \%$ by 2050 , respectively (United Nations 2008). In contrast, the urban populations of Canada and the United States will each increase by approximately $50 \%$ by 2050 (United Nations 2008). These trends are 
worrisome if population growth occurs outside of established metropolitan areas in developing countries, which are home to the majority of the Earth's species.

Such extensive land cover change has prompted the creation of the field of urban ecology. Urban ecology is the study of the ecology of urban areas, broadly defined as those where agriculture is not the primary industry. The extensive changes to climate, the geophysical environment, habitats and disturbance regimes that urbanization engenders have prompted urban ecologists to move away from the traditional study of pristine ecosystems to the study of human-dominated environments and the inclusion of humans as components in 'urban ecosystems'. To this end, two U.S. Long Term Ecological Research sites were recently created in Phoenix and Baltimore to study the ecology of these cities and the explicit role that humans play within them (Grimm et al. 2000).

The study of the effects of urbanization on animal communities has been ongoing since the late 1960s, with a particular focus on birds. Birds are a natural choice of model organism with which to study the effects of urbanization. A large, detailed body of research on bird ecology exists from which to draw to understand the effects of urbanization on birds. In addition, birds are declining globally. Şekercioğlu et al. (2004) found that $21 \%$ of the 9,916 bird species worldwide that have survived past the year 1500 are currently extinction-prone. The evident changes in bird communities wrought by urbanization would also have piqued the curiosity of ecologists, engendering decades of research on the ecology of urban birds. A classic study of the effects of urbanization on birds compared communities in a mature residential development and a climax beech- 
maple forest (Beissinger \& Osborne 1982). Beissinger and Osborne (1982) found that the bird community in Oxford (the residential development) was less diverse, less even and had greater total biomass than the bird community in Hueston Woods (the forest). The diet and foraging behavior of birds also differed between Oxford and Hueston Woods. Oxford's bird community had more seedeaters and omnivores that foraged on the ground and fewer foliage-gleaning insectivores than Hueston Woods. The authors concluded that the high proportion of lawns in Oxford, rich in resources and allowing for increased predator avoidance due to increased visibility, favored ground-foraging flocking species. In contrast, an increase in the level of human disturbance and reductions in vegetative cover and the number of insect species able to colonize exotic ornamental trees in Oxford resulted in the declines of many bird species typical of Hueston Woods.

McDonnell and Pickett's (1990) paper arguing for the application of the gradient paradigm to the study of the ecology of urban areas had a profound influence on future research in the field. The authors suggested that the spatial pattern of urbanization, highdensity city centers surrounded by irregular rings of decreasing development, could be considered a gradient of environmental variation that could be used to explain variation in ecological patterns and processes. In addition, they argued that urbanization resulted in novel changes to the environment, such as changes in disturbance regimes, pollution levels and landscape structure, which could be exploited to increase our understanding of ecological systems. McDonnell and Pickett's (1990) work prompted much research on urban gradients, a classic and oft-cited example being Blair (1996). Blair (1996) 
characterized the land cover and avian communities of six sites along an urban gradient in Palo Alto, California. Blair (1996) reported intermediate peaks in species richness, diversity and density along the gradient and the highest biomass in the most highly developed of the sites, the business district. Blair (1996) also coined the terms 'urban avoiders' for species that reached their maximum density in the least developed site, the biological preserve, 'suburban adaptable' for species that reached their maximum density in the middle of the gradient, and 'urban exploiters' for species that were most dense in the business district. He found that the best predictors of bird community composition along the gradient were the amount of cover in buildings, lawns, and trees and shrubs. Blair (1996) concluded that moderate levels of development increase the amount and diversity of resources available to birds, resulting in the intermediate peaks in species richness and density along the gradient. Since Blair's (1996) study, others have also reported declines in native specialist bird abundance and species richness and increases in introduced bird abundance and species richness with increasing urbanization at a variety of spatial scales (Germaine et al. 1998, Kluza et al. 2000, Miller et al. 2003, Pidgeon et al. 2007, Pennington et al. 2008). Both monotonically decreasing and humped-shaped responses of bird species richness to increasing urbanization have been observed (Lepczyk et al. 2008).

Carabid beetles (Coleoptera: Carabidae) are becoming increasingly the focus of studies of the effects of urbanization, prompted by the creation of the GLOBENET program in the late 1990s (Niemelä et al. 2000). The GLOBENET program is a multi- 
national research effort to understand and mitigate the effects of urbanization on one particular taxon, carabid beetles. GLOBENET studies use a standard protocol to sample carabid beetles in forested fragments surrounded by three land use treatments: rural, suburban and urban (Niemelä et al. 2000). The first GLOBENET study compared carabid beetle communities in three countries: Bulgaria, Canada and Finland (Niemelä et al. 2002). The responses of total beetle abundance and species richness to the urban gradient differed among the three countries: abundance and species richness did not change significantly with increasing urbanization in Bulgaria, abundance (including introduced species) and native species richness increased with increasing urbanization in Canada, and abundance decreased and species richness increased with increasing urbanization in Finland. The urban beetle communities in Canada and Finland were both dominated by single species but this was not the case in Bulgaria. Finally, beetle body size decreased with increasing urbanization in Bulgaria and Finland but not in Canada. Additional GLOBENET studies have expounded on Niemelä et al.'s (2002) work, finding that increasing surrounding urbanization generally results in lower carabid total abundance, either unchanged or lower total species richness, lower forest specialist abundance and species richness and higher generalist and open-habitat abundance and species richness in forest fragments (Ishitani et al. 2003, Magura et al. 2004, Sadler et al. 2006, Elek \& Lövei 2007, Gaublomme et al. 2008, Magura et al. 2008). In addition, it appears that body size and the number of short-winged species decrease in forest fragments 
surrounded by increasing urbanization (Magura et al. 2004, 2006, Sadler et al. 2006, Elek \& Lövei 2007).

Ecological research in human-dominated environments can take two forms: the description of ecological patterns and processes and the study of methods to mitigate human alterations to ecological patterns and processes of interest. Urban ecology to date has been dominated by studies describing patterns and processes along the urban gradient (McDonnell \& Hahs 2008). Some studies have identified local mechanisms to mitigate the impacts of urban development on animal communities (e.g., suburban properties dominated by native plant cover, rather than traditional non-native plant cover, have greater lepidopteran and avian abundance and species richness (Burghardt et al. 2009)) but few have addressed the larger-scale question of how to mitigate the impacts of a given human population on native biodiversity. Given that urban populations are projected to increase well into the future (see above), to be accompanied by rapid and dramatic changes to landscapes over broad spatial scales, an important question is how do we mitigate the impacts of this future growth on native biodiversity? Specifically, how best can we accommodate a given human population in a given landscape to minimize its impacts on native biodiversity? For a given human population, are the impacts to native biodiversity lessened by building at low density over a large area or at high density over a small area? Several authors have called for research to address this question (Marzluff et al. 2001, Sutherland et al. 2009) but to date only a few examples doing so exist. Lenth et al. (2006) compared plant and animal communities in clustered and dispersed 
developments in Colorado and found no significant differences between development types. Mcdonald et al. (2008) projected that future compact urban growth (50\% less per capita consumption of urban land than at present) would result in fewer rare species affected by urbanization by 2030 compared to the baseline scenario (a continuation of current growth trends). Conversely, more rare species would be affected by urbanization by 2030 if future growth were dispersed (50\% more per capita consumption of urban land than at present).

In this thesis, I addressed the question 'at what housing density are the impacts of a given human population on native biodiversity minimized?' using breeding birds (Chapter 1) and carabid beetles (Chapter 2) in Ottawa, Ontario and Gatineau, Quebec, Canada. I empirically sampled both taxa in sites representing a gradient in housing density. I then estimated breeding bird and carabid beetle abundance and species richness in four hypothetical development scenarios representing the trade-off between housing density and sprawl area: Undeveloped, Dispersed, Semi-compact and Compact. My results show that both forest birds and forest beetles are most abundant and speciose when a given human population is accommodated in a landscape at a high density over a small area rather than at a low density over a large area. My thesis is the first to report a difference in breeding bird abundance and species richness among development patterns and the first to use carabid beetles to address the question above. In Chapter 3, I used the empirical data I collected in the sites described above to determine if breeding bird responses to urbanization were indicative of those of carabid beetles. The majority of the 
research on the effects of urbanization on animal communities has been carried out on birds (McDonnell \& Hahs 2008) and consequently, our understanding of how urbanization affects biodiversity is primarily based on birds. This prompted me to use the bird and beetle data I collected at the same sites over a range of housing densities to determine if the generalizations of the effects of urbanization on birds that have emerged from the large literature on urban bird communities could also be applied to ground beetles. In fact, my thesis is the first to sample carabid beetles in the urban matrix. My results indicate that breeding birds and carabid beetles do not respond similarly to increasing housing density and I report novel patterns of response of the latter taxon to urbanization. Finally, I performed the majority of the work described in this thesis. Dr. Lenore Fahrig contributed significantly during the conception and writing phases of the three chapters described herein. 


\section{Chapter 1. The trade-off between housing density and sprawl area: minimizing impacts to forest breeding birds}

\subsection{Summary}

Increasing housing density is generally assumed to confer negative effects on native breeding birds. This implies we should build at low density over the landscape to conserve these species. However, for a given human population, low-density development must cover a large area, resulting in sprawl. A pertinent question is then: at what housing density are the impacts of a given human population on native biodiversity minimized? For a given human population, it is unclear whether the impacts on native biodiversity are less where housing density is high and sprawl area is small or where housing density is low and sprawl area is large. I addressed this question using the abundance and species richness of forest birds in Ottawa, Ontario and Gatineau, Quebec, Canada. My methodology can be described in two parts. First, I counted breeding birds at 22 sites representing a range of housing densities. Second, I used these empirical measurements to estimate forest bird abundance and species richness in four hypothetical development scenarios representing the trade-off between housing density and sprawl area. With the exception of the Undeveloped scenario, forest birds and forest interior birds were most abundant in the Compact scenario and most speciose in the Semicompact scenario, whereas forest edge birds were most abundant and speciose in the Dispersed scenario. I conclude that compact housing development (building at high 
density over a small area) minimizes the impacts of a given human population on forest breeding birds. I suggest that future housing development at the periphery of urban centers be constructed as nodes of compact developments linked with each other and the urban center by roads and surrounded primarily by forested or other natural habitat.

\subsection{Introduction}

Urban populations in both the United States and Canada have increased by more than $130 \%$ since 1950 and are projected to increase by a further $50 \%$ by 2050 (United Nations 2008). A recent trend has been increased exurban development, or low-density housing typically occurring in rural areas on the outskirts of large metropolitan centers. For example, of the land area converted to housing in the United States between 1994 and $1997,80 \%$ occurred outside large metropolitan areas and $57 \%$ of this was at very low densities (one house on 10 or more acres) (Heimlich \& Anderson 2001). Brown et al. (2005) estimated that nearly a quarter of the land surface of the conterminous United States is now covered by exurban development.

An early and continuing trend in the study of urban ecology has been the description of biological patterns, particularly those of birds, along a gradient of increasing urbanization. Initial studies were comparative (e.g., Beissinger \& Osborne 1982), followed by more complex investigations into the relationships between bird community composition and variables describing human settlements at local and landscape scales, such as the composition and configuration of land covers/land uses, housing density and 
building age (e.g., Germaine et al. 1998, Miller et al. 2003, Pidgeon et al. 2007, Lepczyk et al. 2008). An emerging generalization from these studies is that an increase in housing density results in a decrease in the abundance and species richness of native birds.

These findings could be interpreted to suggest that, to conserve native biodiversity, we should build at low density over the landscape. However, to accommodate a given human population, low-density development must cover a large area, resulting in sprawl and significant negative impacts to native plant and animal communities (Odell \& Knight 2001, Maestas et al. 2003, Hansen et al. 2005). A pertinent question is then: at what housing density are the impacts of a given human population on native biodiversity minimized? For a given human population, it is unclear whether the impacts on native biodiversity are less where housing density is high and sprawl area is small or where housing density is low and sprawl area is large.

I evaluated this trade-off using the abundance and species richness of forest breeding birds in Ottawa, Ontario and Gatineau, Quebec, Canada. My methodology can be described in two parts. First, I counted breeding birds in sites of the same size representing a range of housing densities. Second, I used these empirical data to estimate the abundance and species richness of forest breeding birds in four hypothetical development scenarios representing the trade-off between housing density and sprawl area. Development scenarios were hypothetical forested landscapes of the same size that accommodated a given human population at different housing densities, resulting in dispersed, semi-compact and compact development patterns (an undeveloped scenario 
was also created for comparison). I identified the housing density that minimized the impacts of a given human population on forest breeding birds by comparing abundance and species richness estimates among scenarios.

\subsection{Methods}

\subsubsection{Bird abundance data collection}

\subsubsection{Study area}

I sampled breeding bird populations at 22 sites in and around Ottawa, Ontario and Gatineau, Quebec, Canada (Fig. 1.1). The study area encompassed approximately 4,040 $\mathrm{km}^{2}$ on both sides of the Ottawa River. The northern half of the study area forms part of the Southern Laurentians ecoregion of Quebec and is underlain by the Canadian Shield, composed mainly of massive Precambrian granite and gneiss. Elevation is commonly 300-600 $\mathrm{m}$ above sea level. The St. Lawrence Lowlands ecoregion is south of the Ottawa River and is underlain by flat-lying Palaeozoic strata with elevations rarely more than $150 \mathrm{~m}$ above sea level. All housing categories (see below) were approximately equally represented in both ecoregions to account for possible differences in forest composition (Fig. 1.1). In addition, I tested a posteriori for differences in tree community composition between ecoregions using a redundancy analysis. The single constrained eigenvalue was not significant (100 permutations, $F_{l, 2}=2.37, p=0.29$ ).

\subsubsection{Site selection}


I selected four sites in each of four housing density categories: Forested ( 0 dwellings $/ \mathrm{km}^{2}$ ), Exurban ( $<56$ dwellings $/ \mathrm{km}^{2}$, mean $=31+/-9$ (SE) dwellings $/ \mathrm{km}^{2}$ ), Suburban (140-712 dwellings $/ \mathrm{km}^{2}$, mean $=555+/-101(\mathrm{SE})$ dwellings $\left./ \mathrm{km}^{2}\right)$ and Urban $\left(>1,244\right.$ dwellings $/ \mathrm{km}^{2}$, mean $=3,754+/-492$ (SE) dwellings $/ \mathrm{km}^{2}$ ) (Fig. 1.2a). Each site comprised the area within a $500 \mathrm{~m} \times 500 \mathrm{~m}$ square $\left(0.25 \mathrm{~km}^{2}\right)$. In addition to these 16 sites, I selected six forested sites, equal in size to those described above, adjacent to developments of Suburban and Urban housing densities (three sites each) (Fig. 1.2b). In contrast to the Forested sites which were embedded in a larger forested area, these Neighbor sites were chosen to incorporate the possible effects of adjacent urban development on breeding bird populations in forest habitat.

I searched for sites using a combination of historical topographic maps ( $1 / 50,000$, currently produced by the Centre for Topographic Information, Natural Resources Canada, Ottawa, Ontario, Canada) and the most recent aerial photographs available (2002, 1/15,000, produced by the City of Ottawa, Ontario, Canada). Using topographic maps, I located areas that were forested prior to development. I then checked the present housing density of these areas on aerial photographs to determine whether they could be placed into my pre-defined categories. In this way, I selected sites that were not subjected to agricultural use for at least as many years as topographic maps have been produced (approximately 80 years). No other land use, with the exception of urbanization and recreation, occurred at my sites. I also attempted to standardize development age among sites. Unfortunately, Urban sites that were forested prior to development were 
rare, forcing me to select two sites that were developed in the early $19^{\text {th }}$ century. The remainder of the sites were developed between 1922 and the present, with most development occurring in the 1960s. I minimized edge effects by choosing only sites that were surrounded by $>100 \mathrm{~m}$ of development of a similar housing density or forest cover, depending on the category. Due to the scarcity of sites satisfying the above criteria, I was unable to choose sites representing only one forest type. Instead, my sites represented a variety of mature forest types found in the area, such as beech Fagus grandifolia-maple Acer saccharum and cedar Thuya occidentalis-fir Abies balsamea-spruce Picea mariana communities. However, all of my housing categories included a similar representation of forest types, effectively controlling for the variability in forest composition among sites. Site selection was conditional upon landowner consent. Finally, I ground-truthed all sites to ensure they met my criteria. The number of dwellings at each site and in $500 \mathrm{~m} \times 500$ $\mathrm{m}$ developed areas adjacent to Neighbor forest sites were counted on the ground in August 2006.

\subsubsection{Breeding bird surveys}

I counted breeding birds at four stations in each site using the Ontario Forest Bird Monitoring Program protocol (Cadman et al. 1998). At each site, I centered a station in each quarter; stations were thus $250 \mathrm{~m}$ apart (Fig. 1.2). I conducted two point count surveys at each station in 2006, the first between May 24 and June 6 and the second between June 13 and June 28. During each period, I surveyed two sites per day with the exception of one day when I surveyed three sites. Each day, I chose sites from different 
categories and points on the urbanization gradient and as far as possible from one another. The order of sites surveyed per day was reversed between the two surveys to minimize any time-of-day bias in the data. I visited stations within sites in the same order during both surveys.

During each survey, I conducted a 10-minute point count at each station between a half-hour before sunrise and five hours after sunrise. I only performed point counts when the wind was $<3$ on the Beaufort scale and it was not raining. If these conditions were not met, I cancelled the count(s) and resumed on the next possible day. I counted all adult birds seen or heard during the 10-minute period at an unlimited distance from the station. I did not include birds flying at a high altitude and obviously passing over the site.

\subsubsection{Comparison of development scenarios}

\subsubsection{Hypothetical development scenarios}

I used the data described above to estimate forest bird abundance and species richness along a gradient of increasing housing density and decreasing sprawl area. I represented this gradient with hypothetical development scenarios (Fig. 1.3). Development scenarios can be envisioned as forested landscapes of the same size, into which the same number of dwellings were placed, but in contrasting patterns. One end of the gradient, where housing density is low and sprawl area is large, was represented by the Dispersed scenario, which was completely covered by Exurban-density development. The other end of the gradient, where housing density is high and sprawl area is small, was represented by the Compact scenario. The Compact scenario was home to the same number of 
dwellings as the Dispersed scenario but the dwellings were clustered at an Urban density and the remainder of the Compact scenario was undeveloped forest. I also estimated forest bird abundance and species richness for an intermediate development scenario, the Semi-compact scenario. The same number of dwellings as in the other two development scenarios was represented at a Suburban density, with the remainder of the Semi-compact scenario in undeveloped forest. Finally, for comparison, I estimated forest bird abundance and species richness for an Undeveloped scenario, i.e., the same area as for the developed scenarios but covered entirely in forest.

I defined a development scenario as a $22.96 \mathrm{~km}^{2}$ square area, or an area equivalent to 91.83 units of the $500 \mathrm{~m} \times 500 \mathrm{~m}\left(0.25 \mathrm{~km}^{2}\right)$ bird survey sites. I arrived at this development scenario size by calculating the area required to accommodate a given number of dwellings (the mean number of dwellings at my Urban and Urban Neighbor bird survey sites (712 dwellings)) at the lowest housing density (the Exurban density, mean $=31 \mathrm{dwellings} / \mathrm{km}^{2}$ ). In this way, I created the Dispersed scenario, covered entirely by 712 dwellings at the Exurban housing density or, equivalently, 91.83 Exurban bird survey sites. In a similar fashion, I determined the size of the developed area (measured in $\mathrm{km}^{2}$ or in the number of Suburban or Urban bird survey sites) within the Semi-compact and Compact scenarios. For these, I created square developed areas positioned in one corner of each development scenario, to represent the area needed to contain 712 dwellings at the mean Urban or Suburban densities $\left(0.25 \mathrm{~km}^{2}\right.$ and $1.42 \mathrm{~km}^{2}$, respectively). For the Semi-compact and Compact scenarios, I assumed that the forest 
cover adjacent to the developed area had forest bird abundances and species richnesses typical of my Neighbor bird survey sites adjacent to Suburban- and Urban-density development, respectively. I calculated the area of this adjacent forest cover as the number of Neighbor bird survey sites required to line both edges of the developed area. This pattern matches the spatial arrangement of my Neighbor bird survey sites, which shared one complete edge with development (Fig. 1.2b). Finally, I assumed that the remaining area in the Semi-compact and Compact scenarios was typical of my Forested bird survey sites. I assumed the Undeveloped scenario was covered entirely in forest cover typical of my Forested bird survey sites.

\subsubsection{Theoretical forest bird species abundances}

I estimated the abundance of each forest bird species observed during my breeding bird surveys (Table 1.2) for each development scenario. First I calculated the relative abundance of a species at each bird survey site by summing the counts of the species at all four stations in the site during each survey period and selecting the maximum survey count as the relative abundance of the species at the site (Appendix 1). Recall that I measured the area of each development scenario in terms of the numbers of bird survey sites of each housing category making up the development scenario (see above). Therefore, to estimate the total abundance of a species for a development scenario, I moved through the scenario, one site area at a time, and randomly selected a relative abundance for the species from one of the three or four bird survey sites in that housing category (Fig. 1.4). For areas in the development scenario making up proportions of bird 
survey sites, I multiplied the randomly selected abundance value by that proportion. I summed these 91.83 relative abundance values to yield the estimated abundance of a species in the whole development scenario. For example, Fig. 1.4 depicts the estimation of the abundance of a forest bird species in the Semi-compact scenario. The Semicompact scenario is shown as the equivalent area of many bird survey sites in three different categories: Suburban, Suburban Neighbor and Forested. For each site area in the Semi-compact scenario, a relative abundance value for the bird species was randomly selected from among the replicate relative abundance values of the bird survey sites in that housing category. For instance, the developed portion of the Semi-compact scenario has been 'filled in' with relative abundance values of the forest bird species from the four Suburban bird survey sites. The randomly selected abundance values for the entire Semicompact scenario were then summed to yield an estimate of the abundance of the forest bird species over the whole area of the Semi-compact scenario. I repeated this estimation procedure 1,000 times, resulting in an abundance distribution for each species in each development scenario. In the same manner, I also estimated the total abundance of all forest birds in each development scenario and the total abundance of birds belonging to species classified as 'forest interior' and 'forest edge' in each development scenario (Table 1.2).

\subsubsection{Theoretical forest bird species richnesses}

I estimated the species richness of all forest birds, forest interior birds and forest edge birds in each development scenario. Using species accumulation curves constructed for 
each housing category and for each bird group (Colwell \& Coddington 1994), I estimated that during my point counts I observed $>90 \%$ of species predicted to be present in each type of site. Therefore, I assumed that I recorded the entire community of birds present in each housing category. Using this information, I estimated the species richness of each bird group in each development scenario with a procedure similar to that described for abundance. For each site area in a development scenario, I randomly selected an actual sampled site from the appropriate housing density category (Appendix 1) and applied the species observed there to the site area in the development scenario. I repeated this procedure for every site area in the development scenario, successively adding any new species to the development scenario's species list. For areas in the development scenario making up fractions of bird survey site areas, I randomly selected without replacement the observations from one, two or three of the sampling stations within the bird survey site, depending on the size of the fraction of the site area. The development scenario's final species list once every site area had been 'filled' with species was the species richness of that whole development scenario.

Initially, the total number of bird survey sites available for selection differed among development scenarios (four each in the Undeveloped and Dispersed scenarios and 11 each in the Semi-compact and Compact scenarios). For example, recall that the Dispersed scenario can be considered as the equivalent area to 91.83 Exurban bird survey sites. Thus, there were only four Exurban bird survey sites from which species observations could be used to estimate species richness in the Dispersed scenario. The Compact 
scenario, on the other hand, was made up of areas represented by bird survey sites in three housing categories: Urban, Urban Neighbor and Forested. Thus, observations from 11 bird survey sites (four Urban, three Urban Neighbor, and four Forested) could be used to estimate species richness in the Compact scenario. This represented a difference in sample size among the development scenarios, which could bias the results such that the estimated richnesses in the Undeveloped and Dispersed scenarios would be lower than they should be, relative to the richnesses of the Semi-compact and Compact scenarios. I corrected for this by randomly selecting two Forested bird survey sites, one Suburban or Urban site and one Suburban Neighbor or Urban Neighbor site prior to estimating the species richness of each bird group in the Semi-Compact and Compact scenarios. For example, for the Semi-compact scenario, I randomly selected two Forested sites, one Suburban site and one Suburban Neighbor site. These four bird survey sites represented the pool from which species observations could be selected according to the procedure described above. Thus, for the Semi-compact and Compact scenarios, the initial number of bird survey sites available for selection was restricted to four, to equal the number of bird survey sites available for the Undeveloped and Dispersed scenarios. Finally, I repeated the entire procedure just described 1,000 times to yield an estimate of the species richness of each bird group and its associated error in each development scenario. All analyses were carried out in R version 2.6.0 (R Development Core Team 2007). 


\subsection{Results}

\subsubsection{Bird abundance and richness in the survey sites}

I observed 39 native forest bird species during my surveys, 16 of which I classified as forest interior species and 23 as forest edge species (Table 1.2). Species varied in abundance from one individual (Blue-headed Vireo Vireo solitarius, Canada Warbler Wilsonia canadensis, Golden-crowned Kinglet Regulus satrapa, Swainson's Thrush Catharus ustulatus) to 168 individuals (Black-capped Chickadee Poecile atricapilla) across all survey sites. Seven species were detected at only one bird survey site (the four species above plus Mourning Warbler Oporornis philadelphia, Ruffed Grouse Bonasa umbellus, and Warbling Vireo V. gilvus) and the most widespread species, Black-capped Chickadee, was detected at 21 of the 22 bird survey sites.

In the bird survey sites, the abundance and species richness of all forest birds and forest interior birds declined as housing density increased from the Forested to the Urban housing categories (Table 1.1). Neighbor bird survey sites had intermediate values of forest bird and forest interior bird abundance and species richness. Forest edge birds were most abundant and speciose in Exurban bird survey sites, followed closely by Forested and Neighbor sites (Table 1.1).

\subsubsection{Effects of housing density vs. sprawl area}

Over half of the 39 forest bird species observed during my surveys were estimated to be most abundant in the Undeveloped scenario (21 species, 54\%) (Table 1.2, Appendix 2). These 21 species had their second highest abundances and an additional species had 
its highest abundance in the Compact scenario (22 species, 56\%). Approximately onethird of the forest species were most abundant in the Dispersed scenario (13 species, $33 \%)$ and only four species $(10 \%)$ were most abundant in the Semi-compact scenario.

With the exception of the Undeveloped scenario, the abundance of all forest birds and of forest interior birds was highest in the Compact scenario (Fig. 1.5a, b). In contrast, the abundance of forest edge birds was highest in the Dispersed scenario (Fig. 1.5c).

The Undeveloped scenario had the highest estimated species richness for all three bird groups (Fig. 1.6). Considering only the developed scenarios, the species richness of all forest birds and of forest interior birds was highest in the Semi-compact scenario (Fig. 1.6a, b) whereas the species richness of forest edge birds was highest in the Dispersed scenario (Fig. 1.6c).

\subsection{Discussion}

My results indicate that clustering housing development at a Suburban or Urban density minimizes the impacts of a given human population on forest breeding birds. With the exception of the Undeveloped scenario, forest birds, and in particular forest interior birds, were most abundant in the Compact scenario (Fig. 1.5a, b) and most speciose in the Semi-compact scenario (Fig. 1.6a, b). This is intuitive considering that all three scenarios (Undeveloped, Compact and Semi-compact) were made up of a large proportion of continuous forest habitat, and thus contained a large proportion of the species occurring at my Forested sites. The Dispersed scenario resulted in low forest bird and forest interior 
bird abundances (Fig. 1.5a, b) and numbers of species (Fig. 1.6a, b), benefiting forest edge birds instead (Figs. 1.5c, 1.6c).

To my knowledge, only one other study to date has compared animal community structure in clustered and dispersed housing developments. Lenth et al. (2006) compared bird, mammal and plant communities among dispersed developments, clustered developments, and undeveloped areas in Boulder County, Colorado. They reported no significant differences between development types, but found that both types had significantly more non-native and human-commensal species and significantly fewer native and human-sensitive species than undeveloped areas. Lenth et al. (2006) performed their study at a relatively small scale (their largest housing development was $2.92 \mathrm{~km}^{2}$ ). In this study, I estimated forest bird abundance and species richness in hypothetical landscapes of $22.96 \mathrm{~km}^{2}$. As well, the sites used by Lenth et al. (2006) were subjected to grazing pressure in addition to being developed, whereas I assumed that the only other land use in my hypothetical landscapes was recreation. Finally, Lenth et al. (2006) controlled for differences in development density surrounding their sites over a large area whereas my approach did not allow me to do so. These differences highlight the fact that more studies comparing clustered and dispersed developments in various contexts and over a broad range of scales are needed to further elucidate the consequences for biodiversity.

Nevertheless, clustering development is predicted to reduce habitat loss and 
fragmentation by minimizing the amount of edge habitat in a landscape (Theobald et al. 1997). Habitat loss and fragmentation have been shown to negatively affect forest birds in urban areas (Friesen et al. 1995, Mancke \& Gavin 2000, Drinnan 2005). My results support these findings given that I estimated that forest bird and forest interior bird abundances and species richnesses were higher in the Compact and Semi-compact scenarios, respectively, than in the Dispersed scenario, in which forest habitat was presumably more fragmented by houses and roads (Figs. 1.5a, b, 1.6a, b).

Mechanisms operating in my bird survey sites, such as competition from edgeadapted species and increased rates of predation and brood parasitism, could help explain abundance differences among my hypothetical scenarios. Small forest fragments have more edge-adapted bird species and fewer interior-adapted bird species than larger forest fragments (Freemark \& Collins 1992). A similar pattern may be occurring in my development scenarios since I found that forest edge birds were most abundant in the Dispersed scenario (Fig. 1.5c) and the Dispersed scenario had by far the lowest forest interior bird abundance of all development scenarios (Fig. 1.5b). Open woodland birds, species adapted to open areas interspersed with large trees, were also most abundant in the Dispersed scenario (Appendix 3).

Avian nest predators are often implicated in declines of interior or specialist species in urban areas since they generally benefit from the edges and open areas created by development (Engels \& Sexton 1994). In concordance with this, I estimated that three potential nest predators, the American Crow Corvus brachyrhynchos, the Blue Jay 
Cyanocitta cristata and the Common Grackle Quiscalus quiscula, as well as the Brownheaded Cowbird Molothrus ater (a nest parasite) were most abundant in the Dispersed scenario (Table 1.2, Appendices 2, 3). Nest parasitism by the Brown-headed Cowbird has been shown to be higher in forests fragmented by houses, resulting in the production of fewer host fledglings, than in undeveloped areas (Rodewald \& Shustack 2008).

Despite the Compact scenario having the highest abundance of forest birds and forest interior birds among the developed scenarios, I estimated the largest species richness of both these groups to be in the Semi-compact scenario. Similar to the Compact scenario, the Semi-compact scenario had a large amount of continuous forest habitat, but the structure of the Suburban-density development in the Semi-compact scenario may have benefited more forest species than the Urban-density development in the Compact scenario. Landowners in suburban areas plant proportionally more vegetation intentionally for birds than those in urban areas (Lepczyk et al. 2004), which may possibly result in an increase in the number and type of foraging and nesting sites for some forest species. This possibility, in addition to the lower amount of disturbance in Suburban-density development than in Urban-density development (and in Neighboring forest habitat) and the relatively large amount of continuous forest remaining in the Semicompact scenario, likely resulted in my estimating the Semi-compact scenario to have higher species richnesses of forest birds and forest interior birds than the other two developed scenarios. 
In creating my development scenarios, I assumed that development occurred in a corner of the Semi-compact and Compact scenarios. This assumption may have underestimated the edge effects of the development on the surrounding forest habitat and biased my estimates of forest bird abundance and species richness in these scenarios. To determine if this was the case, I repeated my analysis using scenarios with housing developments in the center of each landscape. This resulted in slightly altered results for three species. Pine Warbler Dendroica pinus abundance was highest in the Compact rather than the Semi-compact scenario, Purple Finch Carpodacus purpureus abundance was highest in the Dispersed rather than the Semi-compact scenario, and Yellow-throated Vireo $V$. flavifrons abundance was highest in the Semi-compact rather than the Compact scenario. Despite the similarity in forest bird abundance and species richness estimates between these two development scenario configurations, it is still possible that edge effects extend beyond the $500 \mathrm{~m}$ of my Neighbor sites, and that this distance may be different for Suburban- and Urban-density development. To my knowledge, however, empirical evidence to support a greater edge effect distance is lacking in the literature and, given the large differences I predicted among my scenarios, an increase in edge effect distance is not likely to change my overall results. Nevertheless, this issue warrants further research as does the related question of how large the undeveloped portion of a developed landscape needs to be to maintain populations of sensitive species.

At the regional scale, a network of compact developments can result in greenways or 
large tracts of continuous forest habitat (Arendt 2004). Rather than building outwards from urban centers at low density, as is now the case, I foresee outlying nodal housing developments linked with each other and the urban center by roads and surrounded primarily by forested or other natural habitat. A similar approach to urban planning is already being considered by some communities (e.g., Ingram 2005). Although the roads linking nodal developments would likely have adverse impacts on the biodiversity in greenways, the road density for nodal development would be lower than for typical dispersed housing. Finally, the location of nodal developments would have to be chosen with care to avoid the destruction or alteration of sensitive or rare habitats. For example, although clustering development limits habitat loss in Wisconsin, most clustered developments occur on lakeshores, likely negatively affecting the many sensitive species that rely on these habitats (Gonzalez-Abraham et al. 2007).

In conclusion, this chapter presents evidence that compact as opposed to dispersed housing developments minimize the impacts of a given human population on forest breeding birds. The bundling of roads (Jaeger et al. 2005) has also been shown to minimize impacts on biodiversity given a set of economic constraints. Taken together, this and other studies suggest we must explicitly account for human use of the landscape in order to effectively conserve biodiversity and that a simple but often ignored solution may be to minimize the habitat lost to this use. 


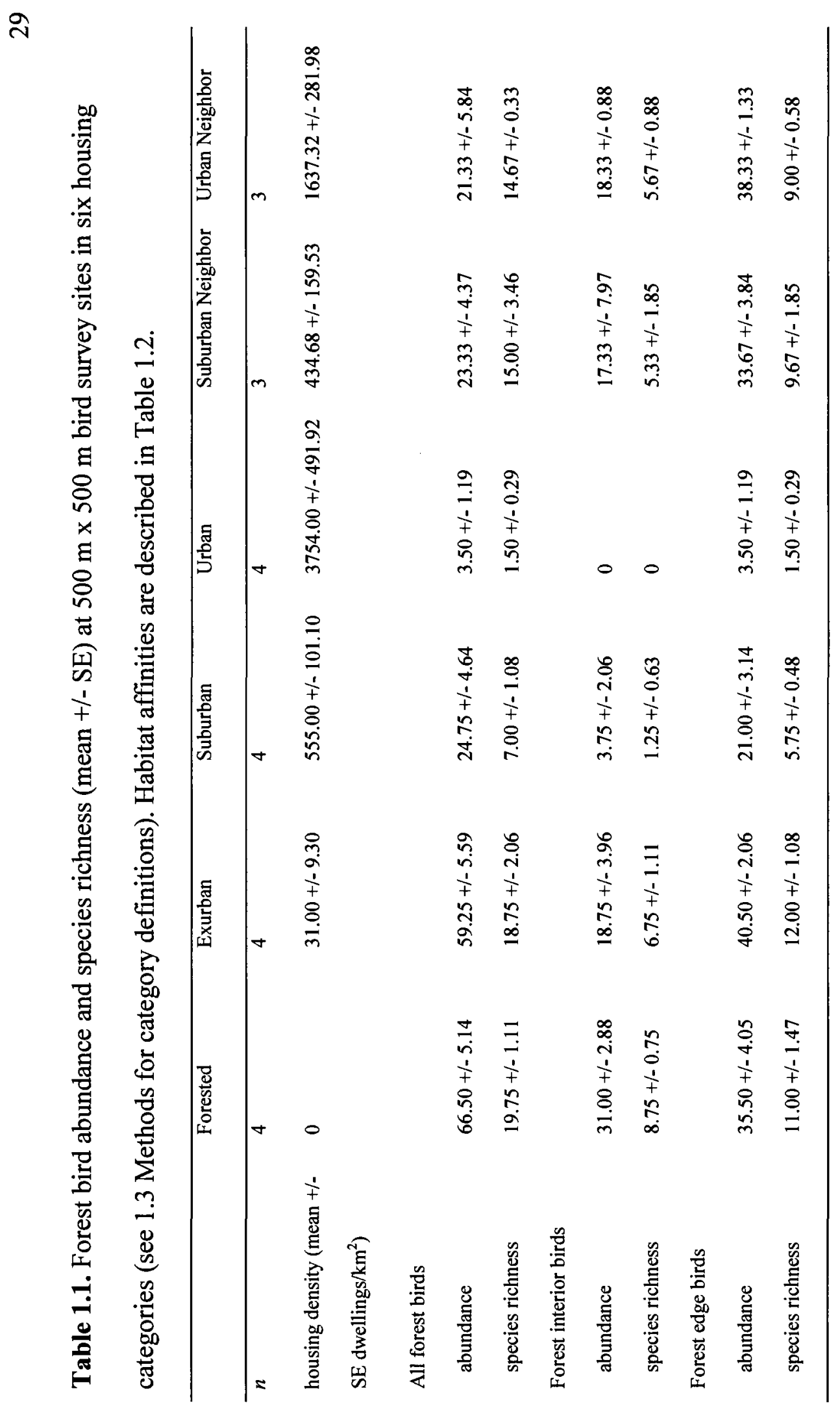


Table 1.2. Forest bird species observed during point count surveys and their estimated abundances in development scenarios. Habitat affinities are based on information in Poole (2005): 'Forest interior' includes species that occur only in forest habitat, being most abundant in the forest interior and avoiding the forest edge; 'Forest edge' includes species that are most common in forest habitat but that also occur in a wide range of other habitat types as well as species that occur both in the forest interior and edge. See Fig. 1.3 for descriptions of scenarios.

\begin{tabular}{|c|c|c|c|}
\hline Common and scientific name & $\begin{array}{l}\text { Habitat } \\
\text { affinity }\end{array}$ & $\begin{array}{l}\text { Developed scenario with } \\
\text { highest abundance }\end{array}$ & $\begin{array}{l}\text { Highest abundance in } \\
\text { Undeveloped scenario? }\end{array}$ \\
\hline $\begin{array}{l}\text { American Redstart } \\
\text { Setophaga ruticilla }\end{array}$ & Forest interior & Compact & Yes \\
\hline $\begin{array}{l}\text { Black-and-white Warbler } \\
\text { Mniotilta varia }\end{array}$ & Forest interior & Dispersed & \\
\hline $\begin{array}{l}\text { Blackburnian Warbler } \\
\text { Dendroica fusca }\end{array}$ & Forest interior & Compact & Yes \\
\hline $\begin{array}{l}\text { Black-throated Blue Warbler } \\
\text { Dendroica caerulescens }\end{array}$ & Forest interior & Compact & Yes \\
\hline $\begin{array}{l}\text { Black-throated Green Warbler } \\
\text { Dendroica virens }\end{array}$ & Forest interior & Compact & Yes \\
\hline $\begin{array}{l}\text { Blue-headed Vireo } \\
\text { Vireo solitarius }\end{array}$ & Forest interior & Semi-compact & \\
\hline $\begin{array}{l}\text { Brown Creeper } \\
\text { Certhia americana }\end{array}$ & Forest interior & Compact & Yes \\
\hline Ovenbird & Forest interior & Compact & Yes \\
\hline
\end{tabular}


Seiurus aurocapillus

Pileated Woodpecker

Forest interior Compact

Yes

Dryocopus pileatus

Pine Warbler

Forest interior Semi-compact

Dendroica pinus

Red-breasted Nuthatch

Forest interior

Dispersed

Sitta canadensis

Ruffed Grouse

Forest interior

Compact

Yes

Bonasa umbellus

Scarlet Tanager

Forest interior

Compact

Yes

Piranga olivacea

Swainson's Thrush

Forest interior

Compact

Yes

Catharus ustulatus

Veery

Forest interior

Compact

Yes

Catharus fuscescens

Yellow-rumped Warbler

Forest interior

Dispersed

Dendroica coronata

Black-capped Chickadee

Forest edge

Dispersed

Poecile atricapilla

Blue Jay

Forest edge

Dispersed

Cyanocitta cristata

Canada Warbler

Forest edge

Compact

Yes

Wilsonia canadensis

Downy Woodpecker

Forest edge

Dispersed

Picoides pubescens 


\begin{tabular}{|c|c|c|}
\hline $\begin{array}{l}\text { Eastern Phoebe } \\
\text { Sayornis phoebe }\end{array}$ & Forest edge & Dispersed \\
\hline $\begin{array}{l}\text { Eastern Wood-Pewee } \\
\text { Contopus virens }\end{array}$ & Forest edge & Compact \\
\hline $\begin{array}{l}\text { Golden-crowned Kinglet } \\
\text { Regulus satrapa }\end{array}$ & Forest edge & Compact \\
\hline $\begin{array}{l}\text { Hairy Woodpecker } \\
\text { Picoides villosus }\end{array}$ & Forest edge & Compact \\
\hline $\begin{array}{l}\text { Hermit Thrush } \\
\text { Catharus guttatus }\end{array}$ & Forest edge & Compact \\
\hline $\begin{array}{l}\text { Least Flycatcher } \\
\text { Empidonax minimus }\end{array}$ & Forest edge & Compact \\
\hline $\begin{array}{l}\text { Mourning Warbler } \\
\text { Oporornis philadelphia }\end{array}$ & Forest edge & Dispersed \\
\hline $\begin{array}{l}\text { Nashville Warbler } \\
\text { Vermivora ruficapilla }\end{array}$ & Forest edge & Dispersed \\
\hline $\begin{array}{l}\text { Purple Finch } \\
\text { Carpodacus purpureus }\end{array}$ & Forest edge & Semi-compact \\
\hline $\begin{array}{l}\text { Red-eyed Vireo } \\
\text { Vireo olivaceus }\end{array}$ & Forest edge & Compact \\
\hline $\begin{array}{l}\text { Rose-breasted Grosbeak } \\
\text { Pheucticus ludovicianus }\end{array}$ & Forest edge & Compact \\
\hline $\begin{array}{l}\text { Ruby-throated Hummingbird } \\
\text { Archilochus colubris }\end{array}$ & Forest edge & Compact \\
\hline Warbling Vireo & Forest edge & Semi-compact \\
\hline
\end{tabular}


Vireo gilvus

White-breasted Nuthatch Forest edge Dispersed

Sitta carolinensis

White-throated Sparrow $\quad$ Forest edge Dispersed

Zonotrichia albicollis

$\begin{array}{lll}\text { Winter Wren } & \text { Forest edge } \quad \text { Dispersed }\end{array}$

Troglodytes troglodytes

Wood Thrush $\quad$ Forest edge $\quad$ Dispersed

Hylocichla mustelina

$\begin{array}{llll}\text { Yellow-bellied Sapsucker } & \text { Forest edge } \quad \text { Compact } & \text { Yes }\end{array}$

Sphyrapicus varius

Yellow-throated Vireo

Forest edge Compact $\quad$ Yes

Vireo flavifrons 


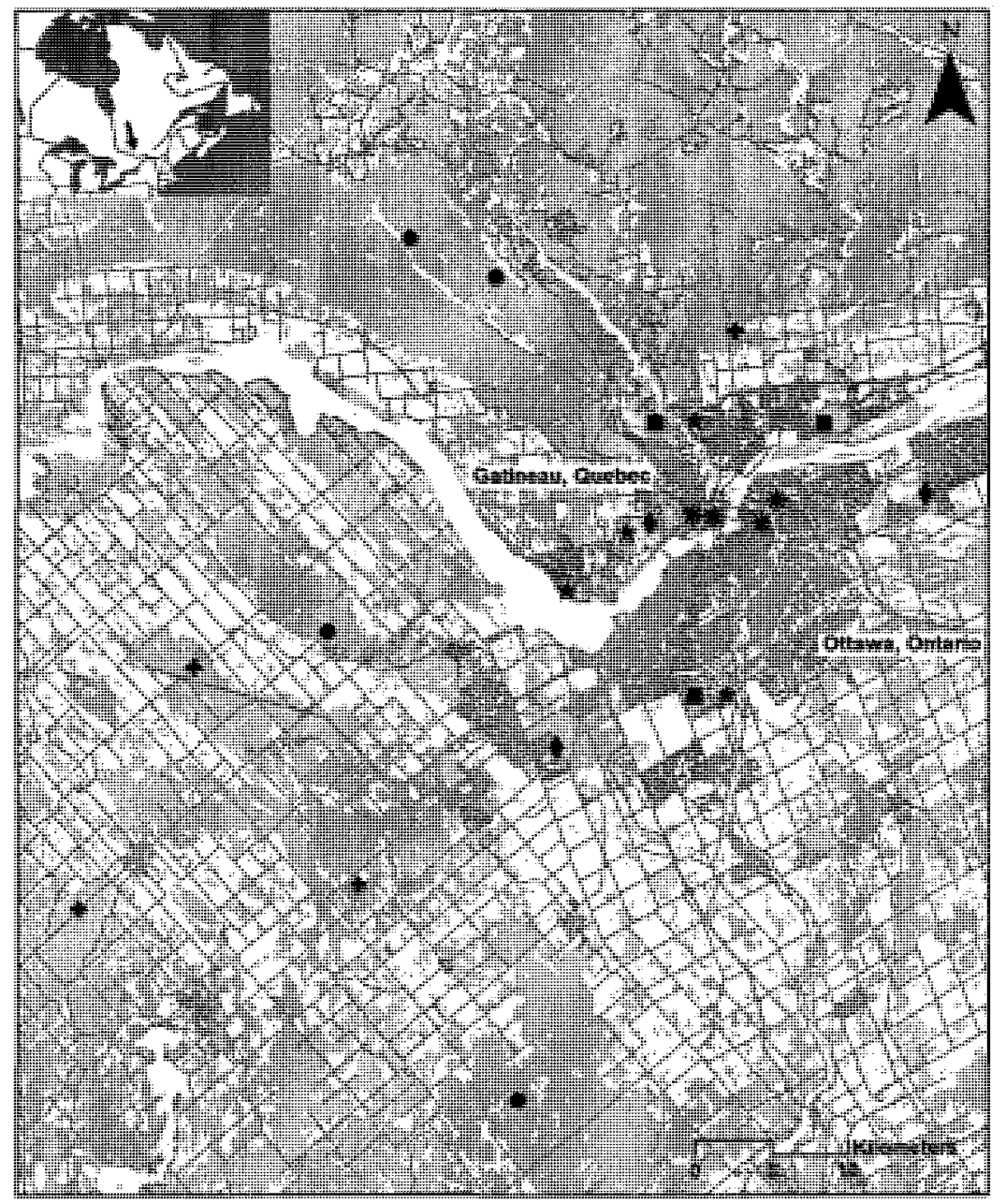

Figure 1.1. The study area surrounding the cities of Ottawa, Ontario and Gatineau, Quebec, Canada. Inset depicts the location of the study area in eastern North America. Bird survey sites are $0.25 \mathrm{~km}^{2}$ areas indicated by symbols representing six housing categories: - Forested $\left(0\right.$ dwellings $\left./ \mathrm{km}^{2}\right),+$ Exurban $\left(<56\right.$ dwellings $\left./ \mathrm{km}^{2}\right), \star$ Suburban (140-712 dwellings $\left./ \mathrm{km}^{2}\right)$, * Urban (>1,244 dwellings $\left./ \mathrm{km}^{2}\right)$; and two categories of forested sites adjacent to developments of Suburban and Urban 
densities: - Suburban Neighbor, $\$ Urban Neighbor. Dark gray lines indicate roads.

Forest cover is in light gray. 


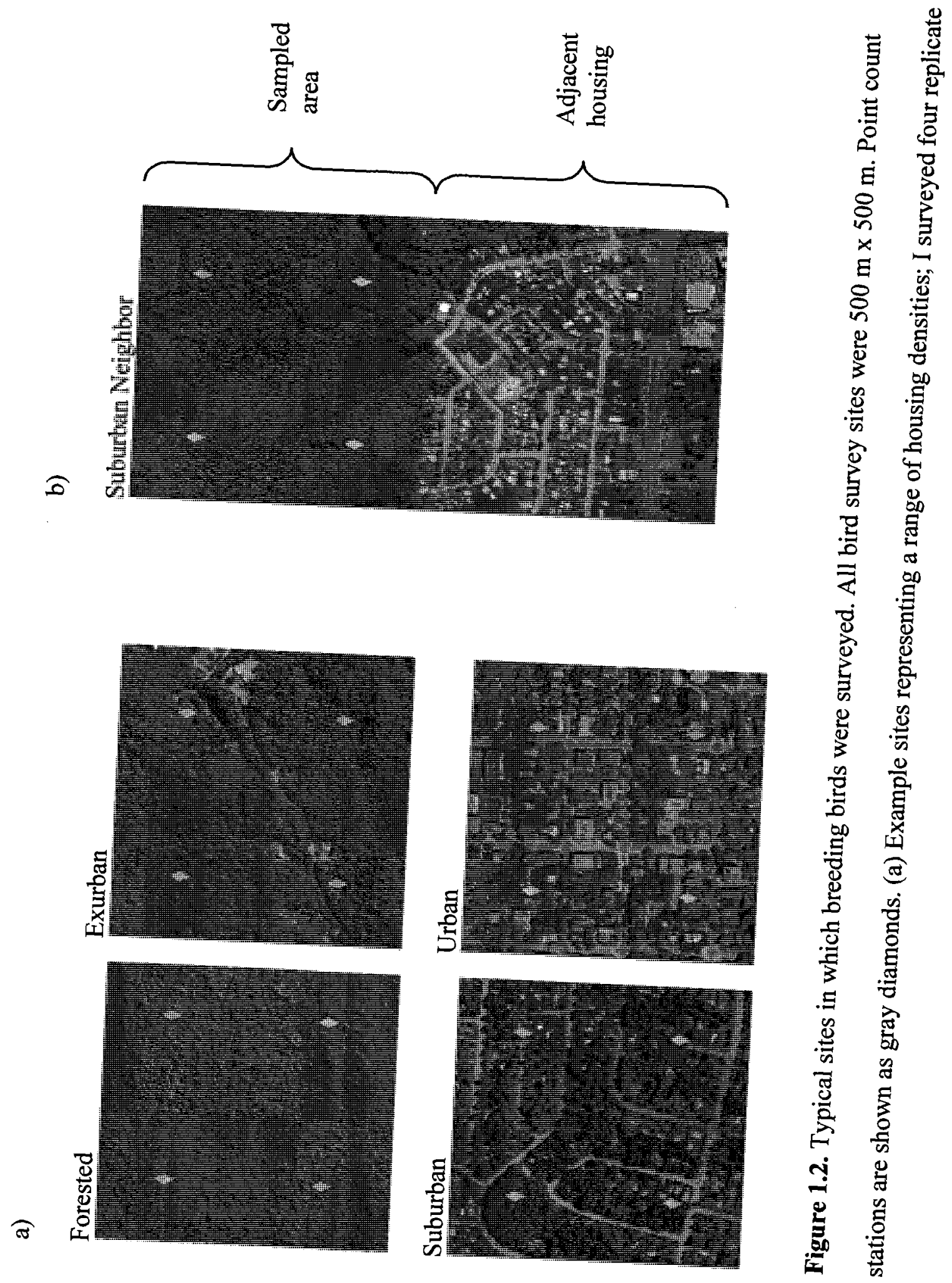




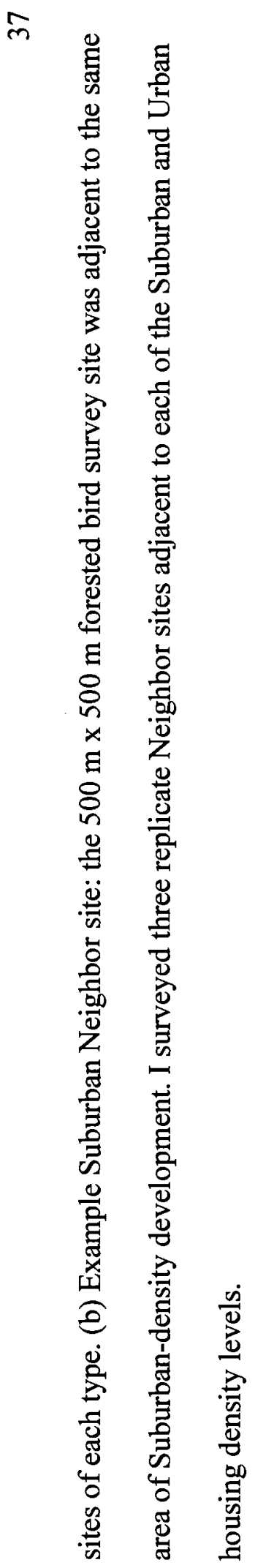




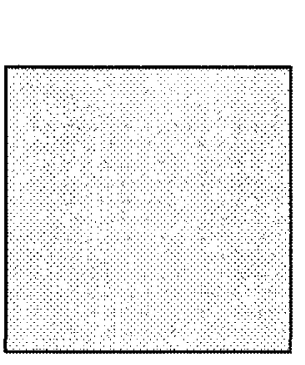

Undeveloped

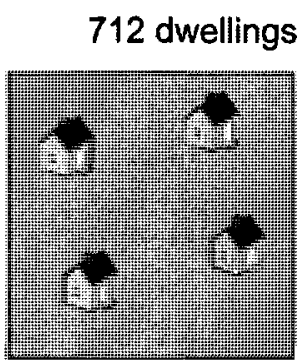

Dispersed

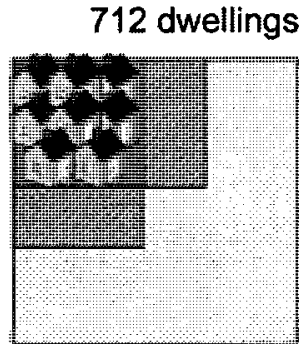

Semi-compact

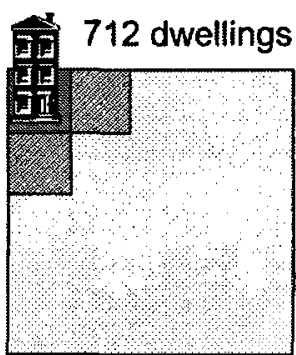

Compact

Housing density

Sprawl area

Figure 1.3. Hypothetical development scenarios representing a gradient of increasing housing density and decreasing sprawl area. For a given forested area (the Undeveloped scenario), the same number of dwellings is depicted at three housing densities, Exurban, Suburban and Urban, resulting in dispersed, semi-compact and compact development patterns, respectively. Hatched areas represent forest habitat adjacent to development, typical of Neighbor sites. Drawings, including proportions of each cover type in each scenario, are not to scale. For example, the developed portion of the Semi-compact scenario was $6.18 \%$ of the total area of the scenario. Scenarios were $22.96 \mathrm{~km}^{2}$. 


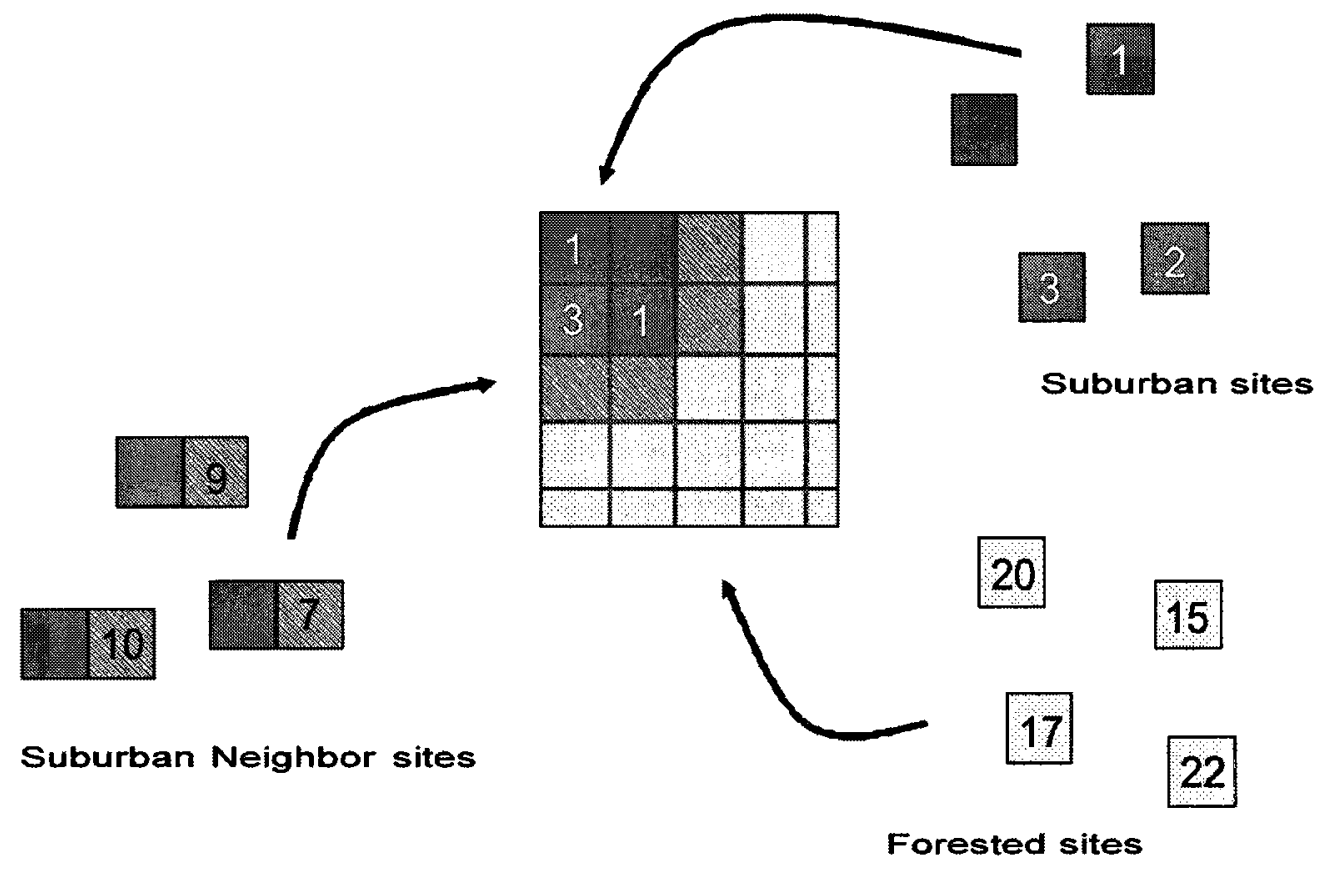

Figure 1.4. Illustration of the method for estimating the abundance of a typical forest bird species in a development scenario. Shown is the Semi-compact scenario (see Fig. 1.3; not to scale). Numbers represent the relative abundance of the species in each bird survey site, calculated from point count data. Three types of bird survey sites make up the Semicompact scenario: Suburban, Forested and Suburban Neighbor. For each site area in the scenario, a relative abundance value was randomly chosen from the replicate bird survey sites in the appropriate housing category. To illustrate this, the developed portion of the scenario has been filled in with randomly chosen relative abundance values from the Suburban bird survey sites. For areas in the development scenario that are smaller than site areas, the relative abundance value was multiplied by the proportion of a site area 
represented. Finally, the randomly selected values for the entire Semi-compact scenario were summed to yield an estimate of the abundance of the forest bird species in the whole development scenario. 
a)

\section{Forest birds}

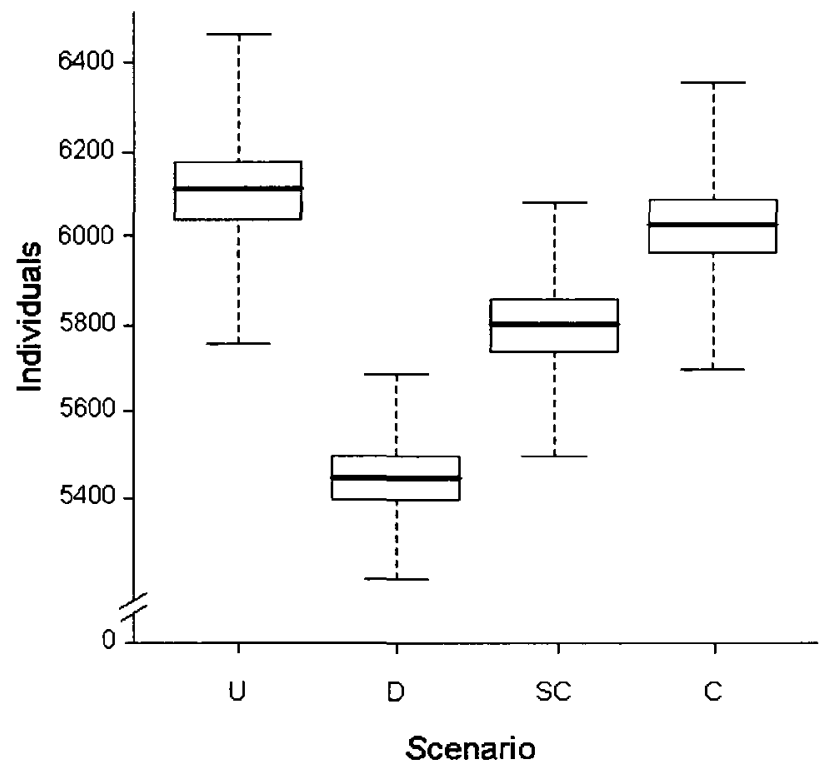

b)

\section{Forest interior birds}

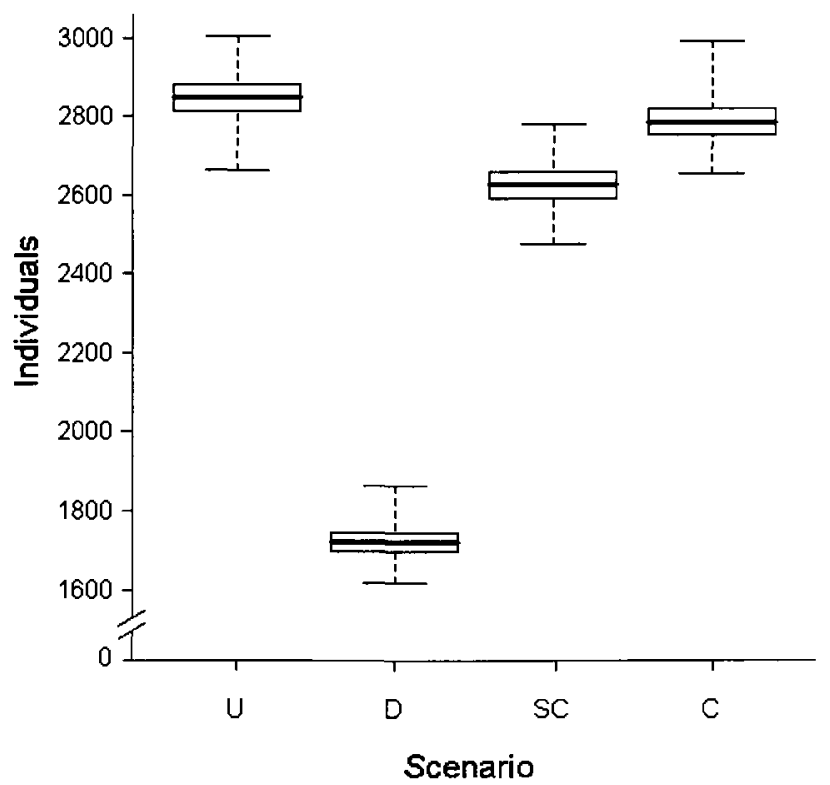


c)

Forest edge birds

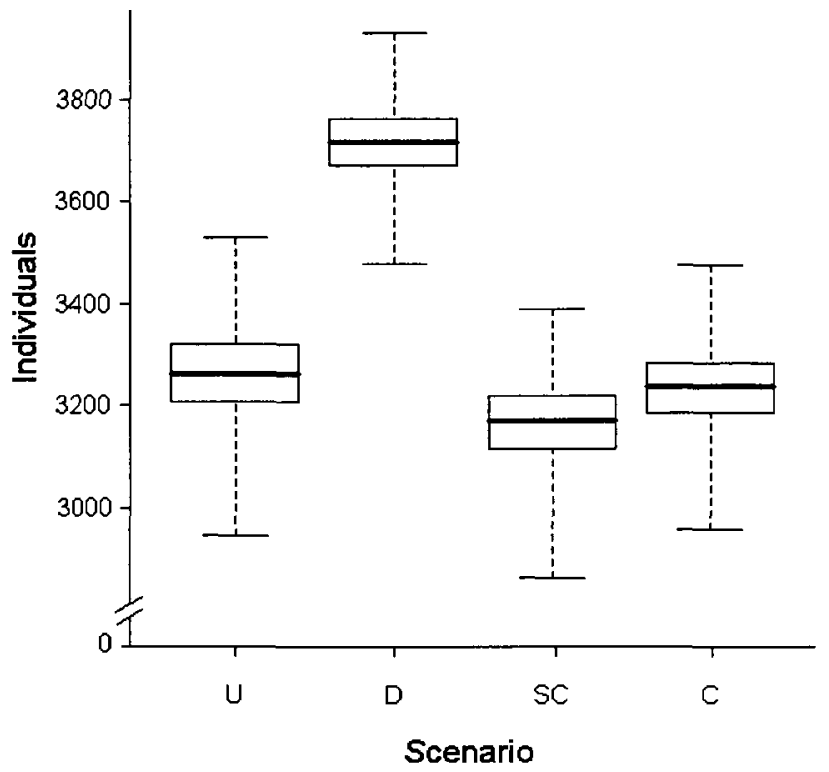

Figure 1.5. The estimated abundances of three bird groups in four hypothetical development scenarios: U, Undeveloped; D, Dispersed; SC, Semi-compact; C, Compact. (a) Forest birds. (b) Forest interior birds. (c) Forest edge birds. The species included in each group are given in Table 1.2. The lower edge of each box is the first quartile, the bold center line is the median and the upper edge is the third quartile of the distribution. Whiskers extend to the minimum and maximum values. 
a)

Forest birds

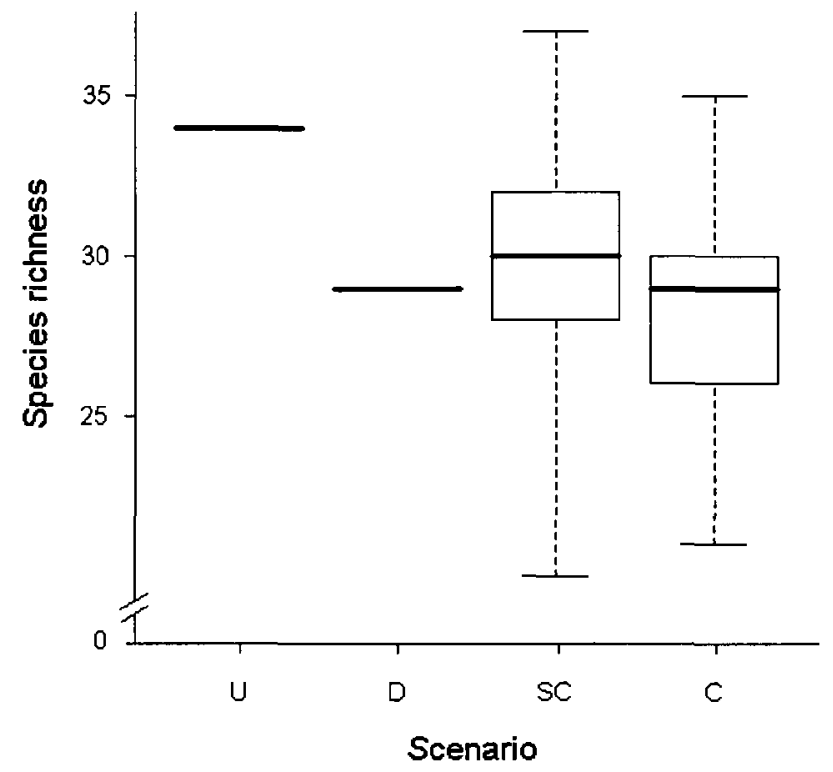

b)

Forest interior birds

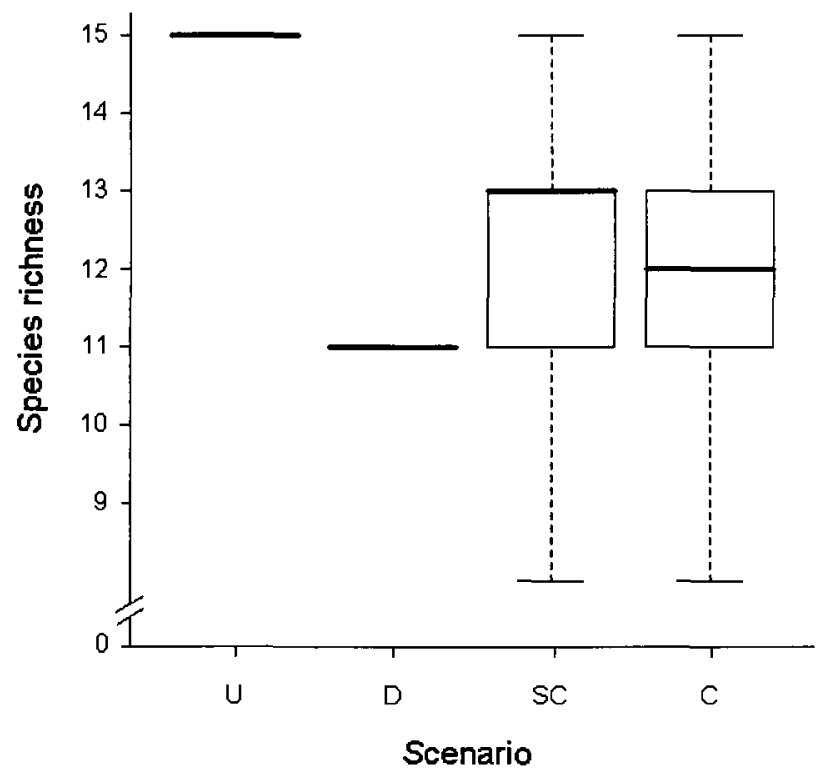


c)

Forest edge birds

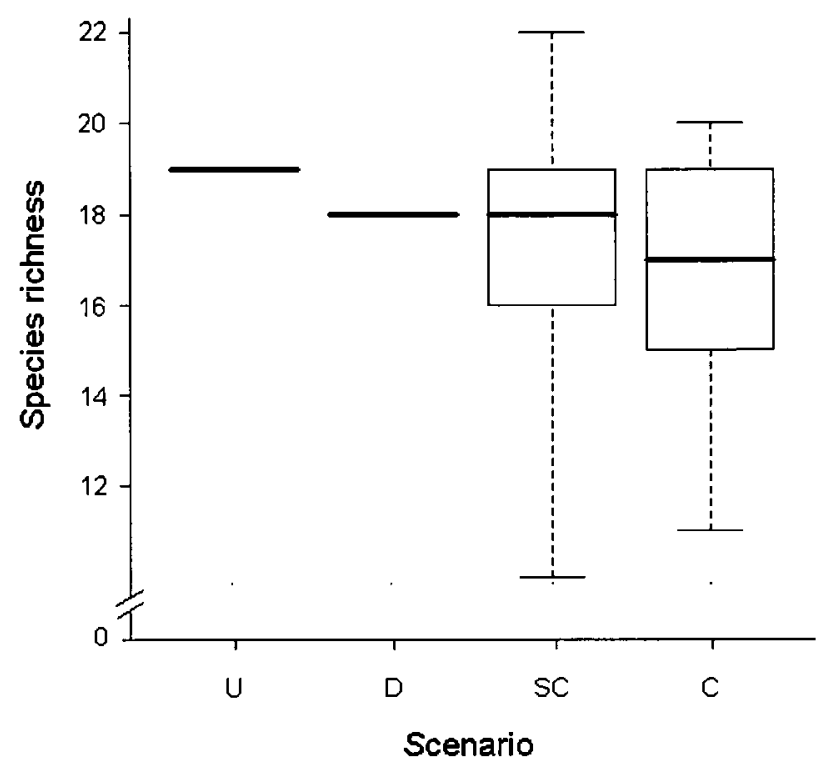

Figure 1.6. The estimated species richnesses of three bird groups in four hypothetical development scenarios: U, Undeveloped; D, Dispersed; SC, Semi-compact; C, Compact. (a) Forest birds. (b) Forest interior birds. (c) Forest edge birds. The species included in each group are given in Table 1.2. The lower edge of each box is the first quartile, the bold center line is the median and the upper edge is the third quartile of the distribution. Whiskers extend to the minimum and maximum values. Species richness estimates for the Undeveloped and Dispersed scenarios had zero variance. This is because all bird species counted in the four Forested survey sites (for the Undeveloped scenario) and the four Exurban survey sites (for the Dispersed scenario) were always estimated to be in at least one of the large number (91.83) of replicate site areas in these scenarios. 


\section{Chapter 2. The trade-off between housing density and sprawl area: minimizing impacts to carabid beetles (Coleoptera: Carabidae)}

\subsection{Summary}

Increasing housing density generally has negative effects on native biodiversity. This implies we should build at low density over the landscape to conserve native species. However, for a given human population, low-density development must cover a large area, resulting in sprawl and significant negative impacts to native plant and animal communities. A pertinent question is then: at what housing density are the impacts of a given human population on native biodiversity minimized? For a given human population, it is unclear whether the impacts on native biodiversity are less where housing density is high and sprawl area is small or where housing density is low and sprawl area is large. In this chapter, I estimated the impacts of a given human population on carabid beetle abundance and species richness in Ottawa, Ontario and Gatineau, Quebec, Canada. My methodology can be described in two parts. First, I collected carabid beetles at 22 sites representing a range of housing densities. I then used these empirical data to estimate the abundance and species richness of carabid beetles in four hypothetical development scenarios representing the trade-off between housing density and sprawl area. My results suggest that clustering development at a high housing density minimizes the impacts of a given human population on carabid beetle diversity. In particular, I found that high-density development over a small area should result in high total beetle species richness, forest beetle abundance and species richness and native 
beetle abundance. In contrast, low-density development over a large area should result in high introduced beetle abundance. My previous work found similar results for forest bird diversity. If these results are general across all forest taxa, then urban planning that strongly favors densification rather than sprawl would minimize urbanization effects on biodiversity.

\subsection{Introduction}

Urbanization generally has negative effects on native biodiversity. An increase in housing density along the rural-urban gradient is accompanied by a decrease in the abundance and species richness of native insects, amphibians, lizards, birds, and mammals (reviewed in McKinney 2002 and Hansen et al. 2005). In particular, populations of native specialist species decline along the rural-urban gradient. Blair (1999) reported the near complete loss of native bird and butterfly species present in a biological preserve in California as housing density increased. Similarly, along a rural-urban gradient in Argentina, native rodent species were only encountered in a natural reserve and parklands with very few buildings (Cavia et al. 2009). Frog and toad populations in Iowan wetlands have also been found to decline with increasing housing density (Pillsbury \& Miller 2008).

The implicit conservation implication of the findings presented above is that we should build at low density over the landscape. However, to accommodate a given human population, low-density development must cover a large area, resulting in sprawl and significant negative impacts to native plant and animal communities (Odell \& Knight 2001, Maestas et al. 2003, Hansen et al. 2005). A pertinent question is then: at what 
housing density are the impacts of a given human population on native biodiversity minimized? For a given human population, it is unclear whether the impacts on native biodiversity are less where housing density is high and sprawl area is small or where housing density is low and sprawl area is large. This question was recently listed as one of the 100 questions that, if answered (and acted upon), would have the greatest impact on the conservation of biological diversity worldwide (Sutherland et al. 2009).

I chose to evaluate the housing density/sprawl area trade-off using carabid beetles (Coleoptera: Carabidae). Carabid beetles were particularly appropriate candidates for my study because of their abundance and diversity and the ease with which they can be sampled. The family Carabidae is also well described taxonomically and individuals can be easily identified to species. In addition, carabid beetles are important prey for many taxa, including salamanders (Andreone et al. 1999), lizards (Hódar et al. 1996), bats (Arlettaz et al. 1993) and birds (Holland et al. 2006). Finally, the response of carabid beetles to urbanization has been quantified. Native forest specialist carabid beetle abundance and species richness in forest fragments has been found to decline with increasing intensity of surrounding urbanization (Sadler et al. 2006, Elek \& Lövei 2007, Gaublomme et al. 2008, Magura et al. 2008).

In this chapter, I estimated the impacts of a given human population on carabid beetle abundance and species richness in Ottawa, Ontario and Gatineau, Quebec, Canada. My methodology can be described in two parts. First, I collected carabid beetles in sites of the same size representing a range of housing densities. I then used these empirical data to estimate the abundance and species richness of carabid beetles in four 
hypothetical development scenarios representing the trade-off between housing density and sprawl area. Development scenarios were hypothetical forested landscapes of the same size that accommodated a given human population at different housing densities, resulting in dispersed, semi-compact and compact development patterns (an undeveloped scenario was also created for comparison). I identified the housing density that minimized the estimated impacts of a given human population on carabid beetles by comparing abundance and species richness estimates among scenarios.

\subsection{Methods}

\subsubsection{Beetle abundance data collection}

\subsubsection{Study area}

I sampled carabid beetle populations at $220.25 \mathrm{~km}^{2}$ sites in and around Ottawa, Ontario and Gatineau, Quebec, Canada (Fig. 2.1). The study area encompassed approximately $4,040 \mathrm{~km}^{2}$ on both sides of the Ottawa River. The northern half of the study area forms part of the Southern Laurentians ecoregion of Quebec and is underlain by the Canadian Shield, composed mainly of massive Precambrian granite and gneiss. Elevation is commonly 300-600 m above sea level. The St. Lawrence Lowlands ecoregion is south of the Ottawa River and is underlain by flat-lying Palaeozoic strata with elevations rarely more than $150 \mathrm{~m}$ above sea level. All housing categories (see below) were approximately equally represented in both ecoregions to account for possible differences in forest composition (Fig. 2.1). In addition, I tested a posteriori for differences in tree community 
composition between ecoregions using a redundancy analysis. The single constrained eigenvalue was not significant (100 permutations, $F_{l, 2}=2.37, p=0.29$ ).

\subsubsection{Site selection}

I selected four sites in each of four housing density categories: Forested ( 0 dwellings $/ \mathrm{km}^{2}$ ), Exurban ( $<56$ dwellings $/ \mathrm{km}^{2}$, mean $\left.=31+/-9(\mathrm{SE}) \mathrm{dwellings} / \mathrm{km}^{2}\right)$, Suburban $\left(140-712\right.$ dwellings $/ \mathrm{km}^{2}$, mean $=555+/-101(\mathrm{SE})$ dwellings $\left./ \mathrm{km}^{2}\right)$ and Urban $\left(>1,244\right.$ dwellings $/ \mathrm{km}^{2}$, mean $=3,754+/-492$ (SE) dwellings $\left./ \mathrm{km}^{2}\right)$ (Fig. 2.2a). Each site comprised the area within a $500 \mathrm{~m} \times 500 \mathrm{~m}$ square $\left(0.25 \mathrm{~km}^{2}\right)$. In addition to these 16 sites, I selected six forested sites, equal in size to those described above, adjacent to developments of Suburban and Urban housing densities (three sites each) (Fig. 2.2b). In contrast to the Forested sites which were embedded in a larger forested area, these Neighbor sites were chosen to incorporate the possible effects of adjacent urban development on carabid beetle populations in forest habitat.

I searched for sites using a combination of historical topographic maps $(\sim 1 / 50,000$, currently produced by the Centre for Topographic Information, Natural Resources Canada, Ottawa, Ontario, Canada) and the most recent aerial photographs available (2002, 1/15,000, produced by the City of Ottawa, Ontario, Canada). Using topographic maps, I located areas that were forested prior to development. I then checked the present housing density of these areas on aerial photographs to determine whether they could be

placed into my pre-defined categories. In this way, I selected sites that were not subjected to agricultural use for at least as many years as topographic maps have been produced (approximately 80 years). No other land use, with the exception of urbanization and 
recreation, occurred at my sites. I also attempted to standardize development age among sites. Unfortunately, Urban sites that were forested prior to development were rare, forcing me to select two sites that were developed in the early $19^{\text {th }}$ century. The remainder of the sites were developed between 1922 and the present, with most development occurring in the 1960s. I minimized edge effects by choosing only sites that were surrounded by $>100 \mathrm{~m}$ of development of a similar housing density or forest cover, depending on the category. Due to the scarcity of sites satisfying the above criteria, I was unable to choose sites representing only one forest type. Instead, my sites represented a variety of mature forest types found in the area, such as beech $F$. grandifolia-maple $A$. saccharum and cedar T. occidentalis-fir $A$. balsamea-spruce $P$. mariana communities. However, all of my housing categories included a similar representation of forest types, effectively controlling for the variability in forest composition among sites. Site selection was conditional upon landowner consent. Finally, I ground-truthed all sites to ensure they met my criteria. The number of dwellings at each site and in $500 \mathrm{~m} \times 500 \mathrm{~m}$ developed areas adjacent to Neighbor forest sites were counted on the ground in August 2006.

\subsubsection{Carabid beetle surveys}

I installed pitfall traps for carabid beetles at eight stations in each site in late April and early May 2007, immediately following the spring thaw (Fig. 2.2). Traps were $125 \mathrm{~m}$ apart. Traps consisted of two plastic cups, approximately $8 \mathrm{~cm}$ wide at the mouth and 10 $\mathrm{cm}$ tall. I buried traps in the ground with the rim of the inner cup flush with the ground surface. The base of the outer cup was punctured to allow for water drainage. I placed a $10 \mathrm{~cm} \times 10 \mathrm{~cm}$ plastic roof, supported by $2.54 \mathrm{~cm}$ nails at each corner, above each trap to 
prevent rain and debris from falling in the trap. I filled traps with $100 \mathrm{~mL}$ of propylene glycol and a drop of dish soap. I opened traps May 14 and replaced trap contents weekly until August 3. Thus, I collected beetles continuously over a 12-week period that encompassed the peak in carabid breeding activity in the region (Levesque \& Levesque 1986). Carabid beetles were identified to species using Lindroth (1961-69).

Nomenclature followed Bousquet and Larochelle (1993).

\subsubsection{Comparison of development scenarios}

\subsubsection{Hypothetical development scenarios}

I used the data described above to estimate carabid beetle abundance and species richness along a gradient of increasing housing density and decreasing sprawl area. I represented this gradient with hypothetical development scenarios (Fig. 2.3). Development scenarios can be envisioned as forested landscapes of the same size, into which the same number of dwellings were placed, but in contrasting patterns. One end of the gradient, where housing density is low and sprawl area is large, was represented by the Dispersed scenario, which was completely covered by Exurban-density development. The other end of the gradient, where housing density is high and sprawl area is small, was represented by the Compact scenario. The Compact scenario was home to the same number of dwellings as the Dispersed scenario but the dwellings were clustered at an Urban density and the remainder of the Compact scenario was undeveloped forest. I also estimated carabid beetle abundance and species richness for an intermediate development scenario, the Semi-compact scenario. The same number of dwellings as in the other two development scenarios was represented at a Suburban density, with the remainder of the 
Semi-compact scenario in undeveloped forest. Finally, for comparison, I estimated carabid beetle abundance and species richness for an Undeveloped scenario, i.e., the same area as for the developed scenarios but covered entirely in forest.

I defined a development scenario as a $22.96 \mathrm{~km}^{2}$ square area, or an area equivalent to 91.83 units of the $500 \mathrm{~m} \times 500 \mathrm{~m}\left(0.25 \mathrm{~km}^{2}\right)$ beetle survey sites. I arrived at this development scenario size by calculating the area required to accommodate a given number of dwellings (the mean number of dwellings at my Urban and Urban Neighbor beetle survey sites (712 dwellings)) at the lowest housing density (the Exurban density, mean $=31 \mathrm{dwellings} / \mathrm{km}^{2}$ ). In this way, I created the Dispersed scenario, covered entirely by 712 dwellings at the Exurban housing density or, equivalently, 91.83 Exurban beetle survey sites. In a similar fashion, I determined the size of the developed area (measured in $\mathrm{km}^{2}$ or in the number of Suburban or Urban bird survey sites) within the Semi-compact and Compact scenarios. For these, I created square developed areas positioned in one corner of each development scenario, to represent the area needed to contain 712 dwellings at the mean Urban or Suburban densities $\left(0.25 \mathrm{~km}^{2}\right.$ and $1.42 \mathrm{~km}^{2}$, respectively). For the Semi-compact and Compact scenarios, I assumed that the forest cover adjacent to the developed area had carabid beetle abundances and species richnesses typical of my Neighbor beetle survey sites adjacent to Suburban- and Urbandensity development, respectively. I calculated the area of this adjacent forest cover as the number of Neighbor beetle survey sites required to line both edges of the developed area. This pattern matches the spatial arrangement of my Neighbor beetle survey sites, which shared one complete edge with development (Fig. 2.2b). Finally, I assumed that 
the remaining area in the Semi-compact and Compact scenarios was typical of my Forested beetle survey sites. I assumed the Undeveloped scenario was covered entirely in forest cover typical of my Forested beetle survey sites.

\subsubsection{Theoretical carabid beetle species abundances}

For each development scenario I estimated the abundance of each carabid beetle species collected during my surveys. First I calculated the relative abundance of a species at each beetle survey site by summing the numbers of individuals of the species collected at all eight stations in the site over the entire survey period (Appendix 4). Recall that I measured the area of each development scenario in terms of the numbers of beetle survey sites of each housing category making up the development scenario (see above). Therefore, to estimate the total abundance of a species for a development scenario, I moved through the scenario, one site area at a time, and randomly selected a relative abundance for the species from one of the three or four beetle survey sites in that housing category (Fig. 2.4). For areas in the development scenario making up proportions of beetle survey sites, I multiplied the randomly selected abundance value by that proportion. I summed these 91.83 relative abundance values to yield the estimated abundance of a species in the whole development scenario. For example, Fig. 2.4 depicts the estimation of the abundance of a beetle species in the Semi-compact scenario. The Semi-compact scenario is shown as the equivalent area of many beetle survey sites in three different housing categories: Suburban, Suburban Neighbor and Forested. For each site area in the Semi-compact scenario, a relative abundance value for the beetle species was randomly selected from among the replicate relative abundance values of the beetle 
survey sites in that housing category. For instance, the developed portion of the Semicompact scenario has been 'filled in' with relative abundance values of the beetle species from the four Suburban beetle survey sites. The randomly selected abundance values for the entire Semi-compact scenario were then summed to yield an estimate of the abundance of the beetle species over the whole area of the Semi-compact scenario. I repeated this estimation procedure 1,000 times, resulting in an abundance distribution for each species in each development scenario. In the same manner, I also estimated the total abundance of all carabid beetles in each development scenario and the abundance of beetles belonging to species classified as 'forest', 'open-habitat', 'native' and 'introduced' in each development scenario (Appendix 5).

\subsubsection{Theoretical carabid beetle species richnesses}

I estimated the species richness of all carabid beetles, forest beetles and open-habitat beetles in each development scenario. Using species accumulation curves constructed for each housing category and for each beetle group (Colwell and Coddington 1994), I estimated that I collected $>89 \%$ of species predicted to be present in each type of site. Therefore, I assumed that I recorded the entire community of beetles present in each housing category. Using this information, I estimated the species richness of each beetle group in each development scenario with a procedure similar to that described for abundance. For each site area in a development scenario, I randomly selected an actual sampled site from the appropriate housing category (Appendix 4) and applied the species observed there to the site area in the development scenario. I repeated this procedure for every site area in the development scenario, successively adding any new species to the 
development scenario's species list. For areas in the development scenario making up fractions of beetle survey site areas, I randomly selected without replacement the observations from two, four or six of the trapping stations within the beetle survey site, depending on the size of the fraction of the site area. The development scenario's final species list once every site area had been 'filled' with species was the species richness of that whole development scenario.

Initially, the total number of beetle survey sites available for selection differed among development scenarios (four each in the Undeveloped and Dispersed scenarios and 11 each in the Semi-compact and Compact scenarios). For example, recall that the Dispersed scenario can be considered as the equivalent area to 91.83 Exurban beetle survey sites. Thus, there were only four Exurban beetle survey sites from which species observations could be used to estimate species richness in the Dispersed scenario. The Compact scenario, on the other hand, was made up of areas represented by beetle survey sites in three housing categories: Urban, Urban Neighbor and Forested. Thus, observations from 11 beetle survey sites (four Urban, three Urban Neighbor, and four Forested) could be used to estimate species richness in the Compact scenario. This represented a difference in sample size among the development scenarios, which could bias the results such that the estimated richnesses in the Undeveloped and Dispersed scenarios would be lower than they should be, relative to the richnesses of the Semicompact and Compact scenarios. I corrected for this by randomly selecting two Forested beetle survey sites, one Suburban or Urban site and one Suburban Neighbor or Urban Neighbor site prior to estimating the species richness of each beetle group in the Semi- 
Compact and Compact scenarios. For example, for the Semi-compact scenario, I randomly selected two Forested sites, one Suburban site and one Suburban Neighbor site. These four beetle survey sites represented the pool from which species observations could be selected according to the procedure described above. Thus, for the Semicompact and Compact scenarios, the initial number of beetle survey sites available for selection was restricted to four, to equal the number of beetle survey sites available for the Undeveloped and Dispersed scenarios. Finally, I repeated the entire procedure just described 1,000 times to yield an estimate of the species richness of each beetle group and its associated error in each development scenario. All analyses were carried out using $\mathrm{R}$ version 2.6.2 ( $\mathrm{R}$ Development Core Team 2008).

\subsection{Results}

\subsubsection{Beetle abundance and richness in the survey sites}

I collected 4,630 individuals from 90 species during my surveys (Appendix 4). I classified 26 species as forest species, 41 species as open-habitat species, 80 species as native species and 10 species as introduced species (Appendix 5). I collected 694 individuals of the most abundant species, Pterostichus mutus, which occurred at 13 of the 22 survey sites (Appendix 4). The most widespread species, Carabus nemoralis, $P$. melanarius and $P$. pensylvanicus, occurred at 17 survey sites each. I collected only one individual of 16 species during my surveys.

The abundance and species richness of carabid beetle groups varied among survey sites (Table 2.1). Total beetle abundance was highest in Suburban Neighbor and Urban 
Neighbor survey sites and total species richness peaked in Exurban survey sites. Forest beetle abundance and species richness declined as housing density increased from the Forested to the Urban housing categories. Suburban Neighbor and Urban Neighbor survey sites had intermediate values of forest beetle abundance and species richness (Table 2.1). Open-habitat beetle abundance was highest in Urban Neighbor survey sites, followed by Suburban survey sites. Open-habitat beetle species richness increased as housing density increased from the Forested to the Urban housing categories, with Suburban Neighbor and Urban Neighbor survey sites having intermediate numbers of open-habitat beetle species (Table 2.1). Finally, native beetle abundance was highest in Urban Neighbor survey sites, followed by Forested sites and introduced beetle abundance was highest in the two Neighbor housing categories (Table 2.1).

\subsubsection{Effects of housing density vs. sprawl area}

Of the three developed scenarios, $40 \%$ of individual carabid beetle species ( 36 species) had their highest estimated abundance in the Compact scenario, 24\% (22 species) had their highest estimated abundance in the Semi-compact scenario and 36\% (32 species) had their highest estimated abundance in the Dispersed scenario (Appendix 5).

I estimated total beetle abundance to be highest in the Semi-compact scenario (Fig. 2.5a). Of the three developed scenarios, I estimated the abundance of forest beetle species to be highest in the Compact scenario (Fig. 2.5b). Open-habitat beetle species abundance was highest in the Semi-compact scenario (Fig. 2.5c). Native beetle abundance was highest in the Compact scenario (Fig. 2.5d) and introduced beetle abundance was highest in the Dispersed scenario (Fig. 2.5e). 
I estimated total beetle species richness to be highest in the Compact scenario (Fig. 2.6a). Forest beetle species richness was also estimated to be highest in the Compact scenario (Fig. 2.6b) and open-habitat beetle species richness was highest in the Semicompact scenario (Fig. 2.6c).

\subsection{Discussion}

My results suggest that clustering development at a Suburban or Urban housing density minimizes the impacts of a given human population on carabid beetle diversity. In particular, I estimated that high-density development over a small area (the Compact scenario) resulted in the highest abundance and species richness of forest beetles when compared to other development patterns (Figs. 2.5b, 2.6b). I also estimated total beetle species richness and the abundance of native beetles to be highest in the Compact scenario (Figs. 2.5d, 2.6a). The Semi-compact scenario had the highest estimated total beetle abundance (Fig. 2.5a), likely due to open-habitat beetles having their highest estimated abundance in this scenario (Fig. 2.5c). Open-habitat beetles were also most speciose in the Semi-compact scenario (Fig. 2.6c). The Dispersed scenario was characterized by the highest estimated abundance of introduced beetles (Fig. 2.5e).

Estimated forest beetle abundance increased with the number of Forested survey site areas in a hypothetical scenario. Forest carabid beetle abundance is negatively correlated with urbanization (Gaublomme et al. 2008, Magura et al. 2008). The pattern of forest beetle abundance in my survey sites supports this assertion, with forest beetle abundance declining as housing density increased from the Forested to the Urban housing categories 
(Table 2.1). Thus, scenarios made up of a large number of Forested survey site areas, in which forest carabid beetles reached their highest abundance (Table 2.1), should intuitively have the highest estimated abundance of this group. This can be clearly seen in Fig. 2.5b where the Undeveloped, Compact and Semi-compact scenarios have, in descending order, both the largest area of hypothetical forest habitat typical of Forested survey sites and the highest estimated abundance of forest beetles.

The high abundance and species richness of open-habitat beetles in Suburban survey sites likely resulted in my estimating the Semi-compact scenario to have the highest abundance and species richness of this group (Table 2.1, Figs. 2.5c, 2.6c). Although Urban and Urban Neighbor survey sites also had high abundances of open-habitat beetles (Table 2.1), I estimated the lowest open-habitat beetle abundance of the developed scenarios to be in the Compact scenario (Fig. 2.5c). This was because the Compact scenario was made up of a small developed area (one Urban survey site area bordered by two Urban Neighbor survey site areas) compared to the Semi-compact scenario (5.66 Suburban survey site areas bordered by 4.76 Suburban Neighbor site areas). The Dispersed scenario had the second highest estimated open-habitat beetle abundance (Fig. 2.5c). Two conclusions can be drawn from these results. First, it appears that open-habitat beetles make use of the microhabitats created by Suburban-density development. To my knowledge, research on the effects of urbanization on carabid beetles has so far been restricted to grassland and forest fragments in a developed matrix (e.g., Magura et al. 2008). The patterns I report here indicate that open-habitat carabid beetles may use the landscape matrix as habitat in addition to that provided by fragments. Second, despite 
Exurban survey sites being poor quality habitat for open-habitat beetles (Exurban survey sites had the lowest open-habitat beetle abundance of all housing categories (Table 2.1)), a large expanse of Exurban-density development (the Dispersed scenario) could result in large populations of these species.

Interestingly, the Dispersed scenario was estimated to have over twice the abundance of introduced beetles as the Semi-compact scenario and over five times the number of introduced beetles as the Compact scenario (Fig. 2.5e). This pattern was likely driven by the second and third most common species I collected during my surveys, C. nemoralis and $P$. melanarius. Both species had their highest estimated abundance in the Dispersed scenario (Appendix 5). As for open-habitat beetle abundance above, Exurban survey sites actually had low abundances of introduced beetles but the large number of Exurban survey site areas in the Dispersed scenario resulted in a high estimated abundance of this group for the whole scenario. This illustrates how the trade-off between housing density and sprawl area mediates the impacts of a given human population on biodiversity. Introduced beetles were twice as abundant in high-density development (Urban survey sites) as in low-density development (Exurban survey sites) (Table 2.1). However, for a given human population, a small area of high-density development surrounded by forest (the Compact scenario) actually had much lower introduced beetle abundance than a large area of low-density development (the Dispersed scenario) (Fig. 2.5e).

In Chapter 1, I found that estimated forest breeding bird abundance and species richness in the same hypothetical scenarios showed similar trends to those reported here for forest carabid beetles. I found that forest birds, and in particular forest interior birds, 
were most abundant in the Compact scenario and most speciose in the Semi-compact scenario (not including the Undeveloped scenario). Similarly, in this chapter, forest carabid beetles were most abundant and speciose in the Compact scenario (not including the Undeveloped scenario) (Figs. 2.5b, 2.6b). These results suggest that building at a high density over a small area minimizes the impacts of a given human population on forest specialist taxa, groups that exhibit strong declines with increasing urbanization (Friesen et al. 1995, Kluza et al. 2000, Sadler et al. 2006, Elek \& Lövei 2007, Pidgeon et al. 2007, Gaublomme et al. 2008, Magura et al. 2008).

Biodiversity conservation in human-dominated landscapes necessitates the explicit incorporation of economic and ecological endpoints in conservation research. In this chapter, I attempted to quantify the impacts to carabid beetles of accommodating a given human population in hypothetical landscapes containing housing at different densities. My estimations of carabid beetle abundance and species richness suggest that building at a high density over a small area minimizes the impacts of a given human population. If this result is general across all forest taxa and all regions of the world, then I predict that widespread implementation of urban planning policies that minimize sprawl area would result in an important advance in the conservation of biological diversity worldwide (Sutherland et al. 2009). 


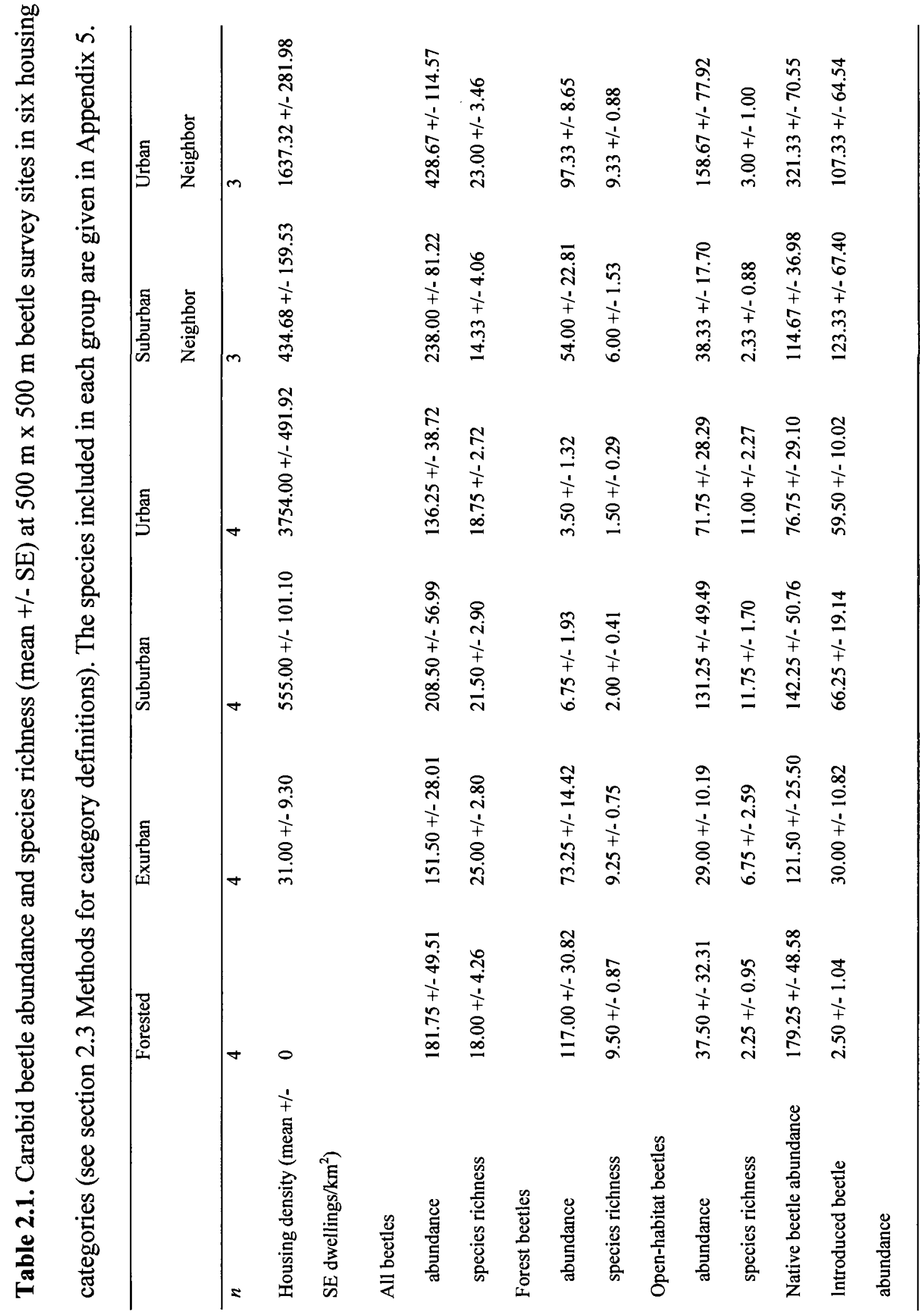




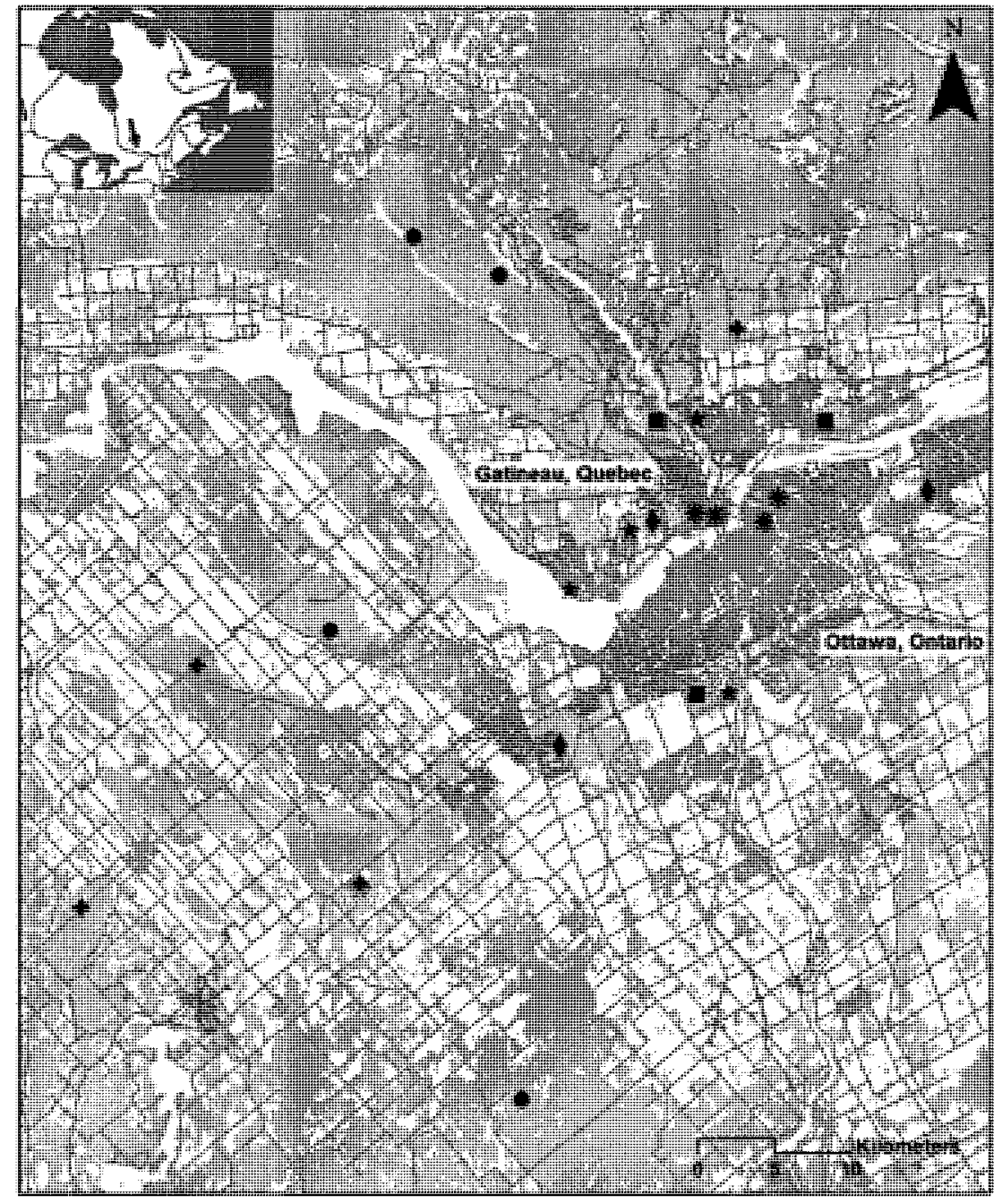

Figure 2.1. The study area surrounding the cities of Ottawa, Ontario and Gatineau, Quebec, Canada. Inset depicts the location of the study area in eastern North America. Beetle survey sites are $0.25 \mathrm{~km}^{2}$ areas indicated by symbols representing six housing categories: $\bullet$ Forested $\left(0\right.$ dwellings $\left./ \mathrm{km}^{2}\right),+$ Exurban $\left(<56 \mathrm{dwellings} / \mathrm{km}^{2}\right), \star$ Suburban (140-712 dwellings/ $\left.\mathrm{km}^{2}\right)$, * Urban ( $>1,244$ dwellings $\left./ \mathrm{km}^{2}\right)$; and two categories of forested sites adjacent to developments of Suburban and Urban 
densities: $\square$ Suburban Neighbor, $\$ Urban Neighbor. Dark gray lines indicate roads.

Forest cover is in light gray. 
*

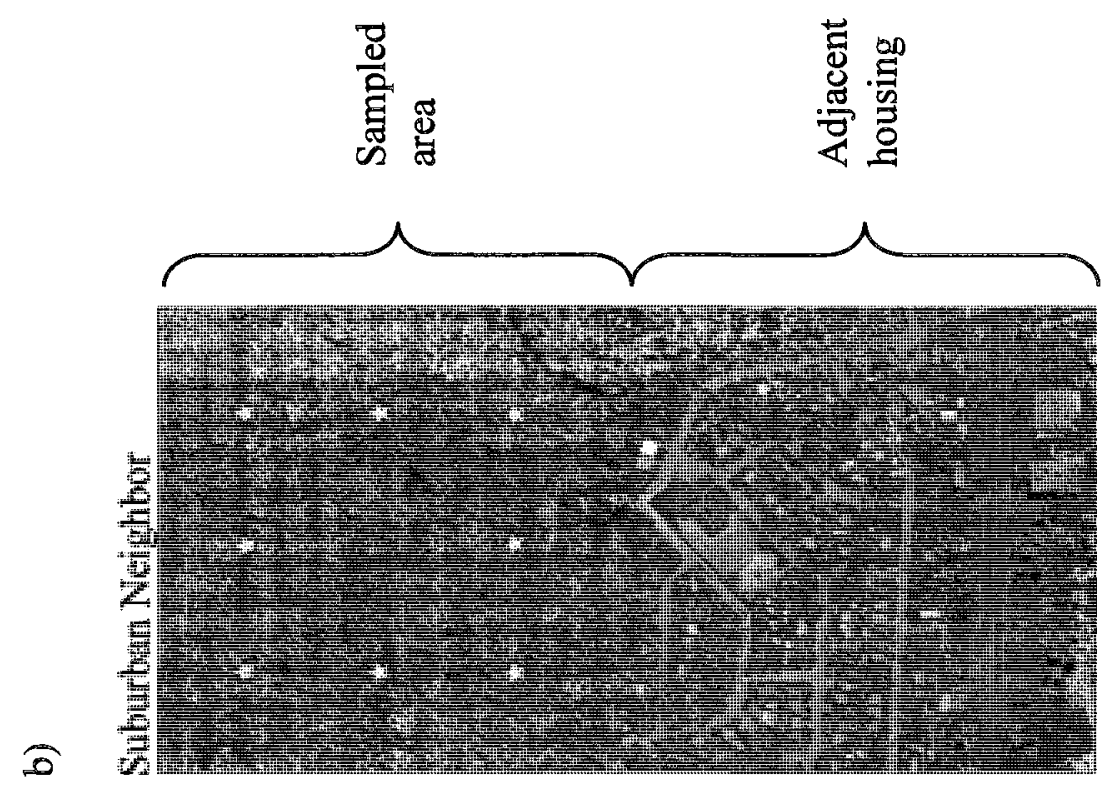

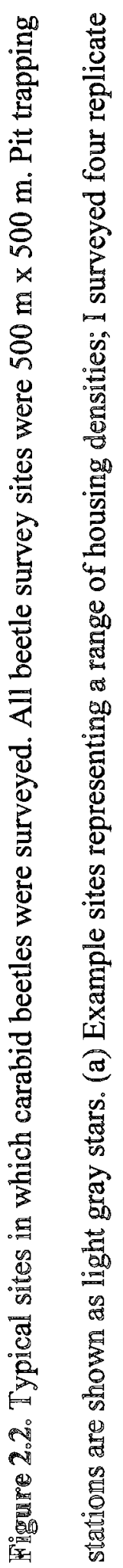
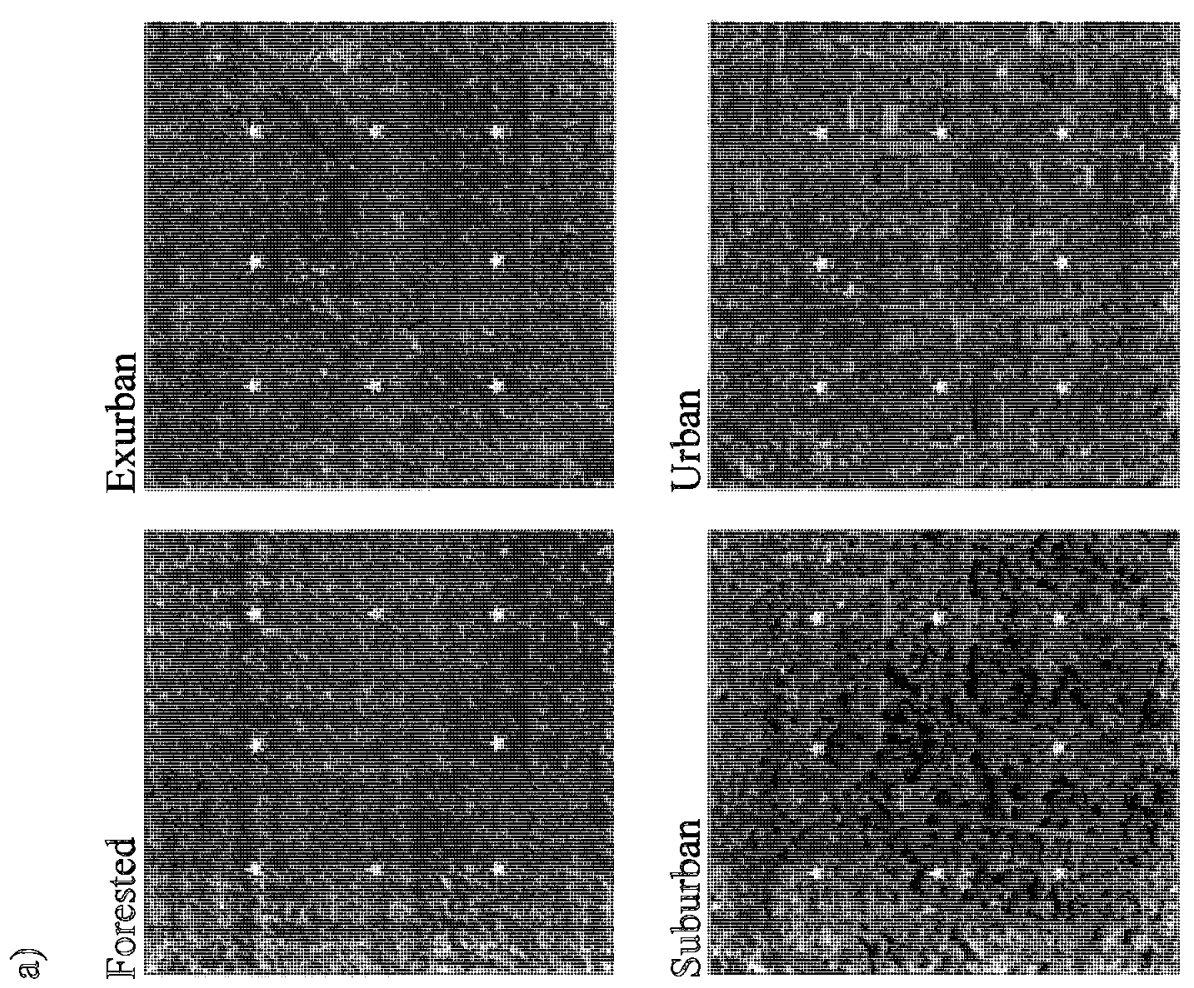


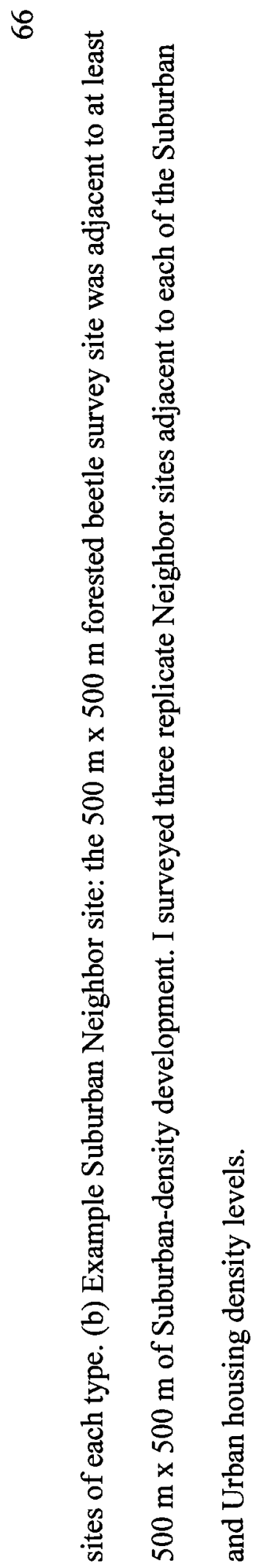




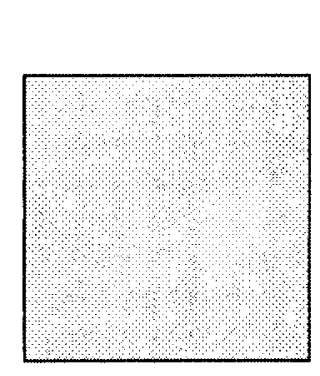

Undeveloped

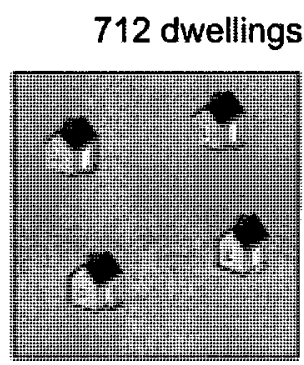

Dispersed

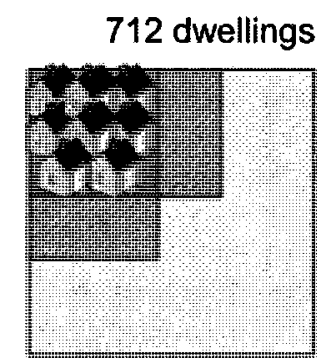

Semi-compact

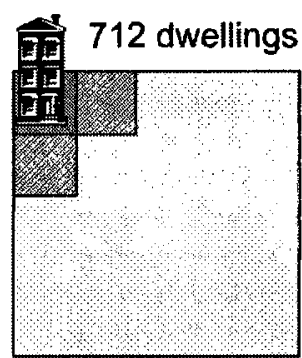

Compact

\section{Housing density}

\section{Sprawl area}

Figure 2.3. Hypothetical development scenarios representing a gradient of increasing housing density and decreasing sprawl area. For a given forested area (the Undeveloped scenario), the same number of dwellings is depicted at three housing densities, Exurban, Suburban and Urban, resulting in dispersed, semi-compact and compact development patterns, respectively. Hatched areas represent forest habitat adjacent to development, typical of Neighbor sites. Drawings, including proportions of each cover type in each scenario, are not to scale. For example, the developed portion of the Semi-compact scenario was $6.18 \%$ of the total area of the scenario. Scenarios were $22.96 \mathrm{~km}^{2}$. 


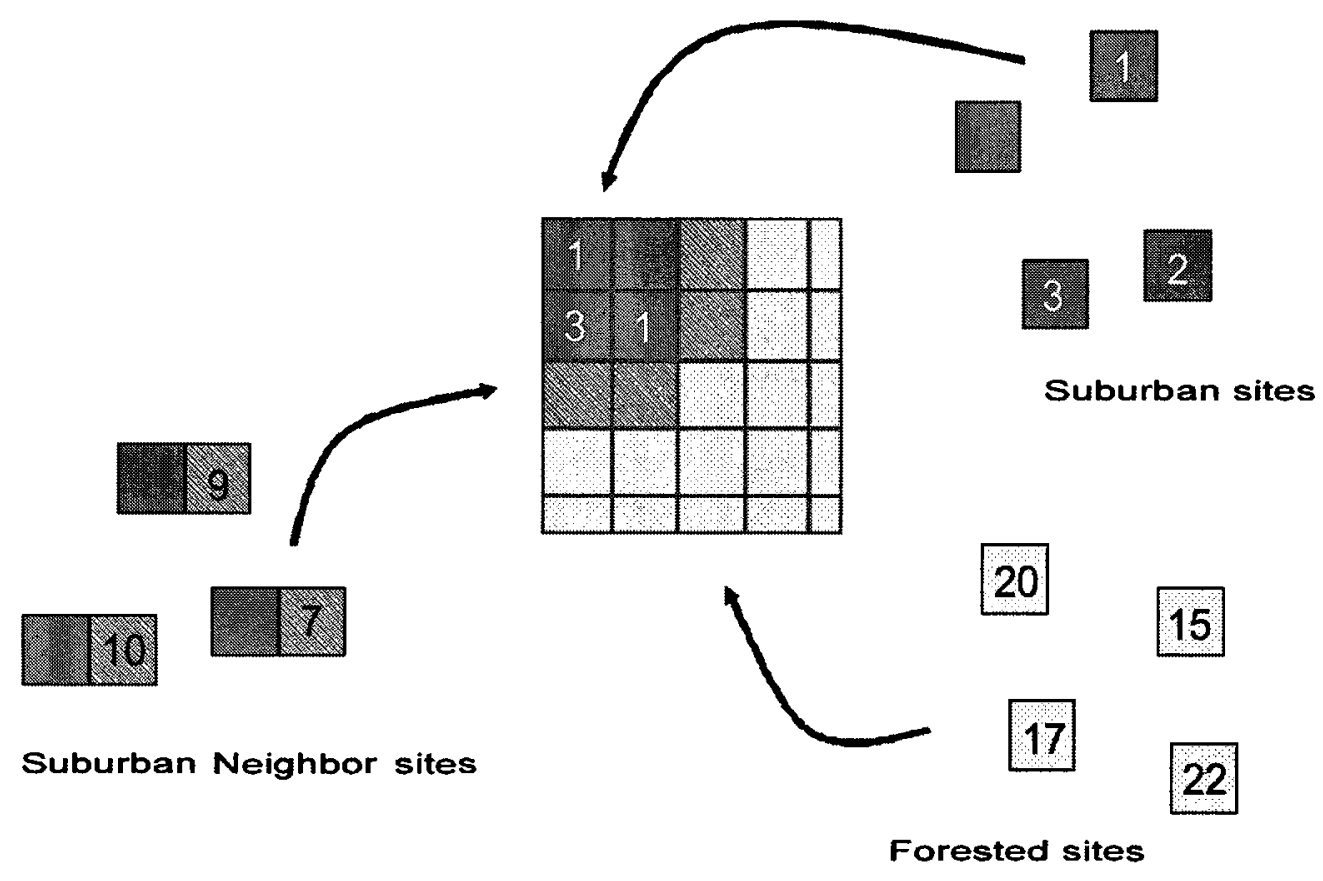

Figure 2.4. Illustration of the method for estimating the abundance of a carabid beetle species in a development scenario. Shown is the Semi-compact scenario (see Fig. 2.3; not to scale). Numbers represent the relative abundance of the species in each beetle survey site, calculated from pitfall trap data. Three types of beetle survey sites make up the Semi-compact scenario: Suburban, Forested and Suburban Neighbor. For each site area in the scenario, a relative abundance value was randomly chosen from the replicate beetle survey sites in the appropriate housing category. To illustrate this, the developed portion of the scenario has been filled in with randomly chosen relative abundance values from the Suburban beetle survey sites. For areas in the development scenario that are smaller than site areas, the relative abundance value was multiplied by the proportion of a site 
area represented. Finally, the randomly selected values for the entire Semi-compact

scenario were summed to yield an estimate of the abundance of the carabid beetle species in the whole development scenario. 
a)

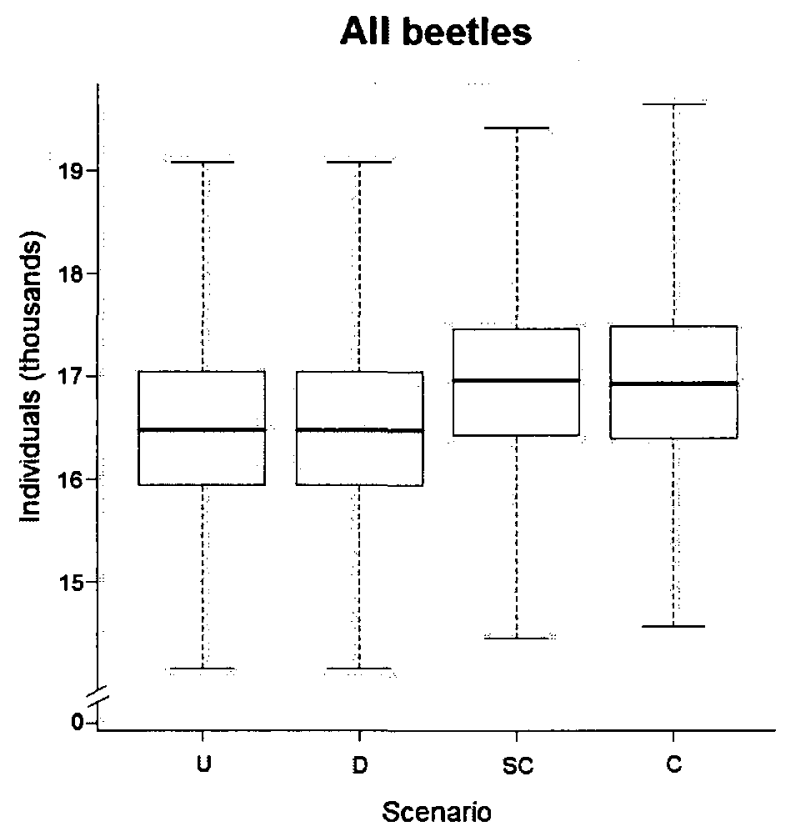

b)

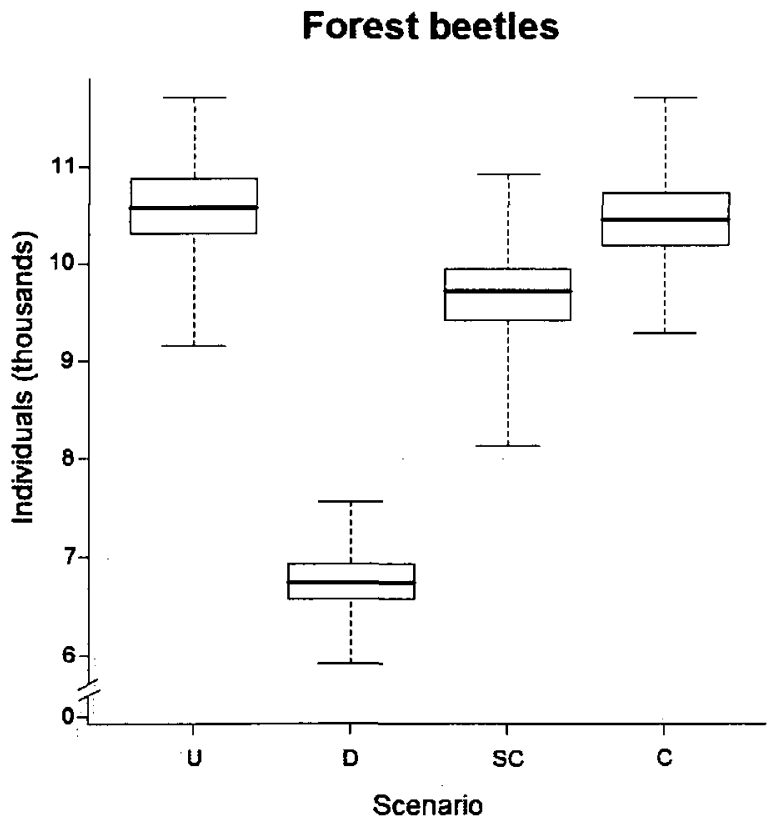


c)

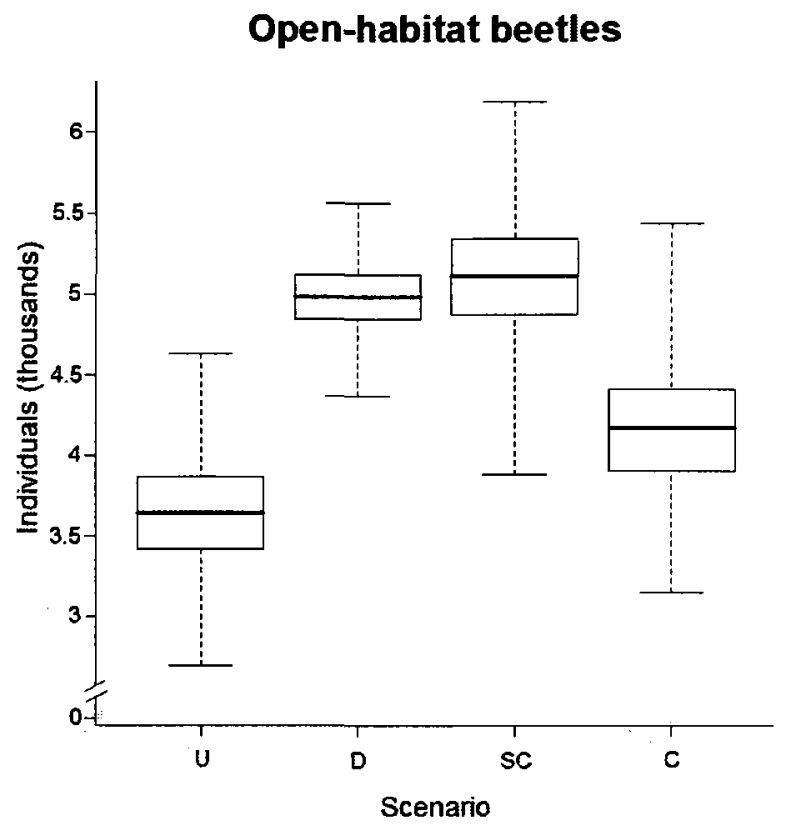

d)

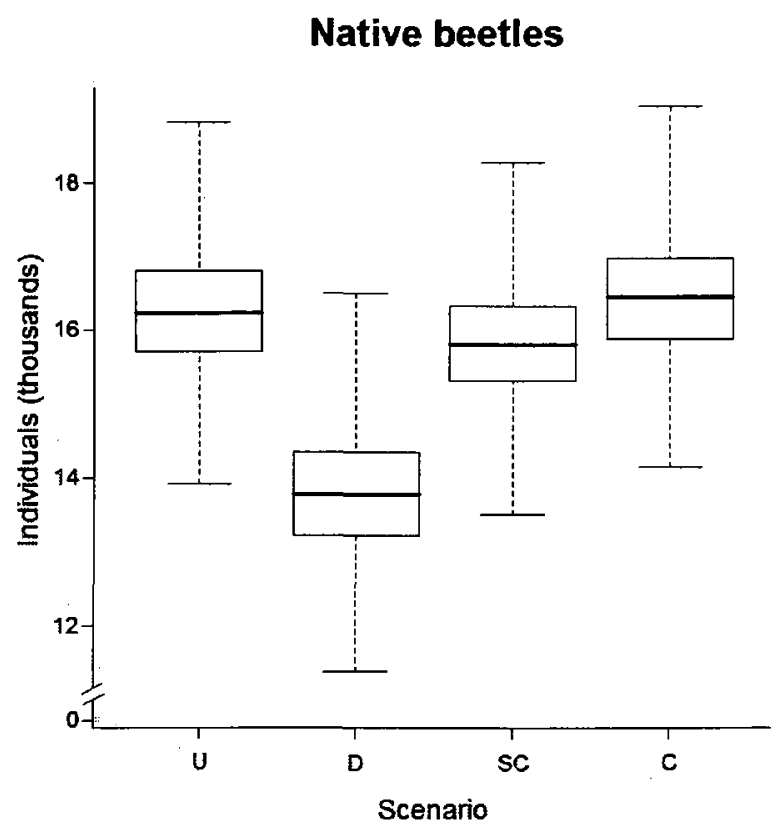


e)

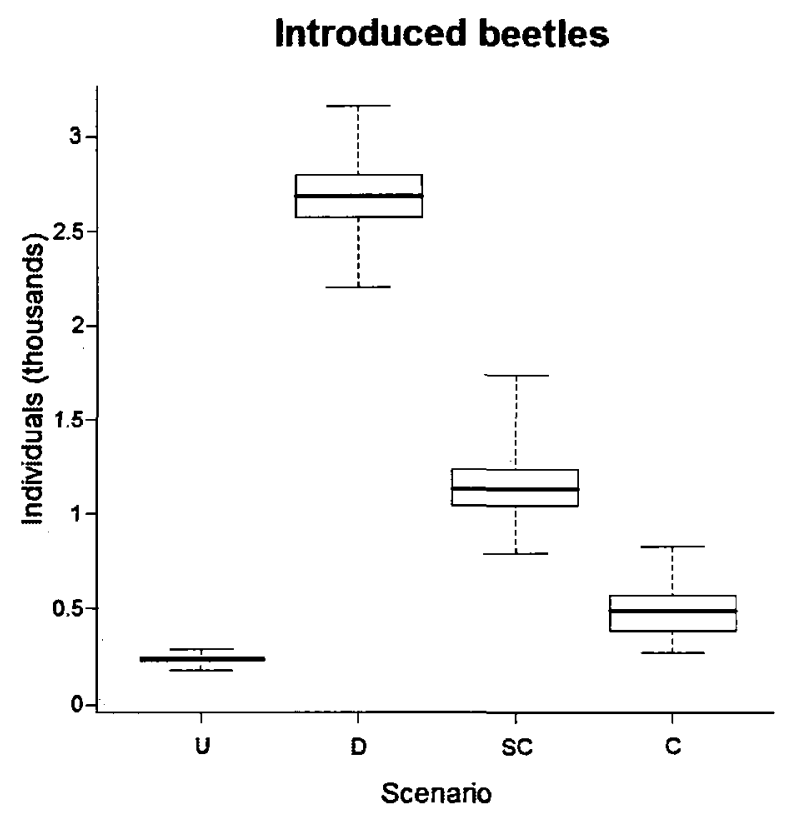

Figure 2.5. The estimated abundances of five carabid beetle groups in four hypothetical development scenarios: U, Undeveloped; D, Dispersed; SC, Semi-compact; C, Compact. (a) All beetles. (b) Forest beetles. (c) Open-habitat beetles. (d) Native beetles. (e) Introduced beetles. The species included in each group are given in Appendix 5. The lower edge of each box is the first quartile, the bold center line is the median and the upper edge is the third quartile of the distribution. Whiskers extend to the minimum and maximum values. 
a)

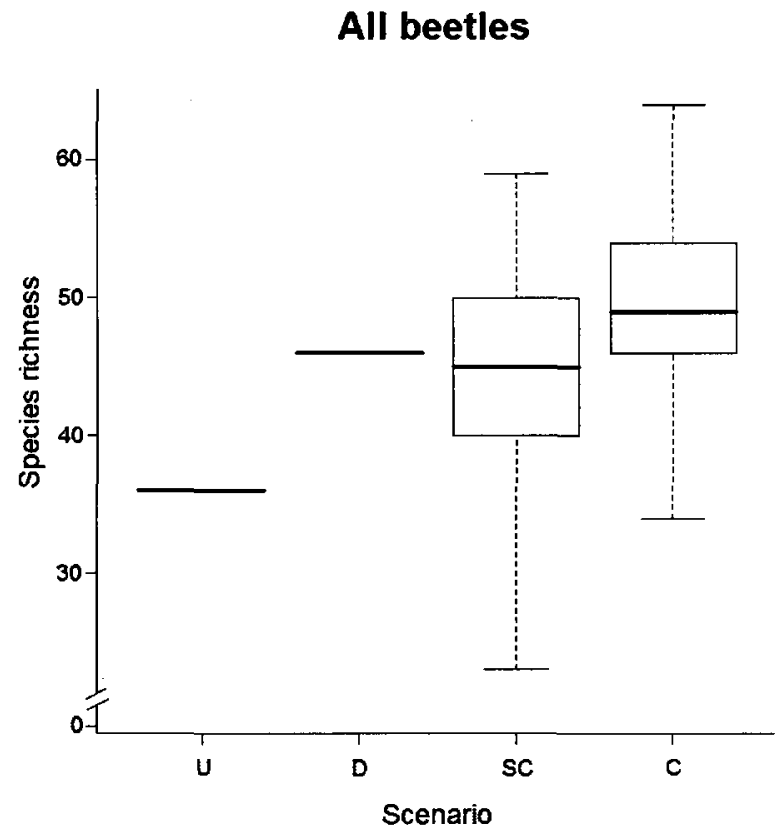

b)

Forest beetles

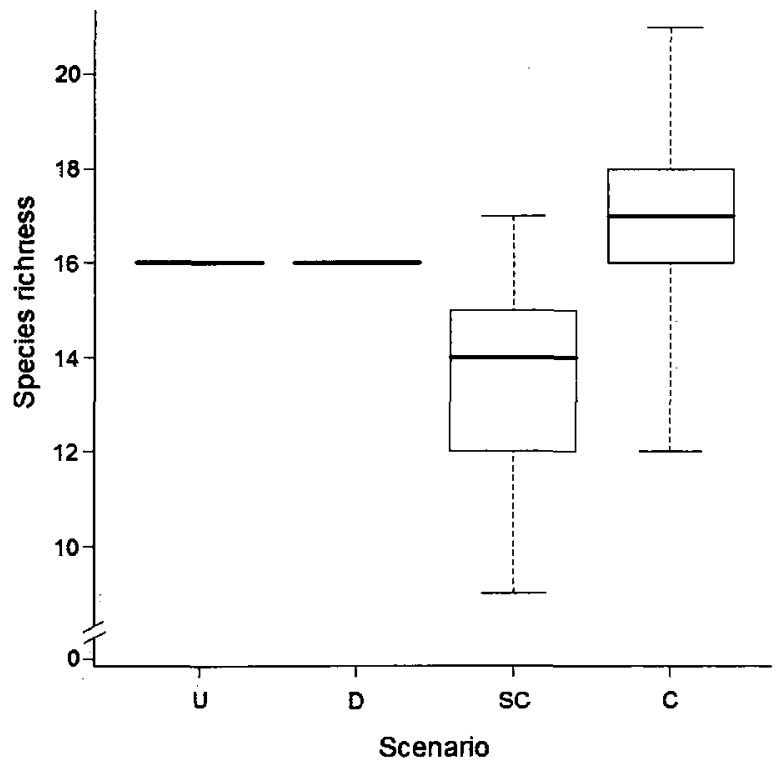


c)

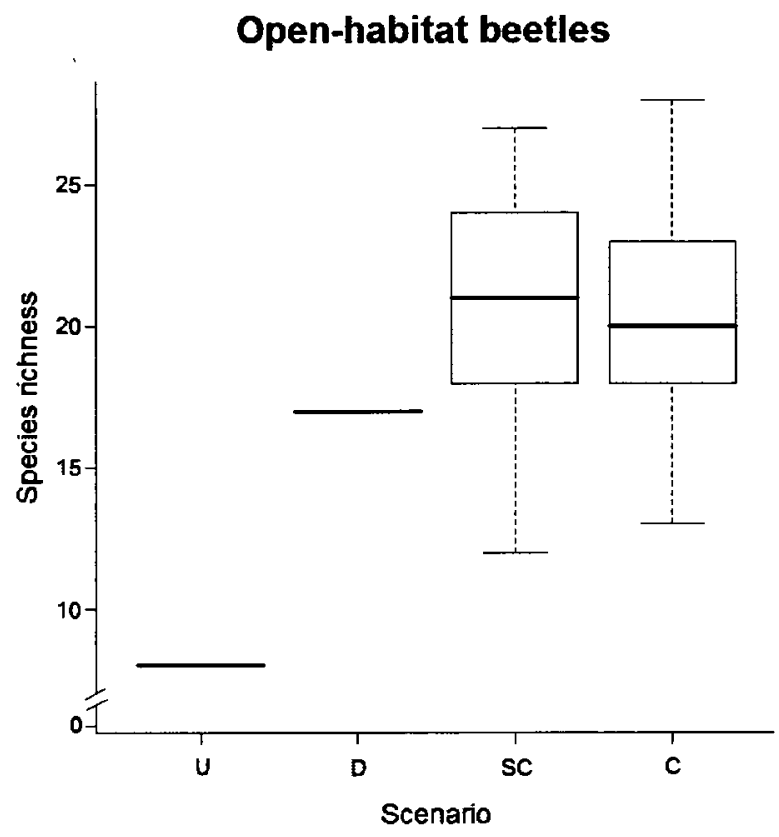

Figure 2.6. The estimated species richnesses of three carabid beetle groups in four hypothetical development scenarios: U, Undeveloped; D, Dispersed; SC, Semi-compact; C, Compact. (a) All beetles. (b) Forest beetles. (c) Open-habitat beetles. The species included in each group are given in Appendix 5. The lower edge of each box is the first quartile, the bold center line is the median and the upper edge is the third quartile of the distribution. Whiskers extend to the minimum and maximum values. Species richness estimates for the Undeveloped and Dispersed scenarios had zero variance. This is because all beetle species collected in the four Forested survey sites (for the Undeveloped scenario) and the four Exurban survey sites (for the Dispersed scenario) were always estimated to be in at least one of the large number (91.83) of replicate site areas in these scenarios. 


\section{Chapter 3. Do birds and beetles show similar responses to urbanization?}

\subsection{Summary}

Biodiversity congruence has long been a topic of interest to ecologists and conservation biologists. A noticeable gap in the study of biodiversity congruence is the lack of studies in human-dominated environments, particularly urban areas. To date, the vast majority of studies in urban areas have been carried out on birds yet it is not known whether the responses of birds to urbanization are correlated with those of other taxa. In this chapter, I compared the responses of breeding birds and carabid beetles to urbanization to determine the congruence between the two taxa. Specifically, I asked whether the emerging generalizations of the effects of urbanization on birds could also be applied to ground beetles. I also directly tested for congruence between birds and ground beetles using correlations between variables describing bird and beetle community structure and correlations between bird and beetle distance matrices. Breeding bird and carabid beetle community data were collected in two groups of sites (each site $0.25 \mathrm{~km}^{2}$ ) in Ottawa, Ontario and Gatineau, Quebec, Canada representing two predictor variables: within-site housing density and neighboring housing density. My analyses indicated that breeding birds and carabid beetles do not respond similarly to increasing within-site housing density but that they do exhibit some similar responses to increasing neighboring housing density. Birds displayed strong declines in diversity, compositional changes, community simplification and community homogenization in response to increasing within-site housing density. Although beetles did exhibit similar changes to birds in forest species 
abundance and richness and introduced species abundance, they showed no patterns of community simplification and only weak patterns of community homogenization with increasing within-site housing density. To better understand and mitigate the effects of urbanization on biodiversity, I suggest that future research should focus on responses of taxa other than birds.

\subsection{Introduction}

Biodiversity congruence has long been a topic of interest to ecologists and conservation biologists (Murphy \& Wilcox 1986). The search for indicator species, whose presence would reliably predict that of unrelated taxa, has been fuelled primarily by the potential benefits to protected area creation and management and the mitigation of human impacts. Despite our best efforts, there will remain many taxa for which little to no information is available, highlighting the importance of congruence between well- and little-known taxa to biodiversity conservation. For this reason, correlations between the species richnesses of different taxa have been the subject of many analyses (Weaver 1995, Allen et al. 1999a, b, Ricketts et al. 1999, Sauberer et al. 2004, Billeter et al. 2008, Xu et al. 2008, Sebastião \& Grelle 2009). More recently, several studies have also evaluated the congruence of community similarity (Heino et al. 2003, Su et al. 2004, Oertli et al. 2005). In general, correlations between taxa are positive and are strongest at large spatial scales, although correlation strength is also context-dependent (Hess et al. 2006).

A noticeable gap in the study of biodiversity congruence is the lack of studies in human-dominated environments, particularly urban areas. Urbanization is proceeding 
rapidly in many parts of the world with important consequences for biodiversity (Mcdonald et al. 2008). However, it is unclear whether different taxa respond similarly to urbanization. To date, the vast majority of studies in urban areas have been carried out on birds (McDonnell \& Hahs 2008). Thus, birds have become a de facto indicator taxon for urbanization due to their inherent appeal and ease of study. In terms of understanding and mitigating the effects of urbanization on biodiversity, it is important to determine whether the responses of birds correlate with the responses of other taxa.

Several generalizations are emerging from the literature of the effects of urbanization on birds. Many studies have reported an overall decrease in bird species richness with increasing urbanization (e.g., housing density, amount of urban land cover) (e.g., Germaine et al. 1998, Miller et al. 2003). In some instances, a humped-shaped response has been observed, with species richness initially increasing at intermediate levels of urbanization and then decreasing at high levels (Blair 1996, Lepczyk et al. 2008). In general, however, highly urbanized areas have far fewer bird species than natural areas. In highly urbanized areas in North America, native specialist species are replaced by introduced species that reach very high abundances, often resulting in an increase in total bird abundance with urbanization (Shochat et al. 2006). Thus, urbanization results in the simplification of the bird community, which is transformed from a diverse assemblage in natural areas to one dominated by a few abundant species. Recently, several authors have also reported that bird communities in different urban areas are more similar to one another than are bird communities in different natural areas, indicating that urbanization results in the homogenization of avian assemblages (Blair 2004, Olden et al. 2006, Sorace 
$\&$ Gustin 2008). The uniform structure of the built-up environment and the wide distribution of the avian species adapted to this environment have resulted in an increase in the similarity between bird communities in cities worldwide (McKinney 2006).

A small number of studies have looked at the effects of urbanization on ground beetle (Coleoptera: Carabidae) communities, focussing on community structure in forest fragments surrounded by varying intensities of urbanization. It appears that urban forest fragments have fewer individuals than suburban or rural forest fragments but it is unclear whether the number of species remains unchanged or declines with urbanization (Niemelä et al. 2002, Ishitani et al. 2003, Magura et al. 2004, Weller \& Ganzhorn 2004, Gaublomme et al. 2008). Ground beetle communities in rural forest fragments are composed mostly of forest specialist species whereas beetle community composition in urban forest fragments is dominated by open-habitat and generalist species (Sadler et al. 2006, Elek \& Lövei 2007, Magura et al. 2008). Finally, it appears that $\beta$-diversity of ground beetles in forest fragments increases with increasing surrounding urbanization so that beetle communities in urban forest fragments are more dissimilar than those in rural ones (Magura et al. 2008).

To my knowledge, no study to date has sampled carabid beetles in the urban matrix. The generalizations of the effects of urbanization on birds described above are in large part based on studies of bird communities in the urban matrix. To determine if bird responses to urbanization are indicative of those of other taxa, such as carabid beetles, the latter must be sampled in the urban matrix as well. We do not know if the urban matrix 
supports similarly poor bird and beetle communities or if a very different response is exhibited by the latter taxon.

In this chapter, I compared the responses of breeding birds and carabid beetles to urbanization to determine the congruence between the two taxa. Specifically, I asked whether the emerging generalizations of the effects of urbanization on birds could also be applied to ground beetles. First, does carabid beetle species richness, particularly the richness of specialist species, decline with urbanization? Second, is there an increase in carabid beetle total abundance with urbanization, due to an increase in the abundance of introduced species? Third, do changes in species richness and abundance translate into the simplification of the carabid beetle community, such that communities become dominated by fewer species with increasing urbanization? Fourth, does community homogenization occur, such that beetle communities in different locations become more similar in their compositions with increasing urbanization? I also directly tested for congruence between birds and ground beetles using correlations between variables describing bird and beetle community structure and correlations between bird and beetle distance matrices. I hypothesized that urbanization is a strong environmental determinant of community structure and as such, birds and beetles should show similar responses to it and be positively correlated.

\subsection{Methods}

I collected relative abundance and species richness data for both birds and ground beetles in two groups of sites: (i) sites representing a gradient in housing density (hereafter 
referred to as 'housing density' sites) and (ii) forested sites adjacent to developments of varying housing densities (hereafter referred to as 'neighboring housing density' sites). All analyses were carried out separately for these two groups of sites. I also carried out analyses at two spatial scales: the site scale and the station scale, the latter being the sampling scale within sites.

\subsubsection{Study area}

I sampled breeding birds and carabid beetles at $250.25 \mathrm{~km}^{2}$ sites in and around Ottawa, Ontario and Gatineau, Quebec, Canada (Fig. 3.1). The study area encompassed approximately $4,040 \mathrm{~km}^{2}$ on both sides of the Ottawa River. The northern half of the study area forms part of the Southern Laurentians ecoregion of Quebec and is underlain by the Canadian Shield, composed mainly of massive Precambrian granite and gneiss. Elevation is commonly 300-600 m above sea level. The St. Lawrence Lowlands ecoregion is south of the Ottawa River and is underlain by flat-lying Palaeozoic strata with elevations rarely more than $150 \mathrm{~m}$ above sea level. All site categories (see below) were approximately equally represented in both ecoregions to account for possible differences in forest composition (Fig. 3.1). In addition, I tested a posteriori for differences in tree community composition between ecoregions using a redundancy analysis. The single constrained eigenvalue was not significant (100 permutations, $F_{1,2}=$ $2.37, p=0.29)$

\subsubsection{Site selection}

I selected four sites in each of four categories representing a gradient in housing density: Forested $\left(0\right.$ dwellings $\left./ \mathrm{km}^{2}\right)$, Exurban $\left(<56\right.$ dwellings $/ \mathrm{km}^{2}$, mean $=31+/-9(\mathrm{SE})$ 
dwellings $\left./ \mathrm{km}^{2}\right)$, Suburban (140-712 dwellings $/ \mathrm{km}^{2}$, mean $=555+/-101$ (SE)

dwellings $\left./ \mathrm{km}^{2}\right)$ and Urban $\left(>1,244\right.$ dwellings $/ \mathrm{km}^{2}$, mean $=3,754+/-492$ (SE)

dwellings $/ \mathrm{km}^{2}$ ) (Fig. 3.2a). Sites in these four categories made up the housing density group of sites described above. Housing density values for each category are consistent with those of several other authors (Kluza et al. 2000, Odell \& Knight 2001, Gillham 2002). Each site comprised the area within a $500 \mathrm{~m} \times 500 \mathrm{~m}$ square $\left(0.25 \mathrm{~km}^{2}\right)$. In addition to these 16 sites, I selected nine forested sites, equal in size to those described above, adjacent to developments of Exurban, Suburban and Urban housing densities (three sites each) (Fig. 3.2b). These Exurban Neighbor, Suburban Neighbor and Urban Neighbor sites, in addition to the Forested sites described above which were adjacent to other forest (no development), made up the neighboring housing density group of sites described previously.

I searched for sites using a combination of historical topographic maps $(\sim 1 / 50,000$, currently produced by the Centre for Topographic Information, Natural Resources Canada, Ottawa, Ontario, Canada) and the most recent aerial photographs available (2002, 1/15,000, produced by the City of Ottawa, Ontario, Canada). Using topographic maps, I located areas that were forested prior to development. I then checked the present housing density of these areas on aerial photographs to determine whether they could be placed into my pre-defined categories. In this way, I selected sites that were not subjected to agricultural use for at least as many years as topographic maps have been produced (approximately 80 years). No other land use, with the exceptions of urbanization and recreation, occurred at my sites. I also attempted to standardize development age among 
sites. Unfortunately, Urban sites that were forested prior to development were rare, forcing me to select two sites that were developed in the early $19^{\text {th }}$ century. The remainder of the sites were developed between 1922 and the present, with most development occurring in the 1960s. I minimized edge effects (with the exception of the forest/development edge in my neighboring housing density sites (Fig. 3.2b)) by choosing only sites that were surrounded by $>100 \mathrm{~m}$ of development of a similar housing density or forest cover, depending on the category. Due to the scarcity of sites satisfying the above criteria, I was unable to choose sites representing only one forest type. Instead, my sites represented a variety of mature forest types found in the area, such as beech $F$. grandifolia-maple $A$. saccharum and cedar T. occidentalis-fir $A$. balsamea-spruce $P$. mariana communities. However, all of the housing density categories (Forested, Exurban, Suburban and Urban) and neighboring housing density categories (Forested, Exurban Neighbor, Suburban Neighbor and Urban Neighbor) included a similar representation of forest types, effectively controlling for the variability in forest composition among sites. Site selection was conditional upon landowner consent. Finally, I ground-truthed all sites to ensure they met my criteria. The number of dwellings at each site and in the $500 \mathrm{~m} \times 500 \mathrm{~m}$ developed areas adjacent to neighboring housing density sites were counted on the ground in August 2006.

\subsubsection{Breeding bird surveys}

I counted breeding birds at four stations in each site using the Ontario Forest Bird Monitoring Program protocol (Cadman et al. 1998). At each site, I centered a station in each quarter; stations were thus $250 \mathrm{~m}$ apart (Fig. 3.2). I conducted two point count 
surveys at each station in 2006, the first between May 24 and June 6 and the second between June 13 and June 28. During each period, I surveyed two sites per day with the exception of one day when I surveyed three sites. Each day, I chose sites from different categories and points on the urbanization gradient and as far as possible from one another. The order of sites surveyed per day was reversed between the two surveys to minimize any time-of-day bias in the data. I visited stations within sites in the same order during both surveys.

During each survey, I conducted a 10-minute point count at each station between a half-hour before sunrise and five hours after sunrise. I only performed point counts when the wind was $<3$ on the Beaufort scale and it was not raining. If these conditions were not met, I cancelled the count(s) and resumed on the next possible day. I counted all adult birds seen or heard during the 10-minute period at an unlimited distance from the station. I did not include birds flying at a high altitude and obviously passing over the site.

I calculated the relative abundance of each species at each station as the maximum number of birds counted during either point count survey. For each species, I summed station relative abundances within each site during each survey and chose the maximum of these two values as the relative abundance of the species at the site. Thus, for both stations and sites, relative abundance values reflected the highest abundance a species achieved in the two surveys.

\subsubsection{Carabid beetle trapping}

I installed pitfall traps for carabid beetles at each bird point count station and at four additional stations in each site in late April and early May 2007, immediately following 
the spring thaw (Fig. 3.2). Traps were $125 \mathrm{~m}$ apart. Initially, a ninth trap was also installed in the center of each site but these traps were only operated for the first week of the season (see below) before being removed. Traps consisted of two plastic cups, approximately $8 \mathrm{~cm}$ wide at the mouth and $10 \mathrm{~cm}$ tall. I buried traps in the ground with the rim of the inner cup flush with the ground surface. The base of the outer cup was punctured to allow for water drainage. I placed a $10 \mathrm{~cm} \times 10 \mathrm{~cm}$ plastic roof, supported by $2.54 \mathrm{~cm}$ nails at each corner, above each trap to prevent rain and debris from falling in the trap. I filled traps with $100 \mathrm{~mL}$ of propylene glycol and a drop of dish soap. I opened traps May 14 and replaced trap contents weekly until August 3. Thus, I collected beetles continuously over a 12-week period that encompassed the peak in carabid breeding activity in the region (Levesque \& Levesque 1986). Carabid beetles were identified to species using Lindroth (1961-1969). Nomenclature followed Bousquet and Larochelle (1993).

I summed the number of individuals of each species collected at each station and at each site over the 12 weeks of sampling to calculate species relative abundances.

Unfortunately, a small number of traps were removed or damaged during sampling which created missing or incomplete values in my dataset. I chose to ignore these omissions because they represented only $3.25 \%$ of the data collected.

\subsubsection{Analyses}

I tested for the effects of urbanization on breeding bird and carabid beetle communities to determine if three aspects of community change along the urbanization gradient occurred in both taxa: (1) compositional changes, (2) community simplification and (3) community 
homogenization. To further determine the congruence between birds and beetles in their responses to urbanization, I tested correlations between bird and beetle descriptors used in the above analyses. I performed all analyses separately for two categorical predictor variables: housing density, represented by the site categories Forested, Exurban, Suburban and Urban, and neighboring housing density, represented by the site categories Forested, Exurban Neighbor, Suburban Neighbor and Urban Neighbor. Analyses that tested the significance of the predictor variables were subject to pseudoreplication at the station scale (stations within a site were not independent observations) and so I carried out these analyses at the site scale only. I performed all other analyses at both the site scale and the station scale. I carried out all analyses using $R$ version $2.6 .2(R$ Development Core Team 2008).

\subsubsection{Compositional changes}

I used general linear models (GLMs) to test for effects of housing density and neighboring housing density on total species richness, total abundance, Simpson's index, Fisher's $\alpha$, the abundance and species richness of habitat affinity groups and the abundance of introduced species of birds and beetles. When the assumptions of normality and/or homoscedasticity were not met, I transformed response variables such that assumptions were no longer violated (Grafen \& Hails 2002). Simpson's index is a proportion so values were transformed by taking the arcsine of the square root (Zar 1999). When the predictor variable had a significant effect, I used Tukey's Honestly Significant Difference Test with $p$-values adjusted for multiple comparisons to determine 
the significant differences between pairs of housing density or neighboring housing density categories.

I classified the habitat affinity of native bird species as 'forest interior', 'forest edge' or 'open-habitat' according to Poole (2005) (Appendix 6). I defined forest interior species as those that occur only in forest habitat, being most abundant in the forest interior and avoiding the forest edge. Species classified as forest edge were those that are most common in forest habitat but also occur in a wide range of other habitat types. I defined open-habitat species as those that occur in a broad range of open habitat types with at most scattered trees and including human-modified environments. I classified the native beetle species I collected as 'forest' or 'open-habitat' species according to Lindroth (1961-1969) (Appendix 6). If the habitat affinity of a species was not recorded in Lindroth (1961-1969), I classified the species according to H. Goulet (Agriculture and Agri-Food Canada, pers. comm.) with two exceptions. The habitat affinity of Cicindela sexguttata was determined according to Schultz (1998) and the habitat affinity of Trichotichnus vulpeculus was determined according to Stanton et al. (2003) and Webster and Bousquet (2008). I defined forest and open-habitat beetle species as having similar habitat affinities as forest interior and forest edge birds and open-habitat birds, respectively. Introduced bird and beetle species were identified according to the aforementioned sources (Appendix 6).

I used redundancy analyses (RDAs) to determine the effects of housing density and neighboring housing density on bird and beetle communities. Community data were Hellinger-transformed prior to analyses (Legendre \& Gallagher 2001). I tested the 
significance of constrained axes and predictor variables using permutation tests (Legendre \& Legendre 1998).

\subsubsection{Community simplification}

I used GLMs to test the effects of housing density and neighboring housing density on the Berger-Parker dominance index of each taxon. The Berger-Parker index is the proportional abundance of the most abundant species in a community and reflects the degree to which a community is dominated by a single species (Berger \& Parker 1970). To meet the assumptions of the tests, I arcsine-transformed the square root of the response variables and, in the case of the test of the effect of housing density on the Berger-Parker index of birds, I applied a negative inverse transformation. For predictor variables with significant effects, I tested the significance of pairwise comparisons of housing density or neighboring housing density categories with Tukey's Honestly Significant Difference Test.

I compared the fit of bird and beetle community data collected at each site and station to four classical species-abundance distribution (SAD) models: the broken stick, the lognormal, the log series and the geometric series (Kempton \& Taylor 1974, Pielou 1975, Wilson 1991). I used Akaike's Information Criterion corrected for small sample sizes $\left(\mathrm{AIC}_{\mathrm{c}}\right)$ to select the distribution(s) best representing community data at each scale (site and station) (Anderson et al. 2000). I only attempted to fit models to stations or sites with $>5$ species because the fit of all models was weak below this threshold. The four selected SAD models represent a progression from an even community (broken stick) to a community dominated by a few very abundant species (geometric series). The 
geometric series is characteristic of communities in disturbed or harsh environments where a small number of factors determine community composition (Whittaker 1965, May 1975, Magurran 2004). As such, I predicted that bird and beetle SADs should become more geometric with increasing urbanization.

The shape of a community's SAD, and hence the fit to the four models above, may be influenced by the number of species in the community (McGill et al. 2007). I attempted to overcome this possible bias by constructing $k$-dominance curves of the bird and beetle communities collected at each site and station (Lambshead et al. 1983). Communities of varying richnesses can be compared in a single plot, with species ranked according to abundance on the abscissa $(k)$ and the cumulative proportional abundance of each species ( $k$-dominance), equivalent to the cumulative Berger-Parker index of each species, on the ordinate. A community is considered to exhibit a greater degree of dominance than another community if its $k$-dominance curve lies above and never intersects that of the other community.

\subsubsection{Community homogenization}

I partitioned the bird and beetle diversity of each site category (Forested, Exurban, Suburban, Urban, Exurban Neighbor, Suburban Neighbor and Urban Neighbor) into $\alpha$ and $\beta$ components according to Crist et al. (2003). The total species richness of each site category $(\gamma)$ was the sum of the average station species richness $\left(\alpha_{1}\right)$, the average species richness among stations $\left(\beta_{1}\right)$ and the average species richness among sites $\left(\beta_{2}\right)$ in that category. Species richness values for each station or site were weighted by the proportion of the total number of individuals found at each station or site. 
I used non-metric multidimensional scaling (NMDS) to determine the similarity in bird community composition among sites and among stations. I also used NMDS to determine beetle community similarity among sites and among stations. Data were standardized by dividing the abundance of each species at each site or station first by the species' maximum abundance at any site or station and then by the total abundance of all species at the site or station (Wisconsin double standardization). I used the Kulczynski distance measure to calculate dissimilarities between pairs of sites or stations (Faith et al. 1987).

I used GLMs to test for effects of housing density and neighboring housing density on the Kulczynski distance between pairs of sites, for birds and beetles. I applied transformations as described above to satisfy the assumptions of normality and homoscedasticity. Transformations were ineffective in the case of the effect of housing density on the distance between beetle communities so I used the non-parametric Kruskal-Wallis Rank Sum Test instead. Tukey's Honestly Significant Difference Test and the Wilcoxon Rank Sum Test with $p$-values adjusted for multiple comparisons were used to test for significant differences between pairs of housing density or neighboring housing density categories when predictor variables were significant.

\subsubsection{Correlations}

I used Kendall's rank correlation coefficient $(\tau)$ to test for correlations between bird and beetle total species richness, total abundance, Simpson's index, Fisher's $\alpha$, the abundance and species richness of habitat affinity groups, the abundance of introduced species and the Berger-Parker index at the site and station scales. I assessed significance at the station 
scale using the same number of degrees of freedom as the site scale because stations were not independent observations. For all correlations, I limited the beetle data to only the four stations at each site where birds were also surveyed (recall that beetles were surveyed at four additional stations to the bird survey stations at each site). Species richness correlations may be subject to biases in sampling effort (Gaston 2000). For this reason, I also tested the correlations between bird and beetle standardized richnesses, calculated by dividing species richnesses by abundances.

Finally, I performed Mantel tests on bird and beetle distance matrices at the site and station scales (Legendre \& Legendre 1998). I used the Kulczynski distance measure to calculate dissimilarities between pairs of sites or stations. I calculated correlations between bird and beetle distance matrices with Kendall's rank correlation coefficient and tested for significance with permutation tests. I did not assess the significance of the Mantel test statistic at the station scale because stations were not independent observations.

\subsection{Results}

I counted 2,435 birds of 76 species and collected 5,145 beetles of 95 species during my surveys (Appendix 7). I counted 203 individuals of the most abundant bird species, the Black-capped Chickadee $P$. atricapilla, and 13 bird species were counted only once during surveys. I trapped 703 individuals of the most abundant beetle species, $P$. mutus, and collected only one individual of 17 beetle species. 


\subsubsection{Effects of housing density}

\subsubsection{Compositional changes}

Housing density had significant effects on bird species richness $\left(F_{3,12}=23.64, p<0.001\right.$, adjusted $\left.R^{2}=0.82\right)$, the Simpson's index of birds $\left(F_{3,12}=54.39, p<0.001\right.$, adjusted $R^{2}=$ $0.91)$ and Fisher's $\alpha$ for birds $\left(F_{3,12}=36.30, p<0.001\right.$, adjusted $\left.R^{2}=0.88\right)$. Species richness and Fisher's $\alpha$ were significantly lower in Urban sites (species richness: mean = $12.00+/-1.08(\mathrm{SE})$ species; Fisher's $\alpha$ : mean $=3.47+/-0.44(\mathrm{SE}))$ than in Suburban sites (species richness: mean $=20.00+/-1.92(\mathrm{SE})$ species; Fisher's $\alpha:$ mean $=7.54+/-0.79$ (SE)), which had significantly fewer bird species and lower $\alpha$-values than Forested (species richness: mean $=29.00+/-2.74(\mathrm{SE})$ species; Fisher's $\alpha$ : mean $=15.46+/-2.27$ $(\mathrm{SE})$ ) or Exurban sites (species richness: mean $=29.50$ +/- 1.76 (SE) species; Fisher's $\alpha$ : mean $=15.28+/-1.22(\mathrm{SE}))$. Simpson's index $(D$; values shown are $1-D)$ was significantly lower in Urban sites (mean $=0.75+/-0.02(\mathrm{SE})$ ) than in the other site categories (Suburban: mean $=0.91+/-0.01(\mathrm{SE})$; Exurban: mean $=0.94+/-0.01(\mathrm{SE})$; Forested: mean $=0.93+/-0.01(\mathrm{SE})$ ). Forest interior and forest edge bird abundance and species richness were significantly different among housing density categories (forest interior bird abundance: $F_{3,12}=28.80, p<0.001$, adjusted $R^{2}=0.85$; forest interior bird species richness: $F_{3,12}=32.64, p<0.001$, adjusted $R^{2}=0.86$; forest edge bird abundance: $F_{3,12}=34.62, p<0.001$, adjusted $R^{2}=0.87$; forest edge bird species richness: $F_{3,12}=$ 18.93, $p<0.001$, adjusted $R^{2}=0.78$ ) (Fig. 3.3a, b). Housing density also had a significant effect on the abundance of introduced bird species $\left(F_{3,12}=62.41, p<0.001\right.$, adjusted $R^{2}=$ 0.92) (Fig. 3.3c). 
The abundance and species richness of forest beetles were also significantly different among housing density categories (abundance: $F_{3,12}=35.20, p<0.001$, adjusted $R^{2}=$ 0.87; species richness: $F_{3,12}=37.24, p<0.001$, adjusted $R^{2}=0.88$ ) (Fig. 3.3a, b). Housing density had a significant effect on open-habitat beetle species richness $\left(F_{3,12}=4.90, p=\right.$ 0.02 , adjusted $\left.R^{2}=0.44\right)$. Suburban (mean $=11.75+/-1.70(\mathrm{SE})$ species) and Urban sites $($ mean $=11.00+/-2.27(\mathrm{SE})$ species) had significantly more open-habitat beetle species than Forested sites (mean $=2.25+/-0.95$ (SE) species). Exurban sites had an intermediate number of open-habitat beetle species (mean $=6.75+/-2.59$ (SE) species) but this was not significantly different from Suburban and Urban sites or from Forested sites. Housing density also had a significant effect on the abundance of introduced beetle species $\left(F_{3,12}=11.74, p<0.001\right.$, adjusted $\left.R^{2}=0.68\right)($ Fig. 3.3c).

Based on the RDA, I found that housing density explained $63 \%$ of the variance in bird community composition $\left(F_{3,12}=6.81, p<0.01\right)$. The first RDA axis explained $48 \%$ of the variance and the second accounted for an additional $12 \%$. Both axes were significant $\left(\operatorname{RDA} 1: F_{1,12}=15.45, p<0.01\right.$; $\left.\operatorname{RDA} 2: F_{1,12}=3.84, p=0.01\right)$. In the twodimensional RDA space, forest interior and forest edge bird species were located near the Forested and Exurban centroids, respectively, whereas open-habitat species were located near the Suburban centroid (Fig. 3.4a). The three introduced bird species were located near the Urban centroid, separate from the rest of the community.

Similarly, RDA indicated that $55 \%$ of the variance in beetle community composition was explained by housing density $\left(F_{3,12}=4.81, p<0.01\right)$. The first RDA axis explained $40 \%$ of the variance and the second explained an additional $9 \%$. Only the first RDA axis 
was significant $\left(F_{l, 12}=10.44, p<0.01\right)$. In the two-dimensional RDA space, forest beetle species were located near the Exurban and Forested centroids whereas open-habitat and introduced beetle species were located near the Suburban and Urban centroids (Fig. $3.4 b)$.

\subsubsection{Community simplification}

Housing density had a significant effect on the Berger-Parker index of birds $\left(F_{3,12}=\right.$ $44.23, p<0.001$, adjusted $R^{2}=0.90$ ). Urban sites had significantly higher index values $($ mean $=0.37+/-0.01(\mathrm{SE}))$ than sites in the other categories (Suburban: mean $=0.16+/-$ $0.02(\mathrm{SE})$; Exurban: mean $=0.12+/-0.02(\mathrm{SE})$; Forested: mean $=0.14+/-0.01(\mathrm{SE})$ ). There was no effect of housing density on the Berger-Parker index of beetles.

In almost every instance, the log series was selected as the best model $\left(\Delta \mathrm{AIC}_{\mathrm{c}}>2\right)$ to describe bird and beetle community structure in the housing density categories at the site and station scales (birds: 16/16 sites, 59/63 stations; beetles: 15/16 sites, 55/66 stations). The log series often arises as a sampling distribution when sample sizes are small (May 1975). This is the likely cause of the ubiquitous fit of the log series to my data and so I chose to assume these fits were artefacts of small sample size and to focus my comparisons among the remaining three SAD models. The geometric series was increasingly selected as a best model to describe bird communities at the site scale as housing density increased (Table 3.1). Three-quarters of the best models selected for bird communities in Urban sites were geometric series. At the station scale, bird communities became increasingly better represented by the broken stick model and less well represented by the lognormal and the geometric series as housing density increased. The 
only trend apparent for beetle communities was an increase in the fit of the lognormal as housing density increased at the station scale (Table 3.1).

At both the site and station scales, the $k$-dominance curves of Urban bird communities were above those of bird communities in other housing density categories (Fig. 3.5a). In contrast, the $k$-dominance curves of beetle communities were not segregated by housing density category (Fig. 3.5b).

\subsubsection{Community homogenization}

Additive partitioning of diversity revealed that the average bird species richness among sites $\left(\beta_{2}\right)$ was lower in the Urban category than in the other housing density categories (Fig. 3.6a). No differences in beetle diversity components among housing density categories were apparent (Fig. 3.6a). The NMDS of bird communities in housing density categories at the site scale showed that Urban and Suburban bird communities were more similar than those in Exurban sites, which were more similar than those in Forested sites (Fig. 3.7a). The similarity among beetle communities in the housing density categories at the site scale showed a congruent but weaker pattern. Beetle communities in Urban and Suburban sites were more similar than those in Exurban and Forested sites (Fig. 3.7a). Suburban sites had the most homogeneous beetle communities. NMDS analyses did not converge to a solution at the station scale for either taxon. Finally, housing density had a significant effect on the Kulczynski distance between pairs of sites for birds $\left(F_{3,20}=\right.$ $15.66, p<0.001$, adjusted $\left.R^{2}=0.66\right)$ and beetles $\left(X^{2}=9.37, p=0.02\right)$. Birds displayed a decline in the Kulczynski distance between sites as housing density increased whereas beetles showed no clear trend (Fig. 3.8). 


\subsubsection{Correlations}

Total bird and total beetle abundances in housing density sites were weakly positively correlated (Table 3.2, Appendix 8). Introduced bird and introduced beetle abundances, forest bird and forest beetle abundances and forest bird and forest beetle species richnesses exhibited relatively strong positive correlations at both spatial scales. Openhabitat bird and open-habitat beetle abundances and open-habitat bird and open-habitat beetle species richnesses exhibited weaker positive correlations in housing density sites and stations (Table 3.2, Appendix 8). When forest bird and beetle and open-habitat bird and beetle species richness values were corrected for sampling effort, the strength of correlations diminished markedly (Table 3.2, Appendix 8). Bird and beetle distance matrices of housing density sites were significantly positively correlated with each other $(\tau=0.53, p<0.001)$. Bird and beetle distance matrices of stations were more weakly positively correlated $(\tau=0.36)$.

\subsubsection{Effects of neighboring housing density}

Few analyses yielded significant effects of neighboring housing density on bird or beetle community structure. No introduced bird species were counted in neighboring housing density sites. The abundance of introduced beetles was one of the few response variables to vary significantly with neighboring housing density $\left(F_{3,9}=11.09, p<0.01\right.$, adjusted $R^{2}$ $=0.72)$. Urban Neighbor (mean $=107.33+/-64.54(\mathrm{SE})$ individuals) and Suburban Neighbor sites $($ mean $=123.33+/-67.40(\mathrm{SE})$ individuals) had significantly more introduced beetles than Forested sites (mean $=2.5+/-1.04(\mathrm{SE})$ individuals) but not Exurban Neighbor sites (mean $=13.00+/-4.51(\mathrm{SE})$ individuals). 
As above, the log series was selected as the best model for nearly all bird and beetle communities (birds: 13/13 sites, 51/52 stations; beetles: 12/13 sites, 54/65 stations) and as above I assumed this was an artefact of small sample sizes and chose to compare the fits of the three remaining SAD models. Bird and beetle communities were increasingly better represented by the geometric series as the housing density of adjacent development increased (Table 3.1). For birds at the site scale, the proportion of best models that were geometric series increased from approximately one third in Forested sites to approximately two thirds in Suburban Neighbor and Urban Neighbor sites. This was accompanied by a decrease in the prevalence of the lognormal model. At both scales, the fit of the geometric series to beetle communities increased as neighboring housing density increased. This trend was stronger at the site scale with nearly all best models for beetles being geometric series rather than lognormal in Suburban Neighbor and Urban Neighbor sites.

The average bird species richness among sites $\left(\beta_{2}\right)$ was lower in the Exurban Neighbor, Suburban Neighbor and Urban Neighbor categories than in the Forested category (Fig. 3.6b). Beetle $\beta_{2}$ was lower in the Suburban Neighbor category than in the other neighboring housing density categories (Fig. 3.6b). For both birds and beetles, NMDS analyses revealed that sites within the Exurban Neighbor, Suburban Neighbor and Urban Neighbor categories were more similar to one another than sites within the Forested category, this trend being slightly stronger for birds (Fig. 3.7b). However, there was much overlap of category polygons indicating that bird and beetle community similarity was not well described by neighboring housing density. As above, NMDS 
analyses did not converge to a solution at the station scale for either taxon. Finally, neighboring housing density had a significant effect on the Kulczynski distance between pairs of sites for birds $\left(F_{3,11}=4.07, p<0.04\right.$, adjusted $\left.R^{2}=0.40\right)$. Pairs of Urban Neighbor sites had significantly lower Kulczynski distances (mean $=0.33+/-0.01(\mathrm{SE})$ ) than pairs of Forested sites (mean $=0.50+/-0.04(\mathrm{SE})$ ), with Suburban Neighbor (mean $=0.42+/-0.03(\mathrm{SE})$ ) and Exurban Neighbor site pairs (mean $=0.50+/-0.01(\mathrm{SE}))$ having intermediate distances that were not significantly different from those of other categories.

Open-habitat bird and open-habitat beetle abundances, as well as open-habitat bird and open-habitat beetle species richnesses, were positively correlated in neighboring housing density sites and stations (Table 3.2, Appendix 8). Standardizing open-habitat bird and open-habitat beetle species richness values yielded much weaker correlations at both spatial scales (Table 3.2, Appendix 8). Bird and beetle distance matrices of neighboring housing density sites were positively correlated $(\tau=0.17, p=0.03)$, as were bird and beetle distance matrices of stations $(\tau=0.14)$.

\subsection{Discussion}

My results indicate that breeding birds and carabid beetles do not respond similarly to increasing housing density but that they do exhibit some similar responses to increasing neighboring housing density. Birds displayed strong declines in diversity, compositional changes (Figs. 3.3, 3.4a), community simplification (Table 3.1, Fig. 3.5a) and community homogenization (Figs. 3.6a, 3.7a, 3.8) in response to increasing housing density. Although beetles did exhibit similar changes to birds in forest species abundance and 
richness and introduced species abundance (Figs. 3.3, 3.4b), they showed no patterns of community simplification (Table 3.1, Fig. 3.5b) and only weak patterns of community homogenization (Figs. 3.6a, 3.7a, 3.8) with increasing housing density. In contrast, both birds and beetles showed no compositional changes with respect to neighboring housing density (with the exception of an increase in introduced beetle abundance with increasing neighboring housing density) and similar patterns of community simplification (Table 3.1) and homogenization (Figs. 3.6b, 3.7b).

In contrast to birds for which increasing housing density resulted in a species-poor community, for beetles increasing housing density resulted in the original forest beetle community being replaced by one adapted to open habitats. Both birds and beetles exhibited declines in forest species abundance and richness with increasing housing density, but only beetles exhibited an increase in the number of open-habitat species with increasing housing density. This trend would explain the weak patterns of community simplification and homogenization exhibited by beetles. If a large number of open-habitat beetle species are found in urban areas, then one would not expect the overall community to be dominated by few species or to be similar to other urban communities.

My results are similar to those of other authors who found higher open-habitat beetle species richness in forest fragments situated in more highly urbanized sites (Elek \& Lövei 2007, Magura et al. 2008). Despite the higher disturbance in urban environments (e.g., pesticides (Bednarska et al. 2009), predation (Shochat et al. 2006)), open-habitat beetle species seem to profit from the availability of suitable microhabitats. Microhabitat variation is an important predictor of carabid distribution in forest habitats (Niemelä et al. 
1992). Similarly, urbanization may create a variety of open microhabitats for beetles, resulting in the increase in open-habitat beetle species richness in my study. Another possibility is that urbanization results in increased slug abundance (Holland et al. 2007), a common prey of some carabid beetle species (e.g., slugs are a major part of the diet of $P$. melanarius (Symondson et al. 2002), an open-habitat beetle species collected in this study). More slugs in urban areas could result in the greater abundance of some openhabitat beetle species, possibly contributing to the increased species richness of this group.

The magnitudes of the correlations I observed between bird and beetle descriptors are consistent with those reported in a recent meta-analysis of between-taxa species richness correlations (Wolters et al. 2006). Wolters et al. (2006) reported an overall average between-taxa correlation of 0.37 . They also distinguished correlations on the basis of spatial scale and taxonomic distance, with average correlations of approximately 0.50 for comparisons between different phyla and at spatial scales similar to those in this study. The birds vs. beetles correlations I reported for forest and open-habitat species richnesses ranged from 0.33 to 0.64 , with the exception of the very small correlations between forest bird and forest beetle species richnesses in neighboring housing density sites (Table 3.2). I did not, however, find any correlation between bird and beetle total species richnesses (Table 3.2). The majority of studies used by Wolters et al. (2006) tested the correlations between taxa in natural systems. The total species richnesses of taxa in human-dominated systems may not be correlated because they exhibit different responses to the dominant environmental gradient structuring the system. This was the 
case with respect to increasing housing density in this study. The lack of response of bird total species richness and beetle total species richness to increasing neighboring housing density does not preclude subtly different patterns of bird total species richness and beetle total species richness in neighboring housing density sites and stations, resulting in very weak correlations. There may also exist a bias against publishing weak correlations, resulting in an overestimation of the average correlation between taxa in Wolters et al. (2006).

It has been suggested that the shape of a community's species-abundance distribution may be a useful indication of disturbance (McGill et al. 2007). For instance, the geometric series characterizes communities in several disturbed systems (Visser 1995, Chung et al. 2000, Caruso \& Migliorini 2006, Qu et al. 2008). The geometric series is also termed the 'niche pre-emption hypothesis' (Magurran 2004): in disturbed environments where one or a few factors determine community composition, the species adapted to the disturbed conditions 'pre-empt' the establishment of additional species by garnering the majority of available resources. Thus, communities in disturbed environments are generally dominated by a few species that reach high abundances. This pattern of pre-emption is evident in urban avian assemblages within which introduced species pre-adapted to the built-up environment are able to dominate. In this study, the fit of the geometric series to bird communities improved with increasing housing density (Table 3.1). In addition, both bird and beetle SADs became increasingly better represented by the geometric series as the housing density of adjacent development increased (Table 3.1). 
However, the patterns I observed in the shape of SADs in response to increasing neighboring housing density were not corroborated by similar patterns in $k$-dominance curves, the shape of which does not depend on the number of species in a community. SADs may only perform reliably as indicators of disturbance when disturbance intensity is high, as was the case for increasing housing density (Table 3.1, Fig. 3.5a). The patterns (or lack thereof) exhibited by bird and beetle SADs in response to increasing housing density were generally consistent with the results of my other analyses, giving credence to the use of these models as indicators of high-intensity disturbance.

Evidence to support the congruence of biodiversity in human-dominated systems is slim (Allen et al. 1999b, Oertli et al. 2005, Billeter et al. 2008, but see Blair 1999, Sauberer et al. 2004). Most studies conclude that correlations among taxa are too weak to be of any predictive use. My results support this conclusion. In particular, birds and carabid beetles exhibited different changes in diversity, community simplification and community homogenization in response to increasing housing density. To better understand and mitigate the effects of urbanization on biodiversity, I suggest that future research should evaluate the responses of taxa other than birds, particularly in light of the scarcity of such work at present (McDonnell \& Hahs 2008). 
$\Xi$

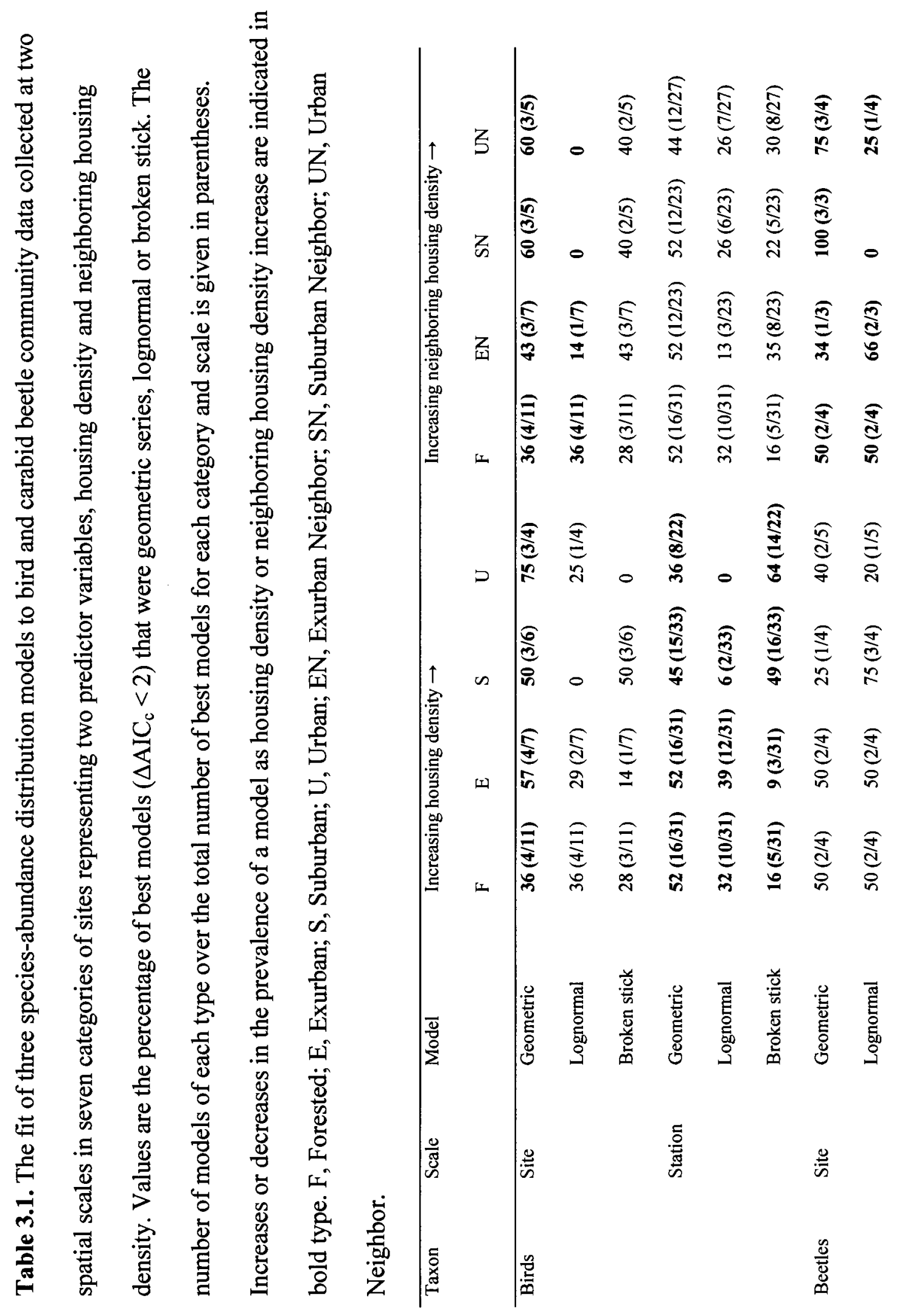


$\stackrel{\varrho}{9}$

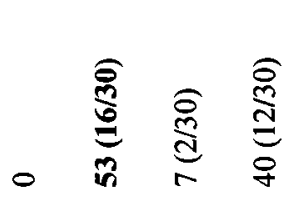

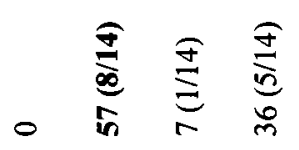

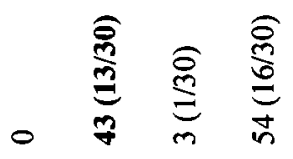

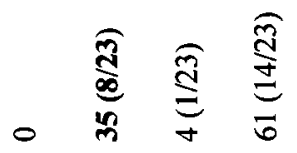

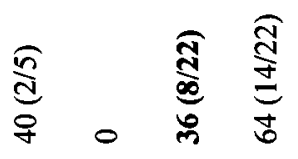

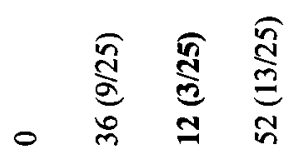

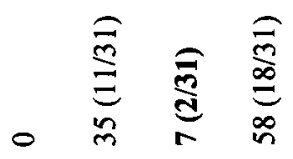

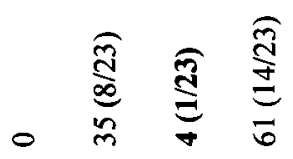

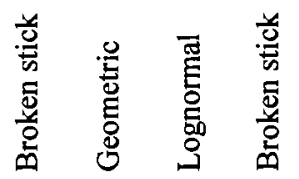

$$
\begin{aligned}
& \text { 㺃 }
\end{aligned}
$$


Table 3.2. Correlations (Kendall's $\tau$ ) between bird and carabid beetle variables describing community structure at two spatial scales in categories representing two predictor variables, housing density and neighboring housing density. No introduced bird species were counted in neighboring housing density categories.

* Significant at $\alpha=0.05 / 50=0.001$ (Bonferroni correction for 50 comparisons).

\begin{tabular}{|c|c|c|c|c|}
\hline \multirow[t]{4}{*}{ Variable } & \multirow{2}{*}{\multicolumn{2}{|c|}{ Housing density }} & \multirow{2}{*}{\multicolumn{2}{|c|}{$\begin{array}{l}\text { Neighboring } \\
\text { housing density }\end{array}$}} \\
\hline & & & & \\
\hline & \multirow{2}{*}{$\begin{array}{l}\text { Site } \\
(n=16)\end{array}$} & \multirow{2}{*}{$\begin{array}{l}\text { Station } \\
(n=64)\end{array}$} & Site & Station \\
\hline & & & $(n=13)$ & $(n=52)$ \\
\hline Total species richness & 0.03 & 0.08 & -0.04 & -0.02 \\
\hline Total abundance & 0.28 & 0.09 & 0.10 & 0.01 \\
\hline Standardized total richness & -0.10 & 0.00 & 0.00 & -0.03 \\
\hline Simpson's index & 0.12 & 0.00 & -0.06 & -0.13 \\
\hline Fisher's $\alpha$ & -0.07 & -0.08 & -0.18 & 0.07 \\
\hline Berger-Parker index & 0.04 & -0.05 & -0.10 & -0.16 \\
\hline Introduced species abundance & 0.58 & 0.45 & NA & NA \\
\hline Forest species abundance & 0.59 & 0.50 & -0.13 & 0.00 \\
\hline Forest species richness & $0.64^{*}$ & 0.52 & 0.03 & -0.04 \\
\hline Standardized forest richness & 0.01 & 0.07 & 0.00 & 0.05 \\
\hline Open-habitat species abundance & 0.36 & 0.38 & 0.39 & 0.31 \\
\hline Open-habitat species richness & 0.43 & 0.35 & 0.43 & 0.33 \\
\hline Standardized open-habitat richness & -0.02 & -0.12 & 0.10 & -0.04 \\
\hline
\end{tabular}




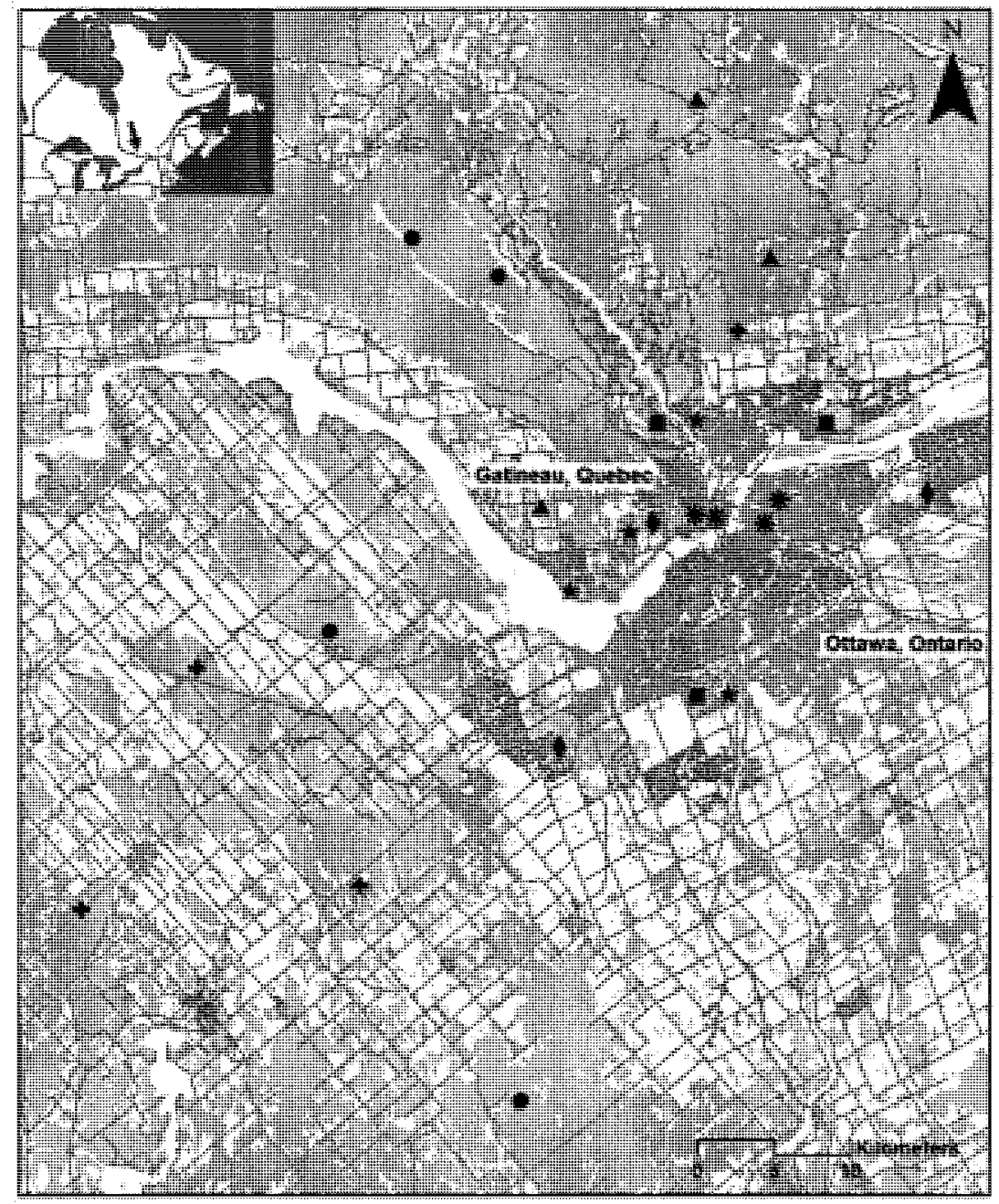

Figure 3.1. The study area surrounding the cities of Ottawa, Ontario and Gatineau, Quebec, Canada. Inset depicts the location of the study area in eastern North America. Sites are $0.25 \mathrm{~km}^{2}$ areas indicated by symbols representing four housing density categories: - Forested $\left(0\right.$ dwellings $\left./ \mathrm{km}^{2}\right),+$ Exurban $\left(<56 \mathrm{dwellings} / \mathrm{km}^{2}\right), \star$ Suburban (140-712 dwellings $\left./ \mathrm{km}^{2}\right)$, *Urban ( $>1,244$ dwellings $\left./ \mathrm{km}^{2}\right)$; and three categories of forested sites adjacent to developments of Exurban, Suburban and Urban 
densities, respectively: $\Delta$ Exurban Neighbor, $\mathbf{\text { Suburban Neighbor, }} \backslash$ Urban Neighbor. Dark gray lines indicate roads. Forest cover is in light gray. 
8
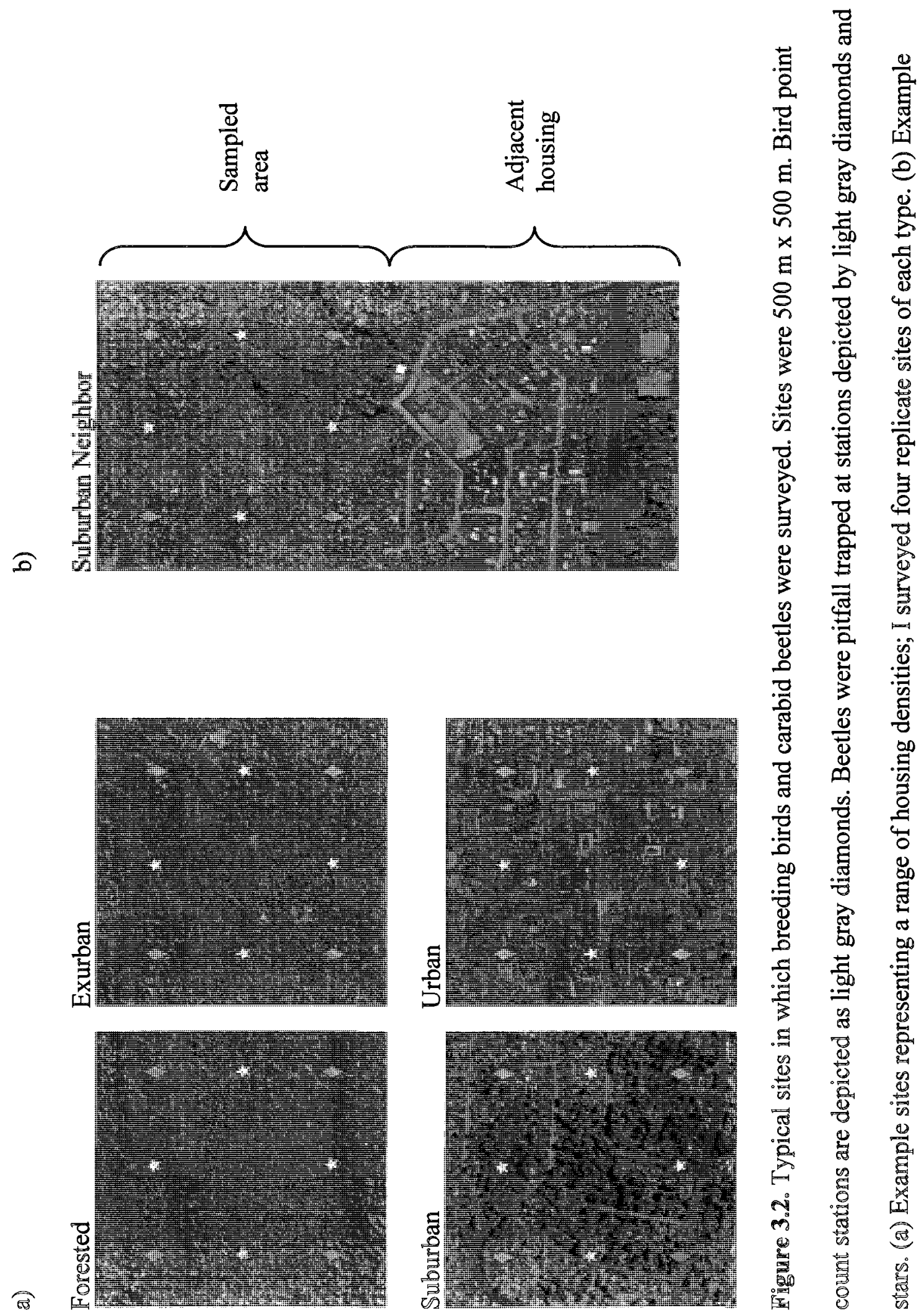


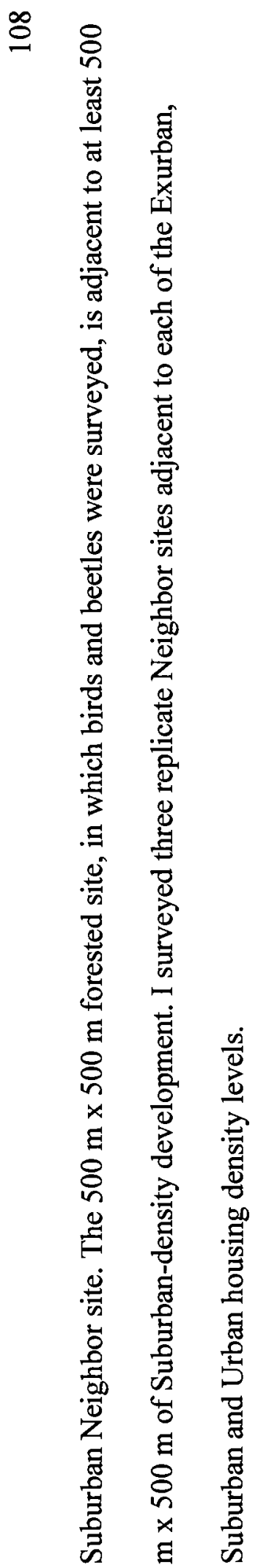


a)

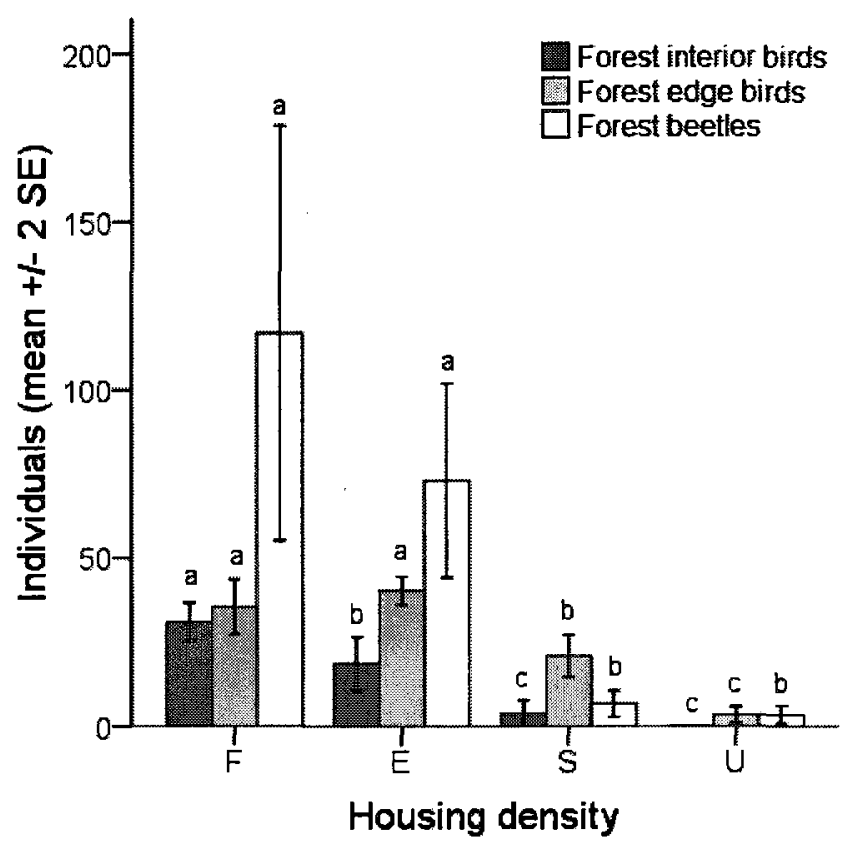

b)

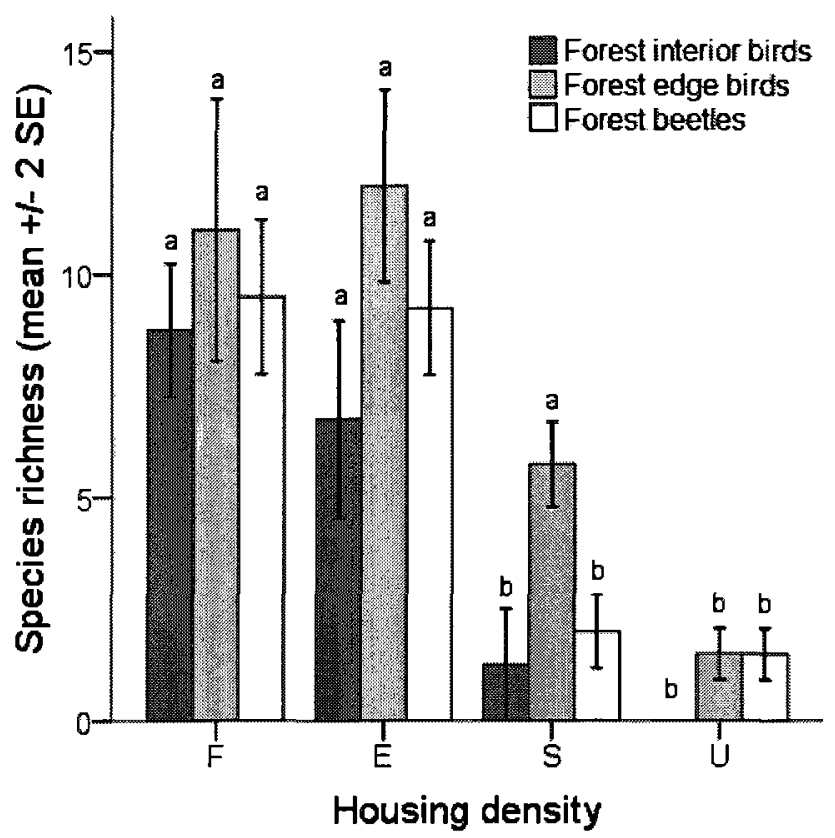


c)

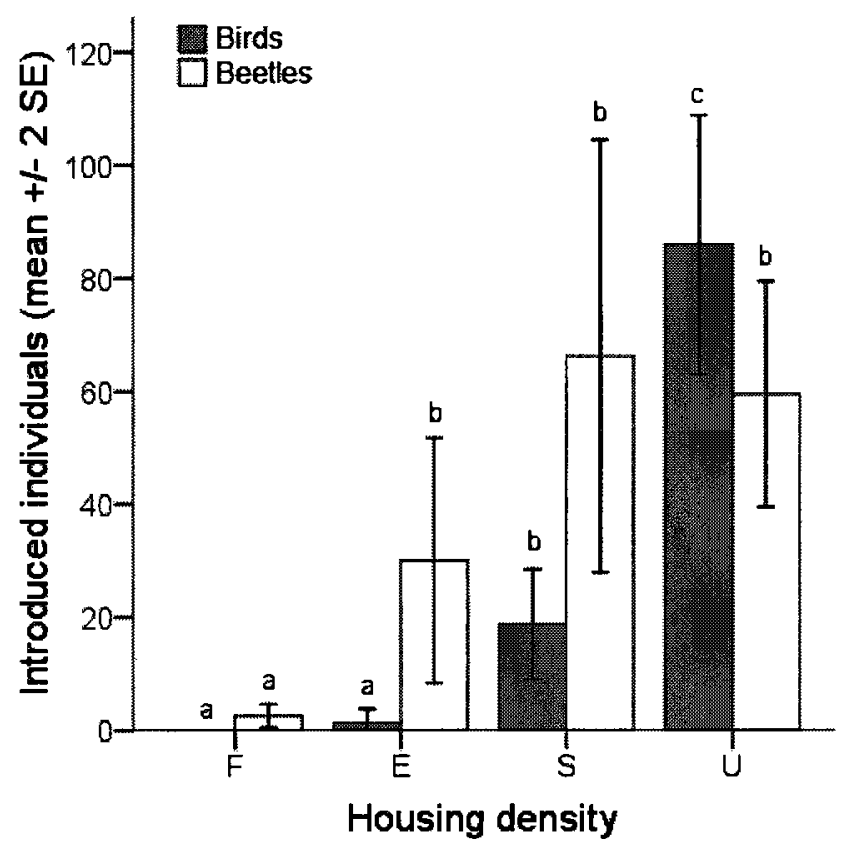

Figure 3.3. The abundance (a) and species richness (b) of forest birds and carabid beetles and the abundance of introduced birds and carabid beetles (c) in Forested (F), Exurban (E), Suburban (S) and Urban (U) sites. Dark gray bars represent forest interior birds in (a) and (b) and introduced birds in (c). Light gray bars represent forest edge birds and open bars represent carabid beetles. Habitat affinities are described in the text. Different lowercase letters above bars indicate significant pairwise differences between site categories within each taxon and habitat affinity group. 

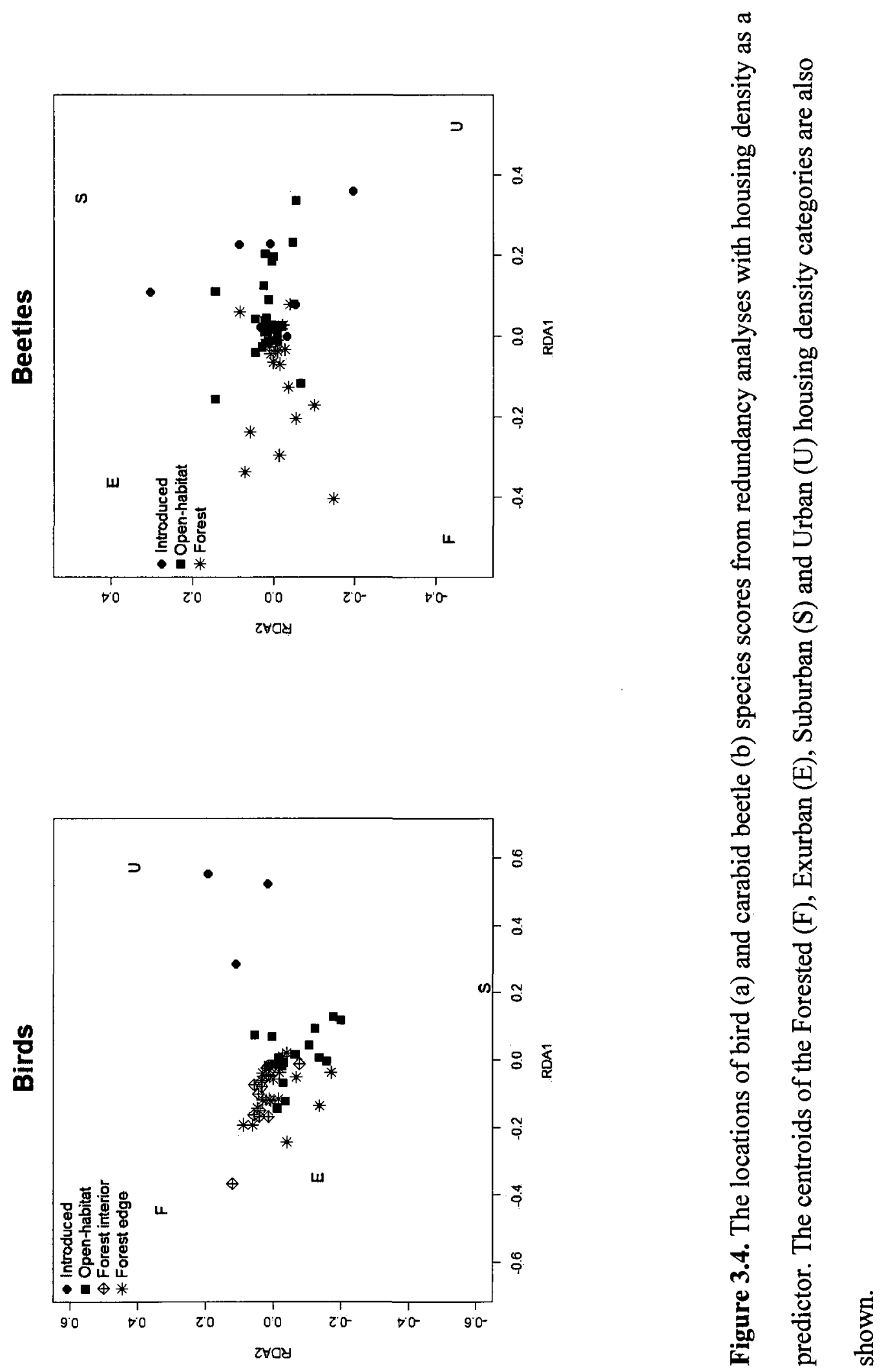

ส

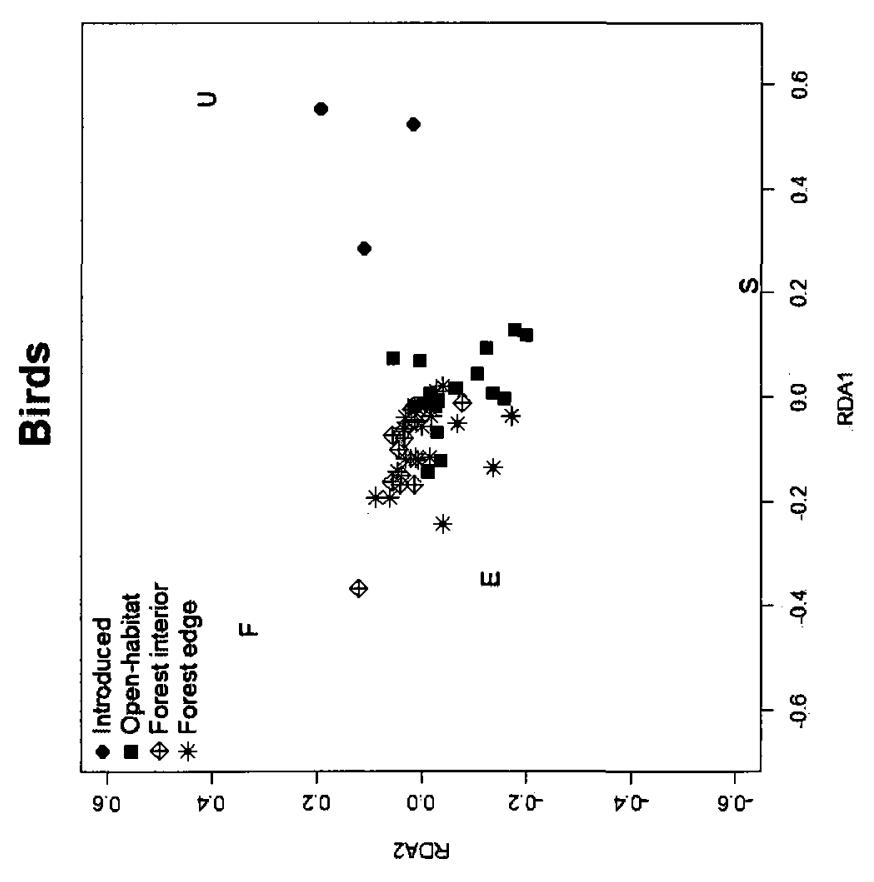



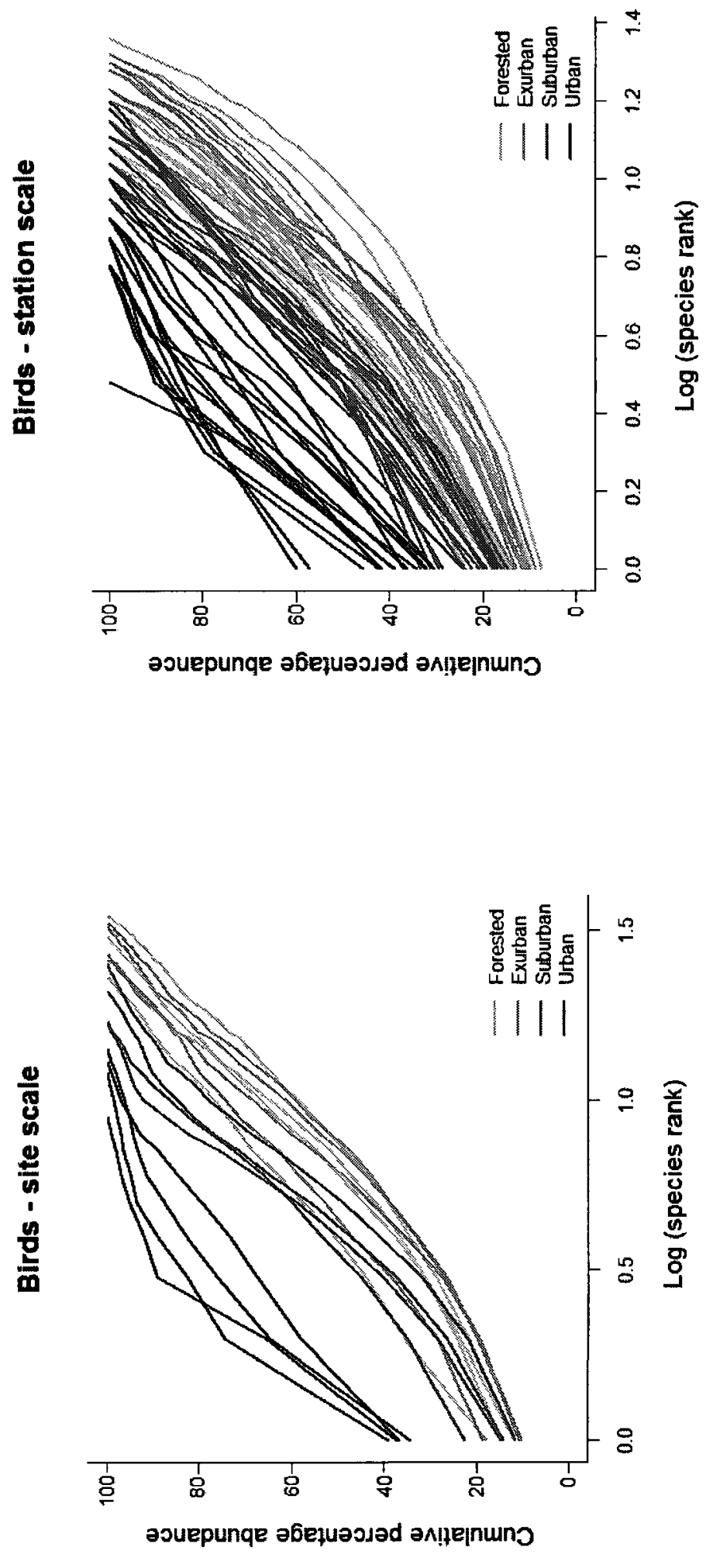
$\cong$

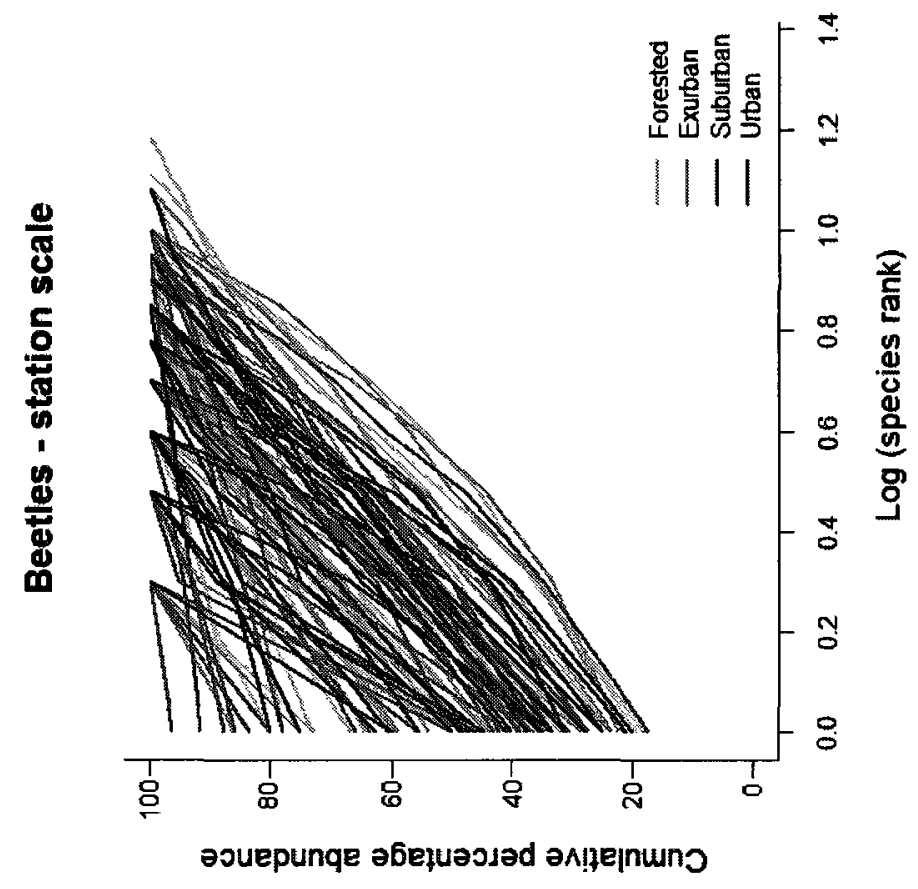

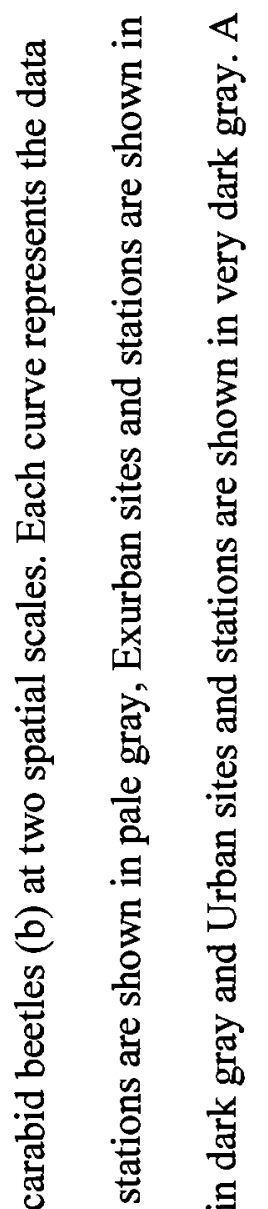

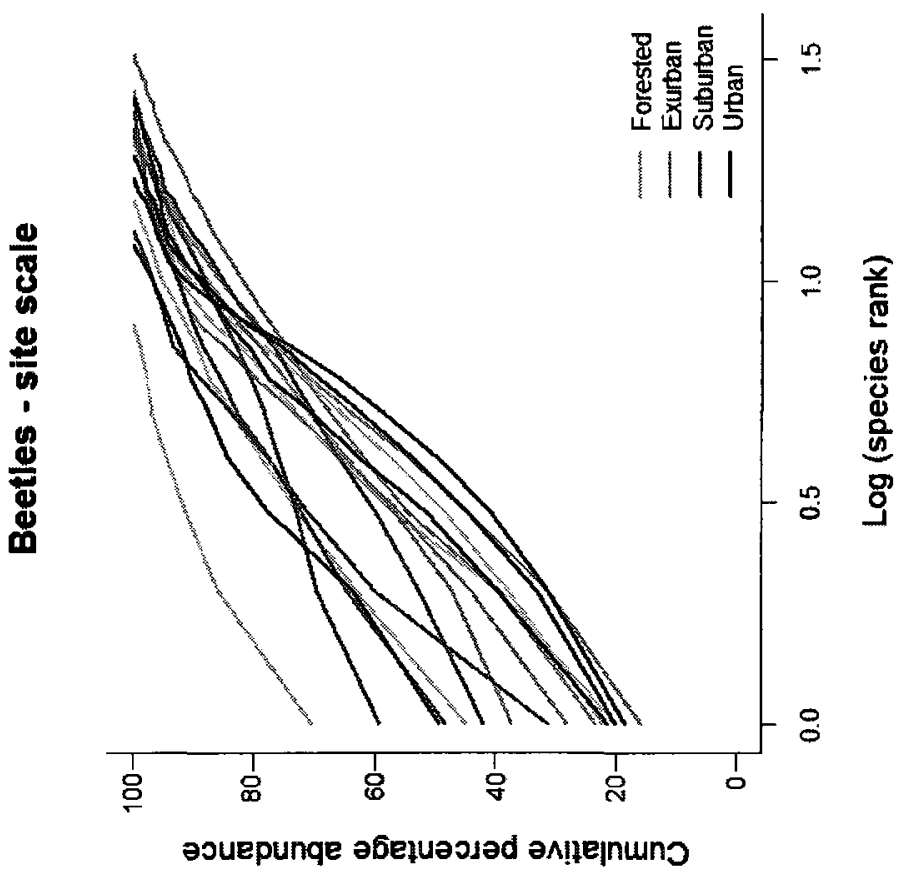

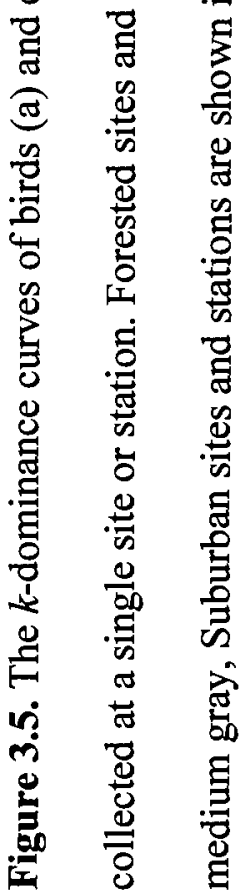


士

$+$

:

尝

हี

密

콣

㺃

告

를

88

灵

횽

O

忽

壱

क

营 吾

굥

.气

है

忌 昌 
n
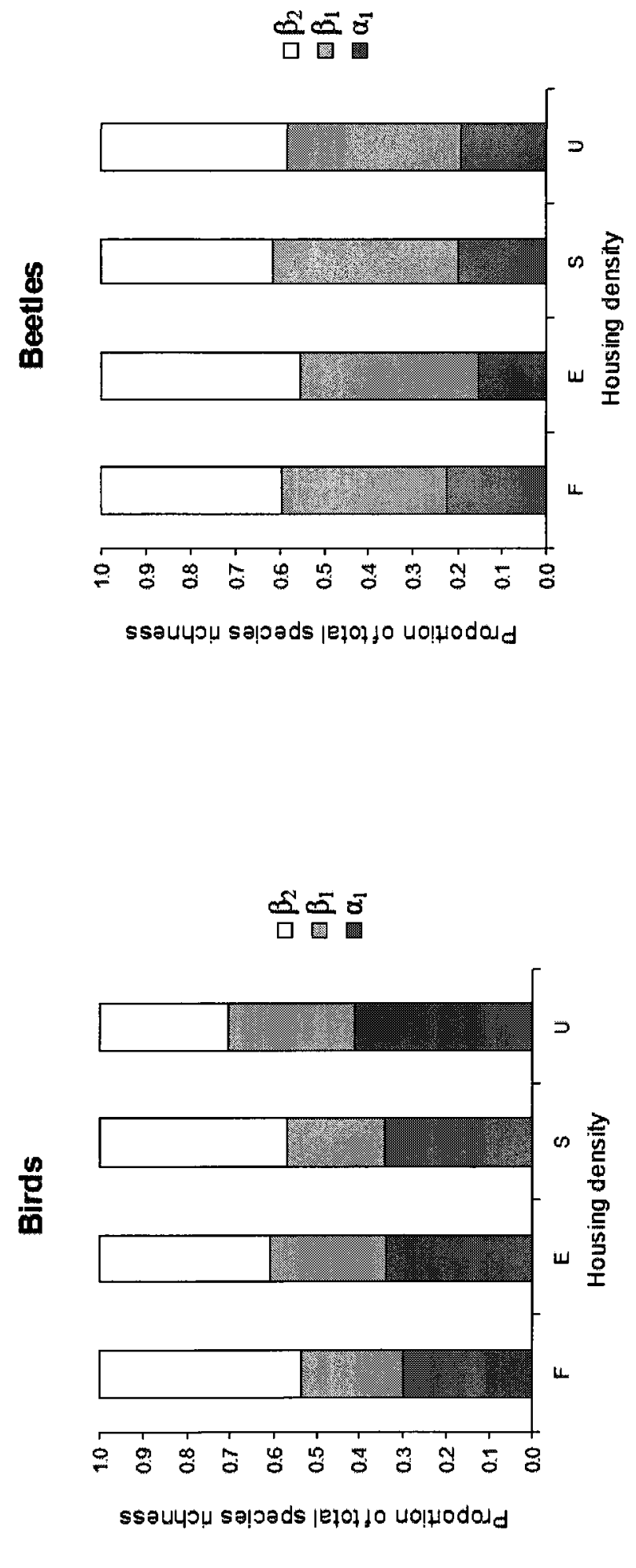
$\underset{1}{2}$

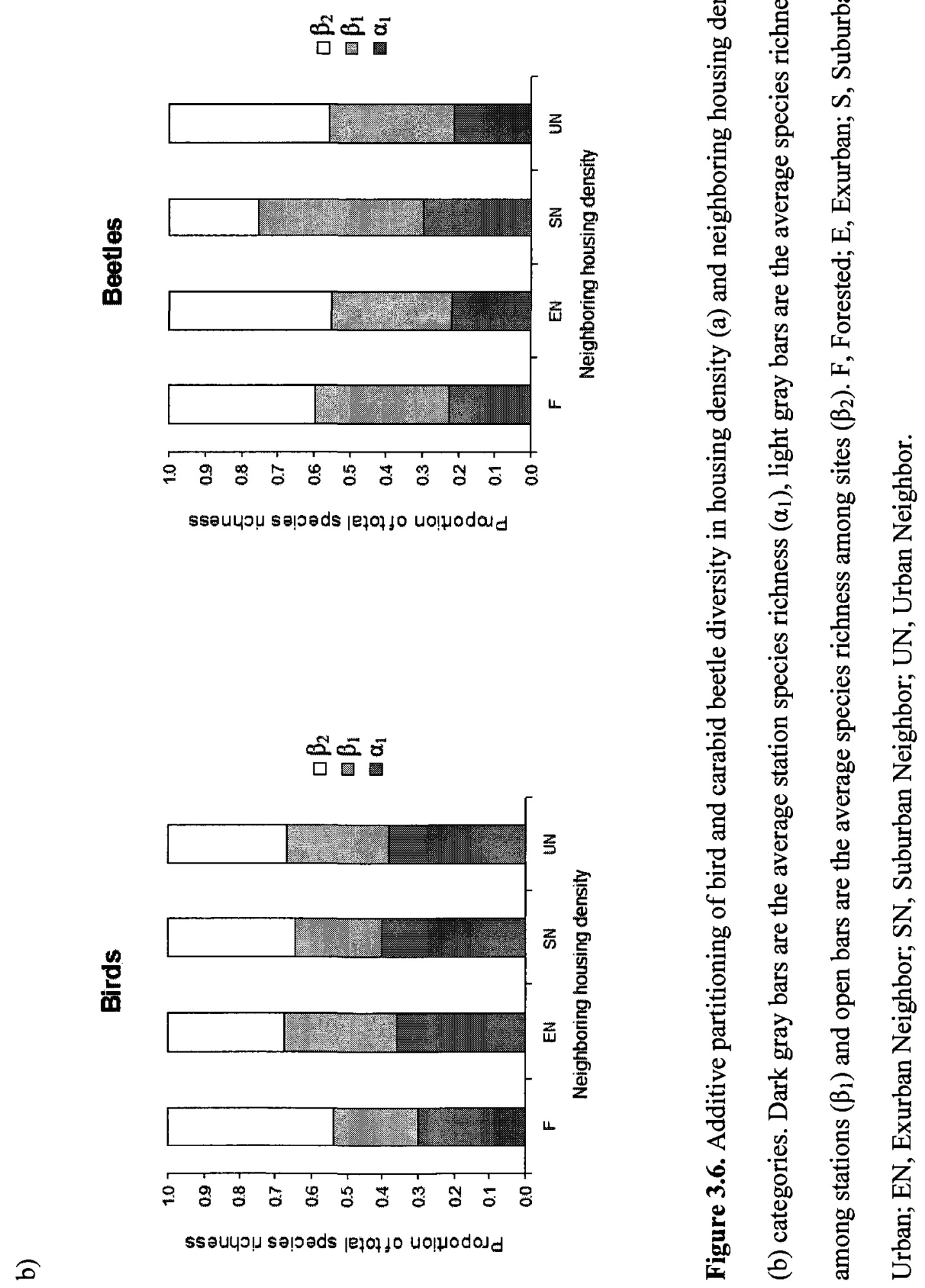


I
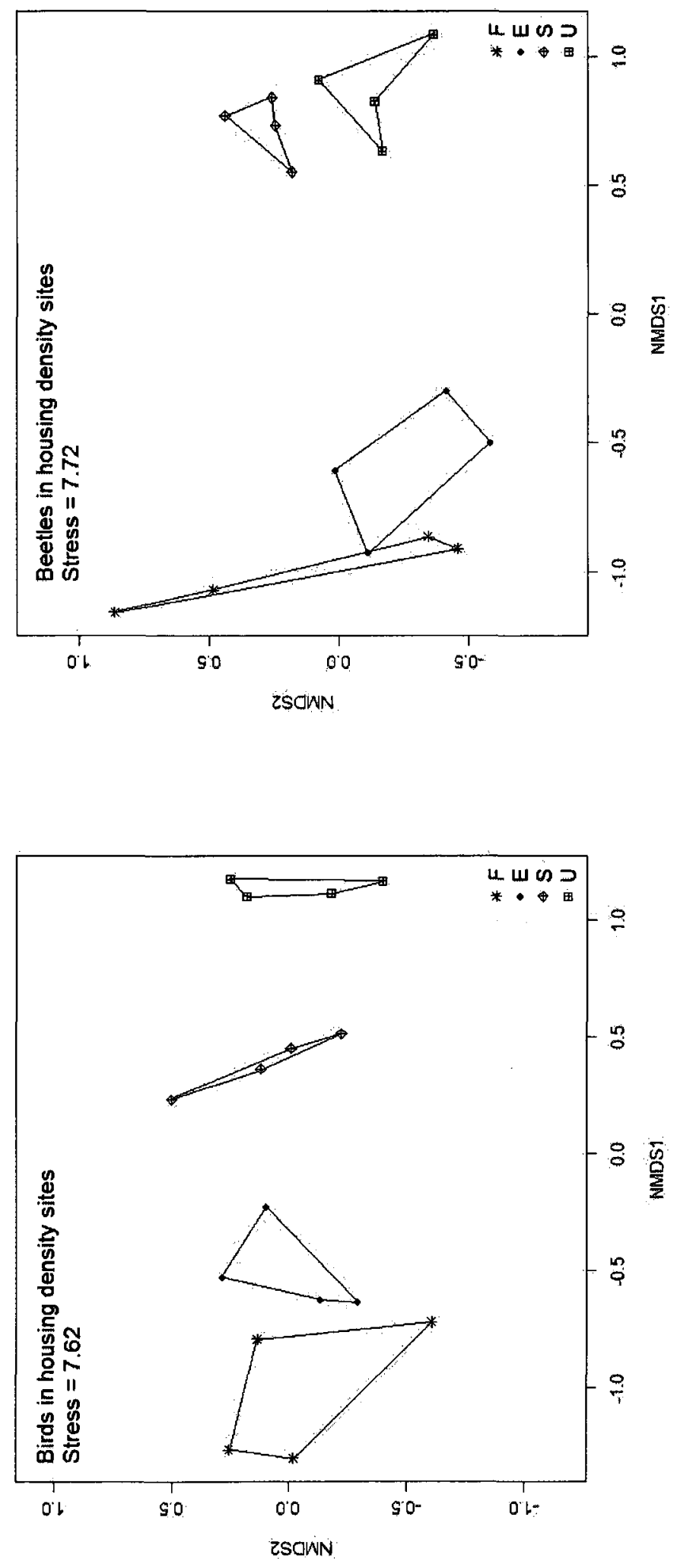
$\cong$
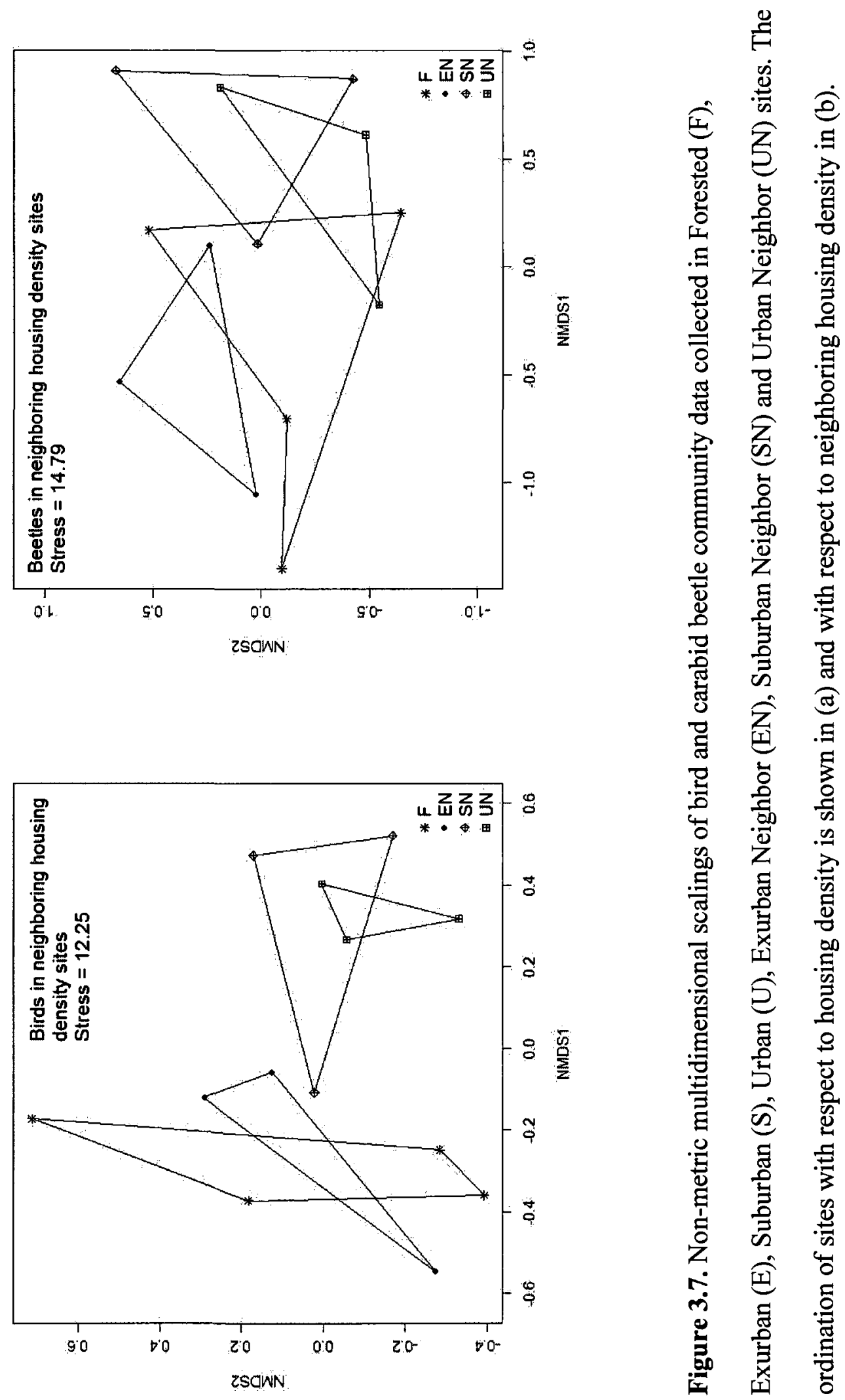


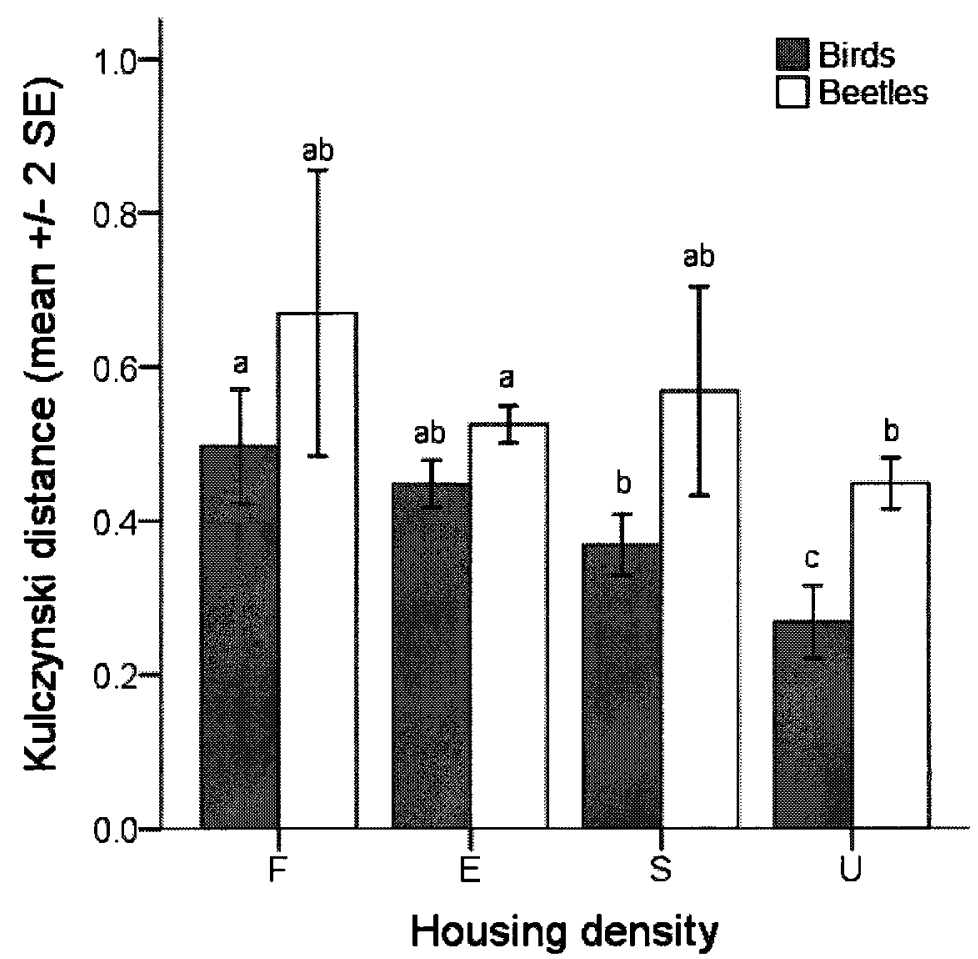

Figure 3.8. The Kulczynski distance between pairs of Forested (F), Exurban (E), Suburban (S) and Urban (U) sites. The Kulczynski distance between two sites is calculated by summing species abundance minima and dividing this value by each site's total abundance. One minus the average of these two values is the distance between the two sites. Dark gray bars represent the distances between bird communities and open bars represent those between carabid beetle communities. Different lowercase letters above bars indicate significant pairwise differences between site categories for each taxon. 


\section{General discussion}

An overall pattern emerges when one considers the results of this thesis. The bird and beetle assemblages that declined with respect to increasing housing density (Chapter 3 ) responded similarly to the housing density/sprawl area trade-off (Chapters 1,2), whereas those that were not negatively affected by increasing housing density showed different responses to the housing density/sprawl area trade-off. Both forest birds (forest interior and forest edge birds) and forest beetles declined in abundance and species richness with increasing housing density (Fig. 3.3) and both exhibited their highest estimated abundance and species richness in the Semi-compact or Compact scenario rather than the Dispersed scenario (Figs. 1.5a, 1.6a, 2.5b, 2.6b). On the other hand, the abundance and species richness of open-habitat birds showed no change while the species richness of open-habitat beetles increased with increasing housing density. Open woodland birds had their highest estimated abundance in the Dispersed scenario (Appendix 3) whereas openhabitat beetles had their highest estimated abundance and species richness in the Semicompact scenario (Figs. 2.5c, 2.6c).

The conservation implications of forest birds and forest beetles exhibiting high abundance and species richness when a given human population is accommodated in a landscape at a high density over a small area rather than at a low density over a large area are profound, particularly if all forest taxa share this response. Brown et al. (2005) estimated that the land area occupied by low-density residential development (between 1 housing unit per acre and 1 housing unit per 40 acres) in the Eastern Temperate Forest ecoregion of the U.S. increased eightfold between 1950 and 2000. If, for the same 
number of dwellings, this development had occurred at a high density over a small area, the amount of habitat spared for forest taxa would potentially have been enormous (recall that the developed scenarios with a large amount of forest cover, the Semi-compact and Compact scenarios, had high estimates of forest bird and forest beetle abundance and species richness). Not all of this spared land would have been high-quality habitat, however. Low-density residential development consumes pristine habitat as well as agricultural land (Brown et al. 2005). Even so, the land area spared from low-density residential development would have represented a valuable resource, as protected areas of current or potential high-quality habitat for forest taxa, as land for agriculture or timber harvesting, or as land with a mixture of conservation and human uses.

Despite the potential retention of a large amount of habitat for forest taxa in the alternate land cover change trajectory described above, human use of the land spared from development complicates any conjecture as to the net effect on forest taxa of building compact rather than dispersed development. For example, it is unclear whether dispersed or compact development benefits forest taxa if the land prior to or post development is subject to timber harvesting. It may be that, for a given landscape subject to timber harvesting prior to development, dispersed development where no harvesting can take place has larger populations of forest taxa than compact development surrounded by forest cover where timber harvesting can continue. Consideration of the net effect of all human uses of a landscape is beyond the scope of this thesis but certainly, investigations into the effects of the interactions among land uses on biodiversity would be a fruitful avenue of study. 
Several questions related to the results of Chapters 1 and 2 deserve attention in future. First, do all taxa that exhibit declines in response to increasing urbanization (i.e., native specialist taxa in addition to forest birds and forest beetles examined in this thesis) have their highest estimated abundances and species richnesses in the Semi-compact or Compact scenario? I expect that landscapes with a small area of high density development and a large area of continuous habitat are likely to have larger populations of native specialist species than landscapes covered entirely by low-density development. If this is the case, the implications described above would have even greater significance to the conservation of global biological diversity. A related question is whether taxa in tropical regions exhibit similar patterns to those in temperate regions. To this end, I have received interest from a colleague in Mexico in replicating my study in the tropical biome (E. Santana-Castellon, Universidad de Guadalajara, pers. comm.).

Second, does using a continuum of housing densities (rather than four categories) affect the overall conclusions of my thesis? And third, do thresholds exist along the housing density/sprawl area gradient, i.e., points on the gradient at which abrupt changes in abundance and species richness occur? In Chapters 1 and 2, I used four categories (Forested, Exurban, Suburban and Urban) to characterize the housing density gradient. A range of values existed within each category but many gaps in housing density values between categories also occurred (e.g., between the highest value in the Suburban category, 712 dwellings $/ \mathrm{km}^{2}$, and the lowest value in the Urban category, 1,244 dwellings $/ \mathrm{km}^{2}$ ). Repeating the methods of Chapters 1 and 2 using a continuum of housing density values would enable a more precise estimate of the housing density that 
minimizes the impacts of a given human population on biodiversity. The use of a continuum of housing density values would also enable the identification of thresholds. It would be very interesting to determine if a threshold exists along the housing density/sprawl area gradient where, for instance, the abundance of introduced species abruptly changes. Introduced species are often implicated in native species declines so this information would be very useful to the conservation of the latter in urban landscapes. However, it is unclear whether thresholds are likely to occur along the housing density/sprawl area gradient. To my knowledge, only one study investigating thresholds in an urban system exists to date. Drinnan (2005) found that bird, frog, plant and fungal species richnesses declined rapidly in forest remnants in a suburban matrix smaller than 2-4 ha. Drinnan (2005) also found that forest interior species dominated remnants larger than 50 ha.

Fourth, how does the shape of the developed area in development scenarios change the overall conclusions of my thesis? And fifth, what effect would other land uses in the development scenarios, such as recreation in the undeveloped portion of a scenario, have on the overall conclusions of my thesis? The reason the Semi-compact and Compact scenarios had high estimates of forest bird and forest beetle abundances and species richnesses was because these scenarios had a large amount of continuous forest cover typical of my Forested survey sites, in which both taxa were most abundant and speciose (Tables 1.1, 2.1). Thus, I predict that a decrease in Forested site areas in the Semicompact and Compact scenarios would result in lower estimates of forest bird and forest beetle abundances and species richnesses. A decrease in Forested site areas in a scenario 
could result from an increase in Neighbor site areas due to the developed portion of a scenario having a more complex shape than the square developed area I used in this thesis, or from a replacement of Forested site areas with Neighbour site areas where recreation occurred. It is difficult to predict what effect these changes would have on one of the overall conclusions of my thesis, that the Semi-compact and Compact scenarios minimize the impacts of a given human population on forest birds and forest beetles. Forest birds and forest beetles were more abundant and speciose in Exurban survey sites than in Neighbor survey sites (with the exception of forest beetles in Urban Neighbor survey sites) (Tables 1.1, 2.1). Thus, a landscape covered entirely in Exurban-density development (the Dispersed scenario) would likely have higher forest bird abundance than a landscape with a small area of Urban-density development and the remainder covered entirely by forest typical of my Urban Neighbor survey sites (the Compact scenario), but how this outcome would change for differing numbers of Neighbor site areas and in the case of forest beetles is unclear.

Finally, how does spatial scale change the overall conclusions of my thesis? Scenario size and structure were determined according to two values: the mean number of dwellings in the Urban and Urban Neighbor housing categories and the mean housing density of Exurban survey sites. Variation in these values will change scenario size, as well as the areas covered by development and neighboring forest cover in the Semicompact and Compact scenarios. Thus, the relative proportions of cover types in the development scenarios will change with spatial scale. The Undeveloped and Dispersed scenarios will be covered entirely in forest cover or Exurban-density development, 
respectively, regardless of spatial scale, whereas the proportions of the Semi-compact and Compact scenarios covered by development and neighboring forest cover will change with spatial scale. To illustrate this, I calculated scenario size and the areas covered by Urban-density development and Urban Neighbor forest cover in the Compact scenario for differing numbers of dwellings and housing density values. To accommodate the maximum number of dwellings in Urban and Urban Neighbor survey sites (1167 dwellings) at the minimum Exurban housing density (12 dwellings $\left./ \mathrm{km}^{2}\right)$, scenario size would have to be $97.25 \mathrm{~km}^{2}$. Urban survey site areas would cover $0.26 \%$, Urban Neighbor survey site areas would cover $0.51 \%$ and Forested survey site areas would cover $99.23 \%$ of the scenario. If one wished to accommodate the minimum number of dwellings in Urban and Urban Neighbor survey sites (311 dwellings) at the maximum Exurban housing density ( 56 dwellings $/ \mathrm{km}^{2}$ ), scenario size would shrink to $5.55 \mathrm{~km}^{2}$, of which $4.50 \%$ would be covered by Urban survey sites areas, $9.00 \%$ would be covered by Urban Neighbor survey site areas and $86.5 \%$ would be covered by Forested survey site areas. These calculations exemplify that the Compact scenario will remain largely composed of Forested survey site areas despite an order of magnitude change in spatial scale (the proportions of Urban, Urban Neighbor and Forested survey site areas for the scenario size used in this thesis $\left(22.96 \mathrm{~km}^{2}\right)$ were $1.09 \%, 2.18 \%$ and $96.73 \%$, respectively). The results I report in Chapters 1 and 2 for forest breeding birds and forest carabid beetles result mainly from the Semi-compact and Compact scenarios being largely made up of Forested survey site areas. Thus, these results are not likely to change significantly with a change in spatial scale of the magnitude described above. However, 
the use of numbers of dwellings and housing densities outside of the ranges observed in the survey sites in this thesis may result in significant changes in the proportions of cover types in the Semi-compact and Compact scenarios, possibly engendering large departures from the breeding bird and carabid beetle estimates calculated here.

Several questions also arise from the results of Chapter 3. First, I found that increasing housing density resulted in an increase in the number of open-habitat beetle species. To my knowledge, this thesis is the first to report patterns of response of carabid beetles in the urban matrix. Thus, many additional questions remain to be addressed concerning carabid beetle communities in the urban matrix. For example, does an increase in microhabitat heterogeneity with urbanization result in an increase in openhabitat beetle species richness? Also, which microhabitat features of the urban environment positively and negatively affect carabid beetle occurrence and abundance? Are urban areas ecological traps for open-habitat beetles? And, does beetle presence in urban areas depend on the availability of source populations from open-habitat areas? Although I found that open-habitat beetles occur in the urban matrix, their survival and reproduction in these areas are unknown. It seems likely that pesticide use in urban areas negatively affects carabid beetle survival and reproduction. If this is the case, source populations in nearby open-habitat areas may be necessary to sustain open-habitat beetle numbers in urban areas. The questions above would engender research with important implications for the conservation of carabid beetles. If urban areas are not sinks for carabid beetle populations and we can identify the habitat features that are associated 
with beetle abundance, then we can improve the amount and quality of habitat for carabid beetles in new and existing urban areas and in so doing, increase beetle populations.

Second, I reported no differences in forest bird and forest beetle abundance and species richness with increasing neighboring housing density. In other words, Suburban Neighbor and Urban Neighbor sites, located in relatively small urban forest fragments (Appendix 9), had similar forest bird and forest beetle abundance and species richness as Forested sites, located in continuous forest. If urban forest fragments in my thesis supported similar forest bird and forest beetle communities within $500 \mathrm{~m}$ of the developed edge as continuous forest, what then is the role of these fragments in maintaining regional forest bird and forest beetle diversity? More generally, what is the conservation value of urban forest fragments and how is this affected by local and landscape factors? Sutherland et al. (2009) have listed this question as one of the 100 questions that, if answered (and acted upon), would have the greatest impact on the conservation of global biological diversity. One explanation for the lack of difference in forest bird and forest beetle abundance and species richness with respect to increasing neighboring housing density is that the forest fragments in which my Neighbor sites were located were large enough to support forest bird and forest beetle populations similar to those in my Forested sites. In addition, the cities of Ottawa and Gatineau are located in a largely forested region (Appendix 9). A forested context surrounding urban forest fragments may be necessary for fragments to support biota similar to that of continuous forest. 
This thesis involved the collection of a large amount of data on breeding bird and carabid beetle communities along an urbanization gradient. I have garnered much information from these data yet still more could be extracted. In future, I plan to use these data to address two questions. First, how do bird and beetle body sizes change along the urbanization gradient? I am interested in comparing the predictions of two classic theories on animal body size, as applied to urbanization. Gray (1989) predicted that increasing disturbance, in my case urbanization, should result in a reduction in mean body size. Conversely, Holling's (1992) textural-discontinuity hypothesis predicts that landscapes dominated by coarse texture should support more large-bodied animals than finely textured landscapes. I hypothesize that high-density urban areas are dominated by coarse texture, in the form of buildings, pavement and lawns, as compared to forests, where finely textured habitat objects, such as leaves, twigs and branches, dominate. The comparison of these two theories on animal body size would shed light on whether theories developed to explain ecological patterns in natural systems can equally be applied to urban systems. Second, are beetle activity periods affected by urbanization? I collected carabid beetles weekly over a 12-week period encompassing the peak activity periods of species in the region. I am interested in describing activity periods for individual species in the region (natural history information of this type is very rare) and testing whether urbanization results in earlier or more rapid emergence of some species, possibly due to the urban heat island effect.

In conclusion, this thesis has made significant contributions to the fields of landscape ecology and urban ecology. I have evaluated the hitherto unknown effects of the trade-off 
between housing density and sprawl area on breeding birds and carabid beetles using a novel method. I have also compared the responses of breeding birds and carabid beetles to urbanization, revealing novel patterns, particularly for the latter taxon. Over the next thirty years, it is my intention to address the questions listed above in order to further our understanding of the effects of urbanization and to identify the manner in which we may mitigate these effects on biological diversity. 


\section{References}

Allen, A.P., T.R. Whittier, P.R. Kaufman, D.P. Larsen, R.J. O’Connor, R.M. Hughes, R.S. Stemberger, S.S. Dixit, R.O. Brinkhurst, A.T. Herlihy and S.G. Paulsen. 1999a. Concordance of taxonomic richness patterns across multiple assemblages in lakes of the northeastern United States. Canadian Journal of Fisheries and Aquatic Sciences 56: 739-747.

Allen, A.P., T.R. Whittier, D.P. Larsen, P.R. Kaufman, R.J. O'Connor, R.M. Hughes, R.S. Stemberger, S.S. Dixit, R.O. Brinkhurst, A.T. Herlihy and S.G. Paulsen. 1999b. Concordance of taxonomic composition patterns across multiple lake assemblages: effects of scale, body size, and land use. Canadian Journal of Fisheries and Aquatic Sciences 56: 2029-2040.

Anderson, D.R., K.P. Burnham and W.L. Thompson. 2000. Null hypothesis testing: problems, prevalence, and an alternative. The Journal of Wildlife Management 64: 912-923.

Andreone, F., S. De Michelis and V. Clima. 1999. A montane amphibian and its feeding habits: Salamandra lanzai (Caudata, Salamandridae) in the Alps of northwestern Italy. Italian Journal of Zoology 66: 45-49.

Arendt, R. 2004. Linked landscapes: creating greenway corridors through conservation subdivision design strategies in the northeastern and central United States. Landscape and Urban Planning 68: 241-269.

Arlettaz, R., M. Ruedi and J. Hausser. 1993. Trophic ecology of two sibling and 
sympatric species of bats - Myotis myotis and Myotis blythii (Chiroptera, Vespertilionidae) - first results. Mammalia 57: 519-531.

Bednarska, A.J., I. Portka, P.E. Kramarz and R. Laskowski. 2009. Combined effect of environmental pollutants (nickel, chlorpyrifos) and temperature on the ground beetle Pterostichus oblongopunctatus (Coleoptera: Carabidae). Environmental Toxicology and Chemistry 28: 864-872.

Beissinger, S.R. and D.R. Osborne. 1982. Effects of urbanization on avian community organization. Condor 84: 75-83.

Berger, W.H. and F.L. Parker. 1970. Diversity of planktonic foraminifera in deep-sea sediments. Science 168: 1345-1347.

Billeter, R., J. Liira, D. Bailey, R. Bugter, P. Arens, I. Augenstein, S. Aviron, J. Baudry, R. Bukacek, F. Burel, M. Cerny, G. De Blust, R. De Cock, T. Diekötter, H. Dietz, J. Dirksen, C. Dormann, W. Durka, M. Frenzel, R. Hamersky, F. Hendrickx, F. Herzog, S. Klotz, B. Koolstra, A. Lausch, D. Le Coeur, J.P. Maelfait, P. Opdam, M. Roubalova, A. Schermann, N. Schermann, T. Schmidt, O. Schweiger, M.J.M. Smulders, M. Speelmans, P. Simova, J. Verboom, W.K.R.E. van Wingerden, M. Zobel and P.J. Edwards. 2008. Indicators for biodiversity in agricultural landscapes: a pan-European study. Journal of Applied Ecology 45: 141-150.

Blair, R.B. 1996. Land use and avian species diversity along an urban gradient. Ecological Applications 6: 506-519.

Blair, R.B. 1999. Birds and butterflies along an urban gradient: surrogate taxa for assessing biodiversity? Ecological Applications 9: 164-170. 
Blair, R.B. 2004. The effects of urban sprawl on birds at multiple levels of biological organization. Ecology \& Society 9: 2. [online] URL: http://www.ecologyandsociety.org/vol9/iss5/art2.

Bousquet, Y. and A. Larochelle. 1993. Catalogue of the Geadephaga (Coleoptera: Trachypachidae, Rhysodidae, Carabidae including Cicindelini) of America north of Mexico. Memoirs of the Entomological Society of Canada 167: 1-397.

Brown, D.G., K.M. Johnson, T.R. Loveland and D.M. Theobald. 2005. Rural land-use trends in the conterminous United States, 1950-2000. Ecological Applications 15: 1851-1863.

Burghardt, K.T., D.W. Tallamy and W.G. Shriver. 2009. Impact of native plants on bird and butterfly biodiversity in suburban landscapes. Conservation Biology 23: 219224.

Cadman, M.D., H.J. Dewar and D.A. Welsh. 1998. The Ontario forest bird monitoring program (1987-1997): goals, methods and species trends observed. Technical Report No. 325. Canadian Wildlife Service, Environment Canada, Ottawa, Canada.

Caruso, T. and M. Migliorini. 2006. A new formulation of the geometric series with applications to oribatid (Acari, Oribatida) species assemblages from humandisturbed Mediterranean areas. Ecological Modelling 195: 402-406.

Cavia, R., G.R. Cueto and O.V. Suárez. 2009. Changes in rodent communities according to the landscape structure in an urban ecosystem. Landscape and Urban Planning 90: $11-19$.

Chung, A.Y.C., P. Eggleton, M.R. Speight, P.M. Hammond and V.K. Chey. 2000. The 
diversity of beetle assemblages in different habitat types in Sabah, Malaysia. Bulletin of Entomological Research 90: 475-496.

City of Ottawa. 2008. Data handbook. Publication No. 25-03. Infrastructure Services and Community Sustainability Department, City of Ottawa, Ottawa, Canada.

Colwell, R.K. and J.A. Coddington. 1994. Estimating terrestrial biodiversity through extrapolation. Philosophical Transactions of the Royal Society B: Biological Sciences 345: 101-118.

Crist, T.O., J.A. Veech, J.C. Gering and K.S. Summerville. 2003. Partitioning species diversity across landscapes and regions: a hierarchical analysis of $\alpha, \beta$, and $\gamma$ diversity. The American Naturalist 162: 734-743.

Drinnan, I.N. 2005. The search for fragmentation thresholds in a southern Sydney suburb. Biological Conservation 124: 339-349.

Elek, Z. and G.L. Lövei. 2007. Patterns in ground beetle (Coleoptera: Carabidae) assemblages along an urbanisation gradient in Denmark. Acta Oecologica 32: 104111.

Engels, T.M. and C.W. Sexton. 1994. Negative correlation of Blue Jays and Goldencheeked Warblers near an urbanizing area. Conservation Biology 8: 286-290.

Faith, D.P., P.R. Minchin and L. Belbin. 1987. Compositional dissimilarity as a robust measure of ecological distance. Vegetatio 69: 57-68.

Freemark, K. and B. Collins. 1992. Landscape ecology of birds breeding in temperate 
forest fragments. Pages 443-454 in J.M. Hagan and D.W. Johnston, editors. Ecology and conservation of Neotropical migrant landbirds. Smithsonian Institute Press, Washington, D.C., U.S.A.

Friesen, L.E., P.F.J. Eagles and R.J. MacKay. 1995. Effects of residential development on forest-dwelling Neotropical migrant songbirds. Conservation Biology 9: 14081414.

Gaston, K.J. 2000. Global patterns in biodiversity. Nature 405: 220-227.

Gaublomme, E., F. Hendrickx, H. Dhuyvetter and K. Desender. 2008. The effects of forest patch size and matrix type on changes in carabid beetle assemblages in an urbanized landscape. Biological Conservation 141: 2585-2596.

Germaine, S.S., S.S. Rosenstock, R.E. Schweinsburg and W.S. Richardson. 1998.

Relationships among breeding birds, habitat, and residential development in Greater Tucson, Arizona. Ecological Applications 8: 680-691.

Gillham, O. 2002. The limitless city: a primer on the urban sprawl debate. Island Press, Washington, D.C., U.S.A.

Gonzalez-Abraham, C.E., V.C. Radeloff, T.J. Hawbaker, R.B. Hammer, S.I. Stewart and M.K. Clayton. 2007. Patterns of houses and habitat loss from 1937 to 1999 in northern Wisconsin, USA. Ecological Applications 17: 2011-2023.

Grafen, A. and R. Hails. 2002. Modern statistics for the life sciences. Oxford University Press, New York, U.S.A.

Gray, J.S. 1989. Effects of environmental stress on species rich assemblages. Biological Journal of the Linnean Society 37: 19-32. 
Grimm, N.B., J.M. Grove, S.T.A. Pickett and C.L. Redman. 2000. Integrated approaches to long-term studies of urban ecological systems. BioScience 50: 571-584.

Hansen, A.J., R.L. Knight, J.M. Marzluff, S. Powell, K. Brown, P.H. Gude and K. Jones. 2005. Effects of exurban development on biodiversity: patterns, mechanisms, and research needs. Ecological Applications 15: 1893-1905.

Heimlich, R.E. and W.D. Anderson. 2001. Development at the urban fringe and beyond: impacts on agriculture and rural land. Agricultural Economic Report No. 803. U.S.D.A. Economic Research Service, Washington, D.C., U.S.A.

Heino, J., T. Muotka, R. Paavola and L. Paasivirta. 2003. Among-taxon congruence in biodiversity patterns: can stream insect diversity be predicted using single taxonomic groups? Canadian Journal of Fisheries and Aquatic Sciences 60: 1039-1049.

Hess, G.R., R.A. Bartel, A.K. Leidner, K.M. Rosenfeld, M.J. Rubino, S.B. Snider and T.H. Ricketts. 2006. Effectiveness of biodiversity indicators varies with extent, grain, and region. Biological Conservation 132: 448-457.

Hódar, J.A., F. Campos and B.A. Rosales. 1996. Trophic ecology of the Ocellated Lizard Lacerta lepida in an arid zone of southern Spain: relationships with availability and daily activity of prey. Journal of Arid Environments 33: 95-107.

Holland, J.M., M.A.S. Hutchison, B. Smith and N.J. Aebischer. 2006. A review of invertebrates and seed-bearing plants as food for farmland birds in Europe. Annals of Applied Biology 148: 49-71.

Holland, K.D., M.J. McDonnell and N.S.G. Williams. 2007. Abundance, species richness 
and feeding preferences of introduced molluscs in native grasslands of Victoria, Australia. Austral Ecology 32: 626-634.

Holling, C.S. 1992. Cross-scale morphology, geometry, and dynamics of ecosystems. Ecological Monographs 62: 447-502.

Ingram, J. 2005. Nodal development: creating compact, complete mixed use communities. Regional District of Nanaimo, Nanaimo, Canada.

Ishitani, M., D.J. Kotze and J. Niemelä. 2003. Changes in carabid beetle assemblages across an urban-rural gradient in Japan. Ecography 26: 481-489.

Jaeger, J.A., L. Fahrig and K.C. Ewald. 2005. Does the configuration of road networks influence the degree to which roads affect wildlife populations? Pages 151-163 in C.L. Irwin, P. Garrett and K.P. McDermott, editors. Proceedings of the 2005 International Conference on Ecology and Transportation. Centre for Transportation and the Environment, North Carolina State University, Raleigh, U.S.A.

Kempton, R.A. and L.R. Taylor. 1974. Log-series and log-normal parameters as diversity discriminants for the Lepidoptera. The Journal of Animal Ecology 43: 381-399.

Kluza, D.A., C.R. Griffin and R.M. DeGraaf. 2000. Housing developments in rural New England: effects on forest birds. Animal Conservation 3: 15-26.

Lambshead, P.J.D., H.M. Platt and K.M. Shaw. 1983. The detection of differences among assemblages of marine benthic species based on an assessment of dominance and diversity. Journal of Natural History 17: 859-874.

Legendre, P. and E.D. Gallagher. 2001. Ecologically meaningful transformations for ordination of species data. Oecologia 129: 271-280. 
Legendre, P. and L. Legendre. 1998. Numerical ecology, 2nd edition. Elsevier, Amsterdam, Netherlands.

Lenth, B.A., R.L. Knight and W.C. Gilgert. 2006. Conservation value of compact housing developments. Conservation Biology 20: 1445-1456.

Lepczyk, C.A., C.H. Flather, V.C. Radeloff, A.M. Pidgeon, R.B. Hammer and J. Liu. 2008. Human impacts on regional avian diversity. Conservation Biology 22: 405416.

Lepczyk, C.A., A.G. Mertig and J. Liu. 2004. Assessing landowner activities related to birds across rural-to-urban landscapes. Environmental Management 33: 110-125.

Levesque, C. and G.-Y. Levesque. 1986. Activité et succession saisonnière de coléoptères épigés d'une forêt décidue du sud du Québec. Le Naturaliste Canadien 113: 39-46.

Lindroth, C.H. 1961-1969. The ground beetles of Canada and Alaska. Opuscula Entomologica: 1-1192.

Maestas, J.D., R.L. Knight and W.C. Gilgert. 2003. Biodiversity across a rural land-use gradient. Conservation Biology 17: 1425-1434.

Magura, T., G.L. Lövei and B. Tóthmérész. 2008. Time-consistent rearrangement of carabid beetle assemblages by an urbanisation gradient in Hungary. Acta Oecologica 34: 233-243.

Magura, T., B. Tóthmérész and G.L. Lövei. 2006. Body size inequality of carabids along an urbanisation gradient. Basic and Applied Ecology 7: 472-482.

Magura, T., B. Tóthmérész and T. Molnár. 2004. Changes in carabid beetle assemblages 
along an urbanisation gradient in the city of Debrecen, Hungary. Landscape Ecology 19: 747-759.

Magurran, A.E. 2004. Measuring biological diversity. Blackwell Science, Oxford, U.K.

Mancke, R.G. and T.A. Gavin. 2000. Breeding bird density in woodlots: effects of depth and buildings at the edges. Ecological Applications 10: 598-611.

Marzluff, J.M., R. Bowman and R. Donnelly. 2001. A historical perspective on urban bird research: trends, terms, and approaches. Pages 1-18 in J.M. Marzluff, J.L. Bowden and R. Donnelly, editors. Avian ecology and conservation in an urbanizing world. Kluwer Academic Publishers, Boston, U.S.A.

May, R.M. 1975. Patterns of species abundance and diversity. Pages 81-120 in M.L. Cody and J.M. Diamond, editors. Ecology and evolution of communities, Belknap Press of Harvard University Press, Cambridge, U.S.A.

Mcdonald, R.I., P. Kareiva and R.T.T. Forman. 2008. The implications of current and future urbanization for global protected areas and biodiversity conservation. Biological Conservation 141: 1695-1703.

McDonnell, M.J. and A.K. Hahs. 2008. The use of gradient analysis studies in advancing our understanding of the ecology of urbanizing landscapes: current status and future directions. Landscape Ecology 23: 1143-1155.

McDonnell, M.J. and S.T.A. Pickett. 1990. Ecosystem structure and function along urban-rural gradients: an unexploited opportunity for ecology. Ecology 71: 12321237.

McGill, B.J., R.S. Etienne, J.S. Gray, D. Alonso, M.J. Anderson, H. Kassa Benecha, M. 
Dornelas, B.J. Enquist, J.L. Green, F. He, A.H. Hurlbert, A.E. Magurran, P.A. Marquet, B.A. Maurer, A. Ostling, C.U. Soykan, K.I. Ugland and E.P. White. 2007. Species abundance distributions: moving beyond single prediction theories to integration within an ecological framework. Ecology Letters 10: 995-1015. McKinney, M.L. 2002. Urbanization, biodiversity, and conservation. BioScience 52: 883890.

McKinney, M.L. 2006. Urbanization as a major cause of biotic homogenization. Biological Conservation 127: 247-260.

Miller, J.R., J.A. Wiens, N.T. Hobbs and D.M. Theobald. 2003. Effects of human settlement on bird communities in lowland riparian areas of Colorado (USA). Ecological Applications 13: 1041-1059.

Murphy, D.D. and B.A. Wilcox. 1986. Butterfly diversity in natural habitat fragments: a test of the validity of vertebrate-based management. Pages 287-292 in J. Verner, M.L. Morrison and C.J. Ralph, editors. Wildlife 2000: modeling habitat relationships of terrestrial vertebrates. University of Wisconsin Press, Madison, U.S.A.

Niemelä, J., Y. Haila, E. Halme, T. Pajunen and P. Punttila. 1992. Small-scale heterogeneity in the spatial distribution of carabid beetles in the southern Finnish taiga. Journal of Biogeography 19: 173-181.

Niemelä, J., J. Kotze, A. Ashworth, P. Brandmayr, K. Desender, T. New, L. Penev, M. Samways and J. Spence. 2000. The search for common anthropogenic impacts on biodiversity: a global network. Journal of Insect Conservation 4: 3-9.

Niemelä, J., D.J. Kotze, S. Venn, L. Penev, I. Stoyanov, J. Spence, D. Hartley and E. 
Montes de Oca. 2002. Carabid beetle assemblages (Coleoptera, Carabidae) across urban-rural gradients: an international comparison. Landscape Ecology 17: 387-401.

Odell, E.A. and R.L. Knight. 2001. Songbird and medium-sized mammal communities associated with exurban development in Pitkin County, Colorado. Conservation Biology 15: 1143-1150.

Oertli, S., A. Müller, D. Steiner, A. Breitenstein and S. Dorn. 2005. Cross-taxon congruence of species diversity and community similarity among three insect taxa in a mosaic landscape. Biological Conservation 126: 195-205.

Olden, J.D., N. LeRoy Poff and M.L. McKinney. 2006. Forecasting faunal and floral homogenization associated with human population geography in North America. Biological Conservation 127: 261-271.

Pennington, D.N., J. Hansel and R.B. Blair. 2008. The conservation value of urban riparian areas for landbirds during spring migration: land cover, scale, and vegetation effects. Biological Conservation 141: 1235-1248.

Pidgeon, A.M., V.C. Radeloff, C.H. Flather, C.A. Lepczyk, M.K. Clayton, T.J. Hawbaker and R.B. Hammer. 2007. Associations of forest bird species richness with housing and landscape patterns across the USA. Ecological Applications 17: 1989-2010.

Pielou, E.C. 1975. Ecological diversity. John Wiley \& Sons, New York, U.S.A.

Pillsbury, F.C. and J.R. Miller. 2008. Habitat and landscape characteristics underlying anuran community structure along an urban-rural gradient. Ecological Applications 18: $1107-1118$.

Platt, R.H. 2004. Toward ecological cities: adapting to the $21^{\text {st }}$ century metropolis. 
Environment 46: 11-27.

Poole, A., editor. 2005. The birds of North America online. Cornell Laboratory of Ornithology, Ithaca, U.S.A. Available from http://bna.birds.cornell.edu/BNA/ (accessed March-October 2007).

Qu, X.-D., M.-Y. Song, Y.-S. Park, Y.N. Oh and T.-S. Chon. 2008. Species abundance patterns of benthic macroinvertebrate communities in polluted streams. Annales de Limnologie - International Journal of Limnology 44: 119-133.

R Development Core Team. 2007. R: a language and environment for statistical Computing, version 2.6.0. R Foundation for Statistical Computing, Vienna, Austria.

R Development Core Team. 2008. R: a language and environment for statistical Computing, version 2.6.2. R Foundation for Statistical Computing, Vienna, Austria. Radeloff, V.C., R.B. Hammer and S.I. Stewart. 2005. Rural and suburban sprawl in the U.S. Midwest from 1940 to 2000 and its relation to forest fragmentation. Conservation Biology 19: 793-805.

Ricketts, T.H., E. Dinerstein, D.M. Olson and C. Loucks. 1999. Who's where in North America: patterns of species richness and the utility of indicator taxa for conservation. BioScience 49: 369-381.

Rodewald, A.D. and D.P. Shustack. 2008. Urban flight: understanding individual and population-level responses of Nearctic-Neotropical migratory birds to urbanization. Journal of Animal Ecology 77: 83-91.

Sadler, J.P., E.C. Small, H. Fiszpan, M.G. Telfer and J. Niemelä. 2006. Investigating 
environmental variation and landscape characteristics of an urban-rural gradient using woodland carabid assemblages. Journal of Biogeography 33: 1126-1138.

Sauberer, N., K.P. Zulka, M. Abensperg-Traun, H.-M. Berg, G. Bieringer, N. Milasowszky, D. Moser, C. Plutzar, M. Pollheimer, C. Storch, R. Tröstl, H. Zechmeister, G. Grabherr. 2004. Surrogate taxa for biodiversity in agricultural landscapes of eastern Austria. Biological Conservation 117: 181-190.

Schultz, T.D. 1998. The utilization of patchy thermal microhabitats by the ectothermic insect predator, Cicindela sexguttata. Ecological Entomology 23: 444-450.

Sebastião, H. and C.E.V. Grelle. 2009. Taxon surrogates among Amazonian mammals: can total species richness be predicted by single orders? Ecological Indicators 9: $160-166$.

Şekercioğlu, C.H., G.C. Daily and P.R. Ehrlich. 2004. Ecosystem consequences of bird declines. Proceedings of the National Academy of Sciences 101: 18042-18047.

Shochat, E., P.S. Warren, S.H. Faeth, N.E. McIntyre and D. Hope. 2006. From patterns to emerging processes in mechanistic urban ecology. Trends in Ecology and Evolution 21: 186-191.

Sorace, A. and M. Gustin. 2008. Homogenisation processes and local effects on avifaunal composition in Italian towns. Acta Oecologica 33: 15-26.

Stanton, R.C., D.J. Horn, F.F. Purrington, J.W. Peacock and E.H. Metzler. 2003. Monitoring selected arthropods. Pages 123-138 in E. Kennedy Sutherland and T.F. Hutchinson, editors. Characteristics of mixed-oak forest ecosystems in southern Ohio 
prior to the reintroduction of fire. General Technical Report No. NE-299. United States Department of Agriculture Forest Service, Newtown Square, U.S.A.

Su, J.C., D.M. Debinski, M.E. Jakubauskas and K. Kindscher. 2004. Beyond species richness: community similarity as a measure of cross-taxon congruence for coarsefilter conservation. Conservation Biology 18: 167-173.

Sutherland, W.J., W.M. Adams, R.B. Aronson, R. Aveling, T.M. Blackburn, S. Broad, G. Ceballos, I.M. Côté, R.M. Cowling, G.A.B. da Fonseca, E. Dinerstein, P.J. Ferraro, E. Fleishman, C. Gascon, M. Hunter Jr., J. Hutton, P. Kareiva, A. Kuria, D.W. Macdonald, K. MacKinnon, F.J. Madgwick, M.B. Mascia, J. McNeely, E.J. MilnerGulland, S. Moon, C.G. Morley, S. Nelson, D. Osborn, M. Pai, E.C.M. Parsons, L.S. Peck, H. Possingham, S.V. Prior, A.S. Pullin, M.R.W. Rands, J. Ranganathan, K.H. Redford, J.P. Rodriguez, F. Seymour, J. Sobel, N.S. Sodhi, A. Stott, K. VanceBorland and A.R. Watkinson. 2009. One hundred questions of importance to the conservation of global biological diversity. Conservation Biology 23: 557-567.

Symondson, W.O.C., D.M. Glen, A.R. Ives, C.J. Langdon and C.W. Wiltshire. 2002. Dynamics of the relationship between a generalist predator and slugs over five years. Ecology 83: 137-147.

Teaford, J.C. 1993. The twentieth century American city, $2^{\text {nd }}$ edition. Johns Hopkins University Press, Baltimore, U.S.A.

Theobald, D.M., J.R. Miller and N.T. Hobbs. 1997. Estimating the cumulative effects of development on wildlife habitat. Landscape and Urban Planning 39: 25-36.

United Nations. 2008. World urbanization prospects: the 2007 revision. Population 
Division of the Department of Economic and Social Affairs of the United Nations Secretariat, New York, U.S.A.

Visser, S. 1995. Ectomycorrhizal fungal succession in jack pine stands following wildfire. New Phytologist 129: 389-401.

Weaver, J.C. 1995. Indicator species and scale of observation. Conservation Biology 9: 939-942.

Webster, R.P. and Y. Bousquet. 2008. New ground beetle (Coleoptera: Carabidae) records in New Brunswick, Canada. Journal of the Acadian Entomological Society 4: 14-24.

Weller, B. and J.U. Ganzhorn. 2004. Carabid beetle community composition, body size, and fluctuating asymmetry along an urban-rural gradient. Basic and Applied Ecology 5: 193-201.

Whittaker, R.H. 1965. Dominance and diversity in land plant communities. Science 147: $250-260$.

Wilson, J.B. 1991. Methods for fitting dominance/diversity curves. Journal of Vegetation Science 2: 35-46.

Wolters, V., J. Bengtsson and A.S. Zaitsev. 2006. Relationship among the species richness of different taxa. Ecology 87: 1886-1895.

Xu, H., J. Wu, Y. Liu, H. Ding, M. Zhang, Y. Wu, Q. Xi and L. Wang. 2008. Biodiversity congruence and conservation strategies: a national test. BioScience 58: $632-639$.

Zar, J.H. 1999. Biostatistical analysis, $4^{\text {th }}$ edition. Prentice Hall, Upper Saddle River, 
U.S.A. 


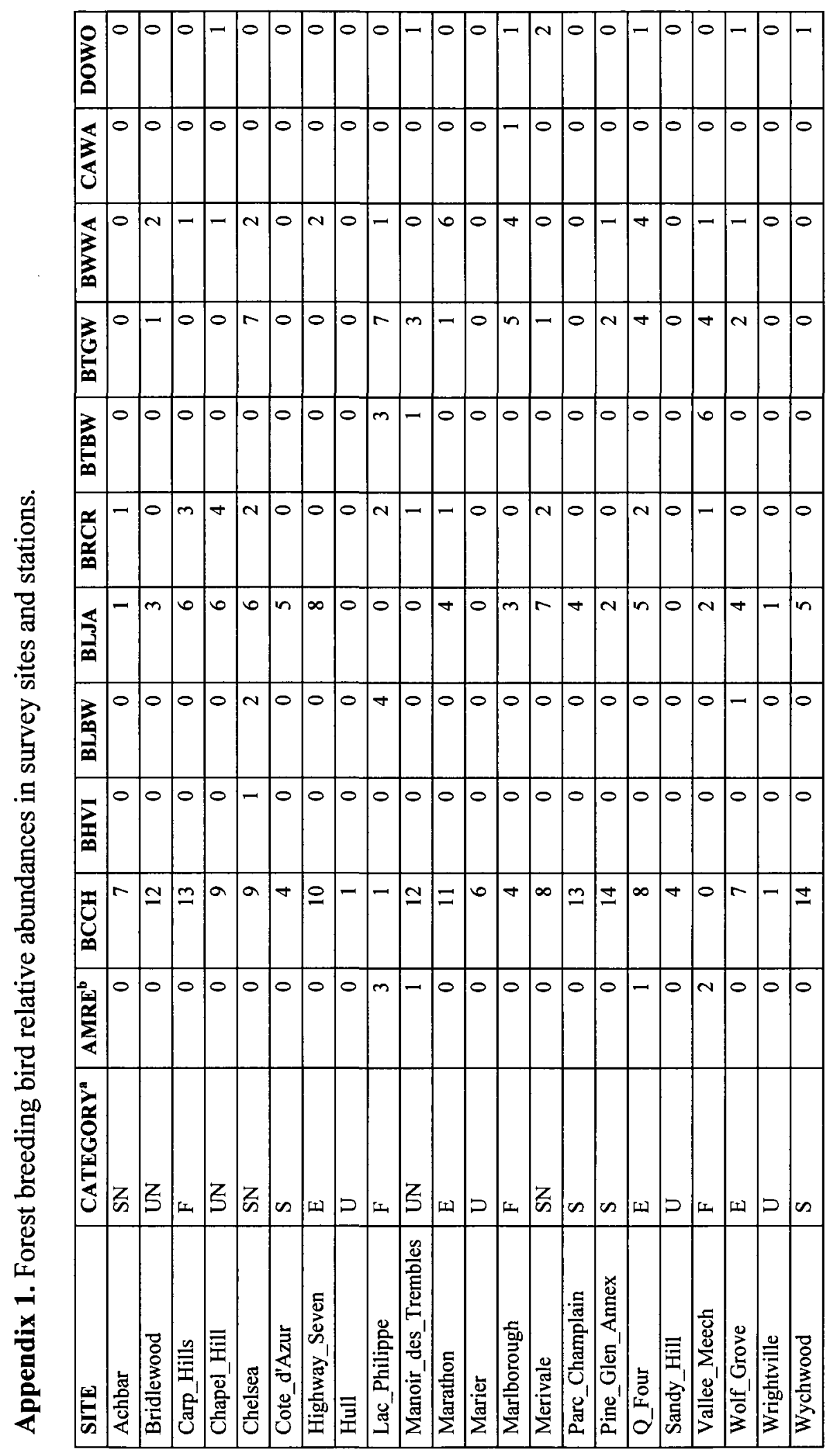


$\Xi$

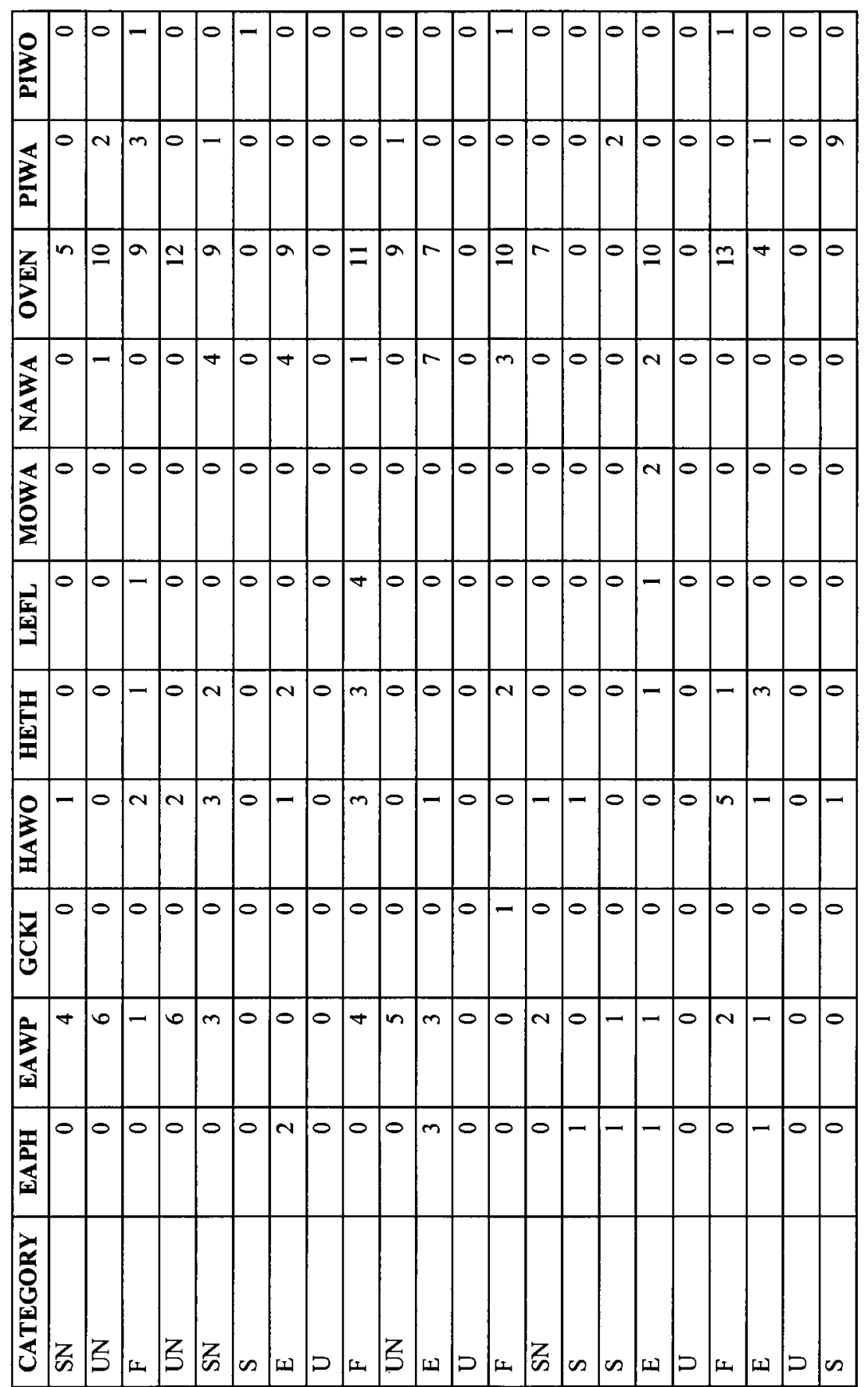

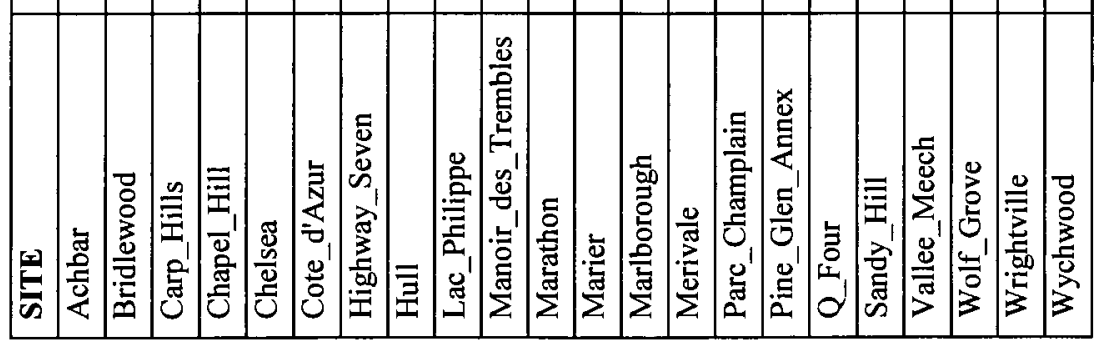




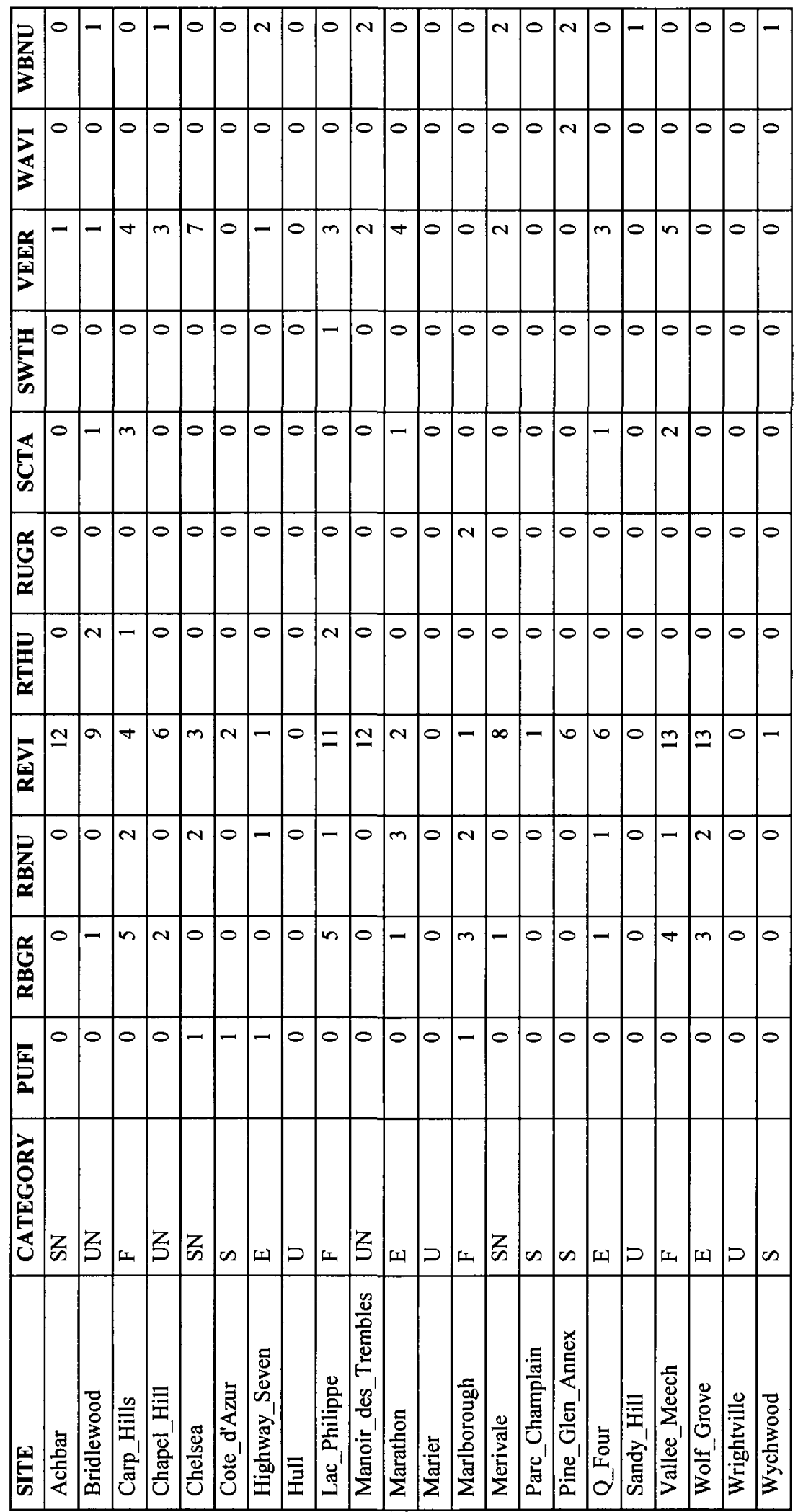




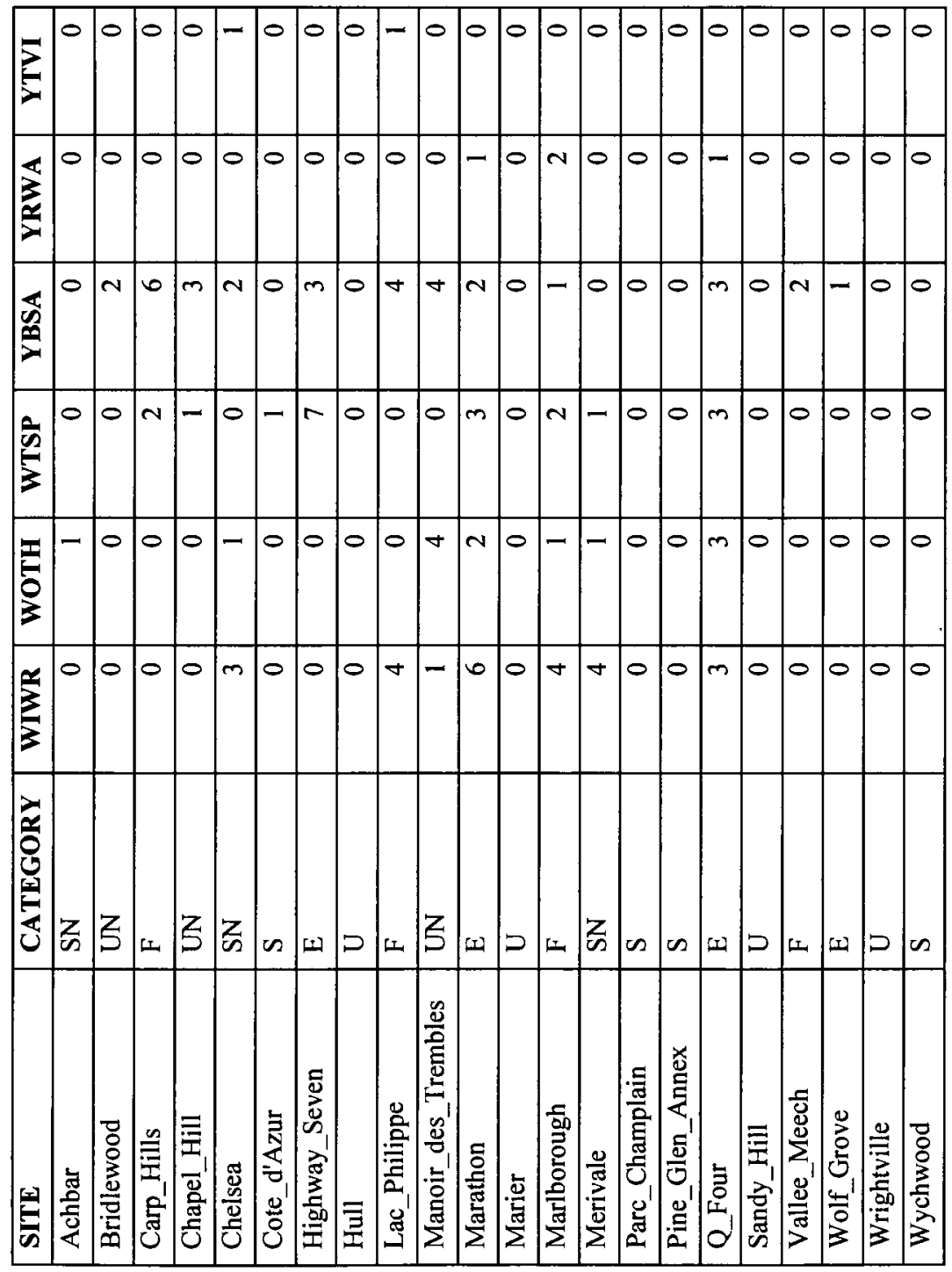




\begin{tabular}{|c|c|c|c|c|c|c|c|c|}
\hline SITE & STATION & CATEGORY ${ }^{\mathrm{a}}$ & AMRE $^{\mathbf{b}}$ & $\overline{\mathrm{BCCH}}$ & BHVI & BLBW & BLJA & BRCR \\
\hline Achbar & $\mathrm{A}$ & SN & 0 & 2 & 0 & 0 & 0 & 1 \\
\hline Achbar & $\mathrm{B}$ & SN & 0 & 3 & 0 & 0 & 0 & 0 \\
\hline Achbar & $\mathrm{C}$ & $\mathrm{SN}$ & 0 & 3 & 0 & 0 & 1 & 0 \\
\hline Achbar & $\bar{D}$ & SN & 0 & 1 & 0 & 0 & 0 & 0 \\
\hline Bridlewood & $\bar{A}$ & $\overline{\mathrm{UN}}$ & 0 & 7 & 0 & 0 & 2 & 0 \\
\hline Bridlewood & B & UN & 0 & 3 & 0 & 0 & 0 & 0 \\
\hline Bridlewood & $\mathrm{C}$ & UN & 0 & 1 & 0 & 0 & 0 & 0 \\
\hline Bridlewood & $\mathrm{D}$ & $\overline{\mathrm{UN}}$ & 0 & 1 & 0 & 0 & 2 & 0 \\
\hline Carp_Hills & $\bar{A}$ & $\mathrm{~F}$ & 0 & 2 & 0 & 0 & 1 & 2 \\
\hline Carp_Hills & $\bar{B}$ & $\mathrm{~F}$ & 0 & 7 & 0 & 0 & 2 & 0 \\
\hline Carp_Hills & $\mathrm{C}$ & $\mathrm{F}$ & 0 & 1 & 0 & 0 & 2 & 1 \\
\hline Carp_Hills & $\bar{D}$ & $\mathrm{~F}$ & 0 & 3 & 0 & 0 & 1 & 1 \\
\hline Chapel_Hill & $\overline{\mathrm{A}}$ & UN & 0 & 4 & 0 & 0 & 2 & 1 \\
\hline Chapel_Hill & B & $\overline{U N}$ & 0 & 2 & 0 & 0 & 1 & 1 \\
\hline Chapel Hill & $\mathrm{C}$ & UN & 0 & 3 & 0 & 0 & 1 & 1 \\
\hline Chapel_Hill & $\bar{D}$ & $\overline{\text { UN }}$ & 0 & 1 & 0 & 0 & 2 & 2 \\
\hline Chelsea & $\bar{A}$ & $\overline{\mathrm{SN}}$ & 0 & 2 & 1 & 0 & 2 & 1 \\
\hline Chelsea & B & $\mathrm{SN}$ & 0 & 0 & 0 & 0 & 0 & 1 \\
\hline Chelsea & $\mathrm{C}$ & SN & 0 & 3 & 0 & 2 & 2 & 1 \\
\hline Chelsea & $\bar{D}$ & $\overline{\mathrm{SN}}$ & 0 & 4 & 0 & 1 & 2 & 0 \\
\hline Cote_d'Azur & $\overline{\mathrm{A}}$ & $S$ & 0 & 2 & 0 & 0 & 2 & 0 \\
\hline Cote_d'Azur & $\bar{B}$ & $\mathrm{~S}$ & 0 & 2 & 0 & 0 & 1 & 0 \\
\hline Cote d'Azur & $\mathrm{C}$ & $\mathrm{S}$ & 0 & 0 & 0 & 0 & 1 & 0 \\
\hline Cote_d'Azur & $\bar{D}$ & $\mathrm{~S}$ & 0 & 1 & 0 & 0 & 2 & 0 \\
\hline Highway_Seven & A & $E$ & 0 & 4 & 0 & 0 & 0 & 0 \\
\hline Highway_Seven & $\mathrm{B}$ & $\mathrm{E}$ & 0 & 3 & 0 & 0 & 1 & 0 \\
\hline Highway_Seven & $\mathrm{C}$ & $\mathrm{E}$ & 0 & 4 & 0 & 0 & 4 & 0 \\
\hline Highway_Seven & $\bar{D}$ & $\bar{E}$ & 0 & 1 & 0 & 0 & 3 & 0 \\
\hline Hull & $\bar{A}$ & $\bar{U}$ & 0 & 0 & 0 & 0 & 0 & 0 \\
\hline Hull & B & $\mathrm{U}$ & 0 & 0 & 0 & 0 & 0 & 0 \\
\hline Hull & $\mathrm{C}$ & $\bar{U}$ & 0 & 1 & 0 & 0 & 0 & 0 \\
\hline Hull & D & $\mathrm{U}$ & 0 & 0 & 0 & 0 & 0 & 0 \\
\hline Lac_Philippe & $\bar{A}$ & $\mathrm{~F}$ & 0 & 0 & 0 & 2 & 0 & 0 \\
\hline Lac_Philippe & $\mathrm{B}$ & $\mathrm{F}$ & 0 & 1 & 0 & 1 & 0 & 2 \\
\hline Lac_Philippe & $\mathrm{C}$ & $\mathrm{F}$ & 2 & 0 & 0 & 1 & 0 & 0 \\
\hline Lac_Philippe & $\overline{\mathrm{D}}$ & $\bar{F}$ & 1 & 0 & 0 & 1 & 0 & 0 \\
\hline Manoir_des_Trembles & $\mathrm{A}$ & $\overline{U N}$ & 0 & 0 & 0 & 0 & 0 & 1 \\
\hline Manoir_des_Trembles & B & UN & 0 & 6 & 0 & 0 & 0 & 0 \\
\hline Manoir_des_Trembles & $\mathrm{C}$ & $\overline{U N}$ & 1 & 7 & 0 & 0 & 0 & 0 \\
\hline Manoir_des_Trembles & $\bar{D}$ & UN & 0 & 3 & 0 & 0 & 0 & 0 \\
\hline Marathon & $\bar{A}$ & $\bar{E}$ & 0 & 2 & 0 & 0 & 1 & 0 \\
\hline Marathon & $\bar{B}$ & $\mathrm{E}$ & 0 & 1 & 0 & 0 & 1 & 1 \\
\hline Marathon & $\mathrm{C}$ & $\mathrm{E}$ & 0 & 5 & 0 & 0 & 0 & 0 \\
\hline Marathon & $\bar{D}$ & $\bar{E}$ & 0 & 4 & 0 & 0 & 2 & 0 \\
\hline
\end{tabular}




\begin{tabular}{|c|c|c|c|c|c|c|c|c|}
\hline Marier & $\mathrm{A}$ & $\bar{U}$ & 0 & 4 & 0 & 0 & 0 & 0 \\
\hline Marier & B & $\mathrm{U}$ & 0 & 0 & 0 & 0 & 0 & 0 \\
\hline Marier & $\mathrm{C}$ & $\bar{U}$ & 0 & 2 & 0 & 0 & 0 & $\overline{0}$ \\
\hline Marier & $\mathrm{D}$ & $\mathrm{U}$ & 0 & 0 & 0 & 0 & 0 & 0 \\
\hline Marlborough & $\overline{\mathrm{A}}$ & $F$ & 0 & 0 & 0 & 0 & 1 & 0 \\
\hline Marlborough & $\mathrm{B}$ & $F$ & 0 & 3 & 0 & 0 & 1 & 0 \\
\hline Marlborough & $\mathrm{C}$ & $\mathrm{F}$ & 0 & 1 & 0 & 0 & 2 & 0 \\
\hline Marlborough & $\overline{\mathrm{D}}$ & $F$ & 0 & 1 & 0 & 0 & 1 & 0 \\
\hline Merivale & $\mathbf{A}$ & $\mathrm{SN}$ & 0 & 3 & 0 & 0 & 2 & 1 \\
\hline Merivale & $\mathrm{B}$ & $\mathrm{SN}$ & 0 & 1 & 0 & 0 & 2 & 1 \\
\hline Merivale & $\mathrm{C}$ & SN & 0 & 4 & 0 & 0 & 0 & 1 \\
\hline Merivale & $\mathrm{D}$ & $\mathrm{SN}$ & 0 & 0 & 0 & 0 & 3 & 1 \\
\hline Parc_Champlain & $\mathrm{A}$ & $\mathrm{S}$ & 0 & 4 & 0 & 0 & 2 & 0 \\
\hline Parc_Champlain & $\mathrm{B}$ & $\mathrm{S}$ & 0 & 4 & 0 & 0 & 0 & 0 \\
\hline Parc_Champlain & $\mathrm{C}$ & $\mathrm{S}$ & 0 & 1 & 0 & 0 & 2 & 0 \\
\hline Parc_Champlain & $\mathrm{D}$ & $\mathrm{S}$ & 0 & 6 & 0 & 0 & 2 & 0 \\
\hline Pine_Glen_Annex & $\mathrm{A}$ & $\mathrm{S}$ & 0 & 3 & 0 & 0 & 0 & 0 \\
\hline Pine_Glen_Annex & $\mathrm{B}$ & $\mathrm{S}$ & 0 & 3 & 0 & 0 & 2 & 0 \\
\hline Pine_Glen_Annex & $\mathrm{C}$ & $\mathrm{S}$ & 0 & 3 & 0 & 0 & 0 & 0 \\
\hline Pine_Glen_Annex & $\mathrm{D}$ & $\mathrm{S}$ & 0 & 5 & 0 & 0 & 0 & $\overline{0}$ \\
\hline Q_Four & $\bar{A}$ & $\mathrm{E}$ & 0 & 3 & 0 & 0 & 0 & 2 \\
\hline Q_Four & $\mathrm{B}$ & $E$ & 1 & 1 & 0 & 0 & 2 & 0 \\
\hline Q_Four & $\mathrm{C}$ & $\mathrm{E}$ & 0 & 2 & 0 & 0 & 3 & 0 \\
\hline Q_Four & $\mathrm{D}$ & $\mathrm{E}$ & 0 & 2 & 0 & 0 & 1 & 0 \\
\hline Sandy_Hill & $\bar{A}$ & $\mathrm{U}$ & 0 & 1 & 0 & 0 & 0 & 0 \\
\hline Sandy_Hill & $\mathrm{B}$ & $\mathrm{U}$ & 0 & 2 & 0 & 0 & 0 & 0 \\
\hline Sandy_Hill & $\mathrm{C}$ & $\mathrm{U}$ & 0 & 1 & 0 & 0 & 0 & 0 \\
\hline Sandy_Hill & $\mathrm{D}$ & $\mathrm{U}$ & 0 & 2 & 0 & 0 & 0 & 0 \\
\hline Vallee_Meech & $\mathrm{A}$ & $\mathrm{F}$ & 0 & 0 & 0 & 0 & 0 & 1 \\
\hline Vallee_Meech & $\mathrm{B}$ & $\bar{F}$ & 0 & 0 & 0 & 0 & 1 & 1 \\
\hline Vallee_Meech & $\mathrm{C}$ & $\mathrm{F}$ & 2 & 0 & 0 & 0 & 1 & 0 \\
\hline Vallee_Meech & $\mathrm{D}$ & $\mathrm{F}$ & 0 & 0 & 0 & 0 & 1 & 0 \\
\hline Wolf Grove & A & $\mathrm{E}$ & 0 & 1 & 0 & 0 & 1 & 0 \\
\hline Wolf_Grove & B & $\bar{E}$ & 0 & 4 & 0 & 0 & 1 & 0 \\
\hline Wolf_Grove & $\mathrm{C}$ & $\mathrm{E}$ & 0 & 2 & 0 & 0 & 2 & 0 \\
\hline Wolf_Grove & $\mathrm{D}$ & $\mathrm{E}$ & 0 & 1 & 0 & 1 & 0 & 0 \\
\hline Wrightville & $\mathrm{A}$ & $\mathrm{U}$ & 0 & 1 & 0 & 0 & 1 & 0 \\
\hline Wrightville & $\mathrm{B}$ & $\mathrm{U}$ & 0 & 0 & 0 & 0 & 0 & 0 \\
\hline Wrightville & $\mathrm{C}$ & $\mathrm{U}$ & 0 & 0 & 0 & 0 & 0 & 0 \\
\hline Wrightville & $\mathrm{D}$ & $\mathrm{U}$ & 0 & 0 & 0 & 0 & 0 & 0 \\
\hline Wychwood & A & $\mathrm{S}$ & 0 & 4 & 0 & 0 & 1 & 0 \\
\hline Wychwood & $\mathrm{B}$ & $\mathrm{S}$ & 0 & 6 & 0 & 0 & 1 & 0 \\
\hline Wychwood & $\bar{C}$ & $\mathrm{~S}$ & 0 & 1 & 0 & 0 & 1 & 0 \\
\hline Wychwood & $\mathrm{D}$ & $\mathrm{S}$ & 0 & 3 & 0 & 0 & 3 & 0 \\
\hline
\end{tabular}




\begin{tabular}{|c|c|c|c|c|c|c|c|c|}
\hline SITE & STATION & CATEGORY & BTBW & BTGW & BWWA & CAWA & DOWO & EAPH \\
\hline Achbar & A & $\mathrm{SN}$ & 0 & 0 & 0 & 0 & 0 & 0 \\
\hline Achbar & $\overline{\mathrm{B}}$ & SN & 0 & 0 & 0 & 0 & 0 & $\overline{0}$ \\
\hline Achbar & $\overline{\mathrm{C}}$ & $\overline{\mathrm{SN}}$ & 0 & $\overline{0}$ & 0 & 0 & 0 & $\overline{0}$ \\
\hline Achbar & D & $\mathrm{SN}$ & 0 & 0 & 0 & 0 & 0 & 0 \\
\hline Bridlewood & A & $\mathrm{UN}$ & 0 & 0 & 0 & 0 & 0 & 0 \\
\hline Bridlewood & $\bar{B}$ & UN & 0 & 0 & 1 & 0 & 0 & 0 \\
\hline Bridlewood & $\mathrm{C}$ & UN & 0 & 0 & 1 & 0 & 0 & 0 \\
\hline Bridlewood & $\bar{D}$ & UN & 0 & 1 & 0 & 0 & 0 & $\overline{0}$ \\
\hline Carp_Hills & $\overline{\mathrm{A}}$ & $\bar{F}$ & 0 & 0 & 1 & 0 & 0 & $\overline{0}$ \\
\hline Carp_Hills & $\mathrm{B}$ & $\mathrm{F}$ & $\overline{0}$ & 0 & 0 & 0 & 0 & $\overline{0}$ \\
\hline Carp_Hills & $\mathrm{C}$ & $\mathrm{F}$ & 0 & 0 & 0 & 0 & 0 & 0 \\
\hline Carp_Hills & $\bar{D}$ & $\mathrm{~F}$ & 0 & 0 & 0 & 0 & 0 & $\overline{0}$ \\
\hline Chapel_Hill & A & UN & 0 & 0 & 0 & 0 & 0 & 0 \\
\hline Chapel_Hill & B & UN & 0 & 0 & 0 & 0 & 0 & $\overline{0}$ \\
\hline Chapel_Hill & $\mathrm{C}$ & UN & 0 & 0 & 1 & 0 & 0 & 0 \\
\hline Chapel_Hill & $\overline{\mathrm{D}}$ & UN & 0 & 0 & 1 & 0 & 1 & 0 \\
\hline Chelsea & A & $\mathrm{SN}$ & 0 & 4 & 1 & 0 & 0 & 0 \\
\hline Chelsea & $\mathrm{B}$ & $\mathrm{SN}$ & 0 & 1 & 1 & 0 & 0 & $\overline{0}$ \\
\hline Chelsea & $\mathrm{C}$ & SN & 0 & 2 & 1 & 0 & 0 & $\overline{0}$ \\
\hline Chelsea & $\bar{D}$ & $\mathrm{SN}$ & 0 & 2 & 0 & 0 & 0 & 0 \\
\hline Cote_d'Azur & $\overline{\mathrm{A}}$ & $S$ & 0 & 0 & 0 & 0 & 0 & $\overline{0}$ \\
\hline Cote_d'Azur & $\bar{B}$ & $\mathrm{~S}$ & 0 & 0 & 0 & 0 & 0 & $\overline{0}$ \\
\hline Cote_d'Azur & $\mathrm{C}$ & $\mathrm{S}$ & 0 & 0 & 0 & 0 & 0 & 0 \\
\hline Cote_d'Azur & $\overline{\mathrm{D}}$ & $S$ & 0 & 0 & 0 & 0 & 0 & $\overline{0}$ \\
\hline Highway_Seven & $\overline{\mathrm{A}}$ & $\mathrm{E}$ & 0 & 0 & 0 & 0 & 0 & 1 \\
\hline Highway_Seven & B & $\mathrm{E}$ & 0 & 0 & 0 & 0 & 0 & $\overline{0}$ \\
\hline Highway_Seven & $\mathrm{C}$ & $\mathrm{E}$ & 0 & 0 & 2 & 0 & 0 & 0 \\
\hline Highway_Seven & $\bar{D}$ & $\mathrm{E}$ & 0 & 0 & 0 & 0 & 0 & 1 \\
\hline Hull & $\mathrm{A}$ & $\mathrm{U}$ & 0 & 0 & 0 & 0 & 0 & 0 \\
\hline Hull & B & $\mathrm{U}$ & 0 & 0 & 0 & 0 & 0 & $\overline{0}$ \\
\hline Hull & $\bar{C}$ & $\bar{U}$ & 0 & 0 & 0 & 0 & 0 & 0 \\
\hline Hull & $\mathrm{D}$ & $\overline{\mathrm{U}}$ & 0 & 0 & 0 & 0 & 0 & 0 \\
\hline Lac_Philippe & $\bar{A}$ & $F$ & 2 & 2 & 0 & 0 & 0 & 0 \\
\hline Lac_Philippe & $\mathrm{B}$ & $\bar{F}$ & 0 & 2 & 1 & 0 & 0 & 0 \\
\hline Lac_Philippe & $\mathrm{C}$ & $\mathrm{F}$ & 1 & 2 & 0 & 0 & 0 & 0 \\
\hline Lac_Philippe & $\mathrm{D}$ & $\mathrm{F}$ & 0 & 1 & 0 & 0 & 0 & 0 \\
\hline Manoir_des_Trembles & $\mathrm{A}$ & $\mathrm{UN}$ & 1 & 1 & 0 & 0 & 0 & 0 \\
\hline Manoir_des_Trembles & B & UN & 0 & 0 & 0 & 0 & 0 & $\overline{0}$ \\
\hline Manoir_des_Trembles & $\mathrm{C}$ & $\overline{\mathrm{UN}}$ & 0 & 0 & 0 & 0 & 0 & $\overline{0}$ \\
\hline Manoir_des_Trembles & $\mathrm{D}$ & UN & 0 & 2 & 0 & 0 & 1 & 0 \\
\hline Marathon & $\bar{A}$ & $\bar{E}$ & 0 & 0 & 3 & 0 & 0 & 1 \\
\hline Marathon & $\mathrm{B}$ & $\mathrm{E}$ & 0 & 0 & 2 & 0 & 0 & 1 \\
\hline Marathon & $\mathrm{C}$ & $\bar{E}$ & 0 & 1 & 0 & 0 & 0 & 1 \\
\hline
\end{tabular}




\begin{tabular}{|c|c|c|c|c|c|c|c|c|}
\hline Marathon & $\mathrm{D}$ & $\mathrm{E}$ & 0 & 0 & 1 & 0 & 0 & 1 \\
\hline Marier & $\mathrm{A}$ & $\bar{U}$ & 0 & 0 & 0 & 0 & 0 & 0 \\
\hline Marier & $\mathrm{B}$ & $\bar{U}$ & 0 & 0 & 0 & 0 & 0 & 0 \\
\hline Marier & $\mathrm{C}$ & $\mathrm{U}$ & 0 & 0 & 0 & 0 & 0 & 0 \\
\hline Marier & $\bar{D}$ & $\bar{U}$ & 0 & 0 & 0 & 0 & 0 & 0 \\
\hline Marlborough & $\overline{\mathrm{A}}$ & $F$ & 0 & 1 & 1 & 1 & 0 & 0 \\
\hline Marlborough & B & $\mathrm{F}$ & 0 & 2 & 0 & 0 & 0 & 0 \\
\hline Marlborough & $\mathrm{C}$ & $\mathrm{F}$ & 0 & 1 & 2 & 0 & 0 & 0 \\
\hline Marlborough & $\overline{\mathrm{D}}$ & $F$ & 0 & 1 & 2 & 0 & 1 & $\overline{0}$ \\
\hline Merivale & A & $\mathrm{SN}$ & 0 & 1 & 0 & 0 & 2 & 0 \\
\hline Merivale & $\bar{B}$ & $\mathrm{SN}$ & 0 & 0 & 0 & 0 & 0 & 0 \\
\hline Merivale & $\mathrm{C}$ & SN & 0 & 0 & 0 & 0 & 0 & 0 \\
\hline Merivale & $\bar{D}$ & $\overline{\mathrm{SN}}$ & 0 & 0 & 0 & 0 & 0 & 0 \\
\hline Parc_Champlain & $\bar{A}$ & 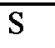 & 0 & 0 & 0 & 0 & 0 & 1 \\
\hline Parc_Champlain & $\bar{B}$ & $\mathrm{~S}$ & 0 & 0 & 0 & 0 & 0 & 0 \\
\hline Parc_Champlain & $\mathrm{C}$ & $S$ & 0 & 0 & 0 & 0 & 0 & 0 \\
\hline Parc_Champlain & $\mathrm{D}$ & $S$ & 0 & 0 & 0 & 0 & 0 & 0 \\
\hline Pine_Glen_Annex & $\bar{A}$ & $S$ & 0 & 1 & 1 & 0 & 0 & 0 \\
\hline Pine_Glen_Annex & $\bar{B}$ & $\mathrm{~S}$ & 0 & 0 & 0 & 0 & 0 & 0 \\
\hline Pine_Glen_Annex & $\mathrm{C}$ & $\mathrm{S}$ & 0 & 0 & 0 & 0 & 0 & 1 \\
\hline Pine_Glen_Annex & $\overline{\mathrm{D}}$ & $S$ & 0 & 1 & 0 & 0 & 0 & 0 \\
\hline Q_Four & $\bar{A}$ & $\bar{E}$ & 0 & 1 & 0 & 0 & 0 & 0 \\
\hline Q_Four & B & $\mathrm{E}$ & 0 & 0 & 3 & 0 & 0 & 1 \\
\hline Q_Four & $\mathrm{C}$ & $\bar{E}$ & 0 & 2 & 0 & 0 & 0 & 1 \\
\hline Q_Four & $\mathrm{D}$ & $\mathbf{E}$ & 0 & 1 & 1 & 0 & 1 & 0 \\
\hline Sandy_Hill & A & $\bar{U}$ & 0 & 0 & 0 & 0 & 0 & 0 \\
\hline Sandy_Hill & $\bar{B}$ & $\overline{\mathrm{U}}$ & 0 & 0 & 0 & 0 & 0 & 0 \\
\hline Sandy_Hill & $\bar{C}$ & $\overline{\mathrm{U}}$ & 0 & 0 & 0 & 0 & 0 & 0 \\
\hline Sandy_Hill & D & $\bar{U}$ & 0 & 0 & 0 & 0 & 0 & 0 \\
\hline Vallee_Meech & $\bar{A}$ & $\bar{F}$ & 1 & 1 & 1 & 0 & 0 & 0 \\
\hline Vallee_Meech & $\mathrm{B}$ & $\mathrm{F}$ & 2 & 1 & 1 & 0 & 0 & 0 \\
\hline Vallee_Meech & $\mathrm{C}$ & $\mathbf{F}$ & 3 & 0 & 0 & 0 & 0 & 0 \\
\hline Vallee_Meech & $\mathrm{D}$ & $\mathbf{F}$ & 1 & 2 & 0 & 0 & 0 & 0 \\
\hline Wolf_Grove & $\bar{A}$ & $\bar{E}$ & 0 & 2 & 0 & 0 & 0 & 0 \\
\hline Wolf_Grove & B & $\mathrm{E}$ & 0 & 0 & 0 & 0 & 0 & 1 \\
\hline Wolf_Grove & $\mathrm{C}$ & $\mathrm{E}$ & 0 & 0 & 0 & 0 & 0 & 0 \\
\hline Wolf_Grove & $\overline{\mathrm{D}}$ & $\mathrm{E}$ & 0 & 0 & 1 & 0 & 1 & 0 \\
\hline Wrightville & $\overline{\mathrm{A}}$ & $\bar{U}$ & 0 & 0 & 0 & 0 & 0 & 0 \\
\hline Wrightville & $\bar{B}$ & $\bar{U}$ & 0 & 0 & 0 & 0 & 0 & 0 \\
\hline Wrightville & $\mathrm{C}$ & $\mathrm{U}$ & 0 & 0 & 0 & 0 & 0 & 0 \\
\hline Wrightville & $\mathrm{D}$ & $\mathrm{U}$ & 0 & 0 & 0 & 0 & 0 & 0 \\
\hline Wychwood & $\mathrm{A}$ & $S$ & 0 & 0 & 0 & 0 & 0 & 0 \\
\hline Wychwood & $\mathrm{B}$ & $S$ & 0 & 0 & 0 & 0 & 1 & 0 \\
\hline Wychwood & $\mathrm{C}$ & $S$ & 0 & 0 & 0 & 0 & 0 & 0 \\
\hline
\end{tabular}




\begin{tabular}{|l|l|l|r|r|r|r|r|r|}
\hline Wychwood & $\mathrm{D}$ & $\mathrm{S}$ & 0 & 0 & 0 & 0 & 0 & 0 \\
\hline
\end{tabular}




\begin{tabular}{|c|c|c|c|c|c|c|c|c|}
\hline SITE & STATION & CATEGORY & EAWP & GCKI & HAWO & HETH & LEFL & MOWA \\
\hline Achbar & A & $\overline{\mathrm{SN}}$ & 1 & $\overline{0}$ & 1 & 0 & 0 & 0 \\
\hline Achbar & $\bar{B}$ & SN & 1 & 0 & 0 & 0 & 0 & 0 \\
\hline Achbar & $\mathrm{C}$ & SN & 2 & 0 & 0 & 0 & 0 & 0 \\
\hline Achbar & $\overline{\mathrm{D}}$ & SN & 0 & 0 & 0 & 0 & 0 & 0 \\
\hline Bridlewood & A & UN & 1 & 0 & 0 & 0 & 0 & 0 \\
\hline Bridlewood & B & $\mathrm{UN}$ & 1 & 0 & 0 & 0 & 0 & 0 \\
\hline Bridlewood & $\mathrm{C}$ & UN & 2 & 0 & 0 & 0 & 0 & 0 \\
\hline Bridlewood & $\bar{D}$ & UN & 2 & 0 & 0 & 0 & 0 & 0 \\
\hline Carp_Hills & $\bar{A}$ & $F$ & 0 & 0 & 1 & 0 & 0 & 0 \\
\hline Carp_Hills & B & $F$ & 0 & 0 & 1 & 0 & 0 & 0 \\
\hline Carp_Hills & $\bar{C}$ & $\mathrm{~F}$ & 1 & 0 & 0 & 1 & 1 & 0 \\
\hline Carp_Hills & $\bar{D}$ & $\mathrm{~F}$ & 0 & 0 & 0 & 0 & 0 & 0 \\
\hline Chapel_Hill & A & $\mathrm{UN}$ & 1 & 0 & 1 & 0 & 0 & 0 \\
\hline Chapel_Hill & B & $\overline{\mathrm{UN}}$ & 2 & 0 & 0 & 0 & 0 & 0 \\
\hline Chapel_Hill & $\mathrm{C}$ & $\mathrm{UN}$ & 1 & 0 & 0 & 0 & 0 & 0 \\
\hline Chapel_Hill & $\mathrm{D}$ & $\mathrm{UN}$ & 2 & 0 & 1 & 0 & 0 & 0 \\
\hline Chelsea & $\bar{A}$ & SN & 1 & 0 & 1 & 0 & 0 & 0 \\
\hline Chelsea & B & SN & 1 & 0 & 1 & 0 & 0 & 0 \\
\hline Chelsea & $\bar{C}$ & $\overline{\mathrm{SN}}$ & 1 & 0 & 1 & 1 & 0 & 0 \\
\hline Chelsea & $\mathrm{D}$ & SN & 1 & 0 & 0 & 1 & 0 & 0 \\
\hline Cote_d'Azur & A & $\mathrm{S}$ & 0 & 0 & 0 & 0 & 0 & 0 \\
\hline Cote_d'Azur & B & $\mathrm{S}$ & 0 & 0 & 0 & 0 & 0 & 0 \\
\hline Cote_d'Azur & $\mathrm{C}$ & $\mathrm{S}$ & 0 & 0 & 0 & 0 & 0 & $\overline{0}$ \\
\hline Cote_d'Azur & $\mathrm{D}$ & $\mathrm{S}$ & 0 & 0 & 0 & 0 & 0 & 0 \\
\hline Highway_Seven & $\bar{A}$ & $\mathrm{E}$ & 0 & 0 & 0 & 1 & 0 & 0 \\
\hline Highway_Seven & B & $E$ & 0 & 0 & 0 & 0 & 0 & 0 \\
\hline Highway_Seven & $\mathrm{C}$ & $\bar{E}$ & 0 & 0 & 0 & 0 & 0 & $\overline{0}$ \\
\hline Highway_Seven & $\mathrm{D}$ & $\mathrm{E}$ & 0 & 0 & 1 & 1 & 0 & 0 \\
\hline Hull & $\bar{A}$ & $\mathrm{U}$ & 0 & 0 & 0 & 0 & 0 & 0 \\
\hline Hull & B & $\bar{U}$ & 0 & 0 & 0 & 0 & 0 & 0 \\
\hline Hull & $\mathrm{C}$ & $\bar{U}$ & 0 & 0 & 0 & 0 & 0 & 0 \\
\hline Hull & $\bar{D}$ & $\bar{U}$ & 0 & 0 & 0 & 0 & 0 & 0 \\
\hline Lac_Philippe & A & $\mathrm{F}$ & 2 & 0 & 1 & 1 & 0 & $\overline{0}$ \\
\hline Lac_Philippe & B & $\mathrm{F}$ & 0 & 0 & 0 & 1 & 0 & 0 \\
\hline Lac_Philippe & $\mathrm{C}$ & $\mathrm{F}$ & 1 & 0 & 0 & 0 & 0 & 0 \\
\hline Lac_Philippe & $\mathrm{D}$ & $\mathrm{F}$ & 1 & 0 & 2 & 1 & 4 & $\overline{0}$ \\
\hline Manoir_des_Trembles & $\bar{A}$ & UN & 2 & 0 & 0 & 0 & 0 & 0 \\
\hline Manoir_des_Trembles & B & $\mathrm{UN}$ & 2 & 0 & 0 & 0 & 0 & $\overline{0}$ \\
\hline Manoir_des_Trembles & $\mathrm{C}$ & $\mathrm{UN}$ & 2 & 0 & 0 & 0 & 0 & 0 \\
\hline Manoir_des_Trembles & $\mathrm{D}$ & $\mathrm{UN}$ & 0 & 0 & 0 & 0 & 0 & 0 \\
\hline Marathon & $\bar{A}$ & $\mathrm{E}$ & 2 & 0 & 1 & 0 & 0 & 0 \\
\hline Marathon & B & $E$ & 1 & 0 & 0 & 0 & 0 & 0 \\
\hline
\end{tabular}




\begin{tabular}{|c|c|c|c|c|c|c|c|c|}
\hline Marathon & $\mathrm{C}$ & $\mathrm{E}$ & 1 & 0 & 1 & 0 & 0 & 0 \\
\hline Marathon & $\bar{D}$ & $\bar{E}$ & 0 & 0 & $\overline{0}$ & 0 & 0 & 0 \\
\hline Marier & $\bar{A}$ & $\mathrm{U}$ & 0 & 0 & 0 & 0 & 0 & 0 \\
\hline Marier & $\bar{B}$ & $\overline{\mathrm{U}}$ & 0 & 0 & 0 & 0 & 0 & 0 \\
\hline Marier & $\mathrm{C}$ & $\mathrm{U}$ & 0 & 0 & 0 & 0 & 0 & 0 \\
\hline Marier & $\overline{\mathrm{D}}$ & $\mathrm{U}$ & 0 & 0 & 0 & 0 & 0 & 0 \\
\hline Marlborough & $\overline{\mathrm{A}}$ & $\mathrm{F}$ & 0 & 0 & 0 & 0 & 0 & 0 \\
\hline Marlborough & $\mathrm{B}$ & $F$ & 0 & 0 & 0 & 1 & 0 & 0 \\
\hline Marlborough & $\overline{\mathrm{C}}$ & $\bar{F}$ & 0 & 1 & 0 & 1 & 0 & 0 \\
\hline Marlborough & $\overline{\mathrm{D}}$ & $F$ & 0 & 0 & 0 & 0 & 0 & 0 \\
\hline Merivale & $\overline{\mathrm{A}}$ & $\overline{\mathrm{SN}}$ & 1 & 0 & 0 & 0 & 0 & 0 \\
\hline Merivale & B & $\overline{\mathrm{SN}}$ & 1 & 0 & 0 & 0 & 0 & 0 \\
\hline Merivale & $\mathrm{C}$ & SN & 0 & 0 & 1 & 0 & 0 & $\overline{0}$ \\
\hline Merivale & $\overline{\mathrm{D}}$ & $\mathrm{SN}$ & 1 & 0 & 0 & 0 & 0 & 0 \\
\hline Parc_Champlain & $\bar{A}$ & $S$ & 0 & 0 & 0 & 0 & 0 & 0 \\
\hline Parc_Champlain & B & $\mathrm{S}$ & 0 & 0 & 0 & 0 & 0 & 0 \\
\hline Parc_Champlain & $\mathrm{C}$ & $\mathrm{S}$ & 0 & 0 & 1 & 0 & 0 & 0 \\
\hline Parc_Champlain & $\bar{D}$ & $\mathrm{~S}$ & 0 & 0 & 0 & 0 & 0 & 0 \\
\hline Pine_Glen_Annex & $\bar{A}$ & $\bar{S}$ & 0 & 0 & 0 & 0 & 0 & 0 \\
\hline Pine_Glen_Annex & B & $\mathrm{S}$ & 0 & 0 & 0 & 0 & 0 & 0 \\
\hline Pine_Glen_Annex & $\mathrm{C}$ & $\mathrm{S}$ & 0 & 0 & 0 & 0 & 0 & 0 \\
\hline Pine_Glen_Annex & $\mathrm{D}$ & $\mathbf{S}$ & 1 & 0 & 0 & 0 & 0 & 0 \\
\hline Q_Four & A & $\mathrm{E}$ & 0 & 0 & 0 & 0 & 1 & 0 \\
\hline$\overline{\text { Q_Four }}$ & $\bar{B}$ & $\mathrm{E}$ & 0 & 0 & 0 & 0 & 0 & 2 \\
\hline$\overline{\text { Q_Four }}$ & $\mathrm{C}$ & $\mathrm{E}$ & 0 & 0 & 0 & 1 & 0 & 0 \\
\hline Q_Four & $\mathrm{D}$ & $\mathrm{E}$ & 1 & 0 & 0 & 0 & 0 & 0 \\
\hline Sandy_Hill & $\overline{\mathrm{A}}$ & $\bar{U}$ & 0 & 0 & 0 & 0 & 0 & 0 \\
\hline Sandy_Hill & B & $\bar{U}$ & 0 & 0 & 0 & 0 & 0 & 0 \\
\hline Sandy_Hill & $\bar{C}$ & $\bar{U}$ & 0 & 0 & 0 & 0 & 0 & 0 \\
\hline Sandy_Hill & $\mathrm{D}$ & $\mathrm{U}$ & 0 & 0 & 0 & 0 & 0 & 0 \\
\hline Vallee_Meech & $\overline{\mathrm{A}}$ & $\mathrm{F}$ & 1 & 0 & 2 & 0 & 0 & 0 \\
\hline Vallee_Meech & B & $F$ & 1 & 0 & 0 & 0 & 0 & 0 \\
\hline Vallee_Meech & $\mathrm{C}$ & $F$ & 0 & 0 & 2 & 0 & 0 & 0 \\
\hline Vallee_Meech & $\mathrm{D}$ & $F$ & 1 & 0 & 1 & 1 & 0 & 0 \\
\hline Wolf_Grove & $\overline{\mathbf{A}}$ & $E$ & 1 & 0 & 0 & 0 & 0 & 0 \\
\hline Wolf_Grove & $\mathrm{B}$ & $\bar{E}$ & 0 & 0 & 1 & 0 & 0 & 0 \\
\hline Wolf_Grove & $\mathrm{C}$ & $\mathrm{E}$ & 0 & 0 & $\overline{0}$ & 3 & 0 & $\overline{0}$ \\
\hline Wolf_Grove & $\mathrm{D}$ & $\mathrm{E}$ & 0 & 0 & 0 & 0 & 0 & $\overline{0}$ \\
\hline Wrightville & $\bar{A}$ & $\bar{U}$ & 0 & 0 & 0 & 0 & 0 & $\overline{0}$ \\
\hline Wrightville & B & $\mathrm{U}$ & 0 & 0 & 0 & 0 & 0 & 0 \\
\hline Wrightville & $\mathrm{C}$ & $\mathrm{U}$ & 0 & 0 & 0 & 0 & 0 & 0 \\
\hline Wrightville & $\mathrm{D}$ & $\mathrm{U}$ & 0 & 0 & 0 & 0 & 0 & 0 \\
\hline Wychwood & $\overline{\mathrm{A}}$ & $S$ & 0 & 0 & 0 & 0 & 0 & $\overline{0}$ \\
\hline
\end{tabular}




\begin{tabular}{|l|l|l|r|r|r|r|r|r|}
\hline Wychwood & B & S & 0 & 0 & 0 & 0 & 0 & 0 \\
\hline Wychwood & C & S & 0 & 0 & 1 & 0 & 0 & 0 \\
\hline Wychwood & D & S & 0 & 0 & 0 & 0 & 0 & 0 \\
\hline
\end{tabular}




\begin{tabular}{|c|c|c|c|c|c|c|c|c|}
\hline SITE & STATION & CATEGORY & NAWA & OVEN & PIWA & PIWO & PUFI & RBGR \\
\hline Achbar & $\mathrm{A}$ & $\mathrm{SN}$ & 0 & 2 & 0 & 0 & 0 & 0 \\
\hline Achbar & $\bar{B}$ & $\mathrm{SN}$ & 0 & 3 & 0 & 0 & 0 & 0 \\
\hline Achbar & $\mathrm{C}$ & $\mathrm{SN}$ & 0 & 1 & 0 & 0 & 0 & 0 \\
\hline Achbar & $\bar{D}$ & $\overline{\mathrm{SN}}$ & 0 & 0 & 0 & 0 & 0 & 0 \\
\hline Bridlewood & $\bar{A}$ & UN & 1 & 3 & 1 & 0 & 0 & 0 \\
\hline Bridlewood & B & UN & 0 & 4 & 0 & 0 & 0 & 0 \\
\hline Bridlewood & $\bar{C}$ & UN & 0 & 2 & 0 & 0 & 0 & 0 \\
\hline Bridlewood & $\mathrm{D}$ & $\overline{U N}$ & 1 & 2 & 1 & 0 & 0 & 1 \\
\hline Carp_Hills & $\overline{\mathrm{A}}$ & $F$ & 0 & 2 & 0 & 0 & 0 & 1 \\
\hline Carp_Hills & $\bar{B}$ & $\mathrm{~F}$ & 0 & 3 & 0 & 0 & 0 & 1 \\
\hline Carp_Hills & $\bar{C}$ & $\mathrm{~F}$ & 0 & 2 & 2 & 0 & 0 & 2 \\
\hline Carp_Hills & D & $\mathrm{F}$ & 0 & 3 & 1 & 1 & 0 & 1 \\
\hline Chapel_Hill & $\overline{\mathrm{A}}$ & UN & 0 & 2 & 0 & 0 & 0 & 1 \\
\hline Chapel_Hill & B & UN & 0 & 3 & 0 & 0 & 0 & 0 \\
\hline Chapel_Hill & $\mathrm{C}$ & UN & 0 & 4 & 0 & 0 & 0 & 1 \\
\hline Chapel_Hill & $\overline{\mathrm{D}}$ & $\overline{U N}$ & 0 & 3 & 0 & 0 & 0 & 1 \\
\hline Chelsea & $\overline{\mathrm{A}}$ & SN & 1 & 1 & 0 & 0 & 1 & 0 \\
\hline Chelsea & B & SN & 0 & 3 & 0 & 0 & 0 & 0 \\
\hline Chelsea & $\bar{C}$ & $\overline{\mathrm{SN}}$ & 2 & 3 & 1 & 0 & 0 & 0 \\
\hline Chelsea & $\mathrm{D}$ & SN & 1 & 3 & 0 & 0 & 1 & 0 \\
\hline Cote_d'Azur & $\overline{\mathrm{A}}$ & $\bar{S}$ & 0 & 0 & 0 & 0 & 0 & 0 \\
\hline Cote_d'Azur & $\overline{\mathrm{B}}$ & $\mathrm{S}$ & 0 & 0 & 0 & 0 & 1 & 0 \\
\hline Cote_d'Azur & $\bar{C}$ & $\mathrm{~S}$ & 0 & 0 & 0 & 0 & 0 & 0 \\
\hline Cote_d'Azur & $\mathrm{D}$ & $\mathrm{S}$ & 0 & 0 & 0 & 1 & 0 & 0 \\
\hline Highway_Seven & $\bar{A}$ & $\bar{E}$ & 1 & 2 & 0 & 0 & 0 & 0 \\
\hline Highway_Seven & B & $\bar{E}$ & 2 & 2 & 0 & 0 & 0 & 0 \\
\hline Highway_Seven & $\mathrm{C}$ & $\bar{E}$ & 0 & 2 & 0 & 0 & 1 & 0 \\
\hline Highway_Seven & $\mathrm{D}$ & $\bar{E}$ & 1 & 3 & 0 & 0 & 0 & $\overline{0}$ \\
\hline Hull & $\bar{A}$ & $\mathrm{U}$ & 0 & 0 & 0 & 0 & 0 & 0 \\
\hline Hull & B & $\mathbf{U}$ & 0 & 0 & 0 & 0 & 0 & 0 \\
\hline Hull & $\mathrm{C}$ & $\bar{U}$ & 0 & 0 & 0 & 0 & 0 & 0 \\
\hline Hull & $\mathrm{D}$ & $\mathrm{U}$ & 0 & 0 & 0 & 0 & 0 & 0 \\
\hline Lac_Philippe & $\overline{\mathrm{A}}$ & $F$ & 0 & 3 & 0 & 0 & 0 & 2 \\
\hline Lac_Philippe & $\bar{B}$ & $\mathrm{~F}$ & 1 & 3 & 0 & 0 & 0 & 1 \\
\hline Lac_Philippe & $\bar{C}$ & $\mathrm{~F}$ & 0 & 3 & 0 & 0 & 0 & 1 \\
\hline Lac_Philippe & $\mathrm{D}$ & $\mathrm{F}$ & 0 & 2 & 0 & 0 & 0 & 1 \\
\hline Manoir_des_Trembles & $\mathrm{A}$ & UN & 0 & 3 & 0 & 0 & 0 & 0 \\
\hline Manoir_des_Trembles & B & $\overline{\mathrm{UN}}$ & 0 & 3 & 1 & 0 & 0 & 0 \\
\hline Manoir_des_Trembles & $\mathrm{C}$ & $\overline{\mathrm{UN}}$ & 0 & 2 & 0 & 0 & 0 & 0 \\
\hline Manoir_des_Trembles & $\mathrm{D}$ & $\overline{\mathrm{UN}}$ & 0 & 3 & 0 & 0 & 0 & 0 \\
\hline Marathon & $\mathrm{A}$ & $\mathrm{E}$ & 0 & 3 & 0 & 0 & 0 & 0 \\
\hline Marathon & $\mathrm{B}$ & $E$ & 2 & 2 & 0 & 0 & 0 & 0 \\
\hline Marathon & $\mathrm{C}$ & $\bar{E}$ & 2 & 2 & 0 & 0 & 0 & $\overline{1}$ \\
\hline Marathon & $\overline{\mathrm{D}}$ & $E$ & 3 & 2 & 0 & 0 & 0 & 0 \\
\hline
\end{tabular}




\begin{tabular}{|c|c|c|c|c|c|c|c|c|}
\hline Marier & A & $\mathrm{U}$ & 0 & 0 & 0 & 0 & 0 & 0 \\
\hline Marier & B & $\mathbf{U}$ & 0 & 0 & 0 & 0 & 0 & 0 \\
\hline Marier & $\mathrm{C}$ & $\mathbf{U}$ & 0 & 0 & 0 & 0 & 0 & 0 \\
\hline Marier & $\mathrm{D}$ & $\overline{\mathrm{U}}$ & 0 & 0 & 0 & 0 & 0 & 0 \\
\hline Marlborough & $\mathrm{A}$ & $F$ & 0 & $\overline{3}$ & 0 & 0 & 0 & 1 \\
\hline Marlborough & B & $F$ & 1 & 2 & 0 & 0 & 0 & 1 \\
\hline Marlborough & $\mathrm{C}$ & $\bar{F}$ & 2 & 3 & 0 & 0 & 0 & 0 \\
\hline Marlborough & $\mathrm{D}$ & $F$ & 1 & 2 & 0 & 1 & 1 & 1 \\
\hline Merivale & $\mathrm{A}$ & $\mathrm{SN}$ & 0 & 2 & 0 & 0 & 0 & 1 \\
\hline Merivale & $\mathrm{B}$ & $\mathrm{SN}$ & 0 & 1 & 0 & 0 & 0 & 0 \\
\hline Merivale & $\mathrm{C}$ & $\overline{\mathrm{SN}}$ & 0 & 2 & 0 & 0 & 0 & 0 \\
\hline Merivale & $\mathrm{D}$ & $\mathrm{SN}$ & 0 & 3 & 0 & 0 & 0 & 0 \\
\hline Parc_Champlain & $\mathrm{A}$ & S & 0 & 0 & 0 & 0 & 0 & 0 \\
\hline Parc_Champlain & $\mathrm{B}$ & $\mathrm{S}$ & 0 & 0 & 0 & 0 & 0 & 0 \\
\hline Parc_Champlain & $\mathrm{C}$ & $\bar{S}$ & 0 & 0 & 0 & 0 & 0 & 0 \\
\hline Parc_Champlain & $\mathrm{D}$ & $\mathbf{S}$ & $\mathbf{0}$ & 0 & $\overline{0}$ & 0 & 0 & 0 \\
\hline Pine_Glen_Annex & $\mathrm{A}$ & $\mathrm{S}$ & 0 & 0 & 1 & 0 & 0 & 0 \\
\hline Pine_Glen_Annex & $\mathrm{B}$ & $S$ & 0 & 0 & 0 & 0 & 0 & 0 \\
\hline Pine_Glen_Annex & $\mathrm{C}$ & $\mathrm{S}$ & 0 & 0 & 0 & 0 & 0 & 0 \\
\hline Pine_Glen_Annex & $\mathrm{D}$ & $S$ & 0 & 0 & 1 & 0 & 0 & 0 \\
\hline Q_Four & $\mathrm{A}$ & $E$ & 0 & 4 & 0 & 0 & 0 & 0 \\
\hline Q_Four & $\mathrm{B}$ & $\mathrm{E}$ & 2 & 1 & 0 & 0 & 0 & 0 \\
\hline Q_Four & $\mathrm{C}$ & $\bar{E}$ & 0 & 3 & 0 & 0 & 0 & 1 \\
\hline Q_Four & $\mathrm{D}$ & $\mathrm{E}$ & 0 & 2 & 0 & 0 & 0 & 0 \\
\hline Sandy_Hill & $\mathrm{A}$ & $\mathrm{U}$ & 0 & 0 & 0 & 0 & 0 & 0 \\
\hline Sandy_Hill & B & $\mathrm{U}$ & 0 & 0 & 0 & 0 & 0 & 0 \\
\hline Sandy_Hill & $\mathrm{C}$ & $\mathrm{U}$ & 0 & 0 & 0 & 0 & 0 & 0 \\
\hline Sandy_Hill & $\mathrm{D}$ & $\mathrm{U}$ & 0 & 0 & 0 & 0 & 0 & 0 \\
\hline Vallee_Meech & $A$ & $\bar{F}$ & 0 & 3 & 0 & 0 & 0 & 1 \\
\hline Vallee_Meech & $\mathrm{B}$ & $\mathrm{F}$ & 0 & 3 & 0 & 1 & 0 & 2 \\
\hline Vallee_Meech & $\mathrm{C}$ & $\mathrm{F}$ & 0 & 3 & 0 & 0 & 0 & 1 \\
\hline Vallee_Meech & $\mathrm{D}$ & $\mathrm{F}$ & 0 & 4 & 0 & 0 & 0 & 0 \\
\hline Wolf_Grove & $\bar{A}$ & $\mathrm{E}$ & 0 & 3 & 0 & 0 & 0 & 0 \\
\hline Wolf_Grove & B & $\mathrm{E}$ & 0 & 0 & 0 & 0 & 0 & 1 \\
\hline Wolf_Grove & $\mathrm{C}$ & $\mathrm{E}$ & 0 & 1 & 0 & 0 & 0 & 1 \\
\hline Wolf_Grove & $\mathrm{D}$ & $\mathrm{E}$ & 0 & 1 & 1 & 0 & 0 & 1 \\
\hline Wrightville & $\mathrm{A}$ & $\mathbf{U}$ & 0 & 0 & 0 & 0 & 0 & 0 \\
\hline Wrightville & B & $\bar{U}$ & 0 & 0 & 0 & 0 & 0 & 0 \\
\hline Wrightville & $\mathrm{C}$ & $\mathrm{U}$ & 0 & 0 & 0 & 0 & 0 & 0 \\
\hline Wrightville & $\bar{D}$ & $\mathrm{U}$ & 0 & 0 & 0 & 0 & 0 & 0 \\
\hline Wychwood & $\mathrm{A}$ & $\mathrm{S}$ & 0 & 0 & 0 & 0 & 0 & 0 \\
\hline Wychwood & $\mathrm{B}$ & $\mathrm{S}$ & 0 & 0 & 2 & 0 & 0 & 0 \\
\hline Wychwood & $\mathrm{C}$ & $\mathrm{S}$ & 0 & 0 & 3 & 0 & 0 & 0 \\
\hline Wychwood & $\mathrm{D}$ & $\mathrm{S}$ & 0 & 0 & 4 & 0 & 0 & 0 \\
\hline
\end{tabular}




\begin{tabular}{|c|c|c|c|c|c|c|c|c|}
\hline SITE & STATION & CATEGORY & $\overline{\text { RBNU }}$ & REVI & RTHU & $\overline{R U G R}$ & SCTA & SWTH \\
\hline Achbar & $\mathrm{A}$ & SN & 0 & 3 & 0 & 0 & 0 & 0 \\
\hline Achbar & $\mathrm{B}$ & SN & 0 & 4 & 0 & 0 & 0 & 0 \\
\hline Achbar & $\bar{C}$ & $\overline{\mathrm{SN}}$ & 0 & 4 & 0 & 0 & 0 & 0 \\
\hline Achbar & $\bar{D}$ & SN & 0 & 3 & 0 & 0 & 0 & 0 \\
\hline Bridlewood & $\overline{\mathrm{A}}$ & UN & 0 & 2 & 0 & 0 & 0 & 0 \\
\hline Bridlewood & B & UN & 0 & 3 & 2 & 0 & 0 & 0 \\
\hline Bridlewood & $\bar{C}$ & UN & 0 & 3 & 0 & 0 & 1 & 0 \\
\hline Bridlewood & $\bar{D}$ & $\mathrm{UN}$ & 0 & 2 & 0 & 0 & 0 & 0 \\
\hline Carp_Hills & $\bar{A}$ & $F$ & 0 & 2 & 1 & 0 & 1 & 0 \\
\hline Carp_Hills & B & $F$ & 2 & 1 & 0 & 0 & 1 & 0 \\
\hline Carp_Hills & $\mathrm{C}$ & $\mathrm{F}$ & 1 & 1 & 0 & 0 & 1 & 0 \\
\hline Carp_Hills & $\bar{D}$ & $\bar{F}$ & 0 & 1 & 0 & 0 & 1 & 0 \\
\hline Chapel_Hill & $\bar{A}$ & $\overline{\mathrm{UN}}$ & 0 & 2 & 0 & 0 & 0 & 0 \\
\hline Chapel_Hill & $\bar{B}$ & UN & 0 & 2 & 0 & 0 & 0 & 0 \\
\hline Chapel_Hill & $\mathrm{C}$ & UN & 0 & 2 & 0 & 0 & 0 & 0 \\
\hline Chapel_Hill & $\mathrm{D}$ & UN & 0 & 1 & 0 & 0 & 0 & 0 \\
\hline Chelsea & $\overline{\mathrm{A}}$ & $\mathrm{SN}$ & 0 & 1 & 0 & 0 & 0 & 0 \\
\hline Chelsea & $\bar{B}$ & $\mathrm{SN}$ & 1 & 2 & 0 & 0 & 0 & 0 \\
\hline Chelsea & $\bar{C}$ & $\overline{\mathrm{SN}}$ & 1 & 2 & 0 & 0 & 0 & $\overline{0}$ \\
\hline Chelsea & $\bar{D}$ & $\overline{\mathrm{SN}}$ & 1 & 0 & 0 & 0 & 0 & 0 \\
\hline Cote_d'Azur & $\overline{\mathrm{A}}$ & $S$ & 0 & 1 & 0 & 0 & 0 & $\overline{0}$ \\
\hline Cote_d'Azur & B & $\mathrm{S}$ & 0 & 1 & 0 & 0 & 0 & 0 \\
\hline Cote_d'Azur & $\mathrm{C}$ & $\mathrm{S}$ & 0 & 0 & 0 & 0 & 0 & 0 \\
\hline Cote_d'Azur & $\mathrm{D}$ & $\mathrm{S}$ & 0 & 1 & 0 & 0 & 0 & $\overline{0}$ \\
\hline Highway_Seven & $\mathrm{A}$ & $\mathrm{E}$ & 0 & 0 & 0 & 0 & 0 & $\overline{0}$ \\
\hline Highway_Seven & $\mathrm{B}$ & $\mathrm{E}$ & 0 & 0 & 0 & 0 & 0 & 0 \\
\hline Highway_Seven & $\bar{C}$ & $\bar{E}$ & 1 & 0 & 0 & 0 & 0 & $\overline{0}$ \\
\hline Highway_Seven & D & $E$ & 1 & 1 & 0 & 0 & 0 & 0 \\
\hline Hull & A & $\mathrm{U}$ & 0 & 0 & 0 & 0 & 0 & 0 \\
\hline Hull & B & $\mathrm{U}$ & 0 & 0 & 0 & 0 & 0 & 0 \\
\hline Hull & $\mathrm{C}$ & $\bar{U}$ & 0 & 0 & 0 & 0 & 0 & $\overline{0}$ \\
\hline Hull & $\mathrm{D}$ & $\mathrm{U}$ & 0 & 0 & 0 & 0 & 0 & 0 \\
\hline Lac_Philippe & $\overline{\mathrm{A}}$ & $\bar{F}$ & 0 & 4 & 0 & 0 & 0 & $\overline{1}$ \\
\hline Lac_Philippe & B & $\mathrm{F}$ & 0 & 2 & 0 & 0 & 0 & 0 \\
\hline Lac_Philippe & $\mathrm{C}$ & $\mathrm{F}$ & 1 & 3 & 2 & 0 & 0 & 0 \\
\hline Lac_Philippe & D & $\mathrm{F}$ & 1 & 2 & 0 & 0 & 0 & 0 \\
\hline Manoir_des_Trembles & $\overline{\mathrm{A}}$ & UN & 0 & 5 & 0 & 0 & 0 & 0 \\
\hline Manoir_des_Trembles & B & UN & 0 & 2 & 0 & 0 & 0 & $\overline{0}$ \\
\hline Manoir_des_Trembles & $\mathrm{C}$ & UN & 0 & 2 & 0 & 0 & 0 & $\overline{0}$ \\
\hline Manoir_des_Trembles & D & $\overline{U N}$ & 0 & 3 & 0 & 0 & 0 & 0 \\
\hline Marathon & $\mathrm{A}$ & $E$ & 1 & 2 & 0 & 0 & 0 & 0 \\
\hline Marathon & $\mathrm{B}$ & $E$ & 2 & 0 & 0 & 0 & 1 & 0 \\
\hline Marathon & $\mathrm{C}$ & $\mathrm{E}$ & 0 & 0 & 0 & 0 & 0 & 0 \\
\hline Marathon & $\bar{D}$ & $\mathrm{E}$ & 1 & 0 & 0 & 0 & 0 & 0 \\
\hline
\end{tabular}




\begin{tabular}{|c|c|c|c|c|c|c|c|c|}
\hline Marier & $\bar{A}$ & $\bar{U}$ & 0 & 0 & 0 & 0 & 0 & 0 \\
\hline Marier & $\bar{B}$ & $\overline{\mathrm{U}}$ & 0 & 0 & 0 & 0 & 0 & 0 \\
\hline Marier & $\mathrm{C}$ & $\mathrm{U}$ & 0 & 0 & 0 & 0 & 0 & 0 \\
\hline Marier & $\bar{D}$ & $\overline{\mathrm{U}}$ & 0 & 0 & 0 & 0 & 0 & $\overline{0}$ \\
\hline Marlborough & $\bar{A}$ & $F$ & 0 & 0 & 0 & 0 & 0 & 0 \\
\hline Marlborough & $\bar{B}$ & $\mathrm{~F}$ & 0 & 0 & 0 & 1 & 0 & 0 \\
\hline Marlborough & $\bar{C}$ & $\bar{F}$ & 1 & 0 & 0 & 0 & 0 & 0 \\
\hline Marlborough & $\bar{D}$ & $\bar{F}$ & 1 & 1 & 0 & 1 & 0 & $\overline{0}$ \\
\hline Merivale & A & $\overline{\mathrm{SN}}$ & 0 & 2 & 0 & 0 & 0 & 0 \\
\hline Merivale & $\bar{B}$ & SN & 0 & 3 & 0 & 0 & 0 & $\overline{0}$ \\
\hline Merivale & $\overline{\mathrm{C}}$ & SN & 0 & 2 & 0 & 0 & 0 & $\overline{0}$ \\
\hline Merivale & $\overline{\mathrm{D}}$ & $\overline{\mathrm{SN}}$ & 0 & 2 & 0 & 0 & 0 & $\overline{0}$ \\
\hline Parc_Champlain & $\overline{\mathrm{A}}$ & $\mathrm{S}$ & 0 & 0 & 0 & 0 & 0 & $\overline{0}$ \\
\hline Parc_Champlain & $\bar{B}$ & $\mathrm{~S}$ & 0 & 0 & 0 & 0 & 0 & 0 \\
\hline Parc_Champlain & $\mathrm{C}$ & $\mathrm{S}$ & 0 & 1 & 0 & 0 & 0 & 0 \\
\hline Parc_Champlain & $\mathrm{D}$ & $\mathrm{S}$ & 0 & 1 & 0 & 0 & 0 & 0 \\
\hline Pine_Glen_Annex & A & $\mathrm{S}$ & 0 & 2 & 0 & 0 & 0 & 0 \\
\hline Pine_Glen_Annex & B & $\mathrm{S}$ & 0 & 0 & 0 & 0 & 0 & 0 \\
\hline Pine_Glen_Annex & $\mathrm{C}$ & $\bar{S}$ & 0 & 1 & 0 & 0 & 0 & 0 \\
\hline Pine_Glen_Annex & $\mathrm{D}$ & $\mathrm{S}$ & 0 & 3 & 0 & 0 & 0 & 0 \\
\hline Q_Four & A & $E$ & 0 & 2 & 0 & 0 & 0 & 0 \\
\hline Q_Four & B & $\mathrm{E}$ & 0 & 1 & 0 & 0 & 0 & 0 \\
\hline Q_Four & $\mathrm{C}$ & $\mathrm{E}$ & 1 & 2 & 0 & 0 & 1 & $\overline{0}$ \\
\hline Q_Four & $\mathrm{D}$ & $\mathrm{E}$ & 1 & 2 & 0 & 0 & 0 & $\overline{0}$ \\
\hline Sandy_Hill & $\overline{\mathrm{A}}$ & $\bar{U}$ & 0 & 0 & 0 & 0 & 0 & 0 \\
\hline Sandy_Hill & B & $\bar{U}$ & 0 & 0 & 0 & 0 & 0 & $\overline{0}$ \\
\hline Sandy_Hill & $\mathrm{C}$ & $\mathrm{U}$ & 0 & 0 & 0 & 0 & 0 & 0 \\
\hline Sandy_Hill & $\bar{D}$ & $\overline{\mathrm{U}}$ & 0 & 0 & 0 & 0 & 0 & $\overline{0}$ \\
\hline Vallee_Meech & A & $F$ & 0 & 3 & 0 & 0 & 0 & $\overline{0}$ \\
\hline Vallee_Meech & $\mathrm{B}$ & $\bar{F}$ & 0 & 3 & 0 & 0 & 1 & $\overline{0}$ \\
\hline Vallee_Meech & $\mathrm{C}$ & $F$ & 1 & 4 & 0 & 0 & 1 & $\overline{0}$ \\
\hline Vallee_Meech & $\bar{D}$ & $F$ & 0 & 3 & 0 & 0 & 0 & $\overline{0}$ \\
\hline Wolf_Grove & $\overline{\mathrm{A}}$ & $E$ & 1 & 3 & 0 & 0 & 0 & $\overline{0}$ \\
\hline Wolf_Grove & B & $E$ & 0 & 3 & 0 & 0 & 0 & 0 \\
\hline Wolf_Grove & $\mathrm{C}$ & $E$ & 0 & 4 & 0 & 0 & 0 & $\overline{0}$ \\
\hline Wolf_Grove & $\bar{D}$ & $\bar{E}$ & 1 & 3 & 0 & 0 & 0 & $\overline{0}$ \\
\hline Wrightville & $\bar{A}$ & $\mathrm{U}$ & 0 & 0 & 0 & 0 & 0 & 0 \\
\hline Wrightville & B & $\mathrm{U}$ & 0 & 0 & 0 & 0 & 0 & 0 \\
\hline Wrightville & $\mathrm{C}$ & $\mathrm{U}$ & 0 & 0 & 0 & 0 & 0 & $\overline{0}$ \\
\hline Wrightville & $\mathrm{D}$ & $\mathrm{U}$ & 0 & 0 & 0 & 0 & 0 & 0 \\
\hline Wychwood & $\overline{\mathrm{A}}$ & $\mathrm{S}$ & 0 & 0 & 0 & 0 & 0 & 0 \\
\hline Wychwood & B & $\mathrm{S}$ & 0 & 0 & 0 & 0 & 0 & 0 \\
\hline Wychwood & $\mathrm{C}$ & $\mathrm{S}$ & 0 & 1 & 0 & 0 & 0 & 0 \\
\hline Wychwood & $\mathrm{D}$ & $\mathrm{S}$ & 0 & 0 & 0 & 0 & 0 & 0 \\
\hline
\end{tabular}




\begin{tabular}{|c|c|c|c|c|c|c|c|c|}
\hline SITE & STATION & CATEGORY & VEER & WAVI & WBNU & WIWR & WOTH & WTSP \\
\hline Achbar & $\mathrm{A}$ & $\mathrm{SN}$ & 0 & 0 & 0 & 0 & 1 & $\overline{0}$ \\
\hline Achbar & $\bar{B}$ & $\mathrm{SN}$ & 0 & $\overline{0}$ & $\overline{0}$ & 0 & 0 & 0 \\
\hline Achbar & $\mathrm{C}$ & SN & 0 & 0 & 0 & 0 & 0 & 0 \\
\hline Achbar & $\overline{\mathrm{D}}$ & SN & 1 & 0 & 0 & 0 & 0 & 0 \\
\hline Bridlewood & $\bar{A}$ & UN & 0 & 0 & 0 & 0 & 0 & 0 \\
\hline Bridlewood & $\bar{B}$ & $\overline{\mathrm{UN}}$ & 1 & 0 & 1 & 0 & 0 & 0 \\
\hline Bridlewood & $\bar{C}$ & $\overline{\mathrm{UN}}$ & 0 & 0 & $\overline{0}$ & 0 & 0 & 0 \\
\hline Bridlewood & $\bar{D}$ & UN & 0 & 0 & 0 & 0 & 0 & 0 \\
\hline Carp_Hills & $\bar{A}$ & $F$ & 1 & 0 & 0 & 0 & 0 & $T$ \\
\hline Carp_Hills & B & $F$ & 1 & 0 & 0 & 0 & 0 & 1 \\
\hline Carp_Hills & $\mathrm{C}$ & $F$ & 1 & 0 & 0 & 0 & 0 & 0 \\
\hline Carp_Hills & $\bar{D}$ & $F$ & 1 & 0 & 0 & 0 & 0 & 1 \\
\hline Chapel_Hill & $\bar{A}$ & UN & 1 & 0 & 1 & 0 & 0 & 1 \\
\hline Chapel_Hill & $\bar{B}$ & UN & 0 & 0 & 0 & 0 & 0 & 0 \\
\hline Chapel_Hill & $\bar{C}$ & $\mathrm{UN}$ & 0 & 0 & 0 & 0 & 0 & 0 \\
\hline Chapel_Hill & $\mathrm{D}$ & UN & 2 & 0 & 0 & 0 & 0 & 0 \\
\hline Chelsea & $\bar{A}$ & SN & 3 & 0 & 0 & 1 & 0 & 0 \\
\hline Chelsea & B & SN & 1 & 0 & 0 & 1 & 1 & 0 \\
\hline Chelsea & $\overline{\mathrm{C}}$ & $\overline{\mathrm{SN}}$ & 1 & 0 & 0 & 1 & 0 & 0 \\
\hline Chelsea & $\bar{D}$ & SN & 2 & 0 & 0 & 1 & 0 & 0 \\
\hline Cote_d'Azur & $\bar{A}$ & $S$ & 0 & 0 & 0 & 0 & 0 & 0 \\
\hline Cote_d'Azur & $\bar{B}$ & $\bar{S}$ & 0 & 0 & 0 & 0 & 0 & 0 \\
\hline Cote_d'Azur & $\bar{C}$ & $S$ & 0 & 0 & 0 & 0 & 0 & 1 \\
\hline Cote_d'Azur & $\bar{D}$ & $S$ & 0 & 0 & 0 & 0 & 0 & 0 \\
\hline Highway_Seven & A & $\bar{E}$ & 1 & 0 & 1 & 0 & 0 & 3 \\
\hline Highway_Seven & $\bar{B}$ & $\bar{E}$ & 0 & 0 & 2 & 0 & 0 & 2 \\
\hline Highway_Seven & $\mathrm{C}$ & $\mathrm{E}$ & 0 & 0 & 0 & 0 & 0 & 1 \\
\hline Highway_Seven & $\mathrm{D}$ & $\mathrm{E}$ & 0 & 0 & 0 & 0 & 0 & 1 \\
\hline Hull & A & $\overline{\mathrm{U}}$ & 0 & 0 & 0 & 0 & 0 & 0 \\
\hline Hull & $\overline{\mathrm{B}}$ & $\overline{\mathrm{U}}$ & 0 & 0 & 0 & 0 & 0 & 0 \\
\hline Hull & $\mathrm{C}$ & $\mathrm{U}$ & 0 & 0 & 0 & 0 & 0 & 0 \\
\hline Hull & $\bar{D}$ & $\overline{\mathrm{U}}$ & 0 & 0 & 0 & 0 & 0 & 0 \\
\hline Lac_Philippe & $\mathrm{A}$ & $F$ & 1 & 0 & 0 & 2 & 0 & 0 \\
\hline Lac_Philippe & B & $F$ & 0 & 0 & 0 & 1 & 0 & 0 \\
\hline Lac_Philippe & $\bar{C}$ & $F$ & 1 & 0 & 0 & 1 & 0 & 0 \\
\hline Lac_Philippe & $\mathrm{D}$ & $\bar{F}$ & 1 & 0 & 0 & 0 & 0 & 0 \\
\hline Manoir_des_Trembles & $\mathrm{A}$ & UN & 0 & 0 & 1 & 1 & 2 & 0 \\
\hline Manoir_des_Trembles & $\mathrm{B}$ & UN & 1 & 0 & 1 & 0 & 1 & 0 \\
\hline Manoir_des_Trembles & $\mathrm{C}$ & $\overline{\mathrm{UN}}$ & 1 & 0 & 1 & 0 & 1 & 0 \\
\hline Manoir_des_Trembles & $\mathrm{D}$ & $\mathrm{UN}$ & 0 & 0 & 1 & 0 & 1 & 0 \\
\hline Marathon & A & $\mathrm{E}$ & 1 & 0 & 0 & 1 & 1 & 2 \\
\hline Marathon & $\mathrm{B}$ & $\mathrm{E}$ & 1 & 0 & 0 & 2 & 1 & 1 \\
\hline Marathon & $\mathrm{C}$ & $E$ & 3 & 0 & 0 & 2 & 0 & 1 \\
\hline
\end{tabular}




\begin{tabular}{|c|c|c|c|c|c|c|c|c|}
\hline Marathon & $\mathrm{D}$ & $\mathrm{E}$ & 1 & 0 & 0 & 1 & 1 & 0 \\
\hline Marier & A & $\mathrm{U}$ & 0 & 0 & 0 & 0 & 0 & 0 \\
\hline Marier & $\mathrm{B}$ & $\bar{U}$ & 0 & 0 & 0 & 0 & 0 & 0 \\
\hline Marier & $\mathrm{C}$ & $\mathrm{U}$ & 0 & 0 & 0 & 0 & 0 & 0 \\
\hline Marier & $\bar{D}$ & $\mathrm{U}$ & 0 & 0 & 0 & 0 & 0 & 0 \\
\hline Marlborough & A & $F$ & 0 & 0 & 0 & 1 & 1 & 0 \\
\hline Marlborough & $\mathrm{B}$ & $F$ & 0 & 0 & 0 & 1 & 0 & 0 \\
\hline Marlborough & $\mathrm{C}$ & $\mathrm{F}$ & 0 & 0 & 0 & 2 & 0 & 1 \\
\hline Marlborough & $\mathrm{D}$ & $F$ & 0 & 0 & 0 & 0 & 0 & 1 \\
\hline Merivale & A & $\mathrm{SN}$ & 1 & 0 & 0 & 2 & 0 & 0 \\
\hline Merivale & $\bar{B}$ & $\mathrm{SN}$ & 0 & 0 & 0 & 0 & 1 & 0 \\
\hline Merivale & $\mathrm{C}$ & $\mathrm{SN}$ & 1 & 0 & 2 & 1 & 0 & 1 \\
\hline Merivale & $\mathrm{D}$ & $\mathrm{SN}$ & 0 & 0 & 0 & 1 & 0 & 0 \\
\hline Parc_Champlain & A & $\mathrm{S}$ & 0 & 0 & 0 & 0 & 0 & 0 \\
\hline Parc_Champlain & $\mathrm{B}$ & $\mathrm{S}$ & 0 & 0 & 0 & 0 & 0 & 0 \\
\hline Parc_Champlain & $\mathrm{C}$ & $\mathrm{S}$ & 0 & 0 & 0 & 0 & 0 & 0 \\
\hline Parc_Champlain & $\mathrm{D}$ & $\mathrm{S}$ & 0 & 0 & 0 & 0 & 0 & 0 \\
\hline Pine_Glen_Annex & $\bar{A}$ & $\mathrm{~S}$ & 0 & 2 & 1 & 0 & 0 & 0 \\
\hline Pine_Glen_Annex & $\mathrm{B}$ & $\mathrm{S}$ & 0 & 0 & 0 & 0 & 0 & 0 \\
\hline Pine_Glen_Annex & $\mathrm{C}$ & $\mathrm{S}$ & 0 & 0 & 1 & 0 & 0 & 0 \\
\hline Pine_Glen_Annex & $\mathrm{D}$ & $\mathrm{S}$ & 0 & 0 & 1 & 0 & 0 & 0 \\
\hline Q_Four & $\mathbf{A}$ & $E$ & 2 & 0 & 0 & 1 & 0 & 0 \\
\hline Q_Four & $\mathrm{B}$ & $E$ & 1 & 0 & 0 & 1 & 1 & 1 \\
\hline Q_Four & $\mathrm{C}$ & $\mathrm{E}$ & 0 & 0 & 0 & 1 & 1 & 1 \\
\hline Q_Four & $\mathrm{D}$ & $E$ & 0 & 0 & 0 & 1 & 1 & 1 \\
\hline Sandy_Hill & A & $\mathrm{U}$ & 0 & 0 & 1 & 0 & 0 & 0 \\
\hline Sandy_Hill & $\mathrm{B}$ & $\mathrm{U}$ & 0 & 0 & 0 & $\overline{0}$ & 0 & 0 \\
\hline Sandy_Hill & $\mathrm{C}$ & $\bar{U}$ & 0 & 0 & 0 & 0 & 0 & 0 \\
\hline Sandy_Hill & $\mathrm{D}$ & $\mathrm{U}$ & 0 & 0 & 0 & 0 & 0 & 0 \\
\hline Vallee_Meech & A & $F$ & 1 & 0 & 0 & 0 & 0 & 0 \\
\hline Vallee_Meech & B & $\mathrm{F}$ & 2 & 0 & 0 & 0 & 0 & 0 \\
\hline Vallee_Meech & $\mathrm{C}$ & $\bar{F}$ & 2 & 0 & 0 & 0 & 0 & 0 \\
\hline Vallee_Meech & $\bar{D}$ & $\mathrm{~F}$ & 1 & 0 & 0 & 0 & 0 & 0 \\
\hline Wolf_Grove & $\mathrm{A}$ & $E$ & 0 & 0 & 0 & 0 & 0 & 0 \\
\hline Wolf_Grove & $\mathrm{B}$ & $E$ & 0 & 0 & 0 & 0 & 0 & 0 \\
\hline Wolf_Grove & $\mathrm{C}$ & $E$ & 0 & 0 & 0 & 0 & 0 & 0 \\
\hline Wolf_Grove & $\mathrm{D}$ & $E$ & 0 & 0 & 0 & 0 & 0 & 0 \\
\hline Wrightville & A & $\mathrm{U}$ & 0 & 0 & 0 & 0 & 0 & 0 \\
\hline Wrightville & B & $\bar{U}$ & 0 & 0 & 0 & 0 & 0 & 0 \\
\hline Wrightville & $\mathrm{C}$ & $\bar{U}$ & 0 & 0 & 0 & 0 & 0 & 0 \\
\hline Wrightville & $\mathrm{D}$ & $\mathrm{U}$ & 0 & 0 & 0 & 0 & 0 & 0 \\
\hline Wychwood & A & $\mathrm{S}$ & 0 & 0 & 0 & 0 & 0 & 0 \\
\hline Wychwood & B & $\mathrm{S}$ & 0 & 0 & 1 & 0 & 0 & 0 \\
\hline Wychwood & $\mathrm{C}$ & $\mathrm{S}$ & 0 & 0 & 0 & 0 & 0 & $\overline{0}$ \\
\hline
\end{tabular}




\begin{tabular}{|l|l|l|l|l|l|l|r|r|}
\hline Wychwood & D & S & 0 & 0 & 0 & 0 & 0 & 0 \\
\hline
\end{tabular}




\begin{tabular}{|c|c|c|c|c|c|}
\hline SITE & STATION & CATEGORY & YBSA & YRWA & YTVI \\
\hline Achbar & $\mathrm{A}$ & SN & 0 & 0 & 0 \\
\hline Achbar & B & SN & 0 & 0 & 0 \\
\hline Achbar & $\overline{\mathrm{C}}$ & $\mathrm{SN}$ & 0 & 0 & $\overline{0}$ \\
\hline Achbar & $\bar{D}$ & $\mathrm{SN}$ & 0 & 0 & $\overline{0}$ \\
\hline Bridlewood & $\mathrm{A}$ & $\overline{\mathrm{UN}}$ & 0 & 0 & $\overline{0}$ \\
\hline Bridlewood & $\bar{B}$ & UN & 1 & 0 & 0 \\
\hline Bridlewood & $\mathrm{C}$ & UN & 1 & 0 & 0 \\
\hline Bridlewood & $\mathrm{D}$ & $\overline{\mathrm{UN}}$ & 0 & 0 & $\overline{0}$ \\
\hline Carp_Hills & $\mathrm{A}$ & $\mathrm{F}$ & 2 & 0 & 0 \\
\hline Carp_Hills & B & $\mathbf{F}$ & 2 & 0 & 0 \\
\hline Carp_Hills & $\mathrm{C}$ & $\bar{F}$ & 2 & 0 & $\overline{0}$ \\
\hline Carp_Hills & $\bar{D}$ & $\bar{F}$ & 1 & 0 & $\overline{0}$ \\
\hline Chapel_Hill & $\mathrm{A}$ & $\overline{\mathrm{UN}}$ & 1 & 0 & 0 \\
\hline Chapel_Hill & B & UN & 1 & 0 & 0 \\
\hline Chapel Hill & $\mathrm{C}$ & UN & 0 & 0 & 0 \\
\hline Chapel_Hill & $\mathrm{D}$ & $\overline{\mathrm{UN}}$ & 1 & 0 & $\overline{0}$ \\
\hline Chelsea & $\bar{A}$ & $\mathrm{SN}$ & 1 & 0 & $\overline{0}$ \\
\hline Chelsea & B & $\mathrm{SN}$ & 0 & 0 & 1 \\
\hline Chelsea & $\mathrm{C}$ & $\overline{\mathrm{SN}}$ & 1 & 0 & 0 \\
\hline Chelsea & $\mathrm{D}$ & $\mathrm{SN}$ & 1 & 0 & 0 \\
\hline Cote_d'Azur & $\mathrm{A}$ & $\mathrm{S}$ & 0 & 0 & 0 \\
\hline Cote_d'Azur & $\mathrm{B}$ & $\mathrm{S}$ & 0 & 0 & 0 \\
\hline Cote_d'Azur & $\mathrm{C}$ & $S$ & 0 & 0 & 0 \\
\hline Cote_d'Azur & $\mathrm{D}$ & $\bar{S}$ & 0 & 0 & 0 \\
\hline Highway_Seven & $A$ & $\mathrm{E}$ & 1 & 0 & 0 \\
\hline Highway_Seven & $\mathrm{B}$ & $E$ & 1 & 0 & 0 \\
\hline Highway_Seven & $\mathrm{C}$ & $\mathrm{E}$ & 0 & 0 & 0 \\
\hline Highway_Seven & $\mathrm{D}$ & $\mathbf{E}$ & 1 & 0 & 0 \\
\hline Hull & $\bar{A}$ & $\bar{U}$ & 0 & 0 & 0 \\
\hline Hull & B & $\mathbf{U}$ & 0 & 0 & 0 \\
\hline Hull & $\mathrm{C}$ & $\mathrm{U}$ & 0 & 0 & 0 \\
\hline Hull & $\mathrm{D}$ & $\mathrm{U}$ & 0 & 0 & 0 \\
\hline Lac_Philippe & $\vec{A}$ & $\mathbf{F}$ & 1 & 0 & 0 \\
\hline Lac_Philippe & $\mathrm{B}$ & $\mathbf{F}$ & 1 & 0 & 0 \\
\hline Lac_Philippe & $\mathrm{C}$ & $\mathbf{F}$ & 1 & 0 & 0 \\
\hline Lac_Philippe & $\bar{D}$ & $\mathbf{F}$ & 1 & 0 & 1 \\
\hline Manoir_des_Trembles & $\bar{A}$ & UN & 1 & 0 & $\overline{0}$ \\
\hline Manoir_des_Trembles & B & $\overline{\mathrm{UN}}$ & 2 & 0 & 0 \\
\hline Manoir_des_Trembles & $\mathrm{C}$ & UN & 1 & 0 & 0 \\
\hline Manoir_des_Trembles & $\mathrm{D}$ & UN & 0 & 0 & 0 \\
\hline Marathon & $\mathrm{A}$ & $\mathbf{E}$ & 1 & 1 & 0 \\
\hline Marathon & B & $\mathrm{E}$ & 2 & 0 & 0 \\
\hline Marathon & $\bar{C}$ & $\mathbf{E}$ & 0 & 0 & 0 \\
\hline Marathon & $\bar{D}$ & $\mathbf{E}$ & 0 & 0 & 0 \\
\hline
\end{tabular}




\begin{tabular}{|c|c|c|c|c|c|}
\hline Marier & $\mathrm{A}$ & $\bar{U}$ & 0 & 0 & 0 \\
\hline Marier & $\bar{B}$ & $\overline{\mathrm{U}}$ & 0 & 0 & 0 \\
\hline Marier & $\bar{C}$ & $\bar{U}$ & 0 & 0 & 0 \\
\hline Marier & $\overline{\mathrm{D}}$ & $\overline{\mathrm{U}}$ & 0 & 0 & 0 \\
\hline Marlborough & A & $\mathrm{F}$ & 0 & 0 & $\overline{0}$ \\
\hline Marlborough & B & $\bar{F}$ & 0 & 0 & 0 \\
\hline Marlborough & $\mathrm{C}$ & $\mathrm{F}$ & 1 & 1 & 0 \\
\hline Marlborough & $\overline{\mathrm{D}}$ & $\bar{F}$ & 0 & 1 & $\overline{0}$ \\
\hline Merivale & A & SN & 0 & 0 & $\overline{0}$ \\
\hline Merivale & $\mathrm{B}$ & SN & 0 & $\overline{0}$ & 0 \\
\hline Merivale & $\bar{C}$ & $\overline{\mathrm{SN}}$ & 0 & 0 & $\overline{0}$ \\
\hline Merivale & $\bar{D}$ & $\mathrm{SN}$ & 0 & 0 & 0 \\
\hline Parc_Champlain & $\bar{A}$ & $\mathrm{~S}$ & 0 & 0 & 0 \\
\hline Parc_Champlain & $\mathrm{B}$ & $S$ & 0 & 0 & 0 \\
\hline Pare_Champlain & $\mathrm{C}$ & $\mathrm{S}$ & 0 & 0 & 0 \\
\hline Parc_Champlain & $\bar{D}$ & $\mathbf{S}$ & 0 & 0 & 0 \\
\hline Pine_Glen_Annex & $\bar{A}$ & $\mathbf{S}$ & 0 & 0 & $\overline{0}$ \\
\hline Pine_Glen_Annex & $\mathrm{B}$ & $\bar{S}$ & 0 & 0 & 0 \\
\hline Pine_Glen_Annex & $\mathrm{C}$ & $\mathrm{S}$ & 0 & 0 & 0 \\
\hline Pine_Glen_Annex & $\mathrm{D}$ & $S$ & 0 & 0 & 0 \\
\hline Q_Four & A & $\mathrm{E}$ & 0 & 1 & 0 \\
\hline Q_Four & $\mathrm{B}$ & $\mathrm{E}$ & 0 & 0 & 0 \\
\hline Q_Four & $\bar{C}$ & $\overline{\mathrm{E}}$ & 2 & 0 & $\overline{0}$ \\
\hline Q_Four & $\bar{D}$ & $\bar{E}$ & 1 & 0 & 0 \\
\hline Sandy_Hill & $\overline{\mathrm{A}}$ & $\overline{\mathrm{U}}$ & 0 & 0 & $\overline{0}$ \\
\hline Sandy_Hill & $\bar{B}$ & $\overline{\mathrm{U}}$ & 0 & 0 & 0 \\
\hline Sandy_Hill & $\mathrm{C}$ & $\mathrm{U}$ & 0 & 0 & 0 \\
\hline Sandy_Hill & $\bar{D}$ & $\bar{U}$ & 0 & 0 & 0 \\
\hline Vallee_Meech & A & $\mathrm{F}$ & 1 & 0 & 0 \\
\hline Vallee_Meech & $\bar{B}$ & $\mathrm{~F}$ & 0 & 0 & 0 \\
\hline Vallee_Meech & $\bar{C}$ & $F$ & 0 & 0 & 0 \\
\hline Vallee_Meech & $\mathrm{D}$ & $F$ & 1 & 0 & 0 \\
\hline Wolf_Grove & $\mathrm{A}$ & $\mathrm{E}$ & 1 & 0 & 0 \\
\hline Wolf_Grove & B & $\mathrm{E}$ & 1 & 0 & 0 \\
\hline Wolf_Grove & $\mathrm{C}$ & $\mathrm{E}$ & 0 & $\overline{0}$ & 0 \\
\hline Wolf_Grove & $\mathrm{D}$ & $E$ & 0 & 0 & 0 \\
\hline Wrightville & $\mathrm{A}$ & $\mathrm{U}$ & 0 & 0 & 0 \\
\hline Wrightville & $\mathrm{B}$ & $\mathrm{U}$ & 0 & 0 & 0 \\
\hline Wrightville & $\mathrm{C}$ & $\mathrm{U}$ & 0 & 0 & 0 \\
\hline Wrightville & $\mathrm{D}$ & $\mathrm{U}$ & 0 & 0 & $\overline{0}$ \\
\hline Wychwood & $\mathrm{A}$ & $\mathrm{S}$ & 0 & 0 & 0 \\
\hline Wychwood & $\mathrm{B}$ & $S$ & 0 & 0 & 0 \\
\hline Wychwood & $\mathrm{C}$ & $\mathrm{S}$ & 0 & 0 & 0 \\
\hline Wychwood & $\bar{D}$ & $\mathrm{~S}$ & 0 & 0 & 0 \\
\hline
\end{tabular}


${ }^{\mathrm{a}} \mathrm{F}=$ Forested, $\mathrm{E}=$ Exurban, $\mathrm{S}=$ Suburban, $\mathrm{U}=$ Urban, $\mathrm{SN}=$ Suburban Neighbor, $\mathrm{UN}=$ Urban Neighbor.

${ }^{\mathrm{b}} \mathrm{AMRE}=$ American Redstart Setophaga ruticilla, $\mathrm{BCCH}=$ Black-capped Chickadee Poecile atricapilla, $\mathrm{BHVI}=$ Blue-headed Vireo Vireo solitarius, $\mathrm{BLBW}=$ Blackburnian Warbler Dendroica fusca, BLJA = Blue Jay Cyanocitta cristata, $\mathrm{BRCR}=$ Brown Creeper Certhia americana, BTBW = Black-throated Blue Warbler Dendroica caerulescens, BTGW = Black-throated Green Warbler Dendroica virens, BWWA = Black-and-White Warbler Mniotilta varia, CAWA = Canada Warbler Wilsonia canadensis, $\mathrm{DOWO}=$ Downy Woodpecker Picoides pubescens, $\mathrm{EAPH}=$ Eastern Phoebe Sayornis phoebe, EAWP = Eastern Wood-Pewee Contopus virens, GCKI = Golden-crowned Kinglet Regulus satrapa, HAWO = Hairy Woodpecker Picoides villosus, HETH = Hermit Thrush Catharus guttatus, LEFL = Least Flycatcher Empidonax minimus, MOWA = Mourning Warbler Oporornis philadelphia, NAWA = Nashville Warbler Vermivora ruficapilla, OVEN = Ovenbird Seiurus aurocapillus, PIWA = Pine Warbler Dendroica pinus, $\mathrm{PIWO}=$ Pileated Woodpecker Dryocopus pileatus, $\mathrm{PUFI}=$ Purple Finch Carpodacus purpureus, $\mathrm{RBGR}=$ Rose-breasted Grosbeak Pheucticus ludovicianus, RBNU = Red-breasted Nuthatch Sitta canadensis, REVI = Redeyed Vireo Vireo olivaceus, RTHU = Ruby-throated Hummingbird Archilochus colubris, RUGR $=$ Ruffed Grouse Bonasa umbellus, SCTA = Scarlet Tanager Piranga olivacea, SWTH = Swainson's Thrush Catharus ustulatus, VEER = Veery Catharus fuscescens, WAVI = Warbling Vireo Vireo gilvus, WBNU $=$ White-breasted Nuthatch Sitta carolinensis, WIWR $=$ Winter Wren Troglodytes troglodytes, WOTH $=$ Wood Thrush 
Hylocichla mustelina, WTSP $=$ White-throated Sparrow Zonotrichia albicollis, YBSA $=$ Yellow-bellied Sapsucker Sphyrapicus varius, YRWA = Yellow-rumped Warbler Dendroica coronata, YTVI = Yellow-throated Vireo Vireo flavifrons. 
Appendix 2. The estimated abundances of 39 forest bird species in four hypothetical development scenarios: U, Undeveloped; D, Dispersed; SC, Semi-compact; C, Compact. The lower edge of each box is the first quartile, the bold center line is the median and the upper edge is the third quartile of the distribution. Whiskers extend to the minimum and maximum values.
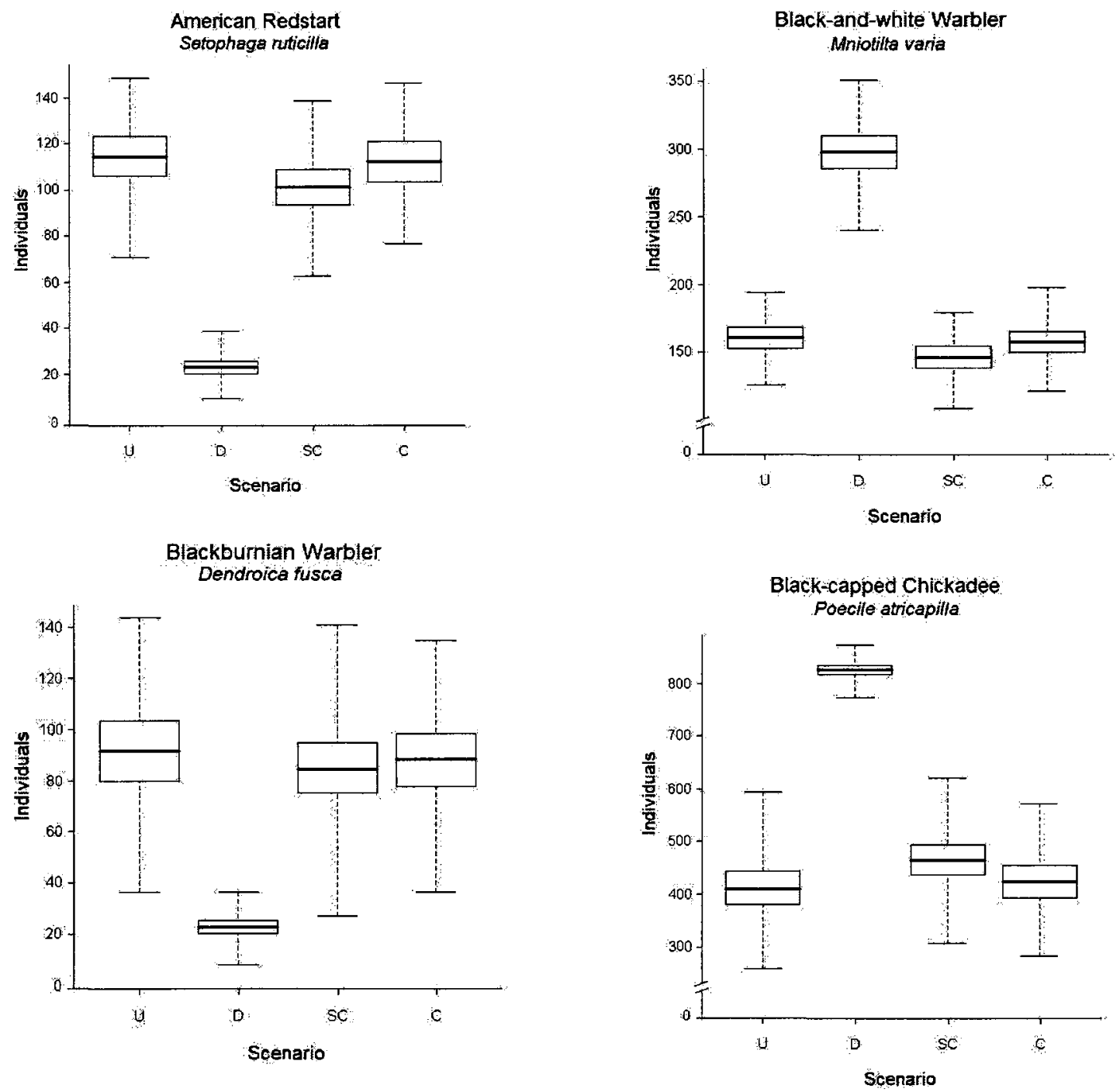

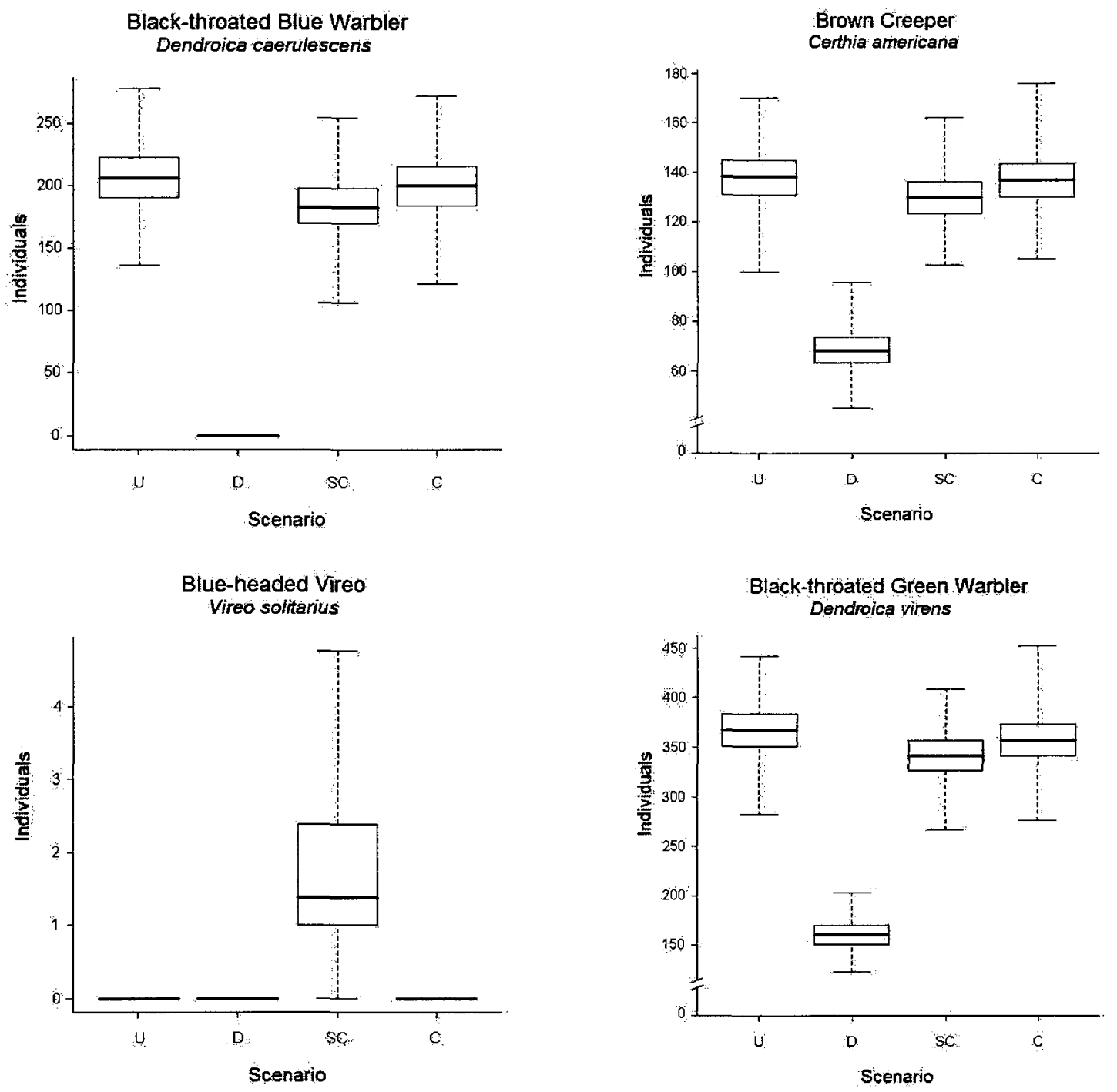

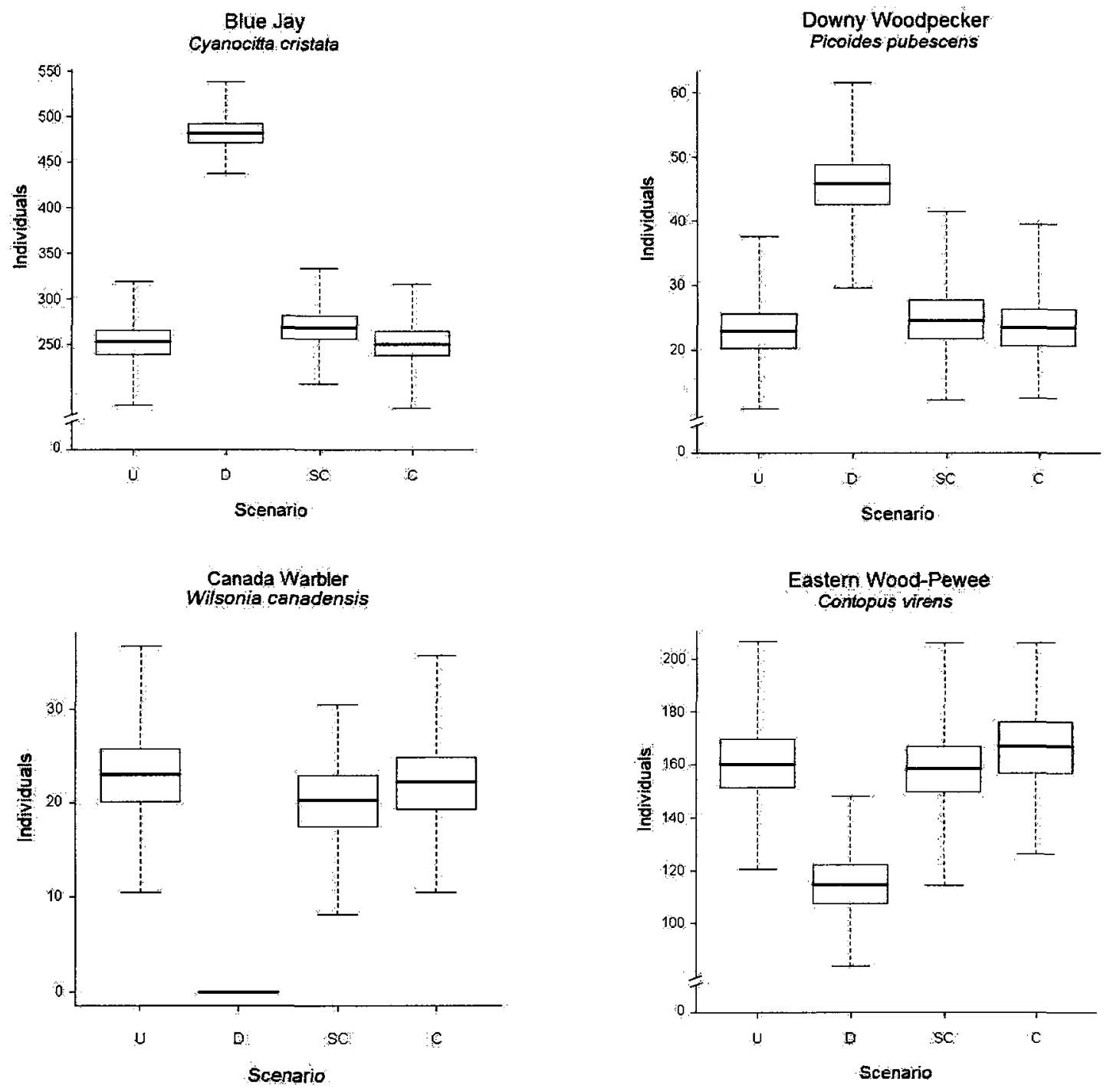

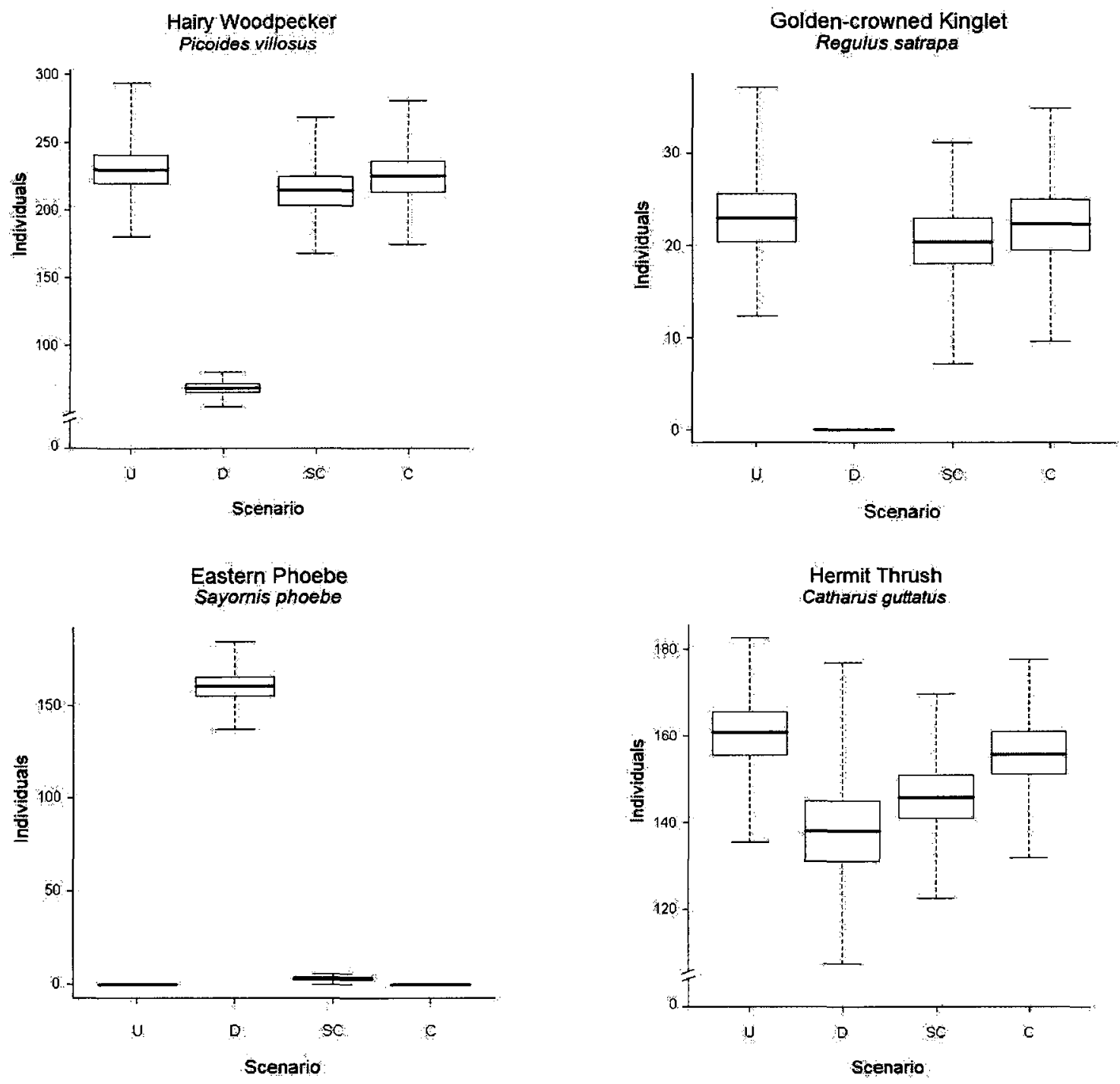

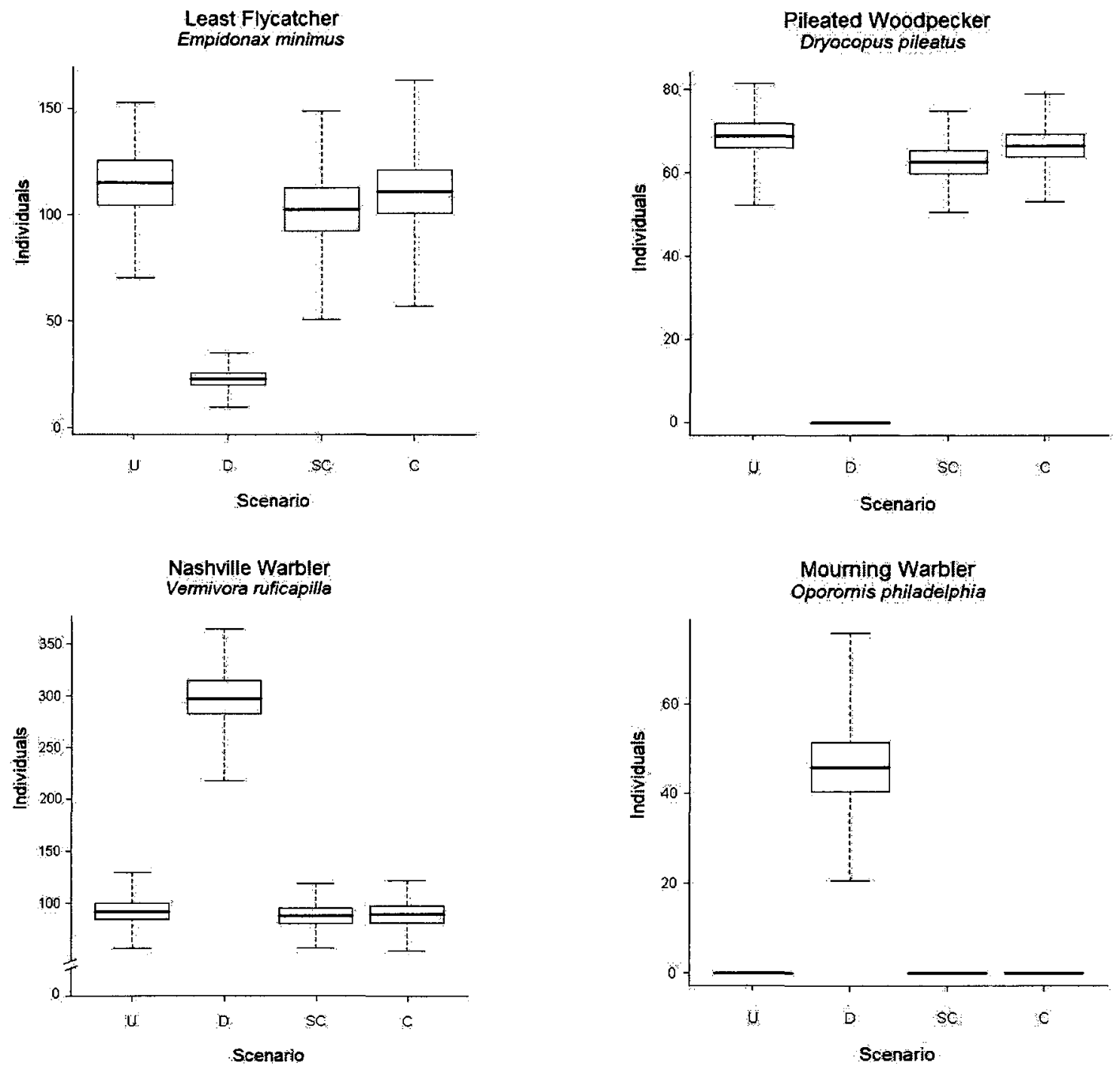

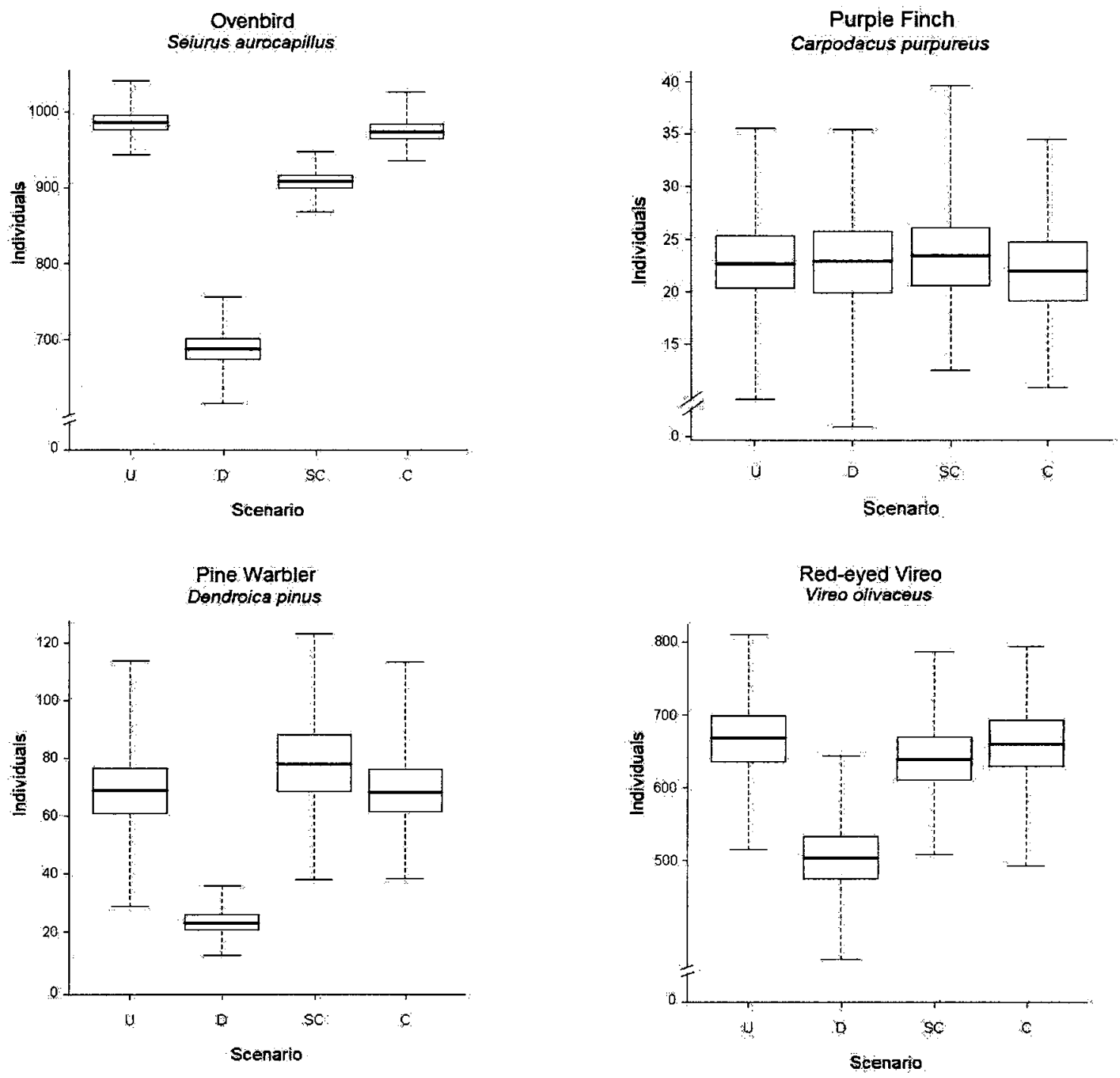
Ruby-throated Hummingbird Archilochus colubris

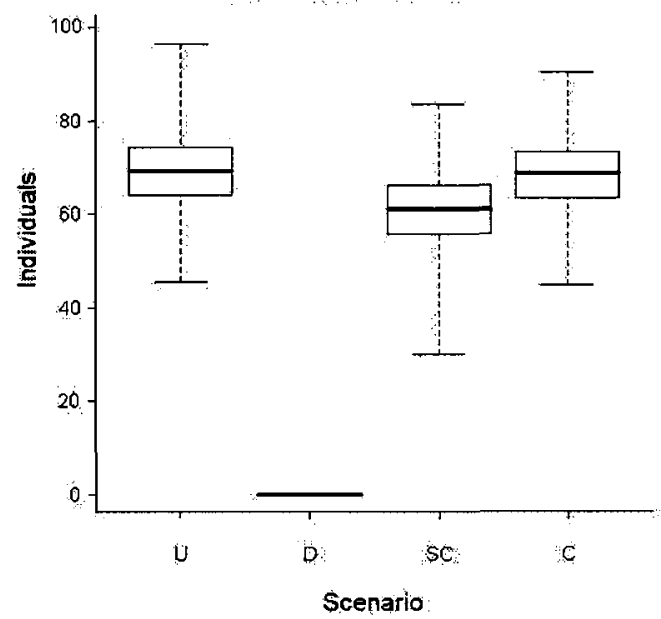

Red-breasted Nuthatch

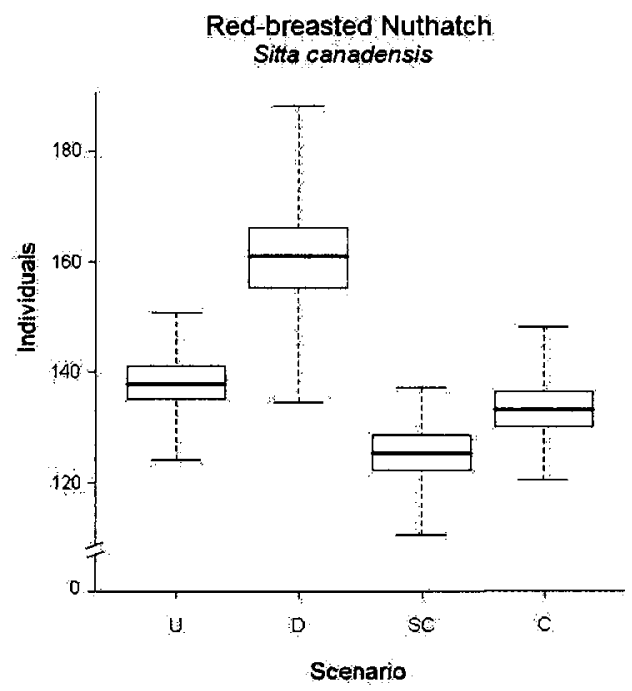

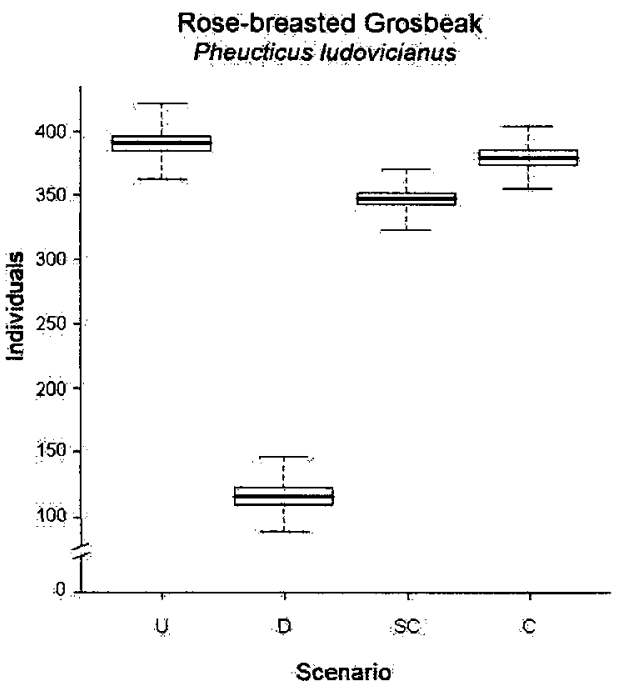

Ruffed Grouse Bonasa umbelius

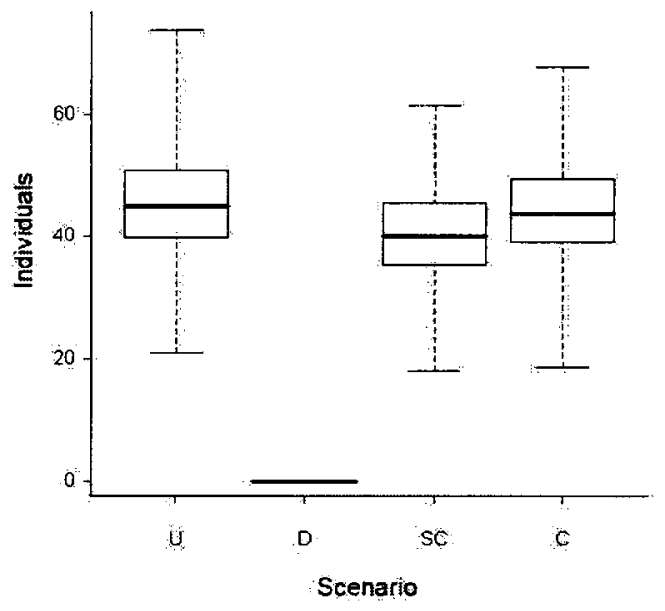



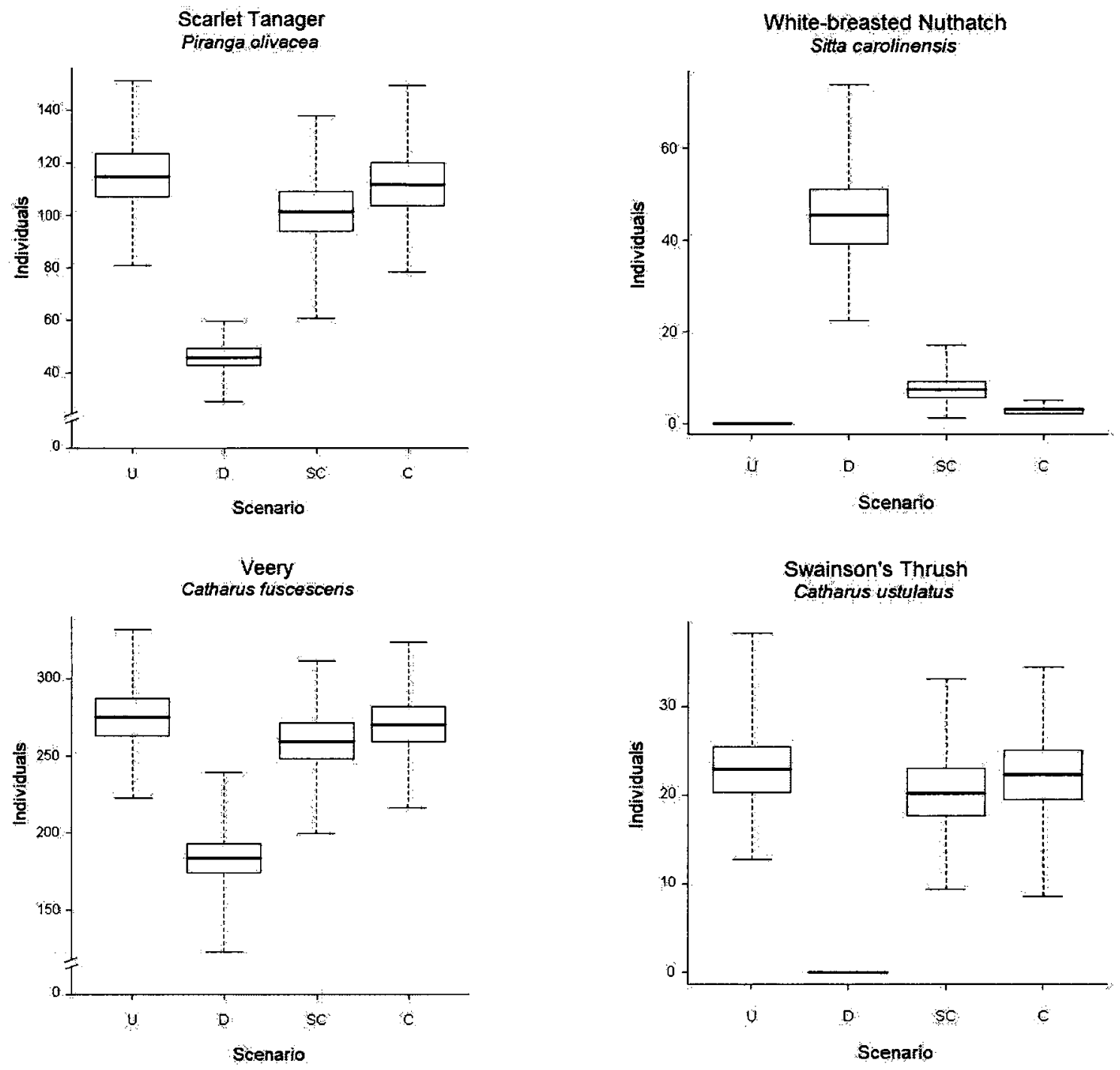

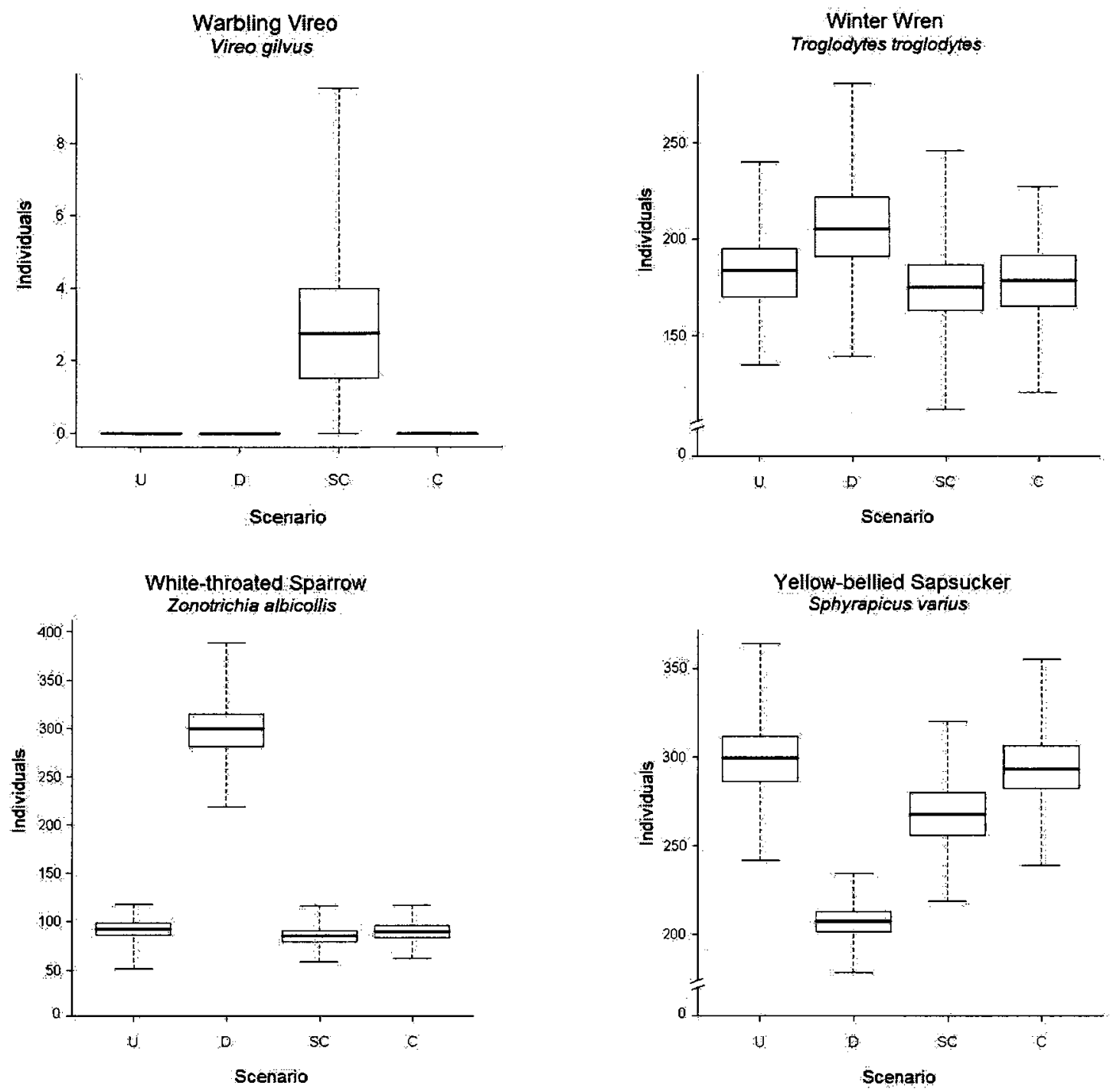

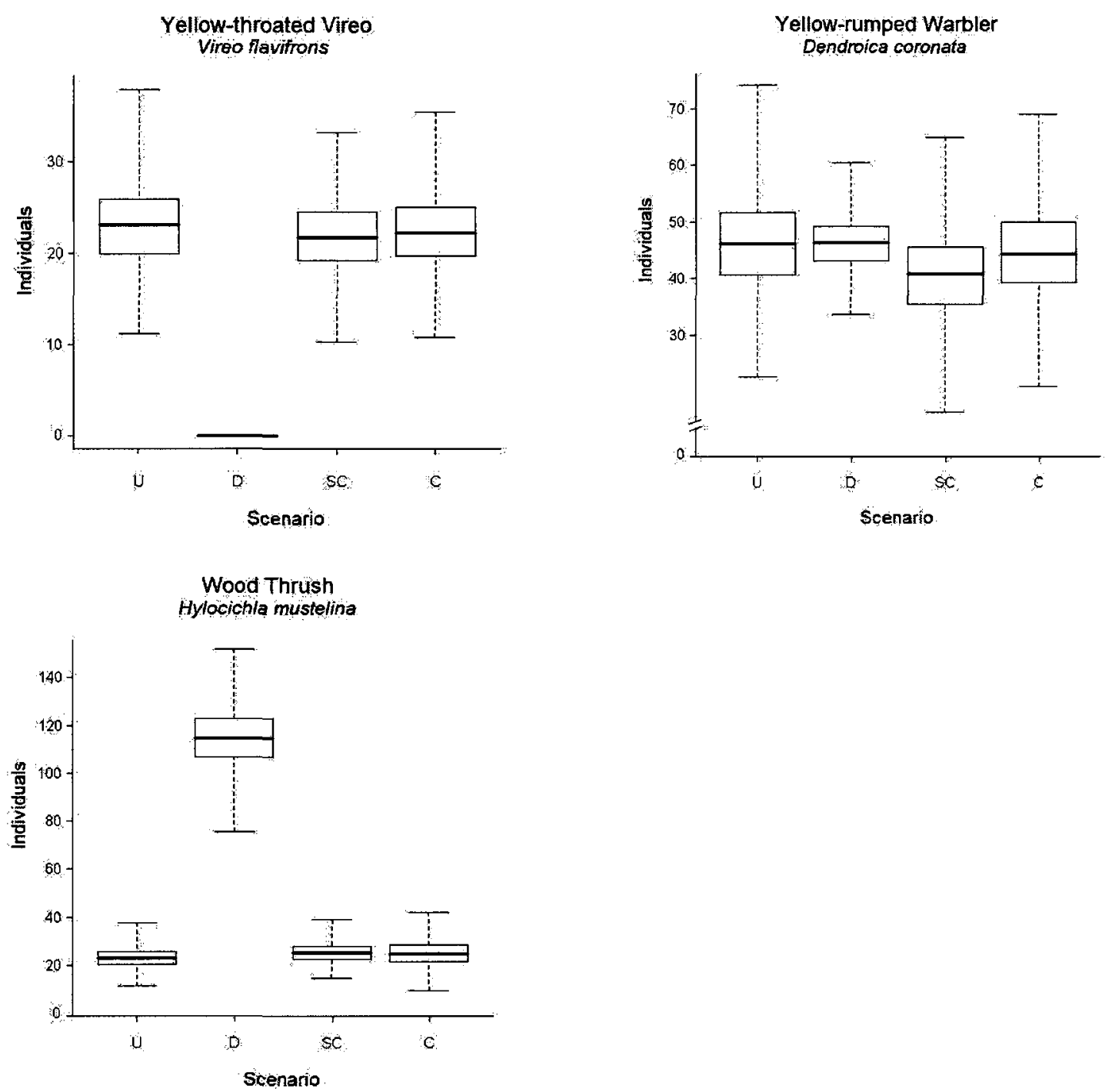
Appendix 3. The estimated abundances of open woodland birds, the American Crow Corvus brachyrhynchos, the Common Grackle Quiscalus quiscula and the Brown-headed Cowbird Molothrus ater in four hypothetical development scenarios: U, Undeveloped; D, Dispersed; SC, Semi-compact; C, Compact. Open woodland birds are species observed during point counts at bird survey sites that are adapted to open areas interspersed with large trees according to Poole (2005). The lower edge of each box is the first quartile, the bold center line is the median and the upper edge is the third quartile of the distribution. Whiskers extend to the minimum and maximum values.
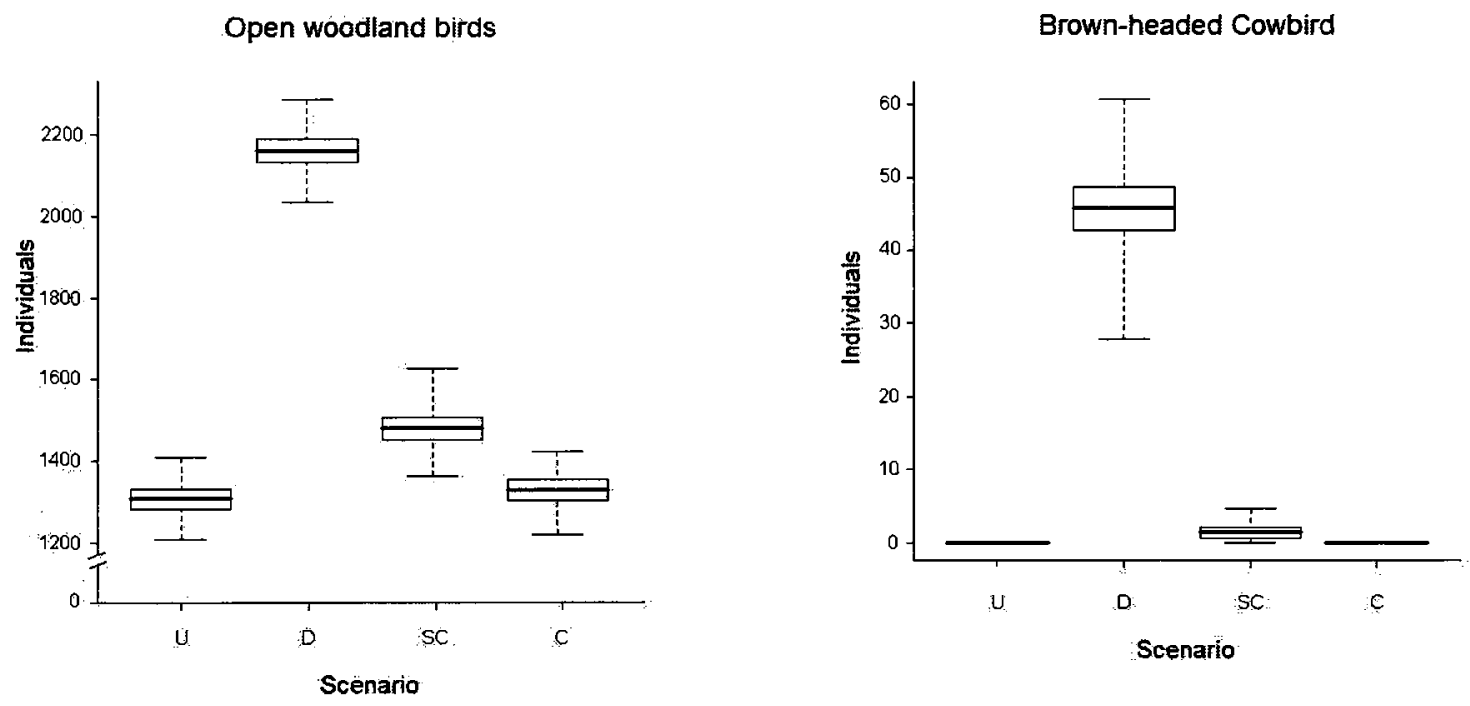

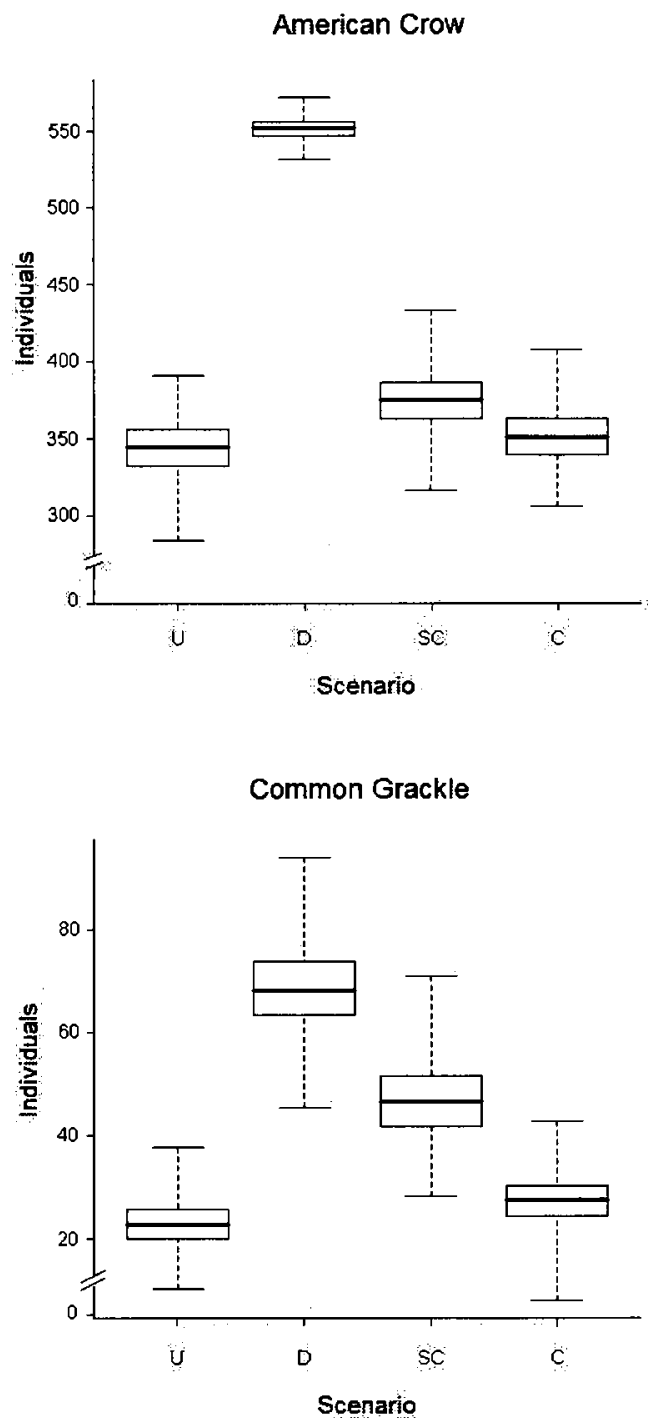


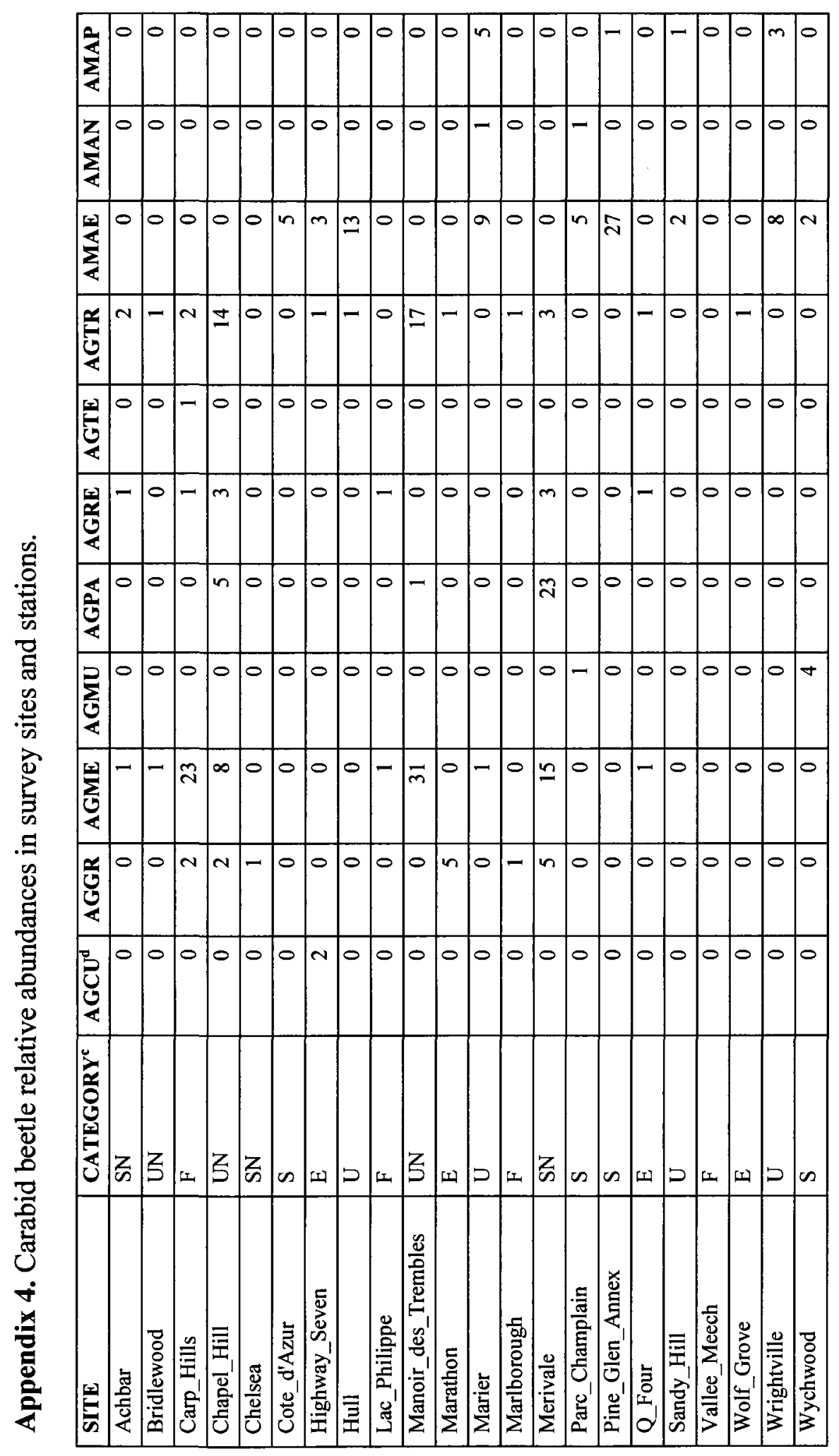



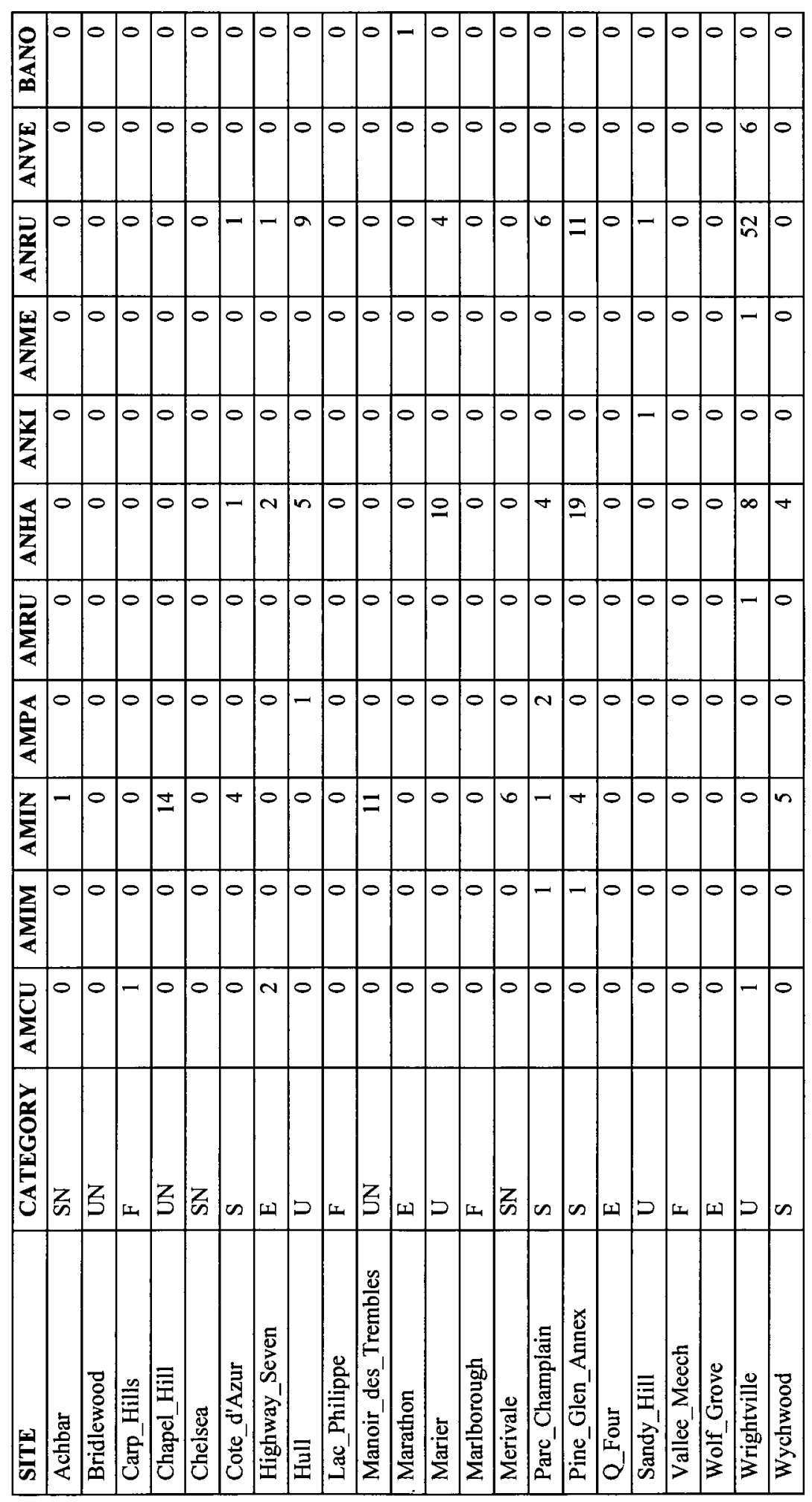


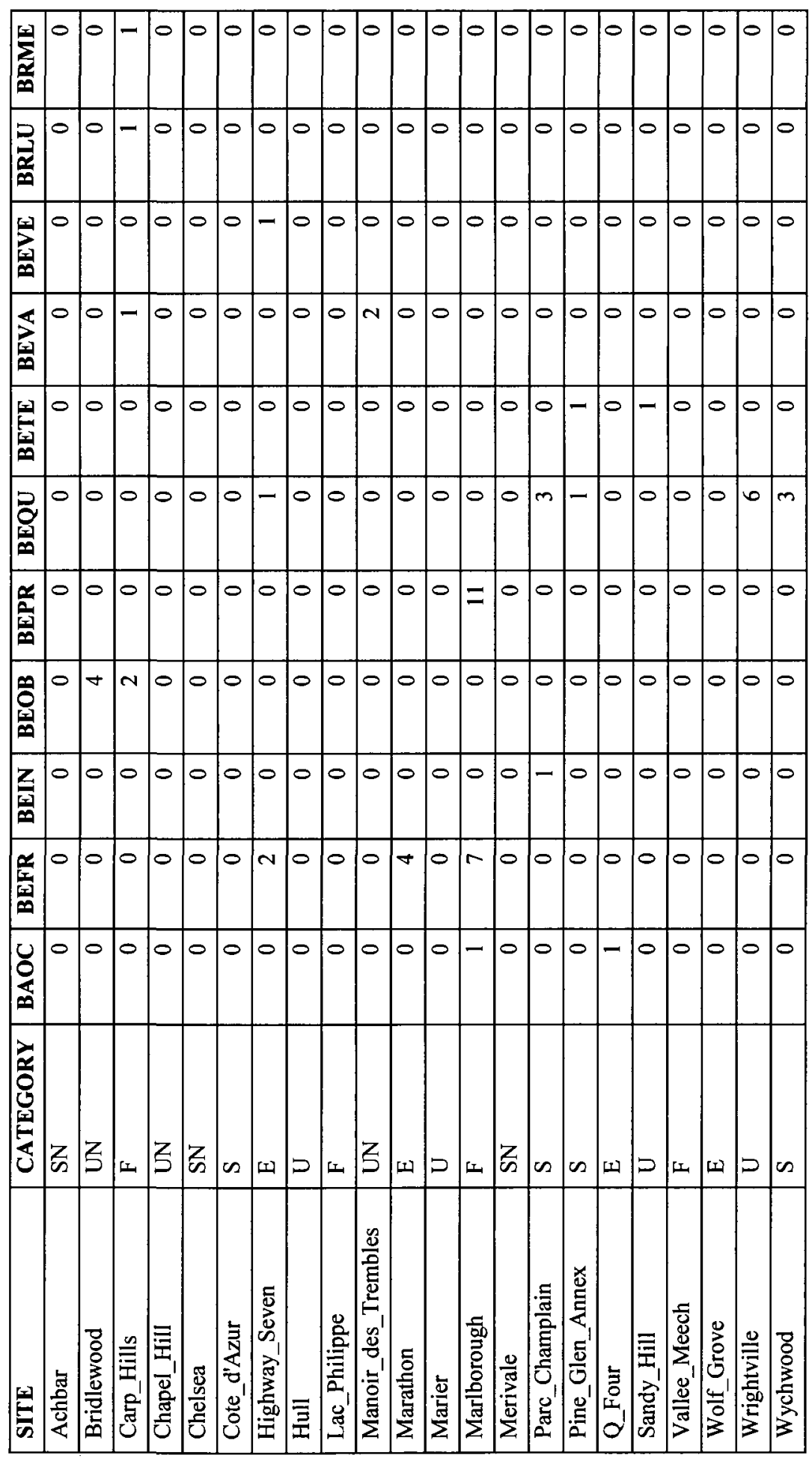



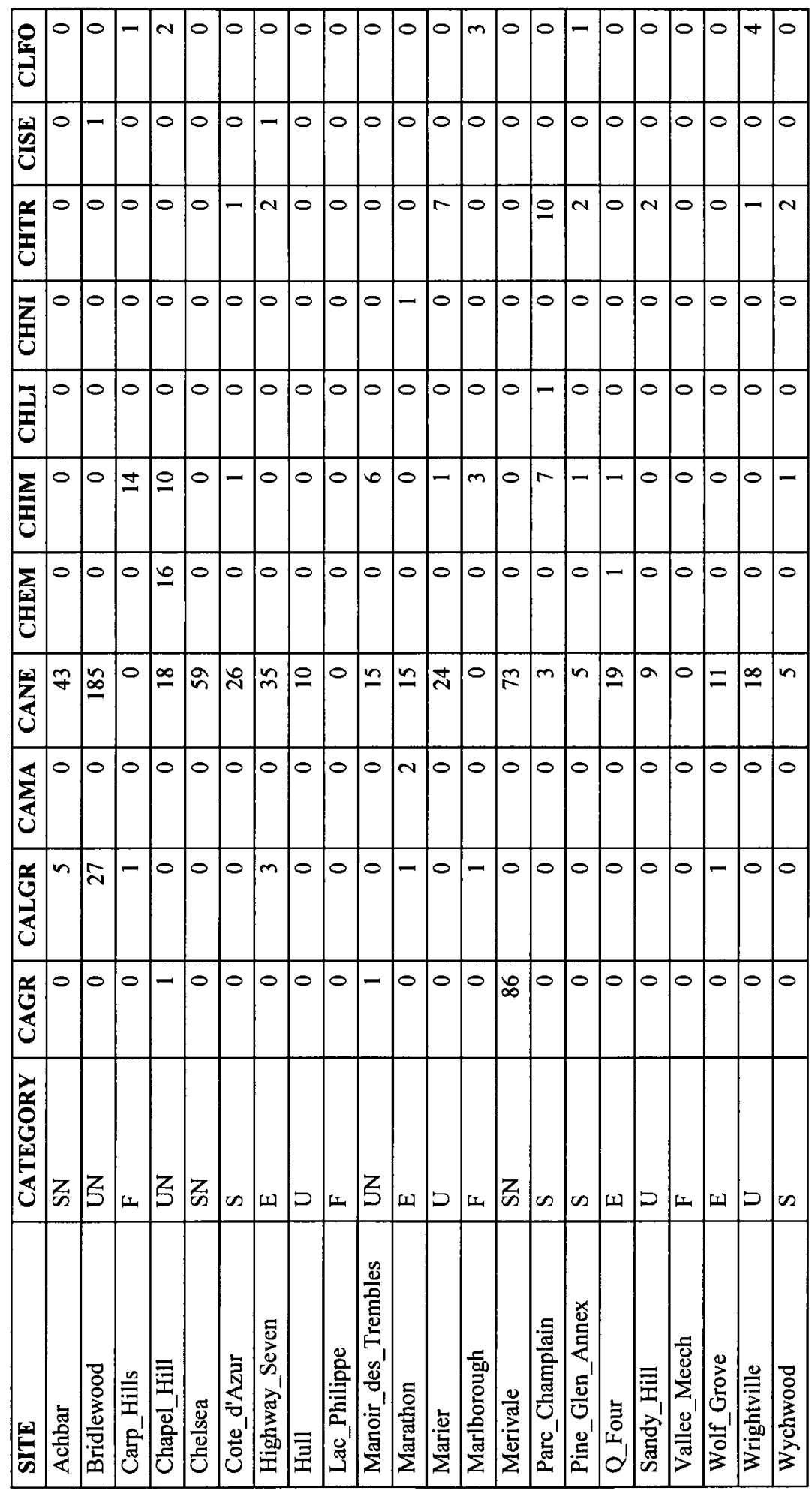


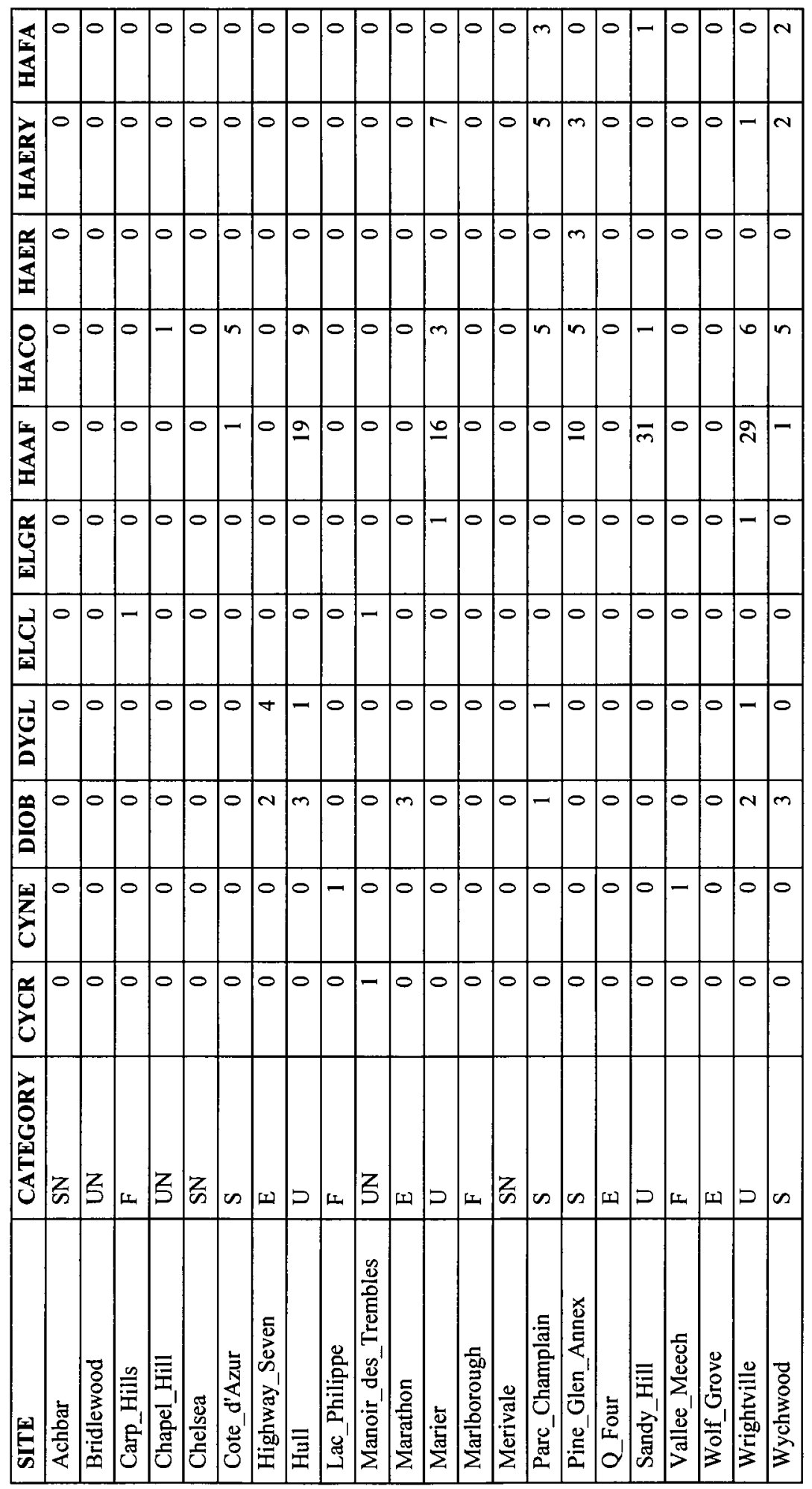




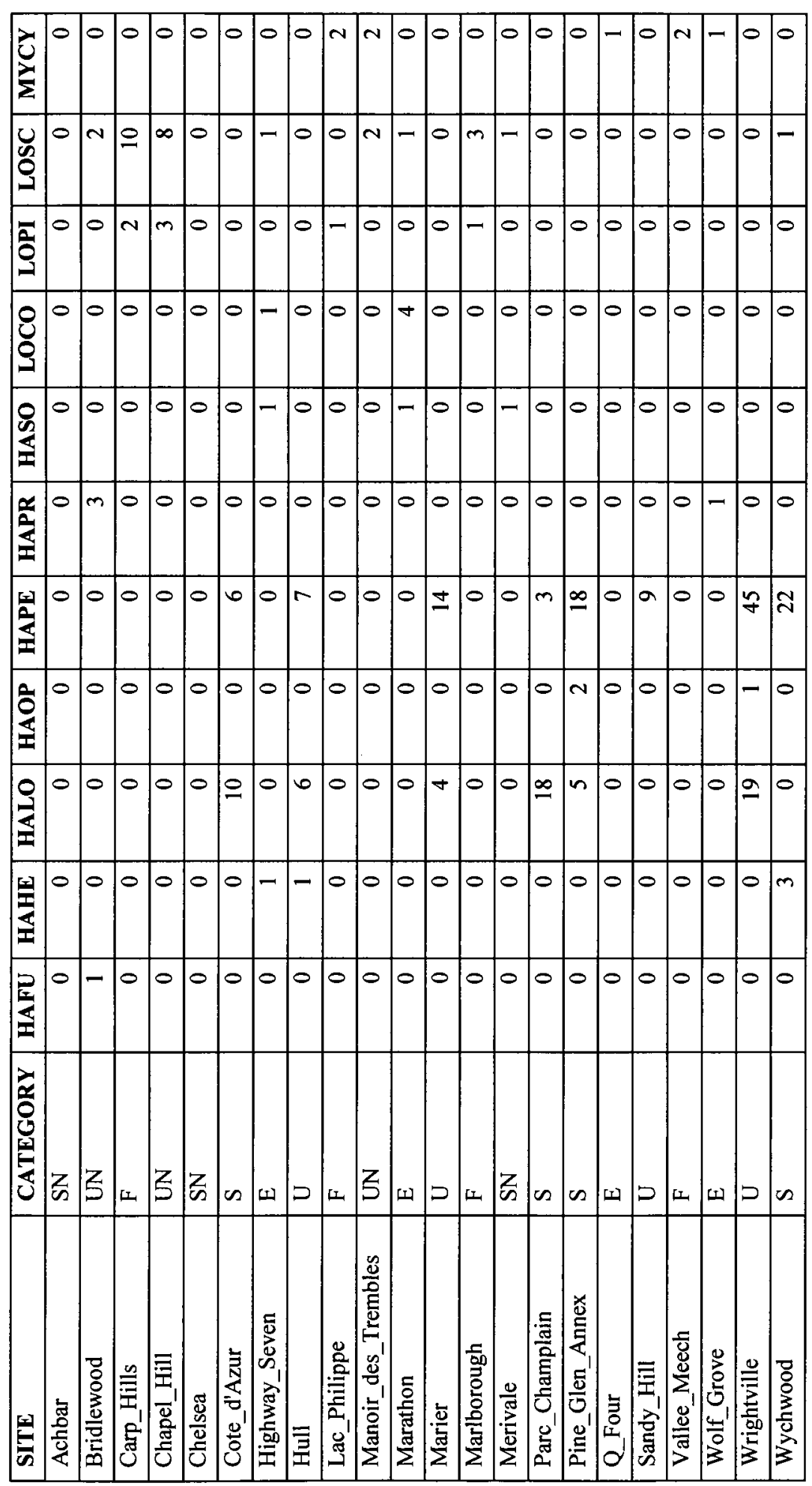




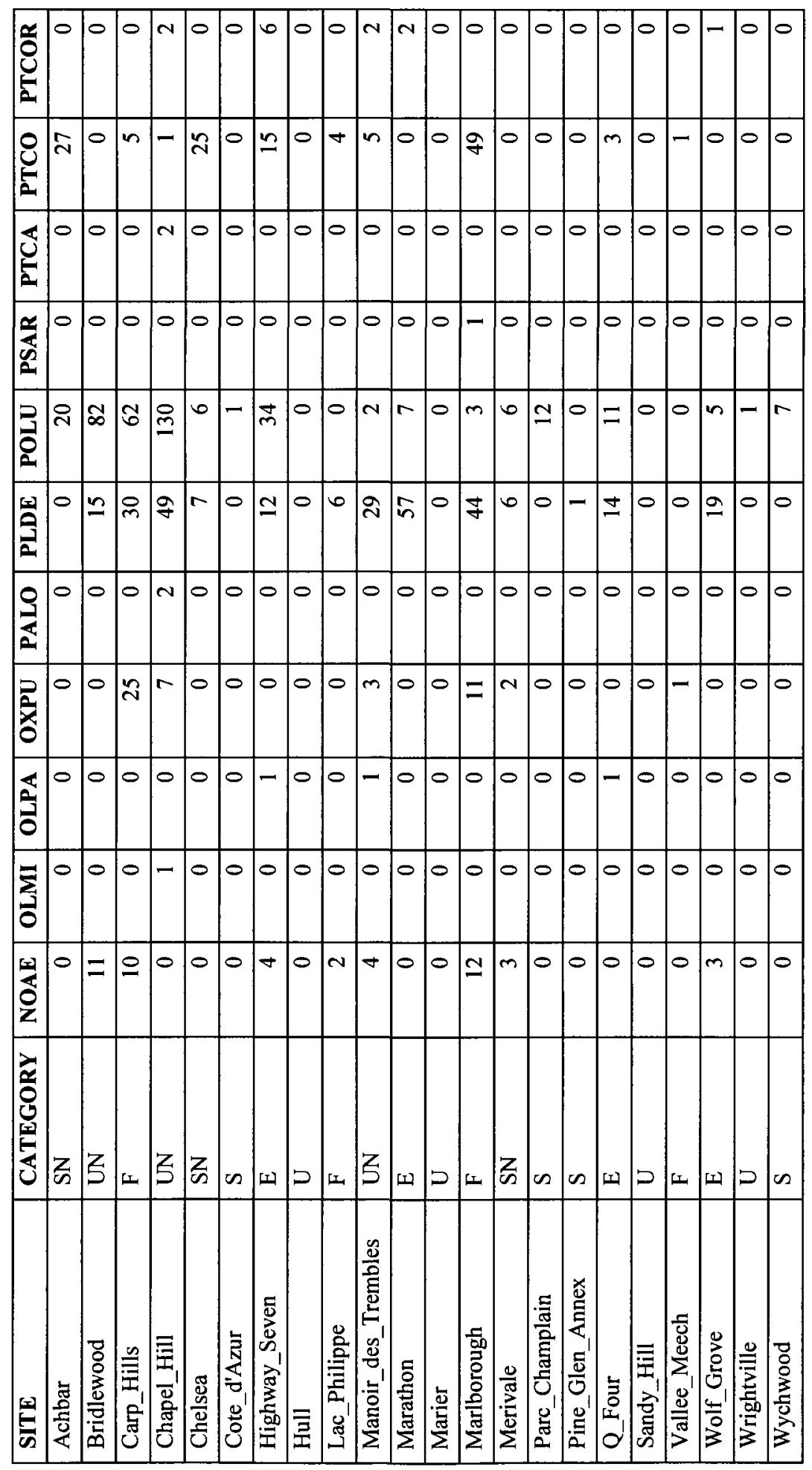




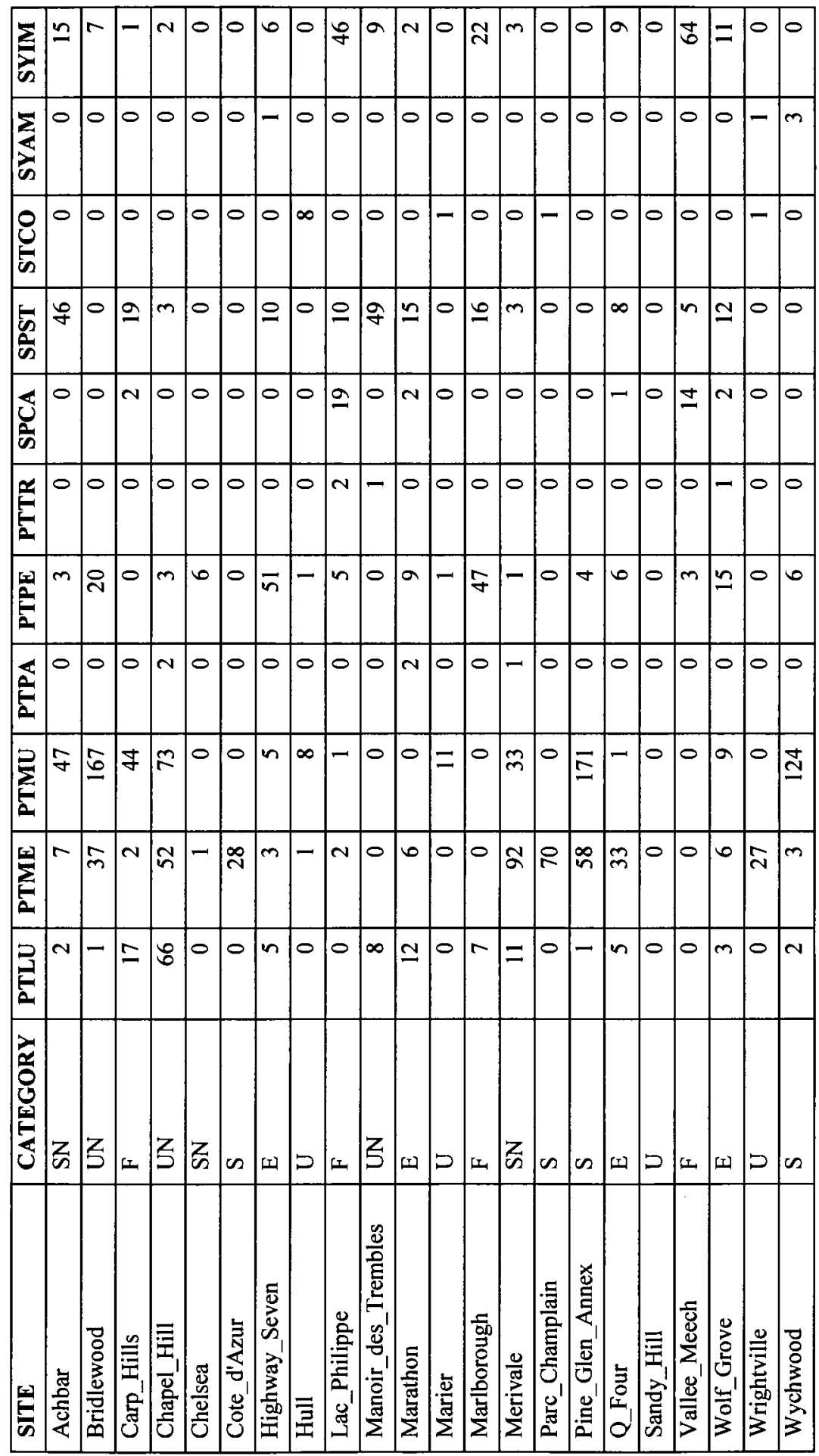




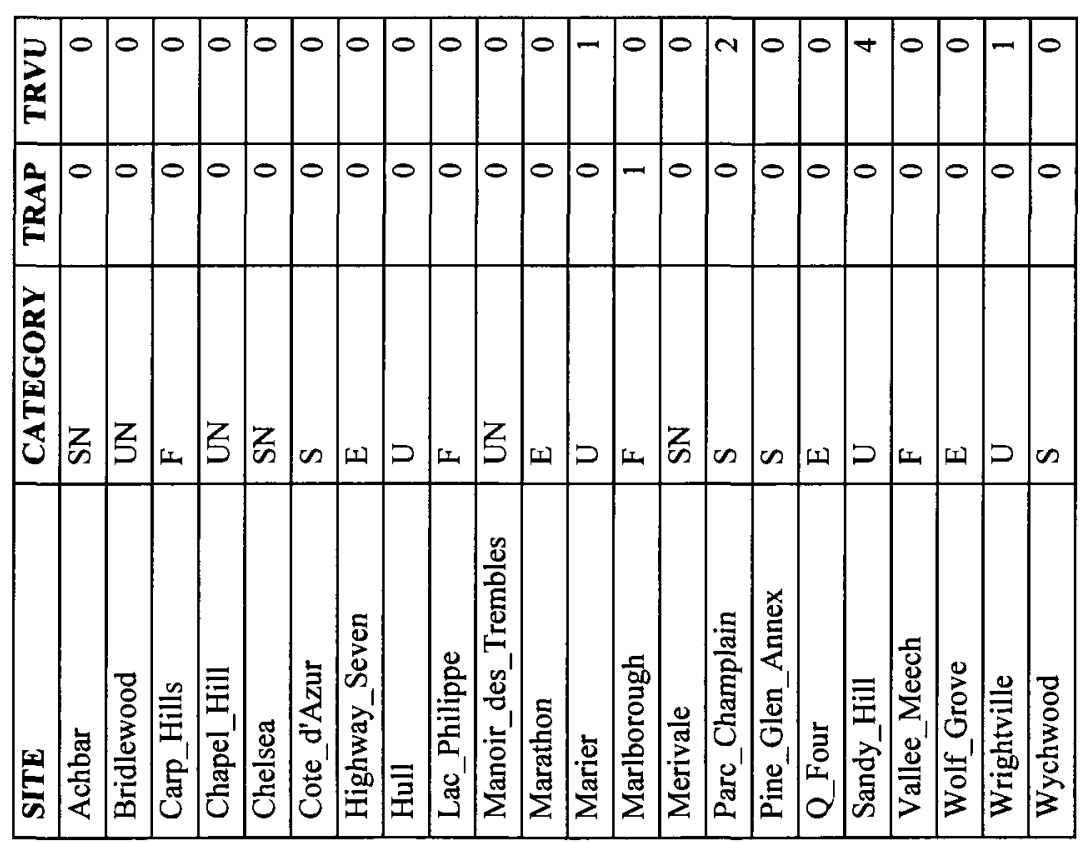




\begin{tabular}{|c|c|c|c|c|c|c|c|c|}
\hline SITE & STATION & CATEGORY $^{c}$ & $\mathbf{A G C U}^{d}$ & AGGR & AGME & AGMU & AGPA & AGRE \\
\hline Achbar & $\mathrm{A}$ & $\mathrm{SN}$ & 0 & 0 & 0 & 0 & 0 & 0 \\
\hline Achbar & $\bar{B}$ & $\overline{\mathrm{SN}}$ & 0 & 0 & 0 & 0 & 0 & $\overline{0}$ \\
\hline Achbar & $\mathrm{C}$ & SN & 0 & 0 & 0 & 0 & 0 & 0 \\
\hline Achbar & $\bar{D}$ & $\overline{\mathrm{SN}}$ & 0 & 0 & 0 & 0 & 0 & 0 \\
\hline Achbar & $\mathrm{E}$ & SN & 0 & 0 & 0 & 0 & 0 & 1 \\
\hline Achbar & $\bar{F}$ & $\overline{\mathrm{SN}}$ & 0 & 0 & 1 & 0 & 0 & $\overline{0}$ \\
\hline Achbar & $\mathrm{H}$ & $\overline{\mathrm{SN}}$ & 0 & 0 & 0 & 0 & 0 & 0 \\
\hline Achbar & I & SN & 0 & 0 & 0 & 0 & 0 & $\overline{0}$ \\
\hline Bridlewood & A & UN & 0 & 0 & 0 & 0 & 0 & $\overline{0}$ \\
\hline Bridlewood & $\bar{B}$ & UN & 0 & 0 & 0 & 0 & 0 & $\overline{0}$ \\
\hline Bridlewood & $\mathrm{C}$ & UN & 0 & 0 & 0 & 0 & 0 & 0 \\
\hline Bridlewood & $\bar{D}$ & $\overline{\mathrm{UN}}$ & 0 & 0 & 0 & 0 & 0 & $\overline{0}$ \\
\hline Bridlewood & $E$ & UN & 0 & 0 & 0 & 0 & 0 & $\overline{0}$ \\
\hline Bridlewood & F & UN & 0 & 0 & 1 & 0 & 0 & $\overline{0}$ \\
\hline Bridlewood & $\mathrm{H}$ & UN & 0 & 0 & 0 & 0 & 0 & $\overline{0}$ \\
\hline Bridlewood & $I$ & UN & 0 & 0 & 0 & 0 & 0 & $\overline{0}$ \\
\hline Carp_Hills & A & $\mathrm{F}$ & 0 & 0 & 0 & 0 & 0 & 0 \\
\hline Carp_Hills & $\mathrm{B}$ & $\mathrm{F}$ & 0 & 1 & 1 & 0 & 0 & 0 \\
\hline Carp_Hills & $\bar{C}$ & $\bar{F}$ & 0 & 0 & 1 & 0 & 0 & $\overline{0}$ \\
\hline Carp_Hills & $\bar{D}$ & $\bar{F}$ & 0 & 0 & 0 & 0 & 0 & $\overline{0}$ \\
\hline Carp_Hills & $E$ & $\mathrm{~F}$ & 0 & 0 & 2 & 0 & 0 & 0 \\
\hline Carp_Hills & $\bar{F}$ & $\bar{F}$ & 0 & 0 & 19 & 0 & 0 & $\overline{0}$ \\
\hline Carp_Hills & $\overline{\mathrm{H}}$ & $\bar{F}$ & 0 & 0 & 0 & 0 & 0 & $\overline{1}$ \\
\hline Carp_Hills & $I$ & $\bar{F}$ & 0 & 1 & 0 & 0 & 0 & $\overline{0}$ \\
\hline Chapel_Hill & $\bar{A}$ & UN & 0 & 0 & 0 & 0 & 0 & $\overline{0}$ \\
\hline Chapel_Hill & $\mathrm{B}$ & UN & 0 & 0 & 0 & 0 & 1 & 3 \\
\hline Chapel_Hill & $\mathrm{C}$ & UN & 0 & 0 & 0 & 0 & 0 & 0 \\
\hline Chapel_Hill & $\overline{\mathrm{D}}$ & UN & 0 & 0 & 0 & 0 & 0 & $\overline{0}$ \\
\hline Chapel_Hill & $E$ & UN & 0 & 1 & 4 & 0 & 3 & 0 \\
\hline Chapel_Hill & $\mathrm{F}$ & $\overline{\text { UN }}$ & 0 & 0 & 0 & 0 & 0 & 0 \\
\hline Chapel_Hill & $\mathrm{H}$ & UN & 0 & 0 & 0 & 0 & 0 & 0 \\
\hline Chapel_Hill & $\bar{I}$ & UN & 0 & 1 & 4 & 0 & 1 & $\overline{0}$ \\
\hline Chelsea & $\mathrm{A}$ & $\mathrm{SN}$ & 0 & 0 & 0 & 0 & 0 & 0 \\
\hline Chelsea & B & $\mathrm{SN}$ & 0 & 0 & 0 & 0 & 0 & 0 \\
\hline Chelsea & $\bar{C}$ & SN & 0 & 1 & 0 & 0 & 0 & $\overline{0}$ \\
\hline Chelsea & $\mathrm{D}$ & $\mathrm{SN}$ & 0 & 0 & 0 & 0 & 0 & 0 \\
\hline Chelsea & $\bar{E}$ & SN & 0 & 0 & 0 & 0 & 0 & $\overline{0}$ \\
\hline Chelsea & $\bar{F}$ & $\mathrm{SN}$ & 0 & 0 & 0 & 0 & 0 & 0 \\
\hline Chelsea & $\mathrm{H}$ & $\overline{\mathrm{SN}}$ & 0 & 0 & 0 & 0 & 0 & 0 \\
\hline Chelsea & I & $\overline{\mathrm{SN}}$ & 0 & 0 & 0 & 0 & 0 & 0 \\
\hline Cote_d'Azur & $\bar{A}$ & $\mathrm{~S}$ & 0 & 0 & 0 & 0 & 0 & 0 \\
\hline Cote_d'Azur & B & $\mathrm{S}$ & 0 & 0 & 0 & 0 & 0 & $\overline{0}$ \\
\hline Cote_d'Azur & $\mathrm{C}$ & $\mathrm{S}$ & 0 & 0 & 0 & 0 & 0 & 0 \\
\hline Cote_d'Azur & $\bar{D}$ & $\mathrm{~S}$ & 0 & 0 & 0 & 0 & 0 & $\overline{0}$ \\
\hline
\end{tabular}




\begin{tabular}{|c|c|c|c|c|c|c|c|c|}
\hline Cote_d'Azur & $E$ & $\mathrm{~S}$ & 0 & 0 & 0 & 0 & 0 & 0 \\
\hline Cote_d'Azur & $\bar{F}$ & $\mathrm{~S}$ & 0 & 0 & 0 & 0 & 0 & $\overline{0}$ \\
\hline Cote_d'Azur & $\mathrm{H}$ & $S$ & 0 & 0 & 0 & 0 & 0 & $\overline{0}$ \\
\hline Cote_d'Azur & I & $\mathrm{S}$ & 0 & 0 & 0 & 0 & 0 & 0 \\
\hline Highway_Seven & $\mathrm{A}$ & $E$ & 0 & 0 & 0 & 0 & 0 & 0 \\
\hline Highway_Seven & $\bar{B}$ & $\bar{E}$ & 0 & 0 & 0 & 0 & 0 & $\overline{0}$ \\
\hline Highway_Seven & $\bar{C}$ & $\mathrm{E}$ & 0 & 0 & 0 & 0 & 0 & $\overline{0}$ \\
\hline Highway_Seven & $\overline{\mathrm{D}}$ & $\bar{E}$ & 0 & 0 & 0 & 0 & 0 & 0 \\
\hline Highway_Seven & $\bar{E}$ & $\bar{E}$ & 2 & 0 & 0 & 0 & 0 & 0 \\
\hline Highway_Seven & $\mathrm{F}$ & $\mathrm{E}$ & 0 & 0 & 0 & 0 & 0 & $\overline{0}$ \\
\hline Highway_Seven & $\mathrm{H}$ & $\mathrm{E}$ & 0 & 0 & 0 & 0 & 0 & $\overline{0}$ \\
\hline Highway_Seven & I & $\mathrm{E}$ & 0 & 0 & 0 & 0 & 0 & 0 \\
\hline Hull & $\bar{A}$ & $\bar{U}$ & 0 & 0 & 0 & 0 & 0 & $\overline{0}$ \\
\hline Hull & B & $\bar{U}$ & 0 & 0 & 0 & 0 & 0 & $\overline{0}$ \\
\hline Hull & $\mathrm{C}$ & $\bar{U}$ & 0 & 0 & 0 & 0 & 0 & $\overline{0}$ \\
\hline Hull & $\overline{\mathrm{D}}$ & $\overline{\mathrm{U}}$ & 0 & 0 & 0 & 0 & 0 & $\overline{0}$ \\
\hline Hull & $\mathrm{E}$ & $\bar{U}$ & 0 & 0 & 0 & 0 & 0 & $\overline{0}$ \\
\hline Hull & $\mathrm{F}$ & $\bar{U}$ & 0 & 0 & 0 & 0 & 0 & $\overline{0}$ \\
\hline Hull & $\overline{\mathrm{H}}$ & $\bar{U}$ & 0 & 0 & 0 & 0 & 0 & $\overline{0}$ \\
\hline Hull & $\mathrm{I}$ & $\mathrm{U}$ & 0 & 0 & 0 & 0 & 0 & 0 \\
\hline Lac_Philippe & $\mathrm{A}$ & $\mathrm{F}$ & 0 & 0 & 0 & 0 & 0 & 0 \\
\hline Lac_Philippe & $\mathrm{B}$ & $\mathrm{F}$ & 0 & 0 & 0 & 0 & 0 & $\overline{0}$ \\
\hline Lac_Philippe & $\mathrm{C}$ & $F$ & 0 & 0 & 0 & 0 & 0 & 0 \\
\hline Lac_Philippe & $\overline{\mathrm{D}}$ & $\mathrm{F}$ & 0 & 0 & 0 & 0 & 0 & 0 \\
\hline Lac_Philippe & $\bar{E}$ & $F$ & 0 & 0 & 0 & 0 & 0 & 0 \\
\hline Lac_Philippe & $F$ & $F$ & 0 & 0 & 0 & 0 & 0 & $\overline{1}$ \\
\hline Lac_Philippe & $\overline{\mathrm{H}}$ & $F$ & 0 & 0 & 1 & 0 & 0 & 0 \\
\hline Lac_Philippe & I & $\mathbf{F}$ & 0 & 0 & 0 & 0 & 0 & 0 \\
\hline Manoir_des_Trembles & A & $\mathrm{UN}$ & 0 & 0 & 0 & 0 & 0 & 0 \\
\hline Manoir_des_Trembles & $\mathrm{B}$ & $\mathrm{UN}$ & 0 & 0 & 0 & 0 & 0 & 0 \\
\hline Manoir_des_Trembles & $\mathrm{C}$ & UN & 0 & 0 & 24 & 0 & 1 & $\overline{0}$ \\
\hline Manoir_des_Trembles & $\mathrm{D}$ & $\mathrm{UN}$ & 0 & 0 & 2 & 0 & 0 & 0 \\
\hline Manoir_des_Trembles & $\mathrm{E}$ & $\mathrm{UN}$ & 0 & 0 & 5 & 0 & 0 & 0 \\
\hline Manoir_des_Trembles & $F$ & $\mathrm{UN}$ & 0 & 0 & 0 & 0 & 0 & 0 \\
\hline Manoir_des_Trembles & $\mathrm{H}$ & $\mathrm{UN}$ & 0 & 0 & 0 & 0 & 0 & 0 \\
\hline Manoir_des_Trembles & I & $\mathrm{UN}$ & 0 & 0 & 0 & 0 & 0 & $\overline{0}$ \\
\hline Marathon & $\mathrm{A}$ & $\mathbf{E}$ & 0 & 0 & 0 & 0 & 0 & 0 \\
\hline Marathon & $\mathrm{B}$ & $\bar{E}$ & 0 & 0 & 0 & 0 & 0 & 0 \\
\hline Marathon & $\mathrm{C}$ & $E$ & 0 & 3 & 0 & 0 & 0 & 0 \\
\hline Marathon & $\mathrm{D}$ & $E$ & 0 & 0 & 0 & 0 & 0 & 0 \\
\hline Marathon & $\mathrm{E}$ & 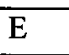 & 0 & 0 & 0 & 0 & 0 & $\overline{0}$ \\
\hline Marathon & $\mathrm{F}$ & $\mathbf{E}$ & 0 & 0 & 0 & 0 & 0 & $\overline{0}$ \\
\hline Marathon & $\mathrm{H}$ & $\bar{E}$ & 0 & 0 & 0 & 0 & 0 & $\overline{0}$ \\
\hline Marathon & I & $E$ & 0 & 2 & 0 & 0 & 0 & 0 \\
\hline Marier & A & $\bar{U}$ & 0 & 0 & 0 & 0 & 0 & 0 \\
\hline
\end{tabular}




\begin{tabular}{|c|c|c|c|c|c|c|c|c|}
\hline Marier & $\mathrm{B}$ & $\mathrm{U}$ & 0 & 0 & 0 & 0 & 0 & 0 \\
\hline Marier & $\mathrm{C}$ & $\mathrm{U}$ & 0 & 0 & 0 & 0 & 0 & $\overline{0}$ \\
\hline Marier & $\bar{D}$ & $\mathrm{U}$ & 0 & 0 & 0 & 0 & 0 & 0 \\
\hline Marier & $\mathrm{E}$ & $\overline{\mathrm{U}}$ & 0 & 0 & 0 & 0 & 0 & 0 \\
\hline Marier & $F$ & $\mathrm{U}$ & 0 & 0 & 1 & 0 & 0 & $\overline{0}$ \\
\hline Marier & $\overline{\mathrm{H}}$ & $\mathrm{U}$ & 0 & 0 & 0 & 0 & 0 & $\overline{0}$ \\
\hline Marier & I & $\overline{\mathrm{U}}$ & 0 & 0 & 0 & 0 & 0 & $\overline{0}$ \\
\hline Marlborough & $\mathrm{A}$ & $F$ & 0 & 0 & 0 & $\overline{0}$ & 0 & 0 \\
\hline Marlborough & $\mathrm{B}$ & $F$ & 0 & 0 & 0 & 0 & 0 & 0 \\
\hline Marlborough & $\mathrm{C}$ & $\bar{F}$ & 0 & 0 & 0 & 0 & 0 & 0 \\
\hline Marlborough & $\overline{\mathrm{D}}$ & $\bar{F}$ & 0 & 0 & 0 & 0 & 0 & 0 \\
\hline Marlborough & $\mathrm{E}$ & $F$ & 0 & 0 & 0 & 0 & 0 & 0 \\
\hline Marlborough & $F$ & $\bar{F}$ & 0 & 1 & 0 & 0 & 0 & 0 \\
\hline Marlborough & $\mathrm{H}$ & $F$ & 0 & 0 & 0 & 0 & 0 & 0 \\
\hline Marlborough & I & $\mathrm{F}$ & 0 & 0 & 0 & 0 & 0 & 0 \\
\hline Merivale & $\bar{A}$ & $\mathrm{SN}$ & 0 & 0 & 0 & 0 & 0 & 0 \\
\hline Merivale & $\mathrm{B}$ & $\overline{\mathrm{SN}}$ & 0 & 0 & 0 & 0 & 0 & 0 \\
\hline Merivale & C & $\overline{\mathrm{SN}}$ & 0 & 0 & 15 & 0 & 1 & 1 \\
\hline Merivale & $\mathrm{D}$ & SN & 0 & 0 & 0 & 0 & 0 & 0 \\
\hline Merivale & $\mathrm{E}$ & $\mathrm{SN}$ & 0 & 0 & 0 & 0 & 4 & 0 \\
\hline Merivale & $F$ & SN & 0 & 0 & 0 & 0 & 0 & 0 \\
\hline Merivale & $\mathrm{H}$ & $\overline{\mathrm{SN}}$ & 0 & 5 & 0 & 0 & 17 & 1 \\
\hline Merivale & I & SN & 0 & 0 & 0 & 0 & 1 & 1 \\
\hline Parc_Champlain & A & $\mathrm{S}$ & 0 & 0 & 0 & 0 & 0 & 0 \\
\hline Parc_Champlain & B & $\mathrm{S}$ & 0 & 0 & 0 & 0 & 0 & 0 \\
\hline Parc_Champlain & $\mathrm{C}$ & $\mathrm{S}$ & 0 & 0 & 0 & 0 & 0 & 0 \\
\hline Parc_Champlain & $\mathrm{D}$ & $\mathrm{S}$ & 0 & 0 & 0 & 0 & 0 & 0 \\
\hline Parc_Champlain & $\mathrm{E}$ & $\mathrm{S}$ & 0 & 0 & 0 & 0 & 0 & 0 \\
\hline Parc_Champlain & $\bar{F}$ & $\mathrm{~S}$ & 0 & 0 & 0 & 1 & 0 & 0 \\
\hline Parc_Champlain & $\mathrm{H}$ & $\mathrm{S}$ & 0 & 0 & 0 & 0 & 0 & 0 \\
\hline Parc_Champlain & I & $S$ & 0 & 0 & 0 & 0 & 0 & 0 \\
\hline PineGlen_Annex & $\bar{A}$ & $\bar{S}$ & 0 & 0 & 0 & 0 & 0 & 0 \\
\hline PineGlen_Annex & $\bar{B}$ & $\mathrm{~S}$ & 0 & 0 & 0 & 0 & 0 & 0 \\
\hline PineGlen_Annex & $\mathrm{C}$ & $\mathrm{S}$ & 0 & 0 & 0 & 0 & 0 & 0 \\
\hline PineGlen_Annex & $\bar{D}$ & $\mathrm{~S}$ & 0 & 0 & 0 & 0 & 0 & 0 \\
\hline PineGlen_Annex & $\mathrm{E}$ & $\mathrm{S}$ & 0 & 0 & 0 & 0 & 0 & 0 \\
\hline PineGlen_Annex & $F$ & $\mathrm{~S}$ & 0 & 0 & 0 & 0 & 0 & 0 \\
\hline PineGlen_Annex & $\mathrm{H}$ & $\mathrm{S}$ & 0 & 0 & 0 & 0 & 0 & 0 \\
\hline PineGlen_Annex & I & $\mathrm{S}$ & 0 & 0 & 0 & 0 & 0 & 0 \\
\hline Q_Four & $\bar{A}$ & $\bar{E}$ & 0 & 0 & 0 & 0 & 0 & 0 \\
\hline Q_Four & B & $\mathrm{E}$ & 0 & 0 & 0 & 0 & 0 & 0 \\
\hline Q_Four & $\bar{C}$ & $\bar{E}$ & 0 & 0 & 0 & 0 & 0 & 1 \\
\hline Q_Four & $\bar{D}$ & $\mathrm{E}$ & 0 & 0 & 0 & 0 & 0 & 0 \\
\hline Q_Four & $E$ & $\bar{E}$ & 0 & 0 & 0 & 0 & 0 & 0 \\
\hline Q_Four & $\bar{F}$ & $\bar{E}$ & 0 & 0 & 1 & 0 & 0 & 0 \\
\hline
\end{tabular}




\begin{tabular}{|c|c|c|c|c|c|c|c|c|}
\hline Q_Four & $\mathrm{H}$ & $E$ & 0 & 0 & 0 & 0 & 0 & 0 \\
\hline Q_Four & I & $E$ & 0 & 0 & 0 & 0 & 0 & 0 \\
\hline Sandy_Hill & $\overline{\mathrm{A}}$ & $\bar{U}$ & 0 & 0 & 0 & 0 & 0 & 0 \\
\hline Sandy_Hill & B & $\overline{\mathrm{U}}$ & 0 & 0 & 0 & $\overline{0}$ & 0 & $\overline{0}$ \\
\hline Sandy_Hill & $\mathrm{C}$ & $\overline{\mathrm{U}}$ & 0 & 0 & 0 & 0 & 0 & 0 \\
\hline Sandy_Hill & $\bar{D}$ & $\mathrm{U}$ & 0 & 0 & 0 & 0 & 0 & $\overline{0}$ \\
\hline Sandy_Hill & $\mathrm{E}$ & $\overline{\mathrm{U}}$ & 0 & 0 & 0 & 0 & 0 & 0 \\
\hline Sandy_Hill & $\bar{F}$ & $\overline{\mathrm{U}}$ & 0 & 0 & 0 & 0 & 0 & 0 \\
\hline Sandy_Hill & $\mathrm{H}$ & $\mathrm{U}$ & 0 & 0 & 0 & 0 & 0 & 0 \\
\hline Sandy_Hill & I & $\mathrm{U}$ & 0 & 0 & 0 & 0 & 0 & 0 \\
\hline Vallee_Meech & $\bar{A}$ & $\bar{F}$ & 0 & 0 & 0 & 0 & 0 & 0 \\
\hline Vallee_Meech & B & $\mathrm{F}$ & 0 & 0 & 0 & 0 & 0 & 0 \\
\hline Vallee_Meech & $\bar{C}$ & $\bar{F}$ & 0 & 0 & 0 & 0 & 0 & 0 \\
\hline Vallee_Meech & $\overline{\mathrm{D}}$ & $\bar{F}$ & 0 & 0 & 0 & 0 & 0 & 0 \\
\hline Vallee_Meech & $\mathrm{E}$ & $\mathrm{F}$ & 0 & 0 & 0 & 0 & 0 & 0 \\
\hline Vallee_Meech & $\bar{F}$ & $\mathrm{~F}$ & 0 & 0 & 0 & 0 & 0 & 0 \\
\hline Vallee_Meech & $\mathrm{H}$ & $\mathrm{F}$ & 0 & 0 & 0 & 0 & 0 & 0 \\
\hline Vallee_Meech & I & $\mathrm{F}$ & 0 & 0 & 0 & 0 & 0 & 0 \\
\hline Wolf_Grove & A & $\mathrm{E}$ & 0 & 0 & 0 & 0 & 0 & 0 \\
\hline Wolf_Grove & $\bar{B}$ & $E$ & 0 & 0 & 0 & 0 & 0 & 0 \\
\hline Wolf_Grove & $\mathrm{C}$ & $E$ & 0 & 0 & 0 & 0 & 0 & 0 \\
\hline Wolf_Grove & $\mathrm{D}$ & $\mathrm{E}$ & 0 & 0 & 0 & 0 & 0 & 0 \\
\hline Wolf_Grove & $\mathrm{E}$ & $\mathrm{E}$ & 0 & 0 & 0 & 0 & 0 & 0 \\
\hline Wolf_Grove & $\mathrm{F}$ & $\mathrm{E}$ & 0 & 0 & 0 & 0 & 0 & 0 \\
\hline Wolf_Grove & $\mathrm{H}$ & $E$ & 0 & 0 & 0 & 0 & 0 & 0 \\
\hline Wolf_Grove & I & $\mathrm{E}$ & 0 & 0 & 0 & 0 & 0 & 0 \\
\hline Wrightville & $\overline{\mathrm{A}}$ & $\overline{\mathrm{U}}$ & 0 & 0 & 0 & 0 & 0 & 0 \\
\hline Wrightville & B & $\bar{U}$ & 0 & 0 & 0 & 0 & 0 & 0 \\
\hline Wrightville & $\mathrm{C}$ & $\bar{U}$ & 0 & 0 & 0 & 0 & 0 & 0 \\
\hline Wrightville & $\bar{D}$ & $\overline{\mathrm{U}}$ & 0 & 0 & 0 & 0 & 0 & 0 \\
\hline Wrightville & $E$ & $\mathrm{U}$ & 0 & 0 & 0 & 0 & 0 & 0 \\
\hline Wrightville & $F$ & $\mathrm{U}$ & 0 & 0 & 0 & 0 & 0 & 0 \\
\hline Wrightville & $\mathrm{H}$ & $\mathrm{U}$ & 0 & 0 & 0 & 0 & 0 & 0 \\
\hline Wrightville & I & $\bar{U}$ & 0 & 0 & 0 & 0 & 0 & 0 \\
\hline Wychwood & $\mathrm{A}$ & $\mathrm{S}$ & 0 & 0 & 0 & 0 & 0 & 0 \\
\hline Wychwood & B & $\mathrm{S}$ & 0 & 0 & 0 & 0 & 0 & 0 \\
\hline Wychwood & $\mathrm{C}$ & $\mathrm{S}$ & 0 & 0 & 0 & 4 & 0 & 0 \\
\hline Wychwood & $\mathrm{D}$ & $\mathrm{S}$ & 0 & 0 & 0 & 0 & 0 & 0 \\
\hline Wychwood & $E$ & $\mathrm{~S}$ & 0 & 0 & 0 & 0 & 0 & $\overline{0}$ \\
\hline Wychwood & $\mathrm{F}$ & $\mathrm{S}$ & 0 & 0 & 0 & 0 & 0 & 0 \\
\hline Wychwood & $\mathrm{H}$ & $\mathrm{S}$ & 0 & 0 & 0 & 0 & 0 & 0 \\
\hline Wychwood & I & $\mathrm{S}$ & 0 & 0 & 0 & 0 & 0 & 0 \\
\hline
\end{tabular}




\begin{tabular}{|c|c|c|c|c|c|c|c|c|}
\hline SITE & STATION & CATEGORY & AGTE & AGTR & AMAE & AMAN & AMAP & $\overline{A M C U}$ \\
\hline Achbar & A & $\mathrm{SN}$ & 0 & 0 & 0 & 0 & 0 & 0 \\
\hline Achbar & $\mathrm{B}$ & $\overline{\mathrm{SN}}$ & 0 & 0 & 0 & 0 & 0 & 0 \\
\hline Achbar & $\mathrm{C}$ & SN & 0 & 0 & 0 & 0 & 0 & $\overline{0}$ \\
\hline Achbar & $\overline{\mathrm{D}}$ & $\overline{\mathrm{SN}}$ & 0 & 0 & 0 & 0 & 0 & $\overline{0}$ \\
\hline Achbar & $\bar{E}$ & $\mathrm{SN}$ & 0 & 2 & 0 & 0 & 0 & $\overline{0}$ \\
\hline Achbar & $F$ & SN & 0 & 0 & 0 & 0 & 0 & 0 \\
\hline Achbar & $\mathrm{H}$ & $\overline{\mathrm{SN}}$ & 0 & 0 & 0 & 0 & 0 & $\overline{0}$ \\
\hline Achbar & I & SN & 0 & 0 & 0 & 0 & 0 & 0 \\
\hline Bridlewood & A & $\overline{\mathrm{UN}}$ & 0 & 0 & 0 & 0 & 0 & 0 \\
\hline Bridlewood & B & $\overline{\mathrm{UN}}$ & 0 & 0 & 0 & 0 & 0 & $\overline{0}$ \\
\hline Bridlewood & $\mathrm{C}$ & UN & 0 & 0 & 0 & 0 & 0 & 0 \\
\hline Bridlewood & $\mathrm{D}$ & $\overline{\mathrm{UN}}$ & 0 & 0 & 0 & 0 & 0 & 0 \\
\hline Bridlewood & $\mathrm{E}$ & UN & 0 & $\overline{0}$ & $\overline{0}$ & 0 & 0 & 0 \\
\hline Bridlewood & $\mathrm{F}$ & $\overline{\mathrm{UN}}$ & 0 & 1 & 0 & 0 & 0 & $\overline{0}$ \\
\hline Bridlewood & $\mathrm{H}$ & UN & 0 & 0 & 0 & 0 & 0 & $\overline{0}$ \\
\hline Bridlewood & I & $\overline{\mathrm{UN}}$ & 0 & $\overline{0}$ & 0 & 0 & 0 & 0 \\
\hline Carp_Hills & $\bar{A}$ & $\mathrm{~F}$ & 0 & 1 & 0 & 0 & 0 & 0 \\
\hline Carp_Hills & $\mathrm{B}$ & F & 0 & 1 & 0 & 0 & 0 & $\overline{0}$ \\
\hline Carp_Hills & $\mathrm{C}$ & $\mathrm{F}$ & 0 & 0 & 0 & 0 & 0 & 0 \\
\hline Carp_Hills & $\mathrm{D}$ & F & 0 & $\overline{0}$ & 0 & 0 & 0 & 1 \\
\hline Carp_Hills & $\mathrm{E}$ & $F$ & 1 & 0 & 0 & 0 & 0 & 0 \\
\hline Carp_Hills & $\mathrm{F}$ & $\mathrm{F}$ & 0 & 0 & 0 & 0 & 0 & 0 \\
\hline Carp_Hills & $\mathrm{H}$ & $\mathrm{F}$ & 0 & 0 & 0 & 0 & 0 & 0 \\
\hline Carp_Hills & I & $\bar{F}$ & 0 & 0 & 0 & 0 & 0 & 0 \\
\hline Chapel_Hill & A & $\overline{\mathrm{UN}}$ & 0 & 0 & 0 & 0 & 0 & $\overline{0}$ \\
\hline Chapel_Hill & B & $\overline{\mathrm{UN}}$ & 0 & 0 & $\overline{0}$ & 0 & 0 & 0 \\
\hline Chapel_Hill & $\mathrm{C}$ & $\overline{\mathrm{UN}}$ & 0 & 0 & 0 & 0 & 0 & $\overline{0}$ \\
\hline Chapel_Hill & $\mathrm{D}$ & $\overline{\mathrm{UN}}$ & 0 & 0 & 0 & 0 & 0 & 0 \\
\hline Chapel_Hill & $\mathrm{E}$ & $\overline{\mathrm{UN}}$ & 0 & 5 & 0 & 0 & 0 & 0 \\
\hline Chapel_Hill & $\mathrm{F}$ & $\overline{U N}$ & 0 & 0 & 0 & 0 & 0 & 0 \\
\hline Chapel_Hill & $\mathrm{H}$ & $\overline{\mathrm{UN}}$ & 0 & 0 & 0 & 0 & 0 & $\overline{0}$ \\
\hline Chapel_Hill & I & UN & 0 & 9 & 0 & 0 & 0 & 0 \\
\hline Chelsea & $\mathrm{A}$ & $\mathrm{SN}$ & 0 & 0 & 0 & 0 & 0 & 0 \\
\hline Chelsea & $\mathrm{B}$ & $\mathrm{SN}$ & 0 & 0 & 0 & 0 & 0 & 0 \\
\hline Chelsea & $\mathrm{C}$ & SN & 0 & 0 & 0 & 0 & 0 & 0 \\
\hline Chelsea & $\mathrm{D}$ & $\mathrm{SN}$ & 0 & 0 & 0 & 0 & 0 & 0 \\
\hline Chelsea & $\mathrm{E}$ & $\mathrm{SN}$ & 0 & 0 & 0 & 0 & 0 & 0 \\
\hline Chelsea & $F$ & $\mathrm{SN}$ & 0 & 0 & 0 & 0 & 0 & 0 \\
\hline Chelsea & $\mathrm{H}$ & SN & 0 & 0 & 0 & 0 & 0 & 0 \\
\hline Chelsea & I & SN & 0 & 0 & 0 & 0 & 0 & 0 \\
\hline Cote_d'Azur & $\mathrm{A}$ & $S$ & 0 & 0 & 0 & 0 & 0 & 0 \\
\hline Cote_d'Azur & $\mathrm{B}$ & $S$ & 0 & 0 & 1 & 0 & 0 & 0 \\
\hline Cote_d'Azur & $\mathrm{C}$ & $S$ & 0 & 0 & 0 & 0 & 0 & 0 \\
\hline
\end{tabular}




\begin{tabular}{|c|c|c|c|c|c|c|c|c|}
\hline Cote_d'Azur & $\bar{D}$ & $\mathrm{~S}$ & 0 & 0 & 0 & 0 & 0 & 0 \\
\hline Cote_d'Azur & $\bar{E}$ & $\mathrm{~S}$ & 0 & 0 & 0 & 0 & 0 & 0 \\
\hline Cote_d'Azur & $F$ & $\mathrm{~S}$ & 0 & 0 & 0 & 0 & $\overline{0}$ & 0 \\
\hline Cote_d'Azur & $\mathrm{H}$ & $\mathrm{S}$ & 0 & 0 & 0 & 0 & 0 & 0 \\
\hline Cote_d'Azur & I & $\mathrm{S}$ & 0 & 0 & 4 & 0 & 0 & 0 \\
\hline Highway_Seven & $\bar{A}$ & $\bar{E}$ & 0 & 0 & 0 & 0 & 0 & 0 \\
\hline Highway_Seven & B & $\mathrm{E}$ & 0 & 0 & 0 & 0 & 0 & 0 \\
\hline Highway_Seven & $\mathrm{C}$ & $\bar{E}$ & 0 & 1 & 0 & 0 & 0 & 0 \\
\hline Highway_Seven & $\bar{D}$ & $\mathrm{E}$ & 0 & 0 & 3 & 0 & 0 & 2 \\
\hline Highway_Seven & $\bar{E}$ & $\bar{E}$ & 0 & 0 & 0 & 0 & 0 & 0 \\
\hline Highway_Seven & $\mathrm{F}$ & $\mathrm{E}$ & 0 & 0 & 0 & 0 & 0 & 0 \\
\hline Highway_Seven & $\overline{\mathrm{H}}$ & $\bar{E}$ & 0 & 0 & 0 & 0 & 0 & 0 \\
\hline Highway_Seven & I & $\bar{E}$ & 0 & 0 & 0 & 0 & 0 & 0 \\
\hline Hull & $\bar{A}$ & $\bar{U}$ & 0 & 0 & 0 & 0 & 0 & 0 \\
\hline Hull & $\bar{B}$ & $\mathrm{U}$ & 0 & 1 & 0 & 0 & 0 & 0 \\
\hline Hull & $\mathrm{C}$ & $\bar{U}$ & 0 & 0 & 0 & 0 & 0 & 0 \\
\hline Hull & $\bar{D}$ & $\mathrm{U}$ & 0 & 0 & 0 & 0 & 0 & 0 \\
\hline Hull & $\mathrm{E}$ & $\mathrm{U}$ & 0 & 0 & 10 & 0 & 0 & 0 \\
\hline Hull & $\bar{F}$ & $\overline{\mathrm{U}}$ & 0 & 0 & 2 & 0 & 0 & 0 \\
\hline Hull & $\mathrm{H}$ & $\bar{U}$ & 0 & 0 & 0 & 0 & 0 & 0 \\
\hline Hull & I & $\overline{\mathrm{U}}$ & 0 & 0 & 1 & 0 & 0 & 0 \\
\hline Lac_Philippe & $\bar{A}$ & $\bar{F}$ & 0 & 0 & 0 & 0 & 0 & 0 \\
\hline Lac_Philippe & B & $\mathrm{F}$ & 0 & 0 & 0 & 0 & 0 & 0 \\
\hline Lac_Philippe & $\mathrm{C}$ & $\mathrm{F}$ & 0 & 0 & 0 & 0 & 0 & 0 \\
\hline Lac_Philippe & $\bar{D}$ & $F$ & 0 & 0 & 0 & 0 & 0 & 0 \\
\hline Lac_Philippe & $\mathrm{E}$ & $\mathrm{F}$ & 0 & 0 & 0 & 0 & 0 & 0 \\
\hline Lac_Philippe & $\bar{F}$ & $\mathrm{~F}$ & 0 & 0 & 0 & 0 & 0 & 0 \\
\hline Lac_Philippe & $\mathrm{H}$ & $\bar{F}$ & 0 & 0 & 0 & 0 & 0 & 0 \\
\hline Lac_Philippe & I & $\bar{F}$ & 0 & 0 & 0 & 0 & 0 & 0 \\
\hline Manoir_des_Trembles & $\bar{A}$ & $\overline{\mathrm{UN}}$ & 0 & 0 & 0 & 0 & 0 & 0 \\
\hline Manoir_des_Trembles & B & UN & 0 & 0 & 0 & 0 & 0 & 0 \\
\hline Manoir_des_Trembles & $\bar{C}$ & $\overline{\mathrm{UN}}$ & 0 & 12 & 0 & 0 & 0 & 0 \\
\hline Manoir_des_Trembles & $\bar{D}$ & UN & 0 & 1 & 0 & 0 & 0 & 0 \\
\hline Manoir_des_Trembles & $\bar{E}$ & $\overline{\mathrm{UN}}$ & 0 & 4 & 0 & 0 & 0 & 0 \\
\hline Manoir_des_Trembles & $\mathrm{F}$ & UN & 0 & 0 & 0 & 0 & 0 & 0 \\
\hline Manoir_des_Trembles & $\mathrm{H}$ & UN & 0 & 0 & 0 & 0 & 0 & 0 \\
\hline Manoir_des_Trembles & I & $\overline{\mathrm{UN}}$ & 0 & 0 & 0 & 0 & 0 & 0 \\
\hline Marathon & $\bar{A}$ & $E$ & 0 & 0 & 0 & 0 & 0 & 0 \\
\hline Marathon & B & $E$ & $\overline{0}$ & 0 & 0 & 0 & 0 & 0 \\
\hline Marathon & $\mathrm{C}$ & $E$ & 0 & 0 & 0 & 0 & 0 & 0 \\
\hline Marathon & $\bar{D}$ & $E$ & 0 & 0 & 0 & 0 & 0 & 0 \\
\hline Marathon & $\mathrm{E}$ & $E$ & 0 & 0 & 0 & 0 & 0 & $\overline{0}$ \\
\hline Marathon & $F$ & $E$ & 0 & 0 & 0 & 0 & 0 & 0 \\
\hline Marathon & $\overline{\mathrm{H}}$ & $\bar{E}$ & 0 & 1 & 0 & 0 & 0 & 0 \\
\hline
\end{tabular}




\begin{tabular}{|c|c|c|c|c|c|c|c|c|}
\hline Marathon & I & $\mathrm{E}$ & 0 & 0 & 0 & 0 & 0 & 0 \\
\hline Marier & $\mathrm{A}$ & U & 0 & 0 & 0 & 0 & 4 & $\overline{0}$ \\
\hline Marier & B & $\overline{\mathrm{U}}$ & 0 & 0 & 7 & 1 & 0 & $\overline{0}$ \\
\hline Marier & $\mathrm{C}$ & $\mathrm{U}$ & 0 & 0 & 0 & 0 & 0 & $\overline{0}$ \\
\hline Marier & $\bar{D}$ & $\bar{U}$ & 0 & 0 & 2 & 0 & 1 & $\overline{0}$ \\
\hline Marier & $E$ & $\mathrm{U}$ & 0 & 0 & 0 & 0 & 0 & 0 \\
\hline Marier & $\bar{F}$ & $\bar{U}$ & 0 & 0 & $\overline{0}$ & 0 & $\overline{0}$ & $\overline{0}$ \\
\hline Marier & $\mathrm{H}$ & $\overline{\mathrm{U}}$ & 0 & 0 & 0 & 0 & 0 & $\overline{0}$ \\
\hline Marier & I & $\mathrm{U}$ & 0 & 0 & 0 & 0 & 0 & 0 \\
\hline Marlborough & $\bar{A}$ & $\mathrm{~F}$ & 0 & 0 & 0 & 0 & 0 & $\overline{0}$ \\
\hline Marlborough & B & $\bar{F}$ & 0 & 0 & 0 & 0 & 0 & 0 \\
\hline Marlborough & $\bar{C}$ & $\mathrm{~F}$ & 0 & 0 & 0 & 0 & 0 & $\overline{0}$ \\
\hline Marlborough & $\bar{D}$ & $\bar{F}$ & 0 & 0 & 0 & 0 & 0 & 0 \\
\hline Marlborough & $\bar{E}$ & F & 0 & 0 & 0 & 0 & 0 & 0 \\
\hline Marlborough & $\mathrm{F}$ & $\mathrm{F}$ & 0 & 1 & 0 & 0 & 0 & 0 \\
\hline Marlborough & $\mathrm{H}$ & $\mathrm{F}$ & 0 & 0 & 0 & 0 & 0 & $\overline{0}$ \\
\hline Marlborough & I & $\bar{F}$ & 0 & 0 & 0 & 0 & 0 & 0 \\
\hline Merivale & $\bar{A}$ & $\overline{\mathrm{SN}}$ & 0 & 0 & 0 & 0 & 0 & $\overline{0}$ \\
\hline Merivale & B & $\overline{\mathrm{SN}}$ & 0 & 0 & 0 & 0 & 0 & $\overline{0}$ \\
\hline Merivale & $\mathrm{C}$ & SN & 0 & 0 & 0 & 0 & 0 & 0 \\
\hline Merivale & $\bar{D}$ & $\overline{\mathrm{SN}}$ & 0 & 0 & 0 & 0 & 0 & $\overline{0}$ \\
\hline Merivale & $\overline{\mathrm{E}}$ & $\overline{\mathrm{SN}}$ & 0 & 0 & 0 & 0 & 0 & $\overline{0}$ \\
\hline Merivale & $\bar{F}$ & $\overline{\mathrm{SN}}$ & 0 & 3 & 0 & 0 & 0 & $\overline{0}$ \\
\hline Merivale & $\mathrm{H}$ & $\overline{\mathrm{SN}}$ & 0 & 0 & 0 & 0 & 0 & 0 \\
\hline Merivale & I & $\overline{\mathrm{SN}}$ & 0 & 0 & 0 & 0 & 0 & $\overline{0}$ \\
\hline Parc_Champlain & $\bar{A}$ & $S$ & 0 & 0 & 4 & 0 & 0 & 0 \\
\hline Parc_Champlain & $\mathrm{B}$ & $\bar{S}$ & 0 & 0 & 0 & 0 & 0 & $\overline{0}$ \\
\hline Parc_Champlain & $\bar{C}$ & $\mathrm{~S}$ & 0 & 0 & 0 & 0 & 0 & 0 \\
\hline Parc_Champlain & $\bar{D}$ & $\bar{S}$ & 0 & 0 & 1 & 0 & 0 & $\overline{0}$ \\
\hline Parc_Champlain & $\bar{E}$ & $S$ & 0 & 0 & 0 & 0 & 0 & 0 \\
\hline Parc_Champlain & $\bar{F}$ & $\bar{S}$ & 0 & $\overline{0}$ & 0 & 0 & $\overline{0}$ & $\overline{0}$ \\
\hline Parc_Champlain & $\mathrm{H}$ & $\mathrm{S}$ & 0 & 0 & 0 & 1 & 0 & 0 \\
\hline Parc_Champlain & I & $\bar{S}$ & 0 & 0 & 0 & 0 & 0 & $\overline{0}$ \\
\hline PineGlen_Annex & $\bar{A}$ & $\mathrm{~S}$ & 0 & 0 & 0 & 0 & 0 & $\overline{0}$ \\
\hline PineGlen_Annex & $\mathrm{B}$ & $\bar{S}$ & 0 & 0 & 0 & 0 & 0 & $\overline{0}$ \\
\hline PineGlen_Annex & $\mathrm{C}$ & $\mathrm{S}$ & 0 & 0 & 19 & 0 & 0 & $\overline{0}$ \\
\hline PineGlen_Annex & $\bar{D}$ & $\mathrm{~S}$ & 0 & 0 & 0 & 0 & 0 & 0 \\
\hline PineGlen_Annex & $\mathrm{E}$ & $\mathbf{S}$ & 0 & 0 & 4 & 0 & 0 & $\overline{0}$ \\
\hline PineGlen_Annex & $\bar{F}$ & $\mathrm{~S}$ & 0 & 0 & 0 & 0 & 0 & $\overline{0}$ \\
\hline PineGlen_Annex & $\mathrm{H}$ & $\mathbf{S}$ & 0 & 0 & 0 & 0 & 0 & $\overline{0}$ \\
\hline PineGlen_Annex & I & $\mathrm{S}$ & 0 & 0 & 4 & 0 & 1 & $\overline{0}$ \\
\hline Q_Four & A & $\mathrm{E}$ & 0 & 0 & 0 & 0 & 0 & 0 \\
\hline Q_Four & $\bar{B}$ & $E$ & 0 & 0 & 0 & 0 & 0 & $\overline{0}$ \\
\hline Q_Four & $\mathrm{C}$ & $\bar{E}$ & 0 & 0 & 0 & 0 & 0 & 0 \\
\hline
\end{tabular}




\begin{tabular}{|c|c|c|c|c|c|c|c|c|}
\hline Q_Four & $\mathrm{D}$ & $\mathrm{E}$ & 0 & 0 & 0 & 0 & 0 & 0 \\
\hline Q_Four & $\bar{E}$ & $\bar{E}$ & 0 & 0 & 0 & 0 & 0 & 0 \\
\hline Q_Four & $\bar{F}$ & $\mathrm{E}$ & 0 & 0 & 0 & 0 & 0 & 0 \\
\hline Q_Four & $\mathrm{H}$ & $\bar{E}$ & 0 & 1 & $\overline{0}$ & 0 & 0 & 0 \\
\hline Q_Four & I & $\mathrm{E}$ & 0 & 0 & 0 & 0 & 0 & 0 \\
\hline Sandy_Hill & $\bar{A}$ & $\bar{U}$ & 0 & 0 & 1 & 0 & 0 & $\overline{0}$ \\
\hline Sandy_Hill & $\mathrm{B}$ & $\bar{U}$ & 0 & 0 & 0 & 0 & 1 & 0 \\
\hline Sandy_Hill & $\bar{C}$ & $\bar{U}$ & 0 & 0 & 1 & 0 & 0 & 0 \\
\hline Sandy_Hill & $\mathrm{D}$ & $\bar{U}$ & 0 & 0 & 0 & 0 & 0 & 0 \\
\hline Sandy_Hill & $\bar{E}$ & $\overline{\mathrm{U}}$ & 0 & 0 & 0 & 0 & 0 & 0 \\
\hline Sandy_Hill & $\mathrm{F}$ & $\bar{U}$ & 0 & 0 & 0 & 0 & 0 & 0 \\
\hline Sandy_Hill & $\mathrm{H}$ & $\overline{\mathrm{U}}$ & 0 & 0 & 0 & 0 & 0 & $\overline{0}$ \\
\hline Sandy_Hill & I & $\mathrm{U}$ & 0 & 0 & 0 & 0 & 0 & 0 \\
\hline Vallee_Meech & $\bar{A}$ & $\bar{F}$ & 0 & 0 & 0 & 0 & 0 & 0 \\
\hline Vallee_Meech & B & $F$ & 0 & 0 & 0 & 0 & 0 & 0 \\
\hline Vallee_Meech & $\mathrm{C}$ & $\bar{F}$ & 0 & 0 & 0 & 0 & 0 & $\overline{0}$ \\
\hline Vallee_Meech & $\mathrm{D}$ & $\mathrm{F}$ & 0 & 0 & 0 & 0 & 0 & 0 \\
\hline Vallee_Meech & $\bar{E}$ & $\bar{F}$ & 0 & 0 & 0 & $\overline{0}$ & 0 & $\overline{0}$ \\
\hline Vallee_Meech & $\mathrm{F}$ & $\mathrm{F}$ & 0 & 0 & 0 & 0 & 0 & 0 \\
\hline Vallee_Meech & $\mathrm{H}$ & $\mathrm{F}$ & 0 & 0 & 0 & 0 & 0 & 0 \\
\hline Vallee_Meech & I & $\mathrm{F}$ & 0 & 0 & 0 & 0 & 0 & 0 \\
\hline Wolf_Grove & $\bar{A}$ & $\bar{E}$ & $\overline{0}$ & 0 & 0 & 0 & 0 & $\overline{0}$ \\
\hline Wolf_Grove & $\bar{B}$ & $\mathrm{E}$ & 0 & 0 & 0 & 0 & 0 & 0 \\
\hline Wolf_Grove & $\mathrm{C}$ & $\mathrm{E}$ & 0 & 0 & 0 & 0 & 0 & 0 \\
\hline Wolf_Grove & $\bar{D}$ & $\mathrm{E}$ & 0 & 0 & 0 & 0 & 0 & 0 \\
\hline Wolf_Grove & $\bar{E}$ & $\bar{E}$ & 0 & 0 & 0 & 0 & 0 & 0 \\
\hline Wolf_Grove & $\mathrm{F}$ & $\mathrm{E}$ & 0 & 1 & 0 & 0 & 0 & 0 \\
\hline Wolf_Grove & $\overline{\mathrm{H}}$ & $\bar{E}$ & 0 & 0 & 0 & 0 & 0 & 0 \\
\hline Wolf_Grove & I & $\mathrm{E}$ & 0 & 0 & 0 & 0 & 0 & 0 \\
\hline Wrightville & $\bar{A}$ & $\bar{U}$ & 0 & 0 & 7 & 0 & 2 & 0 \\
\hline Wrightville & $\mathrm{B}$ & $\mathrm{U}$ & 0 & 0 & 0 & 0 & 0 & 1 \\
\hline Wrightville & $\bar{C}$ & $\overline{\mathrm{U}}$ & 0 & 0 & 0 & 0 & 0 & 0 \\
\hline Wrightville & $\mathrm{D}$ & $\mathrm{U}$ & 0 & 0 & 0 & 0 & 1 & 0 \\
\hline Wrightville & $\mathrm{E}$ & $\overline{\mathrm{U}}$ & 0 & 0 & 1 & 0 & 0 & 0 \\
\hline Wrightville & $\mathrm{F}$ & $\mathrm{U}$ & 0 & 0 & 0 & 0 & 0 & 0 \\
\hline Wrightville & $\mathrm{H}$ & $\mathrm{U}$ & 0 & 0 & 0 & 0 & 0 & 0 \\
\hline Wrightville & I & $\bar{U}$ & 0 & 0 & 0 & 0 & 0 & 0 \\
\hline Wychwood & $\mathrm{A}$ & $\mathrm{S}$ & 0 & 0 & 0 & 0 & 0 & 0 \\
\hline Wychwood & B & $S$ & 0 & 0 & 1 & 0 & 0 & 0 \\
\hline Wychwood & $\mathrm{C}$ & $\mathrm{S}$ & 0 & 0 & 0 & 0 & 0 & 0 \\
\hline Wychwood & $\mathrm{D}$ & $S$ & 0 & 0 & 0 & 0 & 0 & 0 \\
\hline Wychwood & $\mathrm{E}$ & $\mathrm{S}$ & 0 & 0 & 0 & 0 & 0 & 0 \\
\hline Wychwood & $\mathrm{F}$ & $\mathrm{S}$ & 0 & 0 & 1 & 0 & 0 & 0 \\
\hline Wychwood & $\mathrm{H}$ & $\mathrm{S}$ & 0 & 0 & 0 & 0 & 0 & 0 \\
\hline
\end{tabular}




\begin{tabular}{|l|l|l|r|r|r|r|r|r|}
\hline Wychwood & I & S & 0 & 0 & 0 & 0 & 0 & 0 \\
\hline
\end{tabular}




\begin{tabular}{|c|c|c|c|c|c|c|c|c|}
\hline SITE & STATION & CATEGORY & AMIM & AMIN & AMPA & AMRU & ANHA & ANKI \\
\hline Achbar & $\mathrm{A}$ & SN & 0 & 0 & 0 & 0 & 0 & 0 \\
\hline Achbar & B & SN & 0 & 0 & 0 & 0 & 0 & 0 \\
\hline Achbar & $\mathrm{C}$ & SN & 0 & 0 & 0 & 0 & 0 & 0 \\
\hline Achbar & $\mathrm{D}$ & SN & 0 & 0 & 0 & 0 & 0 & 0 \\
\hline Achbar & $E$ & SN & 0 & 1 & 0 & 0 & 0 & $\overline{0}$ \\
\hline Achbar & $\mathrm{F}$ & SN & 0 & 0 & 0 & 0 & 0 & 0 \\
\hline Achbar & $\mathrm{H}$ & $\overline{\text { SN }}$ & 0 & 0 & 0 & 0 & 0 & 0 \\
\hline Achbar & I & SN & 0 & 0 & 0 & 0 & 0 & 0 \\
\hline Bridlewood & A & UN & 0 & 0 & $\overline{0}$ & 0 & 0 & $\overline{0}$ \\
\hline Bridlewood & $\mathrm{B}$ & UN & 0 & 0 & 0 & 0 & 0 & 0 \\
\hline Bridlewood & $\bar{C}$ & UN & 0 & 0 & 0 & 0 & 0 & $\overline{0}$ \\
\hline Bridlewood & $\mathrm{D}$ & $\mathrm{UN}$ & 0 & 0 & 0 & 0 & 0 & 0 \\
\hline Bridlewood & $E$ & UN & 0 & 0 & 0 & 0 & 0 & 0 \\
\hline Bridlewood & $\mathrm{F}$ & UN & 0 & 0 & 0 & 0 & 0 & 0 \\
\hline Bridlewood & $\mathrm{H}$ & UN & 0 & 0 & 0 & 0 & 0 & 0 \\
\hline Bridlewood & I & UN & 0 & 0 & 0 & 0 & 0 & 0 \\
\hline Carp_Hills & A & $F$ & 0 & 0 & 0 & 0 & 0 & 0 \\
\hline Carp_Hills & B & $F$ & 0 & 0 & 0 & 0 & 0 & 0 \\
\hline Carp_Hills & $\mathrm{C}$ & $\mathrm{F}$ & 0 & 0 & 0 & 0 & 0 & 0 \\
\hline Carp_Hills & $\overline{\mathrm{D}}$ & $F$ & 0 & 0 & 0 & 0 & 0 & 0 \\
\hline Carp_Hills & $E$ & $\mathrm{~F}$ & 0 & 0 & 0 & 0 & 0 & 0 \\
\hline Carp_Hills & $\bar{F}$ & $F$ & 0 & 0 & 0 & 0 & 0 & 0 \\
\hline Carp_Hills & $\mathrm{H}$ & $F$ & 0 & 0 & 0 & 0 & 0 & 0 \\
\hline Carp_Hills & I & $F$ & 0 & 0 & 0 & 0 & 0 & 0 \\
\hline Chapel_Hill & $\bar{A}$ & UN & 0 & 0 & 0 & 0 & 0 & 0 \\
\hline Chapel_Hill & $\mathrm{B}$ & $\mathrm{UN}$ & 0 & 7 & 0 & 0 & 0 & 0 \\
\hline Chapel_Hill & $\mathrm{C}$ & UN & 0 & 1 & 0 & 0 & 0 & 0 \\
\hline Chapel_Hill & $\bar{D}$ & $\overline{\mathrm{UN}}$ & 0 & 2 & 0 & 0 & 0 & 0 \\
\hline Chapel_Hill & $\bar{E}$ & $\mathrm{UN}$ & 0 & 0 & 0 & 0 & 0 & 0 \\
\hline Chapel_Hill & $\mathrm{F}$ & UN & 0 & 0 & 0 & 0 & 0 & 0 \\
\hline Chapel_Hill & $\mathrm{H}$ & UN & 0 & 4 & 0 & 0 & 0 & 0 \\
\hline Chapel_Hill & $\bar{I}$ & $\mathrm{UN}$ & 0 & 0 & 0 & 0 & 0 & 0 \\
\hline Chelsea & $\mathrm{A}$ & $\mathrm{SN}$ & 0 & 0 & 0 & 0 & 0 & 0 \\
\hline Chelsea & $\mathrm{B}$ & SN & 0 & 0 & 0 & 0 & 0 & 0 \\
\hline Chelsea & $\mathrm{C}$ & SN & $\overline{0}$ & 0 & 0 & 0 & 0 & 0 \\
\hline Chelsea & $\mathrm{D}$ & SN & 0 & 0 & 0 & 0 & 0 & 0 \\
\hline Chelsea & $\mathrm{E}$ & SN & 0 & 0 & 0 & 0 & 0 & 0 \\
\hline Chelsea & $\mathrm{F}$ & SN & 0 & 0 & 0 & 0 & 0 & 0 \\
\hline Chelsea & $\mathrm{H}$ & SN & 0 & 0 & 0 & 0 & 0 & $\overline{0}$ \\
\hline Chelsea & I & SN & 0 & 0 & 0 & 0 & 0 & 0 \\
\hline Cote_d'Azur & A & $\mathrm{S}$ & 0 & 0 & 0 & 0 & 0 & 0 \\
\hline Cote_d'Azur & $\mathrm{B}$ & $\mathrm{S}$ & 0 & 0 & 0 & 0 & 1 & 0 \\
\hline Cote_d'Azur & $\mathrm{C}$ & $\mathrm{S}$ & 0 & 0 & 0 & 0 & 0 & 0 \\
\hline
\end{tabular}




\begin{tabular}{|c|c|c|c|c|c|c|c|c|}
\hline Cote_d'Azur & $\mathrm{D}$ & $\mathrm{S}$ & 0 & 0 & 0 & 0 & 0 & 0 \\
\hline Cote_d'Azur & $E$ & $\mathrm{~S}$ & 0 & 0 & 0 & 0 & 0 & 0 \\
\hline Cote_d'Azur & $\bar{F}$ & $\mathrm{~S}$ & $\overline{0}$ & 4 & 0 & 0 & 0 & 0 \\
\hline Cote_d'Azur & $\mathrm{H}$ & $\bar{S}$ & 0 & 0 & 0 & 0 & 0 & 0 \\
\hline Cote_d'Azur & I & $\mathrm{S}$ & 0 & 0 & 0 & 0 & 0 & 0 \\
\hline Highway_Seven & $\bar{A}$ & $\mathrm{E}$ & 0 & 0 & 0 & 0 & 0 & 0 \\
\hline Highway_Seven & $\bar{B}$ & $\mathrm{E}$ & 0 & 0 & 0 & 0 & 0 & 0 \\
\hline Highway_Seven & $\mathrm{C}$ & $\mathrm{E}$ & 0 & 0 & 0 & 0 & 0 & 0 \\
\hline Highway_Seven & $\bar{D}$ & $\mathrm{E}$ & 0 & 0 & 0 & 0 & 0 & 0 \\
\hline Highway_Seven & $\bar{E}$ & $E$ & 0 & 0 & 0 & 0 & 2 & 0 \\
\hline Highway_Seven & $\bar{F}$ & $\bar{E}$ & 0 & 0 & 0 & 0 & 0 & 0 \\
\hline Highway_Seven & $\mathrm{H}$ & $\bar{E}$ & 0 & 0 & 0 & 0 & 0 & 0 \\
\hline Highway_Seven & I & $\mathrm{E}$ & 0 & 0 & 0 & 0 & 0 & 0 \\
\hline Hull & $\mathrm{A}$ & $\bar{U}$ & 0 & 0 & 0 & 0 & 0 & 0 \\
\hline Hull & $\mathrm{B}$ & $\overline{\mathrm{U}}$ & 0 & 0 & 0 & 0 & 0 & 0 \\
\hline Hull & $\mathrm{C}$ & $\mathrm{U}$ & 0 & 0 & 0 & 0 & 1 & 0 \\
\hline Hull & $\overline{\mathrm{D}}$ & $\bar{U}$ & 0 & 0 & 0 & 0 & 0 & 0 \\
\hline Hull & $\bar{E}$ & $\overline{\mathrm{U}}$ & 0 & 0 & 1 & 0 & 0 & 0 \\
\hline Hull & $\mathrm{F}$ & $\mathrm{U}$ & 0 & 0 & 0 & 0 & 2 & 0 \\
\hline Hull & $\mathrm{H}$ & $\mathrm{U}$ & 0 & 0 & 0 & 0 & 0 & 0 \\
\hline Hull & I & $\overline{\mathrm{U}}$ & 0 & 0 & 0 & 0 & 2 & 0 \\
\hline Lac_Philippe & $\bar{A}$ & $F$ & 0 & 0 & 0 & 0 & 0 & 0 \\
\hline Lac_Philippe & B & $\bar{F}$ & 0 & 0 & 0 & 0 & 0 & 0 \\
\hline Lac_Philippe & $\mathrm{C}$ & $\bar{F}$ & 0 & 0 & 0 & 0 & 0 & 0 \\
\hline Lac_Philippe & $\overline{\mathrm{D}}$ & $\bar{F}$ & 0 & 0 & 0 & 0 & 0 & $\overline{0}$ \\
\hline Lac_Philippe & $E$ & $F$ & 0 & 0 & 0 & 0 & 0 & 0 \\
\hline Lac_Philippe & $\mathrm{F}$ & $\mathrm{F}$ & 0 & 0 & 0 & 0 & 0 & 0 \\
\hline Lac_Philippe & $\mathrm{H}$ & $F$ & 0 & 0 & 0 & 0 & 0 & 0 \\
\hline Lac_Philippe & I & $\mathrm{F}$ & 0 & 0 & 0 & 0 & 0 & 0 \\
\hline Manoir_des_Trembles & $\mathrm{A}$ & $\overline{\mathrm{UN}}$ & 0 & 0 & 0 & 0 & 0 & $\overrightarrow{0}$ \\
\hline Manoir_des_Trembles & B & UN & 0 & 3 & 0 & 0 & 0 & 0 \\
\hline Manoir_des_Trembles & $\mathrm{C}$ & $\overline{\mathrm{UN}}$ & 0 & 1 & 0 & 0 & 0 & 0 \\
\hline Manoir_des_Trembles & $\bar{D}$ & UN & 0 & 0 & 0 & 0 & 0 & 0 \\
\hline Manoir_des_Trembles & $\mathrm{E}$ & UN & 0 & 1 & 0 & 0 & 0 & 0 \\
\hline Manoir_des_Trembles & $\bar{F}$ & $\overline{\mathrm{UN}}$ & 0 & 1 & 0 & 0 & 0 & 0 \\
\hline Manoir_des_Trembles & $\mathrm{H}$ & $\mathrm{UN}$ & 0 & 5 & 0 & 0 & 0 & 0 \\
\hline Manoir_des_Trembles & I & $\overline{\mathrm{UN}}$ & 0 & 0 & 0 & 0 & 0 & 0 \\
\hline Marathon & $\bar{A}$ & $\mathrm{E}$ & 0 & 0 & 0 & 0 & 0 & 0 \\
\hline Marathon & B & $\bar{E}$ & 0 & 0 & 0 & 0 & 0 & 0 \\
\hline Marathon & $\mathrm{C}$ & $\mathrm{E}$ & 0 & 0 & 0 & 0 & 0 & 0 \\
\hline Marathon & $\bar{D}$ & $\mathrm{E}$ & 0 & 0 & 0 & 0 & 0 & 0 \\
\hline Marathon & $\mathrm{E}$ & $E$ & 0 & 0 & 0 & 0 & 0 & 0 \\
\hline Marathon & $\bar{F}$ & $\bar{E}$ & 0 & 0 & 0 & 0 & 0 & 0 \\
\hline Marathon & $\mathrm{H}$ & $\mathrm{E}$ & 0 & 0 & 0 & 0 & 0 & 0 \\
\hline Marathon & I & $\bar{E}$ & 0 & 0 & 0 & 0 & 0 & 0 \\
\hline
\end{tabular}




\begin{tabular}{|c|c|c|c|c|c|c|c|c|}
\hline Marier & A & $\overline{\mathrm{U}}$ & 0 & 0 & 0 & 0 & 1 & $\overline{0}$ \\
\hline Marier & B & $\overline{\mathrm{U}}$ & 0 & 0 & 0 & 0 & 6 & $\overline{0}$ \\
\hline Marier & $\bar{C}$ & $\mathrm{U}$ & 0 & 0 & 0 & 0 & 0 & 0 \\
\hline Marier & $\mathrm{D}$ & $\overline{\mathrm{U}}$ & 0 & 0 & 0 & 0 & 0 & 0 \\
\hline Marier & $\mathrm{E}$ & $\bar{U}$ & 0 & 0 & 0 & 0 & 0 & $\overline{0}$ \\
\hline Marier & $\mathrm{F}$ & $\bar{U}$ & 0 & 0 & 0 & 0 & 3 & 0 \\
\hline Marier & $\overline{\mathrm{H}}$ & $\mathrm{U}$ & 0 & 0 & 0 & 0 & 0 & 0 \\
\hline Marier & I & $\overline{\mathrm{U}}$ & 0 & 0 & 0 & 0 & 0 & $\overline{0}$ \\
\hline Marlborough & $\bar{A}$ & $F$ & 0 & 0 & 0 & 0 & 0 & $\overline{0}$ \\
\hline Marlborough & $\bar{B}$ & $\mathrm{~F}$ & 0 & 0 & 0 & 0 & 0 & 0 \\
\hline Marlborough & $\overline{\mathrm{C}}$ & $F$ & 0 & 0 & 0 & 0 & 0 & 0 \\
\hline Marlborough & $\bar{D}$ & $F$ & 0 & 0 & 0 & 0 & 0 & $\overline{0}$ \\
\hline Marlborough & $\overline{\mathrm{E}}$ & $F$ & 0 & 0 & 0 & 0 & 0 & 0 \\
\hline Marlborough & $\mathrm{F}$ & $\mathrm{F}$ & 0 & 0 & 0 & 0 & 0 & $\overline{0}$ \\
\hline Marlborough & $\mathrm{H}$ & $\mathrm{F}$ & 0 & 0 & 0 & 0 & 0 & 0 \\
\hline Marlborough & I & $\bar{F}$ & 0 & 0 & 0 & 0 & 0 & 0 \\
\hline Merivale & $\bar{A}$ & $\overline{\mathrm{SN}}$ & 0 & 4 & 0 & 0 & 0 & 0 \\
\hline Merivale & B & SN & 0 & 0 & 0 & 0 & 0 & 0 \\
\hline Merivale & $\bar{C}$ & $\mathrm{SN}$ & 0 & 0 & 0 & 0 & 0 & 0 \\
\hline Merivale & $\overline{\mathrm{D}}$ & $\mathrm{SN}$ & 0 & 0 & 0 & 0 & 0 & 0 \\
\hline Merivale & $\mathrm{E}$ & SN & 0 & 0 & 0 & 0 & 0 & 0 \\
\hline Merivale & $\mathrm{F}$ & $\overline{\mathrm{SN}}$ & 0 & 2 & 0 & 0 & 0 & $\overline{0}$ \\
\hline Merivale & $\overline{\mathrm{H}}$ & $\mathrm{SN}$ & $\overline{0}$ & 0 & 0 & 0 & 0 & 0 \\
\hline Merivale & I & $\mathrm{SN}$ & 0 & 0 & 0 & 0 & 0 & $\overline{0}$ \\
\hline Parc_Champlain & $\bar{A}$ & $\mathbf{S}$ & 0 & 0 & 0 & 0 & 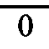 & 0 \\
\hline Parc_Champlain & B & $\bar{S}$ & 0 & 0 & 2 & 0 & 0 & $\overline{0}$ \\
\hline Parc_Champlain & $\bar{C}$ & $\mathrm{~S}$ & 0 & 0 & 0 & 0 & 0 & 0 \\
\hline Parc_Champlain & $\mathrm{D}$ & $S$ & 0 & 1 & 0 & 0 & 0 & $\overline{0}$ \\
\hline Parc_Champlain & $\mathrm{E}$ & $S$ & 0 & 0 & 0 & 0 & 0 & 0 \\
\hline Parc_Champlain & $\mathrm{F}$ & $S$ & 0 & 0 & 0 & 0 & 0 & 0 \\
\hline Parc_Champlain & $\mathrm{H}$ & $S$ & 1 & 0 & 0 & 0 & 4 & $\overline{0}$ \\
\hline Parc_Champlain & I & $S$ & 0 & 0 & 0 & 0 & $\overline{0}$ & 0 \\
\hline PineGlen_Annex & $\bar{A}$ & $S$ & 0 & 1 & 0 & 0 & 0 & 0 \\
\hline PineGlen_Annex & B & $S$ & 0 & 0 & 0 & 0 & 1 & 0 \\
\hline PineGlen_Annex & $\mathrm{C}$ & $S$ & 0 & 0 & 0 & 0 & 7 & 0 \\
\hline PineGlen_Annex & $\bar{D}$ & $S$ & 0 & 0 & 0 & 0 & 0 & 0 \\
\hline PineGlen_Annex & $\bar{E}$ & $\mathrm{~S}$ & 0 & 0 & 0 & 0 & 7 & 0 \\
\hline PineGlen_Annex & $F$ & $S$ & 0 & 1 & 0 & 0 & 0 & 0 \\
\hline PineGlen_Annex & $\mathrm{H}$ & $\mathrm{S}$ & 0 & 0 & 0 & 0 & 4 & 0 \\
\hline PineGlen_Annex & I & $\mathrm{S}$ & 1 & 2 & 0 & 0 & 0 & 0 \\
\hline Q_Four & A & $\bar{E}$ & 0 & 0 & 0 & 0 & 0 & 0 \\
\hline Q_Four & B & $\mathrm{E}$ & 0 & 0 & 0 & 0 & 0 & 0 \\
\hline Q_Four & $\mathrm{C}$ & $\mathrm{E}$ & 0 & 0 & 0 & 0 & 0 & 0 \\
\hline Q_Four & $\bar{D}$ & $\mathrm{E}$ & 0 & 0 & 0 & 0 & 0 & 0 \\
\hline Q_Four & $\bar{E}$ & $\bar{E}$ & 0 & 0 & 0 & 0 & 0 & 0 \\
\hline
\end{tabular}




\begin{tabular}{|c|c|c|c|c|c|c|c|c|}
\hline Q_Four & $F$ & $E$ & 0 & 0 & 0 & 0 & 0 & 0 \\
\hline Q_Four & $\mathrm{H}$ & $E$ & 0 & 0 & 0 & 0 & 0 & $\overline{0}$ \\
\hline Q_Four & $\mathrm{I}$ & $\mathrm{E}$ & 0 & 0 & 0 & 0 & 0 & 0 \\
\hline Sandy_Hill & $A$ & $\mathrm{U}$ & 0 & 0 & 0 & 0 & 0 & 0 \\
\hline Sandy_Hill & $\bar{B}$ & $\mathrm{U}$ & 0 & 0 & 0 & 0 & 0 & 0 \\
\hline Sandy_Hill & C & $\bar{U}$ & 0 & 0 & 0 & 0 & 0 & 0 \\
\hline Sandy_Hill & $\mathrm{D}$ & $\bar{U}$ & 0 & 0 & 0 & 0 & 0 & 0 \\
\hline Sandy_Hill & $\mathrm{E}$ & $\mathbf{U}$ & 0 & 0 & 0 & 0 & 0 & 0 \\
\hline Sandy_Hill & $F$ & $\mathrm{U}$ & 0 & 0 & 0 & 0 & 0 & $\overline{0}$ \\
\hline Sandy_Hill & $\mathrm{H}$ & $\bar{U}$ & 0 & 0 & 0 & 0 & 0 & 1 \\
\hline Sandy_Hill & I & $\mathbf{U}$ & 0 & 0 & 0 & 0 & 0 & 0 \\
\hline Vallee_Meech & $\bar{A}$ & $F$ & 0 & 0 & 0 & 0 & 0 & 0 \\
\hline Vallee_Meech & B & $F$ & 0 & 0 & 0 & 0 & 0 & 0 \\
\hline Vallee_Meech & $\bar{C}$ & $\bar{F}$ & 0 & 0 & 0 & 0 & 0 & 0 \\
\hline Vallee_Meech & $\mathrm{D}$ & $\mathrm{F}$ & 0 & 0 & 0 & 0 & 0 & 0 \\
\hline Vallee_Meech & $\mathrm{E}$ & $F$ & 0 & 0 & 0 & 0 & 0 & 0 \\
\hline Vallee_Meech & $\mathrm{F}$ & $F$ & 0 & 0 & 0 & 0 & 0 & 0 \\
\hline Vallee_Meech & $\mathrm{H}$ & $\bar{F}$ & 0 & 0 & 0 & 0 & 0 & 0 \\
\hline Vallee_Meech & I & $F$ & 0 & 0 & 0 & 0 & 0 & 0 \\
\hline Wolf_Grove & $\mathrm{A}$ & $\mathrm{E}$ & 0 & 0 & 0 & 0 & 0 & 0 \\
\hline Wolf_Grove & $\mathrm{B}$ & $E$ & 0 & 0 & 0 & 0 & 0 & 0 \\
\hline Wolf_Grove & $\mathrm{C}$ & $E$ & 0 & 0 & 0 & 0 & 0 & 0 \\
\hline Wolf_Grove & D & $\bar{E}$ & 0 & 0 & 0 & 0 & 0 & 0 \\
\hline Wolf_Grove & $E$ & $E$ & 0 & 0 & 0 & 0 & 0 & 0 \\
\hline Wolf_Grove & $\mathrm{F}$ & $\mathrm{E}$ & 0 & 0 & 0 & 0 & 0 & 0 \\
\hline Wolf_Grove & $\mathrm{H}$ & $E$ & 0 & 0 & 0 & 0 & 0 & 0 \\
\hline Wolf_Grove & I & $E$ & 0 & 0 & 0 & 0 & 0 & 0 \\
\hline Wrightville & $\mathrm{A}$ & $\mathrm{U}$ & 0 & 0 & 0 & 1 & 4 & 0 \\
\hline Wrightville & $\mathrm{B}$ & $\mathbf{U}$ & 0 & 0 & 0 & 0 & 0 & 0 \\
\hline Wrightville & $\mathrm{C}$ & $\bar{U}$ & 0 & 0 & 0 & 0 & 1 & 0 \\
\hline Wrightville & $\mathrm{D}$ & $\mathrm{U}$ & 0 & 0 & 0 & 0 & 0 & 0 \\
\hline Wrightville & $\bar{E}$ & $\mathrm{U}$ & 0 & 0 & 0 & 0 & 0 & 0 \\
\hline Wrightville & $\mathrm{F}$ & $\overline{\mathrm{U}}$ & 0 & 0 & 0 & 0 & 0 & 0 \\
\hline Wrightville & $\mathrm{H}$ & $\mathrm{U}$ & 0 & 0 & 0 & 0 & 0 & 0 \\
\hline Wrightville & I & $\mathbf{U}$ & 0 & 0 & 0 & 0 & 3 & 0 \\
\hline Wychwood & $\mathrm{A}$ & $\mathrm{S}$ & 0 & 0 & 0 & 0 & 2 & 0 \\
\hline Wychwood & $\mathrm{B}$ & $\mathrm{S}$ & 0 & 1 & 0 & 0 & 0 & 0 \\
\hline Wychwood & $\bar{C}$ & $\mathrm{~S}$ & 0 & 2 & 0 & 0 & 0 & 0 \\
\hline Wychwood & D & $\mathrm{S}$ & 0 & 2 & 0 & 0 & 0 & 0 \\
\hline Wychwood & $\mathbf{E}$ & $\mathrm{S}$ & 0 & 0 & 0 & 0 & 0 & 0 \\
\hline Wychwood & $\mathbf{F}$ & $\mathrm{S}$ & 0 & 0 & 0 & 0 & 0 & 0 \\
\hline Wychwood & $\mathrm{H}$ & $\mathrm{S}$ & 0 & 0 & 0 & 0 & 1 & 0 \\
\hline Wychwood & I & $\mathrm{S}$ & 0 & 0 & 0 & 0 & 1 & 0 \\
\hline
\end{tabular}




\begin{tabular}{|c|c|c|c|c|c|c|c|c|}
\hline SITE & STATION & CATEGORY & ANME & ANRU & ANVE & BANO & BAOC & BEFR \\
\hline Achbar & $\mathrm{A}$ & SN & 0 & 0 & 0 & 0 & 0 & 0 \\
\hline Achbar & $\bar{B}$ & SN & 0 & 0 & 0 & 0 & 0 & $\overline{0}$ \\
\hline Achbar & $\bar{C}$ & $\overline{\mathrm{SN}}$ & 0 & 0 & 0 & 0 & 0 & 0 \\
\hline Achbar & D & $\overline{\mathrm{SN}}$ & 0 & 0 & $\overline{0}$ & $\overline{0}$ & $\overline{0}$ & $\overline{0}$ \\
\hline Achbar & $\bar{E}$ & $\overline{\mathrm{SN}}$ & 0 & 0 & 0 & 0 & 0 & 0 \\
\hline Achbar & $F$ & SN & 0 & 0 & 0 & 0 & 0 & 0 \\
\hline Achbar & $\mathrm{H}$ & $\mathrm{SN}$ & 0 & 0 & 0 & 0 & 0 & 0 \\
\hline Achbar & I & $\mathrm{SN}$ & 0 & 0 & 0 & 0 & 0 & 0 \\
\hline Bridlewood & $\bar{A}$ & UN & 0 & 0 & $\overline{0}$ & 0 & 0 & $\overline{0}$ \\
\hline Bridlewood & $\bar{B}$ & UN & 0 & 0 & 0 & 0 & 0 & 0 \\
\hline Bridlewood & $\mathrm{C}$ & UN & 0 & 0 & 0 & 0 & 0 & 0 \\
\hline Bridlewood & $\mathrm{D}$ & UN & 0 & 0 & 0 & 0 & 0 & 0 \\
\hline Bridlewood & $\bar{E}$ & UN & 0 & 0 & 0 & 0 & 0 & 0 \\
\hline Bridlewood & $\mathrm{F}$ & UN & 0 & 0 & 0 & 0 & 0 & $\overline{0}$ \\
\hline Bridlewood & $\overline{\mathrm{H}}$ & UN & 0 & 0 & 0 & 0 & 0 & 0 \\
\hline Bridlewood & I & UN & 0 & 0 & 0 & 0 & 0 & 0 \\
\hline Carp_Hills & $\mathrm{A}$ & $\bar{F}$ & 0 & 0 & 0 & 0 & 0 & 0 \\
\hline Carp_Hills & $\bar{B}$ & $\bar{F}$ & 0 & 0 & 0 & 0 & 0 & 0 \\
\hline Carp_Hills & $\mathrm{C}$ & F & 0 & 0 & 0 & 0 & 0 & 0 \\
\hline Carp_Hills & $\bar{D}$ & $F$ & 0 & 0 & 0 & 0 & 0 & 0 \\
\hline Carp_Hills & $E$ & $\mathrm{~F}$ & 0 & 0 & 0 & 0 & 0 & $\overline{0}$ \\
\hline Carp_Hills & $\bar{F}$ & $\bar{F}$ & 0 & 0 & 0 & 0 & 0 & $\overline{0}$ \\
\hline Carp_Hills & $\overline{\mathrm{H}}$ & $\bar{F}$ & 0 & 0 & 0 & 0 & 0 & 0 \\
\hline Carp_Hills & I & $\mathrm{F}$ & 0 & 0 & 0 & 0 & 0 & 0 \\
\hline Chapel_Hill & A & UN & 0 & 0 & 0 & 0 & 0 & $\overline{0}$ \\
\hline Chapel_Hill & B & UN & 0 & 0 & 0 & 0 & 0 & $\overline{0}$ \\
\hline Chapel_Hill & $\mathrm{C}$ & UN & 0 & 0 & 0 & 0 & 0 & $\overline{0}$ \\
\hline Chapel_Hill & $\bar{D}$ & UN & 0 & $\overline{0}$ & 0 & 0 & 0 & $\overline{0}$ \\
\hline Chapel_Hill & $\bar{E}$ & UN & 0 & 0 & 0 & 0 & 0 & 0 \\
\hline Chapel_Hill & $\mathrm{F}$ & UN & 0 & 0 & 0 & 0 & 0 & 0 \\
\hline Chapel_Hill & $\mathrm{H}$ & UN & 0 & 0 & 0 & 0 & 0 & 0 \\
\hline Chapel_Hill & I & UN & 0 & 0 & 0 & 0 & 0 & $\overline{0}$ \\
\hline Chelsea & $\mathrm{A}$ & SN & 0 & 0 & 0 & 0 & 0 & $\overline{0}$ \\
\hline Chelsea & $\bar{B}$ & $\overline{\mathrm{SN}}$ & 0 & 0 & 0 & 0 & 0 & $\overline{0}$ \\
\hline Chelsea & $\mathrm{C}$ & $\mathrm{SN}$ & 0 & 0 & 0 & 0 & 0 & $\overline{0}$ \\
\hline Chelsea & $\mathrm{D}$ & SN & 0 & 0 & 0 & 0 & 0 & 0 \\
\hline Chelsea & $\mathrm{E}$ & SN & 0 & 0 & 0 & 0 & 0 & $\overline{0}$ \\
\hline Chelsea & $\mathrm{F}$ & SN & 0 & 0 & 0 & 0 & 0 & 0 \\
\hline Chelsea & $\mathrm{H}$ & $\overline{\mathrm{SN}}$ & 0 & 0 & 0 & 0 & 0 & $\overline{0}$ \\
\hline Chelsea & I & $\mathrm{SN}$ & 0 & 0 & 0 & 0 & 0 & $\overline{0}$ \\
\hline Cote_d'Azur & A & $\mathrm{S}$ & 0 & 0 & 0 & 0 & 0 & 0 \\
\hline Cote_d'Azur & B & $\mathrm{S}$ & 0 & 0 & 0 & 0 & 0 & 0 \\
\hline Cote_d'Azur & $\bar{C}$ & $S$ & 0 & 1 & 0 & 0 & 0 & 0 \\
\hline Cote_d'Azur & $\overline{\mathrm{D}}$ & $\mathrm{S}$ & 0 & 0 & 0 & 0 & 0 & 0 \\
\hline
\end{tabular}




\begin{tabular}{|c|c|c|c|c|c|c|c|c|}
\hline Cote_d'Azur & $\mathrm{E}$ & $\mathrm{S}$ & 0 & 0 & 0 & 0 & 0 & 0 \\
\hline Cote_d'Azur & $\mathrm{F}$ & $\mathrm{S}$ & 0 & 0 & 0 & 0 & 0 & 0 \\
\hline Cote_d'Azur & $\mathrm{H}$ & $\mathrm{S}$ & 0 & 0 & 0 & 0 & 0 & 0 \\
\hline Cote_d'Azur & I & $\mathrm{S}$ & 0 & 0 & 0 & 0 & 0 & 0 \\
\hline Highway_Seven & A & $\mathrm{E}$ & 0 & 0 & 0 & 0 & $\mathbf{0}$ & 2 \\
\hline Highway_Seven & B & $\mathrm{E}$ & 0 & 0 & 0 & 0 & 0 & 0 \\
\hline Highway_Seven & $\bar{C}$ & $\bar{E}$ & 0 & 0 & 0 & 0 & 0 & 0 \\
\hline Highway_Seven & $\bar{D}$ & $\bar{E}$ & 0 & 0 & 0 & 0 & 0 & 0 \\
\hline Highway_Seven & $\mathrm{E}$ & $\mathrm{E}$ & 0 & 0 & 0 & 0 & 0 & 0 \\
\hline Highway_Seven & $\bar{F}$ & $\mathrm{E}$ & 0 & $\overline{0}$ & 0 & 0 & 0 & 0 \\
\hline Highway_Seven & $\mathrm{H}$ & $\mathrm{E}$ & 0 & 1 & 0 & 0 & 0 & 0 \\
\hline Highway_Seven & I & $\mathrm{E}$ & 0 & 0 & 0 & 0 & 0 & 0 \\
\hline Hull & $\bar{A}$ & $\bar{U}$ & 0 & 0 & 0 & $\overline{0}$ & 0 & $\overline{0}$ \\
\hline Hull & B & $\bar{U}$ & 0 & 0 & 0 & 0 & 0 & 0 \\
\hline Hull & $\mathrm{C}$ & $\mathrm{U}$ & 0 & 0 & 0 & 0 & 0 & 0 \\
\hline Hull & $\mathrm{D}$ & $\mathrm{U}$ & 0 & 0 & 0 & 0 & 0 & 0 \\
\hline Hull & $\mathrm{E}$ & $\overline{\mathrm{U}}$ & 0 & 9 & 0 & 0 & 0 & 0 \\
\hline Hull & F & $\bar{U}$ & 0 & 0 & 0 & 0 & 0 & 0 \\
\hline Hull & $\mathrm{H}$ & $\mathrm{U}$ & 0 & 0 & 0 & 0 & 0 & 0 \\
\hline Hull & I & $\overline{\mathrm{U}}$ & 0 & 0 & 0 & 0 & 0 & 0 \\
\hline Lac_Philippe & $\bar{A}$ & $\mathrm{~F}$ & 0 & 0 & 0 & 0 & 0 & 0 \\
\hline Lac_Philippe & B & $\bar{F}$ & 0 & 0 & 0 & 0 & 0 & 0 \\
\hline Lac_Philippe & $\mathrm{C}$ & $\mathrm{F}$ & 0 & 0 & 0 & 0 & 0 & $\overline{0}$ \\
\hline Lac_Philippe & $\mathrm{D}$ & $\mathrm{F}$ & 0 & 0 & 0 & 0 & 0 & 0 \\
\hline Lac_Philippe & $\bar{E}$ & $\bar{F}$ & 0 & 0 & 0 & 0 & 0 & 0 \\
\hline Lac_Philippe & $\bar{F}$ & $\bar{F}$ & 0 & 0 & 0 & 0 & 0 & 0 \\
\hline Lac_Philippe & $\mathrm{H}$ & F & 0 & 0 & 0 & 0 & 0 & 0 \\
\hline Lac_Philippe & I & $\mathrm{F}$ & 0 & 0 & 0 & 0 & 0 & 0 \\
\hline Manoir_des_Trembles & A & UN & 0 & 0 & 0 & 0 & 0 & 0 \\
\hline Manoir_des_Trembles & $\mathrm{B}$ & UN & 0 & 0 & 0 & 0 & 0 & 0 \\
\hline Manoir_des_Trembles & $\mathrm{C}$ & UN & 0 & 0 & 0 & 0 & 0 & 0 \\
\hline Manoir_des_Trembles & $\overline{\mathrm{D}}$ & UN & 0 & 0 & 0 & 0 & 0 & 0 \\
\hline Manoir_des_Trembles & $\bar{E}$ & UN & 0 & 0 & 0 & 0 & 0 & 0 \\
\hline Manoir_des_Trembles & $\mathrm{F}$ & UN & 0 & 0 & 0 & 0 & 0 & 0 \\
\hline Manoir_des_Trembles & $\mathrm{H}$ & UN & 0 & 0 & 0 & 0 & 0 & 0 \\
\hline Manoir_des_Trembles & I & UN & 0 & 0 & 0 & 0 & 0 & 0 \\
\hline Marathon & A & $\mathrm{E}$ & 0 & 0 & 0 & 0 & 0 & 0 \\
\hline Marathon & $\mathrm{B}$ & $E$ & 0 & 0 & 0 & 0 & 0 & 0 \\
\hline Marathon & $\mathrm{C}$ & $E$ & 0 & 0 & 0 & 0 & 0 & 1 \\
\hline Marathon & $\bar{D}$ & $\mathrm{E}$ & 0 & 0 & 0 & 0 & 0 & 0 \\
\hline Marathon & $\mathrm{E}$ & $\mathrm{E}$ & 0 & 0 & 0 & 1 & 0 & 0 \\
\hline Marathon & $\mathrm{F}$ & $\mathrm{E}$ & 0 & 0 & 0 & 0 & 0 & 0 \\
\hline Marathon & $\mathrm{H}$ & $E$ & 0 & 0 & 0 & 0 & 0 & 2 \\
\hline Marathon & $\mathrm{I}$ & $E$ & 0 & 0 & 0 & 0 & 0 & 1 \\
\hline Marier & $\bar{A}$ & $\mathrm{U}$ & 0 & 1 & 0 & 0 & 0 & 0 \\
\hline
\end{tabular}




\begin{tabular}{|c|c|c|c|c|c|c|c|c|}
\hline Marier & $\bar{B}$ & $\overline{\mathrm{U}}$ & 0 & 0 & 0 & 0 & 0 & 0 \\
\hline Marier & $\mathrm{C}$ & $\mathrm{U}$ & 0 & 0 & 0 & 0 & 0 & 0 \\
\hline Marier & $\bar{D}$ & $\bar{U}$ & 0 & 1 & 0 & 0 & 0 & 0 \\
\hline Marier & $E$ & $\overline{\mathrm{U}}$ & 0 & 2 & 0 & 0 & 0 & 0 \\
\hline Marier & $\bar{F}$ & $\overline{\mathrm{U}}$ & $\mathbf{0}$ & 0 & $\overline{0}$ & 0 & 0 & $\overline{0}$ \\
\hline Marier & $\mathrm{H}$ & $\mathrm{U}$ & 0 & 0 & 0 & 0 & 0 & 0 \\
\hline Marier & I & $\overline{\mathrm{U}}$ & 0 & 0 & 0 & 0 & 0 & 0 \\
\hline Marlborough & $\mathrm{A}$ & $\mathrm{F}$ & $\overline{0}$ & 0 & 0 & 0 & 0 & 0 \\
\hline Marlborough & B & $F$ & 0 & 0 & 0 & 0 & 0 & 0 \\
\hline Marlborough & $\mathrm{C}$ & $F$ & 0 & 0 & 0 & 0 & 0 & 0 \\
\hline Marlborough & $\bar{D}$ & $\bar{F}$ & 0 & 0 & 0 & 0 & 0 & 0 \\
\hline Marlborough & $E$ & $\bar{F}$ & 0 & 0 & 0 & 0 & 0 & $\overline{0}$ \\
\hline Marlborough & $\mathbf{F}$ & F & 0 & 0 & 0 & 0 & 0 & 7 \\
\hline Marlborough & $\mathrm{H}$ & $F$ & 0 & 0 & 0 & 0 & 1 & 0 \\
\hline Marlborough & I & F & 0 & 0 & 0 & 0 & 0 & 0 \\
\hline Merivale & $\mathrm{A}$ & SN & 0 & 0 & 0 & 0 & 0 & 0 \\
\hline Merivale & $\bar{B}$ & $\overline{\mathrm{SN}}$ & 0 & 0 & 0 & 0 & 0 & $\overline{0}$ \\
\hline Merivale & $\mathrm{C}$ & $\mathrm{SN}$ & 0 & 0 & 0 & 0 & 0 & 0 \\
\hline Merivale & $\mathrm{D}$ & $\mathrm{SN}$ & 0 & 0 & 0 & 0 & 0 & 0 \\
\hline Merivale & $\bar{E}$ & $\mathrm{SN}$ & 0 & 0 & 0 & 0 & 0 & $\overline{0}$ \\
\hline Merivale & $\mathrm{F}$ & SN & 0 & 0 & 0 & 0 & 0 & 0 \\
\hline Merivale & $\overline{\mathrm{H}}$ & SN & 0 & 0 & 0 & $\overline{0}$ & 0 & 0 \\
\hline Merivale & I & $\mathrm{SN}$ & 0 & 0 & 0 & 0 & 0 & $\overline{0}$ \\
\hline Parc_Champlain & $\bar{A}$ & $\bar{S}$ & 0 & 5 & 0 & 0 & 0 & 0 \\
\hline Parc_Champlain & $\bar{B}$ & $S$ & 0 & 1 & 0 & 0 & 0 & $\overline{0}$ \\
\hline Parc_Champlain & $\mathrm{C}$ & $\mathrm{S}$ & 0 & 0 & 0 & 0 & 0 & 0 \\
\hline Parc_Champlain & $\mathrm{D}$ & $\mathrm{S}$ & 0 & 0 & 0 & 0 & 0 & 0 \\
\hline Parc_Champlain & $E$ & $\bar{S}$ & 0 & 0 & 0 & 0 & 0 & 0 \\
\hline Parc_Champlain & 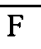 & $\mathrm{S}$ & 0 & 0 & $\overline{0}$ & 0 & 0 & 0 \\
\hline Parc_Champlain & $\mathrm{H}$ & $\mathrm{S}$ & 0 & 0 & 0 & 0 & 0 & 0 \\
\hline Parc_Champlain & I & $\mathrm{S}$ & 0 & 0 & 0 & 0 & 0 & 0 \\
\hline PineGlen_Annex & $\bar{A}$ & $\mathrm{~S}$ & 0 & 2 & 0 & 0 & 0 & 0 \\
\hline PineGlen_Annex & B & $S$ & 0 & 1 & 0 & 0 & 0 & 0 \\
\hline PineGlen_Annex & $\mathrm{C}$ & $S$ & 0 & 0 & 0 & 0 & 0 & $\overline{0}$ \\
\hline PineGlen_Annex & $\bar{D}$ & $\mathrm{~S}$ & 0 & 0 & 0 & 0 & 0 & 0 \\
\hline PineGlen_Annex & $E$ & $S$ & 0 & 7 & 0 & 0 & 0 & 0 \\
\hline PineGlen_Annex & $F$ & $S$ & 0 & 1 & 0 & 0 & 0 & $\overline{0}$ \\
\hline PineGlen_Annex & $\mathrm{H}$ & $S$ & 0 & 0 & 0 & 0 & 0 & 0 \\
\hline PineGlen_Annex & I & $\mathrm{S}$ & 0 & 0 & 0 & 0 & 0 & 0 \\
\hline Q_Four & $\mathrm{A}$ & $\bar{E}$ & 0 & 0 & 0 & 0 & 0 & 0 \\
\hline Q_Four & B & $\mathrm{E}$ & 0 & 0 & 0 & 0 & 0 & 0 \\
\hline Q_Four & $\mathrm{C}$ & $\mathrm{E}$ & 0 & 0 & 0 & 0 & 0 & 0 \\
\hline Q_Four & $\bar{D}$ & $\mathrm{E}$ & 0 & 0 & 0 & 0 & 0 & 0 \\
\hline Q_Four & $\mathrm{E}$ & $E$ & 0 & 0 & 0 & 0 & 1 & 0 \\
\hline$\overline{\text { Q_Four }}$ & $\mathrm{F}$ & $\bar{E}$ & 0 & 0 & 0 & $\overline{0}$ & 0 & $\overline{0}$ \\
\hline
\end{tabular}




\begin{tabular}{|c|c|c|c|c|c|c|c|c|}
\hline Q_Four & $\mathrm{H}$ & $E$ & 0 & 0 & 0 & 0 & 0 & 0 \\
\hline Q_Four & I & $\mathrm{E}$ & 0 & 0 & 0 & 0 & 0 & $\overline{0}$ \\
\hline Sandy_Hill & $\mathrm{A}$ & $\bar{U}$ & 0 & 0 & 0 & 0 & 0 & 0 \\
\hline Sandy_Hill & B & $\overline{\mathrm{U}}$ & 0 & 0 & 0 & 0 & 0 & $\overline{0}$ \\
\hline Sandy_Hill & $\mathrm{C}$ & $\bar{U}$ & 0 & 1 & 0 & 0 & 0 & 0 \\
\hline Sandy_Hill & $\bar{D}$ & $\mathrm{U}$ & 0 & 0 & 0 & 0 & 0 & 0 \\
\hline Sandy_Hill & $\bar{E}$ & $\overline{\mathrm{U}}$ & 0 & 0 & 0 & 0 & 0 & $\overline{0}$ \\
\hline Sandy_Hill & $\bar{F}$ & $\overline{\mathrm{U}}$ & 0 & 0 & 0 & 0 & 0 & $\overline{0}$ \\
\hline Sandy_Hill & $\mathrm{H}$ & $\overline{\mathrm{U}}$ & 0 & 0 & 0 & 0 & 0 & 0 \\
\hline Sandy_Hill & I & $\bar{U}$ & 0 & 0 & 0 & 0 & 0 & 0 \\
\hline Vallee_Meech & $\mathrm{A}$ & $F$ & 0 & 0 & 0 & 0 & 0 & 0 \\
\hline Vallee_Meech & $\bar{B}$ & $F$ & 0 & 0 & 0 & 0 & 0 & $\overline{0}$ \\
\hline Vallee_Meech & $\bar{C}$ & $\bar{F}$ & 0 & 0 & 0 & 0 & 0 & $\overline{0}$ \\
\hline Vallee_Meech & $\mathrm{D}$ & $F$ & 0 & 0 & 0 & 0 & 0 & 0 \\
\hline Vallee_Meech & $\mathrm{E}$ & $\bar{F}$ & 0 & 0 & 0 & 0 & 0 & 0 \\
\hline Vallee_Meech & $\bar{F}$ & $F$ & 0 & 0 & 0 & 0 & 0 & $\overline{0}$ \\
\hline Vallee_Meech & $\mathrm{H}$ & $\mathrm{F}$ & 0 & 0 & 0 & 0 & 0 & $\overline{0}$ \\
\hline Vallee_Meech & I & $\mathrm{F}$ & 0 & 0 & 0 & 0 & 0 & $\overline{0}$ \\
\hline Wolf_Grove & $\overline{\mathrm{A}}$ & $\bar{E}$ & 0 & 0 & 0 & 0 & 0 & $\overline{0}$ \\
\hline Wolf_Grove & B & $\bar{E}$ & 0 & 0 & 0 & 0 & 0 & 0 \\
\hline Wolf_Grove & $\bar{C}$ & $\bar{E}$ & 0 & 0 & 0 & 0 & 0 & $\overline{0}$ \\
\hline Wolf_Grove & D & $\mathrm{E}$ & 0 & 0 & 0 & 0 & 0 & 0 \\
\hline Wolf_Grove & $\mathrm{E}$ & $\mathrm{E}$ & 0 & 0 & 0 & 0 & 0 & 0 \\
\hline Wolf_Grove & $\mathrm{F}$ & $\mathrm{E}$ & 0 & 0 & 0 & 0 & 0 & $\overline{0}$ \\
\hline Wolf_Grove & $\mathrm{H}$ & $\bar{E}$ & 0 & 0 & 0 & 0 & 0 & $\overline{0}$ \\
\hline Wolf_Grove & I & $\bar{E}$ & 0 & 0 & 0 & 0 & 0 & 0 \\
\hline Wrightville & $\bar{A}$ & $\overline{\mathrm{U}}$ & 0 & 0 & 0 & 0 & 0 & $\overline{0}$ \\
\hline Wrightville & $\mathrm{B}$ & $\overline{\mathrm{U}}$ & 0 & 0 & 6 & 0 & 0 & 0 \\
\hline Wrightville & $\bar{C}$ & $\bar{U}$ & 0 & 0 & 0 & 0 & 0 & $\overline{0}$ \\
\hline Wrightville & $\mathrm{D}$ & $\mathrm{U}$ & 1 & 49 & 0 & 0 & 0 & 0 \\
\hline Wrightville & $\bar{E}$ & $\overline{\mathrm{U}}$ & 0 & 1 & 0 & 0 & 0 & $\overline{0}$ \\
\hline Wrightville & $\bar{F}$ & $\overline{\mathrm{U}}$ & 0 & 0 & 0 & 0 & 0 & $\overline{0}$ \\
\hline Wrightville & $\mathrm{H}$ & $\overline{\mathrm{U}}$ & 0 & 1 & 0 & 0 & 0 & $\overline{0}$ \\
\hline Wrightville & I & $\bar{U}$ & 0 & 1 & 0 & 0 & 0 & $\overline{0}$ \\
\hline Wychwood & $\mathrm{A}$ & $S$ & 0 & 0 & 0 & 0 & 0 & 0 \\
\hline Wychwood & B & $S$ & 0 & 0 & 0 & 0 & 0 & $\overline{0}$ \\
\hline Wychwood & $\overline{\mathrm{C}}$ & $\mathrm{S}$ & 0 & 0 & 0 & 0 & 0 & $\overline{0}$ \\
\hline Wychwood & $\bar{D}$ & $\mathrm{~S}$ & 0 & 0 & 0 & 0 & 0 & $\overline{0}$ \\
\hline Wychwood & $\mathrm{E}$ & $\mathrm{S}$ & 0 & 0 & 0 & 0 & 0 & 0 \\
\hline Wychwood & F & $\mathrm{S}$ & 0 & 0 & 0 & 0 & 0 & $\overline{0}$ \\
\hline Wychwood & $\mathbf{H}$ & $S$ & 0 & 0 & 0 & 0 & 0 & 0 \\
\hline Wychwood & I & $\bar{S}$ & 0 & 0 & 0 & $\overline{0}$ & 0 & 0 \\
\hline
\end{tabular}




\begin{tabular}{|c|c|c|c|c|c|c|c|c|}
\hline SITE & STATION & CATEGORY & BEIN & BEOB & BEPR & BEQU & BETE & BEVA \\
\hline Achbar & $\mathrm{A}$ & SN & 0 & 0 & 0 & 0 & 0 & 0 \\
\hline Achbar & B & SN & 0 & 0 & 0 & 0 & 0 & 0 \\
\hline Achbar & $\mathrm{C}$ & $\overline{\mathrm{SN}}$ & 0 & 0 & 0 & 0 & 0 & $\overline{0}$ \\
\hline Achbar & $\bar{D}$ & $\overline{\mathrm{SN}}$ & 0 & 0 & 0 & 0 & 0 & 0 \\
\hline Achbar & $E$ & SN & 0 & 0 & 0 & 0 & 0 & 0 \\
\hline Achbar & $F$ & SN & 0 & 0 & 0 & 0 & 0 & 0 \\
\hline Achbar & $\bar{H}$ & SN & 0 & 0 & 0 & 0 & 0 & 0 \\
\hline Achbar & I & SN & 0 & 0 & 0 & 0 & 0 & $\overline{0}$ \\
\hline Bridlewood & $\bar{A}$ & UN & 0 & 0 & 0 & 0 & 0 & $\overline{0}$ \\
\hline Bridlewood & $\bar{B}$ & UN & 0 & 0 & 0 & 0 & 0 & $\overline{0}$ \\
\hline Bridlewood & $\mathrm{C}$ & UN & 0 & 0 & 0 & 0 & 0 & 0 \\
\hline Bridlewood & $\mathrm{D}$ & UN & 0 & 0 & 0 & 0 & 0 & 0 \\
\hline Bridlewood & $\mathrm{E}$ & $\overline{\mathrm{UN}}$ & 0 & 0 & 0 & 0 & 0 & 0 \\
\hline Bridlewood & $\bar{F}$ & UN & 0 & 3 & 0 & 0 & 0 & 0 \\
\hline Bridlewood & $\mathrm{H}$ & UN & 0 & 1 & 0 & 0 & 0 & $\overline{0}$ \\
\hline Bridlewood & I & UN & 0 & 0 & 0 & 0 & 0 & 0 \\
\hline Carp_Hills & $\overline{\mathrm{A}}$ & $\bar{F}$ & 0 & 0 & 0 & 0 & 0 & 0 \\
\hline Carp_Hills & B & $F$ & 0 & 0 & 0 & 0 & 0 & 0 \\
\hline Carp_Hills & $\mathrm{C}$ & $\bar{F}$ & 0 & 0 & 0 & 0 & 0 & 0 \\
\hline Carp_Hills & $\bar{D}$ & $F$ & 0 & 0 & 0 & 0 & 0 & 0 \\
\hline Carp_Hills & $\bar{E}$ & $\bar{F}$ & 0 & 1 & 0 & 0 & 0 & $\overline{0}$ \\
\hline Carp_Hills & $\bar{F}$ & $\bar{F}$ & 0 & 0 & 0 & 0 & 0 & $\overline{0}$ \\
\hline Carp_Hills & $\mathrm{H}$ & $\mathrm{F}$ & 0 & 0 & 0 & 0 & 0 & 0 \\
\hline Carp_Hills & I & $F$ & 0 & 1 & 0 & 0 & 0 & 1 \\
\hline Chapel_Hill & A & UN & 0 & 0 & 0 & 0 & 0 & 0 \\
\hline Chapel_Hill & B & UN & 0 & 0 & 0 & 0 & 0 & 0 \\
\hline Chapel_Hill & $\mathrm{C}$ & UN & 0 & 0 & 0 & 0 & 0 & 0 \\
\hline Chapel_Hill & $\overline{\mathrm{D}}$ & UN & 0 & 0 & 0 & 0 & 0 & $\overline{0}$ \\
\hline Chapel_Hill & $\mathrm{E}$ & UN & 0 & 0 & 0 & 0 & 0 & 0 \\
\hline Chapel_Hill & $F$ & UN & 0 & 0 & 0 & 0 & 0 & 0 \\
\hline Chapel_Hill & $\mathrm{H}$ & UN & 0 & 0 & 0 & 0 & 0 & $\overline{0}$ \\
\hline Chapel_Hill & I & $\overline{\mathrm{UN}}$ & 0 & 0 & 0 & 0 & 0 & 0 \\
\hline Chelsea & $\overline{\mathrm{A}}$ & $\overline{\mathrm{SN}}$ & 0 & 0 & 0 & 0 & 0 & $\overline{0}$ \\
\hline Chelsea & B & SN & 0 & 0 & 0 & 0 & 0 & $\overline{0}$ \\
\hline Chelsea & $\mathrm{C}$ & $\overline{\mathrm{SN}}$ & 0 & 0 & 0 & 0 & 0 & 0 \\
\hline Chelsea & $\mathrm{D}$ & SN & 0 & 0 & 0 & 0 & 0 & $\overline{0}$ \\
\hline Chelsea & $E$ & $\overline{\mathrm{SN}}$ & 0 & 0 & 0 & 0 & 0 & $\overline{0}$ \\
\hline Chelsea & $\mathrm{F}$ & SN & 0 & 0 & 0 & 0 & 0 & $\overline{0}$ \\
\hline Chelsea & $\mathrm{H}$ & SN & 0 & 0 & 0 & 0 & 0 & 0 \\
\hline Chelsea & $\overline{\mathrm{I}}$ & SN & 0 & 0 & 0 & 0 & 0 & 0 \\
\hline Cote_d'Azur & $\bar{A}$ & $S$ & 0 & 0 & 0 & 0 & 0 & 0 \\
\hline Cote_d'Azur & $\overline{\mathrm{B}}$ & $S$ & 0 & 0 & 0 & 0 & 0 & 0 \\
\hline Cote_d'Azur & $\bar{C}$ & $\bar{S}$ & 0 & 0 & 0 & 0 & 0 & $\overline{0}$ \\
\hline Cote_d'Azur & $\bar{D}$ & $\mathrm{~S}$ & 0 & 0 & 0 & 0 & 0 & 0 \\
\hline
\end{tabular}




\begin{tabular}{|c|c|c|c|c|c|c|c|c|}
\hline Cote_d'Azur & $\bar{E}$ & $\mathrm{~S}$ & 0 & 0 & 0 & 0 & 0 & 0 \\
\hline Cote_d'Azur & $\mathrm{F}$ & $\mathrm{S}$ & 0 & 0 & 0 & 0 & 0 & 0 \\
\hline Cote_d'Azur & $\overline{\mathrm{H}}$ & $\mathrm{S}$ & 0 & 0 & 0 & 0 & 0 & 0 \\
\hline Cote_d'Azur & I & $\mathrm{S}$ & 0 & 0 & 0 & 0 & 0 & 0 \\
\hline Highway Seven & $\bar{A}$ & $\bar{E}$ & 0 & 0 & 0 & 0 & 0 & 0 \\
\hline Highway_Seven & $\bar{B}$ & $E$ & 0 & 0 & 0 & 0 & 0 & 0 \\
\hline Highway_Seven & $\bar{C}$ & $\bar{E}$ & 0 & 0 & 0 & 0 & 0 & 0 \\
\hline Highway_Seven & $\mathrm{D}$ & $E$ & 0 & 0 & 0 & 0 & 0 & 0 \\
\hline Highway_Seven & $\mathrm{E}$ & $E$ & 0 & 0 & 0 & 0 & 0 & 0 \\
\hline Highway_Seven & $\mathrm{F}$ & $E$ & 0 & 0 & 0 & 0 & 0 & 0 \\
\hline Highway_Seven & $\mathbf{H}$ & $\bar{E}$ & 0 & 0 & 0 & 1 & 0 & 0 \\
\hline Highway_Seven & I & $\bar{E}$ & 0 & 0 & 0 & 0 & 0 & $\overline{0}$ \\
\hline Hull & $\overline{\mathrm{A}}$ & $\bar{U}$ & 0 & 0 & 0 & 0 & 0 & 0 \\
\hline Hull & $\bar{B}$ & $\bar{U}$ & 0 & 0 & 0 & 0 & 0 & 0 \\
\hline Hull & $\mathrm{C}$ & $\bar{U}$ & 0 & 0 & 0 & 0 & 0 & 0 \\
\hline Hull & $\bar{D}$ & $\bar{U}$ & 0 & 0 & 0 & 0 & 0 & 0 \\
\hline Hull & $\mathrm{E}$ & $\mathrm{U}$ & 0 & 0 & 0 & 0 & 0 & $\overline{0}$ \\
\hline Hull & $\bar{F}$ & $\bar{U}$ & 0 & 0 & 0 & 0 & 0 & $\overline{0}$ \\
\hline Hull & $\mathrm{H}$ & $\bar{U}$ & 0 & 0 & 0 & 0 & 0 & 0 \\
\hline Hull & I & $\mathrm{U}$ & 0 & 0 & 0 & 0 & 0 & 0 \\
\hline Lac_Philippe & $\bar{A}$ & $\mathrm{~F}$ & 0 & 0 & 0 & 0 & 0 & 0 \\
\hline Lac_Philippe & $\mathrm{B}$ & $\mathrm{F}$ & 0 & 0 & 0 & 0 & 0 & 0 \\
\hline Lac_Philippe & $\mathrm{C}$ & $\bar{F}$ & 0 & 0 & 0 & 0 & 0 & $\overline{0}$ \\
\hline Lac_Philippe & $\bar{D}$ & $\mathrm{~F}$ & 0 & 0 & 0 & 0 & 0 & 0 \\
\hline Lac_Philippe & $\mathrm{E}$ & $\mathrm{F}$ & 0 & 0 & 0 & 0 & 0 & 0 \\
\hline Lac_Philippe & $\mathrm{F}$ & $\bar{F}$ & 0 & 0 & 0 & 0 & 0 & 0 \\
\hline Lac_Philippe & $\mathrm{H}$ & $\mathrm{F}$ & 0 & 0 & 0 & 0 & 0 & 0 \\
\hline Lac_Philippe & I & $\mathrm{F}$ & $\overline{0}$ & 0 & 0 & 0 & 0 & 0 \\
\hline Manoir_des_Trembles & $\bar{A}$ & $\overline{U N}$ & 0 & 0 & 0 & 0 & 0 & 0 \\
\hline Manoir_des_Trembles & $\mathrm{B}$ & $\overline{\mathrm{UN}}$ & 0 & 0 & 0 & 0 & 0 & 0 \\
\hline Manoir_des_Trembles & $\mathrm{C}$ & $\mathrm{UN}$ & 0 & 0 & 0 & 0 & 0 & 2 \\
\hline Manoir_des_Trembles & $\mathrm{D}$ & $\overline{\mathrm{UN}}$ & 0 & 0 & 0 & 0 & 0 & 0 \\
\hline Manoir_des_Trembles & $E$ & $\mathrm{UN}$ & 0 & 0 & 0 & 0 & 0 & 0 \\
\hline Manoir_des_Trembles & $\bar{F}$ & UN & 0 & 0 & 0 & 0 & 0 & $\overline{0}$ \\
\hline Manoir_des_Trembles & $\mathrm{H}$ & $\mathrm{UN}$ & 0 & 0 & 0 & 0 & 0 & 0 \\
\hline Manoir_des_Trembles & I & UN & 0 & 0 & 0 & 0 & 0 & 0 \\
\hline Marathon & A & $\mathrm{E}$ & 0 & 0 & 0 & 0 & 0 & 0 \\
\hline Marathon & B & $E$ & 0 & 0 & 0 & 0 & 0 & $\overline{0}$ \\
\hline Marathon & $\overline{\mathrm{C}}$ & $\bar{E}$ & 0 & 0 & 0 & 0 & 0 & $\overline{0}$ \\
\hline Marathon & $\overline{\mathrm{D}}$ & $\bar{E}$ & 0 & 0 & 0 & 0 & 0 & 0 \\
\hline Marathon & $E$ & $\mathrm{E}$ & 0 & 0 & 0 & 0 & 0 & 0 \\
\hline Marathon & $\mathrm{F}$ & $E$ & 0 & 0 & 0 & 0 & 0 & 0 \\
\hline Marathon & $\mathrm{H}$ & $\bar{E}$ & 0 & 0 & 0 & 0 & 0 & 0 \\
\hline Marathon & I & $\bar{E}$ & 0 & 0 & 0 & 0 & 0 & 0 \\
\hline Marier & $A$ & $\bar{U}$ & 0 & 0 & 0 & 0 & 0 & 0 \\
\hline
\end{tabular}




\begin{tabular}{|c|c|c|c|c|c|c|c|c|}
\hline Marier & B & $\bar{U}$ & 0 & 0 & 0 & 0 & 0 & 0 \\
\hline Marier & $\mathrm{C}$ & $\mathrm{U}$ & 0 & 0 & 0 & 0 & 0 & 0 \\
\hline Marier & $\mathrm{D}$ & $\bar{U}$ & 0 & 0 & 0 & 0 & 0 & 0 \\
\hline Marier & $\mathrm{E}$ & $\overline{\mathrm{U}}$ & 0 & 0 & 0 & 0 & 0 & $\overline{0}$ \\
\hline Marier & $F$ & $\mathrm{U}$ & 0 & 0 & 0 & 0 & 0 & 0 \\
\hline Marier & $\overline{\mathrm{H}}$ & $\bar{U}$ & 0 & 0 & 0 & 0 & 0 & 0 \\
\hline Marier & I & $\overline{\mathrm{U}}$ & 0 & 0 & 0 & 0 & 0 & 0 \\
\hline Marlborough & $\bar{A}$ & $F$ & 0 & 0 & 0 & 0 & 0 & 0 \\
\hline Marlborough & B & $F$ & 0 & 0 & 0 & 0 & 0 & 0 \\
\hline Marlborough & $\bar{C}$ & $F$ & 0 & 0 & 0 & 0 & 0 & 0 \\
\hline Marlborough & $\bar{D}$ & $F$ & 0 & 0 & 0 & 0 & 0 & 0 \\
\hline Marlborough & $\bar{E}$ & $\bar{F}$ & 0 & 0 & 0 & 0 & 0 & 0 \\
\hline Marlborough & $F$ & $F$ & 0 & 0 & 10 & 0 & 0 & 0 \\
\hline Marlborough & $\overline{\mathrm{H}}$ & $F$ & 0 & 0 & 0 & 0 & 0 & 0 \\
\hline Marlborough & I & $\mathrm{F}$ & 0 & 0 & 1 & 0 & 0 & 0 \\
\hline Merivale & $\bar{A}$ & $\overline{\mathrm{SN}}$ & 0 & 0 & 0 & 0 & 0 & 0 \\
\hline Merivale & B & SN & $\overline{0}$ & 0 & 0 & 0 & 0 & 0 \\
\hline Merivale & $\mathrm{C}$ & $\mathrm{SN}$ & 0 & 0 & 0 & 0 & 0 & 0 \\
\hline Merivale & $\bar{D}$ & $\overline{\mathrm{SN}}$ & 0 & 0 & 0 & 0 & 0 & 0 \\
\hline Merivale & $E$ & $\mathrm{SN}$ & 0 & 0 & 0 & 0 & 0 & 0 \\
\hline Merivale & $\mathrm{F}$ & $\mathrm{SN}$ & 0 & 0 & 0 & 0 & 0 & 0 \\
\hline Merivale & $\mathrm{H}$ & $\mathrm{SN}$ & 0 & 0 & 0 & 0 & 0 & 0 \\
\hline Merivale & I & $\overline{\mathrm{SN}}$ & 0 & 0 & 0 & 0 & 0 & 0 \\
\hline Parc_Champlain & $\overrightarrow{\mathrm{A}}$ & $\mathrm{S}$ & 0 & 0 & 0 & 0 & 0 & 0 \\
\hline Parc_Champlain & $\mathrm{B}$ & $\mathrm{S}$ & 1 & 0 & 0 & 2 & 0 & 0 \\
\hline Parc_Champlain & $\mathrm{C}$ & $\mathrm{S}$ & 0 & 0 & 0 & 1 & 0 & 0 \\
\hline Parc_Champlain & $\mathrm{D}$ & $\mathrm{S}$ & 0 & 0 & 0 & 0 & 0 & 0 \\
\hline Parc_Champlain & $\mathrm{E}$ & $\mathrm{S}$ & 0 & 0 & 0 & 0 & 0 & 0 \\
\hline Parc_Champlain & F & $\mathrm{S}$ & 0 & 0 & 0 & 0 & 0 & 0 \\
\hline Parc_Champlain & $\mathrm{H}$ & $\mathrm{S}$ & 0 & 0 & 0 & 0 & 0 & 0 \\
\hline Parc_Champlain & I & $\mathrm{S}$ & 0 & 0 & 0 & 0 & 0 & 0 \\
\hline PineGlen_Annex & $\bar{A}$ & $\mathrm{~S}$ & 0 & 0 & 0 & 0 & 1 & 0 \\
\hline PineGlen_Annex & $\bar{B}$ & $\mathrm{~S}$ & 0 & 0 & 0 & 0 & 0 & 0 \\
\hline PineGlen_Annex & $\mathrm{C}$ & $\mathrm{S}$ & 0 & 0 & 0 & 0 & 0 & 0 \\
\hline PineGlen_Annex & $\mathrm{D}$ & $S$ & 0 & 0 & 0 & 0 & 0 & 0 \\
\hline PineGlen_Annex & $\mathrm{E}$ & $\mathrm{S}$ & 0 & 0 & 0 & 1 & 0 & 0 \\
\hline PineGlen_Annex & $\mathrm{F}$ & $\mathrm{S}$ & 0 & 0 & 0 & 0 & 0 & 0 \\
\hline PineGlen_Annex & $\mathrm{H}$ & $S$ & 0 & 0 & 0 & 0 & 0 & 0 \\
\hline PineGlen_Annex & I & $\mathrm{S}$ & 0 & 0 & 0 & 0 & $\overline{0}$ & $\overline{0}$ \\
\hline Q_Four & A & $\mathrm{E}$ & 0 & 0 & 0 & 0 & 0 & 0 \\
\hline Q Four & B & $\bar{E}$ & 0 & 0 & 0 & 0 & 0 & 0 \\
\hline Q_Four & $\mathrm{C}$ & $\bar{E}$ & 0 & 0 & 0 & 0 & 0 & 0 \\
\hline Q_Four & D & $\mathrm{E}$ & 0 & 0 & 0 & 0 & 0 & 0 \\
\hline Q_Four & $\mathrm{E}$ & $E$ & 0 & 0 & 0 & 0 & 0 & 0 \\
\hline Q_Four & $\mathrm{F}$ & $\mathrm{E}$ & $\overline{0}$ & 0 & 0 & 0 & 0 & 0 \\
\hline
\end{tabular}




\begin{tabular}{|c|c|c|c|c|c|c|c|c|}
\hline Q_Four & $\mathrm{H}$ & $E$ & 0 & 0 & 0 & 0 & 0 & 0 \\
\hline Q_Four & I & $\mathrm{E}$ & $\overline{0}$ & 0 & 0 & 0 & 0 & 0 \\
\hline Sandy_Hill & A & $\mathrm{U}$ & 0 & 0 & 0 & 0 & 1 & 0 \\
\hline Sandy_Hill & $\bar{B}$ & $\bar{U}$ & 0 & 0 & 0 & 0 & 0 & 0 \\
\hline Sandy_Hill & $\mathrm{C}$ & $\mathrm{U}$ & 0 & 0 & 0 & 0 & 0 & 0 \\
\hline Sandy_Hill & $\bar{D}$ & $\bar{U}$ & 0 & 0 & 0 & 0 & 0 & 0 \\
\hline Sandy Hill & $E$ & $\mathrm{U}$ & 0 & 0 & 0 & 0 & 0 & 0 \\
\hline Sandy_Hill & $\mathrm{F}$ & $\bar{U}$ & 0 & 0 & 0 & 0 & 0 & 0 \\
\hline Sandy_Hill & $\mathrm{H}$ & $\bar{U}$ & 0 & 0 & 0 & 0 & 0 & 0 \\
\hline Sandy_Hill & I & $\mathbf{U}$ & 0 & 0 & 0 & 0 & 0 & 0 \\
\hline Vallee_Meech & $\bar{A}$ & $\bar{F}$ & 0 & 0 & $\overline{0}$ & 0 & 0 & 0 \\
\hline Vallee_Meech & $\bar{B}$ & $F$ & 0 & 0 & 0 & 0 & 0 & 0 \\
\hline Vallee_Meech & $\mathrm{C}$ & $\bar{F}$ & 0 & 0 & 0 & 0 & 0 & 0 \\
\hline Vallee_Meech & $\mathrm{D}$ & $F$ & 0 & 0 & 0 & 0 & 0 & 0 \\
\hline Vallee_Meech & $E$ & $\bar{F}$ & 0 & 0 & 0 & 0 & 0 & 0 \\
\hline Vallee_Meech & $\bar{F}$ & $\mathrm{~F}$ & 0 & 0 & 0 & 0 & 0 & 0 \\
\hline Vallee_Meech & $\mathrm{H}$ & $F$ & 0 & 0 & 0 & 0 & 0 & 0 \\
\hline Vallee_Meech & I & $\bar{F}$ & 0 & 0 & 0 & 0 & 0 & 0 \\
\hline Wolf_Grove & $\overline{\mathrm{A}}$ & $E$ & 0 & 0 & 0 & 0 & 0 & 0 \\
\hline Wolf_Grove & B & $\mathrm{E}$ & 0 & 0 & 0 & 0 & 0 & 0 \\
\hline Wolf_Grove & $\bar{C}$ & E & 0 & 0 & 0 & 0 & 0 & 0 \\
\hline Wolf_Grove & $\mathrm{D}$ & $\mathrm{E}$ & 0 & 0 & 0 & 0 & 0 & 0 \\
\hline Wolf_Grove & $\mathrm{E}$ & $\mathrm{E}$ & 0 & 0 & 0 & 0 & 0 & 0 \\
\hline Wolf_Grove & $\bar{F}$ & $E$ & 0 & 0 & 0 & 0 & 0 & 0 \\
\hline Wolf_Grove & $\mathrm{H}$ & $E$ & 0 & 0 & 0 & 0 & 0 & 0 \\
\hline Wolf_Grove & I & $\bar{E}$ & 0 & 0 & 0 & 0 & 0 & 0 \\
\hline Wrightville & $\bar{A}$ & $\mathrm{U}$ & 0 & 0 & 0 & 0 & 0 & 0 \\
\hline Wrightville & B & $\mathrm{U}$ & 0 & 0 & 0 & 0 & 0 & 0 \\
\hline Wrightville & $\mathrm{C}$ & $\bar{U}$ & 0 & 0 & 0 & 0 & 0 & 0 \\
\hline Wrightville & $\mathrm{D}$ & $\mathrm{U}$ & 0 & 0 & 0 & 0 & 0 & 0 \\
\hline Wrightville & $\bar{E}$ & $\mathrm{U}$ & 0 & 0 & 0 & 0 & 0 & 0 \\
\hline Wrightville & $F$ & $\mathrm{U}$ & 0 & 0 & 0 & 0 & 0 & 0 \\
\hline Wrightville & $\mathrm{H}$ & $\bar{U}$ & 0 & 0 & 0 & 6 & 0 & 0 \\
\hline Wrightville & I & $\mathrm{U}$ & 0 & 0 & 0 & 0 & 0 & 0 \\
\hline Wychwood & $\bar{A}$ & $\mathrm{~S}$ & 0 & 0 & 0 & 0 & 0 & 0 \\
\hline Wychwood & B & $\mathrm{S}$ & 0 & 0 & 0 & 2 & 0 & 0 \\
\hline Wychwood & $\bar{C}$ & $\mathrm{~S}$ & 0 & 0 & 0 & 0 & 0 & 0 \\
\hline Wychwood & $\mathrm{D}$ & $\mathrm{S}$ & 0 & 0 & 0 & 0 & 0 & 0 \\
\hline Wychwood & $E$ & $\mathrm{~S}$ & 0 & 0 & 0 & 0 & 0 & 0 \\
\hline Wychwood & $F$ & $\mathrm{~S}$ & 0 & 0 & 0 & 0 & 0 & 0 \\
\hline Wychwood & $\bar{H}$ & $\mathrm{~S}$ & 0 & 0 & 0 & 1 & 0 & 0 \\
\hline Wychwood & I & $\mathrm{S}$ & 0 & 0 & 0 & 0 & 0 & 0 \\
\hline
\end{tabular}




\begin{tabular}{|c|c|c|c|c|c|c|c|c|}
\hline SITE & STATION & CATEGORY & BEVE & BRLU & BRME & CAGR & CALGR & CAMA \\
\hline Achbar & $\mathrm{A}$ & SN & 0 & 0 & 0 & 0 & 0 & $\overline{0}$ \\
\hline Achbar & B & $\mathrm{SN}$ & 0 & 0 & 0 & 0 & 0 & 0 \\
\hline Achbar & $\overline{\mathrm{C}}$ & $\mathrm{SN}$ & 0 & 0 & 0 & 0 & 0 & 0 \\
\hline Achbar & D & $\mathrm{SN}$ & 0 & 0 & 0 & 0 & 4 & 0 \\
\hline Achbar & $E$ & $\overline{\mathrm{SN}}$ & 0 & 0 & 0 & 0 & 0 & 0 \\
\hline Achbar & $\bar{F}$ & SN & 0 & 0 & 0 & 0 & 0 & 0 \\
\hline Achbar & $\mathrm{H}$ & $\mathrm{SN}$ & 0 & 0 & 0 & 0 & 0 & $\overline{0}$ \\
\hline Achbar & I & $\overline{\mathrm{SN}}$ & 0 & 0 & 0 & 0 & 1 & $\overline{0}$ \\
\hline Bridlewood & $\bar{A}$ & $\overline{\mathrm{UN}}$ & 0 & 0 & 0 & 0 & 1 & $\overline{0}$ \\
\hline Bridlewood & B & $\overline{\mathrm{UN}}$ & 0 & 0 & 0 & 0 & 0 & 0 \\
\hline Bridlewood & $\mathrm{C}$ & $\mathrm{UN}$ & 0 & 0 & 0 & 0 & 10 & 0 \\
\hline Bridlewood & $\mathrm{D}$ & UN & 0 & 0 & 0 & 0 & 1 & $\overline{0}$ \\
\hline Bridlewood & $\bar{E}$ & UN & 0 & 0 & 0 & 0 & 0 & 0 \\
\hline Bridlewood & $\bar{F}$ & UN & 0 & 0 & 0 & 0 & 0 & $\overline{0}$ \\
\hline Bridlewood & $\overline{\mathrm{H}}$ & UN & 0 & 0 & 0 & 0 & 7 & 0 \\
\hline Bridlewood & I & UN & $\overline{0}$ & 0 & 0 & 0 & 8 & $\overline{0}$ \\
\hline Carp_Hills & $\overline{\mathrm{A}}$ & $\mathrm{F}$ & 0 & 0 & 0 & 0 & 0 & $\overline{0}$ \\
\hline Carp_Hills & B & $\bar{F}$ & 0 & 0 & 0 & 0 & 0 & $\overline{0}$ \\
\hline Carp_Hills & $\mathrm{C}$ & $\bar{F}$ & 0 & 0 & $\overline{0}$ & 0 & 0 & 0 \\
\hline Carp_Hills & $\mathrm{D}$ & $\bar{F}$ & 0 & $\overline{0}$ & 0 & 0 & 0 & 0 \\
\hline Carp_Hills & $\bar{E}$ & $\bar{F}$ & 0 & 0 & $\overline{0}$ & 0 & 1 & 0 \\
\hline Carp_Hills & $\mathrm{F}$ & F & 0 & 0 & 0 & 0 & 0 & $\overline{0}$ \\
\hline Carp_Hills & $\mathrm{H}$ & $\bar{F}$ & 0 & 1 & 1 & 0 & 0 & 0 \\
\hline Carp_Hills & I & $\bar{F}$ & 0 & 0 & 0 & 0 & 0 & $\overline{0}$ \\
\hline Chapel_Hill & $\overline{\mathrm{A}}$ & $\overline{\text { UN }}$ & 0 & 0 & 0 & 0 & 0 & $\overline{0}$ \\
\hline Chapel_Hill & B & UN & 0 & 0 & 0 & 0 & 0 & 0 \\
\hline Chapel_Hill & $\bar{C}$ & UN & 0 & 0 & 0 & 0 & 0 & 0 \\
\hline Chapel_Hill & $\mathrm{D}$ & $\overline{\mathrm{UN}}$ & 0 & 0 & 0 & 0 & 0 & $\overline{0}$ \\
\hline Chapel_Hill & $\bar{E}$ & $\overline{U N}$ & 0 & 0 & 0 & 0 & 0 & $\overline{0}$ \\
\hline Chapel_Hill & $\mathrm{F}$ & $\mathrm{UN}$ & 0 & 0 & 0 & 0 & 0 & 0 \\
\hline Chapel_Hill & $\mathrm{H}$ & $\overline{U N}$ & 0 & 0 & 0 & 0 & 0 & 0 \\
\hline Chapel_Hill & I & UN & 0 & 0 & 0 & 1 & 0 & $\overline{0}$ \\
\hline Chelsea & $\overline{\mathrm{A}}$ & $\mathrm{SN}$ & 0 & 0 & 0 & 0 & 0 & 0 \\
\hline Chelsea & $\mathrm{B}$ & SN & 0 & 0 & 0 & 0 & 0 & 0 \\
\hline Chelsea & $\mathrm{C}$ & $\overline{\mathrm{SN}}$ & 0 & 0 & 0 & 0 & 0 & 0 \\
\hline Chelsea & $\overline{\mathrm{D}}$ & SN & 0 & 0 & 0 & 0 & 0 & 0 \\
\hline Chelsea & $\bar{E}$ & $\mathrm{SN}$ & 0 & 0 & 0 & 0 & 0 & 0 \\
\hline Chelsea & $\mathrm{F}$ & $\overline{\mathrm{SN}}$ & 0 & 0 & 0 & 0 & 0 & 0 \\
\hline Chelsea & $\mathrm{H}$ & $\overline{\mathrm{SN}}$ & 0 & 0 & 0 & 0 & 0 & 0 \\
\hline Chelsea & I & SN & 0 & 0 & 0 & 0 & 0 & $\overline{0}$ \\
\hline
\end{tabular}




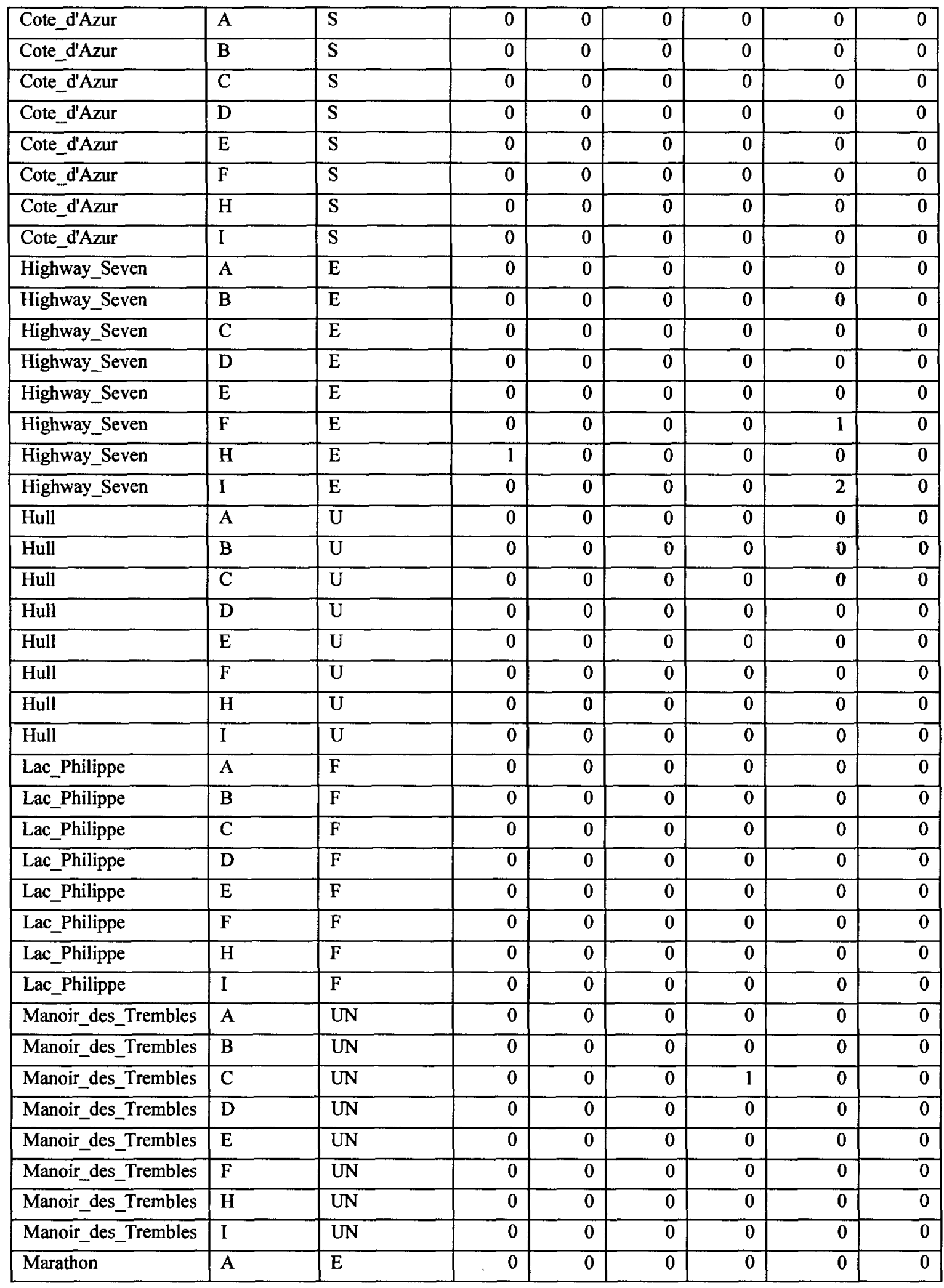




\begin{tabular}{|c|c|c|c|c|c|c|c|c|}
\hline Marathon & B & $E$ & 0 & 0 & 0 & 0 & 1 & 0 \\
\hline Marathon & $\mathrm{C}$ & $E$ & 0 & 0 & 0 & 0 & 0 & 0 \\
\hline Marathon & $\mathrm{D}$ & $E$ & 0 & 0 & 0 & 0 & 0 & 0 \\
\hline Marathon & $E$ & $\mathrm{E}$ & 0 & 0 & 0 & 0 & 0 & 0 \\
\hline Marathon & $F$ & $E$ & 0 & 0 & 0 & 0 & 0 & 2 \\
\hline Marathon & $\mathrm{H}$ & $E$ & 0 & 0 & 0 & 0 & 0 & 0 \\
\hline Marathon & I & $E$ & 0 & 0 & 0 & 0 & 0 & $\overline{0}$ \\
\hline Marier & $\mathrm{A}$ & $\mathrm{U}$ & 0 & 0 & 0 & 0 & 0 & 0 \\
\hline Marier & $\bar{B}$ & $\mathrm{U}$ & 0 & 0 & 0 & 0 & 0 & 0 \\
\hline Marier & $\mathrm{C}$ & $\mathrm{U}$ & 0 & 0 & 0 & 0 & 0 & 0 \\
\hline Marier & $\mathrm{D}$ & $\bar{U}$ & 0 & 0 & 0 & 0 & 0 & 0 \\
\hline Marier & $E$ & $\mathbf{U}$ & 0 & 0 & 0 & 0 & 0 & 0 \\
\hline Marier & $\bar{F}$ & $\mathbf{U}$ & 0 & 0 & 0 & 0 & 0 & 0 \\
\hline Marier & $\mathrm{H}$ & $\mathbf{U}$ & 0 & 0 & 0 & 0 & 0 & 0 \\
\hline Marier & I & $\mathbf{U}$ & 0 & 0 & 0 & 0 & 0 & 0 \\
\hline Marlborough & A & $\mathbf{F}$ & 0 & 0 & 0 & 0 & 0 & 0 \\
\hline Marlborough & B & $\mathbf{F}$ & 0 & 0 & 0 & 0 & 0 & 0 \\
\hline Marlborough & $\mathrm{C}$ & $\mathbf{F}$ & 0 & 0 & 0 & 0 & 0 & $\overline{0}$ \\
\hline Marlborough & $\mathrm{D}$ & $F$ & 0 & 0 & 0 & 0 & 0 & 0 \\
\hline Marlborough & $\mathrm{E}$ & $\mathbf{F}$ & 0 & 0 & 0 & 0 & 0 & 0 \\
\hline Marlborough & $\mathrm{F}$ & $F$ & 0 & 0 & 0 & 0 & 0 & 0 \\
\hline Marlborough & $\mathrm{H}$ & $\mathbf{F}$ & 0 & 0 & 0 & 0 & 0 & 0 \\
\hline Marlborough & I & $\mathbf{F}$ & 0 & 0 & 0 & 0 & 1 & 0 \\
\hline Merivale & $\mathrm{A}$ & SN & 0 & 0 & 0 & 0 & 0 & 0 \\
\hline Merivale & B & $\mathrm{SN}$ & 0 & 0 & 0 & 5 & 0 & 0 \\
\hline Merivale & $\mathrm{C}$ & $\overline{\mathrm{SN}}$ & 0 & 0 & 0 & 23 & 0 & 0 \\
\hline Merivale & $\mathrm{D}$ & $\mathrm{SN}$ & 0 & 0 & 0 & 0 & 0 & 0 \\
\hline Merivale & $E$ & $\mathrm{SN}$ & 0 & 0 & 0 & 23 & 0 & 0 \\
\hline Merivale & $\mathrm{F}$ & $\mathrm{SN}$ & 0 & 0 & 0 & 18 & 0 & $\overline{0}$ \\
\hline Merivale & $\mathrm{H}$ & $\mathrm{SN}$ & 0 & 0 & 0 & 16 & 0 & 0 \\
\hline Merivale & I & $\mathrm{SN}$ & 0 & 0 & 0 & 1 & 0 & 0 \\
\hline Parc_Champlain & $\mathrm{A}$ & $\mathrm{S}$ & 0 & 0 & 0 & 0 & 0 & $\overline{0}$ \\
\hline Parc_Champlain & $\mathrm{B}$ & $\bar{S}$ & 0 & 0 & 0 & 0 & 0 & 0 \\
\hline Parc_Champlain & $\mathrm{C}$ & $\mathbf{S}$ & 0 & 0 & 0 & 0 & 0 & 0 \\
\hline Parc_Champlain & $\mathrm{D}$ & $\mathrm{S}$ & 0 & 0 & 0 & 0 & 0 & 0 \\
\hline Parc_Champlain & $\bar{E}$ & $\mathrm{~S}$ & 0 & 0 & 0 & 0 & 0 & $\overline{0}$ \\
\hline Parc_Champlain & $\mathrm{F}$ & $\mathrm{S}$ & 0 & 0 & 0 & 0 & 0 & 0 \\
\hline Parc_Champlain & $\mathrm{H}$ & $\mathrm{S}$ & 0 & 0 & 0 & 0 & 0 & 0 \\
\hline Parc_Champlain & I & $\mathrm{S}$ & 0 & 0 & 0 & 0 & 0 & 0 \\
\hline PineGlen_Annex & $\mathrm{A}$ & $\mathbf{S}$ & 0 & 0 & 0 & 0 & 0 & 0 \\
\hline PineGlen_Annex & $\mathrm{B}$ & $\mathrm{S}$ & 0 & 0 & 0 & 0 & 0 & $\overline{0}$ \\
\hline
\end{tabular}




\begin{tabular}{|c|c|c|c|c|c|c|c|c|}
\hline PineGlen_Annex & $\bar{C}$ & $\mathbf{S}$ & 0 & 0 & 0 & 0 & 0 & $\overline{0}$ \\
\hline PineGlen_Annex & $\bar{D}$ & $\mathrm{~S}$ & 0 & 0 & 0 & 0 & 0 & $\overline{0}$ \\
\hline PineGlen_Annex & $\mathrm{E}$ & $\mathrm{S}$ & 0 & 0 & 0 & 0 & 0 & 0 \\
\hline PineGlen_Annex & $\bar{F}$ & $\mathrm{~S}$ & 0 & 0 & 0 & 0 & 0 & 0 \\
\hline PineGlen_Annex & $\mathrm{H}$ & $\mathrm{S}$ & 0 & 0 & 0 & 0 & 0 & $\overline{0}$ \\
\hline PineGlen_Annex & I & $\mathrm{S}$ & 0 & 0 & 0 & 0 & 0 & 0 \\
\hline Q_Four & $\bar{A}$ & $\bar{E}$ & 0 & 0 & 0 & 0 & 0 & 0 \\
\hline Q_Four & B & $\bar{E}$ & 0 & 0 & 0 & 0 & 0 & $\overline{0}$ \\
\hline Q_Four & $\mathrm{C}$ & $\mathrm{E}$ & 0 & 0 & 0 & 0 & 0 & $\overline{0}$ \\
\hline Q_Four & $\mathrm{D}$ & $E$ & 0 & 0 & 0 & 0 & 0 & $\overline{0}$ \\
\hline Q_Four & $\bar{E}$ & $\mathrm{E}$ & 0 & 0 & 0 & 0 & 0 & 0 \\
\hline Q_Four & $\bar{F}$ & $\bar{E}$ & 0 & 0 & 0 & 0 & 0 & $\overline{0}$ \\
\hline Q_Four & $\mathrm{H}$ & $\bar{E}$ & 0 & 0 & 0 & 0 & 0 & 0 \\
\hline Q_Four & I & $\bar{E}$ & 0 & 0 & 0 & 0 & 0 & $\overline{0}$ \\
\hline Sandy_Hill & $\bar{A}$ & $\mathrm{U}$ & 0 & 0 & 0 & 0 & 0 & $\overline{0}$ \\
\hline Sandy_Hill & B & $\mathrm{U}$ & 0 & 0 & 0 & 0 & 0 & $\overline{0}$ \\
\hline Sandy_Hill & $\mathrm{C}$ & $\mathrm{U}$ & 0 & 0 & 0 & 0 & 0 & $\overline{0}$ \\
\hline Sandy_Hill & $\mathrm{D}$ & $\mathrm{U}$ & 0 & 0 & 0 & 0 & 0 & 0 \\
\hline Sandy_Hill & $\mathrm{E}$ & $\mathrm{U}$ & 0 & 0 & 0 & 0 & 0 & 0 \\
\hline Sandy_Hill & $F$ & $\mathrm{U}$ & 0 & 0 & 0 & 0 & 0 & 0 \\
\hline Sandy_Hill & $\overline{\mathrm{H}}$ & $\mathrm{U}$ & 0 & 0 & 0 & 0 & 0 & $\overline{0}$ \\
\hline Sandy_Hill & I & $\mathrm{U}$ & 0 & 0 & 0 & 0 & 0 & $\overline{0}$ \\
\hline Vallee_Meech & $\bar{A}$ & $F$ & 0 & 0 & 0 & 0 & 0 & $\overline{0}$ \\
\hline Vallee_Meech & $\bar{B}$ & $F$ & 0 & 0 & 0 & 0 & 0 & 0 \\
\hline Vallee_Meech & $\bar{C}$ & $F$ & 0 & 0 & 0 & 0 & 0 & 0 \\
\hline Vallee_Meech & $\mathrm{D}$ & $F$ & 0 & 0 & 0 & 0 & 0 & 0 \\
\hline Vallee_Meech & $E$ & $F$ & 0 & 0 & 0 & 0 & 0 & 0 \\
\hline Vallee_Meech & $F$ & $\mathbf{F}$ & 0 & 0 & 0 & 0 & 0 & $\overline{0}$ \\
\hline Vallee_Meech & $\mathrm{H}$ & $\mathbf{F}$ & 0 & 0 & 0 & 0 & 0 & $\overline{0}$ \\
\hline Vallee_Meech & I & $F$ & 0 & 0 & 0 & 0 & 0 & 0 \\
\hline Wolf_Grove & $\bar{A}$ & $\mathrm{E}$ & 0 & 0 & 0 & 0 & 0 & 0 \\
\hline Wolf_Grove & B & $\mathrm{E}$ & 0 & 0 & 0 & 0 & 1 & $\overline{0}$ \\
\hline Wolf_Grove & $\mathrm{C}$ & $E$ & 0 & 0 & 0 & 0 & 0 & 0 \\
\hline Wolf_Grove & $\bar{D}$ & $E$ & 0 & 0 & 0 & 0 & 0 & $\overline{0}$ \\
\hline Wolf_Grove & $\bar{E}$ & $\mathrm{E}$ & 0 & 0 & 0 & 0 & 0 & $\overline{0}$ \\
\hline Wolf_Grove & $F$ & $E$ & 0 & 0 & 0 & 0 & 0 & 0 \\
\hline Wolf_Grove & $\mathrm{H}$ & $\mathrm{E}$ & 0 & 0 & 0 & 0 & 0 & 0 \\
\hline Wolf_Grove & I & $\mathrm{E}$ & 0 & 0 & 0 & 0 & 0 & 0 \\
\hline Wrightville & $\bar{A}$ & $\mathrm{U}$ & 0 & 0 & 0 & 0 & 0 & 0 \\
\hline Wrightville & B & $\mathrm{U}$ & 0 & 0 & 0 & 0 & 0 & 0 \\
\hline Wrightville & C & $\bar{U}$ & 0 & 0 & 0 & 0 & 0 & $\overline{0}$ \\
\hline
\end{tabular}




\begin{tabular}{|l|l|l|r|r|r|r|r|r|}
\hline Wrightville & D & U & 0 & 0 & 0 & 0 & 0 & 0 \\
\hline Wrightville & E & U & 0 & 0 & 0 & 0 & 0 & 0 \\
\hline Wrightville & F & U & 0 & 0 & 0 & 0 & 0 & 0 \\
\hline Wrightville & H & U & 0 & 0 & 0 & 0 & 0 & 0 \\
\hline Wrightville & I & U & 0 & 0 & 0 & 0 & 0 & 0 \\
\hline Wychwood & A & S & 0 & 0 & 0 & 0 & 0 & 0 \\
\hline Wychwood & B & S & 0 & 0 & 0 & 0 & 0 & 0 \\
\hline Wychwood & C & S & 0 & 0 & 0 & 0 & 0 & 0 \\
\hline Wychwood & D & S & 0 & 0 & 0 & 0 & 0 & 0 \\
\hline Wychwood & E & S & 0 & 0 & 0 & 0 & 0 & 0 \\
\hline Wychwood & F & S & 0 & 0 & 0 & 0 & 0 & 0 \\
\hline Wychwood & H & S & 0 & 0 & 0 & 0 & 0 & 0 \\
\hline Wychwood & I & S & 0 & 0 & 0 & 0 & 0 & 0 \\
\hline
\end{tabular}




\begin{tabular}{|c|c|c|c|c|c|c|c|c|}
\hline SITE & STATION & CATEGORY & CANE & CHEM & CHIM & CHLI & CHNI & CHTR \\
\hline Achbar & A & $\mathrm{SN}$ & 1 & 0 & 0 & 0 & 0 & 0 \\
\hline Achbar & $\bar{B}$ & $\overline{\mathrm{SN}}$ & 1 & 0 & 0 & 0 & 0 & $\overline{0}$ \\
\hline Achbar & $\mathrm{C}$ & $\overline{\mathrm{SN}}$ & 5 & 0 & 0 & 0 & 0 & $\overline{0}$ \\
\hline Achbar & $\mathrm{D}$ & $\overline{\mathrm{SN}}$ & 10 & 0 & 0 & 0 & 0 & 0 \\
\hline Achbar & $\bar{E}$ & $\overline{\mathrm{SN}}$ & 5 & $\overline{0}$ & 0 & 0 & 0 & $\overline{0}$ \\
\hline Achbar & $\mathrm{F}$ & SN & 9 & 0 & 0 & 0 & 0 & $\overline{0}$ \\
\hline Achbar & $\mathrm{H}$ & SN & 9 & 0 & 0 & 0 & 0 & 0 \\
\hline Achbar & I & $\mathrm{SN}$ & 3 & 0 & 0 & 0 & 0 & 0 \\
\hline Bridlewood & $\bar{A}$ & $\overline{\mathrm{UN}}$ & 14 & 0 & 0 & 0 & 0 & 0 \\
\hline Bridlewood & $\bar{B}$ & $\overline{\mathrm{UN}}$ & 13 & 0 & 0 & 0 & 0 & $\overline{0}$ \\
\hline Bridlewood & $\bar{C}$ & UN & 15 & 0 & 0 & 0 & 0 & $\overline{0}$ \\
\hline Bridlewood & $\mathrm{D}$ & $\overline{\mathrm{UN}}$ & 35 & 0 & 0 & 0 & 0 & 0 \\
\hline Bridlewood & $\bar{E}$ & UN & 29 & 0 & 0 & 0 & 0 & $\overline{0}$ \\
\hline Bridlewood & $F$ & $\mathrm{UN}$ & 23 & 0 & 0 & 0 & 0 & 0 \\
\hline Bridlewood & $\mathrm{H}$ & $\overline{\mathrm{UN}}$ & 27 & 0 & 0 & 0 & 0 & 0 \\
\hline Bridlewood & I & UN & 29 & 0 & 0 & 0 & 0 & 0 \\
\hline Carp_Hills & A & $F$ & 0 & 0 & 1 & 0 & 0 & 0 \\
\hline Carp_Hills & $\mathrm{B}$ & $F$ & 0 & 0 & 6 & 0 & 0 & $\overline{0}$ \\
\hline Carp_Hills & $\bar{C}$ & $\mathrm{~F}$ & 0 & 0 & 1 & 0 & 0 & 0 \\
\hline Carp_Hills & $\mathrm{D}$ & $\mathrm{F}$ & 0 & 0 & 0 & 0 & 0 & 0 \\
\hline Carp_Hills & $\bar{E}$ & $\mathrm{~F}$ & 0 & 0 & 1 & 0 & 0 & 0 \\
\hline Carp_Hills & $\mathrm{F}$ & $\bar{F}$ & 0 & 0 & 3 & 0 & 0 & 0 \\
\hline Carp_Hills & $\mathrm{H}$ & $\bar{F}$ & 0 & 0 & 0 & 0 & 0 & 0 \\
\hline Carp_Hills & I & $\mathrm{F}$ & 0 & 0 & 2 & 0 & 0 & 0 \\
\hline Chapel_Hill & $\bar{A}$ & $\mathrm{UN}$ & 0 & 0 & 0 & 0 & 0 & 0 \\
\hline Chapel_Hill & $\mathrm{B}$ & $\overline{\mathrm{UN}}$ & 2 & 0 & 0 & 0 & 0 & $\overline{0}$ \\
\hline Chapel_Hill & $\mathrm{C}$ & $\mathrm{UN}$ & 5 & 3 & 0 & 0 & 0 & 0 \\
\hline Chapel_Hill & $\mathrm{D}$ & UN & 6 & 7 & 0 & 0 & 0 & 0 \\
\hline Chapel_Hill & $\mathrm{E}$ & UN & 0 & 0 & 2 & 0 & 0 & 0 \\
\hline Chapel_Hill & $\mathrm{F}$ & UN & 0 & 1 & 1 & 0 & 0 & 0 \\
\hline Chapel_Hill & $\mathrm{H}$ & $\overline{U N}$ & 5 & 5 & 0 & 0 & 0 & $\overline{0}$ \\
\hline Chapel_Hill & I & $\overline{U N}$ & 0 & 0 & 7 & 0 & 0 & 0 \\
\hline Chelsea & $\bar{A}$ & $\mathrm{SN}$ & 2 & 0 & 0 & 0 & 0 & 0 \\
\hline Chelsea & B & $\mathrm{SN}$ & 12 & 0 & 0 & 0 & 0 & $\overline{0}$ \\
\hline Chelsea & $\mathrm{C}$ & $\mathrm{SN}$ & 7 & 0 & 0 & 0 & 0 & 0 \\
\hline Chelsea & $\bar{D}$ & $\mathrm{SN}$ & 13 & 0 & 0 & 0 & 0 & 0 \\
\hline Chelsea & $\bar{E}$ & SN & 11 & 0 & 0 & 0 & 0 & 0 \\
\hline Chelsea & F & SN & 0 & 0 & 0 & 0 & 0 & $\overline{0}$ \\
\hline Chelsea & $\mathrm{H}$ & $\mathrm{SN}$ & 11 & 0 & 0 & 0 & 0 & 0 \\
\hline Chelsea & $\mathrm{I}$ & SN & 3 & 0 & 0 & 0 & 0 & 0 \\
\hline Cote_d'Azur & A & $S$ & 1 & 0 & 0 & 0 & 0 & 0 \\
\hline Cote_d'Azur & B & $\mathrm{S}$ & 4 & 0 & 0 & 0 & 0 & 0 \\
\hline Cote_d'Azur & $\mathrm{C}$ & $\mathrm{S}$ & 0 & 0 & 0 & 0 & 0 & 0 \\
\hline Cote_d'Azur & $\bar{D}$ & 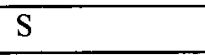 & 0 & 0 & 1 & 0 & 0 & $\overline{1}$ \\
\hline
\end{tabular}




\begin{tabular}{|c|c|c|c|c|c|c|c|c|}
\hline Cote_d'Azur & $\bar{E}$ & $\mathrm{~S}$ & 10 & 0 & 0 & 0 & 0 & 0 \\
\hline Cote_d'Azur & $\mathrm{F}$ & $\mathrm{S}$ & 10 & 0 & 0 & 0 & 0 & 0 \\
\hline Cote_d'Azur & $\mathrm{H}$ & $\mathrm{S}$ & 1 & 0 & 0 & 0 & 0 & 0 \\
\hline Cote_d'Azur & I & $\mathrm{S}$ & 0 & 0 & 0 & 0 & 0 & $\overline{0}$ \\
\hline Highway_Seven & A & $\mathrm{E}$ & 9 & 0 & 0 & 0 & 0 & 0 \\
\hline Highway_Seven & $\bar{B}$ & $\mathrm{E}$ & 1 & 0 & 0 & 0 & 0 & $\overline{0}$ \\
\hline Highway_Seven & $\bar{C}$ & $\bar{E}$ & 0 & 0 & 0 & 0 & 0 & $\overline{0}$ \\
\hline Highway_Seven & $\bar{D}$ & $\mathrm{E}$ & 10 & 0 & 0 & 0 & 0 & $\overline{0}$ \\
\hline Highway_Seven & $E$ & $\mathrm{E}$ & 0 & 0 & 0 & 0 & 0 & 2 \\
\hline Highway_Seven & $\mathrm{F}$ & $E$ & 14 & 0 & 0 & 0 & 0 & 0 \\
\hline Highway_Seven & $\mathrm{H}$ & $E$ & 0 & 0 & 0 & 0 & 0 & 0 \\
\hline Highway_Seven & I & $\bar{E}$ & 1 & 0 & 0 & 0 & 0 & $\overline{0}$ \\
\hline Hull & $\bar{A}$ & $\bar{U}$ & 0 & 0 & 0 & 0 & 0 & $\overline{0}$ \\
\hline Hull & B & $\overline{\mathrm{U}}$ & 2 & 0 & 0 & 0 & 0 & 0 \\
\hline Hull & $\bar{C}$ & $\bar{U}$ & 1 & 0 & 0 & 0 & 0 & $\overline{0}$ \\
\hline Hull & $\mathrm{D}$ & $\bar{U}$ & 0 & 0 & 0 & 0 & 0 & 0 \\
\hline Hull & $\mathrm{E}$ & $\mathrm{U}$ & 0 & 0 & 0 & 0 & 0 & 0 \\
\hline Hull & $\bar{F}$ & $\bar{U}$ & 0 & 0 & 0 & 0 & 0 & $\overline{0}$ \\
\hline Hull & $\mathrm{H}$ & $\overline{\mathrm{U}}$ & 1 & 0 & 0 & 0 & 0 & $\overline{0}$ \\
\hline Hull & I & $\overline{\mathrm{U}}$ & 6 & 0 & 0 & 0 & 0 & $\overline{0}$ \\
\hline Lac_Philippe & $\mathrm{A}$ & $\mathrm{F}$ & 0 & 0 & 0 & 0 & 0 & $\overrightarrow{0}$ \\
\hline Lac_Philippe & B & $\mathrm{F}$ & 0 & 0 & 0 & 0 & 0 & 0 \\
\hline Lac_Philippe & $\mathrm{C}$ & $\mathrm{F}$ & 0 & 0 & 0 & 0 & 0 & 0 \\
\hline Lac_Philippe & $\bar{D}$ & $\mathrm{~F}$ & 0 & 0 & 0 & 0 & 0 & 0 \\
\hline Lac_Philippe & $\bar{E}$ & $\bar{F}$ & 0 & 0 & 0 & 0 & 0 & $\overline{0}$ \\
\hline Lac_Philippe & $\mathrm{F}$ & $\bar{F}$ & 0 & 0 & 0 & 0 & 0 & 0 \\
\hline Lac_Philippe & $\mathrm{H}$ & $\mathrm{F}$ & 0 & 0 & 0 & 0 & 0 & 0 \\
\hline Lac_Philippe & $\mathrm{I}$ & $\mathrm{F}$ & 0 & 0 & 0 & 0 & 0 & 0 \\
\hline Manoir_des_Trembles & A & $\mathrm{UN}$ & 1 & 0 & 0 & 0 & 0 & 0 \\
\hline Manoir_des_Trembles & $\mathrm{B}$ & $\mathrm{UN}$ & 7 & 0 & 0 & 0 & 0 & $\overline{0}$ \\
\hline Manoir_des_Trembles & $\mathrm{C}$ & $\overline{\mathrm{UN}}$ & 0 & 0 & 6 & 0 & 0 & $\overline{0}$ \\
\hline Manoir_des_Trembles & $\bar{D}$ & $\mathrm{UN}$ & 0 & 0 & 0 & 0 & 0 & 0 \\
\hline Manoir_des_Trembles & $\mathrm{E}$ & $\mathrm{UN}$ & 0 & 0 & 0 & 0 & 0 & 0 \\
\hline Manoir_des_Trembles & $\mathrm{F}$ & $\overline{\mathrm{UN}}$ & 2 & 0 & 0 & 0 & 0 & 0 \\
\hline Manoir_des_Trembles & $\mathrm{H}$ & UN & 1 & 0 & 0 & 0 & 0 & 0 \\
\hline Manoir_des_Trembles & I & $\mathrm{UN}$ & 4 & 0 & 0 & 0 & 0 & $\overline{0}$ \\
\hline Marathon & A & $\mathrm{E}$ & 2 & 0 & 0 & 0 & 0 & 0 \\
\hline Marathon & $\mathrm{B}$ & $E$ & 9 & 0 & 0 & 0 & 0 & 0 \\
\hline Marathon & $\mathrm{C}$ & $\mathrm{E}$ & 0 & 0 & 0 & 0 & 0 & $\overline{0}$ \\
\hline Marathon & $\overline{\mathrm{D}}$ & $\mathrm{E}$ & 3 & 0 & 0 & 0 & 0 & $\overline{0}$ \\
\hline Marathon & $E$ & $E$ & 1 & 0 & 0 & 0 & 0 & 0 \\
\hline Marathon & $\mathrm{F}$ & $\mathrm{E}$ & 0 & 0 & 0 & 0 & 0 & 0 \\
\hline Marathon & $\mathrm{H}$ & $\mathrm{E}$ & 0 & 0 & 0 & 0 & 0 & 0 \\
\hline Marathon & I & $\mathrm{E}$ & 0 & 0 & 0 & 0 & 1 & 0 \\
\hline Marier & $\bar{A}$ & $\mathrm{U}$ & 4 & 0 & 0 & 0 & 0 & $\overline{0}$ \\
\hline
\end{tabular}




\begin{tabular}{|c|c|c|c|c|c|c|c|c|}
\hline Marier & B & $\mathrm{U}$ & 2 & 0 & 0 & 0 & 0 & 1 \\
\hline Marier & $\mathrm{C}$ & $\bar{U}$ & 2 & 0 & 0 & 0 & 0 & 2 \\
\hline Marier & $\bar{D}$ & $\overline{\mathbf{U}}$ & 0 & 0 & 0 & 0 & 0 & $\overline{0}$ \\
\hline Marier & $\mathrm{E}$ & $\mathbf{U}$ & 0 & 0 & 0 & 0 & 0 & 0 \\
\hline Marier & $F$ & $\bar{U}$ & 10 & 0 & 0 & 0 & 0 & 0 \\
\hline Marier & $\mathrm{H}$ & $\overline{\mathrm{U}}$ & 4 & 0 & 0 & 0 & 0 & 0 \\
\hline Marier & I & $\mathrm{U}$ & 2 & 0 & 1 & 0 & 0 & 4 \\
\hline Marlborough & A & $\bar{F}$ & 0 & 0 & 0 & 0 & 0 & 0 \\
\hline Marlborough & $\mathrm{B}$ & $\mathrm{F}$ & 0 & 0 & 0 & 0 & 0 & 0 \\
\hline Marlborough & $\mathrm{C}$ & $\bar{F}$ & 0 & 0 & 0 & 0 & 0 & 0 \\
\hline Marlborough & $\bar{D}$ & $F$ & 0 & 0 & 0 & 0 & 0 & 0 \\
\hline Marlborough & $\mathrm{E}$ & $\mathrm{F}$ & 0 & 0 & 0 & 0 & 0 & 0 \\
\hline Marlborough & $\mathrm{F}$ & $\mathrm{F}$ & 0 & 0 & 3 & 0 & 0 & 0 \\
\hline Marlborough & $\mathrm{H}$ & $\bar{F}$ & 0 & 0 & 0 & 0 & 0 & 0 \\
\hline Marlborough & I & $F$ & 0 & 0 & 0 & 0 & 0 & $\overline{0}$ \\
\hline Merivale & $\overline{\mathrm{A}}$ & $\overline{\mathrm{SN}}$ & 6 & 0 & 0 & 0 & 0 & $\overline{0}$ \\
\hline Merivale & $\mathrm{B}$ & SN & 35 & 0 & 0 & 0 & 0 & 0 \\
\hline Merivale & $\mathrm{C}$ & $\overline{\mathrm{SN}}$ & 1 & 0 & 0 & 0 & 0 & 0 \\
\hline Merivale & $\bar{D}$ & $\overline{\mathrm{SN}}$ & 1 & 0 & 0 & 0 & 0 & 0 \\
\hline Merivale & $\mathrm{E}$ & SN & 7 & 0 & 0 & 0 & 0 & 0 \\
\hline Merivale & $\bar{F}$ & SN & 7 & 0 & 0 & 0 & 0 & $\overline{0}$ \\
\hline Merivale & $\mathrm{H}$ & $\mathrm{SN}$ & 3 & 0 & 0 & 0 & 0 & $\overline{0}$ \\
\hline Merivale & I & $\overline{\mathrm{SN}}$ & 13 & 0 & 0 & 0 & 0 & 0 \\
\hline Parc_Champlain & $\bar{A}$ & $\mathrm{~S}$ & 0 & 0 & 0 & 0 & 0 & 0 \\
\hline Parc_Champlain & $\mathrm{B}$ & $\mathrm{S}$ & 1 & 0 & 6 & 0 & 0 & 7 \\
\hline Parc_Champlain & $\mathrm{C}$ & $\mathrm{S}$ & 0 & 0 & 0 & 0 & 0 & 0 \\
\hline Parc_Champlain & $\mathrm{D}$ & $\mathrm{S}$ & 0 & 0 & 0 & 0 & 0 & 1 \\
\hline Parc_Champlain & $\mathrm{E}$ & $\mathrm{S}$ & 0 & 0 & 1 & 0 & 0 & 1 \\
\hline Parc_Champlain & $\mathrm{F}$ & $\mathrm{S}$ & 1 & 0 & 0 & 1 & 0 & 1 \\
\hline Parc_Champlain & $\mathrm{H}$ & $\mathrm{S}$ & 1 & 0 & 0 & 0 & 0 & 0 \\
\hline Parc_Champlain & I & $\mathrm{S}$ & 0 & 0 & 0 & 0 & 0 & 0 \\
\hline PineGlen_Annex & $\bar{A}$ & $\mathrm{~S}$ & 3 & 0 & 0 & 0 & 0 & 1 \\
\hline PineGlen_Annex & $\bar{B}$ & $\mathrm{~S}$ & 0 & 0 & 0 & 0 & 0 & $\overline{0}$ \\
\hline PineGlen_Annex & $\mathrm{C}$ & $\mathrm{S}$ & 0 & 0 & 0 & 0 & 0 & $\overline{0}$ \\
\hline PineGlen_Annex & $\mathrm{D}$ & $\mathrm{S}$ & 0 & 0 & 0 & 0 & 0 & 1 \\
\hline PineGlen_Annex & $\mathrm{E}$ & $\mathrm{S}$ & 0 & 0 & 0 & 0 & 0 & 0 \\
\hline PineGlen_Annex & $\mathrm{F}$ & $\mathrm{S}$ & 0 & 0 & 1 & 0 & 0 & $\overline{0}$ \\
\hline PineGlen_Annex & $\mathrm{H}$ & $\mathrm{S}$ & 2 & 0 & 0 & 0 & 0 & 0 \\
\hline PineGlen_Annex & $\mathrm{I}$ & $\mathrm{S}$ & 0 & 0 & 0 & 0 & 0 & $\overline{0}$ \\
\hline Q_Four & $\overline{\mathrm{A}}$ & $\mathrm{E}$ & 2 & 0 & 0 & 0 & 0 & 0 \\
\hline Q_Four & B & $E$ & 0 & 0 & 0 & 0 & 0 & 0 \\
\hline Q_Four & $\mathrm{C}$ & $E$ & 11 & 0 & 1 & 0 & 0 & 0 \\
\hline Q_Four & $\bar{D}$ & $\bar{E}$ & 5 & 0 & 0 & 0 & 0 & $\overline{0}$ \\
\hline Q_Four & $\mathrm{E}$ & $E$ & 0 & 1 & 0 & 0 & 0 & 0 \\
\hline Q_Four & $\bar{F}$ & $E$ & 0 & 0 & 0 & 0 & 0 & 0 \\
\hline
\end{tabular}




\begin{tabular}{|c|c|c|c|c|c|c|c|c|}
\hline Q_Four & $\mathrm{H}$ & $E$ & 0 & 0 & 0 & 0 & 0 & 0 \\
\hline Q_Four & 1 & $\mathrm{E}$ & 1 & 0 & 0 & 0 & 0 & 0 \\
\hline Sandy_Hill & $\bar{A}$ & $\overrightarrow{\mathrm{U}}$ & 0 & $\overline{0}$ & $\overline{0}$ & 0 & 0 & 0 \\
\hline Sandy_Hill & $\bar{B}$ & $\overline{\mathrm{U}}$ & 0 & 0 & 0 & 0 & 0 & 0 \\
\hline Sandy_Hill & $\mathrm{C}$ & $\bar{U}$ & 0 & 0 & 0 & $\overline{0}$ & 0 & $\overline{0}$ \\
\hline Sandy_Hill & $\mathrm{D}$ & $\overline{\mathrm{U}}$ & 1 & 0 & 0 & 0 & 0 & $\overline{0}$ \\
\hline Sandy_Hill & $\bar{E}$ & $\mathrm{U}$ & 0 & 0 & 0 & 0 & 0 & 0 \\
\hline Sandy_Hill & $\mathrm{F}$ & $\bar{U}$ & 3 & 0 & 0 & 0 & 0 & 0 \\
\hline Sandy_Hill & $\mathrm{H}$ & $\overline{\mathrm{U}}$ & 1 & 0 & 0 & 0 & 0 & 2 \\
\hline Sandy_Hill & $I$ & $\overline{\mathrm{U}}$ & 4 & 0 & 0 & 0 & 0 & 0 \\
\hline Vallee_Meech & $\mathrm{A}$ & $\mathrm{F}$ & 0 & 0 & 0 & 0 & 0 & 0 \\
\hline Vallee_Meech & B & F & 0 & 0 & 0 & 0 & 0 & 0 \\
\hline Vallee_Meech & $\mathrm{C}$ & $\bar{F}$ & 0 & 0 & 0 & 0 & 0 & $\overline{0}$ \\
\hline Vallee_Meech & $\mathrm{D}$ & $F$ & 0 & 0 & 0 & 0 & 0 & 0 \\
\hline Vallee_Meech & $\mathrm{E}$ & $\mathrm{F}$ & 0 & 0 & 0 & 0 & 0 & $\overline{0}$ \\
\hline Vallee_Meech & $\bar{F}$ & $\bar{F}$ & 0 & 0 & 0 & 0 & 0 & 0 \\
\hline Vallee_Meech & $\mathrm{H}$ & F & 0 & 0 & 0 & 0 & 0 & 0 \\
\hline Vallee_Meech & I & $\mathrm{F}$ & 0 & 0 & 0 & 0 & 0 & 0 \\
\hline Wolf_Grove & $\bar{A}$ & $\mathrm{E}$ & 2 & 0 & $\overline{0}$ & 0 & 0 & 0 \\
\hline Wolf_Grove & B & $\mathrm{E}$ & 9 & 0 & 0 & 0 & 0 & 0 \\
\hline Wolf_Grove & $\mathrm{C}$ & $\bar{E}$ & 0 & 0 & 0 & 0 & 0 & 0 \\
\hline Wolf_Grove & $\overline{\mathrm{D}}$ & $\mathrm{E}$ & 0 & 0 & 0 & 0 & 0 & $\overline{0}$ \\
\hline Wolf_Grove & $E$ & $E$ & 0 & 0 & 0 & 0 & 0 & 0 \\
\hline Wolf_Grove & $\mathrm{F}$ & $\mathrm{E}$ & 0 & 0 & 0 & 0 & 0 & 0 \\
\hline Wolf_Grove & $\mathrm{H}$ & $\mathrm{E}$ & 0 & 0 & 0 & 0 & 0 & 0 \\
\hline Wolf_Grove & I & $\mathrm{E}$ & 0 & 0 & 0 & 0 & 0 & 0 \\
\hline Wrightville & A & $\mathrm{U}$ & 0 & 0 & 0 & 0 & 0 & $\overline{0}$ \\
\hline Wrightville & $\mathrm{B}$ & $\mathrm{U}$ & 5 & 0 & 0 & 0 & 0 & 0 \\
\hline Wrightville & $\mathrm{C}$ & $\bar{U}$ & 6 & 0 & 0 & 0 & 0 & 0 \\
\hline Wrightville & $\bar{D}$ & $\bar{U}$ & 0 & 0 & 0 & 0 & 0 & $\overline{0}$ \\
\hline Wrightville & $E$ & $\mathrm{U}$ & 0 & 0 & 0 & 0 & 0 & 0 \\
\hline Wrightville & $\mathrm{F}$ & $\mathrm{U}$ & 1 & 0 & 0 & 0 & 0 & 1 \\
\hline Wrightville & $\mathrm{H}$ & U & 0 & 0 & 0 & 0 & 0 & 0 \\
\hline Wrightville & I & $\mathrm{U}$ & 6 & 0 & 0 & 0 & 0 & 0 \\
\hline Wychwood & $\mathrm{A}$ & $S$ & 0 & 0 & 0 & 0 & 0 & 0 \\
\hline Wychwood & $\mathrm{B}$ & $S$ & 0 & 0 & 0 & 0 & 0 & 0 \\
\hline Wychwood & $\mathrm{C}$ & $\bar{S}$ & 1 & 0 & 1 & 0 & 0 & 0 \\
\hline Wychwood & $\mathrm{D}$ & $\mathrm{S}$ & 0 & 0 & 0 & 0 & 0 & 0 \\
\hline Wychwood & $\mathrm{E}$ & $S$ & 1 & 0 & 0 & 0 & 0 & 1 \\
\hline Wychwood & $\mathrm{F}$ & $\mathrm{S}$ & 0 & 0 & 0 & 0 & 0 & $\overline{0}$ \\
\hline Wychwood & $\mathrm{H}$ & $\mathrm{S}$ & 1 & 0 & 0 & 0 & 0 & 1 \\
\hline Wychwood & I & $\mathrm{S}$ & 2 & 0 & 0 & 0 & 0 & 0 \\
\hline
\end{tabular}




\begin{tabular}{|c|c|c|c|c|c|c|c|c|}
\hline SITE & STATION & CATEGORY & $\begin{array}{l}\text { CISE } \\
\end{array}$ & CLFO & CYCR & CYNE & DIOB & DYGL \\
\hline Achbar & A & SN & 0 & 0 & 0 & 0 & 0 & 0 \\
\hline Achbar & B & SN & 0 & $\overline{0}$ & 0 & 0 & 0 & $\overline{0}$ \\
\hline Achbar & $\bar{C}$ & $\overline{\mathrm{SN}}$ & 0 & 0 & 0 & 0 & 0 & 0 \\
\hline Achbar & $\mathrm{D}$ & $\mathrm{SN}$ & 0 & 0 & 0 & 0 & 0 & 0 \\
\hline Achbar & $\mathrm{E}$ & $\overline{\mathrm{SN}}$ & 0 & 0 & 0 & 0 & 0 & 0 \\
\hline Achbar & $F$ & SN & 0 & 0 & 0 & 0 & 0 & $\overline{0}$ \\
\hline Achbar & $\mathrm{H}$ & $\mathrm{SN}$ & 0 & 0 & 0 & 0 & 0 & $\overline{0}$ \\
\hline Achbar & I & SN & 0 & 0 & 0 & 0 & 0 & $\overline{0}$ \\
\hline Bridlewood & $\overline{\mathrm{A}}$ & UN & 0 & 0 & 0 & 0 & 0 & $\overline{0}$ \\
\hline Bridlewood & B & UN & 0 & 0 & 0 & 0 & 0 & 0 \\
\hline Bridlewood & $\overline{\mathrm{C}}$ & $\overline{\mathrm{UN}}$ & 0 & 0 & 0 & 0 & 0 & $\overline{0}$ \\
\hline Bridlewood & $\mathrm{D}$ & UN & 0 & 0 & 0 & 0 & 0 & $\overline{0}$ \\
\hline Bridlewood & $\mathrm{E}$ & UN & 1 & 0 & 0 & 0 & 0 & $\overline{0}$ \\
\hline Bridlewood & $\mathrm{F}$ & UN & 0 & 0 & 0 & 0 & 0 & $\overline{0}$ \\
\hline Bridlewood & $\mathrm{H}$ & UN & 0 & 0 & 0 & 0 & 0 & $\overline{0}$ \\
\hline Bridlewood & I & UN & 0 & 0 & 0 & 0 & 0 & $\overline{0}$ \\
\hline Carp_Hills & $\bar{A}$ & $\mathrm{~F}$ & 0 & 1 & 0 & 0 & 0 & $\overline{0}$ \\
\hline Carp_Hills & B & $F$ & 0 & 0 & 0 & 0 & 0 & $\overline{0}$ \\
\hline Carp_Hills & $\mathrm{C}$ & $\mathrm{F}$ & 0 & 0 & 0 & 0 & 0 & $\overline{0}$ \\
\hline Carp_Hills & $\bar{D}$ & $\mathrm{~F}$ & 0 & 0 & 0 & 0 & 0 & $\overline{0}$ \\
\hline Carp_Hills & $\mathrm{E}$ & $\mathrm{F}$ & 0 & 0 & 0 & 0 & 0 & 0 \\
\hline Carp_Hills & $\mathrm{F}$ & $\mathrm{F}$ & 0 & 0 & 0 & 0 & 0 & $\overline{0}$ \\
\hline Carp_Hills & $\overline{\mathrm{H}}$ & $\overline{\mathrm{F}}$ & 0 & 0 & 0 & 0 & 0 & 0 \\
\hline Carp_Hills & I & $\mathrm{F}$ & 0 & 0 & 0 & 0 & 0 & $\overline{0}$ \\
\hline Chapel_Hill & $\overline{\mathrm{A}}$ & UN & 0 & 0 & 0 & 0 & 0 & $\overline{0}$ \\
\hline Chapel_Hill & B & $\overline{\mathrm{UN}}$ & 0 & 0 & 0 & 0 & 0 & 0 \\
\hline Chapel_Hill & $\mathrm{C}$ & UN & 0 & 0 & 0 & 0 & 0 & 0 \\
\hline Chapel_Hill & $\overline{\mathrm{D}}$ & UN & 0 & 0 & 0 & 0 & 0 & $\overline{0}$ \\
\hline Chapel_Hill & $E$ & UN & 0 & 1 & 0 & 0 & 0 & 0 \\
\hline Chapel_Hill & $\bar{F}$ & UN & 0 & 1 & 0 & 0 & 0 & $\overline{0}$ \\
\hline Chapel_Hill & $\mathrm{H}$ & UN & 0 & 0 & 0 & 0 & 0 & 0 \\
\hline Chapel_Hill & I & UN & 0 & 0 & 0 & 0 & 0 & 0 \\
\hline Chelsea & $\overrightarrow{\mathrm{A}}$ & $\mathrm{SN}$ & 0 & 0 & 0 & 0 & 0 & 0 \\
\hline Chelsea & B & SN & 0 & 0 & 0 & 0 & 0 & 0 \\
\hline Chelsea & $\mathrm{C}$ & $\mathrm{SN}$ & 0 & 0 & 0 & 0 & 0 & $\overline{0}$ \\
\hline Chelsea & $\overline{\mathrm{D}}$ & $\overline{\mathrm{SN}}$ & 0 & 0 & 0 & 0 & 0 & $\overline{0}$ \\
\hline Chelsea & $E$ & $\overline{\mathrm{SN}}$ & 0 & 0 & 0 & 0 & 0 & $\overline{0}$ \\
\hline Chelsea & $\mathrm{F}$ & $\mathrm{SN}$ & 0 & 0 & 0 & 0 & 0 & 0 \\
\hline Chelsea & $\mathrm{H}$ & SN & 0 & 0 & 0 & 0 & 0 & 0 \\
\hline Chelsea & $\mathrm{I}$ & $\mathrm{SN}$ & 0 & 0 & 0 & 0 & 0 & 0 \\
\hline Cote_d'Azur & $\bar{A}$ & $S$ & 0 & 0 & 0 & 0 & 0 & $\overline{0}$ \\
\hline Cote_d'Azur & B & $\mathrm{S}$ & 0 & 0 & 0 & 0 & 0 & 0 \\
\hline Cote_d'Azur & $\bar{C}$ & $S$ & 0 & 0 & 0 & 0 & 0 & 0 \\
\hline Cote_d'Azur & $\mathrm{D}$ & $\mathrm{S}$ & 0 & 0 & 0 & 0 & 0 & 0 \\
\hline
\end{tabular}




\begin{tabular}{|c|c|c|c|c|c|c|c|c|}
\hline Cote_d'Azur & $\bar{E}$ & $S$ & 0 & 0 & 0 & 0 & 0 & 0 \\
\hline Cote_d'Azur & $F$ & $\mathrm{~S}$ & 0 & 0 & 0 & 0 & 0 & 0 \\
\hline Cote d'Azur & $\bar{H}$ & $\mathrm{~S}$ & 0 & 0 & 0 & 0 & 0 & 0 \\
\hline Cote_d'Azur & I & $\mathrm{S}$ & 0 & 0 & 0 & 0 & 0 & 0 \\
\hline Highway_Seven & $\overline{\mathrm{A}}$ & $\bar{E}$ & 0 & 0 & 0 & 0 & 0 & 0 \\
\hline Highway_Seven & $\bar{B}$ & $\mathrm{E}$ & 0 & 0 & 0 & 0 & 0 & 0 \\
\hline Highway_Seven & $\mathrm{C}$ & $\mathrm{E}$ & 0 & 0 & 0 & 0 & 0 & 0 \\
\hline Highway_Seven & $\mathrm{D}$ & $\bar{E}$ & 0 & 0 & 0 & 0 & 0 & 2 \\
\hline Highway_Seven & $\bar{E}$ & $\bar{E}$ & 0 & 0 & 0 & 0 & 0 & 0 \\
\hline Highway_Seven & $F$ & $\overline{\mathrm{E}}$ & 0 & 0 & 0 & 0 & 0 & 0 \\
\hline Highway_Seven & $\overline{\mathrm{H}}$ & $\overline{\mathrm{E}}$ & 1 & 0 & 0 & 0 & 2 & 2 \\
\hline Highway_Seven & I & $\mathrm{E}$ & 0 & 0 & 0 & 0 & 0 & 0 \\
\hline Hull & $\mathrm{A}$ & $\overline{\mathrm{U}}$ & 0 & 0 & 0 & 0 & 0 & 0 \\
\hline Hull & $\bar{B}$ & $\overline{\mathrm{U}}$ & 0 & 0 & 0 & 0 & 0 & 0 \\
\hline Hull & $\mathrm{C}$ & $\bar{U}$ & 0 & 0 & 0 & 0 & 0 & 0 \\
\hline Hull & $\overline{\mathrm{D}}$ & $\overline{\mathrm{U}}$ & 0 & 0 & 0 & 0 & 0 & 0 \\
\hline Hull & $\bar{E}$ & $\bar{U}$ & 0 & 0 & 0 & 0 & 0 & 0 \\
\hline Hull & $\bar{F}$ & $\overline{\mathrm{U}}$ & 0 & 0 & 0 & 0 & 0 & 1 \\
\hline Hull & $\mathrm{H}$ & $\overline{\mathrm{U}}$ & 0 & 0 & 0 & 0 & 0 & 0 \\
\hline Hull & I & $\mathrm{U}$ & 0 & 0 & 0 & 0 & 3 & 0 \\
\hline Lac_Philippe & $\bar{A}$ & $\bar{F}$ & 0 & 0 & 0 & 0 & 0 & 0 \\
\hline Lac_Philippe & $\bar{B}$ & $\mathrm{~F}$ & 0 & 0 & 0 & 1 & 0 & 0 \\
\hline Lac_Philippe & $\mathrm{C}$ & $\mathrm{F}$ & 0 & 0 & 0 & 0 & 0 & 0 \\
\hline Lac_Philippe & $\mathrm{D}$ & $\mathrm{F}$ & 0 & 0 & 0 & 0 & 0 & 0 \\
\hline Lac_Philippe & $\mathrm{E}$ & $\mathrm{F}$ & 0 & 0 & 0 & 0 & 0 & 0 \\
\hline Lac_Philippe & $\mathrm{F}$ & $\mathrm{F}$ & 0 & 0 & 0 & 0 & 0 & 0 \\
\hline Lac_Philippe & $\overline{\mathrm{H}}$ & $\bar{F}$ & 0 & 0 & 0 & 0 & 0 & 0 \\
\hline Lac_Philippe & I & $\mathrm{F}$ & 0 & 0 & 0 & 0 & 0 & $\overline{0}$ \\
\hline Manoir_des_Trembles & $\overline{\mathrm{A}}$ & $\overline{\mathrm{UN}}$ & 0 & 0 & 0 & 0 & 0 & 0 \\
\hline Manoir_des_Trembles & B & $\overline{\mathrm{UN}}$ & 0 & 0 & 0 & 0 & 0 & 0 \\
\hline Manoir_des_Trembles & $\mathrm{C}$ & $\overline{\mathrm{UN}}$ & 0 & 0 & 0 & 0 & 0 & 0 \\
\hline Manoir_des_Trembles & $\bar{D}$ & UN & 0 & 0 & 0 & $\overline{0}$ & 0 & 0 \\
\hline Manoir_des_Trembles & $\bar{E}$ & $\overline{\mathrm{UN}}$ & 0 & 0 & 0 & 0 & 0 & 0 \\
\hline Manoir_des_Trembles & $\mathrm{F}$ & UN & 0 & 0 & 0 & 0 & 0 & 0 \\
\hline Manoir_des_Trembles & $\mathrm{H}$ & $\overline{\mathrm{UN}}$ & 0 & $\overline{0}$ & 1 & 0 & 0 & 0 \\
\hline Manoir_des_Trembles & I & UN & 0 & 0 & 0 & 0 & 0 & 0 \\
\hline Marathon & $\overline{\mathrm{A}}$ & $\mathrm{E}$ & 0 & 0 & 0 & 0 & 0 & 0 \\
\hline Marathon & B & $\mathrm{E}$ & 0 & 0 & 0 & 0 & 0 & 0 \\
\hline Marathon & $\bar{C}$ & $\bar{E}$ & 0 & 0 & 0 & $\overline{0}$ & 0 & 0 \\
\hline Marathon & $\mathrm{D}$ & $\bar{E}$ & 0 & 0 & 0 & 0 & 3 & 0 \\
\hline Marathon & $\bar{E}$ & $\mathrm{E}$ & 0 & 0 & 0 & 0 & 0 & 0 \\
\hline Marathon & $\mathrm{F}$ & $\mathrm{E}$ & 0 & 0 & 0 & 0 & 0 & 0 \\
\hline Marathon & $\mathrm{H}$ & $E$ & 0 & 0 & 0 & 0 & 0 & 0 \\
\hline Marathon & $\mathrm{I}$ & $E$ & 0 & 0 & 0 & 0 & 0 & 0 \\
\hline Marier & $\mathrm{A}$ & $\bar{U}$ & 0 & 0 & 0 & 0 & 0 & 0 \\
\hline
\end{tabular}




\begin{tabular}{|c|c|c|c|c|c|c|c|c|}
\hline Marier & $\mathrm{B}$ & $\bar{U}$ & 0 & 0 & 0 & 0 & 0 & 0 \\
\hline Marier & $\mathrm{C}$ & $\overline{\mathrm{U}}$ & 0 & 0 & 0 & 0 & 0 & $\overline{0}$ \\
\hline Marier & $\bar{D}$ & $\overline{\mathrm{U}}$ & 0 & 0 & 0 & 0 & 0 & 0 \\
\hline Marier & $\bar{E}$ & $\bar{U}$ & 0 & 0 & 0 & 0 & 0 & 0 \\
\hline Marier & $\mathrm{F}$ & $\bar{U}$ & 0 & 0 & 0 & 0 & 0 & 0 \\
\hline Marier & $\overline{\mathrm{H}}$ & $\mathrm{U}$ & 0 & 0 & 0 & 0 & 0 & 0 \\
\hline Marier & I & $\mathrm{U}$ & 0 & 0 & 0 & 0 & 0 & 0 \\
\hline Marlborough & $\bar{A}$ & $\bar{F}$ & 0 & 0 & 0 & 0 & 0 & 0 \\
\hline Marlborough & B & $F$ & 0 & 0 & 0 & 0 & 0 & 0 \\
\hline Marlborough & $\mathrm{C}$ & $F$ & $\overline{0}$ & 0 & 0 & 0 & 0 & 0 \\
\hline Marlborough & $\mathrm{D}$ & $F$ & 0 & 0 & 0 & 0 & 0 & 0 \\
\hline Marlborough & $\bar{E}$ & $F$ & 0 & 0 & 0 & 0 & 0 & 0 \\
\hline Marlborough & $F$ & $F$ & 0 & 3 & 0 & 0 & 0 & 0 \\
\hline Marlborough & $\mathrm{H}$ & $F$ & 0 & 0 & 0 & 0 & 0 & 0 \\
\hline Marlborough & I & $\mathrm{F}$ & 0 & 0 & 0 & 0 & 0 & 0 \\
\hline Merivale & $\overline{\mathrm{A}}$ & $\overline{\mathrm{SN}}$ & 0 & 0 & 0 & 0 & 0 & 0 \\
\hline Merivale & B & $\mathrm{SN}$ & 0 & 0 & 0 & 0 & 0 & 0 \\
\hline Merivale & $\mathrm{C}$ & SN & 0 & 0 & 0 & 0 & 0 & 0 \\
\hline Merivale & $\mathrm{D}$ & $\overline{\mathrm{SN}}$ & 0 & 0 & 0 & 0 & 0 & 0 \\
\hline Merivale & $E$ & SN & 0 & 0 & 0 & 0 & 0 & 0 \\
\hline Merivale & $F$ & $\overline{\mathrm{SN}}$ & 0 & 0 & 0 & 0 & 0 & 0 \\
\hline Merivale & $\overline{\mathrm{H}}$ & $\overline{\mathrm{SN}}$ & 0 & 0 & 0 & 0 & 0 & 0 \\
\hline Merivale & I & $\overline{\mathrm{SN}}$ & 0 & 0 & 0 & 0 & 0 & 0 \\
\hline Parc_Champlain & $\mathrm{A}$ & $\mathrm{S}$ & 0 & 0 & 0 & 0 & 0 & 0 \\
\hline Parc_Champlain & B & $\mathrm{S}$ & 0 & 0 & 0 & 0 & 0 & 0 \\
\hline Parc_Champlain & $\mathrm{C}$ & $\mathrm{S}$ & 0 & 0 & 0 & 0 & 0 & 0 \\
\hline Parc_Champlain & $\mathrm{D}$ & $\mathrm{S}$ & 0 & 0 & 0 & 0 & 0 & 0 \\
\hline Parc_Champlain & $\bar{E}$ & $\mathrm{~S}$ & 0 & 0 & 0 & 0 & 1 & 0 \\
\hline Parc_Champlain & F & $\mathrm{S}$ & 0 & 0 & 0 & 0 & 0 & 0 \\
\hline Parc_Champlain & $\mathrm{H}$ & $\mathrm{S}$ & 0 & 0 & 0 & 0 & 0 & 1 \\
\hline Parc_Champlain & I & $\mathrm{S}$ & 0 & 0 & 0 & 0 & 0 & 0 \\
\hline PineGlen_Annex & $\bar{A}$ & $\mathrm{~S}$ & 0 & 0 & 0 & 0 & 0 & 0 \\
\hline PineGlen_Annex & $\mathrm{B}$ & $\mathrm{S}$ & 0 & 1 & 0 & 0 & 0 & 0 \\
\hline PineGlen_Annex & $\mathrm{C}$ & $\mathrm{S}$ & 0 & 0 & 0 & 0 & 0 & 0 \\
\hline PineGlen_Annex & $\mathrm{D}$ & $\mathrm{S}$ & 0 & 0 & 0 & 0 & 0 & 0 \\
\hline PineGlen_Annex & $E$ & $\mathrm{~S}$ & 0 & 0 & 0 & 0 & 0 & 0 \\
\hline PineGlen_Annex & $F$ & $\mathrm{~S}$ & 0 & 0 & 0 & 0 & 0 & 0 \\
\hline PineGlen_Annex & $\mathrm{H}$ & $\mathrm{S}$ & 0 & 0 & 0 & 0 & 0 & 0 \\
\hline PineGlen_Annex & I & $\mathrm{S}$ & 0 & 0 & 0 & 0 & 0 & 0 \\
\hline Q_Four & $\mathrm{A}$ & $E$ & 0 & 0 & 0 & 0 & 0 & 0 \\
\hline Q_Four & B & $E$ & 0 & 0 & 0 & 0 & 0 & 0 \\
\hline Q_Four & $\mathrm{C}$ & $E$ & 0 & 0 & 0 & 0 & 0 & 0 \\
\hline Q_Four & $\mathrm{D}$ & $E$ & 0 & 0 & 0 & 0 & 0 & 0 \\
\hline Q_Four & $E$ & $E$ & 0 & 0 & 0 & 0 & 0 & 0 \\
\hline Q_Four & $\mathrm{F}$ & $E$ & 0 & 0 & 0 & 0 & 0 & 0 \\
\hline
\end{tabular}




\begin{tabular}{|c|c|c|c|c|c|c|c|c|}
\hline Q_Four & $\mathbf{H}$ & $E$ & 0 & 0 & 0 & 0 & 0 & 0 \\
\hline Q_Four & I & $\mathrm{E}$ & 0 & 0 & 0 & 0 & 0 & 0 \\
\hline Sandy_Hill & $\overline{\mathrm{A}}$ & $\bar{U}$ & 0 & 0 & 0 & 0 & 0 & $\overline{0}$ \\
\hline Sandy_Hill & B & $\bar{U}$ & 0 & 0 & 0 & 0 & 0 & $\overline{0}$ \\
\hline Sandy_Hill & $\bar{C}$ & $\bar{U}$ & 0 & 0 & 0 & 0 & 0 & $\overline{0}$ \\
\hline Sandy_Hill & $\bar{D}$ & $\bar{U}$ & 0 & 0 & 0 & 0 & 0 & 0 \\
\hline Sandy_Hill & $\mathrm{E}$ & $\bar{U}$ & 0 & 0 & 0 & 0 & 0 & $\overline{0}$ \\
\hline Sandy_Hill & $\mathrm{F}$ & $\mathrm{U}$ & 0 & 0 & 0 & 0 & 0 & 0 \\
\hline Sandy_Hill & $\mathrm{H}$ & $\overline{\mathrm{U}}$ & 0 & 0 & 0 & 0 & 0 & 0 \\
\hline Sandy_Hill & I & $\mathrm{U}$ & 0 & 0 & 0 & 0 & 0 & 0 \\
\hline Vallee_Meech & $\bar{A}$ & $\bar{F}$ & 0 & 0 & 0 & 1 & 0 & $\overline{0}$ \\
\hline Vallee_Meech & B & $F$ & 0 & 0 & 0 & 0 & 0 & 0 \\
\hline Vallee_Meech & $\mathrm{C}$ & $\bar{F}$ & 0 & 0 & 0 & 0 & 0 & $\overline{0}$ \\
\hline Vallee_Meech & D & $\mathrm{F}$ & 0 & 0 & 0 & 0 & $\overline{0}$ & 0 \\
\hline Vallee_Meech & $E$ & $\mathrm{~F}$ & 0 & 0 & 0 & 0 & 0 & 0 \\
\hline Vallee_Meech & $F$ & $F$ & 0 & 0 & 0 & 0 & 0 & 0 \\
\hline Vallee_Meech & $\mathrm{H}$ & $\mathrm{F}$ & 0 & 0 & 0 & 0 & 0 & $\overline{0}$ \\
\hline Vallee_Meech & I & $\bar{F}$ & 0 & 0 & 0 & 0 & 0 & $\overline{0}$ \\
\hline Wolf_Grove & $\mathrm{A}$ & $E$ & 0 & 0 & 0 & 0 & 0 & 0 \\
\hline Wolf_Grove & B & $E$ & 0 & 0 & 0 & 0 & 0 & $\overline{0}$ \\
\hline Wolf_Grove & $\mathrm{C}$ & $\mathrm{E}$ & 0 & 0 & 0 & 0 & 0 & 0 \\
\hline Wolf_Grove & $\mathrm{D}$ & $E$ & 0 & 0 & 0 & 0 & 0 & 0 \\
\hline Wolf_Grove & $E$ & $\mathrm{E}$ & 0 & 0 & 0 & 0 & 0 & 0 \\
\hline Wolf_Grove & $\mathrm{F}$ & $\mathrm{E}$ & 0 & 0 & 0 & 0 & 0 & 0 \\
\hline Wolf_Grove & $\mathrm{H}$ & $\bar{E}$ & 0 & 0 & 0 & 0 & 0 & 0 \\
\hline Wolf_Grove & I & $E$ & 0 & 0 & 0 & 0 & 0 & 0 \\
\hline Wrightville & $\overline{\mathrm{A}}$ & $\bar{U}$ & 0 & 0 & 0 & 0 & 2 & $\overline{0}$ \\
\hline Wrightville & B & $\mathrm{U}$ & 0 & 0 & 0 & 0 & 0 & 0 \\
\hline Wrightville & $\overline{\mathrm{C}}$ & $\bar{U}$ & 0 & 0 & 0 & 0 & 0 & 1 \\
\hline Wrightville & $\bar{D}$ & $\mathrm{U}$ & 0 & 0 & 0 & 0 & 0 & 0 \\
\hline Wrightville & $E$ & $\bar{U}$ & 0 & 0 & 0 & 0 & 0 & 0 \\
\hline Wrightville & $F$ & $\mathrm{U}$ & 0 & 2 & 0 & 0 & 0 & 0 \\
\hline Wrightville & $\mathrm{H}$ & $\overline{\mathrm{U}}$ & 0 & 2 & 0 & 0 & 0 & 0 \\
\hline Wrightville & I & $\bar{U}$ & 0 & 0 & 0 & 0 & 0 & 0 \\
\hline Wychwood & $\mathrm{A}$ & $\mathrm{S}$ & 0 & 0 & 0 & 0 & 0 & 0 \\
\hline Wychwood & B & $S$ & 0 & 0 & 0 & 0 & 0 & 0 \\
\hline Wychwood & $\mathrm{C}$ & $\mathrm{S}$ & 0 & 0 & 0 & 0 & 1 & 0 \\
\hline Wychwood & $\bar{D}$ & $S$ & 0 & 0 & 0 & 0 & 0 & $\overline{0}$ \\
\hline Wychwood & $\mathrm{E}$ & $\mathrm{S}$ & 0 & 0 & 0 & 0 & 0 & 0 \\
\hline Wychwood & $\mathrm{F}$ & $S$ & 0 & 0 & 0 & 0 & 0 & 0 \\
\hline Wychwood & $\mathrm{H}$ & $\mathrm{S}$ & 0 & 0 & 0 & 0 & 0 & 0 \\
\hline Wychwood & I & $\mathrm{S}$ & 0 & 0 & 0 & 0 & 2 & 0 \\
\hline
\end{tabular}




\begin{tabular}{|c|c|c|c|c|c|c|c|c|}
\hline SITE & STATION & CATEGORY & ELCL & ELGR & HAAF & HACO & HAER & HAERY \\
\hline Achbar & A & SN & 0 & 0 & 0 & 0 & 0 & 0 \\
\hline Achbar & $\bar{B}$ & $\overline{S N}$ & 0 & 0 & 0 & 0 & 0 & 0 \\
\hline Achbar & $\mathrm{C}$ & SN & 0 & 0 & 0 & 0 & 0 & 0 \\
\hline Achbar & $\bar{D}$ & SN & 0 & 0 & 0 & 0 & 0 & 0 \\
\hline Achbar & $\bar{E}$ & SN & 0 & 0 & 0 & 0 & 0 & 0 \\
\hline Achbar & $\mathrm{F}$ & SN & 0 & 0 & 0 & 0 & 0 & 0 \\
\hline Achbar & $\mathrm{H}$ & SN & 0 & 0 & 0 & 0 & 0 & 0 \\
\hline Achbar & I & SN & 0 & 0 & 0 & 0 & 0 & $\overline{0}$ \\
\hline Bridlewood & $\bar{A}$ & UN & 0 & 0 & 0 & 0 & 0 & $\overline{0}$ \\
\hline Bridlewood & $\bar{B}$ & $\overline{U N}$ & 0 & 0 & 0 & 0 & 0 & 0 \\
\hline Bridlewood & $\mathrm{C}$ & UN & 0 & 0 & 0 & 0 & 0 & $\overline{0}$ \\
\hline Bridlewood & $\mathrm{D}$ & UN & 0 & 0 & 0 & 0 & 0 & $\overline{0}$ \\
\hline Bridlewood & $\mathrm{E}$ & $\overline{\mathrm{UN}}$ & 0 & 0 & 0 & 0 & 0 & $\overline{0}$ \\
\hline Bridlewood & $F$ & UN & 0 & 0 & 0 & 0 & 0 & $\overline{0}$ \\
\hline Bridlewood & $\mathrm{H}$ & UN & 0 & 0 & 0 & 0 & 0 & 0 \\
\hline Bridlewood & I & UN & 0 & 0 & 0 & 0 & 0 & $\overline{0}$ \\
\hline Carp_Hills & $\bar{A}$ & $\mathrm{~F}$ & 0 & 0 & 0 & 0 & 0 & 0 \\
\hline Carp_Hills & B & $\mathrm{F}$ & 0 & 0 & 0 & 0 & 0 & 0 \\
\hline Carp_Hills & $\bar{C}$ & $\bar{F}$ & 0 & 0 & 0 & 0 & 0 & 0 \\
\hline Carp_Hills & $\mathrm{D}$ & $\mathrm{F}$ & 0 & 0 & 0 & 0 & 0 & 0 \\
\hline Carp_Hills & $\bar{E}$ & $\mathrm{~F}$ & 0 & 0 & 0 & 0 & 0 & 0 \\
\hline Carp_Hills & $\mathrm{F}$ & $\mathrm{F}$ & 0 & 0 & 0 & 0 & 0 & 0 \\
\hline Carp_Hills & $\mathrm{H}$ & F & 0 & 0 & 0 & 0 & 0 & $\overline{0}$ \\
\hline Carp_Hills & I & 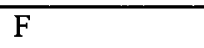 & 1 & 0 & 0 & 0 & 0 & 0 \\
\hline Chapel_Hill & A & UN & 0 & 0 & 0 & 0 & 0 & 0 \\
\hline Chapel_Hill & $\bar{B}$ & UN & 0 & 0 & 0 & 0 & 0 & 0 \\
\hline Chapel_Hill & $\mathrm{C}$ & UN & 0 & 0 & 0 & 0 & 0 & $\overline{0}$ \\
\hline Chapel_Hill & $\mathrm{D}$ & UN & 0 & 0 & 0 & 0 & 0 & $\overline{0}$ \\
\hline Chapel_Hill & $\mathrm{E}$ & UN & 0 & 0 & 0 & 0 & 0 & 0 \\
\hline Chapel_Hill & $\bar{F}$ & UN & 0 & 0 & 0 & 0 & 0 & 0 \\
\hline Chapel_Hill & $\mathrm{H}$ & UN & 0 & 0 & 0 & 1 & 0 & 0 \\
\hline Chapel_Hill & I & UN & 0 & 0 & 0 & 0 & 0 & 0 \\
\hline Chelsea & $\mathrm{A}$ & $\overline{\mathrm{SN}}$ & 0 & 0 & 0 & 0 & 0 & $\overline{0}$ \\
\hline Chelsea & B & SN & 0 & 0 & 0 & 0 & 0 & $\overline{0}$ \\
\hline Chelsea & $\mathrm{C}$ & SN & 0 & 0 & 0 & 0 & 0 & 0 \\
\hline Chelsea & $\mathrm{D}$ & SN & 0 & 0 & 0 & 0 & 0 & 0 \\
\hline Chelsea & $\mathrm{E}$ & $\mathrm{SN}$ & 0 & 0 & 0 & 0 & 0 & 0 \\
\hline Chelsea & $\mathrm{F}$ & $\overline{\mathrm{SN}}$ & 0 & 0 & 0 & 0 & 0 & 0 \\
\hline Chelsea & $\mathrm{H}$ & $\mathrm{SN}$ & 0 & 0 & 0 & 0 & 0 & 0 \\
\hline Chelsea & I & $\mathrm{SN}$ & 0 & 0 & 0 & 0 & 0 & 0 \\
\hline Cote_d'Azur & $\bar{A}$ & $\mathrm{~S}$ & 0 & 0 & 0 & 0 & 0 & 0 \\
\hline Cote_d'Azur & B & $\mathrm{S}$ & 0 & 0 & 0 & 0 & 0 & 0 \\
\hline
\end{tabular}




\begin{tabular}{|c|c|c|c|c|c|c|c|c|}
\hline Cote_d'Azur & $\mathrm{C}$ & $\mathrm{S}$ & 0 & 0 & 0 & 0 & 0 & 0 \\
\hline Cote d'Azur & $\mathrm{D}$ & $\mathrm{S}$ & 0 & 0 & 0 & 0 & 0 & 0 \\
\hline Cote_d'Azur & $\bar{E}$ & $\mathbf{S}$ & 0 & 0 & 0 & 0 & 0 & 0 \\
\hline Cote_d'Azur & $\bar{F}$ & $\mathrm{~S}$ & 0 & 0 & 1 & 5 & 0 & 0 \\
\hline Cote_d'Azur & $\mathrm{H}$ & $\mathrm{S}$ & 0 & 0 & 0 & 0 & 0 & 0 \\
\hline Cote_d'Azur & I & $\mathrm{S}$ & 0 & 0 & 0 & 0 & 0 & 0 \\
\hline Highway_Seven & $\mathrm{A}$ & $\mathrm{E}$ & 0 & 0 & 0 & 0 & 0 & 0 \\
\hline Highway_Seven & B & $\mathrm{E}$ & 0 & 0 & 0 & 0 & 0 & 0 \\
\hline Highway_Seven & $\mathrm{C}$ & $E$ & 0 & 0 & 0 & 0 & 0 & 0 \\
\hline Highway_Seven & $\mathrm{D}$ & $\mathrm{E}$ & 0 & 0 & 0 & 0 & 0 & 0 \\
\hline Highway_Seven & $\mathrm{E}$ & $\mathrm{E}$ & 0 & 0 & 0 & 0 & 0 & 0 \\
\hline Highway_Seven & $\mathrm{F}$ & $E$ & 0 & 0 & 0 & 0 & 0 & 0 \\
\hline Highway_Seven & $\mathrm{H}$ & $\mathrm{E}$ & 0 & 0 & 0 & 0 & 0 & 0 \\
\hline Highway_Seven & I & $E$ & 0 & 0 & 0 & 0 & 0 & 0 \\
\hline Hull & $\bar{A}$ & $\overline{\mathrm{U}}$ & 0 & 0 & 0 & 0 & 0 & 0 \\
\hline Hull & $\mathrm{B}$ & $\mathrm{U}$ & 0 & 0 & 5 & 0 & 0 & 0 \\
\hline Hull & $\mathrm{C}$ & $\bar{U}$ & 0 & 0 & 0 & 0 & 0 & 0 \\
\hline Hull & $\mathrm{D}$ & $\mathrm{U}$ & 0 & 0 & 0 & 0 & 0 & 0 \\
\hline Hull & $E$ & $\mathrm{U}$ & 0 & 0 & 1 & 2 & 0 & 0 \\
\hline Hull & $\mathrm{F}$ & $\mathrm{U}$ & 0 & 0 & 3 & 2 & 0 & $\overline{0}$ \\
\hline Hull & $\mathrm{H}$ & $\mathrm{U}$ & 0 & 0 & 9 & 5 & 0 & 0 \\
\hline Hull & I & $\mathrm{U}$ & 0 & 0 & 1 & 0 & 0 & 0 \\
\hline Lac_Philippe & $\mathrm{A}$ & $\mathrm{F}$ & 0 & 0 & 0 & 0 & 0 & 0 \\
\hline Lac_Philippe & $\mathrm{B}$ & $\bar{F}$ & 0 & 0 & 0 & 0 & 0 & $\overline{0}$ \\
\hline Lac_Philippe & $\mathrm{C}$ & $\mathrm{F}$ & 0 & 0 & 0 & 0 & 0 & 0 \\
\hline Lac_Philippe & $\mathrm{D}$ & $\mathrm{F}$ & 0 & 0 & 0 & 0 & 0 & 0 \\
\hline Lac_Philippe & $\mathrm{E}$ & $\mathrm{F}$ & 0 & 0 & 0 & 0 & 0 & 0 \\
\hline Lac_Philippe & $\mathrm{F}$ & $\mathrm{F}$ & 0 & 0 & 0 & 0 & 0 & 0 \\
\hline Lac_Philippe & $\mathrm{H}$ & $\mathrm{F}$ & 0 & 0 & 0 & 0 & 0 & 0 \\
\hline Lac_Philippe & I & $\mathrm{F}$ & 0 & 0 & 0 & 0 & 0 & 0 \\
\hline Manoir_des_Trembles & A & UN & 0 & 0 & 0 & 0 & 0 & 0 \\
\hline Manoir_des_Trembles & $\bar{B}$ & UN & 0 & 0 & 0 & 0 & 0 & 0 \\
\hline Manoir_des_Trembles & $\mathrm{C}$ & $\mathrm{UN}$ & 1 & 0 & 0 & 0 & 0 & 0 \\
\hline Manoir_des_Trembles & $\mathrm{D}$ & UN & 0 & 0 & 0 & 0 & 0 & 0 \\
\hline Manoir_des_Trembles & $\mathrm{E}$ & $\mathrm{UN}$ & 0 & 0 & 0 & 0 & 0 & $\overline{0}$ \\
\hline Manoir_des_Trembles & $\mathbf{F}$ & $\mathrm{UN}$ & 0 & 0 & 0 & 0 & 0 & 0 \\
\hline Manoir_des_Trembles & $\mathrm{H}$ & UN & 0 & 0 & 0 & 0 & 0 & 0 \\
\hline Manoir_des_Trembles & $I$ & UN & 0 & 0 & 0 & 0 & 0 & 0 \\
\hline Marathon & $\mathrm{A}$ & $E$ & 0 & 0 & 0 & 0 & 0 & 0 \\
\hline Marathon & B & $\mathrm{E}$ & 0 & 0 & 0 & 0 & 0 & $\overline{0}$ \\
\hline Marathon & $\mathrm{C}$ & $\mathrm{E}$ & 0 & 0 & 0 & 0 & 0 & 0 \\
\hline Marathon & $\mathrm{D}$ & $\mathrm{E}$ & 0 & 0 & 0 & 0 & 0 & 0 \\
\hline Marathon & $\mathrm{E}$ & $\mathrm{E}$ & 0 & 0 & 0 & 0 & 0 & 0 \\
\hline
\end{tabular}




\begin{tabular}{|c|c|c|c|c|c|c|c|c|}
\hline Marathon & $F$ & $\mathrm{E}$ & 0 & 0 & 0 & 0 & 0 & 0 \\
\hline Marathon & $\mathrm{H}$ & $\bar{E}$ & 0 & 0 & 0 & 0 & 0 & 0 \\
\hline Marathon & I & $\bar{E}$ & 0 & 0 & 0 & 0 & 0 & 0 \\
\hline Marier & $\bar{A}$ & $\mathrm{U}$ & 0 & 1 & 4 & 0 & 0 & 1 \\
\hline Marier & B & $\mathrm{U}$ & 0 & 0 & 2 & 0 & 0 & 0 \\
\hline Marier & C & $\mathrm{U}$ & 0 & 0 & 2 & 0 & 0 & 5 \\
\hline Marier & $\bar{D}$ & $\bar{U}$ & 0 & 0 & 1 & 0 & 0 & 0 \\
\hline Marier & $\mathrm{E}$ & $\bar{U}$ & 0 & 0 & 2 & 0 & 0 & 0 \\
\hline Marier & $\bar{F}$ & $\mathrm{U}$ & 0 & 0 & 3 & 1 & 0 & 0 \\
\hline Marier & $\overline{\mathrm{H}}$ & $\bar{U}$ & 0 & 0 & 0 & 2 & 0 & 1 \\
\hline Marier & I & $\mathrm{U}$ & 0 & 0 & 2 & 0 & 0 & 0 \\
\hline Marlborough & $\bar{A}$ & $\mathbf{F}$ & 0 & 0 & 0 & 0 & 0 & $\overline{0}$ \\
\hline Marlborough & B & $\bar{F}$ & 0 & 0 & 0 & 0 & 0 & 0 \\
\hline Marlborough & $\mathrm{C}$ & $F$ & 0 & 0 & 0 & 0 & 0 & $\overline{0}$ \\
\hline Marlborough & $\mathrm{D}$ & $F$ & 0 & 0 & 0 & 0 & 0 & 0 \\
\hline Marlborough & $\bar{E}$ & $F$ & 0 & 0 & 0 & 0 & 0 & $\overline{0}$ \\
\hline Marlborough & $F$ & $F$ & 0 & 0 & 0 & 0 & 0 & 0 \\
\hline Marlborough & $\mathrm{H}$ & $F$ & 0 & 0 & 0 & 0 & 0 & 0 \\
\hline Marlborough & I & $\bar{F}$ & 0 & 0 & 0 & 0 & 0 & 0 \\
\hline Merivale & $\mathrm{A}$ & SN & 0 & 0 & 0 & 0 & 0 & 0 \\
\hline Merivale & B & $\mathrm{SN}$ & 0 & 0 & 0 & 0 & 0 & 0 \\
\hline Merivale & $\mathrm{C}$ & $\overline{\mathrm{SN}}$ & 0 & 0 & 0 & 0 & 0 & 0 \\
\hline Merivale & $\mathrm{D}$ & $\mathrm{SN}$ & 0 & 0 & 0 & 0 & 0 & 0 \\
\hline Merivale & $\mathrm{E}$ & SN & 0 & 0 & 0 & 0 & 0 & 0 \\
\hline Merivale & $F$ & $\overline{\mathrm{SN}}$ & 0 & 0 & 0 & 0 & 0 & 0 \\
\hline Merivale & $\mathrm{H}$ & SN & 0 & 0 & 0 & 0 & 0 & 0 \\
\hline Merivale & I & $\mathrm{SN}$ & 0 & 0 & 0 & 0 & 0 & 0 \\
\hline Parc_Champlain & $\bar{A}$ & $\mathrm{~S}$ & 0 & 0 & 0 & 1 & 0 & 0 \\
\hline Parc_Champlain & B & $\mathrm{S}$ & 0 & 0 & 0 & 0 & 0 & 0 \\
\hline Parc_Champlain & $\mathrm{C}$ & $\mathrm{S}$ & 0 & 0 & 0 & 0 & 0 & 0 \\
\hline Parc_Champlain & $\mathrm{D}$ & $\mathrm{S}$ & 0 & 0 & 0 & 1 & 0 & 3 \\
\hline Parc_Champlain & $\bar{E}$ & $\mathrm{~S}$ & 0 & 0 & 0 & 0 & 0 & 0 \\
\hline Parc_Champlain & $F$ & $\mathrm{~S}$ & 0 & 0 & 0 & 2 & 0 & 2 \\
\hline Parc_Champlain & $\mathrm{H}$ & $\mathrm{S}$ & 0 & 0 & 0 & 1 & 0 & 0 \\
\hline Parc_Champlain & I & $\bar{S}$ & 0 & 0 & 0 & 0 & 0 & 0 \\
\hline PineGlen_Annex & A & $S$ & 0 & 0 & 0 & 0 & 1 & 0 \\
\hline PineGlen_Annex & $\bar{B}$ & $\bar{S}$ & 0 & 0 & 0 & 0 & 0 & 0 \\
\hline PineGlen_Annex & $\mathrm{C}$ & $S$ & 0 & 0 & 3 & 0 & 0 & 0 \\
\hline PineGlen_Annex & D & $\mathrm{S}$ & 0 & 0 & 0 & 0 & 0 & 0 \\
\hline PineGlen_Annex & $\bar{E}$ & $\mathrm{~S}$ & 0 & 0 & 0 & 1 & 2 & 0 \\
\hline PineGlen_Annex & $\mathbf{F}$ & $\bar{S}$ & 0 & 0 & 3 & 0 & 0 & 1 \\
\hline PineGlen_Annex & $\mathrm{H}$ & $\overline{\mathrm{S}}$ & 0 & 0 & 1 & 0 & 0 & 0 \\
\hline PineGlen_Annex & $\bar{I}$ & $\mathrm{~S}$ & 0 & 0 & 3 & 4 & 0 & 2 \\
\hline
\end{tabular}




\begin{tabular}{|c|c|c|c|c|c|c|c|c|}
\hline Q_Four & $\mathrm{A}$ & $\mathrm{E}$ & 0 & 0 & 0 & 0 & 0 & 0 \\
\hline Q_Four & $\mathrm{B}$ & $E$ & 0 & 0 & 0 & 0 & 0 & 0 \\
\hline Q_Four & $\mathrm{C}$ & $\mathrm{E}$ & 0 & 0 & 0 & 0 & 0 & 0 \\
\hline$\overline{\text { Q_Four }}$ & $\mathrm{D}$ & $\bar{E}$ & 0 & 0 & 0 & 0 & 0 & $\overline{0}$ \\
\hline Q_Four & $\mathrm{E}$ & $\mathrm{E}$ & 0 & 0 & 0 & 0 & 0 & 0 \\
\hline Q_Four & $F$ & $\mathrm{E}$ & 0 & 0 & 0 & 0 & 0 & 0 \\
\hline Q_Four & $\mathrm{H}$ & $E$ & 0 & 0 & 0 & 0 & 0 & 0 \\
\hline Q_Four & I & $\mathrm{E}$ & 0 & 0 & 0 & 0 & 0 & 0 \\
\hline Sandy_Hill & $\overline{\mathrm{A}}$ & $\bar{U}$ & 0 & 0 & 1 & 0 & 0 & $\overline{0}$ \\
\hline Sandy_Hill & B & U & 0 & 0 & 8 & 1 & 0 & 0 \\
\hline Sandy_Hill & $\mathrm{C}$ & $\bar{U}$ & 0 & 0 & 12 & 0 & 0 & 0 \\
\hline Sandy_Hill & $\bar{D}$ & $\bar{U}$ & 0 & 0 & 6 & 0 & 0 & 0 \\
\hline Sandy_Hill & $\mathrm{E}$ & $\mathrm{U}$ & 0 & 0 & 1 & 0 & 0 & 0 \\
\hline Sandy_Hill & $F$ & $\mathrm{U}$ & 0 & 0 & 2 & 0 & 0 & 0 \\
\hline Sandy_Hill & $\mathrm{H}$ & $\mathrm{U}$ & 0 & 0 & 0 & 0 & 0 & 0 \\
\hline Sandy_Hill & I & $\overline{\mathrm{U}}$ & 0 & 0 & 1 & 0 & 0 & 0 \\
\hline Vallee_Meech & A & $\mathrm{F}$ & 0 & 0 & 0 & 0 & 0 & 0 \\
\hline Vallee_Meech & B & $\mathrm{F}$ & 0 & 0 & 0 & 0 & 0 & 0 \\
\hline Vallee_Meech & $\mathrm{C}$ & $\mathrm{F}$ & 0 & 0 & 0 & 0 & 0 & 0 \\
\hline Vallee_Meech & D & $\bar{F}$ & 0 & 0 & 0 & 0 & $\overline{0}$ & 0 \\
\hline Vallee_Meech & $E$ & $F$ & 0 & 0 & 0 & 0 & 0 & 0 \\
\hline Vallee_Meech & $F$ & $\mathrm{~F}$ & 0 & 0 & 0 & 0 & 0 & 0 \\
\hline Vallee_Meech & $\mathrm{H}$ & $\mathrm{F}$ & 0 & 0 & 0 & 0 & 0 & 0 \\
\hline Vallee_Meech & I & $\bar{F}$ & 0 & 0 & 0 & 0 & 0 & 0 \\
\hline Wolf_Grove & $\bar{A}$ & $\mathrm{E}$ & 0 & 0 & 0 & 0 & 0 & 0 \\
\hline Wolf_Grove & B & $\mathrm{E}$ & 0 & 0 & 0 & 0 & 0 & $\overline{0}$ \\
\hline Wolf_Grove & $\mathrm{C}$ & $\mathrm{E}$ & 0 & 0 & 0 & 0 & 0 & 0 \\
\hline Wolf_Grove & $\bar{D}$ & $\mathrm{E}$ & 0 & 0 & 0 & 0 & 0 & $\overline{0}$ \\
\hline Wolf_Grove & $\mathrm{E}$ & $\mathrm{E}$ & 0 & 0 & 0 & 0 & 0 & $\overline{0}$ \\
\hline Wolf_Grove & $F$ & $\mathrm{E}$ & 0 & 0 & 0 & 0 & 0 & $\overline{0}$ \\
\hline Wolf_Grove & $\mathrm{H}$ & $\mathrm{E}$ & 0 & 0 & 0 & 0 & 0 & 0 \\
\hline Wolf_Grove & $I$ & $\mathrm{E}$ & 0 & 0 & 0 & 0 & 0 & 0 \\
\hline Wrightville & $\bar{A}$ & $\mathrm{U}$ & 0 & 0 & 9 & 6 & 0 & 1 \\
\hline Wrightville & B & $\bar{U}$ & 0 & 0 & 1 & 0 & 0 & $\overline{0}$ \\
\hline Wrightville & $\mathrm{C}$ & $\mathrm{U}$ & 0 & 0 & 0 & 0 & 0 & 0 \\
\hline Wrightville & $\bar{D}$ & $\mathrm{U}$ & 0 & 0 & 16 & 0 & 0 & $\overline{0}$ \\
\hline Wrightville & $\mathrm{E}$ & $\bar{U}$ & 0 & 0 & 1 & 0 & 0 & $\overline{0}$ \\
\hline Wrightville & $\mathrm{F}$ & $\mathrm{U}$ & 0 & 1 & 0 & 0 & 0 & 0 \\
\hline Wrightville & $\mathrm{H}$ & $\bar{U}$ & 0 & 0 & 1 & 0 & 0 & $\overline{0}$ \\
\hline Wrightville & I & $\mathrm{U}$ & $\overline{0}$ & 0 & 1 & 0 & 0 & 0 \\
\hline Wychwood & A & $S$ & 0 & 0 & 0 & 0 & 0 & 0 \\
\hline Wychwood & $\mathrm{B}$ & $\mathbf{S}$ & 0 & 0 & 1 & 2 & 0 & 0 \\
\hline Wychwood & $\bar{C}$ & $S$ & 0 & 0 & 0 & 0 & 0 & $\overline{0}$ \\
\hline
\end{tabular}




\begin{tabular}{|l|l|l|r|r|r|r|r|r|}
\hline Wychwood & D & S & 0 & 0 & 0 & 0 & 0 & 1 \\
\hline Wychwood & E & S & 0 & 0 & 0 & 0 & 0 & 0 \\
\hline Wychwood & F & S & 0 & 0 & 0 & 0 & 0 & 0 \\
\hline Wychwood & H & S & 0 & 0 & 0 & 3 & 0 & 1 \\
\hline Wychwood & I & S & 0 & 0 & 0 & 0 & 0 & 0 \\
\hline
\end{tabular}




\begin{tabular}{|c|c|c|c|c|c|c|c|c|}
\hline $\begin{array}{l}\text { SITE } \\
\end{array}$ & STATION & CATEGORY & HAFA & HAFU & HAHE & HALO & HAOP & HAPE \\
\hline Achbar & $\mathrm{A}$ & SN & 0 & 0 & 0 & 0 & 0 & 0 \\
\hline Achbar & $\mathrm{B}$ & SN & 0 & 0 & 0 & 0 & 0 & 0 \\
\hline Achbar & $\mathrm{C}$ & $\overline{\mathrm{SN}}$ & 0 & 0 & 0 & 0 & 0 & 0 \\
\hline Achbar & $\mathrm{D}$ & SN & 0 & 0 & 0 & 0 & 0 & 0 \\
\hline Achbar & $E$ & SN & 0 & 0 & 0 & 0 & 0 & 0 \\
\hline Achbar & $\bar{F}$ & $\overline{\mathrm{SN}}$ & 0 & 0 & 0 & 0 & 0 & 0 \\
\hline Achbar & $\mathrm{H}$ & SN & 0 & 0 & 0 & 0 & 0 & 0 \\
\hline Achbar & I & SN & 0 & 0 & 0 & 0 & 0 & 0 \\
\hline Bridlewood & $\bar{A}$ & $\overline{\mathrm{UN}}$ & 0 & 0 & 0 & 0 & 0 & 0 \\
\hline Bridlewood & $\mathrm{B}$ & $\mathrm{UN}$ & 0 & 0 & 0 & 0 & 0 & 0 \\
\hline Bridlewood & $\mathrm{C}$ & $\mathrm{UN}$ & 0 & 0 & 0 & 0 & 0 & 0 \\
\hline Bridlewood & $\mathrm{D}$ & $\overline{\mathrm{UN}}$ & 0 & 1 & 0 & 0 & 0 & 0 \\
\hline Bridlewood & $E$ & UN & 0 & 0 & 0 & 0 & 0 & 0 \\
\hline Bridlewood & $\bar{F}$ & UN & 0 & 0 & 0 & 0 & 0 & 0 \\
\hline Bridlewood & $\mathrm{H}$ & UN & 0 & 0 & 0 & 0 & 0 & 0 \\
\hline Bridlewood & I & UN & 0 & 0 & 0 & 0 & 0 & 0 \\
\hline Carp_Hills & A & $F$ & 0 & 0 & 0 & 0 & 0 & 0 \\
\hline Carp_Hills & B & $F$ & 0 & 0 & 0 & 0 & 0 & 0 \\
\hline Carp_Hills & $\overline{\mathrm{C}}$ & $\bar{F}$ & 0 & 0 & 0 & 0 & 0 & 0 \\
\hline Carp_Hills & $\mathrm{D}$ & $\mathrm{F}$ & 0 & 0 & 0 & 0 & 0 & 0 \\
\hline Carp_Hills & $\mathrm{E}$ & $F$ & 0 & 0 & 0 & 0 & 0 & 0 \\
\hline Carp_Hills & $F$ & $F$ & 0 & 0 & 0 & 0 & 0 & 0 \\
\hline Carp_Hills & $\mathrm{H}$ & $F$ & 0 & 0 & 0 & 0 & 0 & 0 \\
\hline Carp_Hills & $\mathrm{I}$ & $F$ & 0 & 0 & 0 & 0 & 0 & 0 \\
\hline Chapel_Hill & $\bar{A}$ & $\overline{\mathrm{UN}}$ & 0 & 0 & 0 & 0 & 0 & 0 \\
\hline Chapel_Hill & B & UN & 0 & 0 & 0 & $\overline{0}$ & 0 & 0 \\
\hline Chapel_Hill & $\mathrm{C}$ & UN & 0 & 0 & 0 & 0 & 0 & 0 \\
\hline Chapel_Hill & $\mathrm{D}$ & $\overline{\mathrm{UN}}$ & 0 & 0 & 0 & 0 & 0 & 0 \\
\hline Chapel_Hill & $E$ & UN & 0 & 0 & 0 & 0 & 0 & 0 \\
\hline Chapel_Hill & $\mathrm{F}$ & UN & 0 & 0 & 0 & 0 & 0 & 0 \\
\hline Chapel_Hill & $\mathrm{H}$ & UN & 0 & 0 & 0 & 0 & 0 & 0 \\
\hline Chapel_Hill & $\mathrm{I}$ & UN & 0 & 0 & 0 & 0 & 0 & 0 \\
\hline Chelsea & $\bar{A}$ & $\mathrm{SN}$ & 0 & 0 & 0 & 0 & 0 & 0 \\
\hline Chelsea & B & $\mathrm{SN}$ & 0 & 0 & 0 & 0 & 0 & 0 \\
\hline Chelsea & $\mathrm{C}$ & SN & 0 & 0 & 0 & 0 & 0 & 0 \\
\hline Chelsea & $\mathrm{D}$ & SN & 0 & 0 & 0 & 0 & 0 & 0 \\
\hline Chelsea & $\mathrm{E}$ & SN & $\overline{0}$ & 0 & 0 & 0 & 0 & 0 \\
\hline Chelsea & $F$ & $\mathrm{SN}$ & 0 & 0 & 0 & 0 & 0 & 0 \\
\hline Chelsea & $\overline{\mathrm{H}}$ & $\overline{\mathrm{SN}}$ & 0 & 0 & 0 & 0 & 0 & 0 \\
\hline Chelsea & I & SN & 0 & 0 & 0 & 0 & 0 & 0 \\
\hline Cote_d'Azur & $\bar{A}$ & $\mathrm{~S}$ & 0 & 0 & 0 & 0 & 0 & 1 \\
\hline Cote_d'Azur & B & $\mathrm{S}$ & 0 & 0 & 0 & 0 & 0 & 1 \\
\hline Cote_d'Azur & $\mathrm{C}$ & $\mathrm{S}$ & 0 & 0 & 0 & 0 & 0 & 1 \\
\hline Cote_d'Azur & $\mathrm{D}$ & $S$ & 0 & 0 & 0 & 2 & 0 & 1 \\
\hline
\end{tabular}




\begin{tabular}{|c|c|c|c|c|c|c|c|c|}
\hline Cote_d'Azur & $\mathrm{E}$ & $\mathbf{S}$ & 0 & 0 & 0 & 0 & 0 & 1 \\
\hline Cote_d'Azur & $\mathrm{F}$ & $\bar{S}$ & 0 & 0 & 0 & 7 & 0 & 1 \\
\hline Cote_d'Azur & $\mathrm{H}$ & $\mathrm{S}$ & 0 & 0 & 0 & 0 & 0 & 0 \\
\hline Cote_d'Azur & I & $\mathrm{S}$ & 0 & 0 & 0 & 1 & 0 & 0 \\
\hline Highway_Seven & A & $\mathrm{E}$ & $\mathbf{0}$ & 0 & 0 & 0 & $\begin{array}{lll}0 & & \\
\end{array}$ & $\begin{array}{lll}0 & & \\
\end{array}$ \\
\hline Highway_Seven & $\overline{\mathrm{B}}$ & $\bar{E}$ & 0 & 0 & 0 & 0 & 0 & 0 \\
\hline Highway_Seven & $\bar{C}$ & $E$ & 0 & 0 & 0 & 0 & 0 & 0 \\
\hline Highway_Seven & $\bar{D}$ & $\mathrm{E}$ & 0 & 0 & 0 & 0 & 0 & 0 \\
\hline Highway_Seven & $\bar{E}$ & $\mathrm{E}$ & 0 & 0 & 0 & 0 & 0 & 0 \\
\hline Highway_Seven & F & $\bar{E}$ & 0 & 0 & 0 & 0 & 0 & 0 \\
\hline Highway_Seven & $\mathrm{H}$ & $E$ & 0 & 0 & 1 & 0 & $\begin{array}{l}0 \\
0\end{array}$ & $\overline{0}$ \\
\hline Highway_Seven & $\mathrm{I}$ & $\bar{E}$ & 0 & 0 & 0 & 0 & 0 & $\overline{0}$ \\
\hline Hull & $\mathrm{A}$ & $\overline{\mathrm{U}}$ & 0 & 0 & 0 & 0 & 0 & 0 \\
\hline Hull & B & $\mathrm{U}$ & 0 & 0 & 0 & 0 & 0 & 0 \\
\hline Hull & $\mathrm{C}$ & $\overline{\mathrm{U}}$ & 0 & 0 & 0 & 0 & 0 & 0 \\
\hline Hull & $\overline{\mathrm{D}}$ & $\bar{U}$ & 0 & 0 & 0 & 0 & 0 & 0 \\
\hline Hull & $\mathrm{E}$ & $\bar{U}$ & 0 & 0 & 0 & 2 & 0 & 2 \\
\hline Hull & $F$ & $\bar{U}$ & 0 & 0 & 0 & 0 & 0 & 1 \\
\hline Hull & $\mathrm{H}$ & $\mathrm{U}$ & 0 & 0 & 1 & 4 & 0 & 2 \\
\hline Hull & I & $\bar{U}$ & 0 & 0 & 0 & 0 & 0 & 2 \\
\hline Lac_Philippe & $\mathrm{A}$ & $\mathrm{F}$ & 0 & 0 & 0 & 0 & 0 & 0 \\
\hline Lac_Philippe & B & $\mathrm{F}$ & 0 & 0 & 0 & 0 & 0 & 0 \\
\hline Lac_Philippe & $\mathrm{C}$ & $\mathrm{F}$ & 0 & 0 & 0 & 0 & 0 & 0 \\
\hline Lac_Philippe & $\bar{D}$ & $\bar{F}$ & $\overline{0}$ & 0 & 0 & 0 & 0 & 0 \\
\hline Lac_Philippe & $E$ & $\mathrm{~F}$ & 0 & 0 & 0 & 0 & 0 & 0 \\
\hline Lac_Philippe & $F$ & $\mathrm{~F}$ & 0 & 0 & 0 & 0 & 0 & $\overline{0}$ \\
\hline Lac_Philippe & $\mathrm{H}$ & $\mathrm{F}$ & 0 & 0 & 0 & 0 & 0 & 0 \\
\hline Lac_Philippe & I & $\bar{F}$ & 0 & 0 & 0 & 0 & 0 & 0 \\
\hline Manoir_des_Trembles & $\bar{A}$ & $\mathrm{UN}$ & 0 & 0 & 0 & 0 & 0 & 0 \\
\hline Manoir_des_Trembles & $\mathrm{B}$ & $\overline{\mathrm{UN}}$ & 0 & 0 & 0 & 0 & 0 & 0 \\
\hline Manoir_des_Trembles & $\mathrm{C}$ & $\overline{\mathrm{UN}}$ & $\mathbf{0}$ & 0 & 0 & $\mathbf{0}$ & 0 & $\overline{0}$ \\
\hline Manoir_des_Trembles & $\mathrm{D}$ & UN & 0 & 0 & 0 & 0 & 0 & 0 \\
\hline Manoir_des_Trembles & $\mathrm{E}$ & UN & 0 & 0 & 0 & 0 & 0 & 0 \\
\hline Manoir_des_Trembles & $\mathrm{F}$ & $\overline{\mathrm{UN}}$ & 0 & 0 & 0 & 0 & 0 & 0 \\
\hline Manoir_des_Trembles & $\mathrm{H}$ & UN & 0 & 0 & 0 & 0 & 0 & 0 \\
\hline Manoir_des_Trembles & I & UN & 0 & 0 & 0 & 0 & 0 & 0 \\
\hline Marathon & $\mathrm{A}$ & $E$ & 0 & 0 & 0 & 0 & 0 & 0 \\
\hline Marathon & $\mathrm{B}$ & $\mathrm{E}$ & 0 & 0 & 0 & 0 & 0 & 0 \\
\hline Marathon & $\mathrm{C}$ & $\mathrm{E}$ & 0 & 0 & 0 & 0 & 0 & 0 \\
\hline Marathon & $\mathrm{D}$ & $E$ & 0 & 0 & 0 & 0 & 0 & 0 \\
\hline Marathon & $E$ & $E$ & 0 & $\mathbf{0}$ & 0 & 0 & 0 & 0 \\
\hline Marathon & $F$ & $\bar{E}$ & 0 & 0 & 0 & 0 & 0 & 0 \\
\hline Marathon & $\mathrm{H}$ & $\mathrm{E}$ & 0 & 0 & 0 & 0 & 0 & 0 \\
\hline Marathon & I & $\bar{E}$ & 0 & 0 & 0 & 0 & 0 & 0 \\
\hline Marier & $\bar{A}$ & $\mathrm{U}$ & 0 & $\overline{0}$ & 0 & 0 & 0 & 3 \\
\hline
\end{tabular}




\begin{tabular}{|c|c|c|c|c|c|c|c|c|}
\hline Marier & $\mathrm{B}$ & $\mathrm{U}$ & 0 & 0 & 0 & 0 & 0 & 1 \\
\hline Marier & $\mathrm{C}$ & $\bar{U}$ & 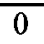 & 0 & 0 & 2 & 0 & 1 \\
\hline Marier & $\bar{D}$ & $\mathrm{U}$ & 0 & 0 & 0 & 0 & 0 & 3 \\
\hline Marier & $\mathrm{E}$ & $\bar{U}$ & 0 & 0 & 0 & 0 & 0 & 2 \\
\hline Marier & $\mathrm{F}$ & $\mathrm{U}$ & 0 & 0 & 0 & 0 & 0 & 0 \\
\hline Marier & $\mathrm{H}$ & $\mathrm{U}$ & $\overline{0}$ & 0 & 0 & 2 & 0 & 3 \\
\hline Marier & I & $\bar{U}$ & 0 & 0 & 0 & 0 & 0 & 1 \\
\hline Marlborough & $\mathrm{A}$ & $\mathrm{F}$ & 0 & 0 & 0 & 0 & 0 & 0 \\
\hline Marlborough & $\mathrm{B}$ & $\mathrm{F}$ & 0 & 0 & 0 & 0 & 0 & 0 \\
\hline Marlborough & $\mathrm{C}$ & $\mathrm{F}$ & 0 & 0 & 0 & 0 & 0 & 0 \\
\hline Marlborough & $\mathrm{D}$ & $F$ & 0 & 0 & 0 & 0 & 0 & 0 \\
\hline Marlborough & $\mathrm{E}$ & $\vec{F}$ & 0 & 0 & 0 & 0 & 0 & $\overline{0}$ \\
\hline Marlborough & $\mathrm{F}$ & $\mathrm{F}$ & 0 & 0 & 0 & 0 & 0 & 0 \\
\hline Marlborough & $\mathrm{H}$ & $\mathrm{F}$ & 0 & 0 & 0 & 0 & 0 & $\overline{0}$ \\
\hline Marlborough & I & $\bar{F}$ & 0 & 0 & 0 & 0 & 0 & 0 \\
\hline Merivale & $\mathrm{A}$ & $\mathrm{SN}$ & 0 & 0 & 0 & 0 & 0 & 0 \\
\hline Merivale & $\mathrm{B}$ & $\mathrm{SN}$ & 0 & 0 & 0 & 0 & 0 & 0 \\
\hline Merivale & $\mathrm{C}$ & $\overline{\mathrm{SN}}$ & 0 & 0 & 0 & 0 & 0 & 0 \\
\hline Merivale & $\mathrm{D}$ & SN & 0 & 0 & 0 & 0 & 0 & 0 \\
\hline Merivale & $\bar{E}$ & SN & 0 & 0 & 0 & 0 & 0 & 0 \\
\hline Merivale & $F$ & $\overline{\mathrm{SN}}$ & 0 & 0 & 0 & 0 & 0 & 0 \\
\hline Merivale & $\mathrm{H}$ & SN & 0 & 0 & 0 & 0 & 0 & 0 \\
\hline Merivale & I & $\mathrm{SN}$ & 0 & 0 & 0 & 0 & 0 & 0 \\
\hline Parc_Champlain & $\mathrm{A}$ & $\mathrm{S}$ & 0 & 0 & 0 & 1 & 0 & 0 \\
\hline Parc_Champlain & $\mathrm{B}$ & $\mathrm{S}$ & 0 & 0 & 0 & 0 & 0 & 0 \\
\hline Parc_Champlain & $\mathrm{C}$ & $\mathrm{S}$ & 0 & 0 & 0 & 0 & 0 & $\overline{0}$ \\
\hline Parc_Champlain & $\mathrm{D}$ & $\mathrm{S}$ & 1 & 0 & 0 & 5 & 0 & 1 \\
\hline Parc_Champlain & $\mathrm{E}$ & $\mathrm{S}$ & 1 & 0 & 0 & 0 & 0 & 0 \\
\hline Parc_Champlain & $F$ & $\mathrm{~S}$ & 1 & 0 & 0 & 7 & 0 & 1 \\
\hline Parc_Champlain & $\mathrm{H}$ & $\bar{S}$ & 0 & 0 & 0 & 5 & 0 & 0 \\
\hline Parc_Champlain & $\mathrm{I}$ & $\mathrm{S}$ & 0 & 0 & 0 & 0 & 0 & 1 \\
\hline PineGlen_Annex & $\mathrm{A}$ & $\mathrm{S}$ & 0 & 0 & 0 & 0 & 0 & 0 \\
\hline PineGlen_Annex & $\mathrm{B}$ & $\mathrm{S}$ & 0 & 0 & 0 & 0 & 0 & 0 \\
\hline PineGlen_Annex & $\mathrm{C}$ & $\mathrm{S}$ & 0 & 0 & 0 & 0 & 0 & 0 \\
\hline PineGlen_Annex & $\mathrm{D}$ & $\mathrm{S}$ & 0 & 0 & 0 & 0 & 0 & 0 \\
\hline PineGlen_Annex & $\mathrm{E}$ & $\mathrm{S}$ & 0 & 0 & 0 & 1 & 1 & 18 \\
\hline PineGlen_Annex & $\mathrm{F}$ & $\mathrm{S}$ & 0 & 0 & 0 & 0 & 0 & 0 \\
\hline PineGlen_Annex & $\mathrm{H}$ & $\mathrm{S}$ & 0 & 0 & 0 & 1 & 0 & $\overline{0}$ \\
\hline PineGlen_Annex & I & $\mathrm{S}$ & 0 & 0 & 0 & 3 & 1 & 0 \\
\hline Q_Four & $\mathrm{A}$ & $\mathbf{E}$ & 0 & 0 & 0 & 0 & 0 & 0 \\
\hline Q_Four & $\mathrm{B}$ & $\mathbf{E}$ & 0 & 0 & 0 & 0 & 0 & 0 \\
\hline Q_Four & $\mathrm{C}$ & $\mathbf{E}$ & 0 & 0 & 0 & 0 & 0 & 0 \\
\hline Q_Four & $\mathrm{D}$ & $\mathbf{E}$ & 0 & 0 & 0 & 0 & 0 & 0 \\
\hline Q_Four & $\mathrm{E}$ & $\bar{E}$ & 0 & 0 & 0 & 0 & 0 & 0 \\
\hline Q_Four & $F$ & $\bar{E}$ & 0 & 0 & 0 & 0 & 0 & 0 \\
\hline
\end{tabular}




\begin{tabular}{|c|c|c|c|c|c|c|c|c|}
\hline Q_Four & $\overline{\mathrm{H}}$ & $E$ & 0 & 0 & 0 & 0 & 0 & 0 \\
\hline Q_Four & I & $\bar{E}$ & 0 & 0 & 0 & 0 & 0 & 0 \\
\hline Sandy_Hill & $\bar{A}$ & $\mathrm{U}$ & 0 & 0 & 0 & 0 & 0 & 1 \\
\hline Sandy_Hill & $\mathbf{B}$ & $\mathrm{U}$ & 0 & 0 & 0 & 0 & 0 & 7 \\
\hline Sandy_Hill & $\bar{C}$ & $\overline{\mathrm{U}}$ & 0 & 0 & 0 & 0 & 0 & 1 \\
\hline Sandy_Hill & $\bar{D}$ & $\overline{\mathrm{U}}$ & 1 & 0 & 0 & 0 & 0 & 0 \\
\hline Sandy_Hill & $\bar{E}$ & $\bar{U}$ & 0 & $\overline{0}$ & 0 & 0 & 0 & 0 \\
\hline Sandy_Hill & $\mathrm{F}$ & $\overline{\mathrm{U}}$ & 0 & 0 & 0 & 0 & 0 & 0 \\
\hline Sandy_Hill & $\mathrm{H}$ & $\mathrm{U}$ & 0 & 0 & 0 & 0 & 0 & 0 \\
\hline Sandy_Hill & $I$ & $\bar{U}$ & 0 & 0 & 0 & 0 & 0 & 0 \\
\hline Vallee_Meech & A & $\overline{\mathrm{F}}$ & 0 & 0 & 0 & 0 & 0 & 0 \\
\hline Vallee_Meech & B & $\bar{F}$ & 0 & 0 & 0 & 0 & 0 & 0 \\
\hline Vallee_Meech & $\mathrm{C}$ & $\bar{F}$ & 0 & 0 & 0 & 0 & 0 & 0 \\
\hline Vallee_Meech & $\bar{D}$ & $\mathrm{~F}$ & 0 & 0 & 0 & 0 & 0 & 0 \\
\hline Vallee_Meech & $E$ & $\bar{F}$ & 0 & 0 & 0 & 0 & 0 & $\overline{0}$ \\
\hline Vallee_Meech & $\mathrm{F}$ & $F$ & 0 & 0 & 0 & 0 & 0 & 0 \\
\hline Vallee_Meech & $\mathrm{H}$ & $\bar{F}$ & 0 & 0 & 0 & 0 & 0 & 0 \\
\hline Vallee_Meech & I & $\mathrm{F}$ & 0 & 0 & 0 & 0 & 0 & 0 \\
\hline Wolf_Grove & $\bar{A}$ & $\mathrm{E}$ & 0 & 0 & 0 & 0 & 0 & 0 \\
\hline Wolf_Grove & B & $\mathrm{E}$ & 0 & 0 & 0 & 0 & 0 & 0 \\
\hline Wolf_Grove & $\mathrm{C}$ & $\mathrm{E}$ & 0 & 0 & 0 & 0 & 0 & 0 \\
\hline Wolf_Grove & $\mathrm{D}$ & $\mathrm{E}$ & 0 & 0 & 0 & 0 & $\overline{0}$ & 0 \\
\hline Wolf_Grove & $E$ & $\bar{E}$ & 0 & 0 & 0 & 0 & 0 & 0 \\
\hline Wolf_Grove & $\mathrm{F}$ & $\mathrm{E}$ & 0 & 0 & 0 & 0 & 0 & 0 \\
\hline Wolf_Grove & $\mathrm{H}$ & $\mathrm{E}$ & 0 & 0 & 0 & 0 & $\overline{0}$ & 0 \\
\hline Wolf_Grove & I & $\mathrm{E}$ & 0 & 0 & 0 & 0 & 0 & 0 \\
\hline Wrightville & $\mathrm{A}$ & $\mathrm{U}$ & 0 & 0 & 0 & 18 & 1 & 24 \\
\hline Wrightville & B & $\bar{U}$ & 0 & 0 & 0 & 0 & 0 & 0 \\
\hline Wrightville & $\mathrm{C}$ & $\bar{U}$ & 0 & 0 & 0 & 0 & 0 & 1 \\
\hline Wrightville & $\mathrm{D}$ & $\bar{U}$ & 0 & 0 & 0 & 1 & 0 & 12 \\
\hline Wrightville & $\mathrm{E}$ & $\overline{\mathrm{U}}$ & 0 & 0 & 0 & 0 & 0 & 1 \\
\hline Wrightville & $\mathrm{F}$ & $\mathrm{U}$ & 0 & 0 & 0 & 0 & 0 & 0 \\
\hline Wrightville & $\mathrm{H}$ & $\bar{U}$ & 0 & 0 & 0 & 0 & 0 & 3 \\
\hline Wrightville & I & $\bar{U}$ & $\overline{0}$ & 0 & 0 & 0 & 0 & 4 \\
\hline Wychwood & $\bar{A}$ & $\mathrm{~S}$ & 0 & 0 & 0 & 0 & 0 & 1 \\
\hline Wychwood & B & $\bar{S}$ & 1 & 0 & 0 & 0 & 0 & 5 \\
\hline Wychwood & $\mathrm{C}$ & $\bar{S}$ & 0 & 0 & 0 & 0 & 0 & 0 \\
\hline Wychwood & $\mathrm{D}$ & $\mathbf{S}$ & 1 & 0 & 1 & 0 & 0 & 3 \\
\hline Wychwood & $\bar{E}$ & $\mathrm{~S}$ & $\overline{0}$ & 0 & 0 & 0 & 0 & 1 \\
\hline Wychwood & $\mathrm{F}$ & $\mathrm{S}$ & 0 & 0 & 1 & 0 & 0 & 7 \\
\hline Wychwood & $\mathrm{H}$ & $\mathrm{S}$ & 0 & 0 & 0 & 0 & 0 & 4 \\
\hline Wychwood & I & $\mathrm{S}$ & 0 & 0 & 1 & 0 & 0 & 1 \\
\hline
\end{tabular}




\begin{tabular}{|c|c|c|c|c|c|c|c|c|}
\hline SITE & STATION & CATEGORY & HAPR & HASO & LOCO & LOPI & LOSC & MYCY \\
\hline Achbar & A & $\mathrm{SN}$ & 0 & 0 & 0 & 0 & 0 & 0 \\
\hline Achbar & B & SN & 0 & 0 & 0 & 0 & 0 & 0 \\
\hline Achbar & $\mathrm{C}$ & $\overline{\mathrm{SN}}$ & $\overline{0}$ & 0 & 0 & 0 & 0 & $\overline{0}$ \\
\hline Achbar & $\bar{D}$ & $\overline{\mathrm{SN}}$ & 0 & 0 & 0 & 0 & 0 & 0 \\
\hline Achbar & $\bar{E}$ & $\overline{\mathrm{SN}}$ & 0 & 0 & 0 & 0 & 0 & 0 \\
\hline Achbar & $\bar{F}$ & SN & 0 & 0 & 0 & 0 & 0 & 0 \\
\hline Achbar & $\mathrm{H}$ & $\overline{\mathrm{SN}}$ & 0 & 0 & 0 & 0 & 0 & 0 \\
\hline Achbar & I & SN & 0 & 0 & 0 & 0 & 0 & 0 \\
\hline Bridlewood & $\bar{A}$ & $\overline{\mathrm{UN}}$ & 0 & 0 & 0 & 0 & 0 & 0 \\
\hline Bridlewood & $\mathrm{B}$ & $\mathrm{UN}$ & 0 & 0 & 0 & 0 & 0 & 0 \\
\hline Bridlewood & $\mathrm{C}$ & $\overline{U N}$ & 3 & 0 & 0 & 0 & 1 & $\overline{0}$ \\
\hline Bridlewood & $\overline{\mathrm{D}}$ & $\overline{\mathrm{UN}}$ & 0 & 0 & 0 & 0 & 1 & $\overline{0}$ \\
\hline Bridlewood & $\bar{E}$ & UN & 0 & 0 & 0 & 0 & 0 & 0 \\
\hline Bridlewood & $F$ & UN & 0 & 0 & 0 & 0 & 0 & 0 \\
\hline Bridlewood & $\mathrm{H}$ & UN & 0 & 0 & 0 & 0 & 0 & 0 \\
\hline Bridlewood & I & UN & 0 & 0 & 0 & 0 & 0 & $\overline{0}$ \\
\hline Carp_Hills & $\bar{A}$ & $\mathrm{~F}$ & 0 & 0 & 0 & 0 & I & $\overline{0}$ \\
\hline Carp_Hills & $\mathrm{B}$ & $\mathrm{F}$ & 0 & 0 & 0 & 1 & 4 & 0 \\
\hline Carp_Hills & $\mathrm{C}$ & $\mathrm{F}$ & 0 & 0 & 0 & 0 & 0 & $\overline{0}$ \\
\hline Carp_Hills & $\bar{D}$ & $\bar{F}$ & 0 & 0 & 0 & 0 & 0 & 0 \\
\hline Carp_Hills & $\bar{E}$ & $\mathrm{~F}$ & 0 & 0 & 0 & 1 & 2 & $\overline{0}$ \\
\hline Carp_Hills & $F$ & $\bar{F}$ & 0 & 0 & 0 & 0 & 1 & $\overline{0}$ \\
\hline Carp_Hills & $\mathrm{H}$ & $F$ & 0 & 0 & 0 & 0 & 1 & $\overline{0}$ \\
\hline Carp_Hills & I & $\bar{F}$ & 0 & 0 & 0 & 0 & 1 & $\overline{0}$ \\
\hline Chapel_Hill & $\mathrm{A}$ & $\mathrm{UN}$ & 0 & 0 & 0 & 2 & 1 & 0 \\
\hline Chapel_Hill & B & UN & 0 & 0 & 0 & 0 & 0 & $\overline{0}$ \\
\hline Chapel_Hill & $\mathrm{C}$ & UN & 0 & 0 & 0 & 0 & 0 & $\overline{0}$ \\
\hline Chapel_Hill & $\mathrm{D}$ & $\mathrm{UN}$ & 0 & 0 & 0 & 0 & 0 & $\overline{0}$ \\
\hline Chapel_Hill & $E$ & $\overline{\mathrm{UN}}$ & 0 & 0 & 0 & $T$ & 0 & 0 \\
\hline Chapel_Hill & $\mathrm{F}$ & UN & 0 & 0 & 0 & 0 & 0 & $\overline{0}$ \\
\hline Chapel_Hill & $\mathrm{H}$ & $\mathrm{UN}$ & 0 & 0 & 0 & 0 & 0 & $\overline{0}$ \\
\hline Chapel_Hill & I & $\overline{\mathrm{UN}}$ & 0 & 0 & 0 & 0 & 7 & $\overline{0}$ \\
\hline Chelsea & $\bar{A}$ & SN & 0 & 0 & 0 & 0 & 0 & $\overline{0}$ \\
\hline Chelsea & $\mathrm{B}$ & $\overline{\mathrm{SN}}$ & 0 & 0 & 0 & 0 & 0 & 0 \\
\hline Chelsea & $\bar{C}$ & SN & 0 & 0 & 0 & 0 & 0 & 0 \\
\hline Chelsea & $\mathrm{D}$ & $\mathrm{SN}$ & 0 & 0 & 0 & 0 & 0 & 0 \\
\hline Chelsea & $\bar{E}$ & SN & 0 & 0 & 0 & 0 & 0 & 0 \\
\hline Chelsea & $\mathrm{F}$ & SN & 0 & 0 & 0 & 0 & 0 & $\overline{0}$ \\
\hline Chelsea & $\mathrm{H}$ & $\mathrm{SN}$ & 0 & 0 & 0 & 0 & 0 & $\overline{0}$ \\
\hline Chelsea & I & SN & 0 & 0 & 0 & 0 & 0 & 0 \\
\hline Cote_d'Azur & $\mathrm{A}$ & $S$ & 0 & 0 & 0 & 0 & 0 & 0 \\
\hline Cote_d'Azur & B & $\mathrm{S}$ & 0 & 0 & 0 & 0 & 0 & 0 \\
\hline Cote_d'Azur & $\mathrm{C}$ & $S$ & 0 & 0 & 0 & 0 & 0 & 0 \\
\hline Cote_d'Azur & $\mathrm{D}$ & $\mathrm{S}$ & 0 & 0 & 0 & 0 & 0 & 0 \\
\hline
\end{tabular}




\begin{tabular}{|c|c|c|c|c|c|c|c|c|}
\hline Cote_d'Azur & $\mathrm{E}$ & $\mathrm{S}$ & 0 & 0 & 0 & 0 & 0 & 0 \\
\hline Cote_d'Azur & $\mathrm{F}$ & $\mathrm{S}$ & $\mathbf{0}$ & 0 & 0 & $\mathbf{0}$ & 0 & 0 \\
\hline Cote_d'Azur & $\overline{\mathrm{H}}$ & $S$ & 0 & 0 & 0 & $\overline{0}$ & 0 & $\overline{0}$ \\
\hline Cote_d'Azur & I & $\overline{\mathrm{S}}$ & 0 & 0 & 0 & 0 & 0 & 0 \\
\hline Highway_Seven & $\bar{A}$ & $\bar{E}$ & $\overline{0}$ & 0 & 0 & 0 & 0 & 0 \\
\hline Highway_Seven & $\bar{B}$ & $\bar{E}$ & 0 & 0 & 0 & 0 & 0 & $\overline{0}$ \\
\hline Highway_Seven & $\mathrm{C}$ & $\mathrm{E}$ & 0 & 0 & 0 & 0 & 0 & 0 \\
\hline Highway_Seven & $\bar{D}$ & $\bar{E}$ & 0 & 0 & 0 & 0 & 0 & 0 \\
\hline Highway_Seven & $\bar{E}$ & $\bar{E}$ & 0 & 0 & 1 & 0 & 1 & $\overline{0}$ \\
\hline Highway_Seven & $F$ & $\mathrm{E}$ & 0 & 0 & 0 & 0 & 0 & $\overline{0}$ \\
\hline Highway_Seven & $\mathrm{H}$ & $\bar{E}$ & 0 & 1 & 0 & 0 & 0 & 0 \\
\hline Highway_Seven & $\bar{I}$ & $\mathrm{E}$ & 0 & 0 & 0 & 0 & 0 & 0 \\
\hline Hull & $\bar{A}$ & $\overline{\mathrm{U}}$ & 0 & 0 & 0 & 0 & 0 & 0 \\
\hline Hull & $\mathrm{B}$ & $\mathrm{U}$ & 0 & 0 & 0 & 0 & 0 & 0 \\
\hline Hull & $\mathrm{C}$ & $\overline{\mathrm{U}}$ & 0 & $\overline{0}$ & 0 & 0 & 0 & 0 \\
\hline Hull & $\bar{D}$ & $\mathrm{U}$ & 0 & 0 & 0 & 0 & 0 & 0 \\
\hline Hull & $\mathrm{E}$ & $\mathrm{U}$ & 0 & 0 & 0 & 0 & 0 & 0 \\
\hline Hull & $\mathrm{F}$ & $\bar{U}$ & 0 & $\overline{0}$ & 0 & 0 & 0 & $\overline{0}$ \\
\hline Hull & $\mathrm{H}$ & $\mathrm{U}$ & 0 & 0 & 0 & 0 & 0 & 0 \\
\hline Hull & I & $\mathrm{U}$ & 0 & 0 & 0 & 0 & 0 & 0 \\
\hline Lac_Philippe & A & $\mathrm{F}$ & 0 & 0 & 0 & 0 & 0 & 0 \\
\hline Lac_Philippe & $\mathrm{B}$ & $\mathrm{F}$ & 0 & 0 & 0 & 0 & 0 & 1 \\
\hline Lac_Philippe & $\mathrm{C}$ & $\bar{F}$ & 0 & 0 & 0 & 0 & 0 & 0 \\
\hline Lac_Philippe & $\mathrm{D}$ & $\mathrm{F}$ & 0 & 0 & 0 & 0 & 0 & 1 \\
\hline Lac_Philippe & $\mathrm{E}$ & $\mathrm{F}$ & 0 & 0 & 0 & 0 & 0 & 0 \\
\hline Lac_Philippe & $\mathrm{F}$ & $\mathrm{F}$ & 0 & 0 & 0 & 0 & 0 & 0 \\
\hline Lac_Philippe & $\mathrm{H}$ & $\mathrm{F}$ & 0 & 0 & 0 & 1 & 0 & 0 \\
\hline Lac_Philippe & I & $\mathrm{F}$ & 0 & 0 & 0 & 0 & 0 & 0 \\
\hline Manoir_des_Trembles & $\bar{A}$ & $\overline{\mathrm{UN}}$ & 0 & 0 & 0 & 0 & 0 & $\overline{0}$ \\
\hline Manoir_des_Trembles & $\mathrm{B}$ & $\mathrm{UN}$ & 0 & 0 & 0 & 0 & 0 & 0 \\
\hline Manoir_des_Trembles & $\bar{C}$ & $\overline{\mathrm{UN}}$ & 0 & $\overline{0}$ & 0 & 0 & 2 & 0 \\
\hline Manoir_des_Trembles & $\mathrm{D}$ & $\overline{\mathrm{UN}}$ & 0 & 0 & 0 & 0 & 0 & 1 \\
\hline Manoir_des_Trembles & $\mathrm{E}$ & UN & 0 & 0 & 0 & 0 & 0 & 0 \\
\hline Manoir_des_Trembles & $\mathrm{F}$ & $\mathrm{UN}$ & 0 & 0 & 0 & 0 & 0 & 0 \\
\hline Manoir_des_Trembles & $\overline{\mathrm{H}}$ & UN & 0 & 0 & 0 & 0 & 0 & 1 \\
\hline Manoir_des_Trembles & I & $\overline{U N}$ & 0 & 0 & 0 & 0 & 0 & 0 \\
\hline Marathon & $\bar{A}$ & $\mathrm{E}$ & 0 & 0 & 0 & 0 & 0 & 0 \\
\hline Marathon & $\mathrm{B}$ & $E$ & 0 & 0 & 0 & 0 & 0 & $\overline{0}$ \\
\hline Marathon & $\mathrm{C}$ & $\mathbf{E}$ & 0 & 0 & 2 & 0 & 1 & 0 \\
\hline Marathon & $\mathrm{D}$ & $\mathrm{E}$ & 0 & 1 & 0 & 0 & 0 & 0 \\
\hline Marathon & $\mathrm{E}$ & $\mathrm{E}$ & 0 & 0 & 0 & 0 & 0 & 0 \\
\hline Marathon & $\mathrm{F}$ & $E$ & 0 & 0 & 2 & 0 & 0 & 0 \\
\hline Marathon & $\mathrm{H}$ & $\mathrm{E}$ & 0 & 0 & 0 & 0 & 0 & 0 \\
\hline Marathon & I & $\bar{E}$ & 0 & 0 & 0 & 0 & 0 & 0 \\
\hline Marier & $A$ & $\overline{\mathrm{U}}$ & 0 & 0 & 0 & 0 & 0 & 0 \\
\hline
\end{tabular}




\begin{tabular}{|c|c|c|c|c|c|c|c|c|}
\hline Marier & $\mathrm{B}$ & $\bar{U}$ & 0 & 0 & 0 & 0 & 0 & 0 \\
\hline Marier & $\mathrm{C}$ & $\overline{\mathrm{U}}$ & 0 & 0 & 0 & 0 & 0 & 0 \\
\hline Marier & $\mathrm{D}$ & $\bar{U}$ & 0 & 0 & 0 & 0 & 0 & 0 \\
\hline Marier & $\mathrm{E}$ & $\bar{U}$ & 0 & 0 & 0 & 0 & 0 & 0 \\
\hline Marier & $F$ & $\bar{U}$ & 0 & 0 & 0 & 0 & 0 & 0 \\
\hline Marier & $\bar{H}$ & $\bar{U}$ & 0 & 0 & 0 & 0 & 0 & $\overline{0}$ \\
\hline Marier & I & $\overline{\mathrm{U}}$ & 0 & 0 & 0 & 0 & 0 & 0 \\
\hline Marlborough & $\bar{A}$ & $F$ & 0 & 0 & 0 & 0 & 0 & 0 \\
\hline Marlborough & $\mathrm{B}$ & $\mathrm{F}$ & 0 & 0 & 0 & 0 & 0 & 0 \\
\hline Marlborough & $\mathrm{C}$ & $\mathrm{F}$ & 0 & 0 & 0 & 0 & 0 & 0 \\
\hline Marlborough & $\overline{\mathrm{D}}$ & $F$ & 0 & 0 & 0 & 0 & 2 & 0 \\
\hline Marlborough & $\mathrm{E}$ & $\bar{F}$ & 0 & 0 & 0 & 0 & 0 & 0 \\
\hline Marlborough & $\mathrm{F}$ & $F$ & 0 & 0 & 0 & 1 & 0 & 0 \\
\hline Marlborough & $\mathrm{H}$ & $F$ & 0 & 0 & 0 & 0 & 1 & 0 \\
\hline Marlborough & I & $F$ & 0 & 0 & 0 & 0 & 0 & 0 \\
\hline Merivale & A & $\mathrm{SN}$ & 0 & 0 & 0 & 0 & 0 & 0 \\
\hline Merivale & $\mathrm{B}$ & $\mathrm{SN}$ & 0 & 0 & 0 & 0 & 0 & 0 \\
\hline Merivale & $\mathrm{C}$ & $\mathrm{SN}$ & 0 & 0 & 0 & 0 & 0 & 0 \\
\hline Merivale & $\mathrm{D}$ & $\overline{\mathrm{SN}}$ & 0 & 0 & 0 & 0 & 0 & 0 \\
\hline Merivale & $\mathrm{E}$ & $\mathrm{SN}$ & 0 & 0 & 0 & 0 & 0 & 0 \\
\hline Merivale & $F$ & SN & 0 & 1 & 0 & 0 & 0 & 0 \\
\hline Merivale & $\mathrm{H}$ & $\mathrm{SN}$ & 0 & 0 & 0 & 0 & 1 & 0 \\
\hline Merivale & $\mathrm{I}$ & $\overline{\mathrm{SN}}$ & 0 & 0 & 0 & 0 & 0 & 0 \\
\hline Parc_Champlain & A & $\mathrm{S}$ & 0 & 0 & 0 & 0 & 0 & 0 \\
\hline Parc_Champlain & $\mathrm{B}$ & $\mathrm{S}$ & 0 & 0 & 0 & 0 & 0 & 0 \\
\hline Parc_Champlain & $\mathrm{C}$ & $\mathrm{S}$ & 0 & 0 & 0 & 0 & 0 & 0 \\
\hline Parc_Champlain & $\mathrm{D}$ & $\mathrm{S}$ & 0 & 0 & 0 & 0 & 0 & 0 \\
\hline Parc_Champlain & $E$ & $\mathrm{~S}$ & 0 & 0 & 0 & 0 & 0 & 0 \\
\hline Parc_Champlain & $\mathrm{F}$ & $\mathrm{S}$ & 0 & 0 & 0 & 0 & 0 & 0 \\
\hline Parc_Champlain & $\mathrm{H}$ & $\mathrm{S}$ & 0 & 0 & 0 & 0 & 0 & 0 \\
\hline Parc_Champlain & I & $\mathrm{S}$ & 0 & 0 & 0 & 0 & 0 & 0 \\
\hline PineGlen_Annex & $\mathrm{A}$ & $\mathrm{S}$ & 0 & 0 & 0 & 0 & 0 & 0 \\
\hline PineGlen_Annex & B & $\mathrm{S}$ & 0 & 0 & 0 & 0 & 0 & 0 \\
\hline PineGlen_Annex & $\mathrm{C}$ & $\mathrm{S}$ & 0 & 0 & 0 & 0 & 0 & 0 \\
\hline PineGlen_Annex & $\mathrm{D}$ & $\mathrm{S}$ & 0 & 0 & 0 & 0 & 0 & 0 \\
\hline PineGlen_Annex & $E$ & $\mathrm{~S}$ & 0 & 0 & 0 & 0 & 0 & 0 \\
\hline PineGlen_Annex & $\mathrm{F}$ & $\mathrm{S}$ & 0 & 0 & 0 & 0 & 0 & $\overline{0}$ \\
\hline PineGlen_Annex & $\mathrm{H}$ & $\mathrm{S}$ & 0 & 0 & 0 & 0 & 0 & 0 \\
\hline PineGlen_Annex & I & $\mathrm{S}$ & 0 & 0 & 0 & 0 & 0 & 0 \\
\hline Q_Four & $\mathrm{A}$ & $E$ & 0 & 0 & 0 & 0 & 0 & 0 \\
\hline Q_Four & $\mathrm{B}$ & $\mathrm{E}$ & 0 & 0 & 0 & 0 & 0 & 0 \\
\hline Q_Four & $\mathrm{C}$ & 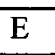 & 0 & 0 & 0 & 0 & 0 & 1 \\
\hline Q_Four & $\mathrm{D}$ & $\mathrm{E}$ & 0 & 0 & 0 & 0 & 0 & 0 \\
\hline Q_Four & $E$ & $\mathrm{E}$ & 0 & 0 & 0 & 0 & 0 & 0 \\
\hline Q_Four & $\mathrm{F}$ & $\mathrm{E}$ & 0 & 0 & $\overline{0}$ & 0 & 0 & 0 \\
\hline
\end{tabular}




\begin{tabular}{|c|c|c|c|c|c|c|c|c|}
\hline Q_Four & $\mathrm{H}$ & $E$ & 0 & 0 & 0 & 0 & 0 & 0 \\
\hline Q_Four & I & $\bar{E}$ & 0 & 0 & 0 & 0 & 0 & $\overline{0}$ \\
\hline Sandy_Hill & $\bar{A}$ & $\overline{\mathrm{U}}$ & 0 & 0 & 0 & 0 & 0 & 0 \\
\hline Sandy_Hill & $\bar{B}$ & $\bar{U}$ & 0 & 0 & 0 & 0 & 0 & 0 \\
\hline Sandy_Hill & $\mathrm{C}$ & $\mathrm{U}$ & 0 & 0 & 0 & 0 & 0 & 0 \\
\hline Sandy_Hill & D & $\bar{U}$ & 0 & 0 & 0 & 0 & 0 & 0 \\
\hline Sandy_Hill & $\mathrm{E}$ & $\mathbf{U}$ & 0 & 0 & 0 & 0 & 0 & 0 \\
\hline Sandy_Hill & $\vec{F}$ & $\mathbf{U}$ & 0 & 0 & 0 & 0 & 0 & 0 \\
\hline Sandy_Hill & $\mathrm{H}$ & $\mathrm{U}$ & 0 & 0 & 0 & 0 & 0 & 0 \\
\hline Sandy_Hill & I & $\overline{\mathrm{U}}$ & 0 & 0 & 0 & 0 & 0 & 0 \\
\hline Vallee_Meech & A & $F$ & 0 & 0 & 0 & 0 & 0 & $\overline{0}$ \\
\hline Vallee_Meech & $\mathrm{B}$ & $\mathrm{F}$ & 0 & 0 & 0 & 0 & 0 & 0 \\
\hline Vallee_Meech & $\mathrm{C}$ & $F$ & 0 & 0 & 0 & 0 & 0 & 0 \\
\hline Vallee_Meech & D & $F$ & 0 & 0 & 0 & 0 & 0 & 0 \\
\hline Vallee_Meech & $\bar{E}$ & $F$ & 0 & 0 & 0 & 0 & 0 & 0 \\
\hline Vallee_Meech & $F$ & $F$ & 0 & 0 & 0 & 0 & 0 & 1 \\
\hline Vallee_Meech & $\mathrm{H}$ & $F$ & 0 & 0 & 0 & 0 & 0 & 0 \\
\hline Vallee_Meech & I & $F$ & 0 & 0 & 0 & 0 & 0 & 1 \\
\hline Wolf_Grove & $\mathrm{A}$ & $E$ & 0 & 0 & 0 & 0 & 0 & 0 \\
\hline Wolf_Grove & $\mathrm{B}$ & $E$ & 0 & 0 & 0 & 0 & 0 & 0 \\
\hline Wolf_Grove & $\bar{C}$ & $\mathrm{E}$ & 0 & 0 & 0 & 0 & 0 & $\overline{0}$ \\
\hline Wolf_Grove & $\mathrm{D}$ & $E$ & 0 & 0 & 0 & 0 & 0 & 0 \\
\hline Wolf_Grove & $\bar{E}$ & $\bar{E}$ & 0 & 0 & 0 & 0 & 0 & 0 \\
\hline Wolf_Grove & $\mathrm{F}$ & $E$ & 1 & 0 & 0 & 0 & 0 & 0 \\
\hline Wolf_Grove & $\overline{\mathrm{H}}$ & $\bar{E}$ & 0 & 0 & 0 & 0 & 0 & 1 \\
\hline Wolf_Grove & I & E & 0 & 0 & 0 & 0 & 0 & 0 \\
\hline Wrightville & $\mathrm{A}$ & $\mathrm{U}$ & 0 & 0 & 0 & 0 & 0 & 0 \\
\hline Wrightville & B & $\bar{U}$ & 0 & 0 & 0 & 0 & 0 & 0 \\
\hline Wrightville & $\mathrm{C}$ & $\mathrm{U}$ & 0 & 0 & 0 & 0 & 0 & 0 \\
\hline Wrightville & $\mathrm{D}$ & $\mathrm{U}$ & 0 & 0 & 0 & 0 & 0 & $\overline{0}$ \\
\hline Wrightville & $E$ & $\mathbf{U}$ & 0 & 0 & 0 & 0 & 0 & 0 \\
\hline Wrightville & $\mathrm{F}$ & $\mathrm{U}$ & 0 & 0 & 0 & 0 & 0 & 0 \\
\hline Wrightville & $\mathrm{H}$ & $\overline{\mathrm{U}}$ & 0 & 0 & 0 & 0 & 0 & 0 \\
\hline Wrightville & I & $\bar{U}$ & 0 & 0 & 0 & 0 & 0 & 0 \\
\hline Wychwood & A & $S$ & 0 & 0 & 0 & 0 & 0 & 0 \\
\hline Wychwood & B & $S$ & 0 & 0 & 0 & 0 & 0 & 0 \\
\hline Wychwood & $\mathrm{C}$ & $S$ & 0 & 0 & 0 & 0 & 1 & 0 \\
\hline Wychwood & $\bar{D}$ & $S$ & 0 & 0 & 0 & 0 & 0 & 0 \\
\hline Wychwood & $E$ & $S$ & 0 & 0 & 0 & 0 & 0 & 0 \\
\hline Wychwood & $F$ & $\mathrm{~S}$ & 0 & 0 & 0 & 0 & 0 & 0 \\
\hline Wychwood & $\mathrm{H}$ & $S$ & 0 & 0 & 0 & 0 & 0 & 0 \\
\hline Wychwood & I & $S$ & 0 & 0 & 0 & 0 & 0 & 0 \\
\hline
\end{tabular}




\begin{tabular}{|c|c|c|c|c|c|c|c|c|}
\hline SITE & STATION & CATEGORY & NOAE & OLMI & OLPA & OXPU & PALO & PLDE \\
\hline Achbar & $\mathrm{A}$ & SN & 0 & 0 & 0 & 0 & 0 & 0 \\
\hline Achbar & B & $\overline{\mathrm{SN}}$ & 0 & 0 & 0 & 0 & 0 & 0 \\
\hline Achbar & $\mathrm{C}$ & $\mathrm{SN}$ & 0 & 0 & 0 & 0 & 0 & 0 \\
\hline Achbar & $\bar{D}$ & $\overline{\mathrm{SN}}$ & 0 & 0 & 0 & 0 & 0 & 0 \\
\hline Achbar & $E$ & SN & 0 & 0 & 0 & 0 & 0 & 0 \\
\hline Achbar & $F$ & $\mathrm{SN}$ & 0 & 0 & 0 & 0 & 0 & $\overline{0}$ \\
\hline Achbar & $\overline{\mathrm{H}}$ & $\mathrm{SN}$ & 0 & 0 & 0 & 0 & 0 & 0 \\
\hline Achbar & I & $\overline{\mathrm{SN}}$ & 0 & 0 & 0 & 0 & 0 & 0 \\
\hline Bridlewood & $\overline{\mathrm{A}}$ & UN & 0 & 0 & 0 & 0 & 0 & 2 \\
\hline Bridlewood & B & UN & 8 & 0 & 0 & 0 & 0 & 6 \\
\hline Bridlewood & $\bar{C}$ & UN & 0 & 0 & 0 & 0 & 0 & $\overline{0}$ \\
\hline Bridlewood & $\bar{D}$ & UN & 0 & 0 & 0 & 0 & 0 & 1 \\
\hline Bridlewood & $E$ & $\mathrm{UN}$ & 0 & 0 & 0 & 0 & 0 & 2 \\
\hline Bridlewood & $\bar{F}$ & $\overline{\mathrm{UN}}$ & 1 & 0 & 0 & 0 & 0 & $\overline{4}$ \\
\hline Bridlewood & $\mathrm{H}$ & UN & 0 & 0 & 0 & 0 & 0 & $\overline{0}$ \\
\hline Bridlewood & I & UN & 2 & 0 & 0 & 0 & 0 & 0 \\
\hline Carp_Hills & $\mathrm{A}$ & $F$ & 8 & 0 & 0 & 1 & 0 & $\overline{0}$ \\
\hline Carp_Hills & $\mathrm{B}$ & $\mathrm{F}$ & 0 & 0 & 0 & 14 & 0 & 11 \\
\hline Carp_Hills & $\overline{\mathrm{C}}$ & $F$ & 2 & 0 & 0 & 2 & 0 & 0 \\
\hline Carp_Hills & $\bar{D}$ & $F$ & 0 & 0 & 0 & 0 & 0 & 0 \\
\hline Carp_Hills & $E$ & $F$ & 0 & 0 & 0 & 4 & 0 & 4 \\
\hline Carp_Hills & $F$ & $F$ & 0 & 0 & 0 & 4 & 0 & 14 \\
\hline Carp_Hills & $\mathrm{H}$ & $F$ & 0 & 0 & 0 & 0 & 0 & 0 \\
\hline Carp_Hills & I & $F$ & 0 & 0 & 0 & 0 & 0 & 1 \\
\hline Chapel_Hill & $\bar{A}$ & $\mathrm{UN}$ & 0 & 0 & 0 & 0 & 0 & 7 \\
\hline Chapel_Hill & $\bar{B}$ & $\mathrm{UN}$ & 0 & 0 & 0 & 1 & 0 & 1 \\
\hline Chapel_Hill & $\mathrm{C}$ & $\overline{\mathrm{UN}}$ & 0 & 0 & 0 & 0 & 0 & 0 \\
\hline Chapel_Hill & $\mathrm{D}$ & UN & 0 & 0 & 0 & 0 & 0 & 0 \\
\hline Chapel_Hill & $E$ & $\mathrm{UN}$ & 0 & 0 & 0 & 6 & 0 & 33 \\
\hline Chapel_Hill & F & $\overline{\mathrm{UN}}$ & 0 & 0 & 0 & 0 & 2 & $\overline{2}$ \\
\hline Chapel_Hill & $\mathrm{H}$ & $\mathrm{UN}$ & 0 & 0 & 0 & 0 & 0 & 0 \\
\hline Chapel_Hill & I & $\overline{\mathrm{UN}}$ & 0 & 1 & 0 & 0 & 0 & 6 \\
\hline Chelsea & $\overline{\mathrm{A}}$ & SN & 0 & 0 & 0 & 0 & 0 & $\overline{0}$ \\
\hline Chelsea & B & $\overline{\mathrm{SN}}$ & 0 & 0 & 0 & 0 & 0 & 0 \\
\hline Chelsea & $\mathrm{C}$ & SN & 0 & 0 & 0 & 0 & 0 & 0 \\
\hline Chelsea & $\mathrm{D}$ & SN & 0 & 0 & 0 & 0 & 0 & $\overline{6}$ \\
\hline Chelsea & $\mathrm{E}$ & SN & 0 & 0 & 0 & 0 & 0 & $\overline{0}$ \\
\hline Chelsea & $F$ & $\overline{\mathrm{SN}}$ & 0 & 0 & 0 & 0 & 0 & 1 \\
\hline Chelsea & $\mathrm{H}$ & $\overline{\mathrm{SN}}$ & 0 & 0 & 0 & 0 & 0 & $\overline{0}$ \\
\hline Chelsea & I & $\mathrm{SN}$ & 0 & 0 & 0 & 0 & 0 & $\overline{0}$ \\
\hline Cote_d'Azur & $\mathrm{A}$ & $\mathrm{S}$ & 0 & 0 & 0 & 0 & 0 & 0 \\
\hline Cote_d'Azur & $\bar{B}$ & $\mathrm{~S}$ & 0 & 0 & 0 & 0 & 0 & $\overline{0}$ \\
\hline Cote_d'Azur & $\mathrm{C}$ & $\mathrm{S}$ & 0 & 0 & 0 & 0 & 0 & $\overline{0}$ \\
\hline Cote_d'Azur & $\mathrm{D}$ & $\mathrm{S}$ & 0 & 0 & 0 & 0 & 0 & 0 \\
\hline
\end{tabular}




\begin{tabular}{|c|c|c|c|c|c|c|c|c|}
\hline Cote_d'Azur & $\bar{E}$ & $\mathrm{~S}$ & 0 & 0 & 0 & 0 & 0 & 0 \\
\hline Cote_d'Azur & F & $\mathrm{S}$ & 0 & 0 & 0 & 0 & 0 & 0 \\
\hline Cote_d'Azur & $\mathrm{H}$ & $\mathrm{S}$ & 0 & 0 & 0 & 0 & 0 & 0 \\
\hline Cote d'Azur & I & $\mathrm{S}$ & 0 & 0 & 0 & 0 & 0 & 0 \\
\hline Highway_Seven & $\bar{A}$ & $\bar{E}$ & 3 & 0 & 0 & 0 & 0 & $\overline{7}$ \\
\hline Highway_Seven & $\mathrm{B}$ & $\bar{E}$ & 0 & 0 & 0 & 0 & $\overline{0}$ & 0 \\
\hline Highway_Seven & $\mathrm{C}$ & $E$ & 0 & 0 & 1 & 0 & 0 & 1 \\
\hline Highway_Seven & $\mathrm{D}$ & $E$ & 0 & 0 & 0 & 0 & 0 & 0 \\
\hline Highway_Seven & $E$ & $E$ & 0 & 0 & 0 & 0 & 0 & 0 \\
\hline Highway_Seven & $\bar{F}$ & $\bar{E}$ & $\bar{I}$ & 0 & 0 & 0 & 0 & 3 \\
\hline Highway_Seven & $\mathrm{H}$ & $\bar{E}$ & 0 & 0 & 0 & 0 & 0 & $\overline{0}$ \\
\hline Highway_Seven & I & $E$ & 0 & 0 & 0 & 0 & 0 & 1 \\
\hline Hull & $\bar{A}$ & $\overline{\mathrm{U}}$ & 0 & 0 & 0 & 0 & 0 & 0 \\
\hline Hull & $\mathrm{B}$ & $\overline{\mathrm{U}}$ & 0 & 0 & 0 & 0 & 0 & 0 \\
\hline Hull & $\mathrm{C}$ & $\bar{U}$ & 0 & 0 & 0 & 0 & 0 & 0 \\
\hline Hull & D & $\bar{U}$ & 0 & 0 & 0 & 0 & 0 & 0 \\
\hline Hull & $\mathrm{E}$ & $\mathrm{U}$ & 0 & 0 & 0 & 0 & 0 & 0 \\
\hline Hull & $\bar{F}$ & $\overline{\mathrm{U}}$ & 0 & 0 & 0 & 0 & 0 & $\overline{0}$ \\
\hline Hull & $\mathrm{H}$ & $\overline{\mathrm{U}}$ & 0 & 0 & 0 & 0 & 0 & $\overline{0}$ \\
\hline Hull & I & $\mathrm{U}$ & 0 & 0 & 0 & 0 & 0 & 0 \\
\hline Lac_Philippe & $\bar{A}$ & $\bar{F}$ & 0 & 0 & 0 & 0 & 0 & $\overline{0}$ \\
\hline Lac_Philippe & $\mathrm{B}$ & $\mathrm{F}$ & 0 & 0 & 0 & 0 & 0 & 0 \\
\hline Lac_Philippe & $\mathrm{C}$ & $\mathrm{F}$ & 0 & 0 & 0 & 0 & 0 & $\overline{0}$ \\
\hline Lac_Philippe & $\overline{\mathrm{D}}$ & $F$ & 1 & 0 & 0 & 0 & 0 & $\overline{0}$ \\
\hline Lac_Philippe & $E$ & $\mathrm{~F}$ & 0 & 0 & 0 & 0 & 0 & 0 \\
\hline Lac_Philippe & $\mathrm{F}$ & $\mathrm{F}$ & 1 & 0 & 0 & 0 & 0 & 0 \\
\hline Lac_Philippe & $\mathrm{H}$ & $\mathrm{F}$ & 0 & 0 & 0 & 0 & 0 & 6 \\
\hline Lac_Philippe & I & $\mathrm{F}$ & 0 & 0 & 0 & 0 & 0 & 0 \\
\hline Manoir_des_Trembles & $\bar{A}$ & $\overline{\mathrm{UN}}$ & 0 & 0 & 0 & 0 & 0 & 1 \\
\hline Manoir_des_Trembles & $\mathrm{B}$ & $\overline{\mathrm{UN}}$ & 0 & 0 & 0 & 1 & 0 & 3 \\
\hline Manoir_des_Trembles & C & UN & 0 & 0 & 0 & 0 & 0 & 14 \\
\hline Manoir_des_Trembles & $\bar{D}$ & $\mathrm{UN}$ & 0 & 0 & 0 & 0 & 0 & 6 \\
\hline Manoir_des_Trembles & $\bar{E}$ & $\overline{\mathrm{UN}}$ & 2 & 0 & 0 & 0 & 0 & 1 \\
\hline Manoir_des_Trembles & $\mathrm{F}$ & UN & 1 & 0 & 0 & 1 & 0 & 1 \\
\hline Manoir_des_Trembles & $\mathrm{H}$ & $\mathrm{UN}$ & 1 & 0 & 0 & 0 & 0 & 1 \\
\hline Manoir_des_Trembles & I & UN & 0 & 0 & 1 & 1 & 0 & 2 \\
\hline Marathon & $\mathrm{A}$ & $\mathrm{E}$ & 0 & 0 & 0 & 0 & 0 & $\overline{0}$ \\
\hline Marathon & $\mathrm{B}$ & $E$ & 0 & 0 & 0 & 0 & 0 & 11 \\
\hline Marathon & $\mathrm{C}$ & $\mathrm{E}$ & 0 & 0 & 0 & 0 & 0 & 31 \\
\hline Marathon & $\mathrm{D}$ & $E$ & 0 & 0 & 0 & 0 & 0 & 0 \\
\hline Marathon & $\mathrm{E}$ & $\bar{E}$ & 0 & 0 & 0 & 0 & 0 & 7 \\
\hline Marathon & F & $\bar{E}$ & 0 & 0 & 0 & 0 & 0 & $\overline{0}$ \\
\hline Marathon & $\mathrm{H}$ & $E$ & 0 & 0 & 0 & 0 & 0 & 8 \\
\hline Marathon & I & $E$ & 0 & 0 & 0 & 0 & 0 & 0 \\
\hline Marier & $\bar{A}$ & $\overline{\mathrm{U}}$ & 0 & 0 & 0 & 0 & 0 & 0 \\
\hline
\end{tabular}




\begin{tabular}{|c|c|c|c|c|c|c|c|c|}
\hline Marier & B & $\mathrm{U}$ & 0 & 0 & 0 & 0 & 0 & 0 \\
\hline Marier & $\mathrm{C}$ & $\mathrm{U}$ & 0 & 0 & 0 & 0 & 0 & 0 \\
\hline Marier & $\mathrm{D}$ & $\overline{\mathrm{U}}$ & 0 & 0 & 0 & 0 & 0 & $\overline{0}$ \\
\hline Marier & $\bar{E}$ & $\bar{U}$ & 0 & 0 & 0 & 0 & 0 & 0 \\
\hline Marier & $F$ & $\bar{U}$ & 0 & 0 & 0 & 0 & 0 & 0 \\
\hline Marier & $\overline{\mathrm{H}}$ & $\overline{\mathrm{U}}$ & 0 & 0 & 0 & 0 & 0 & 0 \\
\hline Marier & I & $\overline{\mathrm{U}}$ & 0 & 0 & 0 & 0 & 0 & 0 \\
\hline Marlborough & $\overline{\mathrm{A}}$ & $F$ & 4 & 0 & 0 & 1 & 0 & 5 \\
\hline Marlborough & $\mathrm{B}$ & $F$ & 1 & 0 & 0 & 0 & 0 & 1 \\
\hline Marlborough & $\mathrm{C}$ & $\mathrm{F}$ & 1 & 0 & 0 & 0 & 0 & 2 \\
\hline Marlborough & $\bar{D}$ & $F$ & 2 & 0 & 0 & 0 & 0 & 16 \\
\hline Marlborough & $E$ & $F$ & 0 & 0 & 0 & 0 & 0 & 2 \\
\hline Marlborough & $\bar{F}$ & $F$ & 1 & 0 & 0 & 10 & 0 & 12 \\
\hline Marlborough & $\mathrm{H}$ & $F$ & 2 & 0 & 0 & 0 & 0 & 3 \\
\hline Marlborough & I & $F$ & 1 & 0 & 0 & 0 & 0 & 3 \\
\hline Merivale & $\bar{A}$ & SN & 0 & 0 & 0 & 0 & 0 & $\overline{0}$ \\
\hline Merivale & $\mathrm{B}$ & SN & 2 & 0 & 0 & 0 & 0 & 0 \\
\hline Merivale & $\mathrm{C}$ & $\overline{\mathrm{SN}}$ & 0 & 0 & 0 & 0 & 0 & 5 \\
\hline Merivale & $\bar{D}$ & $\mathrm{SN}$ & 0 & 0 & 0 & 0 & 0 & 0 \\
\hline Merivale & $\bar{E}$ & SN & 0 & 0 & 0 & 0 & 0 & 1 \\
\hline Merivale & $F$ & $\mathrm{SN}$ & 1 & 0 & 0 & 0 & 0 & 0 \\
\hline Merivale & $\mathrm{H}$ & SN & 0 & 0 & 0 & 2 & 0 & 0 \\
\hline Merivale & I & $\overline{\mathrm{SN}}$ & 0 & 0 & 0 & 0 & 0 & 0 \\
\hline Parc_Champlain & $\bar{A}$ & $\mathrm{~S}$ & 0 & 0 & 0 & 0 & 0 & $\overline{0}$ \\
\hline Parc_Champlain & $\mathrm{B}$ & $\mathrm{S}$ & 0 & 0 & 0 & 0 & 0 & 0 \\
\hline Parc_Champlain & $\mathrm{C}$ & $\mathrm{S}$ & 0 & 0 & 0 & 0 & 0 & 0 \\
\hline Parc_Champlain & $\overline{\mathrm{D}}$ & $\mathrm{S}$ & 0 & 0 & 0 & 0 & 0 & $\overline{0}$ \\
\hline Parc_Champlain & $E$ & $\mathrm{~S}$ & 0 & 0 & 0 & 0 & 0 & 0 \\
\hline Parc_Champlain & $F$ & $\mathrm{~S}$ & 0 & 0 & 0 & 0 & 0 & $\overline{0}$ \\
\hline Parc_Champlain & $\mathrm{H}$ & $\mathrm{S}$ & 0 & 0 & 0 & 0 & 0 & 0 \\
\hline Parc_Champlain & I & $\mathrm{S}$ & 0 & 0 & 0 & 0 & 0 & 0 \\
\hline PineGlen_Annex & $\bar{A}$ & $\mathrm{~S}$ & 0 & 0 & 0 & 0 & 0 & 0 \\
\hline PineGlen_Annex & $\mathrm{B}$ & $\mathrm{S}$ & 0 & 0 & 0 & 0 & 0 & 0 \\
\hline PineGlen_Annex & $\mathrm{C}$ & $\mathrm{S}$ & 0 & 0 & 0 & 0 & 0 & 0 \\
\hline PineGlen_Annex & $\mathrm{D}$ & $\mathrm{S}$ & 0 & 0 & 0 & 0 & 0 & 0 \\
\hline PineGlen_Annex & $E$ & $\mathbf{S}$ & 0 & 0 & 0 & 0 & 0 & 0 \\
\hline PineGlen_Annex & $F$ & $\bar{S}$ & 0 & 0 & 0 & 0 & 0 & 0 \\
\hline PineGlen_Annex & $\mathrm{H}$ & $\mathrm{S}$ & 0 & 0 & 0 & 0 & 0 & 1 \\
\hline PineGlen_Annex & $\mathrm{I}$ & $\mathrm{S}$ & 0 & 0 & 0 & 0 & 0 & 0 \\
\hline Q_Four & $\bar{A}$ & $E$ & 0 & 0 & 0 & 0 & 0 & 0 \\
\hline Q_Four & $\bar{B}$ & $\mathrm{E}$ & 0 & 0 & 0 & 0 & 0 & 0 \\
\hline Q_Four & $\mathrm{C}$ & $E$ & 0 & 0 & 0 & 0 & 0 & 6 \\
\hline Q_Four & $\bar{D}$ & $E$ & 0 & 0 & 0 & 0 & 0 & $\overline{0}$ \\
\hline Q_Four & $E$ & $E$ & 0 & 0 & 1 & 0 & 0 & 0 \\
\hline Q_Four & $F$ & E & 0 & 0 & 0 & 0 & 0 & 2 \\
\hline
\end{tabular}




\begin{tabular}{|c|c|c|c|c|c|c|c|c|}
\hline Q_Four & $\mathrm{H}$ & $\mathrm{E}$ & 0 & 0 & 0 & 0 & 0 & 3 \\
\hline Q_Four & I & $\bar{E}$ & 0 & 0 & 0 & 0 & 0 & 3 \\
\hline Sandy_Hill & $\bar{A}$ & $\mathrm{U}$ & 0 & 0 & 0 & 0 & 0 & 0 \\
\hline Sandy_Hill & $\bar{B}$ & $\overline{\mathrm{U}}$ & 0 & 0 & 0 & 0 & 0 & $\overline{0}$ \\
\hline Sandy_Hill & $\mathrm{C}$ & $\mathrm{U}$ & 0 & 0 & 0 & 0 & 0 & 0 \\
\hline Sandy_Hill & $\overline{\mathrm{D}}$ & $\overline{\mathrm{U}}$ & 0 & 0 & 0 & 0 & 0 & $\overline{0}$ \\
\hline Sandy_Hill & $E$ & $\mathbf{U}$ & 0 & 0 & 0 & 0 & 0 & 0 \\
\hline Sandy_Hill & $\mathrm{F}$ & $U$ & 0 & 0 & 0 & 0 & 0 & 0 \\
\hline Sandy_Hill & $\overline{\mathrm{H}}$ & $\mathrm{U}$ & 0 & 0 & 0 & 0 & 0 & 0 \\
\hline Sandy_Hill & I & $\mathrm{U}$ & 0 & 0 & 0 & 0 & 0 & 0 \\
\hline Vallee_Meech & A & $\mathrm{F}$ & 0 & 0 & 0 & 0 & 0 & 0 \\
\hline Vallee_Meech & $\bar{B}$ & $\mathrm{~F}$ & 0 & 0 & 0 & 0 & 0 & 0 \\
\hline Vallee_Meech & $\mathrm{C}$ & $\bar{F}$ & 0 & 0 & 0 & 0 & 0 & 0 \\
\hline Vallee_Meech & D & $F$ & 0 & 0 & 0 & 0 & 0 & 0 \\
\hline Vallee_Meech & $\bar{E}$ & $\bar{F}$ & 0 & 0 & 0 & 0 & 0 & $\overline{0}$ \\
\hline Vallee_Meech & $\bar{F}$ & $\bar{F}$ & 0 & 0 & $\overline{0}$ & 0 & $\overline{0}$ & 0 \\
\hline Vallee_Meech & $\overline{\mathrm{H}}$ & $\bar{F}$ & 0 & 0 & 0 & 1 & 0 & $\overline{0}$ \\
\hline Vallee_Meech & I & $\mathrm{F}$ & 0 & 0 & 0 & 0 & 0 & 0 \\
\hline Wolf_Grove & $\mathrm{A}$ & $\mathrm{E}$ & 0 & 0 & 0 & 0 & 0 & 0 \\
\hline Wolf_Grove & $\mathrm{B}$ & $E$ & 0 & 0 & 0 & 0 & 0 & 11 \\
\hline Wolf_Grove & $\overline{\mathrm{C}}$ & $E$ & 2 & 0 & 0 & 0 & 0 & 0 \\
\hline Wolf_Grove & $\mathrm{D}$ & $\mathrm{E}$ & $\overline{0}$ & 0 & 0 & 0 & 0 & 0 \\
\hline Wolf_Grove & $\bar{E}$ & $\mathrm{E}$ & 0 & 0 & 0 & 0 & 0 & $\overline{0}$ \\
\hline Wolf_Grove & $\mathrm{F}$ & $\bar{E}$ & 0 & 0 & 0 & 0 & 0 & 8 \\
\hline Wolf_Grove & $\mathrm{H}$ & $\mathrm{E}$ & 0 & 0 & 0 & 0 & 0 & 0 \\
\hline Wolf_Grove & I & $\mathrm{E}$ & 1 & 0 & 0 & 0 & 0 & 0 \\
\hline Wrightville & A & $\mathrm{U}$ & 0 & 0 & 0 & 0 & 0 & 0 \\
\hline Wrightville & B & $\overline{\mathrm{U}}$ & 0 & 0 & 0 & 0 & 0 & 0 \\
\hline Wrightville & $\mathrm{C}$ & $\overline{\mathrm{U}}$ & 0 & 0 & 0 & 0 & 0 & 0 \\
\hline Wrightville & $\mathrm{D}$ & $\overline{\mathrm{U}}$ & 0 & 0 & 0 & 0 & 0 & $\overline{0}$ \\
\hline Wrightville & $\mathrm{E}$ & $\mathrm{U}$ & 0 & 0 & 0 & 0 & 0 & 0 \\
\hline Wrightville & $\mathrm{F}$ & $\mathrm{U}$ & 0 & 0 & 0 & 0 & 0 & 0 \\
\hline Wrightville & $\mathrm{H}$ & $\bar{U}$ & 0 & 0 & 0 & 0 & 0 & 0 \\
\hline Wrightville & 1 & $\mathrm{U}$ & 0 & 0 & 0 & 0 & 0 & 0 \\
\hline Wychwood & A & $S$ & 0 & 0 & 0 & 0 & 0 & 0 \\
\hline Wychwood & $\mathrm{B}$ & $\mathrm{S}$ & 0 & 0 & 0 & 0 & 0 & 0 \\
\hline Wychwood & $\mathrm{C}$ & $\mathrm{S}$ & 0 & 0 & 0 & 0 & 0 & 0 \\
\hline Wychwood & $\bar{D}$ & $S$ & 0 & 0 & 0 & 0 & 0 & 0 \\
\hline Wychwood & $\mathrm{E}$ & $\mathrm{S}$ & 0 & 0 & 0 & 0 & 0 & 0 \\
\hline Wychwood & $F$ & $S$ & 0 & 0 & 0 & 0 & 0 & $\overline{0}$ \\
\hline Wychwood & $\mathrm{H}$ & $S$ & 0 & 0 & 0 & 0 & 0 & 0 \\
\hline Wychwood & I & $S$ & 0 & 0 & 0 & 0 & 0 & 0 \\
\hline
\end{tabular}




\begin{tabular}{|c|c|c|c|c|c|c|c|c|}
\hline SITE & STATION & CATEGORY & POLU & PSAR & PTCA & PTCO & PTCOR & $\overline{\text { PTLU }}$ \\
\hline Achbar & $\mathrm{A}$ & SN & 0 & 0 & 0 & 2 & 0 & 0 \\
\hline Achbar & $\mathrm{B}$ & SN & 0 & 0 & 0 & 10 & 0 & $\overline{0}$ \\
\hline Achbar & $\mathrm{C}$ & $\mathrm{SN}$ & 0 & 0 & 0 & 0 & 0 & $\overline{0}$ \\
\hline Achbar & D & SN & 4 & 0 & 0 & 0 & 0 & $\overline{0}$ \\
\hline Achbar & $\bar{E}$ & $\overline{\mathrm{SN}}$ & 16 & 0 & 0 & 11 & 0 & 2 \\
\hline Achbar & $F$ & $\overline{\mathrm{SN}}$ & 0 & 0 & 0 & 2 & 0 & 0 \\
\hline Achbar & $\overline{\mathrm{H}}$ & SN & 0 & 0 & 0 & 1 & 0 & 0 \\
\hline Achbar & I & $\mathrm{SN}$ & 0 & 0 & 0 & 1 & 0 & 0 \\
\hline Bridlewood & $\bar{A}$ & UN & 1 & 0 & 0 & 0 & 0 & 0 \\
\hline Bridlewood & $\bar{B}$ & UN & 3 & 0 & 0 & 0 & 0 & 0 \\
\hline Bridlewood & $\bar{C}$ & UN & 0 & 0 & 0 & 0 & 0 & $\overline{0}$ \\
\hline Bridlewood & $\mathrm{D}$ & $\overline{\mathrm{UN}}$ & 0 & 0 & 0 & 0 & 0 & $\overline{0}$ \\
\hline Bridlewood & $\bar{E}$ & UN & 47 & 0 & 0 & 0 & 0 & $\overline{0}$ \\
\hline Bridlewood & $F$ & $\overline{\mathrm{UN}}$ & 22 & 0 & 0 & 0 & 0 & $\overline{0}$ \\
\hline Bridlewood & $\mathrm{H}$ & UN & 1 & 0 & 0 & 0 & 0 & $\overline{0}$ \\
\hline Bridlewood & I & UN & 8 & 0 & 0 & 0 & 0 & 1 \\
\hline Carp_Hills & A & $\mathrm{F}$ & 1 & 0 & 0 & 0 & 0 & $\overline{0}$ \\
\hline Carp_Hills & B & $F$ & 7 & 0 & 0 & 5 & 0 & $\overline{4}$ \\
\hline Carp_Hills & $\mathrm{C}$ & $\bar{F}$ & 3 & 0 & 0 & 0 & $\overline{0}$ & 0 \\
\hline Carp_Hills & $\mathrm{D}$ & $\mathrm{F}$ & 0 & 0 & 0 & $\overline{0}$ & 0 & 0 \\
\hline Carp_Hills & $E$ & $\mathrm{~F}$ & 14 & 0 & 0 & 0 & 0 & 2 \\
\hline Carp_Hills & $\bar{F}$ & $\bar{F}$ & 32 & 0 & 0 & 0 & 0 & $\overline{9}$ \\
\hline Carp_Hills & $\mathrm{H}$ & $\mathrm{F}$ & 4 & 0 & 0 & 0 & 0 & $\overline{0}$ \\
\hline Carp_Hills & $\mathrm{I}$ & $\mathrm{F}$ & 1 & 0 & 0 & 0 & 0 & 2 \\
\hline Chapel_Hill & A & UN & 61 & 0 & 0 & 0 & 0 & 8 \\
\hline Chapel_Hill & $\mathrm{B}$ & UN & 7 & 0 & 0 & 0 & 0 & 0 \\
\hline Chapel_Hill & $\bar{C}$ & UN & 1 & 0 & 0 & 0 & 0 & $\overline{0}$ \\
\hline Chapel_Hill & $\bar{D}$ & $\mathrm{UN}$ & 28 & $\overline{0}$ & 0 & 0 & 0 & 0 \\
\hline Chapel_Hill & $E$ & UN & 20 & 0 & 0 & 0 & 0 & 24 \\
\hline Chapel_Hill & $\mathrm{F}$ & UN & 11 & 0 & 0 & 1 & 0 & 4 \\
\hline Chapel_Hill & $\mathrm{H}$ & UN & 1 & 0 & 0 & 0 & 0 & 2 \\
\hline Chapel_Hill & I & $\mathrm{UN}$ & 1 & 0 & 2 & 0 & 2 & 28 \\
\hline Chelsea & $\bar{A}$ & SN & 0 & 0 & 0 & 6 & 0 & 0 \\
\hline Chelsea & $\bar{B}$ & $\mathrm{SN}$ & 1 & 0 & 0 & 0 & 0 & $\overline{0}$ \\
\hline Chelsea & $\mathrm{C}$ & $\mathrm{SN}$ & 0 & 0 & 0 & 1 & 0 & $\overline{0}$ \\
\hline Chelsea & D & $\mathrm{SN}$ & 0 & 0 & 0 & 8 & 0 & 0 \\
\hline Chelsea & $\mathrm{E}$ & $\mathrm{SN}$ & 3 & 0 & 0 & 1 & 0 & 0 \\
\hline Chelsea & $\bar{F}$ & $\mathrm{SN}$ & 0 & 0 & 0 & 1 & 0 & 0 \\
\hline Chelsea & $\overline{\mathrm{H}}$ & $\overline{\mathrm{SN}}$ & 2 & 0 & 0 & 3 & 0 & $\overline{0}$ \\
\hline Chelsea & I & $\mathrm{SN}$ & 0 & 0 & 0 & 5 & 0 & 0 \\
\hline Cote_d'Azur & $\overline{\mathrm{A}}$ & $S$ & 0 & 0 & 0 & 0 & 0 & 0 \\
\hline Cote_d'Azur & $\mathrm{B}$ & $S$ & 0 & 0 & 0 & 0 & 0 & 0 \\
\hline Cote_d'Azur & $\mathrm{C}$ & $S$ & 0 & 0 & 0 & 0 & 0 & 0 \\
\hline Cote_d'Azur & $\bar{D}$ & $S$ & 0 & 0 & 0 & 0 & 0 & 0 \\
\hline
\end{tabular}




\begin{tabular}{|c|c|c|c|c|c|c|c|c|}
\hline Cote_d'Azur & $\bar{E}$ & $\mathrm{~S}$ & 0 & 0 & 0 & 0 & 0 & 0 \\
\hline Cote_d'Azur & $F$ & $\mathrm{~S}$ & 0 & 0 & 0 & 0 & 0 & 0 \\
\hline Cote_d'Azur & $\overline{\mathrm{H}}$ & $\mathrm{S}$ & 1 & 0 & 0 & 0 & 0 & 0 \\
\hline Cote_d'Azur & 1 & $\mathrm{~S}$ & 0 & 0 & 0 & 0 & 0 & 0 \\
\hline Highway_Seven & $\bar{A}$ & $\mathrm{E}$ & 8 & 0 & 0 & 11 & 0 & 0 \\
\hline Highway_Seven & $\bar{B}$ & $E$ & 2 & 0 & 0 & 0 & 0 & 1 \\
\hline Highway_Seven & $\bar{C}$ & $\mathrm{E}$ & 4 & 0 & 0 & 1 & 1 & 1 \\
\hline Highway_Seven & $\mathrm{D}$ & $\bar{E}$ & 15 & 0 & 0 & 0 & 0 & 0 \\
\hline Highway_Seven & $\overline{\mathrm{E}}$ & $\mathrm{E}$ & 2 & 0 & 0 & 0 & 5 & 3 \\
\hline Highway_Seven & $\mathrm{F}$ & $E$ & 0 & 0 & 0 & 1 & 0 & 0 \\
\hline Highway_Seven & $\mathrm{H}$ & $E$ & 3 & 0 & 0 & 0 & 0 & 0 \\
\hline Highway_Seven & $\mathrm{I}$ & $\mathrm{E}$ & 0 & 0 & 0 & 2 & 0 & 0 \\
\hline Hull & $\overline{\mathrm{A}}$ & $\bar{U}$ & 0 & 0 & 0 & 0 & 0 & 0 \\
\hline Hull & B & $\mathrm{U}$ & 0 & 0 & 0 & 0 & 0 & 0 \\
\hline Hull & $\mathrm{C}$ & $\mathrm{U}$ & 0 & 0 & 0 & 0 & 0 & 0 \\
\hline Hull & $\mathrm{D}$ & U & 0 & 0 & 0 & 0 & 0 & 0 \\
\hline Hull & $\bar{E}$ & $\mathrm{U}$ & 0 & 0 & 0 & 0 & 0 & 0 \\
\hline Hull & $\mathrm{F}$ & $\mathrm{U}$ & 0 & 0 & 0 & 0 & 0 & 0 \\
\hline Hull & $\mathrm{H}$ & $\mathrm{U}$ & 0 & 0 & 0 & 0 & 0 & 0 \\
\hline Hull & 1 & $\bar{U}$ & 0 & 0 & 0 & 0 & 0 & 0 \\
\hline Lac_Philippe & $\mathrm{A}$ & $\mathrm{F}$ & 0 & 0 & 0 & 0 & 0 & 0 \\
\hline Lac_Philippe & $\mathrm{B}$ & $\mathrm{F}$ & 0 & 0 & 0 & 0 & 0 & 0 \\
\hline Lac_Philippe & $\mathrm{C}$ & $\bar{F}$ & 0 & 0 & 0 & 0 & 0 & 0 \\
\hline Lac_Philippe & $\mathrm{D}$ & $\mathrm{F}$ & 0 & 0 & 0 & 1 & 0 & 0 \\
\hline Lac_Philippe & $\bar{E}$ & $\mathrm{~F}$ & 0 & 0 & 0 & 0 & 0 & 0 \\
\hline Lac_Philippe & $F$ & $\mathrm{~F}$ & 0 & 0 & 0 & 2 & 0 & 0 \\
\hline Lac_Philippe & $\mathrm{H}$ & $\mathrm{F}$ & 0 & 0 & 0 & 1 & 0 & 0 \\
\hline Lac_Philippe & 1 & $F$ & 0 & 0 & 0 & 0 & 0 & 0 \\
\hline Manoir_des_Trembles & A & $\mathrm{UN}$ & 0 & 0 & 0 & 0 & 0 & 0 \\
\hline Manoir_des_Trembles & $\bar{B}$ & $\mathrm{UN}$ & 0 & 0 & 0 & 0 & 0 & 0 \\
\hline Manoir_des_Trembles & $\mathrm{C}$ & $\overline{\mathrm{UN}}$ & 0 & 0 & 0 & 0 & 1 & 6 \\
\hline Manoir_des_Trembles & $\mathrm{D}$ & $\mathrm{UN}$ & 0 & 0 & 0 & 4 & 0 & 0 \\
\hline Manoir_des_Trembles & $\mathrm{E}$ & $\mathrm{UN}$ & 0 & 0 & 0 & 0 & 1 & 2 \\
\hline Manoir_des_Trembles & $\mathrm{F}$ & $\mathrm{UN}$ & 1 & 0 & 0 & 1 & 0 & 0 \\
\hline Manoir_des_Trembles & $\mathrm{H}$ & $\mathrm{UN}$ & 0 & 0 & 0 & 0 & 0 & 0 \\
\hline Manoir_des_Trembles & 1 & $\mathrm{UN}$ & 1 & 0 & 0 & 0 & 0 & 0 \\
\hline Marathon & $\mathrm{A}$ & $\bar{E}$ & 0 & 0 & 0 & 0 & 0 & 0 \\
\hline Marathon & B & $\mathrm{E}$ & 0 & 0 & 0 & 0 & 0 & 0 \\
\hline Marathon & $\mathrm{C}$ & $\mathrm{E}$ & 1 & 0 & 0 & 0 & 1 & 9 \\
\hline Marathon & $\mathrm{D}$ & $\mathrm{E}$ & 0 & 0 & 0 & 0 & 0 & 0 \\
\hline Marathon & $\bar{E}$ & $\bar{E}$ & 1 & 0 & 0 & 0 & 0 & 0 \\
\hline Marathon & $\mathrm{F}$ & $\bar{E}$ & 0 & 0 & 0 & 0 & 0 & 0 \\
\hline Marathon & $\mathrm{H}$ & $\mathrm{E}$ & 4 & 0 & 0 & 0 & 0 & 2 \\
\hline Marathon & I & $\mathrm{E}$ & 1 & 0 & 0 & 0 & 1 & 1 \\
\hline Marier & $\bar{A}$ & $\bar{U}$ & 0 & 0 & 0 & 0 & 0 & 0 \\
\hline
\end{tabular}




\begin{tabular}{|c|c|c|c|c|c|c|c|c|}
\hline Marier & $\bar{B}$ & $\bar{U}$ & 0 & 0 & $\overline{0}$ & 0 & 0 & 0 \\
\hline Marier & $\mathrm{C}$ & $\bar{U}$ & 0 & 0 & 0 & 0 & 0 & 0 \\
\hline Marier & $\bar{D}$ & $\bar{U}$ & 0 & 0 & 0 & 0 & 0 & 0 \\
\hline Marier & $\bar{E}$ & $\bar{U}$ & 0 & 0 & 0 & 0 & 0 & 0 \\
\hline Marier & $\mathrm{F}$ & $\bar{U}$ & 0 & 0 & 0 & 0 & 0 & 0 \\
\hline Marier & $\mathrm{H}$ & $\mathbf{U}$ & 0 & 0 & 0 & 0 & 0 & 0 \\
\hline Marier & I & $\bar{U}$ & 0 & 0 & 0 & 0 & 0 & 0 \\
\hline Marlborough & $\overline{\mathrm{A}}$ & $\mathrm{F}$ & 0 & 0 & 0 & 0 & 0 & 0 \\
\hline Marlborough & $\mathrm{B}$ & $\bar{F}$ & 0 & 0 & 0 & 10 & 0 & $\overline{0}$ \\
\hline Marlborough & $\mathrm{C}$ & $F$ & 0 & 0 & 0 & 5 & 0 & 0 \\
\hline Marlborough & $\mathrm{D}$ & $\mathrm{F}$ & 2 & 0 & 0 & 14 & 0 & 0 \\
\hline Marlborough & $\mathrm{E}$ & $\overline{\mathrm{F}}$ & $\overline{0}$ & 0 & 0 & 2 & 0 & 0 \\
\hline Marlborough & $\bar{F}$ & $\bar{F}$ & 1 & 1 & 0 & 2 & 0 & 7 \\
\hline Marlborough & $\mathrm{H}$ & $\bar{F}$ & 0 & 0 & 0 & 10 & 0 & $\overline{0}$ \\
\hline Marlborough & I & $\bar{F}$ & 0 & 0 & 0 & 6 & 0 & $\overline{0}$ \\
\hline Merivale & $\bar{A}$ & $\mathrm{SN}$ & 2 & 0 & 0 & 0 & 0 & $\overline{0}$ \\
\hline Merivale & $\mathrm{B}$ & SN & 0 & 0 & 0 & 0 & 0 & 1 \\
\hline Merivale & $\mathrm{C}$ & $\overline{\mathrm{SN}}$ & 1 & 0 & 0 & 0 & 0 & 5 \\
\hline Merivale & $\overline{\mathrm{D}}$ & $\mathrm{SN}$ & 1 & 0 & 0 & 0 & 0 & $\overline{0}$ \\
\hline Merivale & $\bar{E}$ & $\overline{\mathrm{SN}}$ & 2 & 0 & 0 & 0 & 0 & $\overline{0}$ \\
\hline Merivale & $\bar{F}$ & SN & 0 & 0 & 0 & 0 & 0 & $\overline{4}$ \\
\hline Merivale & $\overline{\mathrm{H}}$ & $\mathrm{SN}$ & 0 & 0 & 0 & 0 & 0 & 0 \\
\hline Merivale & I & $\mathrm{SN}$ & 0 & 0 & 0 & 0 & 0 & 1 \\
\hline Parc_Champlain & $\overline{\mathrm{A}}$ & $S$ & 0 & 0 & 0 & 0 & 0 & 0 \\
\hline Parc_Champlain & B & $S$ & 1 & 0 & 0 & 0 & 0 & 0 \\
\hline Parc_Champlain & $\mathrm{C}$ & $\mathbf{S}$ & 5 & 0 & 0 & 0 & 0 & 0 \\
\hline Parc_Champlain & $\overline{\mathrm{D}}$ & $\bar{S}$ & 0 & 0 & $\overline{0}$ & 0 & 0 & $\overline{0}$ \\
\hline Parc_Champlain & $\bar{E}$ & $\bar{S}$ & 4 & 0 & 0 & 0 & 0 & $\overline{0}$ \\
\hline Parc_Champlain & F & $S$ & 0 & 0 & 0 & 0 & 0 & 0 \\
\hline Parc_Champlain & $\mathrm{H}$ & $\mathrm{S}$ & 2 & 0 & 0 & 0 & 0 & 0 \\
\hline Parc_Champlain & I & $\mathbf{S}$ & 0 & 0 & 0 & 0 & 0 & 0 \\
\hline PineGlen_Annex & $\bar{A}$ & $\mathbf{S}$ & 0 & 0 & 0 & 0 & 0 & $\overline{0}$ \\
\hline PineGlen_Annex & $\bar{B}$ & $\bar{S}$ & 0 & 0 & 0 & 0 & 0 & $\overline{0}$ \\
\hline PineGlen_Annex & $\mathrm{C}$ & $S$ & 0 & 0 & 0 & 0 & 0 & 0 \\
\hline PineGlen_Annex & $\mathrm{D}$ & $\bar{S}$ & 0 & 0 & 0 & 0 & 0 & 0 \\
\hline PineGlen_Annex & $\mathrm{E}$ & $\mathbf{S}$ & 0 & 0 & 0 & 0 & 0 & 0 \\
\hline PineGlen_Annex & $\mathrm{F}$ & $S$ & 0 & 0 & 0 & 0 & 0 & 0 \\
\hline PineGlen_Annex & $\mathrm{H}$ & $S$ & 0 & 0 & 0 & 0 & 0 & $\overline{1}$ \\
\hline PineGlen_Annex & I & $S$ & 0 & 0 & 0 & $\mathbf{0}$ & 0 & $\overline{0}$ \\
\hline Q_Four & $\overline{\mathrm{A}}$ & $\bar{E}$ & 0 & 0 & 0 & 0 & 0 & 0 \\
\hline Q_Four & B & $\bar{E}$ & 0 & 0 & 0 & 0 & 0 & 0 \\
\hline Q Four & $\mathrm{C}$ & $\mathrm{E}$ & 0 & 0 & 0 & 1 & 0 & 0 \\
\hline Q_Four & $\bar{D}$ & $\mathrm{E}$ & 1 & 0 & 0 & 0 & 0 & 0 \\
\hline Q_Four & $\bar{E}$ & $E$ & 10 & 0 & 0 & 1 & 0 & 3 \\
\hline Q_Four & $\mathrm{F}$ & $\bar{E}$ & 0 & 0 & 0 & 0 & 0 & 2 \\
\hline
\end{tabular}




\begin{tabular}{|c|c|c|c|c|c|c|c|c|}
\hline Q_Four & $\mathrm{H}$ & $\mathrm{E}$ & 0 & 0 & 0 & 1 & 0 & 0 \\
\hline Q_Four & $\mathrm{I}$ & $\bar{E}$ & 0 & 0 & 0 & 0 & 0 & 0 \\
\hline Sandy_Hill & $\bar{A}$ & $\overline{\mathrm{U}}$ & 0 & 0 & 0 & 0 & 0 & $\overline{0}$ \\
\hline Sandy_Hill & $\bar{B}$ & $\overline{\mathrm{U}}$ & 0 & 0 & 0 & 0 & 0 & $\overline{0}$ \\
\hline Sandy_Hill & $\mathrm{C}$ & $\mathrm{U}$ & 0 & 0 & 0 & 0 & 0 & 0 \\
\hline Sandy_Hill & $\mathrm{D}$ & $\overline{\mathrm{U}}$ & 0 & 0 & 0 & 0 & 0 & 0 \\
\hline Sandy_Hill & $\bar{E}$ & $\mathrm{U}$ & 0 & 0 & 0 & 0 & 0 & 0 \\
\hline Sandy_Hill & $F$ & $\overline{\mathrm{U}}$ & 0 & 0 & 0 & 0 & 0 & $\overline{0}$ \\
\hline Sandy_Hill & $\mathrm{H}$ & $\mathrm{U}$ & 0 & 0 & 0 & 0 & 0 & 0 \\
\hline Sandy_Hill & I & $\mathrm{U}$ & 0 & 0 & 0 & 0 & 0 & $\overline{0}$ \\
\hline Vallee_Meech & A & $\mathrm{F}$ & 0 & 0 & 0 & 0 & 0 & $\overline{0}$ \\
\hline Vallee_Meech & $\overline{\mathrm{B}}$ & $\mathrm{F}$ & 0 & 0 & 0 & 0 & 0 & $\overline{0}$ \\
\hline Vallee_Meech & $\mathrm{C}$ & $\mathrm{F}$ & 0 & 0 & 0 & 0 & 0 & $\overline{0}$ \\
\hline Vallee_Meech & $\mathrm{D}$ & $F$ & 0 & 0 & 0 & 1 & 0 & 0 \\
\hline Vallee_Meech & $E$ & $\mathrm{~F}$ & 0 & 0 & 0 & 0 & 0 & 0 \\
\hline Vallee_Meech & $\mathrm{F}$ & F & 0 & 0 & 0 & 0 & 0 & $\overline{0}$ \\
\hline Vallee_Meech & $\mathrm{H}$ & $\mathrm{F}$ & 0 & 0 & 0 & 0 & 0 & 0 \\
\hline Vallee_Meech & I & $\mathrm{F}$ & 0 & 0 & 0 & 0 & 0 & $\overline{0}$ \\
\hline Wolf_Grove & $\mathrm{A}$ & $E$ & 0 & 0 & 0 & 0 & 0 & 0 \\
\hline Wolf_Grove & $\bar{B}$ & $E$ & 0 & 0 & 0 & 0 & 0 & 0 \\
\hline Wolf_Grove & $\mathrm{C}$ & $\bar{E}$ & 0 & 0 & 0 & 0 & 0 & $\overline{0}$ \\
\hline Wolf_Grove & $\mathrm{D}$ & $\mathrm{E}$ & 2 & 0 & 0 & 0 & 0 & 1 \\
\hline Wolf_Grove & $\mathrm{E}$ & $\mathrm{E}$ & 0 & 0 & 0 & 0 & 0 & 0 \\
\hline Wolf_Grove & $\mathrm{F}$ & $E$ & 3 & 0 & 0 & 0 & 1 & 2 \\
\hline Wolf_Grove & $\mathrm{H}$ & $\mathrm{E}$ & 0 & 0 & 0 & 0 & 0 & 0 \\
\hline Wolf_Grove & I & $\bar{E}$ & 0 & 0 & 0 & 0 & 0 & $\overline{0}$ \\
\hline Wrightville & $\mathrm{A}$ & $\overline{\mathrm{U}}$ & 0 & 0 & 0 & 0 & 0 & 0 \\
\hline Wrightville & B & $\mathrm{U}$ & 0 & 0 & 0 & 0 & 0 & $\overline{0}$ \\
\hline Wrightville & $\mathrm{C}$ & $\mathrm{U}$ & 0 & 0 & 0 & 0 & 0 & 0 \\
\hline Wrightville & $\mathrm{D}$ & $\bar{U}$ & 0 & 0 & 0 & 0 & 0 & $\overline{0}$ \\
\hline Wrightville & $\bar{E}$ & $\overline{\mathrm{U}}$ & 0 & 0 & 0 & 0 & 0 & $\overline{0}$ \\
\hline Wrightville & $\mathrm{F}$ & $\mathrm{U}$ & 0 & 0 & 0 & 0 & 0 & 0 \\
\hline Wrightville & $\mathrm{H}$ & $\mathrm{U}$ & 1 & 0 & 0 & 0 & 0 & $\overline{0}$ \\
\hline Wrightville & I & $\mathrm{U}$ & 0 & 0 & 0 & 0 & 0 & $\overline{0}$ \\
\hline Wychwood & A & $S$ & 0 & 0 & 0 & 0 & 0 & $\overline{0}$ \\
\hline Wychwood & $\bar{B}$ & $S$ & 3 & 0 & 0 & 0 & 0 & 0 \\
\hline Wychwood & $\mathrm{C}$ & $S$ & 2 & 0 & 0 & 0 & 0 & 2 \\
\hline Wychwood & $\mathrm{D}$ & $S$ & 0 & 0 & 0 & 0 & 0 & 0 \\
\hline Wychwood & $\mathrm{E}$ & $\mathbf{S}$ & 0 & 0 & 0 & 0 & 0 & 0 \\
\hline Wychwood & $\mathrm{F}$ & $S$ & 0 & 0 & 0 & 0 & 0 & 0 \\
\hline Wychwood & $\mathrm{H}$ & $S$ & 0 & 0 & 0 & 0 & 0 & 0 \\
\hline Wychwood & I & $\mathbf{S}$ & 2 & 0 & 0 & 0 & 0 & 0 \\
\hline
\end{tabular}




\begin{tabular}{|c|c|c|c|c|c|c|c|c|}
\hline SITE & STATION & CATEGORY & PTME & PTMU & PTPA & PTPE & PTTR & $\overline{\text { SPCA }}$ \\
\hline Achbar & $\mathrm{A}$ & SN & 0 & 18 & 0 & 3 & 0 & 0 \\
\hline Achbar & $\mathrm{B}$ & $\overline{\mathrm{SN}}$ & 1 & 0 & $\overline{0}$ & 0 & 0 & 0 \\
\hline Achbar & $\mathrm{C}$ & $\overline{\mathrm{SN}}$ & 1 & 5 & $\overline{0}$ & $\overline{0}$ & 0 & 0 \\
\hline Achbar & $\mathrm{D}$ & $\overline{\mathrm{SN}}$ & 4 & 5 & 0 & 0 & 0 & 0 \\
\hline Achbar & $E$ & SN & 0 & 0 & 0 & 0 & 0 & 0 \\
\hline Achbar & $F$ & SN & 1 & 15 & 0 & 0 & 0 & 0 \\
\hline Achbar & $\overline{\mathrm{H}}$ & SN & 0 & 4 & 0 & 0 & 0 & 0 \\
\hline Achbar & I & $\overline{\mathrm{SN}}$ & 0 & 0 & 0 & 0 & 0 & $\overline{0}$ \\
\hline Bridlewood & $\mathrm{A}$ & UN & 0 & 2 & 0 & 11 & 0 & 0 \\
\hline Bridlewood & B & UN & 5 & 23 & 0 & 3 & 0 & $\overline{0}$ \\
\hline Bridlewood & $\mathrm{C}$ & UN & 0 & 50 & 0 & 2 & 0 & 0 \\
\hline Bridlewood & $\mathrm{D}$ & UN & 15 & 10 & 0 & 1 & 0 & 0 \\
\hline Bridlewood & $\bar{E}$ & UN & 9 & 26 & 0 & 0 & 0 & 0 \\
\hline Bridlewood & $F$ & $\overline{\mathrm{UN}}$ & 3 & 2 & 0 & 2 & 0 & $\overline{0}$ \\
\hline Bridlewood & $\mathrm{H}$ & UN & 1 & 8 & 0 & 0 & 0 & 0 \\
\hline Bridlewood & I & UN & 4 & 46 & 0 & 1 & 0 & $\overline{0}$ \\
\hline Carp_Hills & $\bar{A}$ & $\mathrm{~F}$ & 0 & 14 & 0 & 0 & 0 & 0 \\
\hline Carp_Hills & $\mathrm{B}$ & $F$ & 0 & 0 & 0 & 0 & 0 & 0 \\
\hline Carp_Hills & $\overline{\mathrm{C}}$ & $F$ & 1 & 3 & 0 & 0 & 0 & $\overline{0}$ \\
\hline Carp_Hills & $\bar{D}$ & $\bar{F}$ & 0 & 0 & 0 & 0 & 0 & 0 \\
\hline Carp_Hills & $E$ & $F$ & 0 & 0 & 0 & 0 & 0 & 2 \\
\hline Carp_Hills & $F$ & $F$ & 1 & 0 & 0 & 0 & 0 & 0 \\
\hline Carp_Hills & $\mathrm{H}$ & $F$ & 0 & 27 & 0 & 0 & 0 & $\overline{0}$ \\
\hline Carp_Hills & I & $F$ & 0 & 0 & 0 & 0 & 0 & 0 \\
\hline Chapel_Hill & $\bar{A}$ & UN & 13 & 0 & 0 & 1 & 0 & 0 \\
\hline Chapel_Hill & $\bar{B}$ & $\mathrm{UN}$ & 7 & 5 & 0 & 0 & 0 & $\overline{0}$ \\
\hline Chapel_Hill & $\mathrm{C}$ & UN & 0 & 7 & 0 & 1 & 0 & $\overline{0}$ \\
\hline Chapel_Hill & $\mathrm{D}$ & UN & 0 & 48 & 0 & 1 & 0 & 0 \\
\hline Chapel_Hill & $E$ & UN & 22 & 0 & 0 & 0 & 0 & $\overline{0}$ \\
\hline Chapel_Hill & $F$ & UN & 10 & 1 & 1 & 0 & 0 & $\overline{0}$ \\
\hline Chapel_Hill & $\mathrm{H}$ & $\overline{\mathrm{UN}}$ & 0 & 12 & 0 & 0 & 0 & 0 \\
\hline Chapel_Hill & I & $\mathrm{UN}$ & 0 & 0 & 1 & 0 & 0 & $\overline{0}$ \\
\hline Chelsea & $\bar{A}$ & $\mathrm{SN}$ & 0 & 0 & 0 & 2 & 0 & 0 \\
\hline Chelsea & $\mathrm{B}$ & $\overline{\mathrm{SN}}$ & 0 & 0 & 0 & 0 & 0 & $\overline{0}$ \\
\hline Chelsea & $\mathrm{C}$ & $\mathrm{SN}$ & 0 & 0 & 0 & 0 & 0 & 0 \\
\hline Chelsea & $\mathrm{D}$ & $\mathrm{SN}$ & 1 & 0 & 0 & 1 & 0 & 0 \\
\hline Chelsea & $E$ & $\mathrm{SN}$ & 0 & 0 & 0 & 0 & 0 & $\overline{0}$ \\
\hline Chelsea & $F$ & $\mathrm{SN}$ & 0 & 0 & 0 & 0 & 0 & $\overline{0}$ \\
\hline Chelsea & $\mathrm{H}$ & $\mathrm{SN}$ & 0 & 0 & 0 & 3 & 0 & $\overline{0}$ \\
\hline Chelsea & I & SN & 0 & 0 & 0 & 0 & 0 & 0 \\
\hline Cote_d'Azur & $\mathrm{A}$ & $S$ & 0 & 0 & 0 & 0 & 0 & 0 \\
\hline Cote_d'Azur & B & $S$ & 4 & 0 & 0 & 0 & 0 & 0 \\
\hline Cote_d'Azur & $\mathrm{C}$ & $\mathrm{S}$ & 12 & 0 & 0 & 0 & 0 & $\overline{0}$ \\
\hline Cote_d'Azur & $\overline{\mathrm{D}}$ & $S$ & 1 & 0 & 0 & 0 & 0 & $\overline{0}$ \\
\hline
\end{tabular}




\begin{tabular}{|c|c|c|c|c|c|c|c|c|}
\hline Cote_d'Azur & $\mathrm{E}$ & $\mathrm{S}$ & 10 & 0 & 0 & 0 & 0 & $\overline{0}$ \\
\hline Cote_d'Azur & $\mathrm{F}$ & $\mathrm{S}$ & 1 & 0 & 0 & 0 & 0 & 0 \\
\hline Cote_d'Azur & $\mathrm{H}$ & $\bar{S}$ & 0 & 0 & 0 & 0 & 0 & $\overline{0}$ \\
\hline Cote_d'Azur & I & $\mathrm{S}$ & 0 & 0 & 0 & 0 & 0 & $\overline{0}$ \\
\hline Highway_Seven & $\bar{A}$ & $E$ & 0 & 0 & 0 & 15 & 0 & $\mathbf{0}$ \\
\hline Highway_Seven & $\bar{B}$ & $\mathrm{E}$ & 2 & 1 & 0 & 0 & 0 & $\overline{0}$ \\
\hline Highway_Seven & $\bar{C}$ & $\bar{E}$ & 0 & 0 & 0 & 2 & 0 & $\overline{0}$ \\
\hline Highway_Seven & $\bar{D}$ & $E$ & 0 & 1 & 0 & 0 & 0 & 0 \\
\hline Highway_Seven & $E$ & $E$ & 0 & 0 & 0 & 0 & 0 & 0 \\
\hline Highway_Seven & $\mathrm{F}$ & $\mathrm{E}$ & 0 & 3 & 0 & 2 & 0 & $\overline{0}$ \\
\hline Highway_Seven & $\mathrm{H}$ & $\mathrm{E}$ & 0 & 0 & 0 & 0 & 0 & $\overline{0}$ \\
\hline Highway_Seven & I & $\bar{E}$ & 1 & 0 & 0 & 32 & 0 & $\overline{0}$ \\
\hline Hull & $\overline{\mathrm{A}}$ & $\overline{\mathrm{U}}$ & 0 & 0 & 0 & 0 & 0 & $\overline{0}$ \\
\hline Hull & B & $\mathrm{U}$ & 0 & 0 & 0 & 0 & 0 & $\overline{0}$ \\
\hline Hull & $\mathrm{C}$ & $\bar{U}$ & 1 & 0 & 0 & 1 & 0 & $\overline{0}$ \\
\hline Hull & $\bar{D}$ & $\bar{U}$ & 0 & 0 & 0 & 0 & 0 & 0 \\
\hline Hull & $\bar{E}$ & $\bar{U}$ & 0 & 7 & 0 & 0 & 0 & $\overline{0}$ \\
\hline Hull & $\bar{F}$ & $\overline{\mathrm{U}}$ & 0 & 0 & 0 & 0 & 0 & $\overline{0}$ \\
\hline Hull & $\mathrm{H}$ & $\mathrm{U}$ & 0 & 0 & 0 & 0 & 0 & $\overline{0}$ \\
\hline Hull & I & $\bar{U}$ & 0 & 1 & 0 & 0 & 0 & 0 \\
\hline Lac_Philippe & A & $\bar{F}$ & 0 & 0 & 0 & 0 & 0 & 1 \\
\hline Lac_Philippe & $\mathrm{B}$ & $\bar{F}$ & 0 & 0 & 0 & 0 & 0 & 2 \\
\hline Lac_Philippe & $\mathrm{C}$ & $\mathrm{F}$ & 0 & 0 & 0 & 0 & 0 & 4 \\
\hline Lac_Philippe & $\mathrm{D}$ & $\mathrm{F}$ & 1 & 0 & 0 & 1 & 0 & 4 \\
\hline Lac_Philippe & $\bar{E}$ & $\bar{F}$ & 0 & 0 & 0 & 0 & 1 & 1 \\
\hline Lac_Philippe & $\mathrm{F}$ & $\mathrm{F}$ & 1 & 1 & 0 & 1 & 0 & 5 \\
\hline Lac_Philippe & $\overline{\mathrm{H}}$ & $\bar{F}$ & 0 & 0 & 0 & 0 & 0 & $\overline{0}$ \\
\hline Lac_Philippe & I & $\mathrm{F}$ & 0 & 0 & 0 & 3 & 1 & 2 \\
\hline Manoir_des_Trembles & $\mathrm{A}$ & $\mathrm{UN}$ & 0 & 0 & 0 & 0 & 0 & 0 \\
\hline Manoir_des_Trembles & $\mathrm{B}$ & $\overline{\mathrm{UN}}$ & 0 & 0 & 0 & 0 & 0 & $\overline{0}$ \\
\hline Manoir_des_Trembles & $\bar{C}$ & $\overline{\mathrm{UN}}$ & 0 & 0 & 0 & 0 & 0 & $\overline{0}$ \\
\hline Manoir_des_Trembles & $\bar{D}$ & UN & 0 & 0 & 0 & 0 & 0 & 0 \\
\hline Manoir_des_Trembles & $\mathrm{E}$ & UN & 0 & 0 & 0 & 0 & 0 & 0 \\
\hline Manoir_des_Trembles & $F$ & $\overline{\mathrm{UN}}$ & 0 & 0 & 0 & 0 & 1 & 0 \\
\hline Manoir_des_Trembles & $\overline{\mathrm{H}}$ & UN & 0 & 0 & 0 & 0 & 0 & 0 \\
\hline Manoir_des_Trembles & $\bar{I}$ & $\mathrm{UN}$ & 0 & 0 & 0 & 0 & 0 & $\overline{0}$ \\
\hline Marathon & A & $\mathrm{E}$ & 0 & 0 & 0 & 1 & 0 & 0 \\
\hline Marathon & B & $\mathrm{E}$ & 3 & 0 & 0 & 2 & 0 & 2 \\
\hline Marathon & $\mathrm{C}$ & $\mathrm{E}$ & 0 & 0 & 1 & 0 & 0 & 0 \\
\hline Marathon & $\mathrm{D}$ & $\bar{E}$ & 2 & 0 & 0 & 0 & 0 & 0 \\
\hline Marathon & $\bar{E}$ & $\bar{E}$ & 0 & 0 & 0 & 2 & 0 & 0 \\
\hline Marathon & $\mathrm{F}$ & $\mathrm{E}$ & 0 & 0 & 0 & 0 & 0 & 0 \\
\hline Marathon & $\mathrm{H}$ & $\mathrm{E}$ & 1 & 0 & 0 & 4 & 0 & 0 \\
\hline Marathon & I & $\mathrm{E}$ & 0 & 0 & 1 & 0 & 0 & $\overline{0}$ \\
\hline Marier & $\bar{A}$ & $\bar{U}$ & 0 & 0 & $\overline{0}$ & 0 & 0 & 0 \\
\hline
\end{tabular}




\begin{tabular}{|c|c|c|c|c|c|c|c|c|}
\hline Marier & $\mathrm{B}$ & $\mathrm{U}$ & 0 & 0 & 0 & 0 & 0 & 0 \\
\hline Marier & $\mathrm{C}$ & $\mathrm{U}$ & 0 & 2 & 0 & 0 & 0 & 0 \\
\hline Marier & $\mathrm{D}$ & $\mathrm{U}$ & 0 & 0 & 0 & 0 & 0 & 0 \\
\hline Marier & $E$ & $\overline{\mathrm{U}}$ & 0 & 0 & 0 & 0 & 0 & 0 \\
\hline Marier & $\bar{F}$ & $\mathrm{U}$ & 0 & 0 & 0 & 0 & 0 & 0 \\
\hline Marier & $\overline{\mathrm{H}}$ & $\bar{U}$ & 0 & 3 & 0 & 0 & 0 & $\overline{0}$ \\
\hline Marier & $I$ & $\overline{\mathrm{U}}$ & 0 & 6 & 0 & 1 & 0 & 0 \\
\hline Marlborough & $\overline{\mathrm{A}}$ & $\bar{F}$ & 0 & 0 & 0 & 7 & 0 & 0 \\
\hline Marlborough & $\bar{B}$ & $\bar{F}$ & 0 & 0 & 0 & 4 & 0 & 0 \\
\hline Marlborough & $\mathrm{C}$ & $F$ & 0 & 0 & 0 & 0 & 0 & 0 \\
\hline Marlborough & $\bar{D}$ & $\bar{F}$ & 0 & 0 & 0 & 12 & 0 & 0 \\
\hline Marlborough & $E$ & $F$ & 0 & 0 & 0 & 4 & 0 & 0 \\
\hline Marlborough & $F$ & $\bar{F}$ & 0 & 0 & 0 & 0 & 0 & 0 \\
\hline Marlborough & $\mathrm{H}$ & $F$ & 0 & 0 & 0 & 12 & 0 & 0 \\
\hline Marlborough & I & $\bar{F}$ & 0 & 0 & 0 & 8 & 0 & 0 \\
\hline Merivale & A & SN & 20 & 11 & 0 & 0 & 0 & 0 \\
\hline Merivale & B & SN & 9 & 6 & 0 & 1 & 0 & 0 \\
\hline Merivale & $\mathrm{C}$ & $\overline{\mathrm{SN}}$ & 48 & 0 & 1 & 0 & 0 & 0 \\
\hline Merivale & $\overline{\mathrm{D}}$ & $\overline{\mathrm{SN}}$ & 2 & 0 & 0 & 0 & 0 & $\overline{0}$ \\
\hline Merivale & $E$ & $\overline{\mathrm{SN}}$ & 6 & 0 & 0 & 0 & 0 & $\overline{0}$ \\
\hline Merivale & $F$ & $\overline{\mathrm{SN}}$ & 1 & 1 & 0 & 0 & 0 & 0 \\
\hline Merivale & $\mathrm{H}$ & SN & 1 & 1 & 0 & 0 & 0 & 0 \\
\hline Merivale & I & SN & 5 & 14 & 0 & 0 & 0 & $\overline{0}$ \\
\hline Parc_Champlain & A & $\mathbf{S}$ & 11 & 0 & 0 & 0 & 0 & $\overline{0}$ \\
\hline Parc_Champlain & $\bar{B}$ & $\mathbf{S}$ & 2 & 0 & 0 & 0 & 0 & $\overline{0}$ \\
\hline Parc_Champlain & $\bar{C}$ & $\mathrm{~S}$ & 3 & 0 & 0 & 0 & 0 & $\overline{0}$ \\
\hline Parc_Champlain & $\mathrm{D}$ & $\mathrm{S}$ & 6 & 0 & 0 & 0 & 0 & 0 \\
\hline Parc_Champlain & $\mathrm{E}$ & $S$ & 0 & 0 & 0 & 0 & 0 & 0 \\
\hline Parc_Champlain & $F$ & $\mathbf{S}$ & 33 & 0 & 0 & 0 & 0 & 0 \\
\hline Parc_Champlain & $\mathrm{H}$ & $\mathrm{S}$ & 10 & 0 & 0 & 0 & 0 & 0 \\
\hline Parc_Champlain & I & $\mathrm{S}$ & 5 & 0 & 0 & 0 & 0 & $\overline{0}$ \\
\hline PineGlen_Annex & $\bar{A}$ & $\mathrm{~S}$ & 1 & 7 & 0 & 1 & 0 & 0 \\
\hline PineGlen_Annex & B & $\mathrm{S}$ & 0 & 0 & 0 & 0 & 0 & $\overline{0}$ \\
\hline PineGlen_Annex & $\bar{C}$ & $\mathrm{~S}$ & 18 & 0 & 0 & 0 & 0 & 0 \\
\hline PineGlen_Annex & $\mathrm{D}$ & $\mathrm{S}$ & 26 & 0 & 0 & 0 & 0 & 0 \\
\hline PineGlen_Annex & $E$ & $\mathrm{~S}$ & 0 & 0 & 0 & 0 & 0 & 0 \\
\hline PineGlen_Annex & $\mathrm{F}$ & $\mathrm{S}$ & 1 & 0 & 0 & 0 & 0 & 0 \\
\hline PineGlen_Annex & $\overline{\mathrm{H}}$ & $\mathrm{S}$ & 10 & 164 & 0 & 3 & 0 & $\overline{0}$ \\
\hline PineGlen_Annex & I & $\mathrm{S}$ & 2 & 0 & 0 & 0 & 0 & $\overline{0}$ \\
\hline Q_Four & A & $\mathrm{E}$ & 10 & 0 & 0 & 0 & 0 & 0 \\
\hline Q_Four & $\mathrm{B}$ & $\mathbf{E}$ & 0 & 0 & 0 & 0 & 0 & $\overline{0}$ \\
\hline Q_Four & $\mathrm{C}$ & $E$ & 6 & 0 & 0 & 1 & 0 & 0 \\
\hline Q_Four & $\mathrm{D}$ & $E$ & 6 & 0 & 0 & 0 & 0 & 0 \\
\hline Q Four & $\bar{E}$ & $\mathrm{E}$ & 0 & 0 & 0 & 0 & 0 & 0 \\
\hline Q_Four & $\bar{F}$ & $E$ & 2 & 0 & 0 & 1 & 0 & 0 \\
\hline
\end{tabular}




\begin{tabular}{|c|c|c|c|c|c|c|c|c|}
\hline Q_Four & $\mathrm{H}$ & $\bar{E}$ & 2 & 0 & 0 & 4 & 0 & 0 \\
\hline Q_Four & I & $E$ & 7 & 1 & 0 & 0 & 0 & 1 \\
\hline Sandy_Hill & $\bar{A}$ & $\overline{\mathrm{U}}$ & 0 & 0 & 0 & 0 & 0 & 0 \\
\hline Sandy_Hill & B & $\overline{\mathrm{U}}$ & 0 & 0 & 0 & 0 & 0 & 0 \\
\hline Sandy_Hill & $\mathrm{C}$ & $\bar{U}$ & 0 & 0 & 0 & 0 & 0 & 0 \\
\hline Sandy_Hill & $\mathrm{D}$ & $\bar{U}$ & 0 & 0 & 0 & 0 & 0 & $\overline{0}$ \\
\hline Sandy_Hill & $E$ & $\overline{\mathrm{U}}$ & 0 & 0 & 0 & 0 & 0 & 0 \\
\hline Sandy_Hill & $F$ & $\overline{\mathrm{U}}$ & 0 & 0 & 0 & 0 & 0 & 0 \\
\hline Sandy_Hill & $\mathrm{H}$ & $\mathrm{U}$ & 0 & 0 & 0 & 0 & 0 & 0 \\
\hline Sandy_Hill & I & $\overline{\mathrm{U}}$ & 0 & 0 & 0 & 0 & $\overline{0}$ & 0 \\
\hline Vallee_Meech & $\bar{A}$ & $F$ & 0 & 0 & 0 & 1 & 0 & 2 \\
\hline Vallee_Meech & B & $\bar{F}$ & 0 & 0 & 0 & 0 & 0 & 1 \\
\hline Vallee_Meech & $\mathrm{C}$ & $F$ & 0 & 0 & 0 & 0 & 0 & 1 \\
\hline Vallee_Meech & $\bar{D}$ & $\mathrm{~F}$ & 0 & 0 & 0 & 0 & 0 & 4 \\
\hline Vallee_Meech & $E$ & $\bar{F}$ & 0 & 0 & 0 & 0 & 0 & 3 \\
\hline Vallee_Meech & $F$ & $F$ & 0 & 0 & 0 & 1 & 0 & 1 \\
\hline Vallee_Meech & $\mathrm{H}$ & $\mathrm{F}$ & 0 & 0 & 0 & 1 & 0 & 0 \\
\hline Vallee_Meech & I & $\mathrm{F}$ & 0 & 0 & 0 & 0 & 0 & 2 \\
\hline Wolf_Grove & $\overline{\mathrm{A}}$ & $E$ & 0 & 0 & 0 & 1 & 0 & 0 \\
\hline Wolf_Grove & B & $\bar{E}$ & 3 & 0 & 0 & 2 & 0 & 2 \\
\hline Wolf_Grove & $\mathrm{C}$ & $\mathrm{E}$ & 0 & 0 & 0 & 1 & 0 & 0 \\
\hline Wolf_Grove & $\mathrm{D}$ & $\mathrm{E}$ & 2 & 7 & 0 & 0 & 0 & 0 \\
\hline Wolf_Grove & $\mathrm{E}$ & $\mathrm{E}$ & 0 & 1 & 0 & 3 & 0 & 0 \\
\hline Wolf_Grove & $F$ & $\mathrm{E}$ & 0 & 1 & 0 & 0 & 0 & $\overline{0}$ \\
\hline Wolf_Grove & $\mathrm{H}$ & $\mathrm{E}$ & 1 & 0 & 0 & 2 & 1 & 0 \\
\hline Wolf_Grove & I & $\mathrm{E}$ & 0 & 0 & 0 & 6 & 0 & 0 \\
\hline Wrightville & $\bar{A}$ & $\mathrm{U}$ & 2 & 0 & 0 & 0 & 0 & 0 \\
\hline Wrightville & B & $\mathrm{U}$ & 0 & 0 & 0 & 0 & 0 & 0 \\
\hline Wrightville & $\mathrm{C}$ & $\overline{\mathrm{U}}$ & 9 & 0 & 0 & 0 & 0 & 0 \\
\hline Wrightville & $\mathrm{D}$ & $\mathrm{U}$ & 1 & 0 & 0 & 0 & 0 & 0 \\
\hline Wrightville & $\bar{E}$ & $\mathrm{U}$ & 1 & 0 & 0 & 0 & 0 & 0 \\
\hline Wrightville & F & $\overline{\mathrm{U}}$ & 0 & 0 & 0 & 0 & 0 & 0 \\
\hline Wrightville & $\mathrm{H}$ & $\mathrm{U}$ & 0 & 0 & 0 & 0 & 0 & 0 \\
\hline Wrightville & I & $\mathrm{U}$ & 14 & 0 & 0 & 0 & 0 & 0 \\
\hline Wychwood & $\mathrm{A}$ & $\mathrm{S}$ & 1 & 4 & 0 & 0 & 0 & 0 \\
\hline Wychwood & B & $\mathrm{S}$ & 0 & 2 & 0 & 0 & 0 & 0 \\
\hline Wychwood & $\bar{C}$ & $S$ & 0 & 71 & 0 & 6 & 0 & 0 \\
\hline Wychwood & $\mathrm{D}$ & $S$ & 0 & 5 & 0 & 0 & 0 & 0 \\
\hline Wychwood & $E$ & $\mathrm{~S}$ & 0 & 32 & 0 & 0 & 0 & 0 \\
\hline Wychwood & $\mathrm{F}$ & $\mathrm{S}$ & 0 & 2 & 0 & 0 & 0 & 0 \\
\hline Wychwood & $\mathrm{H}$ & $\mathrm{S}$ & 1 & 0 & 0 & 0 & 0 & 0 \\
\hline Wychwood & I & $\mathrm{S}$ & 1 & 8 & 0 & 0 & 0 & 0 \\
\hline
\end{tabular}




\begin{tabular}{|c|c|c|c|c|c|c|c|c|}
\hline SITE & STATION & CATEGORY & SPST & STCO & SYAM & SYIM & TRAP & TRVU \\
\hline Achbar & $\mathrm{A}$ & $\mathrm{SN}$ & 2 & 0 & 0 & 0 & 0 & 0 \\
\hline Achbar & $\bar{B}$ & SN & 14 & 0 & 0 & 7 & 0 & 0 \\
\hline Achbar & $\bar{C}$ & SN & 2 & 0 & 0 & 1 & 0 & 0 \\
\hline Achbar & D & SN & 2 & 0 & 0 & 0 & 0 & 0 \\
\hline Achbar & $E$ & SN & 8 & 0 & 0 & 1 & 0 & 0 \\
\hline Achbar & $F$ & SN & 1 & 0 & 0 & 0 & 0 & 0 \\
\hline Achbar & $\mathbf{H}$ & SN & 11 & 0 & 0 & 4 & 0 & 0 \\
\hline Achbar & I & SN & 6 & 0 & 0 & 2 & 0 & 0 \\
\hline Bridlewood & $\mathrm{A}$ & UN & 0 & 0 & 0 & 0 & 0 & 0 \\
\hline Bridlewood & B & UN & 0 & 0 & 0 & 4 & 0 & 0 \\
\hline Bridlewood & $\bar{C}$ & UN & 0 & 0 & 0 & 2 & 0 & 0 \\
\hline Bridlewood & $\mathrm{D}$ & UN & 0 & 0 & 0 & 0 & 0 & 0 \\
\hline Bridlewood & $\bar{E}$ & $\mathrm{UN}$ & 0 & 0 & 0 & 1 & 0 & 0 \\
\hline Bridlewood & $F$ & UN & 0 & 0 & 0 & 0 & 0 & 0 \\
\hline Bridlewood & $\mathrm{H}$ & UN & 0 & 0 & 0 & 0 & 0 & $\overline{0}$ \\
\hline Bridlewood & I & $\overline{\mathrm{UN}}$ & 0 & 0 & 0 & 0 & 0 & 0 \\
\hline Carp_Hills & $\bar{A}$ & $F$ & 2 & 0 & 0 & 0 & 0 & 0 \\
\hline Carp_Hills & B & $\mathrm{F}$ & 4 & 0 & 0 & 0 & 0 & 0 \\
\hline Carp_Hills & $\mathrm{C}$ & $F$ & 8 & 0 & 0 & 0 & 0 & $\overline{0}$ \\
\hline Carp_Hills & $\bar{D}$ & $F$ & 1 & 0 & 0 & 1 & 0 & 0 \\
\hline Carp_Hills & $\mathrm{E}$ & $F$ & 2 & 0 & 0 & 0 & 0 & $\overline{0}$ \\
\hline Carp_Hills & $F$ & $F$ & 0 & 0 & 0 & 0 & 0 & $\overline{0}$ \\
\hline Carp_Hills & $\overline{\mathrm{H}}$ & $\bar{F}$ & 2 & 0 & 0 & 0 & 0 & $\overline{0}$ \\
\hline Carp_Hills & I & $F$ & 0 & 0 & 0 & 0 & 0 & 0 \\
\hline Chapel_Hill & $\bar{A}$ & UN & 0 & 0 & 0 & 0 & 0 & 0 \\
\hline Chapel_Hill & $\bar{B}$ & $\overline{\mathrm{UN}}$ & 1 & 0 & 0 & 0 & 0 & 0 \\
\hline Chapel_Hill & $\mathrm{C}$ & $\mathrm{UN}$ & 1 & 0 & 0 & 0 & 0 & 0 \\
\hline Chapel_Hill & $\bar{D}$ & UN & 1 & 0 & 0 & 0 & 0 & $\overline{0}$ \\
\hline Chapel_Hill & $\bar{E}$ & UN & 0 & 0 & 0 & 0 & 0 & 0 \\
\hline Chapel_Hill & $F$ & UN & 0 & 0 & 0 & 0 & 0 & 0 \\
\hline Chapel_Hill & $\mathbf{H}$ & UN & 0 & 0 & 0 & 2 & 0 & 0 \\
\hline Chapel_Hill & I & UN & 0 & 0 & 0 & 0 & 0 & $\overline{0}$ \\
\hline Chelsea & $\overline{\mathrm{A}}$ & SN & 0 & 0 & 0 & 0 & 0 & 0 \\
\hline Chelsea & $\bar{B}$ & $\overline{\mathrm{SN}}$ & 0 & 0 & 0 & 0 & 0 & 0 \\
\hline Chelsea & $\mathrm{C}$ & SN & 0 & 0 & 0 & 0 & 0 & 0 \\
\hline Chelsea & $\bar{D}$ & SN & 0 & 0 & 0 & 0 & 0 & 0 \\
\hline Chelsea & $\bar{E}$ & $\mathrm{SN}$ & 0 & 0 & 0 & 0 & 0 & $\overline{0}$ \\
\hline Chelsea & $F$ & $\mathrm{SN}$ & 0 & 0 & 0 & 0 & 0 & 0 \\
\hline Chelsea & $\mathrm{H}$ & SN & 0 & 0 & 0 & 0 & 0 & 0 \\
\hline Chelsea & $I$ & SN & 0 & 0 & 0 & 0 & 0 & 0 \\
\hline Cote_d'Azur & $\mathrm{A}$ & $S$ & 0 & 0 & 0 & 0 & 0 & 0 \\
\hline Cote_d'Azur & B & $\bar{S}$ & 0 & 0 & 0 & 0 & 0 & $\overline{0}$ \\
\hline Cote_d'Azur & $\mathrm{C}$ & $S$ & 0 & 0 & 0 & 0 & 0 & 0 \\
\hline Cote_d'Azur & $\mathrm{D}$ & $\mathrm{S}$ & 0 & 0 & 0 & 0 & 0 & 0 \\
\hline
\end{tabular}




\begin{tabular}{|c|c|c|c|c|c|c|c|c|}
\hline Cote_d'Azur & $\bar{E}$ & $\mathrm{~S}$ & 0 & 0 & 0 & 0 & 0 & 0 \\
\hline Cote_d'Azur & $\mathrm{F}$ & $S$ & 0 & 0 & 0 & 0 & 0 & 0 \\
\hline Cote_d'Azur & $\overline{\mathrm{H}}$ & $\mathrm{S}$ & 0 & 0 & 0 & 0 & 0 & 0 \\
\hline Cote_d'Azur & $\mathrm{I}$ & $\mathrm{S}$ & 0 & 0 & 0 & 0 & 0 & 0 \\
\hline Highway_Seven & A & $\mathrm{E}$ & 8 & 0 & 0 & 1 & 0 & 0 \\
\hline Highway_Seven & B & $\bar{E}$ & 0 & 0 & 0 & 0 & 0 & 0 \\
\hline Highway_Seven & $\mathrm{C}$ & $E$ & 1 & 0 & 0 & 4 & 0 & $\overline{0}$ \\
\hline Highway_Seven & $\overline{\mathrm{D}}$ & $\bar{E}$ & 0 & 0 & 0 & 0 & 0 & 0 \\
\hline Highway_Seven & E & $\bar{E}$ & 0 & 0 & 0 & 0 & 0 & 0 \\
\hline Highway_Seven & $\bar{F}$ & $E$ & 0 & 0 & 0 & 0 & 0 & 0 \\
\hline Highway_Seven & $\mathrm{H}$ & $\mathrm{E}$ & 0 & 0 & 1 & 0 & 0 & 0 \\
\hline Highway_Seven & $\mathrm{I}$ & $E$ & 1 & 0 & 0 & 1 & 0 & 0 \\
\hline Hull & $\mathrm{A}$ & $\mathrm{U}$ & 0 & 0 & 0 & 0 & 0 & 0 \\
\hline Hull & B & $\mathrm{U}$ & 0 & 0 & 0 & 0 & 0 & 0 \\
\hline Hull & $\mathrm{C}$ & $\mathrm{U}$ & 0 & 0 & 0 & 0 & 0 & 0 \\
\hline Hull & $\bar{D}$ & $\overline{\mathrm{U}}$ & 0 & 0 & 0 & 0 & 0 & 0 \\
\hline Hull & $\bar{E}$ & $\overline{\mathrm{U}}$ & 0 & 2 & 0 & 0 & 0 & $\overline{0}$ \\
\hline Hull & $\mathrm{F}$ & $\mathrm{U}$ & 0 & 6 & 0 & 0 & 0 & 0 \\
\hline Hull & $\mathrm{H}$ & $\mathrm{U}$ & 0 & 0 & 0 & 0 & 0 & 0 \\
\hline Hull & $\bar{I}$ & $\bar{U}$ & 0 & 0 & 0 & 0 & 0 & $\overline{0}$ \\
\hline Lac_Philippe & $\bar{A}$ & $\mathrm{~F}$ & 3 & 0 & 0 & 4 & 0 & 0 \\
\hline Lac_Philippe & $\bar{B}$ & $\bar{F}$ & 0 & 0 & 0 & 8 & 0 & $\overline{0}$ \\
\hline Lac_Philippe & $\bar{C}$ & $\bar{F}$ & 0 & 0 & 0 & 1 & 0 & $\overline{0}$ \\
\hline Lac_Philippe & $\mathrm{D}$ & $\mathrm{F}$ & 2 & 0 & 0 & 6 & 0 & 0 \\
\hline Lac_Philippe & $\mathrm{E}$ & $\mathrm{F}$ & 1 & 0 & 0 & 2 & 0 & 0 \\
\hline Lac_Philippe & $\mathrm{F}$ & $\mathrm{F}$ & 3 & 0 & 0 & 19 & 0 & 0 \\
\hline Lac_Philippe & $\mathrm{H}$ & $\mathrm{F}$ & 1 & 0 & 0 & 0 & 0 & $\overline{0}$ \\
\hline Lac_Philippe & I & $\mathrm{F}$ & 0 & 0 & 0 & 6 & 0 & $\overline{0}$ \\
\hline Manoir_des_Trembles & $\bar{A}$ & $\overline{\mathrm{UN}}$ & 8 & 0 & 0 & 0 & 0 & 0 \\
\hline Manoir_des_Trembles & B & $\overline{\mathrm{UN}}$ & 2 & 0 & 0 & 2 & 0 & 0 \\
\hline Manoir_des_Trembles & $\mathrm{C}$ & $\overline{\mathrm{UN}}$ & 0 & 0 & 0 & 0 & 0 & 0 \\
\hline Manoir_des_Trembles & $\overline{\mathrm{D}}$ & UN & 6 & 0 & 0 & 1 & 0 & 0 \\
\hline Manoir_des_Trembles & $E$ & UN & 10 & 0 & 0 & 0 & 0 & 0 \\
\hline Manoir_des_Trembles & $F$ & $\overline{\mathrm{UN}}$ & 12 & 0 & 0 & 1 & 0 & 0 \\
\hline Manoir_des_Trembles & $\overline{\mathrm{H}}$ & $\overline{\mathrm{UN}}$ & 1 & 0 & 0 & 4 & 0 & 0 \\
\hline Manoir_des_Trembles & I & $\overline{\mathrm{UN}}$ & 10 & 0 & 0 & 1 & 0 & 0 \\
\hline Marathon & A & $\mathbf{E}$ & 2 & 0 & 0 & 2 & 0 & 0 \\
\hline Marathon & B & $\bar{E}$ & 5 & $\overline{0}$ & 0 & 0 & 0 & 0 \\
\hline Marathon & $\mathrm{C}$ & $\mathrm{E}$ & 2 & 0 & 0 & 0 & 0 & 0 \\
\hline Marathon & $\overline{\mathrm{D}}$ & $\bar{E}$ & $\overline{0}$ & 0 & 0 & 0 & 0 & $\overline{0}$ \\
\hline Marathon & $\bar{E}$ & $\mathrm{E}$ & 4 & 0 & 0 & 0 & 0 & 0 \\
\hline Marathon & $\mathrm{F}$ & $E$ & 0 & 0 & 0 & 0 & 0 & 0 \\
\hline Marathon & $\mathrm{H}$ & $E$ & 1 & 0 & 0 & 0 & 0 & $\overline{0}$ \\
\hline Marathon & I & $E$ & 1 & 0 & 0 & 0 & 0 & 0 \\
\hline Marier & $\overline{\mathrm{A}}$ & $\bar{U}$ & $\mathbf{0}$ & 0 & 0 & 0 & 0 & 0 \\
\hline
\end{tabular}




\begin{tabular}{|c|c|c|c|c|c|c|c|c|}
\hline Marier & $\bar{B}$ & $\mathrm{U}$ & 0 & 0 & 0 & 0 & 0 & 0 \\
\hline Marier & $\mathrm{C}$ & $\bar{U}$ & 0 & 0 & 0 & 0 & 0 & $\overline{0}$ \\
\hline Marier & D & $\bar{U}$ & 0 & 1 & 0 & $\overline{0}$ & $\overline{0}$ & $\overline{0}$ \\
\hline Marier & $\bar{E}$ & $\overline{\mathrm{U}}$ & 0 & 0 & 0 & 0 & 0 & 0 \\
\hline Marier & $\mathrm{F}$ & $\bar{U}$ & 0 & 0 & 0 & 0 & 0 & 0 \\
\hline Marier & $\mathrm{H}$ & $\bar{U}$ & 0 & 0 & 0 & 0 & 0 & 1 \\
\hline Marier & $I$ & $\bar{U}$ & 0 & 0 & 0 & 0 & 0 & 0 \\
\hline Marlborough & $\bar{A}$ & $F$ & 1 & 0 & 0 & 4 & 0 & 0 \\
\hline Marlborough & $\bar{B}$ & $F$ & 1 & 0 & 0 & 3 & 0 & 0 \\
\hline Marlborough & $\bar{C}$ & $\bar{F}$ & 2 & 0 & 0 & 2 & 0 & 0 \\
\hline Marlborough & $\bar{D}$ & $\bar{F}$ & 7 & 0 & 0 & 1 & 0 & 0 \\
\hline Marlborough & $\mathrm{E}$ & $F$ & 0 & 0 & 0 & 0 & 1 & 0 \\
\hline Marlborough & $\mathrm{F}$ & $F$ & 2 & 0 & 0 & 0 & 0 & 0 \\
\hline Marlborough & $\mathrm{H}$ & $F$ & 3 & 0 & 0 & 10 & 0 & $\overline{0}$ \\
\hline Marlborough & $I$ & $F$ & 0 & 0 & 0 & 2 & 0 & 0 \\
\hline Merivale & $\bar{A}$ & $\mathrm{SN}$ & 1 & 0 & 0 & 0 & 0 & 0 \\
\hline Merivale & B & $\overline{\mathrm{SN}}$ & 0 & 0 & 0 & 2 & 0 & 0 \\
\hline Merivale & $\mathrm{C}$ & $\mathrm{SN}$ & 0 & 0 & 0 & 0 & 0 & 0 \\
\hline Merivale & $\mathrm{D}$ & SN & 2 & 0 & 0 & 0 & 0 & 0 \\
\hline Merivale & $\bar{E}$ & $\overline{\mathrm{SN}}$ & 0 & 0 & 0 & 0 & 0 & 0 \\
\hline Merivale & $\bar{F}$ & $\overline{\mathrm{SN}}$ & 0 & 0 & 0 & 0 & 0 & 0 \\
\hline Merivale & $\mathrm{H}$ & $\mathrm{SN}$ & 0 & 0 & 0 & 0 & 0 & 0 \\
\hline Merivale & I & $\overline{\mathrm{SN}}$ & 0 & 0 & 0 & 1 & 0 & $\overline{0}$ \\
\hline Parc_Champlain & A & $S$ & 0 & 1 & 0 & 0 & 0 & 0 \\
\hline Parc_Champlain & B & $\mathrm{S}$ & 0 & 0 & 0 & 0 & 0 & 0 \\
\hline Parc_Champlain & $\mathrm{C}$ & $\mathrm{S}$ & 0 & 0 & 0 & 0 & 0 & 0 \\
\hline Parc_Champlain & $\mathrm{D}$ & $S$ & 0 & 0 & 0 & 0 & 0 & 2 \\
\hline Parc_Champlain & $\bar{E}$ & $\mathrm{~S}$ & 0 & 0 & 0 & 0 & 0 & 0 \\
\hline Parc_Champlain & $\bar{F}$ & $\mathrm{~S}$ & 0 & 0 & 0 & 0 & 0 & 0 \\
\hline Parc_Champlain & $\mathrm{H}$ & $\bar{S}$ & 0 & 0 & 0 & 0 & 0 & 0 \\
\hline Parc_Champlain & I & $S$ & 0 & 0 & 0 & 0 & 0 & 0 \\
\hline PineGlen_Annex & $\bar{A}$ & $\mathrm{~S}$ & 0 & 0 & 0 & 0 & 0 & 0 \\
\hline PineGlen_Annex & B & $S$ & 0 & 0 & 0 & 0 & 0 & 0 \\
\hline PineGlen_Annex & $\mathrm{C}$ & $S$ & 0 & 0 & 0 & 0 & 0 & 0 \\
\hline PineGlen_Annex & $\mathrm{D}$ & $S$ & 0 & 0 & 0 & 0 & 0 & 0 \\
\hline PineGlen_Annex & $E$ & $S$ & 0 & 0 & 0 & 0 & 0 & 0 \\
\hline PineGlen_Annex & $\mathrm{F}$ & $\mathrm{S}$ & 0 & 0 & 0 & 0 & 0 & 0 \\
\hline PineGlen_Annex & $\mathrm{H}$ & $S$ & 0 & 0 & 0 & 0 & 0 & 0 \\
\hline PineGlen_Annex & I & $S$ & 0 & 0 & 0 & 0 & 0 & $\overline{0}$ \\
\hline Q_Four & A & $E$ & 1 & 0 & 0 & 4 & 0 & 0 \\
\hline Q_Four & $\mathrm{B}$ & $\mathrm{E}$ & 0 & 0 & 0 & 1 & 0 & 0 \\
\hline Q_Four & $\mathrm{C}$ & $\mathrm{E}$ & 1 & 0 & 0 & 1 & 0 & 0 \\
\hline Q_Four & D & $\bar{E}$ & 0 & 0 & 0 & 0 & 0 & 0 \\
\hline Q_Four & $\bar{E}$ & $E$ & 0 & 0 & 0 & 0 & 0 & 0 \\
\hline Q_Four & $\bar{F}$ & $\mathrm{E}$ & 3 & 0 & 0 & 0 & 0 & 0 \\
\hline
\end{tabular}




\begin{tabular}{|c|c|c|c|c|c|c|c|c|}
\hline Q_Four & $\mathrm{H}$ & $E$ & 2 & 0 & 0 & 3 & 0 & 0 \\
\hline Q Four & I & $E$ & 1 & 0 & 0 & 0 & 0 & 0 \\
\hline Sandy_Hill & $\mathrm{A}$ & $\mathrm{U}$ & 0 & 0 & 0 & 0 & 0 & 0 \\
\hline Sandy_Hill & B & $\bar{U}$ & 0 & 0 & 0 & 0 & 0 & 0 \\
\hline Sandy_Hill & $\mathrm{C}$ & $\bar{U}$ & 0 & 0 & 0 & 0 & 0 & 0 \\
\hline Sandy_Hill & $\bar{D}$ & $\bar{U}$ & $\overline{0}$ & 0 & 0 & 0 & 0 & 0 \\
\hline Sandy_Hill & $\bar{E}$ & $\overline{\mathrm{U}}$ & 0 & 0 & 0 & 0 & 0 & 0 \\
\hline Sandy_Hill & $\mathrm{F}$ & $\overline{\mathrm{U}}$ & 0 & 0 & 0 & 0 & 0 & 0 \\
\hline Sandy_Hill & $\mathrm{H}$ & $\bar{U}$ & 0 & 0 & 0 & 0 & 0 & 0 \\
\hline Sandy_Hill & I & $\mathrm{U}$ & 0 & 0 & 0 & 0 & 0 & 4 \\
\hline Vallee_Meech & $\mathrm{A}$ & $\mathrm{F}$ & 1 & 0 & 0 & 9 & 0 & 0 \\
\hline Vallee_Meech & B & $\mathrm{F}$ & 0 & $\overline{0}$ & 0 & 3 & 0 & 0 \\
\hline Vallee_Meech & $\bar{C}$ & $F$ & 0 & 0 & 0 & 4 & 0 & 0 \\
\hline Vallee_Meech & $\bar{D}$ & $\bar{F}$ & 3 & 0 & 0 & 6 & 0 & 0 \\
\hline Vallee_Meech & $\bar{E}$ & $\bar{F}$ & 0 & 0 & 0 & 8 & 0 & 0 \\
\hline Vallee_Meech & $\mathrm{F}$ & $\bar{F}$ & 0 & 0 & 0 & 19 & 0 & $\overline{0}$ \\
\hline Vallee_Meech & $\mathrm{H}$ & $\mathrm{F}$ & 1 & 0 & 0 & 3 & 0 & 0 \\
\hline Vallee_Meech & I & $\mathrm{F}$ & 0 & 0 & 0 & 12 & 0 & 0 \\
\hline Wolf_Grove & A & $\mathrm{E}$ & 2 & 0 & $\overline{0}$ & 2 & 0 & 0 \\
\hline Wolf_Grove & $\bar{B}$ & $\mathrm{E}$ & 5 & 0 & 0 & 0 & 0 & $\overline{0}$ \\
\hline Wolf_Grove & $\bar{C}$ & $\mathrm{E}$ & 2 & 0 & 0 & 2 & 0 & 0 \\
\hline Wolf_Grove & D & $\mathrm{E}$ & 1 & 0 & 0 & 0 & 0 & 0 \\
\hline Wolf_Grove & $\mathrm{E}$ & $\mathrm{E}$ & 0 & 0 & 0 & 0 & 0 & 0 \\
\hline Wolf_Grove & $F$ & $E$ & 1 & 0 & 0 & 0 & 0 & 0 \\
\hline Wolf_Grove & $\mathrm{H}$ & $\mathrm{E}$ & 1 & 0 & 0 & 7 & 0 & 0 \\
\hline Wolf_Grove & I & $\mathrm{E}$ & 0 & 0 & 0 & 0 & 0 & 0 \\
\hline Wrightville & $\bar{A}$ & $\bar{U}$ & 0 & 0 & 0 & 0 & 0 & 0 \\
\hline Wrightville & $\bar{B}$ & $\overline{\mathrm{U}}$ & 0 & 0 & 0 & 0 & 0 & 0 \\
\hline Wrightville & $\mathrm{C}$ & $\bar{U}$ & 0 & 1 & 0 & 0 & 0 & 1 \\
\hline Wrightville & $\mathrm{D}$ & $\mathrm{U}$ & 0 & 0 & 0 & 0 & 0 & 0 \\
\hline Wrightville & $\mathrm{E}$ & $\mathrm{U}$ & 0 & 0 & 0 & 0 & 0 & 0 \\
\hline Wrightville & $F$ & $\bar{U}$ & 0 & 0 & 0 & 0 & 0 & 0 \\
\hline Wrightville & $\mathrm{H}$ & $\mathrm{U}$ & 0 & 0 & 1 & 0 & 0 & 0 \\
\hline Wrightville & I & $\overline{\mathrm{U}}$ & 0 & 0 & 0 & 0 & 0 & 0 \\
\hline Wychwood & A & $S$ & 0 & 0 & 2 & 0 & 0 & 0 \\
\hline Wychwood & B & $\mathrm{S}$ & 0 & 0 & 0 & 0 & 0 & 0 \\
\hline Wychwood & C & $\mathrm{S}$ & 0 & 0 & 0 & 0 & 0 & 0 \\
\hline Wychwood & D & $\mathrm{S}$ & 0 & 0 & 0 & 0 & 0 & 0 \\
\hline Wychwood & $\bar{E}$ & $S$ & 0 & 0 & 0 & 0 & 0 & 0 \\
\hline Wychwood & $\mathrm{F}$ & $S$ & 0 & 0 & 0 & 0 & 0 & 0 \\
\hline Wychwood & $\mathrm{H}$ & $\mathrm{S}$ & 0 & 0 & 0 & 0 & 0 & 0 \\
\hline Wychwood & I & $\mathrm{S}$ & 0 & 0 & 1 & 0 & 0 & 0 \\
\hline
\end{tabular}


${ }^{c} \mathrm{~F}=$ Forested, $\mathrm{E}=$ Exurban, $\mathrm{S}=$ Suburban, $\mathrm{U}=\mathrm{Urban}, \mathrm{SN}=$ Suburban Neighbor, $\mathrm{UN}=$ Urban Neighbor.

${ }^{\mathrm{d}} \mathrm{AGCU}=$ Agonum cupripenne, $\mathrm{AGGR}=$ Agonum gratiosum, $\mathrm{AGME}=$ Agonum melanarium, $\mathrm{AGMU}=$ Agonum muelleri, $\mathrm{AGPA}=$ Agonum palustre, $\mathrm{AGRE}=$ Agonum retractum, $\mathrm{AGTE}=$ Agonum tenue, $\mathrm{AGTR}=$ Agonum trigeminum, $\mathrm{AMAE}=$ Amara aenea, $\mathrm{AMAN}=$ Amara angustata, $\mathrm{AMAP}=$ Amara apricaria, $\mathrm{AMCU}=$ Amara cupreolata, $\mathrm{AMIM}=$ Amara impuncticollis, $\mathrm{AMIN}=$ Amphasia interstitialis, $\mathrm{AMPA}=$ Amara patruelis, $\mathrm{AMRU}=$ Amara rubric, $\mathrm{ANHA}=$ Anisodactylus harrisii, $\mathrm{ANKI}=$ Anisodactylus kirbyi, $\mathrm{ANME}=$ Anisodactylus merula, $\mathrm{ANRU}=$ Anisodactylus rusticus, ANVE $=$ Anisodactylus verticalis, $\mathrm{BANO}=$ Badister notatus, $\mathrm{BAOC}=$ Badister ocularis, $\mathrm{BEFR}=$ Bembidion frontale, $\mathrm{BEIN}=$ Bembidion inaequale, $\mathrm{BEOB}=$ Bembidion obtusum, $\mathrm{BEPR}=$ Bembidion praticola, $\mathrm{BEQU}=$ Bembidion quadrimaculatum oppositum, $\mathrm{BETE}=$ Bembidion tetracolum, $\mathrm{BEVA}=$ Bembidion variegatum, $\mathrm{BEVE}=$ Bembidion versicolor, $\mathrm{BRLU}=$ Bradycellus lugubris, $\mathrm{BRME}=$ Brachinus medius, CAGR $=$ Carabus granulatus,, $\mathrm{CALGR}=$ Calathus gregarius, CAMA $=$ Carabus maeander, $\mathrm{CANE}=$ Carabus nemoralis, $\mathrm{CHEM}=$ Chlaenius emarginatus, $\mathrm{CHIM}=$ Chlaenius impunctifrons, $\mathrm{CHLI}=$ Chlaenius lithophilus, $\mathrm{CHNI}=$ Chlaenius niger, $\mathrm{CHTR}$ $=$ Chlaenius tricolor, $\mathrm{CISE}=$ Cicindela sexguttata, $\mathrm{CLFO}=$ Clivina fossor, $\mathrm{CYCR}=$ Cymindis cribricollis, $\mathrm{CYNE}=$ Cymindis neglectus, $\mathrm{DIOB}=$ Diplocheila obtusa, $\mathrm{DYGL}$ $=$ Dyschirius globulosus, $\mathrm{ELCL}=$ Elaphrus clairvillei, $\mathrm{ELGR}=$ Elaphropus granarius, $\mathrm{HAAF}=$ Harpalus affinis, $\mathrm{HACO}=$ Harpalus compare, $\mathrm{HAER}=$ Harpalus eraticus, HAERY $=$ Harpalus erythropus, HAFA = Harpalus faunus, HAFU = Harpalus 
fulvilabris, $\mathrm{HAHE}=$ Harpalus herbivagus, $\mathrm{HALO}=$ Harpalus longicollis, $\mathrm{HAOP}=$ Harpalus opacipennis, HAPE = Harpalus pensylvanicus, HAPR $=$ Harpalus providens, HASO $=$ Harpalus somnulentus, $\mathrm{LOCO}=$ Loxandrus commutabilis, $\mathrm{LOPI}=$ Loricera pilicornis, LOSC $=$ Lophoglossus scrutator, $\mathrm{MYCY}=$ Myas cyanescens, $\mathrm{NOAE}=$ Notiophilus aeneus, OLMI = Olisthopus micans, OLPA = Olisthopus parmatus, $\mathrm{OXPU}=$ Oxypselaphus pusillus, $\mathrm{PALO}=$ Patrobus longicornis, $\mathrm{PLDE}=$ Platynus decentis, $\mathrm{POLU}$ $=$ Poecilus lucublandus lucublandus, $\mathrm{PSAR}=$ Pseudamara arenaria, $\mathrm{PTCA}=$ Pterostichus caudicalis, $\mathrm{PTCO}=$ Pterostichus coracinus, $\mathrm{PTCOR}=$ Pterostichus corvinus, $\mathrm{PTLU}=$ Pterostichus luctuosus, $\mathrm{PTME}=$ Pterostichus melanarius, $\mathrm{PTMU}=$ Pterostichus mutus, $\mathrm{PTPA}=$ Pterostichus patruelis, $\mathrm{PTPE}=$ Pterostichus pensylvanicus, PTTR $=$ Pterostichus tristis, SPCA $=$ Sphaeroderus canadensis canadensis, SPST $=$ Sphaeroderus stenostomus lecontei, $\mathrm{STCO}=$ Stenolophus conjunctus, $\mathrm{SYAM}=$ Syntomus americanus, $\mathrm{SYIM}=$ Synuchus impunctatus, $\mathrm{TRAP}=$ Trechus apicalis, $\mathrm{TRVU}=$ Trichotichnus vulpeculus. 
Appendix 5. Carabid beetle species collected during pitfall trapping and their estimated abundances in development scenarios. I classified beetles as 'native', 'introduced', 'forest' and 'open-habitat' species according to Lindroth (1961-1969). I defined forest species as those that occur primarily in forested or wooded habitat, and in some cases open country. I defined open-habitat species as those occurring in a variety of openhabitat types (e.g., open woods, meadows, fields) including roadsides, gravel pits and cultivated ground. If the habitat affinity of a species was not recorded in Lindroth (19611969), I classified the species according to H. Goulet (Agriculture and Agri-Food Canada, pers. comm.) with two exceptions. The habitat affinity of Cicindela sexguttata was determined according to Schultz (1998) and the habitat affinity of Trichotichnus vulpeculus was determined according to Stanton et al. (2003) and Webster and Bousquet (2008).

\begin{tabular}{|c|c|c|c|c|}
\hline & Scientific name & $\begin{array}{l}\text { Habitat } \\
\text { affinity }\end{array}$ & $\begin{array}{l}\text { Developed } \\
\text { scenario with } \\
\text { highest } \\
\text { abundance }\end{array}$ & $\begin{array}{l}\text { Highest } \\
\text { abundance } \\
\text { in } \\
\text { Undeveloped } \\
\text { scenario? }\end{array}$ \\
\hline Native beetles & $\begin{array}{l}\text { Agonum cupripenne } \\
\text { Agonum gratiosum } \\
\text { Agonum melanarium } \\
\text { Agonum palustre } \\
\text { Agonum retractum } \\
\text { Agonum tenue }\end{array}$ & $\begin{array}{l}\text { Open-habitat } \\
\text { Forest }\end{array}$ & $\begin{array}{l}\text { Dispersed } \\
\text { Dispersed } \\
\text { Compact } \\
\text { Semi-compact } \\
\text { Semi-compact } \\
\text { Compact }\end{array}$ & \\
\hline
\end{tabular}




\begin{tabular}{|c|c|c|}
\hline Agonum trigeminum & & Dispersed \\
\hline Amara angustata & Open-habitat & Semi-compact \\
\hline Amara cupreolata & Open-habitat & Dispersed \\
\hline Amara impuncticollis & Open-habitat & Semi-compact \\
\hline Amara patruelis & Open-habitat & Semi-compact \\
\hline Amara rubrica & Open-habitat & Compact \\
\hline Amphasia interstitialis & Forest & Semi-compact \\
\hline Anisodactylus harrisii & Open-habitat & Dispersed \\
\hline Anisodactylus kirbyi & & Compact \\
\hline Anisodactylus merula & Open-habitat & Compact \\
\hline Anisodactylus rusticus & Open-habitat & Semi-compact \\
\hline Anisodactylus verticalis & Forest & Compact \\
\hline Badister notatus & & Dispersed \\
\hline Badister ocularis & & Dispersed \\
\hline Bembidion frontale & & Compact \\
\hline Bembidion inaequale & & Semi-compact \\
\hline Bembidion praticola & Forest & Compact \\
\hline $\begin{array}{l}\text { Bembidion quadrimaculatum } \\
\text { oppositum }\end{array}$ & Open-habitat & Dispersed \\
\hline Bembidion variegatum & & Compact \\
\hline Bembidion versicolor & & Dispersed \\
\hline Brachinus medius & & Compact \\
\hline Bradycellus lugubris & Open-habitat & Compact \\
\hline Calathus gregarius & Forest & Dispersed \\
\hline Carabus maeander & Open-habitat & Dispersed \\
\hline
\end{tabular}




\begin{tabular}{|c|c|c|}
\hline Chlaenius emarginatus & Forest & Dispersed \\
\hline Chlaenius impunctifrons & & Compact \\
\hline Chlaenius lithophilus & & Semi-compact \\
\hline Chlaenius niger & & Dispersed \\
\hline Chlaenius tricolor & Open-habitat & Dispersed \\
\hline Cicindela sexguttata & Forest & Dispersed \\
\hline Cymindis cribricollis & Forest & Compact \\
\hline Cymindis neglectus & Forest & Compact \\
\hline Diplocheila obtusa & Open-habitat & Dispersed \\
\hline Dyschirius globulosus & & Dispersed \\
\hline Elaphropus granarius & Open-habitat & Compact \\
\hline Elaphrus clairvillei & Forest & Dispersed \\
\hline Harpalus compar & Open-habitat & Semi-compact \\
\hline Harpalus eraticus & Open-habitat & Semi-compact \\
\hline Harpalus erythropus & Open-habitat & Semi-compact \\
\hline Harpalus faunus & Open-habitat & Semi-compact \\
\hline Harpalus fulvilabris & Forest & Compact \\
\hline Harpalus herbivagus & Open-habitat & Dispersed \\
\hline Harpalus longicollis & Open-habitat & Semi-compact \\
\hline Harpalus opacipennis & Open-habitat & Semi-compact \\
\hline Harpalus pensylvanicus & Open-habitat & Semi-compact \\
\hline Harpalus providens & Forest & Dispersed \\
\hline Harpalus somnulentus & Open-habitat & Dispersed \\
\hline Lophoglossus scrutator & & Compact \\
\hline Loricera pilicornis & & Compact \\
\hline
\end{tabular}




\begin{tabular}{|c|c|c|}
\hline Loxandrus commutabilis & Open-habitat & Dispersed \\
\hline Myas cyanescens & Forest & Compact \\
\hline Notiophilus aeneus & Forest & Compact \\
\hline Olisthopus micans & Forest & Compact \\
\hline Olisthopus parmatus & Forest & Dispersed \\
\hline Oxypselaphus pusillus & Open-habitat & Compact \\
\hline Patrobus longicornis & Open-habitat & Compact \\
\hline Platynus decentis & Forest & Dispersed \\
\hline Poecilus lucublandus & Open-habitat & Compact \\
\hline \multicolumn{3}{|l|}{ lucublandus } \\
\hline Pseudamara arenaria & Forest & Compact \\
\hline Pterostichus caudicalis & \multirow{3}{*}{ Forest } & Compact \\
\hline Pterostichus coracinus & & Compact \\
\hline Pterostichus corvinus & & Dispersed \\
\hline Pterostichus luctuosus & \multirow{3}{*}{ Open-habitat } & Dispersed \\
\hline Pterostichus mutus & & Semi-compact \\
\hline Pterostichus patruelis & & Dispersed \\
\hline Pterostichus pensylvanicus & Forest & Dispersed \\
\hline Pterostichus tristis & Forest & Compact \\
\hline Sphaeroderus canadensis & Forest & Compact \\
\hline canadensis & & \\
\hline Sphaeroderus stenostomus & Forest & Compact \\
\hline lecontei & & \\
\hline Stenolophus conjunctus & Open-habitat & Semi-compact \\
\hline Syntomus americanus & Open-habitat & Dispersed \\
\hline
\end{tabular}




$\begin{array}{llll}\text { Synuchus impunctatus } & \text { Forest } & \text { Compact } & \text { Yes } \\ \text { Trechus apicalis } & \text { Forest } & \text { Compact } & \text { Yes } \\ \text { Trichotichnus vulpeculus } & \text { Forest } & \text { Semi-compact } & \\ \text { Introduced beetles } & \text { Agonum muelleri } & \text { Open-habitat } & \text { Semi-compact } \\ \text { Amara aenea } & \text { Open-habitat } & \text { Dispersed } \\ \text { Amara apricaria } & \text { Open-habitat } & \text { Compact } \\ \text { Bembidion obtusum } & \text { Open-habitat } & \text { Compact } \\ \text { Bembidion tetracolum } & \text { Open-habitat } & \text { Semi-compact } \\ \text { Carabus granulatus } & \text { Open-habitat } & \text { Semi-compact } \\ \text { Carabus nemoralis } & \text { Open-habitat } & \text { Dispersed } \\ \text { Clivina fossor } & \text { Open-habitat } & \text { Compact } \\ \text { Harpalus affinis } & \text { Open-habitat } & \text { Compact } \\ \text { Pterostichus melanarius } & \text { Open-habitat } & \text { Dispersed }\end{array}$


Appendix 6. Native breeding bird and carabid beetle species classified as 'forest interior', 'forest edge', 'forest' or 'open-habitat' species. Introduced bird and beetle species are also listed.

\begin{tabular}{|c|c|c|c|}
\hline & Common name & Scientific name & Habitat affinity \\
\hline \multirow[t]{21}{*}{ Native birds } & American Redstart & Setophaga ruticilla & Forest interior \\
\hline & Black-and-White Warbler & Mniotilta varia & Forest interior \\
\hline & Black-throated Blue Warbler & Dendroica caerulescens & Forest interior \\
\hline & Black-throated Green Warbler & Dendroica virens & Forest interior \\
\hline & Blackburnian Warbler & Dendroica fusca & Forest interior \\
\hline & Blue-headed Vireo & Vireo solitarius & Forest interior \\
\hline & Brown Creeper & Certhia americana & Forest interior \\
\hline & Ovenbird & Seiurus aurocapillus & Forest interior \\
\hline & Pileated Woodpecker & Dryocopus pileatus & Forest interior \\
\hline & Pine Warbler & Dendroica pinus & Forest interior \\
\hline & Red-breasted Nuthatch & Sitta canadensis & Forest interior \\
\hline & Ruffed Grouse & Bonasa umbellus & Forest interior \\
\hline & Scarlet Tanager & Piranga olivacea & Forest interior \\
\hline & Swainson's Thrush & Catharus ustulatus & Forest interior \\
\hline & Veery & Catharus fuscescens & Forest interior \\
\hline & Yellow-rumped Warbler & Dendroica coronata & Forest interior \\
\hline & Black-capped Chickadee & Poecile atricapilla & Forest edge \\
\hline & Blue Jay & Cyanocitta cristata & Forest edge \\
\hline & Canada Warbler & Wilsonia canadensis & Forest edge \\
\hline & Downy Woodpecker & Picoides pubescens & Forest edge \\
\hline & Eastern Phoebe & Sayornis phoebe & Forest edge \\
\hline
\end{tabular}




\begin{tabular}{|c|c|c|}
\hline Eastern Wood-Pewee & Contopus virens & Forest edge \\
\hline Golden-crowned Kinglet & Regulus satrapa & Forest edge \\
\hline Hairy Woodpecker & Picoides villosus & Forest edge \\
\hline Hermit Thrush & Catharus guttatus & Forest edge \\
\hline Least Flycatcher & Empidonax minimus & Forest edge \\
\hline Mourning Warbler & Oporornis philadelphia & Forest edge \\
\hline Nashville Warbler & Vermivora ruficapilla & Forest edge \\
\hline Purple Finch & Carpodacus purpureus & Forest edge \\
\hline Red-eyed Vireo & Vireo olivaceus & Forest edge \\
\hline Rose-breasted Grosbeak & Pheucticus ludovicianus & Forest edge \\
\hline Ruby-throated Hummingbird & Archilochus colubris & Forest edge \\
\hline Warbling Vireo & Vireo gilvus & Forest edge \\
\hline White-breasted Nuthatch & Sitta carolinensis & Forest edge \\
\hline White-throated Sparrow & Zonotrichia albicollis & Forest edge \\
\hline Winter Wren & Troglodytes troglodytes & Forest edge \\
\hline Wood Thrush & Hylocichla mustelina & Forest edge \\
\hline Yellow-bellied Sapsucker & Sphyrapicus varius & Forest edge \\
\hline Yellow-throated Vireo & Vireo flavifrons & Forest edge \\
\hline American Crow & Corvus brachyrhynchos & Open-habitat \\
\hline American Goldfinch & Carduelis tristis & Open-habitat \\
\hline American Robin & Turdus migratorius & Open-habitat \\
\hline Baltimore Oriole & Icterus galbula & Open-habitat \\
\hline Black-billed Cuckoo & Coccyzus erythropthalmus & Open-habitat \\
\hline Brown-headed Cowbird & Molothrus ater & Open-habitat \\
\hline Cedar Waxwing & Bombycilla cedrorum & Open-habitat \\
\hline
\end{tabular}




\begin{tabular}{|c|c|c|c|}
\hline & Chimney Swift & Chaetura pelagica & Open-habitat \\
\hline & Chipping Sparrow & Spizella passerina & Open-habitat \\
\hline & Common Grackle & Quiscalus quiscula & Open-habitat \\
\hline & Common Yellowthroat & Geothlypis trichas & Open-habitat \\
\hline & Great Crested Flycatcher & Myiarchus crinitus & Open-habitat \\
\hline & House Finch & Carpodacus mexicanus & Open-habitat \\
\hline & Killdeer & Charadrius vociferus & Open-habitat \\
\hline & Mourning Dove & Zenaida macroura & Open-habitat \\
\hline & Northern Cardinal & Cardinalis cardinalis & Open-habitat \\
\hline & Northern Flicker & Colaptes auratus & Open-habitat \\
\hline & Red-headed Woodpecker & Melanerpes erythrocephalus & Open-habitat \\
\hline & Song Sparrow & Melospiza melodia & Open-habitat \\
\hline & Yellow Warbler & Dendroica petechia & Open-habitat \\
\hline & Yellow-billed Cuckoo & Coccyzus americanus & Open-habitat \\
\hline Introduced birds & European Starling & Sturnus vulgaris & \\
\hline & House Sparrow & Passer domesticus & \\
\hline & Rock Pigeon & Columba livia & \\
\hline Native beetles & & Agonum retractum & Forest \\
\hline & & Amphasia interstitialis & Forest \\
\hline & & Anisodactylus verticalis & Forest \\
\hline & & Bembidion muscicola & Forest \\
\hline & & Bembidion praticola & Forest \\
\hline & & Calathus gregarius & Forest \\
\hline & & Chlaenius emarginatus & Forest \\
\hline & & Cicindela sexguttata & Forest \\
\hline
\end{tabular}




\begin{tabular}{|c|c|}
\hline Cymindis cribricollis & Forest \\
\hline Cymindis neglectus & Forest \\
\hline Elaphrus clairvillei & Forest \\
\hline Harpalus fulvilabris & Forest \\
\hline Harpalus providens & Forest \\
\hline Myas cyanescens & Forest \\
\hline Notiophilus aeneus & Forest \\
\hline Olisthopus micans & Forest \\
\hline Olisthopus parmatus & Forest \\
\hline Platynus decentis & Forest \\
\hline Pseudamara arenaria & Forest \\
\hline Pterostichus coracinus & Forest \\
\hline Pterostichus lachrymosus & Forest \\
\hline Pterostichus pensylvanicus & Forest \\
\hline Pterostichus tristis & Forest \\
\hline Sphaeroderus canadensis & Forest \\
\hline canadensis & \\
\hline Sphaeroderus stenostomus & Forest \\
\hline lecontei & \\
\hline Synuchus impunctatus & Forest \\
\hline Trechus apicalis & Forest \\
\hline Trichotichnus vulpeculus & Forest \\
\hline Agonum cupripenne & Open-habitat \\
\hline Amara angustata & Open-habitat \\
\hline Amara cupreolata & Open-habitat \\
\hline
\end{tabular}


Amara impuncticollis

Amara patruelis

Amara rubrica

Anisodactylus harrisii

Anisodactylus merula

Anisodactylus rusticus

Bembidion quadrimaculatum

oppositum

Bradycellus lugubris

Carabus maeander

Chlaenius tricolor

Diplocheila obtusa

Elaphropus granarius

Harpalus compar

Harpalus eraticus

Harpalus erythropus

Harpalus faunus

Harpalus herbivagus

Harpalus longicollis

Harpalus opacipennis

Harpalus pensylvanicus

Harpalus somnulentus

Loxandrus commutabilis

Oxypselaphus pusillus

Patrobus longicornis
Open-habitat

Open-habitat

Open-habitat

Open-habitat

Open-habitat

Open-habitat

Open-habitat

Open-habitat

Open-habitat

Open-habitat

Open-habitat

Open-habitat

Open-habitat

Open-habitat

Open-habitat

Open-habitat

Open-habitat

Open-habitat

Open-habitat

Open-habitat

Open-habitat

Open-habitat

Open-habitat

Open-habitat 
Poecilus lucublandus

lucublandus

Pterostichus mutus

Stenolophus conjunctus

Syntomus americanus

Introduced beetles

Agonum muelleri

Amara aenea

Amara apricaria

Bembidion obtusum

Bembidion tetracolum

Carabus granulatus

Carabus nemoralis

Clivina fossor

Harpalus affinis

Pterostichus melanarius
Open-habitat

Open-habitat

Open-habitat

Open-habitat 


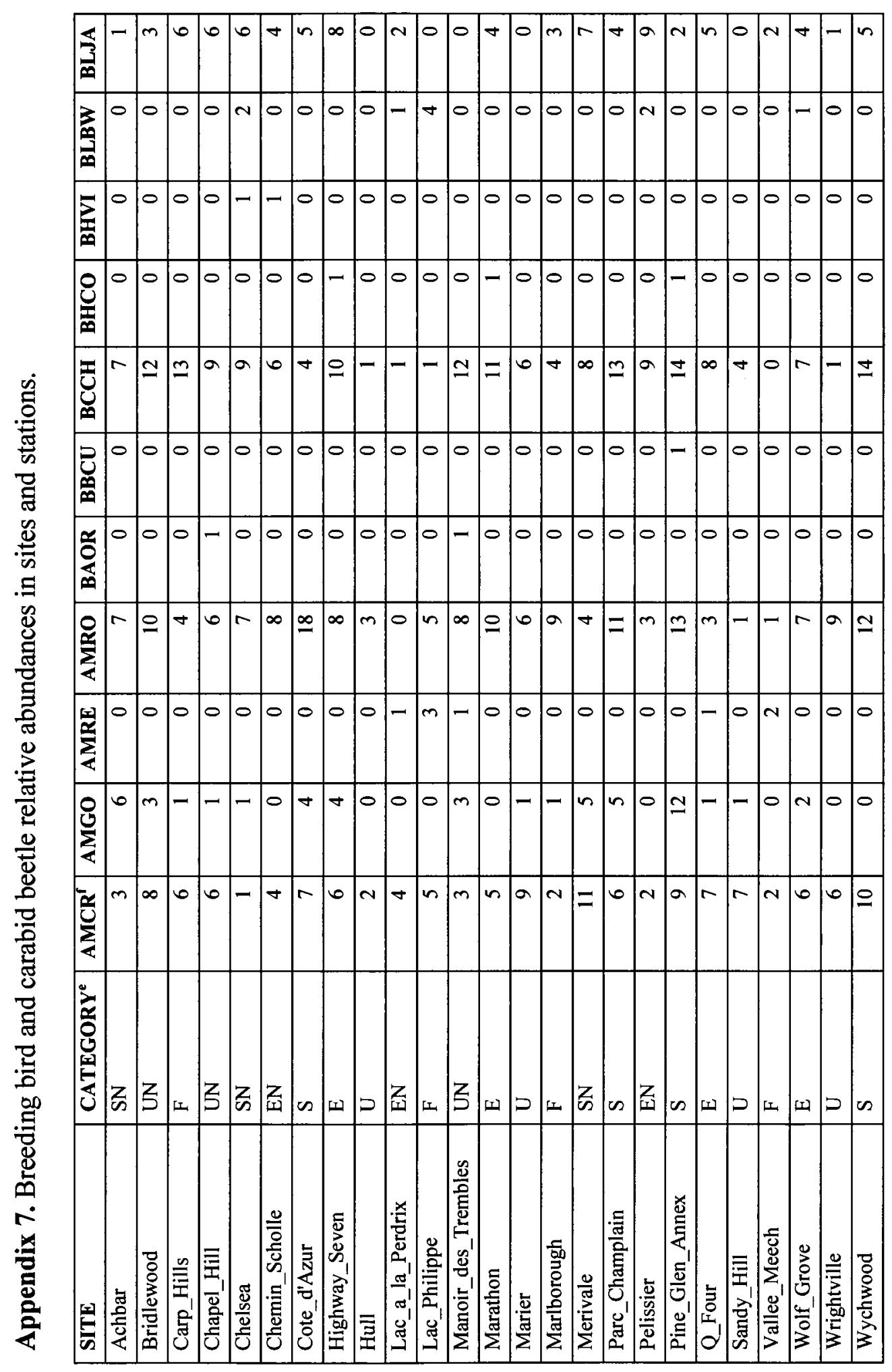




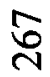
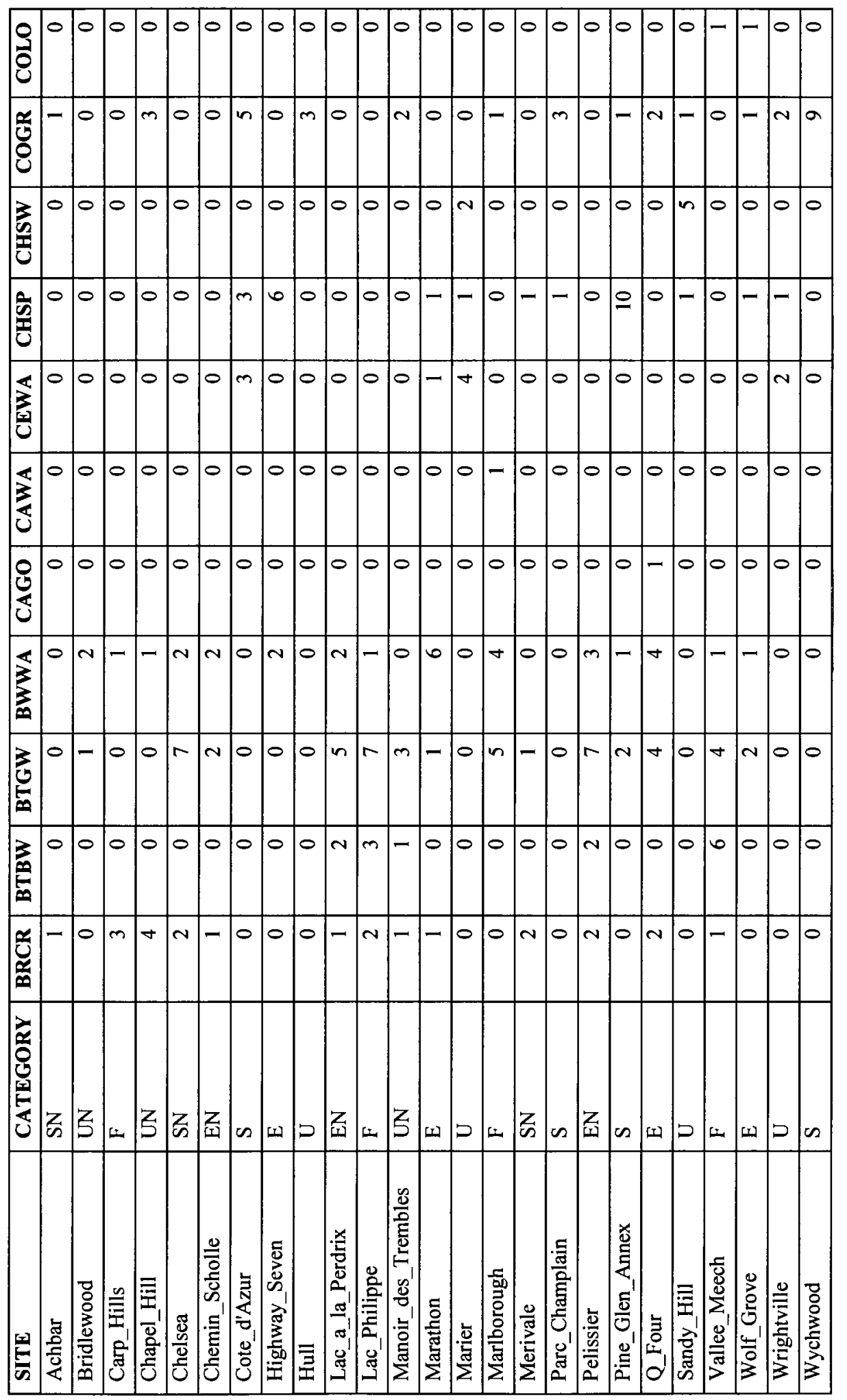


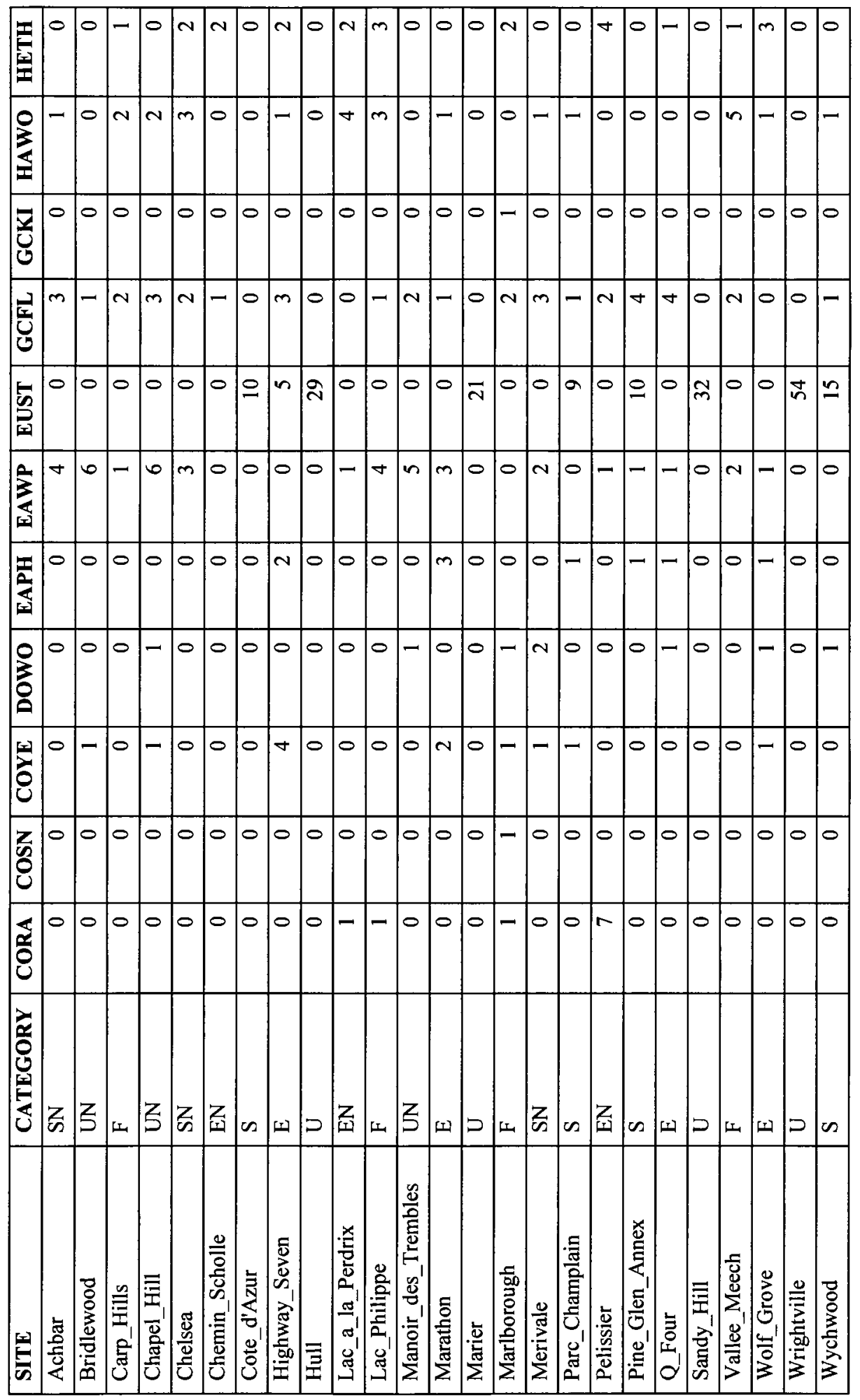


8

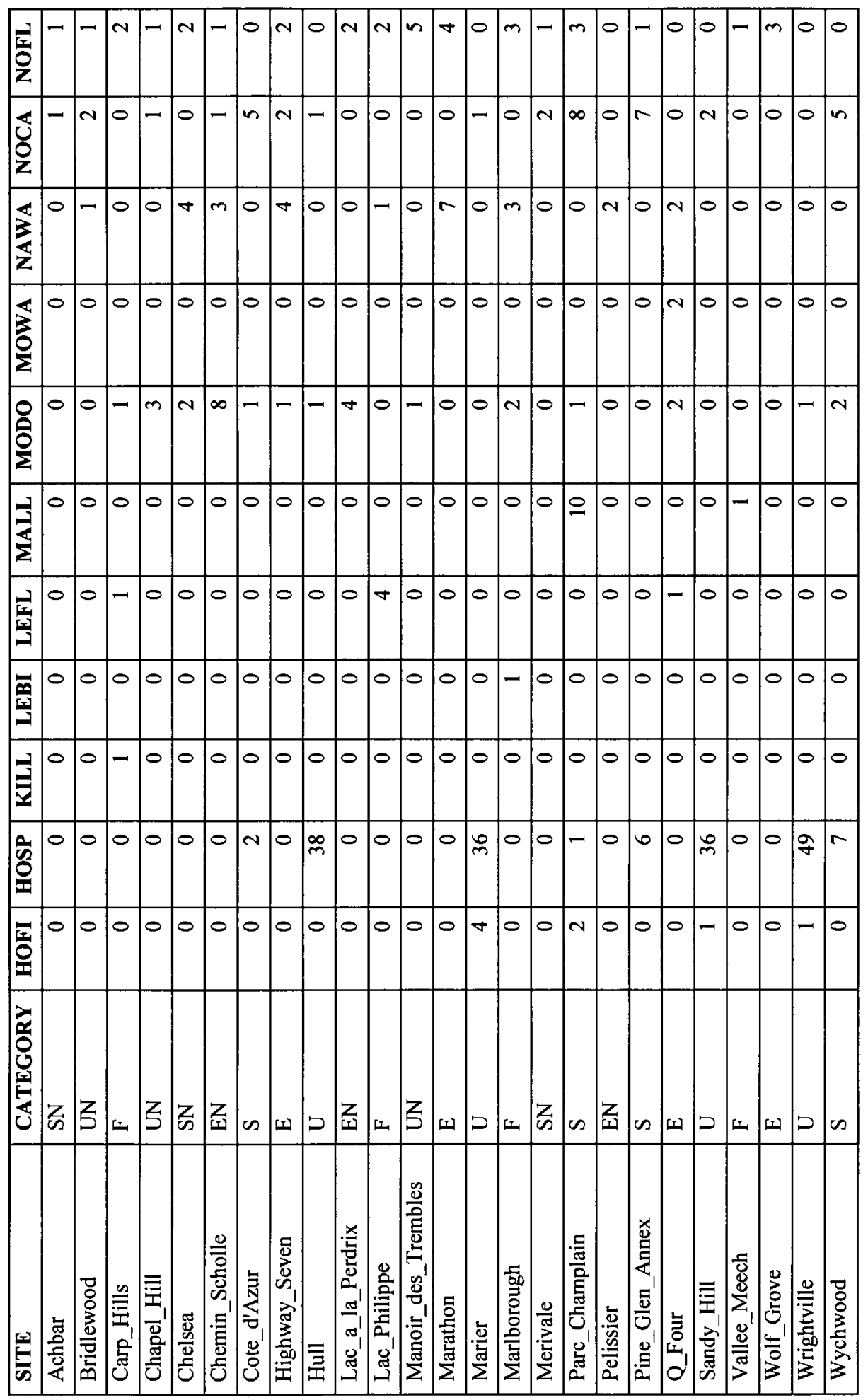


ำ

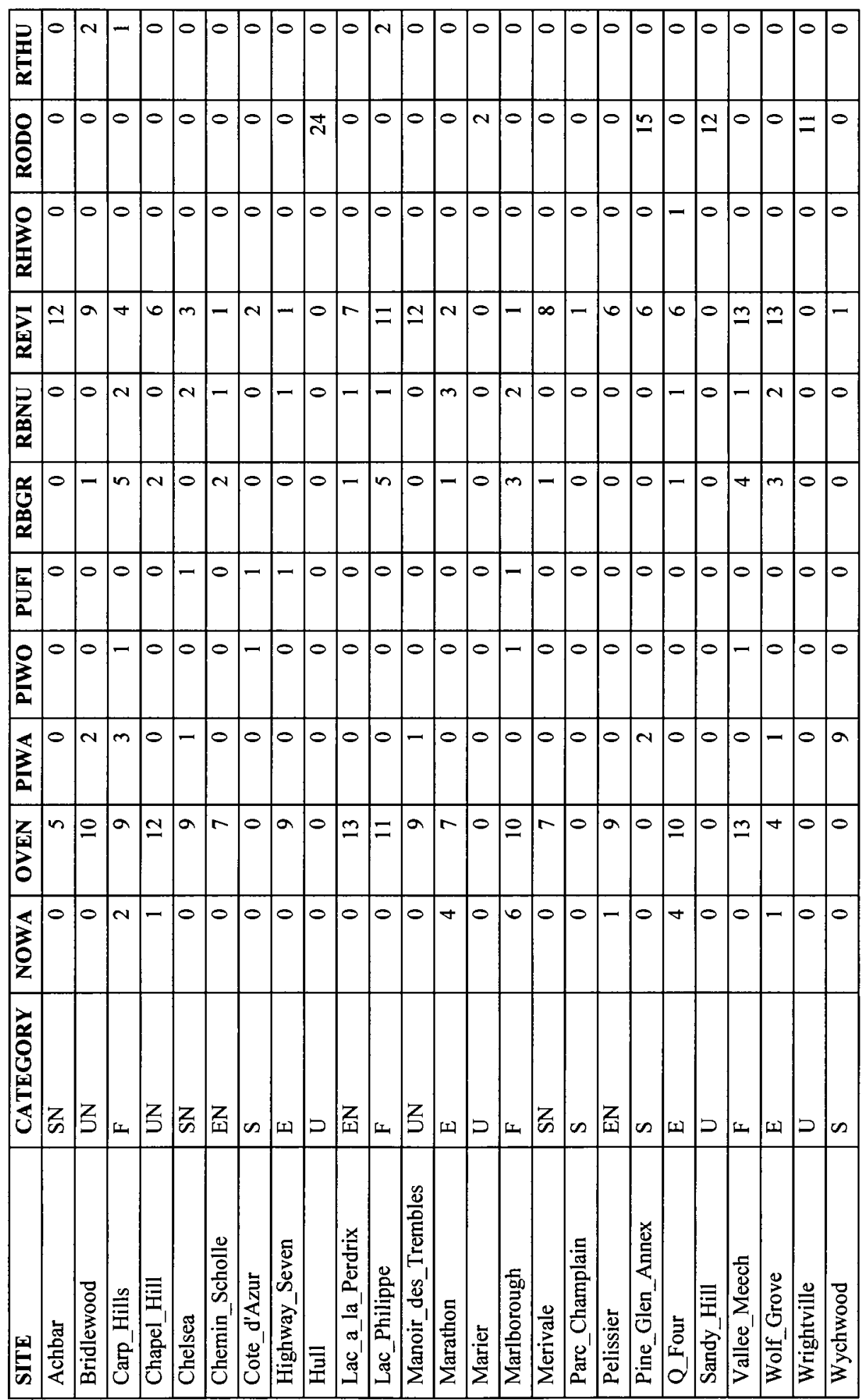




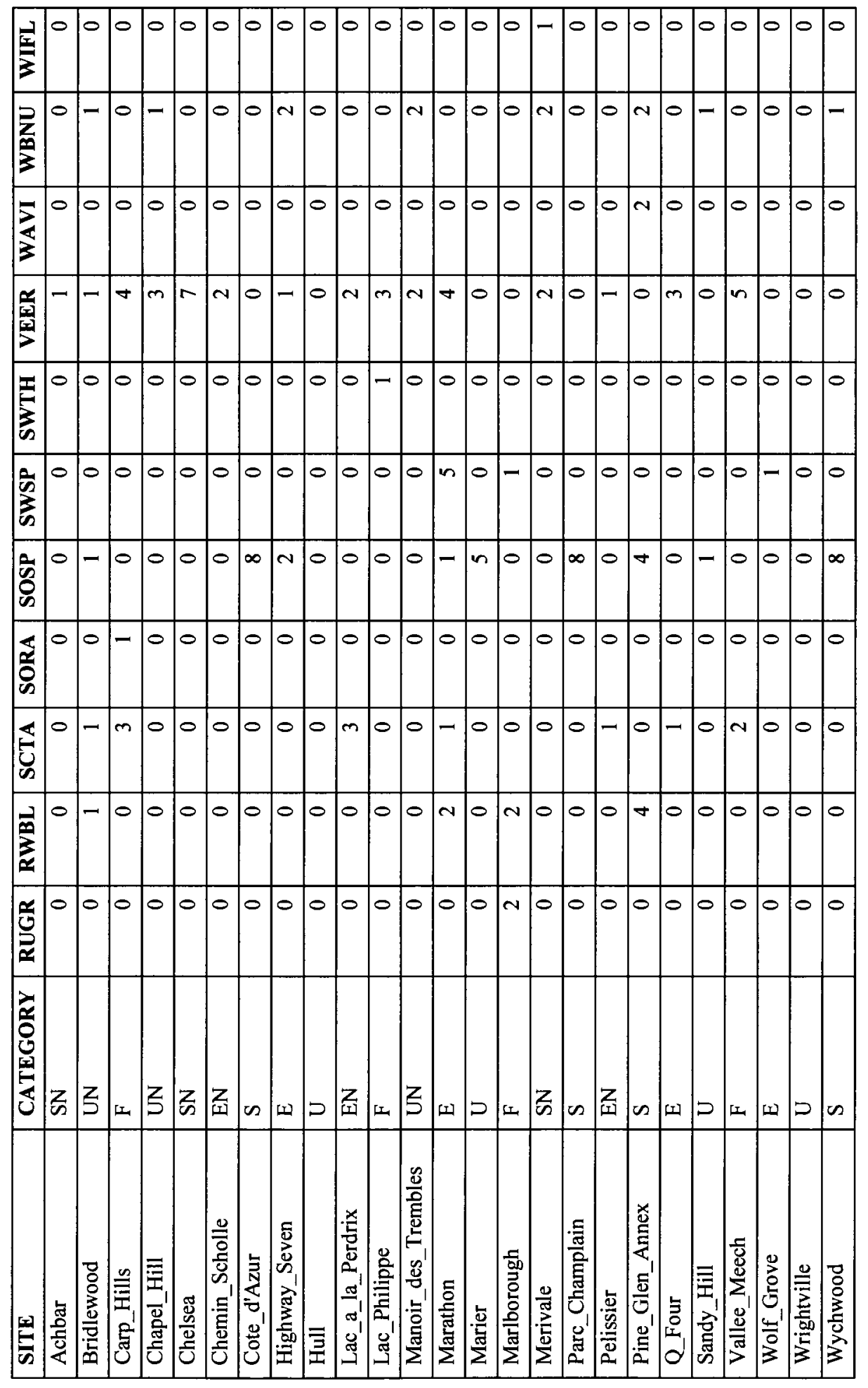




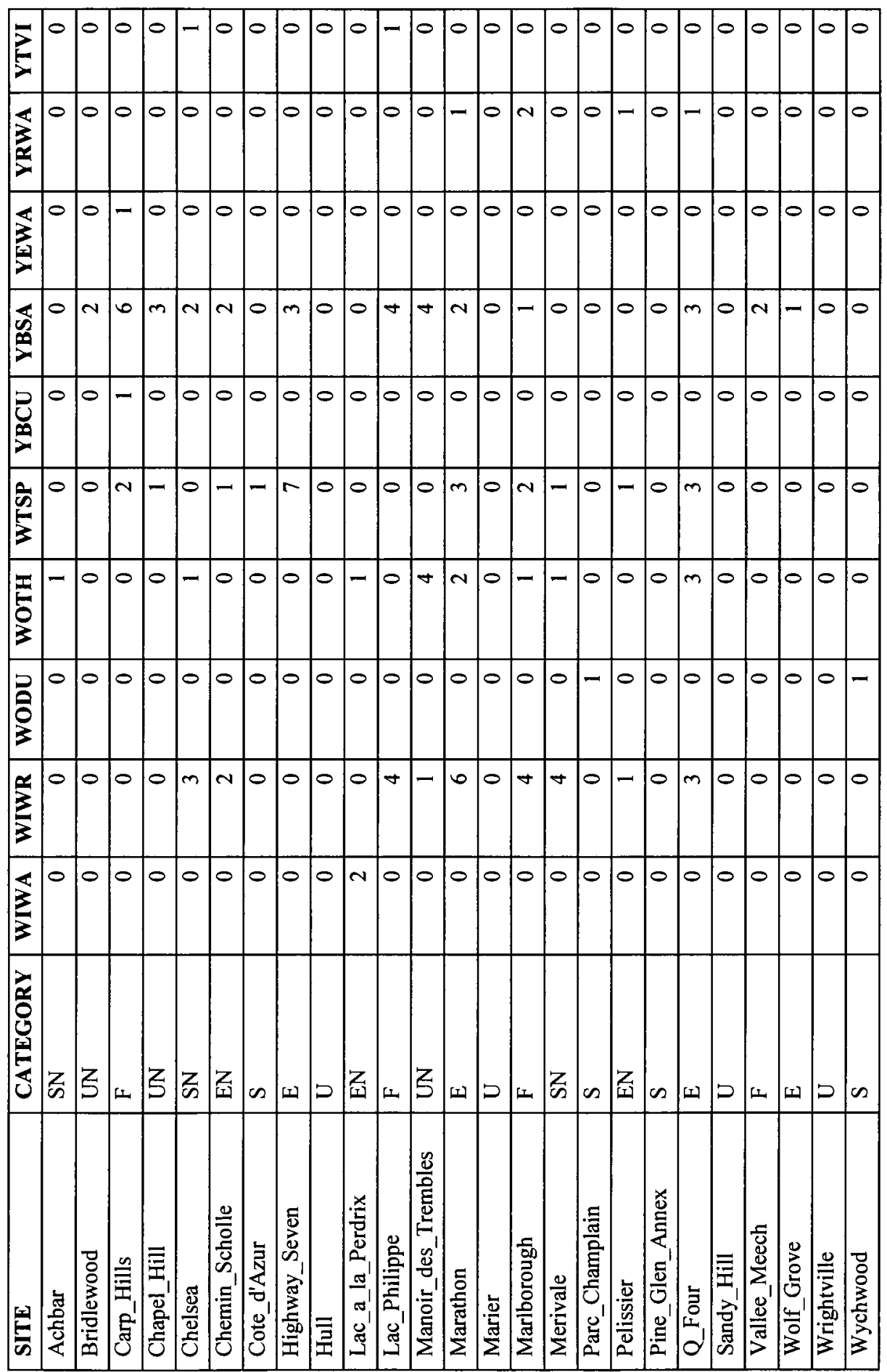




\begin{tabular}{|c|c|c|c|c|c|c|c|c|}
\hline SITE & STATION & CATEGORY & $\mathbf{A M C R}^{r}$ & AMGO & AMRE & AMRO & BAOR & BBCU \\
\hline Achbar & A & $\mathrm{SN}$ & 1 & 3 & 0 & 1 & 0 & 0 \\
\hline Achbar & B & SN & 1 & 1 & 0 & 1 & 0 & $\mathbf{0}$ \\
\hline Achbar & $\mathrm{C}$ & SN & 1 & 2 & 0 & 2 & 0 & $\mathbf{0}$ \\
\hline Achbar & $\bar{D}$ & $\overline{\mathrm{SN}}$ & 1 & 1 & 0 & 3 & 0 & $\overline{0}$ \\
\hline Bridlewood & $\mathrm{A}$ & UN & 3 & 2 & 0 & 2 & 0 & 0 \\
\hline Bridlewood & $\mathrm{B}$ & $\mathrm{UN}$ & 2 & 0 & 0 & 2 & 0 & $\overline{0}$ \\
\hline Bridlewood & $\mathrm{C}$ & $\mathrm{UN}$ & 2 & 1 & $\overline{0}$ & 5 & 0 & $\overline{0}$ \\
\hline Bridlewood & $\overline{\mathrm{D}}$ & UN & 2 & 0 & 0 & 1 & 0 & $\overline{0}$ \\
\hline Carp_Hills & $\bar{A}$ & $F$ & 3 & 0 & 0 & 0 & 0 & $\overline{0}$ \\
\hline Carp_Hills & $\bar{B}$ & $\bar{F}$ & 1 & 1 & 0 & 2 & 0 & $\overline{0}$ \\
\hline Carp_Hills & $\mathrm{C}$ & $\bar{F}$ & 2 & 0 & 0 & 0 & 0 & $\overline{0}$ \\
\hline Carp_Hills & $\mathrm{D}$ & $F$ & 1 & 0 & 0 & 2 & 0 & $\overline{0}$ \\
\hline Chapel_Hill & A & UN & 1 & 0 & 0 & 1 & 1 & 0 \\
\hline Chapel_Hill & $\bar{B}$ & UN & 1 & 0 & 0 & 2 & 0 & $\overline{0}$ \\
\hline Chapel_Hill & $\mathrm{C}$ & UN & 2 & 1 & 0 & 2 & 0 & $\mathbf{0}$ \\
\hline Chapel_Hill & $\overline{\mathrm{D}}$ & UN & 2 & 0 & 0 & 2 & 0 & $\overline{0}$ \\
\hline Chelsea & $\mathrm{A}$ & SN & 0 & 0 & 0 & 2 & 0 & $\overline{0}$ \\
\hline Chelsea & B & SN & 1 & 1 & 0 & 3 & 0 & $\overline{0}$ \\
\hline Chelsea & $\overline{\mathrm{C}}$ & $\overline{\mathrm{SN}}$ & 0 & 0 & 0 & 2 & 0 & $\overline{0}$ \\
\hline Chelsea & $\bar{D}$ & SN & 1 & 0 & 0 & 1 & 0 & $\overline{0}$ \\
\hline Chemin_Scholle & $\bar{A}$ & $\mathrm{EN}$ & 1 & 0 & 0 & 3 & 0 & $\mathbf{0}$ \\
\hline Chemin_Scholle & $\overline{\mathrm{B}}$ & $\overline{\mathrm{EN}}$ & 1 & 0 & 0 & 3 & 0 & 0 \\
\hline Chemin_Scholle & $\mathrm{C}$ & $\overline{\mathrm{EN}}$ & 2 & 0 & 0 & 2 & 0 & $\overline{0}$ \\
\hline Chemin_Scholle & $\mathrm{D}$ & EN & 1 & 0 & 0 & 2 & 0 & $\overline{0}$ \\
\hline Cote_d'Azur & A & $\mathrm{S}$ & 3 & 0 & 0 & 7 & 0 & $\overline{0}$ \\
\hline Cote_d'Azur & $\mathrm{B}$ & $\mathrm{S}$ & 2 & 1 & 0 & 4 & 0 & 0 \\
\hline Cote_d'Azur & $\mathrm{C}$ & $S$ & 2 & 2 & 0 & 4 & 0 & 0 \\
\hline Cote_d'Azur & $\overline{\mathrm{D}}$ & $S$ & 2 & 1 & 0 & 5 & 0 & $\overline{0}$ \\
\hline Highway_Seven & A & $\bar{E}$ & 1 & 2 & 0 & 3 & 0 & 0 \\
\hline Highway_Seven & B & $\bar{E}$ & 1 & 1 & 0 & 2 & 0 & $\overline{0}$ \\
\hline Highway_Seven & $\mathrm{C}$ & $E$ & 2 & 1 & 0 & 2 & 0 & 0 \\
\hline Highway_Seven & $\overline{\mathrm{D}}$ & $E$ & 3 & 1 & 0 & 2 & 0 & 0 \\
\hline Hull & $\bar{A}$ & $\mathrm{U}$ & 1 & 0 & 0 & 2 & 0 & 0 \\
\hline Hull & $\mathrm{B}$ & $\mathrm{U}$ & 0 & 0 & 0 & 1 & 0 & $\overline{0}$ \\
\hline Hull & $\mathrm{C}$ & $\mathrm{U}$ & 1 & 0 & 0 & 2 & 0 & 0 \\
\hline Hull & $\bar{D}$ & $\mathrm{U}$ & 0 & 0 & 0 & 0 & 0 & $\overline{0}$ \\
\hline Lac_a_la_Perdrix & A & EN & 0 & 0 & 0 & 0 & 0 & 0 \\
\hline Lac_a_la_Perdrix & $\bar{B}$ & EN & 4 & 0 & 1 & 0 & 0 & 0 \\
\hline Lac_a_la_Perdrix & $\bar{C}$ & EN & 0 & 0 & 0 & 0 & 0 & 0 \\
\hline Lac_a_la_Perdrix & $\mathrm{D}$ & EN & 0 & 0 & 0 & 0 & 0 & 0 \\
\hline Lac_Philippe & A & $\mathrm{F}$ & 1 & 0 & 0 & 0 & 0 & 0 \\
\hline Lac_Philippe & $\mathrm{B}$ & $\mathrm{F}$ & 3 & 0 & 0 & 2 & 0 & 0 \\
\hline Lac_Philippe & $\bar{C}$ & $F$ & 1 & 0 & 2 & 0 & 0 & $\overline{0}$ \\
\hline Lac_Philippe & $\bar{D}$ & $\mathrm{~F}$ & $\mathbf{0}$ & 0 & 1 & 3 & 0 & $\overline{0}$ \\
\hline
\end{tabular}




\begin{tabular}{|c|c|c|c|c|c|c|c|c|}
\hline Manoir_des_Trembles & $\bar{A}$ & UN & 1 & 0 & 0 & 1 & 0 & 0 \\
\hline Manoir_des_Trembles & $\mathrm{B}$ & $\overline{\mathrm{UN}}$ & 1 & 1 & 0 & 4 & 0 & 0 \\
\hline Manoir_des_Trembles & $\mathrm{C}$ & UN & 0 & 2 & 1 & 1 & 1 & 0 \\
\hline Manoir_des_Trembles & $\bar{D}$ & UN & 2 & 0 & 0 & 2 & 0 & $\overline{0}$ \\
\hline Marathon & A & $\bar{E}$ & 2 & 0 & 0 & 4 & 0 & 0 \\
\hline Marathon & $\mathrm{B}$ & $\mathrm{E}$ & 1 & 0 & 0 & 3 & 0 & 0 \\
\hline Marathon & $\mathrm{C}$ & $\mathrm{E}$ & 2 & 0 & 0 & 2 & 0 & 0 \\
\hline Marathon & $\overline{\mathrm{D}}$ & $\bar{E}$ & 1 & 0 & 0 & 3 & 0 & 0 \\
\hline Marier & $\bar{A}$ & $\overline{\mathrm{U}}$ & 4 & 0 & 0 & 2 & 0 & $\overline{0}$ \\
\hline Marier & B & $\mathrm{U}$ & 1 & 0 & 0 & 1 & 0 & 0 \\
\hline Marier & $\mathrm{C}$ & $\mathrm{U}$ & 3 & 1 & 0 & 2 & 0 & $\overline{0}$ \\
\hline Marier & $\bar{D}$ & $\mathrm{U}$ & 3 & 0 & 0 & 1 & 0 & 0 \\
\hline Marlborough & A & $F$ & 0 & 0 & 0 & 2 & 0 & 0 \\
\hline Marlborough & B & $\mathrm{F}$ & 0 & 1 & 0 & 3 & 0 & 0 \\
\hline Marlborough & $\mathrm{C}$ & $F$ & 2 & 0 & 0 & 2 & 0 & 0 \\
\hline Marlborough & $\bar{D}$ & $F$ & 0 & 0 & 0 & 2 & 0 & $\overline{0}$ \\
\hline Merivale & $\bar{A}$ & $\overline{\mathrm{SN}}$ & 3 & 0 & 0 & 2 & 0 & 0 \\
\hline Merivale & B & SN & 2 & 1 & 0 & 0 & 0 & $\overline{0}$ \\
\hline Merivale & $\mathrm{C}$ & SN & 3 & 1 & 0 & 0 & 0 & 0 \\
\hline Merivale & $\mathrm{D}$ & $\mathrm{SN}$ & 3 & 3 & 0 & 2 & 0 & $\overline{0}$ \\
\hline Parc_Champlain & $\bar{A}$ & $\mathrm{~S}$ & 3 & $\mathbf{0}$ & 0 & 3 & 0 & 0 \\
\hline Parc_Champlain & B & $\mathrm{S}$ & 2 & 2 & 0 & 4 & 0 & 0 \\
\hline Parc_Champlain & $\mathrm{C}$ & $\mathrm{S}$ & 2 & 0 & 0 & 2 & 0 & 0 \\
\hline Parc_Champlain & $\mathrm{D}$ & $S$ & 2 & 3 & 0 & 2 & 0 & 0 \\
\hline Pelissier & $\bar{A}$ & $\overline{\mathrm{EN}}$ & 0 & 0 & 0 & 0 & 0 & 0 \\
\hline Pelissier & B & EN & 2 & 0 & 0 & 1 & 0 & 0 \\
\hline Pelissier & $\mathrm{C}$ & EN & 0 & 0 & 0 & 0 & 0 & 0 \\
\hline Pelissier & $\mathrm{D}$ & EN & 0 & 0 & 0 & 2 & 0 & 0 \\
\hline PineGlen_Annex & $\mathrm{A}$ & $\mathrm{S}$ & 1 & 1 & 0 & 4 & 0 & 0 \\
\hline PineGlen_Annex & $\mathrm{B}$ & $\mathrm{S}$ & 5 & 2 & 0 & 2 & 0 & 0 \\
\hline PineGlen_Annex & $\mathrm{C}$ & $S$ & 2 & 6 & 0 & 4 & 0 & 1 \\
\hline PineGlen_Annex & $\mathrm{D}$ & $\mathrm{S}$ & 1 & 4 & 0 & 3 & 0 & 0 \\
\hline Q_Four & $\mathrm{A}$ & $E$ & 2 & 0 & 0 & 0 & 0 & 0 \\
\hline Q_Four & $\bar{B}$ & $\mathrm{E}$ & 3 & 0 & 1 & 1 & 0 & 0 \\
\hline Q_Four & $\mathrm{C}$ & $\mathrm{E}$ & 1 & 0 & 0 & 0 & 0 & $\overline{0}$ \\
\hline Q_Four & $\mathrm{D}$ & $E$ & 2 & 1 & 0 & 2 & 0 & $\overline{0}$ \\
\hline Sandy_Hill & $\mathrm{A}$ & $\mathrm{U}$ & 4 & 0 & 0 & 0 & 0 & 0 \\
\hline Sandy_Hill & $\mathrm{B}$ & $\mathrm{U}$ & 2 & 1 & 0 & 1 & 0 & 0 \\
\hline Sandy_Hill & $\mathrm{C}$ & $\mathrm{U}$ & 2 & 0 & 0 & 0 & 0 & 0 \\
\hline Sandy_Hill & $\bar{D}$ & $\mathrm{U}$ & 2 & 1 & 0 & 0 & 0 & 0 \\
\hline Vallee_Meech & $\bar{A}$ & $F$ & 0 & 0 & 0 & 0 & 0 & 0 \\
\hline Vallee_Meech & $\mathrm{B}$ & $\mathrm{F}$ & 1 & 0 & 0 & 0 & 0 & 0 \\
\hline Vallee_Meech & $\mathrm{C}$ & $F$ & 1 & 0 & 2 & 0 & 0 & 0 \\
\hline Vallee_Meech & $\mathrm{D}$ & $\mathrm{F}$ & 0 & 0 & 0 & 1 & 0 & 0 \\
\hline Wolf_Grove & A & $\mathrm{E}$ & 0 & 1 & 0 & 1 & 0 & 0 \\
\hline
\end{tabular}




\begin{tabular}{|l|l|l|r|r|r|r|r|r|}
\hline Wolf_Grove & B & E & 2 & 0 & 0 & 2 & 0 & 0 \\
\hline Wolf_Grove & C & E & 3 & 1 & 0 & 1 & 0 & 0 \\
\hline Wolf_Grove & D & E & 1 & 0 & 0 & 3 & 0 & 0 \\
\hline Wrightville & A & U & 1 & 0 & 0 & 6 & 0 & 0 \\
\hline Wrightville & B & U & 1 & 0 & 0 & 2 & 0 & 0 \\
\hline Wrightville & C & U & 3 & 0 & 0 & 1 & 0 & 0 \\
\hline Wrightville & D & U & 1 & 0 & 0 & 1 & 0 & 0 \\
\hline Wychwood & A & S & 3 & 0 & 0 & 5 & 0 & 0 \\
\hline Wychwood & B & S & 3 & 0 & 0 & 3 & 0 & 0 \\
\hline Wychwood & C & S & 3 & 0 & 0 & 1 & 0 & 0 \\
\hline Wychwood & D & S & 2 & 0 & 0 & 3 & 0 & 0 \\
\hline
\end{tabular}




\begin{tabular}{|c|c|c|c|c|c|c|c|c|}
\hline SITE & STATION & CATEGORY & BCCH & BHCO & BHVI & BLBW & BLJA & BRCR \\
\hline Achbar & $\mathrm{A}$ & SN & 2 & 0 & 0 & 0 & 0 & 1 \\
\hline Achbar & B & SN & 3 & 0 & 0 & 0 & 0 & 0 \\
\hline Achbar & $\bar{C}$ & SN & 3 & 0 & 0 & 0 & 1 & 0 \\
\hline Achbar & $\bar{D}$ & SN & 1 & 0 & 0 & 0 & 0 & 0 \\
\hline Bridlewood & $\bar{A}$ & UN & 7 & 0 & 0 & 0 & 2 & 0 \\
\hline Bridlewood & $\bar{B}$ & UN & 3 & 0 & 0 & 0 & 0 & 0 \\
\hline Bridlewood & $\bar{C}$ & UN & 1 & 0 & 0 & 0 & 0 & 0 \\
\hline Bridlewood & $\bar{D}$ & UN & 1 & $\overline{0}$ & 0 & 0 & 2 & 0 \\
\hline Carp_Hills & $\mathrm{A}$ & $F$ & 2 & 0 & 0 & 0 & 1 & 2 \\
\hline Carp_Hills & B & $F$ & 7 & 0 & 0 & 0 & 2 & 0 \\
\hline Carp_Hills & $\mathrm{C}$ & $\bar{F}$ & 1 & 0 & 0 & 0 & 2 & 1 \\
\hline Carp_Hills & $\mathrm{D}$ & $F$ & 3 & 0 & 0 & 0 & 1 & 1 \\
\hline Chapel_Hill & $\bar{A}$ & UN & 4 & 0 & 0 & 0 & 2 & 1 \\
\hline Chapel_Hill & $\bar{B}$ & UN & 2 & 0 & 0 & 0 & 1 & 1 \\
\hline Chapel_Hill & $\mathrm{C}$ & UN & 3 & 0 & 0 & 0 & 1 & 1 \\
\hline Chapel_Hill & $\bar{D}$ & UN & 1 & 0 & 0 & 0 & 2 & 2 \\
\hline Chelsea & $\bar{A}$ & SN & 2 & 0 & 1 & 0 & 2 & 1 \\
\hline Chelsea & B & SN & 0 & 0 & 0 & 0 & 0 & 1 \\
\hline Chelsea & $\mathrm{C}$ & $\overline{\mathrm{SN}}$ & 3 & 0 & 0 & 2 & 2 & 1 \\
\hline Chelsea & $\bar{D}$ & $\overline{\mathrm{SN}}$ & 4 & 0 & 0 & 1 & 2 & 0 \\
\hline Chemin_Scholle & $\mathrm{A}$ & EN & 1 & 0 & 1 & 0 & 2 & 1 \\
\hline Chemin_Scholle & B & EN & 2 & 0 & 0 & 0 & 1 & 0 \\
\hline Chemin_Scholle & $\mathrm{C}$ & $\overline{E N}$ & 0 & 0 & 0 & 0 & 1 & 0 \\
\hline Chemin_Scholle & $\mathrm{D}$ & $\overline{\mathrm{EN}}$ & 3 & 0 & 0 & 0 & 1 & 0 \\
\hline Cote_d'Azur & A & $\mathrm{S}$ & 2 & 0 & 0 & 0 & 2 & 0 \\
\hline Cote_d'Azur & $\mathrm{B}$ & $\mathrm{S}$ & 2 & 0 & 0 & 0 & 1 & 0 \\
\hline Cote_d'Azur & $\mathrm{C}$ & $\mathrm{S}$ & 0 & 0 & 0 & 0 & 1 & 0 \\
\hline Cote_d'Azur & $\mathrm{D}$ & $\mathrm{S}$ & 1 & 0 & 0 & 0 & 2 & 0 \\
\hline Highway_Seven & A & $\mathrm{E}$ & 4 & 0 & 0 & 0 & 0 & 0 \\
\hline Highway_Seven & B & $\mathrm{E}$ & 3 & 0 & 0 & 0 & 1 & 0 \\
\hline Highway_Seven & $\mathrm{C}$ & $\bar{E}$ & 4 & 0 & 0 & 0 & 4 & 0 \\
\hline Highway_Seven & $\mathrm{D}$ & $\bar{E}$ & 1 & 1 & 0 & 0 & 3 & 0 \\
\hline Hull & $\bar{A}$ & $\bar{U}$ & 0 & 0 & 0 & 0 & 0 & 0 \\
\hline Hull & B & $\mathrm{U}$ & 0 & 0 & 0 & 0 & 0 & 0 \\
\hline Hull & $\mathrm{C}$ & $\bar{U}$ & 1 & 0 & 0 & 0 & 0 & 0 \\
\hline Hull & $\bar{D}$ & $\mathrm{U}$ & 0 & 0 & 0 & 0 & 0 & 0 \\
\hline Lac_a_la_Perdrix & $\overline{\mathrm{A}}$ & $\overline{\mathrm{EN}}$ & 0 & 0 & 0 & 0 & 0 & 0 \\
\hline Lac_a_la_Perdrix & B & $\overline{\mathrm{EN}}$ & 0 & 0 & 0 & 0 & 1 & 0 \\
\hline Lac_a_la_Perdrix & $\mathrm{C}$ & EN & 1 & 0 & 0 & 0 & 1 & 0 \\
\hline Lac_a_la_Perdrix & $\mathrm{D}$ & EN & 1 & 0 & 0 & 1 & 0 & 1 \\
\hline Lac_Philippe & A & $F$ & 0 & 0 & 0 & 2 & 0 & 0 \\
\hline Lac_Philippe & $\bar{B}$ & $F$ & 1 & 0 & 0 & 1 & 0 & 2 \\
\hline Lac_Philippe & $\mathrm{C}$ & $F$ & 0 & 0 & 0 & 1 & 0 & 0 \\
\hline Lac_Philippe & $\mathrm{D}$ & $F$ & 0 & 0 & 0 & 1 & 0 & 0 \\
\hline
\end{tabular}




\begin{tabular}{|c|c|c|c|c|c|c|c|c|}
\hline Manoir_des_Trembles & A & $\overline{\mathrm{UN}}$ & 0 & 0 & 0 & 0 & 0 & 1 \\
\hline Manoir_des_Trembles & $\mathrm{B}$ & $\overline{\mathrm{UN}}$ & 6 & 0 & 0 & 0 & 0 & 0 \\
\hline Manoir_des_Trembles & $\mathrm{C}$ & $\overline{\mathrm{UN}}$ & 7 & 0 & 0 & 0 & 0 & 0 \\
\hline Manoir_des_Trembles & $\bar{D}$ & $\overline{\mathrm{UN}}$ & 3 & 0 & 0 & 0 & 0 & $\overline{0}$ \\
\hline Marathon & A & $\mathrm{E}$ & 2 & 0 & 0 & $\mathbf{0}$ & 1 & 0 \\
\hline Marathon & $\bar{B}$ & $\bar{E}$ & 1 & 0 & 0 & 0 & 1 & 1 \\
\hline Marathon & $\mathrm{C}$ & $E$ & 5 & 1 & 0 & 0 & 0 & 0 \\
\hline Marathon & $\bar{D}$ & E & 4 & 0 & 0 & 0 & 2 & 0 \\
\hline Marier & $\bar{A}$ & $\mathrm{U}$ & 4 & 0 & 0 & 0 & 0 & 0 \\
\hline Marier & $\bar{B}$ & $\overline{\mathrm{U}}$ & 0 & 0 & 0 & 0 & 0 & $\overline{0}$ \\
\hline Marier & $\bar{C}$ & $\overline{\mathrm{U}}$ & 2 & 0 & $\mathbf{0}$ & $\mathbf{0}$ & 0 & $\overline{0}$ \\
\hline Marier & $\bar{D}$ & $\bar{U}$ & 0 & 0 & 0 & 0 & 0 & $\overline{0}$ \\
\hline Marlborough & A & $\mathrm{F}$ & 0 & 0 & 0 & 0 & 1 & 0 \\
\hline Marlborough & $\mathrm{B}$ & $\bar{F}$ & 3 & 0 & 0 & 0 & 1 & $\overline{0}$ \\
\hline Marlborough & $\mathrm{C}$ & $\mathrm{F}$ & 1 & 0 & 0 & 0 & 2 & 0 \\
\hline Marlborough & $\mathrm{D}$ & $\bar{F}$ & 1 & 0 & 0 & 0 & 1 & 0 \\
\hline Merivale & $\bar{A}$ & $\mathrm{SN}$ & 3 & 0 & 0 & 0 & 2 & 1 \\
\hline Merivale & $\bar{B}$ & SN & 1 & 0 & 0 & 0 & 2 & 1 \\
\hline Merivale & $\bar{C}$ & $\mathrm{SN}$ & 4 & 0 & 0 & 0 & 0 & 1 \\
\hline Merivale & $\bar{D}$ & $\mathrm{SN}$ & 0 & 0 & 0 & 0 & 3 & 1 \\
\hline Parc_Champlain & A & $S$ & 4 & 0 & 0 & 0 & 2 & 0 \\
\hline Parc_Champlain & $\mathrm{B}$ & $\mathrm{S}$ & 4 & 0 & 0 & 0 & 0 & 0 \\
\hline Parc_Champlain & $\mathrm{C}$ & $\mathrm{S}$ & 1 & 0 & 0 & 0 & 2 & 0 \\
\hline Parc_Champlain & $\mathrm{D}$ & $S$ & 6 & 0 & 0 & 0 & 2 & $\overline{0}$ \\
\hline Pelissier & $\bar{A}$ & $\mathrm{EN}$ & 2 & 0 & 0 & 0 & 1 & 0 \\
\hline Pelissier & $\bar{B}$ & $\overline{\mathrm{EN}}$ & 1 & 0 & 0 & 0 & 3 & 1 \\
\hline Pelissier & $\mathrm{C}$ & $\mathrm{EN}$ & 4 & 0 & 0 & 2 & 2 & 1 \\
\hline Pelissier & $\mathrm{D}$ & EN & 3 & 0 & 0 & 0 & 3 & 0 \\
\hline PineGlen_Annex & $\bar{A}$ & $\mathrm{~S}$ & 3 & 0 & 0 & 0 & 0 & 0 \\
\hline PineGlen_Annex & $\mathrm{B}$ & $\mathrm{S}$ & 3 & 1 & 0 & 0 & 2 & 0 \\
\hline PineGlen_Annex & $\mathrm{C}$ & $S$ & 3 & 0 & 0 & 0 & 0 & 0 \\
\hline PineGlen_Annex & $\bar{D}$ & $S$ & 5 & 0 & 0 & 0 & 0 & 0 \\
\hline Q_Four & A & $E$ & 3 & 0 & 0 & 0 & 0 & 2 \\
\hline Q_Four & $\mathrm{B}$ & $E$ & 1 & 0 & 0 & 0 & 2 & 0 \\
\hline Q_Four & $\mathrm{C}$ & $E$ & 2 & 0 & 0 & 0 & 3 & 0 \\
\hline Q_Four & $\mathrm{D}$ & $\mathrm{E}$ & 2 & 0 & 0 & 0 & 1 & 0 \\
\hline Sandy_Hill & $\bar{A}$ & $\bar{U}$ & 1 & 0 & 0 & 0 & 0 & 0 \\
\hline Sandy_Hill & $\mathrm{B}$ & $\mathrm{U}$ & 2 & 0 & 0 & 0 & 0 & 0 \\
\hline Sandy_Hill & $\mathrm{C}$ & $\mathrm{U}$ & 1 & 0 & 0 & 0 & 0 & 0 \\
\hline Sandy_Hill & $\mathrm{D}$ & $\mathrm{U}$ & 2 & 0 & 0 & 0 & 0 & 0 \\
\hline Vallee_Meech & A & $\mathrm{F}$ & 0 & 0 & 0 & 0 & 0 & 1 \\
\hline Vallee_Meech & $\mathrm{B}$ & $\bar{F}$ & 0 & 0 & 0 & 0 & 1 & 1 \\
\hline Vallee_Meech & $\mathrm{C}$ & $\mathrm{F}$ & 0 & 0 & 0 & 0 & 1 & 0 \\
\hline Vallee_Meech & $\bar{D}$ & $\bar{F}$ & 0 & 0 & 0 & 0 & 1 & 0 \\
\hline Wolf_Grove & $\bar{A}$ & $\bar{E}$ & 1 & 0 & 0 & 0 & 1 & $\overline{0}$ \\
\hline
\end{tabular}




\begin{tabular}{|l|l|l|r|r|r|r|r|r|}
\hline Wolf_Grove & B & E & 4 & 0 & 0 & 0 & 1 & 0 \\
\hline Wolf_Grove & C & E & 2 & 0 & 0 & 0 & 2 & 0 \\
\hline Wolf_Grove & D & E & 1 & 0 & 0 & 1 & 0 & 0 \\
\hline Wrightville & A & U & 1 & 0 & 0 & 0 & 1 & 0 \\
\hline Wrightville & B & U & 0 & 0 & 0 & 0 & 0 & 0 \\
\hline Wrightville & C & U & 0 & 0 & 0 & 0 & 0 & 0 \\
\hline Wrightville & D & U & 0 & 0 & 0 & 0 & 0 & 0 \\
\hline Wychwood & A & S & 4 & 0 & 0 & 0 & 1 & 0 \\
\hline Wychwood & B & S & 6 & 0 & 0 & 0 & 1 & 0 \\
\hline Wychwood & C & S & 1 & 0 & 0 & 0 & 1 & 0 \\
\hline Wychwood & D & S & 3 & 0 & 0 & 0 & 3 & 0 \\
\hline
\end{tabular}




\begin{tabular}{|c|c|c|c|c|c|c|c|c|}
\hline SITE & STATION & CATEGORY & BTBW & BTGW & BWWA & CAGO & CAWA & CEWA \\
\hline Achbar & $\mathrm{A}$ & SN & 0 & 0 & 0 & 0 & 0 & $\overline{0}$ \\
\hline Achbar & $\bar{B}$ & SN & 0 & 0 & 0 & 0 & 0 & 0 \\
\hline Achbar & $\mathrm{C}$ & SN & 0 & 0 & 0 & 0 & 0 & 0 \\
\hline Achbar & $\bar{D}$ & SN & 0 & 0 & 0 & 0 & 0 & 0 \\
\hline Bridlewood & $\bar{A}$ & UN & 0 & 0 & 0 & 0 & 0 & 0 \\
\hline Bridlewood & $\mathrm{B}$ & UN & 0 & 0 & 1 & 0 & 0 & 0 \\
\hline Bridlewood & $\mathrm{C}$ & UN & 0 & 0 & 1 & 0 & 0 & 0 \\
\hline Bridlewood & D & $\overline{\mathrm{UN}}$ & 0 & 1 & 0 & 0 & 0 & 0 \\
\hline Carp_Hills & $\overline{\mathrm{A}}$ & $F$ & 0 & 0 & 1 & 0 & 0 & 0 \\
\hline Carp_Hills & $\bar{B}$ & $\bar{F}$ & 0 & 0 & 0 & $\overline{0}$ & 0 & 0 \\
\hline Carp_Hills & $\mathrm{C}$ & $F$ & 0 & 0 & 0 & 0 & 0 & 0 \\
\hline Carp_Hills & $\mathrm{D}$ & $F$ & 0 & 0 & 0 & 0 & 0 & $\overline{0}$ \\
\hline Chapel_Hill & $\mathrm{A}$ & UN & 0 & 0 & 0 & 0 & 0 & 0 \\
\hline Chapel_Hill & B & UN & 0 & 0 & 0 & 0 & 0 & 0 \\
\hline Chapel_Hill & $\mathrm{C}$ & UN & 0 & 0 & 1 & $\begin{array}{l}0 \\
0\end{array}$ & 0 & 0 \\
\hline Chapel_Hill & $\overline{\mathrm{D}}$ & $\overline{\mathrm{UN}}$ & 0 & 0 & 1 & 0 & 0 & $\overline{0}$ \\
\hline Chelsea & $\bar{A}$ & SN & 0 & 4 & 1 & 0 & 0 & 0 \\
\hline Chelsea & B & $\overline{\mathrm{SN}}$ & 0 & 1 & 1 & 0 & 0 & $\overline{0}$ \\
\hline Chelsea & $\mathrm{C}$ & SN & 0 & 2 & 1 & 0 & 0 & 0 \\
\hline Chelsea & $\bar{D}$ & SN & 0 & 2 & 0 & 0 & 0 & $\overline{0}$ \\
\hline Chemin_Scholle & $\bar{A}$ & EN & 0 & 0 & 1 & 0 & 0 & $\overline{0}$ \\
\hline Chemin_Scholle & $\bar{B}$ & $\overline{\text { EN }}$ & 0 & 1 & 0 & 0 & 0 & 0 \\
\hline Chemin_Scholle & $\mathrm{C}$ & EN & 0 & 2 & 1 & 0 & 0 & $\overline{0}$ \\
\hline Chemin_Scholle & $\overline{\mathrm{D}}$ & $\overline{\mathrm{EN}}$ & 0 & 0 & 0 & 0 & 0 & $\overline{0}$ \\
\hline Cote_d'Azur & $\bar{A}$ & $\mathrm{~S}$ & 0 & 0 & 0 & 0 & 0 & 0 \\
\hline Cote_d'Azur & $\mathrm{B}$ & $\mathrm{S}$ & 0 & 0 & 0 & 0 & 0 & $\overline{0}$ \\
\hline Cote_d'Azur & $\mathrm{C}$ & $\mathrm{S}$ & 0 & 0 & 0 & 0 & 0 & 3 \\
\hline Cote d'Azur & $\mathrm{D}$ & $\mathrm{S}$ & 0 & 0 & 0 & 0 & 0 & 0 \\
\hline Highway_Seven & $\bar{A}$ & $E$ & 0 & 0 & 0 & 0 & 0 & $\overline{0}$ \\
\hline Highway_Seven & B & $\bar{E}$ & 0 & 0 & 0 & 0 & 0 & $\overline{0}$ \\
\hline Highway_Seven & $\bar{C}$ & $\bar{E}$ & 0 & 0 & 2 & 0 & 0 & 0 \\
\hline Highway_Seven & $\overline{\mathrm{D}}$ & $\bar{E}$ & 0 & 0 & 0 & 0 & 0 & $\overline{0}$ \\
\hline Hull & A & $\mathbf{U}$ & 0 & 0 & 0 & 0 & $\overline{0}$ & $\overline{0}$ \\
\hline Hull & B & $\overline{\mathbf{U}}$ & 0 & 0 & 0 & 0 & 0 & $\overline{0}$ \\
\hline Hull & $\mathrm{C}$ & $\mathbf{U}$ & 0 & 0 & 0 & 0 & 0 & 0 \\
\hline Hull & $\bar{D}$ & $\bar{U}$ & 0 & 0 & 0 & 0 & 0 & 0 \\
\hline Lac_a_la_Perdrix & $\overline{\mathrm{A}}$ & $\overline{\mathrm{EN}}$ & 1 & 2 & 0 & 0 & 0 & 0 \\
\hline Lac_a_la_Perdrix & $\mathrm{B}$ & $\overline{\mathrm{EN}}$ & 1 & 1 & 0 & 0 & 0 & $\overline{0}$ \\
\hline Lac_a_la_Perdrix & $\bar{C}$ & $\overline{\mathrm{EN}}$ & 0 & 1 & 1 & 0 & 0 & $\overline{0}$ \\
\hline Lac_a_la_Perdrix & $\bar{D}$ & EN & 0 & 2 & 1 & 0 & 0 & 0 \\
\hline Lac_Philippe & $\overline{\mathrm{A}}$ & $F$ & 2 & 2 & 0 & 0 & 0 & $\overline{0}$ \\
\hline Lac_Philippe & $\bar{B}$ & $\mathrm{~F}$ & 0 & 2 & 1 & 0 & 0 & 0 \\
\hline Lac_Philippe & $\mathrm{C}$ & $\bar{F}$ & 1 & 2 & 0 & 0 & 0 & 0 \\
\hline Lac_Philippe & $\mathrm{D}$ & $\mathrm{F}$ & 0 & 1 & 0 & 0 & 0 & 0 \\
\hline
\end{tabular}




\begin{tabular}{|c|c|c|c|c|c|c|c|c|}
\hline Manoir_des_Trembles & A & UN & 1 & 1 & 0 & 0 & 0 & 0 \\
\hline Manoir_des_Trembles & $\mathrm{B}$ & UN & 0 & 0 & 0 & 0 & 0 & 0 \\
\hline Manoir des Trembles & $\mathrm{C}$ & UN & 0 & 0 & 0 & 0 & 0 & 0 \\
\hline Manoir_des_Trembles & $\overline{\mathrm{D}}$ & UN & 0 & 2 & 0 & 0 & 0 & 0 \\
\hline Marathon & $\bar{A}$ & $\mathrm{E}$ & 0 & 0 & 3 & 0 & $\mathbf{0}$ & 1 \\
\hline Marathon & $\bar{B}$ & $\mathrm{E}$ & $\overline{0}$ & 0 & 2 & 0 & 0 & $\overline{0}$ \\
\hline Marathon & $\mathrm{C}$ & $\bar{E}$ & 0 & 1 & 0 & 0 & 0 & 0 \\
\hline Marathon & $\mathrm{D}$ & $\mathrm{E}$ & 0 & 0 & 1 & 0 & 0 & 0 \\
\hline Marier & $\mathrm{A}$ & $\mathrm{U}$ & 0 & 0 & 0 & 0 & 0 & 0 \\
\hline Marier & B & $\mathrm{U}$ & 0 & 0 & 0 & 0 & 0 & 2 \\
\hline Marier & $\mathrm{C}$ & $\mathrm{U}$ & 0 & 0 & 0 & 0 & 0 & 2 \\
\hline Marier & $\overline{\mathrm{D}}$ & $\overline{\mathrm{U}}$ & 0 & 0 & 0 & 0 & 0 & 0 \\
\hline Marlborough & $\overline{\mathrm{A}}$ & $\mathrm{F}$ & 0 & 1 & 1 & 0 & 1 & 0 \\
\hline Marlborough & $\bar{B}$ & $F$ & 0 & 2 & 0 & 0 & 0 & 0 \\
\hline Marlborough & $\mathrm{C}$ & $\bar{F}$ & 0 & 1 & 2 & 0 & 0 & 0 \\
\hline Marlborough & $\bar{D}$ & $F$ & 0 & 1 & 2 & 0 & 0 & 0 \\
\hline Merivale & $\overline{\mathrm{A}}$ & $\mathrm{SN}$ & 0 & 1 & 0 & 0 & 0 & 0 \\
\hline Merivale & $\mathrm{B}$ & $\overline{\mathrm{SN}}$ & 0 & 0 & 0 & 0 & 0 & 0 \\
\hline Merivale & $\bar{C}$ & $\mathrm{SN}$ & 0 & 0 & 0 & 0 & 0 & 0 \\
\hline Merivale & $\overline{\mathrm{D}}$ & $\mathrm{SN}$ & 0 & 0 & 0 & 0 & 0 & 0 \\
\hline Parc_Champlain & $\overline{\mathrm{A}}$ & $\mathrm{S}$ & 0 & 0 & 0 & 0 & 0 & 0 \\
\hline Parc_Champlain & $\mathrm{B}$ & $S$ & 0 & 0 & 0 & 0 & 0 & 0 \\
\hline Parc_Champlain & $\mathrm{C}$ & $\mathrm{S}$ & 0 & 0 & 0 & 0 & 0 & 0 \\
\hline Parc_Champlain & $\bar{D}$ & $S$ & 0 & 0 & 0 & 0 & 0 & 0 \\
\hline Pelissier & $\bar{A}$ & $\mathrm{EN}$ & 1 & 1 & 1 & 0 & 0 & 0 \\
\hline Pelissier & $\mathrm{B}$ & $\overline{\mathrm{EN}}$ & 0 & 2 & 1 & 0 & 0 & 0 \\
\hline Pelissier & $\mathrm{C}$ & EN & 1 & 2 & 0 & 0 & 0 & 0 \\
\hline Pelissier & $\overline{\mathrm{D}}$ & $\overline{\mathrm{EN}}$ & 0 & 3 & 1 & 0 & 0 & 0 \\
\hline PineGlen_Annex & A & $S$ & 0 & 1 & 1 & 0 & 0 & 0 \\
\hline PineGlen_Annex & $\mathrm{B}$ & $\mathrm{S}$ & 0 & 0 & 0 & 0 & 0 & 0 \\
\hline PineGlen_Annex & $\mathrm{C}$ & $\mathrm{S}$ & 0 & 0 & 0 & 0 & 0 & 0 \\
\hline PineGlen_Annex & $\mathrm{D}$ & $S$ & 0 & 1 & 0 & 0 & 0 & 0 \\
\hline Q_Four & $\overline{\mathrm{A}}$ & $\mathrm{E}$ & 0 & 1 & 0 & 1 & 0 & 0 \\
\hline Q_Four & $\mathrm{B}$ & $\bar{E}$ & 0 & 0 & 3 & 0 & 0 & 0 \\
\hline Q_Four & $\mathrm{C}$ & $\mathrm{E}$ & 0 & 2 & 0 & 0 & 0 & 0 \\
\hline Q_Four & $\mathrm{D}$ & $\mathrm{E}$ & 0 & 1 & 1 & 0 & 0 & $\overline{0}$ \\
\hline Sandy_Hill & $\mathrm{A}$ & $\mathrm{U}$ & 0 & 0 & 0 & 0 & 0 & 0 \\
\hline Sandy_Hill & $\mathrm{B}$ & $\bar{U}$ & 0 & 0 & 0 & 0 & 0 & 0 \\
\hline Sandy_Hill & $\bar{C}$ & $\bar{U}$ & 0 & 0 & 0 & 0 & 0 & 0 \\
\hline Sandy_Hill & $\bar{D}$ & $\mathrm{U}$ & 0 & 0 & 0 & 0 & 0 & 0 \\
\hline Vallee_Meech & A & $F$ & 1 & 1 & 1 & 0 & 0 & 0 \\
\hline Vallee_Meech & $\bar{B}$ & $\mathrm{~F}$ & 2 & 1 & 1 & 0 & 0 & 0 \\
\hline Vallee_Meech & $\mathrm{C}$ & $\mathrm{F}$ & 3 & 0 & 0 & 0 & 0 & 0 \\
\hline Vallee_Meech & $\bar{D}$ & $\bar{F}$ & 1 & 2 & 0 & 0 & 0 & $\overline{0}$ \\
\hline Wolf_Grove & $\overline{\mathrm{A}}$ & $\mathrm{E}$ & 0 & 2 & 0 & 0 & 0 & 0 \\
\hline
\end{tabular}




\begin{tabular}{|l|l|l|r|r|r|r|r|r|}
\hline Wolf_Grove & B & E & 0 & 0 & 0 & 0 & 0 & 0 \\
\hline Wolf_Grove & C & E & 0 & 0 & 0 & 0 & 0 & 0 \\
\hline Wolf_Grove & D & E & 0 & 0 & 1 & 0 & 0 & 0 \\
\hline Wrightville & A & U & 0 & 0 & 0 & 0 & 0 & 0 \\
\hline Wrightville & B & U & 0 & 0 & 0 & 0 & 0 & 0 \\
\hline Wrightville & C & U & 0 & 0 & 0 & 0 & 0 & 0 \\
\hline Wrightville & D & U & 0 & 0 & 0 & 0 & 0 & 2 \\
\hline Wychwood & A & S & 0 & 0 & 0 & 0 & 0 & 0 \\
\hline Wychwood & B & S & 0 & 0 & 0 & 0 & 0 & 0 \\
\hline Wychwood & C & S & 0 & 0 & 0 & 0 & 0 & 0 \\
\hline Wychwood & D & S & 0 & 0 & 0 & 0 & 0 & 0 \\
\hline
\end{tabular}




\begin{tabular}{|c|c|c|c|c|c|c|c|c|}
\hline SITE & STATION & CATEGORY & CHSP & CHSW & COGR & COLO & CORA & COSN \\
\hline Achbar & $\mathrm{A}$ & SN & 0 & 0 & 0 & 0 & 0 & 0 \\
\hline Achbar & B & SN & 0 & 0 & 0 & 0 & 0 & 0 \\
\hline Achbar & $\mathrm{C}$ & SN & 0 & 0 & 0 & 0 & 0 & 0 \\
\hline Achbar & $\mathrm{D}$ & SN & 0 & 0 & 1 & 0 & 0 & $\overline{0}$ \\
\hline Bridlewood & $\bar{A}$ & UN & $\mathbf{0}$ & 0 & 0 & 0 & 0 & 0 \\
\hline Bridlewood & $\bar{B}$ & UN & 0 & 0 & 0 & 0 & 0 & 0 \\
\hline Bridlewood & $\mathrm{C}$ & UN & 0 & 0 & 0 & 0 & 0 & 0 \\
\hline Bridlewood & D & UN & 0 & 0 & 0 & 0 & 0 & 0 \\
\hline Carp_Hills & A & $F$ & 0 & 0 & 0 & 0 & 0 & 0 \\
\hline Carp Hills & $\mathrm{B}$ & $F$ & 0 & 0 & 0 & 0 & 0 & 0 \\
\hline Carp_Hills & $\bar{C}$ & $F$ & 0 & 0 & 0 & 0 & 0 & 0 \\
\hline Carp_Hills & $\overline{\mathrm{D}}$ & $F$ & 0 & 0 & 0 & 0 & 0 & 0 \\
\hline Chapel_Hill & $\bar{A}$ & UN & 0 & 0 & 2 & 0 & 0 & 0 \\
\hline Chapel_Hill & $\bar{B}$ & UN & 0 & 0 & 1 & 0 & 0 & 0 \\
\hline Chapel_Hill & $\mathrm{C}$ & UN & 0 & 0 & 0 & 0 & 0 & 0 \\
\hline Chapel_Hill & $\mathrm{D}$ & UN & 0 & 0 & 0 & 0 & 0 & 0 \\
\hline Chelsea & $\bar{A}$ & SN & 0 & 0 & 0 & 0 & 0 & 0 \\
\hline Chelsea & $\bar{B}$ & SN & 0 & 0 & 0 & 0 & 0 & 0 \\
\hline Chelsea & $\bar{C}$ & SN & 0 & 0 & 0 & 0 & 0 & 0 \\
\hline Chelsea & $\bar{D}$ & $\overline{\mathrm{SN}}$ & 0 & 0 & 0 & 0 & 0 & 0 \\
\hline Chemin_Scholle & A & EN & 0 & 0 & $\overline{0}$ & 0 & 0 & 0 \\
\hline Chemin_Scholle & B & $\overline{\mathrm{EN}}$ & 0 & 0 & 0 & 0 & 0 & 0 \\
\hline Chemin_Scholle & $\mathrm{C}$ & EN & 0 & 0 & 0 & 0 & 0 & 0 \\
\hline Chemin_Scholle & $\mathrm{D}$ & EN & 0 & 0 & 0 & 0 & 0 & 0 \\
\hline Cote_d'Azur & $\bar{A}$ & $\mathrm{~S}$ & 0 & 0 & 0 & 0 & 0 & 0 \\
\hline Cote_d'Azur & $\bar{B}$ & $\mathrm{~S}$ & 2 & $\overline{0}$ & $\overline{4}$ & 0 & 0 & 0 \\
\hline Cote_d'Azur & $\bar{C}$ & $\mathrm{~S}$ & 0 & 0 & 2 & 0 & 0 & 0 \\
\hline Cote_d'Azur & $\mathrm{D}$ & $\mathrm{S}$ & 1 & 0 & 0 & 0 & 0 & 0 \\
\hline Highway_Seven & $\mathrm{A}$ & $\mathrm{E}$ & 1 & 0 & 0 & 0 & 0 & 0 \\
\hline Highway_Seven & B & $E$ & 3 & 0 & 0 & 0 & 0 & 0 \\
\hline Highway_Seven & $\bar{C}$ & $\bar{E}$ & 1 & 0 & 0 & 0 & 0 & 0 \\
\hline Highway_Seven & $\bar{D}$ & $\mathrm{E}$ & 2 & 0 & 0 & 0 & 0 & 0 \\
\hline Hull & A & $\mathrm{U}$ & 0 & 0 & 1 & 0 & 0 & 0 \\
\hline Hull & B & $\bar{U}$ & 0 & 0 & 2 & 0 & 0 & 0 \\
\hline Hull & $\mathrm{C}$ & $U$ & 0 & 0 & 0 & 0 & 0 & 0 \\
\hline Hull & $\bar{D}$ & $\bar{U}$ & 0 & 0 & 0 & 0 & 0 & 0 \\
\hline Lac_a_la_Perdrix & $\overline{\mathrm{A}}$ & EN & 0 & 0 & 0 & 0 & 1 & 0 \\
\hline Lac_a_la_Perdrix & $\bar{B}$ & EN & 0 & 0 & 0 & 0 & 0 & 0 \\
\hline Lac_a_la_Perdrix & $\bar{C}$ & EN & 0 & 0 & 0 & 0 & 0 & 0 \\
\hline Lac_a_la_Perdrix & $\bar{D}$ & EN & 0 & 0 & 0 & 0 & 0 & 0 \\
\hline Lac_Philippe & $\bar{A}$ & $F$ & 0 & 0 & 0 & 0 & 1 & 0 \\
\hline Lac_Philippe & $\mathrm{B}$ & $F$ & 0 & 0 & 0 & 0 & 0 & 0 \\
\hline Lac_Philippe & $\mathrm{C}$ & F & 0 & 0 & 0 & 0 & 0 & 0 \\
\hline Lac_Philippe & $\mathrm{D}$ & $\mathbf{F}$ & 0 & 0 & 0 & 0 & 0 & 0 \\
\hline
\end{tabular}




\begin{tabular}{|c|c|c|c|c|c|c|c|c|}
\hline Manoir_des_Trembles & $\bar{A}$ & UN & 0 & 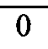 & 0 & 0 & 0 & 0 \\
\hline Manoir_des_Trembles & $\bar{B}$ & $\overline{\mathrm{UN}}$ & 0 & 0 & 2 & 0 & 0 & 0 \\
\hline Manoir_des_Trembles & $\mathrm{C}$ & UN & 0 & 0 & 0 & 0 & 0 & 0 \\
\hline Manoir_des_Trembles & $\bar{D}$ & UN & 0 & 0 & 0 & 0 & 0 & 0 \\
\hline Marathon & $\bar{A}$ & $\bar{E}$ & 0 & 0 & 0 & 0 & 0 & 0 \\
\hline Marathon & B & $\mathrm{E}$ & 0 & $\mathbf{0}$ & 0 & 0 & 0 & 0 \\
\hline Marathon & $\bar{C}$ & $\bar{E}$ & 0 & $\overline{0}$ & 0 & 0 & 0 & $\overline{0}$ \\
\hline Marathon & $\bar{D}$ & $\mathrm{E}$ & 1 & $\begin{array}{ll}0 \\
0\end{array}$ & 0 & 0 & 0 & 0 \\
\hline Marier & $\bar{A}$ & $\mathrm{U}$ & 1 & 0 & 0 & 0 & 0 & 0 \\
\hline Marier & $\bar{B}$ & $\bar{U}$ & 0 & 0 & $\overline{0}$ & 0 & 0 & 0 \\
\hline Marier & $\mathrm{C}$ & $\mathrm{U}$ & 0 & $\mathbf{0}$ & 0 & 0 & 0 & $\overline{0}$ \\
\hline Marier & $\overline{\mathrm{D}}$ & $\bar{U}$ & 0 & 2 & 0 & 0 & 0 & $\overline{0}$ \\
\hline Marlborough & A & $\mathrm{F}$ & 0 & 0 & 0 & 0 & 0 & 0 \\
\hline Marlborough & $\bar{B}$ & F & 0 & 0 & 0 & 0 & 0 & 0 \\
\hline Marlborough & $\mathrm{C}$ & $\mathrm{F}$ & 0 & 0 & 0 & 0 & 1 & 1 \\
\hline Marlborough & $\bar{D}$ & $\mathrm{~F}$ & 0 & 0 & 1 & 0 & 0 & 0 \\
\hline Merivale & A & SN & 0 & 0 & 0 & 0 & 0 & 0 \\
\hline Merivale & $\bar{B}$ & SN & 0 & 0 & 0 & 0 & 0 & $\overline{0}$ \\
\hline Merivale & $\mathrm{C}$ & SN & 1 & 0 & 0 & 0 & 0 & 0 \\
\hline Merivale & $\overline{\mathrm{D}}$ & SN & 0 & 0 & 0 & 0 & 0 & 0 \\
\hline Parc_Champlain & $\bar{A}$ & $\mathrm{~S}$ & 0 & 0 & 0 & 0 & 0 & 0 \\
\hline Parc_Champlain & $\mathrm{B}$ & $S$ & 0 & 0 & 2 & 0 & 0 & 0 \\
\hline Parc_Champlain & $\bar{C}$ & $\mathrm{~S}$ & 1 & 0 & 1 & 0 & 0 & 0 \\
\hline Parc_Champlain & $\bar{D}$ & $\mathrm{~S}$ & 0 & 0 & 0 & 0 & 0 & 0 \\
\hline Pelissier & $\bar{A}$ & EN & 0 & 0 & 0 & 0 & 0 & 0 \\
\hline Pelissier & $\bar{B}$ & $\overline{\mathrm{EN}}$ & 0 & 0 & 0 & 0 & 0 & $\overline{0}$ \\
\hline Pelissier & $\overline{\mathrm{C}}$ & EN & 0 & 0 & 0 & 0 & 0 & $\overline{0}$ \\
\hline Pelissier & $\bar{D}$ & $\overline{\mathrm{EN}}$ & 0 & $\overline{0}$ & 0 & 0 & 7 & $\overline{0}$ \\
\hline PineGlen_Annex & $\bar{A}$ & $S$ & 3 & 0 & 0 & 0 & 0 & 0 \\
\hline PineGlen_Annex & $\mathrm{B}$ & $S$ & 4 & 0 & 1 & 0 & 0 & $\overline{0}$ \\
\hline PineGlen_Annex & $\mathrm{C}$ & $\mathrm{S}$ & 1 & 0 & 0 & 0 & 0 & $\overline{0}$ \\
\hline PineGlen_Annex & $\overline{\mathrm{D}}$ & $S$ & 2 & 0 & 0 & 0 & 0 & $\overline{0}$ \\
\hline Q_Four & $\bar{A}$ & $\bar{E}$ & 0 & 0 & 0 & 0 & 0 & 0 \\
\hline Q_Four & $\mathrm{B}$ & $\mathrm{E}$ & 0 & 0 & 2 & 0 & 0 & $\overline{0}$ \\
\hline Q_Four & $\mathrm{C}$ & $\mathrm{E}$ & 0 & 0 & 0 & 0 & 0 & $\overline{0}$ \\
\hline Q_Four & $\mathrm{D}$ & $E$ & 0 & 0 & 0 & 0 & 0 & $\overline{0}$ \\
\hline Sandy_Hill & A & $\mathrm{U}$ & 0 & 0 & 0 & 0 & 0 & 0 \\
\hline Sandy_Hill & B & $\mathrm{U}$ & 1 & 0 & 0 & 0 & 0 & $\overline{0}$ \\
\hline Sandy_Hill & $\bar{C}$ & $\mathrm{U}$ & 0 & 5 & 0 & 0 & 0 & 0 \\
\hline Sandy_Hill & $\bar{D}$ & $\mathrm{U}$ & 0 & 0 & 1 & 0 & 0 & 0 \\
\hline Vallee_Meech & $\mathrm{A}$ & $\mathrm{F}$ & 0 & 0 & 0 & 0 & 0 & 0 \\
\hline Vallee_Meech & B & $\mathrm{F}$ & 0 & 0 & 0 & 0 & 0 & $\overline{0}$ \\
\hline Vallee_Meech & $\mathrm{C}$ & $F$ & 0 & 0 & 0 & 0 & 0 & $\overline{0}$ \\
\hline Vallee_Meech & $\bar{D}$ & $F$ & 0 & 0 & 0 & 1 & $\overline{0}$ & 0 \\
\hline Wolf_Grove & $\bar{A}$ & $\mathrm{E}$ & 1 & 0 & 0 & 0 & 0 & 0 \\
\hline
\end{tabular}




\begin{tabular}{|l|l|l|r|r|r|r|r|r|}
\hline Wolf_Grove & B & E & 0 & 0 & 0 & 0 & 0 & 0 \\
\hline Wolf_Grove & C & E & 0 & 0 & 1 & 0 & 0 & 0 \\
\hline Wolf_Grove & D & E & 0 & 0 & 0 & 1 & 0 & 0 \\
\hline Wrightville & A & U & 0 & 0 & 0 & 0 & 0 & 0 \\
\hline Wrightville & B & U & 1 & 0 & 1 & 0 & 0 & 0 \\
\hline Wrightville & C & U & 0 & 0 & 1 & 0 & 0 & 0 \\
\hline Wrightville & D & U & 0 & 0 & 0 & 0 & 0 & 0 \\
\hline Wychwood & A & S & 0 & 0 & 1 & 0 & 0 & 0 \\
\hline Wychwood & B & S & 0 & 0 & 0 & 0 & 0 & 0 \\
\hline Wychwood & C & S & 0 & 0 & 5 & 0 & 0 & 0 \\
\hline Wychwood & D & S & 0 & 0 & 4 & 0 & 0 & 0 \\
\hline
\end{tabular}




\begin{tabular}{|c|c|c|c|c|c|c|c|c|}
\hline SITE & STATION & CATEGORY & COYE & Dowo & EAPH & EAWP & EUST & GCFL \\
\hline Achbar & $\mathrm{A}$ & SN & 0 & 0 & 0 & 1 & 0 & 1 \\
\hline Achbar & $\mathrm{B}$ & $\overline{\mathrm{SN}}$ & 0 & 0 & 0 & 1 & 0 & 1 \\
\hline Achbar & $\mathrm{C}$ & SN & 0 & 0 & 0 & 2 & 0 & 1 \\
\hline Achbar & $\bar{D}$ & SN & 0 & 0 & 0 & 0 & $\overline{0}$ & 0 \\
\hline Bridlewood & $\overline{\mathrm{A}}$ & $\overline{\mathrm{UN}}$ & 0 & 0 & 0 & 1 & 0 & 1 \\
\hline Bridlewood & $\mathrm{B}$ & $\mathrm{UN}$ & 0 & 0 & 0 & 1 & 0 & 0 \\
\hline Bridlewood & $\mathrm{C}$ & UN & 0 & 0 & 0 & 2 & 0 & 0 \\
\hline Bridlewood & $\bar{D}$ & UN & 1 & 0 & 0 & 2 & 0 & 1 \\
\hline Carp_Hills & $\overline{\mathrm{A}}$ & $F$ & 0 & 0 & 0 & 0 & 0 & 1 \\
\hline Carp_Hills & $\bar{B}$ & $F$ & 0 & 0 & 0 & 0 & 0 & 1 \\
\hline Carp_Hills & $\mathrm{C}$ & $\bar{F}$ & 0 & $\overline{0}$ & 0 & 1 & 0 & $\overline{0}$ \\
\hline Carp_Hills & $\bar{D}$ & $\bar{F}$ & 0 & 0 & 0 & 0 & 0 & 1 \\
\hline Chapel_Hill & A & $\mathrm{UN}$ & 0 & 0 & 0 & 1 & 0 & 1 \\
\hline Chapel_Hill & $\mathrm{B}$ & $\mathrm{UN}$ & 0 & 0 & 0 & 2 & 0 & 1 \\
\hline Chapel_Hill & $\mathrm{C}$ & UN & 0 & 0 & 0 & 1 & 0 & 1 \\
\hline Chapel_Hill & $\bar{D}$ & $\mathrm{UN}$ & 1 & 1 & 0 & 2 & 0 & 1 \\
\hline Chelsea & A & $\mathrm{SN}$ & 0 & 0 & 0 & 1 & 0 & 0 \\
\hline Chelsea & $\overline{\mathrm{B}}$ & $\overline{\mathrm{SN}}$ & 0 & 0 & 0 & 1 & 0 & $\overline{0}$ \\
\hline Chelsea & $\bar{C}$ & $\mathrm{SN}$ & 0 & 0 & 0 & 1 & 0 & 1 \\
\hline Chelsea & $\mathrm{D}$ & SN & 0 & 0 & 0 & 1 & 0 & 1 \\
\hline Chemin_Scholle & $\mathrm{A}$ & $\overline{\mathrm{EN}}$ & 0 & 0 & 0 & 0 & 0 & 1 \\
\hline Chemin_Scholle & B & $\overline{\mathrm{EN}}$ & 0 & 0 & 0 & 0 & 0 & 0 \\
\hline Chemin_Scholle & $\mathrm{C}$ & $\overline{\mathrm{EN}}$ & 0 & 0 & 0 & 0 & 0 & $\overline{0}$ \\
\hline Chemin_Scholle & $\bar{D}$ & $\overline{\mathrm{EN}}$ & 0 & 0 & 0 & 0 & 0 & 0 \\
\hline Cote_d'Azur & $\mathrm{A}$ & $\mathrm{S}$ & 0 & 0 & 0 & 0 & 7 & 0 \\
\hline Cote_d'Azur & B & $S$ & 0 & 0 & 0 & 0 & 2 & 0 \\
\hline Cote_d'Azur & $\mathrm{C}$ & $S$ & 0 & 0 & 0 & 0 & 1 & 0 \\
\hline Cote_d'Azur & $\mathrm{D}$ & $\mathrm{S}$ & 0 & 0 & 0 & 0 & 0 & 0 \\
\hline Highway_Seven & $\mathrm{A}$ & $\mathrm{E}$ & 1 & 0 & 1 & 0 & 0 & 1 \\
\hline Highway_Seven & $\mathrm{B}$ & $\mathrm{E}$ & 2 & 0 & 0 & 0 & 2 & 1 \\
\hline Highway_Seven & $\mathrm{C}$ & $\bar{E}$ & 1 & 0 & 0 & 0 & 2 & 0 \\
\hline Highway_Seven & $\mathrm{D}$ & $\bar{E}$ & 0 & 0 & 1 & 0 & 1 & 1 \\
\hline Hull & $\bar{A}$ & $\bar{U}$ & 0 & 0 & 0 & 0 & 4 & 0 \\
\hline Hull & B & $\bar{U}$ & 0 & 0 & 0 & 0 & 7 & 0 \\
\hline Hull & $\mathrm{C}$ & $\mathrm{U}$ & 0 & 0 & 0 & 0 & 10 & 0 \\
\hline Hull & $\mathrm{D}$ & $\mathrm{U}$ & 0 & 0 & 0 & 0 & 14 & 0 \\
\hline Lac_a_la_Perdrix & A & EN & 0 & 0 & 0 & 0 & 0 & 0 \\
\hline Lac_a_la_Perdrix & $\mathrm{B}$ & EN & 0 & 0 & 0 & 1 & 0 & 0 \\
\hline Lac_a_la_Perdrix & $\bar{C}$ & $\overline{\mathrm{EN}}$ & 0 & 0 & 0 & 0 & 0 & 0 \\
\hline Lac_a_la_Perdrix & $\bar{D}$ & EN & 0 & 0 & 0 & 0 & 0 & 0 \\
\hline Lac_Philippe & $\mathrm{A}$ & $F$ & 0 & 0 & 0 & 2 & 0 & 0 \\
\hline Lac_Philippe & B & $F$ & 0 & 0 & 0 & 0 & 0 & 0 \\
\hline Lac_Philippe & $\mathrm{C}$ & $F$ & 0 & 0 & 0 & 1 & 0 & 0 \\
\hline Lac_Philippe & $\bar{D}$ & $F$ & 0 & 0 & 0 & 1 & 0 & 1 \\
\hline
\end{tabular}




\begin{tabular}{|c|c|c|c|c|c|c|c|c|}
\hline Manoir_des_Trembles & A & UN & 0 & 0 & 0 & 2 & 0 & 0 \\
\hline Manoir des Trembles & $\mathrm{B}$ & UN & 0 & 0 & 0 & 2 & 0 & 0 \\
\hline Manoir_des_Trembles & $\mathrm{C}$ & $\overline{\mathrm{UN}}$ & 0 & 0 & 0 & 2 & 0 & 2 \\
\hline Manoir_des_Trembles & $\bar{D}$ & UN & 0 & 1 & 0 & 0 & 0 & 0 \\
\hline Marathon & $\bar{A}$ & $E$ & 0 & 0 & 1 & 2 & 0 & 0 \\
\hline Marathon & $\mathrm{B}$ & $\bar{E}$ & 0 & 0 & 1 & 1 & 0 & 0 \\
\hline Marathon & $\mathrm{C}$ & $\mathrm{E}$ & 1 & 0 & 1 & 1 & 0 & 1 \\
\hline Marathon & $\bar{D}$ & $\bar{E}$ & 1 & 0 & 1 & 0 & 0 & 0 \\
\hline Marier & $\bar{A}$ & $\bar{U}$ & 0 & 0 & 0 & 0 & 4 & $\overline{0}$ \\
\hline Marier & $\mathrm{B}$ & $\bar{U}$ & 0 & 0 & 0 & 0 & 4 & $\overline{0}$ \\
\hline Marier & $\mathrm{C}$ & $\bar{U}$ & 0 & 0 & 0 & 0 & 7 & 0 \\
\hline Marier & $\mathrm{D}$ & $\overline{\mathrm{U}}$ & 0 & 0 & 0 & 0 & 6 & 0 \\
\hline Marlborough & $\bar{A}$ & $\mathrm{~F}$ & 0 & 0 & 0 & 0 & 0 & 1 \\
\hline Marlborough & $\mathrm{B}$ & $\mathrm{F}$ & 0 & 0 & 0 & 0 & 0 & 1 \\
\hline Marlborough & $\mathrm{C}$ & $\mathrm{F}$ & 0 & 0 & 0 & 0 & 0 & 0 \\
\hline Marlborough & $\mathrm{D}$ & $\mathrm{F}$ & 1 & 1 & 0 & 0 & 0 & 0 \\
\hline Merivale & $\overline{\mathrm{A}}$ & $\overline{\text { SN }}$ & 1 & 2 & 0 & 1 & 0 & 1 \\
\hline Merivale & B & SN & 0 & 0 & 0 & 1 & 0 & 1 \\
\hline Merivale & $\mathrm{C}$ & SN & 0 & 0 & 0 & 0 & 0 & 0 \\
\hline Merivale & $\mathrm{D}$ & $\overline{\mathrm{SN}}$ & 0 & 0 & 0 & 1 & 0 & 1 \\
\hline Parc_Champlain & $\bar{A}$ & $\mathrm{~S}$ & 0 & 0 & 1 & 0 & 2 & 1 \\
\hline Parc_Champlain & $\mathrm{B}$ & $\mathrm{S}$ & 0 & 0 & 0 & 0 & 6 & 0 \\
\hline Parc_Champlain & $\mathrm{C}$ & $\mathrm{S}$ & 1 & 0 & 0 & 0 & 1 & $\overline{0}$ \\
\hline Parc Champlain & $\mathrm{D}$ & $\mathrm{S}$ & 0 & 0 & 0 & 0 & 0 & 0 \\
\hline Pelissier & $\mathrm{A}$ & EN & 0 & 0 & 0 & 0 & 0 & $\overline{0}$ \\
\hline Pelissier & B & EN & 0 & 0 & 0 & 0 & 0 & 0 \\
\hline Pelissier & $\mathrm{C}$ & EN & 0 & 0 & 0 & 0 & 0 & 2 \\
\hline Pelissier & $\mathrm{D}$ & EN & 0 & 0 & 0 & 1 & 0 & 0 \\
\hline PineGlen Annex & $\bar{A}$ & $\mathrm{~S}$ & 0 & 0 & 0 & 0 & 0 & 1 \\
\hline PineGlen_Annex & $\bar{B}$ & $\mathrm{~S}$ & 0 & 0 & 0 & 0 & 1 & 1 \\
\hline PineGlen_Annex & $\mathrm{C}$ & $\mathrm{S}$ & 0 & 0 & 1 & 0 & 8 & 1 \\
\hline PineGlen_Annex & $\mathrm{D}$ & $\mathrm{S}$ & 0 & 0 & 0 & 1 & 1 & 2 \\
\hline Q_Four & A & $\mathrm{E}$ & 0 & 0 & 0 & 0 & 0 & 0 \\
\hline Q_Four & B & $E$ & 0 & 0 & 1 & 0 & 0 & 1 \\
\hline Q_Four & $\mathrm{C}$ & $E$ & 0 & 0 & 1 & 0 & 0 & 1 \\
\hline Q_Four & $\overline{\mathrm{D}}$ & $E$ & 0 & 1 & 0 & 1 & 0 & 2 \\
\hline Sandy_Hill & $\mathrm{A}$ & $\mathrm{U}$ & 0 & 0 & 0 & 0 & 4 & 0 \\
\hline Sandy_Hill & B & U & 0 & 0 & 0 & 0 & 14 & 0 \\
\hline Sandy_Hill & $\mathrm{C}$ & $\bar{U}$ & 0 & 0 & 0 & 0 & 12 & 0 \\
\hline Sandy_Hill & $\mathrm{D}$ & $\bar{U}$ & 0 & 0 & 0 & 0 & 7 & 0 \\
\hline Vallee_Meech & $\overline{\mathrm{A}}$ & $\bar{F}$ & 0 & 0 & 0 & 1 & 0 & 0 \\
\hline Vallee_Meech & B & $F$ & 0 & 0 & 0 & 1 & 0 & 1 \\
\hline Vallee_Meech & $\mathrm{C}$ & $\bar{F}$ & 0 & 0 & 0 & 0 & 0 & 1 \\
\hline Vallee_Meech & $\mathrm{D}$ & $\bar{F}$ & 0 & 0 & 0 & 1 & 0 & 1 \\
\hline Wolf_Grove & A & $E$ & 1 & 0 & 0 & 1 & 0 & 0 \\
\hline
\end{tabular}




\begin{tabular}{|l|l|l|r|r|r|r|r|r|}
\hline Wolf_Grove & B & E & 0 & 0 & 1 & 0 & 0 & 0 \\
\hline Wolf_Grove & C & E & 0 & 0 & 0 & 0 & 0 & 0 \\
\hline Wolf_Grove & D & E & 0 & 1 & 0 & 0 & 0 & 0 \\
\hline Wrightville & A & U & 0 & 0 & 0 & 0 & 10 & 0 \\
\hline Wrightville & B & U & 0 & 0 & 0 & 0 & 13 & 0 \\
\hline Wrightville & C & U & 0 & 0 & 0 & 0 & 11 & 0 \\
\hline Wrightville & D & U & 0 & 0 & 0 & 0 & 20 & 0 \\
\hline Wychwood & A & S & 0 & 0 & 0 & 0 & 3 & 0 \\
\hline Wychwood & B & S & 0 & 1 & 0 & 0 & 6 & 0 \\
\hline Wychwood & C & S & 0 & 0 & 0 & 0 & 5 & 0 \\
\hline Wychwood & D & S & 0 & 0 & 0 & 0 & 1 & 1 \\
\hline
\end{tabular}




\begin{tabular}{|c|c|c|c|c|c|c|c|c|}
\hline SITE & STATION & CATEGORY & GCKI & HAWO & HETH & HOFI & HOSP & KILL \\
\hline Achbar & A & SN & 0 & 1 & 0 & 0 & 0 & 0 \\
\hline Achbar & $\overline{\mathrm{B}}$ & $\mathrm{SN}$ & 0 & 0 & 0 & 0 & 0 & 0 \\
\hline Achbar & $\bar{C}$ & $\overline{\mathrm{SN}}$ & 0 & 0 & 0 & 0 & 0 & 0 \\
\hline Achbar & $\mathrm{D}$ & SN & 0 & 0 & 0 & 0 & 0 & 0 \\
\hline Bridlewood & A & UN & 0 & 0 & 0 & 0 & 0 & 0 \\
\hline Bridlewood & $\mathrm{B}$ & UN & 0 & 0 & 0 & 0 & 0 & 0 \\
\hline Bridlewood & $\mathrm{C}$ & UN & 0 & 0 & 0 & 0 & 0 & 0 \\
\hline Bridlewood & $\mathrm{D}$ & UN & 0 & 0 & 0 & 0 & 0 & 0 \\
\hline Carp_Hills & $\bar{A}$ & $\overline{\mathrm{F}}$ & 0 & 1 & $\overline{0}$ & 0 & 0 & 0 \\
\hline Carp_Hills & B & $\bar{F}$ & 0 & 1 & 0 & 0 & 0 & 0 \\
\hline Carp_Hills & $\mathrm{C}$ & $\mathrm{F}$ & 0 & 0 & 1 & 0 & 0 & 0 \\
\hline Carp_Hills & $\bar{D}$ & $\mathrm{~F}$ & 0 & 0 & 0 & 0 & 0 & 1 \\
\hline Chapel_Hill & $\mathrm{A}$ & UN & 0 & 1 & 0 & 0 & 0 & 0 \\
\hline Chapel_Hill & $\mathrm{B}$ & UN & 0 & 0 & 0 & 0 & 0 & 0 \\
\hline Chapel_Hill & $\mathrm{C}$ & UN & $\mathbf{0}$ & $\mathbf{0}$ & 0 & $\mathbf{0}$ & 0 & $\mathbf{0}$ \\
\hline Chapel_Hill & $\bar{D}$ & $\mathrm{UN}$ & 0 & 1 & 0 & 0 & 0 & 0 \\
\hline Chelsea & $\bar{A}$ & $\mathrm{SN}$ & 0 & 1 & 0 & 0 & 0 & 0 \\
\hline Chelsea & B & $\mathrm{SN}$ & 0 & 1 & $\overline{0}$ & 0 & 0 & 0 \\
\hline Chelsea & $\mathrm{C}$ & SN & 0 & 1 & 1 & 0 & 0 & 0 \\
\hline Chelsea & $\bar{D}$ & SN & 0 & 0 & 1 & 0 & 0 & 0 \\
\hline Chemin_Scholle & $\mathrm{A}$ & $\mathrm{EN}$ & 0 & 0 & 0 & 0 & 0 & 0 \\
\hline Chemin_Scholle & $\mathrm{B}$ & EN & 0 & 0 & 1 & 0 & 0 & 0 \\
\hline Chemin_Scholle & $\mathrm{C}$ & EN & 0 & 0 & 1 & 0 & 0 & 0 \\
\hline Chemin_Scholle & $\mathrm{D}$ & $\overline{E N}$ & 0 & 0 & 0 & 0 & 0 & 0 \\
\hline Cote_d'Azur & $\mathrm{A}$ & $\mathrm{S}$ & 0 & 0 & 0 & 0 & 0 & 0 \\
\hline Cote_d'Azur & $\mathrm{B}$ & $\mathrm{S}$ & 0 & 0 & 0 & 0 & 2 & 0 \\
\hline Cote_d'Azur & $\mathrm{C}$ & $S$ & 0 & 0 & 0 & 0 & 0 & 0 \\
\hline Cote_d'Azur & $\mathrm{D}$ & $\mathrm{S}$ & 0 & 0 & 0 & 0 & 0 & 0 \\
\hline Highway_Seven & A & $E$ & 0 & 0 & 1 & 0 & 0 & 0 \\
\hline Highway_Seven & $\bar{B}$ & $\bar{E}$ & 0 & 0 & 0 & 0 & 0 & 0 \\
\hline Highway_Seven & $\mathrm{C}$ & $E$ & 0 & 0 & 0 & 0 & 0 & 0 \\
\hline Highway_Seven & $\mathrm{D}$ & $E$ & 0 & 1 & 1 & 0 & 0 & 0 \\
\hline Hull & $\mathrm{A}$ & $U$ & 0 & 0 & 0 & 0 & 12 & 0 \\
\hline Hull & $\mathrm{B}$ & $\mathrm{U}$ & 0 & 0 & 0 & 0 & 11 & 0 \\
\hline Hull & $\mathrm{C}$ & $\mathrm{U}$ & 0 & 0 & 0 & 0 & 3 & 0 \\
\hline Hull & $\mathrm{D}$ & $\mathrm{U}$ & 0 & 0 & 0 & 0 & 14 & 0 \\
\hline Lac_a_la_Perdrix & $\mathrm{A}$ & EN & 0 & 0 & 0 & 0 & 0 & 0 \\
\hline Lac_a_la_Perdrix & $\mathrm{B}$ & EN & 0 & 1 & 1 & 0 & 0 & 0 \\
\hline Lac_a_la_Perdrix & $\mathrm{C}$ & EN & 0 & 2 & 0 & 0 & 0 & 0 \\
\hline Lac_a_la_Perdrix & $\mathrm{D}$ & EN & 0 & 1 & 1 & 0 & 0 & 0 \\
\hline Lac_Philippe & $\mathrm{A}$ & $\mathrm{F}$ & 0 & 1 & 1 & 0 & 0 & 0 \\
\hline Lac_Philippe & $\mathrm{B}$ & $F$ & 0 & 0 & 1 & 0 & 0 & 0 \\
\hline Lac_Philippe & $\mathrm{C}$ & $\mathrm{F}$ & 0 & 0 & 0 & 0 & 0 & 0 \\
\hline Lac_Philippe & $\bar{D}$ & $F$ & 0 & 2 & 1 & 0 & 0 & 0 \\
\hline
\end{tabular}




\begin{tabular}{|c|c|c|c|c|c|c|c|c|}
\hline Manoir_des_Trembles & $\overline{\mathrm{A}}$ & $\overline{\mathrm{UN}}$ & 0 & 0 & 0 & 0 & 0 & 0 \\
\hline Manoir_des_Trembles & $\mathrm{B}$ & UN & 0 & 0 & 0 & 0 & 0 & 0 \\
\hline Manoir_des_Trembles & $\bar{C}$ & UN & 0 & 0 & 0 & 0 & 0 & $\overline{0}$ \\
\hline Manoir_des_Trembles & $\overline{\mathrm{D}}$ & UN & 0 & 0 & 0 & 0 & 0 & 0 \\
\hline Marathon & $\bar{A}$ & $E$ & 0 & 1 & 0 & 0 & 0 & 0 \\
\hline Marathon & $\mathrm{B}$ & $\mathrm{E}$ & 0 & 0 & 0 & 0 & 0 & 0 \\
\hline Marathon & $\mathrm{C}$ & E & 0 & 1 & 0 & 0 & 0 & $\overline{0}$ \\
\hline Marathon & $\mathrm{D}$ & $\mathrm{E}$ & 0 & 0 & 0 & 0 & 0 & 0 \\
\hline Marier & $\bar{A}$ & $\overline{\mathrm{U}}$ & 0 & 0 & 0 & 1 & 10 & 0 \\
\hline Marier & $\mathrm{B}$ & $\mathrm{U}$ & 0 & 0 & 0 & 1 & 15 & 0 \\
\hline Marier & $\mathrm{C}$ & $\bar{U}$ & 0 & 0 & 0 & 1 & 10 & 0 \\
\hline Marier & $\mathrm{D}$ & $\mathrm{U}$ & 0 & 0 & 0 & 1 & 7 & 0 \\
\hline Marlborough & $\bar{A}$ & $\mathrm{~F}$ & 0 & 0 & 0 & 0 & 0 & 0 \\
\hline Marlborough & $\mathrm{B}$ & $\mathrm{F}$ & 0 & 0 & 1 & 0 & 0 & 0 \\
\hline Marlborough & $\mathrm{C}$ & $F$ & 1 & 0 & 1 & 0 & 0 & 0 \\
\hline Marlborough & $\mathrm{D}$ & $\mathrm{F}$ & 0 & 0 & 0 & 0 & 0 & 0 \\
\hline Merivale & A & SN & 0 & 0 & 0 & 0 & 0 & 0 \\
\hline Merivale & $\mathrm{B}$ & SN & 0 & 0 & 0 & 0 & 0 & 0 \\
\hline Merivale & $\mathrm{C}$ & SN & 0 & 1 & 0 & 0 & 0 & 0 \\
\hline Merivale & $\mathrm{D}$ & $\mathrm{SN}$ & 0 & 0 & 0 & 0 & 0 & 0 \\
\hline Parc_Champlain & $\bar{A}$ & $\mathrm{~S}$ & 0 & 0 & 0 & 2 & 0 & 0 \\
\hline Parc_Champlain & $\mathrm{B}$ & $\mathrm{S}$ & 0 & 0 & 0 & 0 & 1 & 0 \\
\hline Parc_Champlain & $\mathrm{C}$ & $\mathrm{S}$ & 0 & 1 & 0 & 0 & 0 & 0 \\
\hline Parc_Champlain & $\bar{D}$ & $\mathrm{~S}$ & 0 & 0 & 0 & 0 & 0 & 0 \\
\hline Pelissier & A & $\overline{\mathrm{EN}}$ & 0 & 0 & 1 & 0 & 0 & 0 \\
\hline Pelissier & $\mathrm{B}$ & EN & 0 & 0 & 1 & 0 & 0 & 0 \\
\hline Pelissier & $\mathrm{C}$ & $\mathrm{EN}$ & 0 & 0 & 1 & 0 & 0 & 0 \\
\hline Pelissier & $\mathrm{D}$ & $\overline{\mathrm{EN}}$ & 0 & 0 & 1 & 0 & 0 & 0 \\
\hline PineGlen_Annex & A & $\mathrm{S}$ & 0 & 0 & 0 & 0 & 0 & 0 \\
\hline PineGlen_Annex & $\mathrm{B}$ & $\mathrm{S}$ & 0 & 0 & 0 & 0 & 3 & 0 \\
\hline PineGlen_Annex & $\mathrm{C}$ & $\mathrm{S}$ & 0 & 0 & 0 & 0 & 3 & 0 \\
\hline PineGlen_Annex & $\mathrm{D}$ & $\mathrm{S}$ & 0 & 0 & 0 & 0 & 0 & 0 \\
\hline Q_Four & A & $\mathrm{E}$ & 0 & 0 & 0 & 0 & 0 & 0 \\
\hline Q_Four & B & $\bar{E}$ & 0 & 0 & 0 & 0 & 0 & 0 \\
\hline Q_Four & $\mathrm{C}$ & $E$ & 0 & 0 & 1 & 0 & 0 & 0 \\
\hline Q_Four & $\mathrm{D}$ & $\mathrm{E}$ & 0 & 0 & 0 & 0 & 0 & 0 \\
\hline Sandy_Hill & $\bar{A}$ & $\mathrm{U}$ & 0 & 0 & 0 & 0 & 7 & 0 \\
\hline Sandy_Hill & $\bar{B}$ & $\bar{U}$ & 0 & 0 & 0 & 0 & 7 & 0 \\
\hline Sandy_Hill & $\mathrm{C}$ & $\overline{\mathrm{U}}$ & 0 & 0 & 0 & 1 & 16 & 0 \\
\hline Sandy_Hill & $\mathrm{D}$ & $\mathrm{U}$ & 0 & 0 & 0 & 0 & 9 & 0 \\
\hline Vallee_Meech & A & $\mathrm{F}$ & 0 & 2 & 0 & 0 & 0 & 0 \\
\hline Vallee_Meech & B & $\mathrm{F}$ & 0 & 0 & 0 & 0 & 0 & 0 \\
\hline Vallee_Meech & $\mathrm{C}$ & $\mathrm{F}$ & 0 & 2 & 0 & 0 & 0 & 0 \\
\hline Vallee_Meech & $\mathrm{D}$ & $\mathrm{F}$ & 0 & 1 & 1 & 0 & 0 & 0 \\
\hline Wolf_Grove & $\mathrm{A}$ & $\bar{E}$ & 0 & 0 & 0 & 0 & 0 & 0 \\
\hline
\end{tabular}




\begin{tabular}{|l|l|l|r|r|r|r|r|r|}
\hline Wolf_Grove & B & E & 0 & 1 & 0 & 0 & 0 & 0 \\
\hline Wolf_Grove & C & E & 0 & 0 & 3 & 0 & 0 & 0 \\
\hline Wolf_Grove & D & E & 0 & 0 & 0 & 0 & 0 & 0 \\
\hline Wrightville & A & U & 0 & 0 & 0 & 0 & 12 & 0 \\
\hline Wrightville & B & U & 0 & 0 & 0 & 0 & 10 & 0 \\
\hline Wrightville & C & U & 0 & 0 & 0 & 0 & 13 & 0 \\
\hline Wrightville & D & U & 0 & 0 & 0 & 1 & 15 & 0 \\
\hline Wychwood & A & S & 0 & 0 & 0 & 0 & 2 & 0 \\
\hline Wychwood & B & S & 0 & 0 & 0 & 0 & 3 & 0 \\
\hline Wychwood & C & S & 0 & 1 & 0 & 0 & 2 & 0 \\
\hline Wychwood & D & S & 0 & 0 & 0 & 0 & 2 & 0 \\
\hline
\end{tabular}




\begin{tabular}{|c|c|c|c|c|c|c|c|c|}
\hline$\overline{\text { SITE }}$ & STATION & CATEGORY & LEBI & LEFL & MALL & MODO & MOWA & NAWA \\
\hline Achbar & $\mathrm{A}$ & SN & 0 & 0 & 0 & 0 & 0 & 0 \\
\hline Achbar & B & SN & 0 & 0 & 0 & 0 & 0 & 0 \\
\hline Achbar & $\mathrm{C}$ & $\overline{\mathrm{SN}}$ & $\overline{0}$ & 0 & 0 & 0 & 0 & $\overline{0}$ \\
\hline Achbar & $\overline{\mathrm{D}}$ & $\mathrm{SN}$ & 0 & 0 & 0 & 0 & 0 & 0 \\
\hline Bridlewood & $\mathrm{A}$ & UN & 0 & 0 & 0 & 0 & 0 & 1 \\
\hline Bridlewood & B & UN & 0 & 0 & 0 & 0 & 0 & 0 \\
\hline Bridlewood & $\bar{C}$ & $\overline{\mathrm{UN}}$ & 0 & 0 & 0 & 0 & 0 & 0 \\
\hline Bridlewood & $\mathrm{D}$ & $\overline{\mathrm{UN}}$ & 0 & 0 & 0 & 0 & 0 & 1 \\
\hline Carp_Hills & $\bar{A}$ & $\mathrm{~F}$ & 0 & 0 & 0 & 0 & 0 & 0 \\
\hline Carp_Hills & $\bar{B}$ & $\bar{F}$ & 0 & 0 & 0 & 0 & 0 & 0 \\
\hline Carp_Hills & $\mathrm{C}$ & $\mathrm{F}$ & 0 & 1 & $\overline{0}$ & 0 & 0 & $\overline{0}$ \\
\hline Carp_Hills & $\bar{D}$ & $\mathrm{~F}$ & 0 & 0 & 0 & 1 & 0 & 0 \\
\hline Chapel_Hill & $\mathrm{A}$ & UN & 0 & 0 & 0 & 0 & 0 & 0 \\
\hline Chapel_Hill & $\bar{B}$ & $\overline{\mathrm{UN}}$ & $\overline{0}$ & 0 & 0 & 1 & 0 & 0 \\
\hline Chapel_Hill & $\bar{C}$ & UN & 0 & 0 & 0 & 1 & 0 & 0 \\
\hline Chapel_Hill & $\mathrm{D}$ & UN & 0 & 0 & 0 & 1 & 0 & 0 \\
\hline Chelsea & A & $\mathrm{SN}$ & 0 & 0 & 0 & 0 & 0 & 1 \\
\hline Chelsea & B & $\overline{\mathrm{SN}}$ & 0 & 0 & 0 & 1 & 0 & 0 \\
\hline Chelsea & $\bar{C}$ & $\overline{\mathrm{SN}}$ & 0 & 0 & 0 & 1 & 0 & 2 \\
\hline Chelsea & $\bar{D}$ & SN & 0 & 0 & 0 & 1 & $\overline{0}$ & 1 \\
\hline Chemin_Scholle & $\mathrm{A}$ & $\mathrm{EN}$ & 0 & 0 & 0 & 2 & 0 & 1 \\
\hline Chemin_Scholle & $\bar{B}$ & $\overline{\mathrm{EN}}$ & 0 & 0 & 0 & 2 & 0 & 1 \\
\hline Chemin_Scholle & $\mathrm{C}$ & EN & 0 & 0 & 0 & 2 & 0 & 0 \\
\hline Chemin_Scholle & $\mathrm{D}$ & EN & 0 & 0 & 0 & 2 & 0 & 2 \\
\hline Cote_d'Azur & $\mathrm{A}$ & $\mathrm{S}$ & 0 & 0 & 0 & 1 & 0 & 0 \\
\hline Cote_d'Azur & B & $\bar{S}$ & 0 & 0 & 0 & 0 & 0 & $\overline{0}$ \\
\hline Cote_d'Azur & $\mathrm{C}$ & $\mathrm{S}$ & 0 & 0 & 0 & 0 & 0 & 0 \\
\hline Cote_d'Azur & $\bar{D}$ & $\mathrm{~S}$ & 0 & 0 & 0 & 0 & 0 & 0 \\
\hline Highway_Seven & A & $E$ & 0 & 0 & 0 & 0 & 0 & 1 \\
\hline Highway_Seven & B & $\mathrm{E}$ & 0 & 0 & 0 & 0 & 0 & 2 \\
\hline Highway_Seven & $\mathrm{C}$ & $\mathrm{E}$ & 0 & 0 & 0 & 0 & 0 & $\overline{0}$ \\
\hline Highway_Seven & $\mathrm{D}$ & $\mathrm{E}$ & 0 & 0 & 0 & 1 & 0 & 1 \\
\hline Hull & A & $\bar{U}$ & 0 & 0 & 0 & 0 & 0 & 0 \\
\hline Hull & $\bar{B}$ & $\bar{U}$ & 0 & 0 & 0 & 0 & 0 & $\overline{0}$ \\
\hline Hull & $\bar{C}$ & $\bar{U}$ & 0 & 0 & 0 & 1 & 0 & 0 \\
\hline Hull & $\mathrm{D}$ & $\mathrm{U}$ & 0 & 0 & 0 & 0 & 0 & 0 \\
\hline Lac_a_la_Perdrix & A & EN & 0 & 0 & 0 & 1 & 0 & 0 \\
\hline Lac_a_la_Perdrix & B & $\overline{\mathrm{EN}}$ & 0 & 0 & 0 & 0 & 0 & 0 \\
\hline Lac_a_la_Perdrix & $\mathrm{C}$ & $\overline{\mathrm{EN}}$ & 0 & 0 & 0 & 2 & 0 & 0 \\
\hline Lac_a_la_Perdrix & $\bar{D}$ & $\overline{\mathrm{EN}}$ & 0 & 0 & 0 & 1 & 0 & 0 \\
\hline Lac_Philippe & $\mathrm{A}$ & $\mathrm{F}$ & 0 & 0 & 0 & 0 & 0 & 0 \\
\hline Lac_Philippe & $\mathrm{B}$ & $\mathrm{F}$ & 0 & 0 & 0 & 0 & 0 & 1 \\
\hline Lac_Philippe & $\mathrm{C}$ & $\bar{F}$ & 0 & 0 & 0 & 0 & 0 & 0 \\
\hline Lac_Philippe & $\bar{D}$ & $\bar{F}$ & 0 & 4 & 0 & 0 & 0 & 0 \\
\hline
\end{tabular}




\begin{tabular}{|c|c|c|c|c|c|c|c|c|}
\hline Manoir_des_Trembles & $\bar{A}$ & $\mathrm{UN}$ & 0 & 0 & 0 & 1 & 0 & 0 \\
\hline Manoir_des_Trembles & $\bar{B}$ & UN & 0 & 0 & 0 & 0 & 0 & 0 \\
\hline Manoir_des_Trembles & $\mathrm{C}$ & $\overline{\mathrm{UN}}$ & 0 & 0 & 0 & 0 & 0 & 0 \\
\hline Manoir_des_Trembles & $\bar{D}$ & UN & 0 & 0 & 0 & 0 & 0 & 0 \\
\hline Marathon & $\bar{A}$ & $\bar{E}$ & 0 & 0 & 0 & 0 & 0 & 0 \\
\hline Marathon & $\overline{\mathrm{B}}$ & $\bar{E}$ & 0 & 0 & 0 & 0 & 0 & 2 \\
\hline Marathon & $\mathrm{C}$ & $\mathrm{E}$ & 0 & 0 & 0 & 0 & 0 & 2 \\
\hline Marathon & $\bar{D}$ & $\bar{E}$ & 0 & 0 & 0 & 0 & 0 & 3 \\
\hline Marier & $\bar{A}$ & $\overline{\mathrm{U}}$ & 0 & 0 & 0 & 0 & 0 & 0 \\
\hline Marier & $\bar{B}$ & $\mathrm{U}$ & 0 & 0 & 0 & 0 & 0 & 0 \\
\hline Marier & $\mathrm{C}$ & $\mathrm{U}$ & 0 & 0 & 0 & 0 & 0 & 0 \\
\hline Marier & $\mathrm{D}$ & $\bar{U}$ & 0 & 0 & 0 & 0 & 0 & 0 \\
\hline Marlborough & $\bar{A}$ & $\mathrm{~F}$ & 0 & 0 & 0 & 0 & $\overline{0}$ & 0 \\
\hline Marlborough & $\mathrm{B}$ & $\mathrm{F}$ & 0 & 0 & 0 & 1 & 0 & 1 \\
\hline Marlborough & $\bar{C}$ & $\bar{F}$ & 1 & 0 & 0 & $\overline{0}$ & 0 & 2 \\
\hline Marlborough & $\mathrm{D}$ & $\mathrm{F}$ & 0 & 0 & 0 & 1 & 0 & 1 \\
\hline Merivale & $\bar{A}$ & $\overline{\mathrm{SN}}$ & 0 & 0 & 0 & 0 & 0 & 0 \\
\hline Merivale & $\overline{\mathrm{B}}$ & $\mathrm{SN}$ & 0 & 0 & 0 & 0 & 0 & 0 \\
\hline Merivale & $\mathrm{C}$ & $\mathrm{SN}$ & 0 & 0 & 0 & 0 & 0 & 0 \\
\hline Merivale & $\mathrm{D}$ & $\mathrm{SN}$ & 0 & 0 & 0 & 0 & 0 & 0 \\
\hline Parc_Champlain & A & $\mathrm{S}$ & 0 & 0 & 0 & 0 & 0 & 0 \\
\hline Parc_Champlain & B & $\mathrm{S}$ & 0 & 0 & 0 & 0 & 0 & 0 \\
\hline Parc_Champlain & $\mathrm{C}$ & $\mathrm{S}$ & 0 & 0 & 10 & 0 & 0 & 0 \\
\hline Parc_Champlain & $\bar{D}$ & $\mathrm{~S}$ & 0 & 0 & 0 & 1 & 0 & 0 \\
\hline Pelissier & $\bar{A}$ & $\overline{\mathrm{EN}}$ & 0 & 0 & 0 & 0 & 0 & 1 \\
\hline Pelissier & B & $\overline{\mathrm{EN}}$ & 0 & 0 & 0 & 0 & 0 & 0 \\
\hline Pelissier & $\mathrm{C}$ & EN & 0 & 0 & 0 & 0 & 0 & 1 \\
\hline Pelissier & $\bar{D}$ & EN & 0 & 0 & 0 & 0 & 0 & 0 \\
\hline PineGlen_Annex & $\bar{A}$ & $\mathrm{~S}$ & 0 & 0 & 0 & 0 & 0 & $\overline{0}$ \\
\hline PineGlen_Annex & $\mathrm{B}$ & $S$ & 0 & 0 & 0 & 0 & 0 & 0 \\
\hline PineGlen_Annex & $\mathrm{C}$ & $S$ & 0 & 0 & 0 & 0 & 0 & $\overline{0}$ \\
\hline PineGlen_Annex & $\bar{D}$ & $\mathrm{~S}$ & 0 & 0 & 0 & 0 & 0 & $\overline{0}$ \\
\hline Q_Four & $\mathrm{A}$ & $\mathrm{E}$ & 0 & 1 & 0 & 0 & 0 & 0 \\
\hline Q_Four & $\mathrm{B}$ & $\mathrm{E}$ & 0 & 0 & 0 & 2 & 2 & 2 \\
\hline Q_Four & $\mathrm{C}$ & $\mathrm{E}$ & 0 & 0 & 0 & 0 & 0 & 0 \\
\hline Q_Four & $\mathrm{D}$ & $\mathrm{E}$ & 0 & 0 & 0 & 0 & 0 & $\overline{0}$ \\
\hline Sandy_Hill & $\bar{A}$ & $\mathrm{U}$ & 0 & 0 & 0 & 0 & 0 & 0 \\
\hline Sandy_Hill & $\mathrm{B}$ & $\mathrm{U}$ & 0 & 0 & 0 & 0 & 0 & 0 \\
\hline Sandy_Hill & $\mathrm{C}$ & $\overline{\mathrm{U}}$ & 0 & 0 & 0 & 0 & 0 & $\overline{0}$ \\
\hline Sandy_Hill & $\bar{D}$ & $\mathrm{U}$ & 0 & 0 & 0 & 0 & 0 & 0 \\
\hline Vallee_Meech & $\bar{A}$ & $\mathrm{~F}$ & 0 & 0 & 1 & 0 & 0 & 0 \\
\hline Vallee_Meech & B & $F$ & 0 & 0 & 0 & 0 & 0 & 0 \\
\hline Vallee_Meech & $\mathrm{C}$ & $\mathrm{F}$ & 0 & 0 & 0 & 0 & 0 & 0 \\
\hline Vallee_Meech & $\mathrm{D}$ & $\mathrm{F}$ & 0 & 0 & 0 & 0 & 0 & 0 \\
\hline Wolf_Grove & $\mathrm{A}$ & $\bar{E}$ & 0 & 0 & 0 & 0 & 0 & 0 \\
\hline
\end{tabular}




\begin{tabular}{|l|l|l|r|r|r|r|r|r|}
\hline Wolf_Grove & B & E & 0 & 0 & 0 & 0 & 0 & 0 \\
\hline Wolf_Grove & C & E & 0 & 0 & 0 & 0 & 0 & 0 \\
\hline Wolf_Grove & D & E & 0 & 0 & 0 & 0 & 0 & 0 \\
\hline Wrightville & A & U & 0 & 0 & 0 & 0 & 0 & 0 \\
\hline Wrightville & B & U & 0 & 0 & 0 & 1 & 0 & 0 \\
\hline Wrightville & C & U & 0 & 0 & 0 & 0 & 0 & 0 \\
\hline Wrightville & D & U & 0 & 0 & 0 & 0 & 0 & 0 \\
\hline Wychwood & A & S & 0 & 0 & 0 & 1 & 0 & 0 \\
\hline Wychwood & B & S & 0 & 0 & 0 & 0 & 0 & 0 \\
\hline Wychwood & C & S & 0 & 0 & 0 & 0 & 0 & 0 \\
\hline Wychwood & D & S & 0 & 0 & 0 & 1 & 0 & 0 \\
\hline
\end{tabular}




\begin{tabular}{|c|c|c|c|c|c|c|c|c|}
\hline SITE & STATION & CATEGORY & NOCA & NOFL & NOWA & OVEN & PIWA & $\overline{\text { PIWO }}$ \\
\hline Achbar & $\mathrm{A}$ & SN & 1 & 1 & 0 & 2 & 0 & 0 \\
\hline Achbar & $\bar{B}$ & $\overline{\mathrm{SN}}$ & 0 & 0 & 0 & 3 & 0 & $\overline{0}$ \\
\hline Achbar & $\bar{C}$ & $\overline{\mathrm{SN}}$ & 1 & 0 & 0 & 1 & 0 & 0 \\
\hline Achbar & $\mathrm{D}$ & $\overline{\mathrm{SN}}$ & 0 & 0 & 0 & 0 & 0 & $\overline{0}$ \\
\hline Bridlewood & $\overline{\mathrm{A}}$ & $\mathrm{UN}$ & 1 & 0 & 0 & 3 & 1 & 0 \\
\hline Bridlewood & B & $\overline{\mathrm{UN}}$ & 1 & 0 & 0 & 4 & 0 & $\overline{0}$ \\
\hline Bridlewood & $\mathrm{C}$ & UN & 0 & 1 & 0 & 2 & 0 & 0 \\
\hline Bridlewood & $\mathrm{D}$ & $\overline{\mathrm{UN}}$ & 0 & 0 & 0 & 2 & 1 & 0 \\
\hline Carp_Hills & $\bar{A}$ & $\mathrm{~F}$ & 0 & 0 & 1 & 2 & 0 & 0 \\
\hline Carp_Hills & $\bar{B}$ & $F$ & 0 & 1 & 1 & 3 & 0 & 0 \\
\hline Carp_Hills & $\bar{C}$ & $F$ & 0 & 0 & 0 & 2 & 2 & 0 \\
\hline Carp_Hills & $\bar{D}$ & $F$ & 0 & 1 & 0 & 3 & 1 & 1 \\
\hline Chapel_Hill & $\overline{\mathrm{A}}$ & $\mathrm{UN}$ & 0 & 0 & 1 & 2 & 0 & 0 \\
\hline Chapel_Hill & B & $\overline{\mathrm{UN}}$ & 0 & 0 & 0 & 3 & 0 & 0 \\
\hline Chapel_Hill & $\mathrm{C}$ & $\overline{U N}$ & 1 & 0 & 0 & 4 & 0 & $\overline{0}$ \\
\hline Chapel_Hill & $\mathrm{D}$ & $\overline{U N}$ & 0 & 1 & 0 & 3 & 0 & 0 \\
\hline Chelsea & A & $\overline{\mathrm{SN}}$ & 0 & 1 & 0 & 1 & 0 & 0 \\
\hline Chelsea & B & $\overline{\mathrm{SN}}$ & 0 & 1 & 0 & 3 & 0 & $\overline{0}$ \\
\hline Chelsea & $\mathrm{C}$ & $\mathrm{SN}$ & 0 & 1 & 0 & 3 & 1 & 0 \\
\hline Chelsea & $\mathrm{D}$ & $\mathrm{SN}$ & 0 & 0 & 0 & 3 & 0 & 0 \\
\hline Chemin_Scholle & A & EN & 1 & 0 & 0 & 1 & 0 & 0 \\
\hline Chemin_Scholle & $\bar{B}$ & EN & 0 & 0 & 0 & 1 & 0 & 0 \\
\hline Chemin_Scholle & $\mathrm{C}$ & EN & 0 & 1 & 0 & 3 & 0 & $\overline{0}$ \\
\hline Chemin_Scholle & $\mathrm{D}$ & $\mathrm{EN}$ & 0 & 0 & 0 & 3 & 0 & 0 \\
\hline Cote_d'Azur & $\bar{A}$ & $\mathbf{S}$ & 2 & 0 & 0 & 0 & 0 & 0 \\
\hline Cote_d'Azur & $\bar{B}$ & $\bar{S}$ & 1 & 0 & 0 & 0 & 0 & 0 \\
\hline Cote_d'Azur & $\mathrm{C}$ & $\mathrm{S}$ & 2 & 0 & 0 & 0 & 0 & 0 \\
\hline Cote d'Azur & $\bar{D}$ & $\mathrm{~S}$ & 2 & 0 & 0 & 0 & 0 & 1 \\
\hline Highway_Seven & $\mathrm{A}$ & $\mathrm{E}$ & 0 & 1 & 0 & 2 & 0 & 0 \\
\hline Highway_Seven & $\mathrm{B}$ & $\bar{E}$ & 0 & 1 & 0 & 2 & 0 & 0 \\
\hline Highway_Seven & $\overline{\mathrm{C}}$ & $\bar{E}$ & 2 & 0 & 0 & 2 & 0 & 0 \\
\hline Highway_Seven & $\mathrm{D}$ & $E$ & 1 & 1 & 0 & 3 & 0 & $\overline{0}$ \\
\hline Hull & $\mathrm{A}$ & $\mathrm{U}$ & 0 & 0 & 0 & 0 & 0 & 0 \\
\hline Hull & B & $\mathrm{U}$ & 1 & 0 & 0 & 0 & 0 & 0 \\
\hline Hull & $\mathrm{C}$ & $\bar{U}$ & 0 & 0 & 0 & 0 & 0 & $\overline{0}$ \\
\hline Hull & $\mathrm{D}$ & $\mathrm{U}$ & 0 & 0 & 0 & 0 & 0 & $\overline{0}$ \\
\hline Lac_a_la_Perdrix & A & EN & 0 & 1 & 0 & 3 & 0 & 0 \\
\hline Lac_a_la_Perdrix & $\mathrm{B}$ & EN & 0 & 1 & 0 & 3 & 0 & 0 \\
\hline Lac_a_la_Perdrix & $\mathrm{C}$ & EN & 0 & 0 & 0 & 4 & 0 & 0 \\
\hline Lac_a_la_Perdrix & $\mathrm{D}$ & EN & 0 & 0 & 0 & 3 & 0 & 0 \\
\hline Lac_Philippe & $\mathrm{A}$ & $F$ & 0 & 1 & 0 & 3 & 0 & 0 \\
\hline Lac_Philippe & $\bar{B}$ & $F$ & 0 & 0 & 0 & 3 & 0 & $\overline{0}$ \\
\hline Lac_Philippe & $\bar{C}$ & $\mathbf{F}$ & 0 & 0 & 0 & 3 & 0 & 0 \\
\hline Lac_Philippe & $\bar{D}$ & $\bar{F}$ & 0 & 1 & 0 & 2 & 0 & 0 \\
\hline
\end{tabular}




\begin{tabular}{|c|c|c|c|c|c|c|c|c|}
\hline Manoir_des_Trembles & $\bar{A}$ & UN & 0 & 1 & 0 & 3 & 0 & 0 \\
\hline Manoir_des_Trembles & B & $\overline{\mathrm{UN}}$ & 0 & 2 & 0 & 3 & 1 & 0 \\
\hline Manoir_des_Trembles & $\bar{C}$ & UN & 0 & 2 & 0 & 2 & 0 & 0 \\
\hline Manoir_des_Trembles & $\bar{D}$ & UN & 0 & 0 & 0 & 3 & 0 & 0 \\
\hline Marathon & $\mathrm{A}$ & $\mathrm{E}$ & 0 & 0 & 1 & 3 & 0 & 0 \\
\hline Marathon & B & $\mathrm{E}$ & 0 & 2 & 1 & 2 & 0 & 0 \\
\hline Marathon & $\mathrm{C}$ & $\bar{E}$ & 0 & 1 & 2 & 2 & 0 & $\overline{0}$ \\
\hline Marathon & $\bar{D}$ & $E$ & 0 & 1 & 1 & 2 & 0 & 0 \\
\hline Marier & $\bar{A}$ & $\overline{\mathrm{U}}$ & 0 & 0 & 0 & 0 & 0 & $\overline{0}$ \\
\hline Marier & B & $\mathrm{U}$ & 0 & 0 & 0 & 0 & 0 & 0 \\
\hline Marier & $\mathrm{C}$ & $\mathrm{U}$ & 0 & 0 & 0 & 0 & 0 & $\overline{0}$ \\
\hline Marier & $\mathrm{D}$ & $\bar{U}$ & 1 & 0 & $\mathbf{0}$ & 0 & 0 & 0 \\
\hline Marlborough & $\bar{A}$ & $\mathbf{F}$ & 0 & 0 & 2 & 3 & 0 & $\overline{0}$ \\
\hline Marlborough & $\bar{B}$ & $\mathbf{F}$ & 0 & 1 & 2 & 2 & 0 & $\overline{0}$ \\
\hline Marlborough & $\bar{C}$ & $\bar{F}$ & 0 & 1 & 1 & 3 & 0 & $\overline{0}$ \\
\hline Marlborough & $\bar{D}$ & $\bar{F}$ & 0 & 1 & 1 & 2 & 0 & 1 \\
\hline Merivale & $\overline{\mathrm{A}}$ & SN & 1 & 0 & 0 & 2 & 0 & 0 \\
\hline Merivale & $\bar{B}$ & $\overline{\mathrm{SN}}$ & 1 & 1 & 0 & 1 & 0 & $\overline{0}$ \\
\hline Merivale & $\mathrm{C}$ & SN & 0 & 0 & 0 & 2 & 0 & $\overline{0}$ \\
\hline Merivale & $\overline{\mathrm{D}}$ & $\mathrm{SN}$ & 0 & 1 & 0 & 3 & 0 & 0 \\
\hline Parc_Champlain & $\overline{\mathrm{A}}$ & $\mathrm{S}$ & 3 & 0 & 0 & 0 & 0 & 0 \\
\hline Parc_Champlain & B & $S$ & 1 & 1 & 0 & 0 & 0 & $\overline{0}$ \\
\hline Parc_Champlain & $\mathrm{C}$ & $\mathrm{S}$ & 2 & 2 & 0 & 0 & 0 & 0 \\
\hline Parc_Champlain & $\bar{D}$ & $\bar{S}$ & 2 & 0 & 0 & 0 & 0 & 0 \\
\hline Pelissier & $\bar{A}$ & EN & 0 & 0 & 0 & 3 & 0 & $\overline{0}$ \\
\hline Pelissier & B & $\overline{\mathrm{EN}}$ & 0 & 0 & 0 & 3 & 0 & $\overline{0}$ \\
\hline Pelissier & $\mathrm{C}$ & EN & 0 & 0 & 1 & 2 & 0 & 0 \\
\hline Pelissier & $\bar{D}$ & $\overline{\mathrm{EN}}$ & 0 & 0 & 0 & 2 & 0 & 0 \\
\hline PineGlen_Annex & $\bar{A}$ & $\mathrm{~S}$ & 3 & 0 & 0 & 0 & 1 & 0 \\
\hline PineGlen_Annex & $\bar{B}$ & $\mathrm{~S}$ & 2 & 1 & 0 & 0 & 0 & 0 \\
\hline PineGlen_Annex & $\mathrm{C}$ & $S$ & 2 & 0 & 0 & 0 & 0 & 0 \\
\hline PineGlen_Annex & $\overline{\mathrm{D}}$ & $\bar{S}$ & 1 & 0 & 0 & 0 & 1 & 0 \\
\hline Q_Four & $\bar{A}$ & $\mathrm{E}$ & 0 & 0 & 0 & 4 & 0 & 0 \\
\hline Q_Four & B & $\mathrm{E}$ & 0 & 0 & 2 & 1 & $\overline{0}$ & 0 \\
\hline Q_Four & $\mathrm{C}$ & $\mathrm{E}$ & 0 & 0 & 2 & 3 & 0 & 0 \\
\hline Q_Four & $\bar{D}$ & $\mathrm{E}$ & 0 & 0 & 0 & 2 & $\overline{0}$ & 0 \\
\hline Sandy_Hill & $\bar{A}$ & $\bar{U}$ & 0 & 0 & 0 & $\overline{0}$ & 0 & 0 \\
\hline Sandy_Hill & B & $\bar{U}$ & 1 & 0 & 0 & 0 & 0 & 0 \\
\hline Sandy_Hill & $\bar{C}$ & $\overline{\mathrm{U}}$ & 0 & 0 & 0 & 0 & 0 & $\overline{0}$ \\
\hline Sandy_Hill & D & $\mathrm{U}$ & 1 & 0 & 0 & 0 & 0 & 0 \\
\hline Vallee_Meech & $\mathrm{A}$ & $F$ & 0 & 0 & 0 & 3 & 0 & $\overline{0}$ \\
\hline Vallee_Meech & $\bar{B}$ & $\bar{F}$ & 0 & 0 & $\begin{array}{ll}0 \\
0\end{array}$ & 3 & 0 & 1 \\
\hline Vallee_Meech & $\overline{\mathrm{C}}$ & 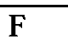 & $\overline{0}$ & 0 & 0 & 3 & 0 & 0 \\
\hline Vallee_Meech & D & $\mathrm{F}$ & 0 & 1 & 0 & 4 & 0 & 0 \\
\hline Wolf Grove & A & $\mathrm{E}$ & 0 & 0 & 1 & 3 & 0 & 0 \\
\hline
\end{tabular}




\begin{tabular}{|l|l|l|r|r|r|r|r|r|}
\hline Wolf_Grove & B & E & 0 & 0 & 0 & 0 & 0 & 0 \\
\hline Wolf_Grove & C & E & 0 & 1 & 0 & 1 & 0 & 0 \\
\hline Wolf_Grove & D & E & 0 & 2 & 0 & 1 & 1 & 0 \\
\hline Wrightville & A & U & 0 & 0 & 0 & 0 & 0 & 0 \\
\hline Wrightville & B & U & 0 & 0 & 0 & 0 & 0 & 0 \\
\hline Wrightville & C & U & 0 & 0 & 0 & 0 & 0 & 0 \\
\hline Wrightville & D & U & 0 & 0 & 0 & 0 & 0 & 0 \\
\hline Wychwood & A & S & 2 & 0 & 0 & 0 & 0 & 0 \\
\hline Wychwood & B & S & 1 & 0 & 0 & 0 & 2 & 0 \\
\hline Wychwood & C & S & 1 & 0 & 0 & 0 & 3 & 0 \\
\hline Wychwood & D & S & 1 & 0 & 0 & 0 & 4 & 0 \\
\hline
\end{tabular}




\begin{tabular}{|c|c|c|c|c|c|c|c|c|}
\hline SITE & STATION & CATEGORY & PUFI & RBGR & RBNU & REVI & RHWO & RODO \\
\hline Achbar & A & SN & 0 & 0 & 0 & 3 & 0 & 0 \\
\hline Achbar & B & $\overline{\mathrm{SN}}$ & 0 & 0 & 0 & 4 & 0 & $\overline{0}$ \\
\hline Achbar & $\mathrm{C}$ & $\overline{\mathrm{SN}}$ & 0 & 0 & 0 & 4 & 0 & 0 \\
\hline Achbar & $\mathrm{D}$ & SN & 0 & 0 & 0 & 3 & 0 & $\overline{0}$ \\
\hline Bridlewood & $\bar{A}$ & UN & 0 & 0 & 0 & 2 & 0 & $\overline{0}$ \\
\hline Bridlewood & $\bar{B}$ & $\overline{\mathrm{UN}}$ & 0 & 0 & 0 & 3 & 0 & $\overline{0}$ \\
\hline Bridlewood & $\mathrm{C}$ & UN & 0 & 0 & 0 & 3 & 0 & 0 \\
\hline Bridlewood & $\mathrm{D}$ & UN & 0 & 1 & 0 & 2 & 0 & 0 \\
\hline Carp Hills & A & $\mathrm{F}$ & 0 & 1 & 0 & 2 & 0 & $\overline{0}$ \\
\hline Carp_Hills & B & $\mathrm{F}$ & 0 & 1 & 2 & 1 & 0 & $\overline{0}$ \\
\hline Carp_Hills & $\overline{\mathrm{C}}$ & $\bar{F}$ & $\overline{0}$ & 2 & 1 & 1 & 0 & $\overline{0}$ \\
\hline Carp_Hills & $\bar{D}$ & $\mathrm{~F}$ & 0 & 1 & 0 & 1 & 0 & $\overline{0}$ \\
\hline Chapel Hill & $\bar{A}$ & $\mathrm{UN}$ & 0 & 1 & 0 & 2 & 0 & 0 \\
\hline Chapel_Hill & B & UN & 0 & 0 & 0 & 2 & 0 & 0 \\
\hline Chapel_Hill & $\mathrm{C}$ & UN & 0 & 1 & 0 & 2 & 0 & 0 \\
\hline Chapel_Hill & D & UN & 0 & 1 & 0 & 1 & 0 & 0 \\
\hline Chelsea & $\bar{A}$ & SN & 1 & 0 & 0 & 1 & 0 & 0 \\
\hline Chelsea & $\bar{B}$ & $\overline{\mathrm{SN}}$ & 0 & 0 & 1 & 2 & 0 & $\overline{0}$ \\
\hline Chelsea & $\mathrm{C}$ & $\overline{\mathrm{SN}}$ & 0 & 0 & 1 & 2 & 0 & $\overline{0}$ \\
\hline Chelsea & $\bar{D}$ & $\overline{\mathrm{SN}}$ & 1 & 0 & 1 & 0 & 0 & 0 \\
\hline Chemin_Scholle & $\bar{A}$ & EN & 0 & 1 & 0 & 0 & 0 & 0 \\
\hline Chemin_Scholle & B & EN & 0 & 0 & 0 & 1 & 0 & $\overline{0}$ \\
\hline Chemin_Scholle & $\mathrm{C}$ & EN & 0 & 0 & 0 & 0 & 0 & $\overline{0}$ \\
\hline Chemin_Scholle & $\mathrm{D}$ & EN & 0 & 1 & 1 & 0 & 0 & 0 \\
\hline Cote_d'Azur & $\bar{A}$ & $\mathbf{S}$ & 0 & 0 & 0 & 1 & 0 & $\overline{0}$ \\
\hline Cote_d'Azur & $\overline{\mathrm{B}}$ & $\bar{S}$ & 1 & 0 & 0 & 1 & 0 & $\overline{0}$ \\
\hline Cote_d'Azur & $\bar{C}$ & $\bar{S}$ & 0 & 0 & 0 & 0 & 0 & $\overline{0}$ \\
\hline Cote_d'Azur & $\bar{D}$ & $\mathrm{~S}$ & 0 & 0 & 0 & 1 & 0 & 0 \\
\hline Highway_Seven & $\bar{A}$ & $E$ & 0 & 0 & 0 & 0 & 0 & $\overline{0}$ \\
\hline Highway_Seven & $\bar{B}$ & $\mathrm{E}$ & 0 & 0 & 0 & 0 & 0 & $\overline{0}$ \\
\hline Highway_Seven & $\bar{C}$ & $E$ & 1 & 0 & 1 & 0 & 0 & $\overline{0}$ \\
\hline Highway_Seven & $\bar{D}$ & $E$ & 0 & 0 & 1 & 1 & 0 & 0 \\
\hline Hull & $\overline{\mathrm{A}}$ & $\overline{\mathrm{U}}$ & 0 & 0 & 0 & 0 & 0 & 1 \\
\hline Hull & $\bar{B}$ & $\mathrm{U}$ & 0 & 0 & 0 & 0 & 0 & 14 \\
\hline Hull & $\mathrm{C}$ & $\mathrm{U}$ & 0 & 0 & 0 & 0 & 0 & 6 \\
\hline Hull & $\mathrm{D}$ & $\mathrm{U}$ & 0 & 0 & 0 & 0 & 0 & 13 \\
\hline Lac_a_la_Perdrix & A & EN & 0 & 0 & 0 & 1 & 0 & 0 \\
\hline Lac_a_la_Perdrix & $\bar{B}$ & $\overline{\mathrm{EN}}$ & 0 & 0 & 0 & 3 & 0 & 0 \\
\hline Lac_a_la_Perdrix & $\bar{C}$ & $\overline{\mathrm{EN}}$ & 0 & 0 & 0 & 2 & 0 & $\overline{0}$ \\
\hline Lac_a_la_Perdrix & $\mathrm{D}$ & $\mathrm{EN}$ & 0 & 1 & 1 & 2 & 0 & $\overline{0}$ \\
\hline Lac_Philippe & $\mathrm{A}$ & $\mathrm{F}$ & 0 & 2 & 0 & 4 & 0 & 0 \\
\hline Lac_Philippe & $\bar{B}$ & F & 0 & 1 & 0 & 2 & 0 & $\overline{0}$ \\
\hline Lac_Philippe & $\mathrm{C}$ & $\mathbf{F}$ & 0 & 1 & 1 & 3 & 0 & 0 \\
\hline Lac_Philippe & $\bar{D}$ & $F$ & 0 & 1 & 1 & 2 & 0 & $\overline{0}$ \\
\hline
\end{tabular}




\begin{tabular}{|c|c|c|c|c|c|c|c|c|}
\hline Manoir_des_Trembles & A & UN & 0 & 0 & 0 & 5 & 0 & 0 \\
\hline Manoir_des_Trembles & B & UN & 0 & 0 & 0 & 2 & 0 & $\overline{0}$ \\
\hline Manoir_des_Trembles & $\mathrm{C}$ & $\overline{\mathrm{UN}}$ & 0 & $\overline{0}$ & 0 & 2 & 0 & 0 \\
\hline Manoir_des_Trembles & $\bar{D}$ & UN & 0 & 0 & 0 & 3 & 0 & 0 \\
\hline Marathon & A & $\bar{E}$ & $\mathbf{0}$ & 0 & 1 & 2 & 0 & 0 \\
\hline Marathon & $\overline{\mathrm{B}}$ & $\mathrm{E}$ & 0 & 0 & 2 & 0 & 0 & 0 \\
\hline Marathon & $\mathrm{C}$ & $\mathrm{E}$ & $\mathbf{0}$ & 1 & 0 & 0 & 0 & 0 \\
\hline Marathon & $\bar{D}$ & $\bar{E}$ & 0 & 0 & 1 & 0 & 0 & 0 \\
\hline Marier & $\bar{A}$ & $\bar{U}$ & 0 & 0 & 0 & 0 & 0 & 0 \\
\hline Marier & B & $\bar{U}$ & 0 & 0 & 0 & 0 & 0 & 1 \\
\hline Marier & $\mathrm{C}$ & $\bar{U}$ & 0 & 0 & 0 & 0 & $\overline{0}$ & $\overline{2}$ \\
\hline Marier & $\overline{\mathrm{D}}$ & $\bar{U}$ & 0 & 0 & 0 & 0 & 0 & 0 \\
\hline Marlborough & $\bar{A}$ & $\mathrm{~F}$ & 0 & 1 & 0 & $\overline{0}$ & 0 & $\overline{0}$ \\
\hline Marlborough & $\bar{B}$ & $\bar{F}$ & 0 & 1 & 0 & 0 & 0 & $\overline{0}$ \\
\hline Marlborough & $\mathrm{C}$ & $\bar{F}$ & 0 & 0 & 1 & 0 & 0 & 0 \\
\hline Marlborough & $\mathrm{D}$ & $\bar{F}$ & 1 & 1 & 1 & 1 & 0 & 0 \\
\hline Merivale & $\bar{A}$ & $\mathrm{SN}$ & 0 & 1 & 0 & 2 & 0 & 0 \\
\hline Merivale & B & $\mathrm{SN}$ & 0 & 0 & 0 & 3 & 0 & 0 \\
\hline Merivale & $\mathrm{C}$ & SN & 0 & 0 & 0 & 2 & 0 & $\overline{0}$ \\
\hline Merivale & $\overline{\mathrm{D}}$ & $\overline{\mathrm{SN}}$ & 0 & 0 & 0 & 2 & 0 & $\overline{0}$ \\
\hline Parc_Champlain & $\bar{A}$ & $S$ & 0 & 0 & 0 & 0 & 0 & 0 \\
\hline Parc_Champlain & $\mathrm{B}$ & $S$ & 0 & 0 & 0 & 0 & 0 & 0 \\
\hline Parc_Champlain & $\mathrm{C}$ & $S$ & 0 & 0 & 0 & 1 & 0 & $\overline{0}$ \\
\hline Parc_Champlain & $\mathrm{D}$ & $\bar{S}$ & 0 & 0 & 0 & 1 & 0 & 0 \\
\hline Pelissier & A & $\mathrm{EN}$ & 0 & 0 & 0 & 2 & 0 & $\overline{0}$ \\
\hline Pelissier & B & EN & 0 & 0 & 0 & 2 & 0 & $\overline{0}$ \\
\hline Pelissier & $\bar{C}$ & $\overline{\mathrm{EN}}$ & 0 & 0 & 0 & 1 & 0 & 0 \\
\hline Pelissier & $\overline{\mathrm{D}}$ & $\overline{\mathrm{EN}}$ & $\overline{0}$ & 0 & 0 & 1 & 0 & $\overline{0}$ \\
\hline PineGlen_Annex & $\bar{A}$ & $S$ & 0 & 0 & 0 & 2 & 0 & 0 \\
\hline PineGlen_Annex & $\mathbf{B}$ & $\mathrm{S}$ & 0 & 0 & 0 & 0 & 0 & 15 \\
\hline PineGlen_Annex & $\mathrm{C}$ & $S$ & 0 & 0 & 0 & 1 & $\mathbf{0}$ & 1 \\
\hline PineGlen_Annex & $\overline{\mathrm{D}}$ & $S$ & 0 & 0 & 0 & 3 & 0 & 0 \\
\hline Q_Four & $\bar{A}$ & $\bar{E}$ & 0 & 0 & $\overline{0}$ & 2 & 0 & $\overline{0}$ \\
\hline Q_Four & B & $\bar{E}$ & $\overline{0}$ & 0 & 0 & 1 & 1 & 0 \\
\hline Q_Four & $\mathrm{C}$ & $E$ & 0 & 1 & 1 & 2 & 0 & 0 \\
\hline Q_Four & $\mathrm{D}$ & $\mathrm{E}$ & 0 & 0 & 1 & 2 & $\overline{0}$ & 0 \\
\hline Sandy_Hill & A & $\mathrm{U}$ & 0 & 0 & 0 & 0 & 0 & 5 \\
\hline Sandy_Hill & $\mathrm{B}$ & $\mathrm{U}$ & 0 & 0 & 0 & 0 & 0 & 3 \\
\hline Sandy_Hill & $\bar{C}$ & $\overline{\mathrm{U}}$ & 0 & 0 & 0 & $\overline{0}$ & 0 & $\overline{4}$ \\
\hline Sandy_Hill & $\bar{D}$ & $\mathrm{U}$ & 0 & 0 & 0 & 0 & 0 & 5 \\
\hline Vallee_Meech & $\bar{A}$ & $F$ & 0 & 1 & 0 & 3 & 0 & $\overline{0}$ \\
\hline Vallee_Meech & $\mathrm{B}$ & $F$ & 0 & 2 & 0 & 3 & 0 & 0 \\
\hline Vallee_Meech & $\mathrm{C}$ & $\mathrm{F}$ & 0 & 1 & 1 & 4 & 0 & 0 \\
\hline Vallee_Meech & $\bar{D}$ & $\bar{F}$ & 0 & 0 & 0 & 3 & 0 & $\overline{0}$ \\
\hline Wolf_Grove & $\overline{\mathrm{A}}$ & $\mathrm{E}$ & 0 & 0 & 1 & 3 & 0 & $\overline{0}$ \\
\hline
\end{tabular}




\begin{tabular}{|l|l|l|r|r|r|r|r|r|}
\hline Wolf_Grove & B & E & 0 & 1 & 0 & 3 & 0 & 0 \\
\hline Wolf_Grove & C & E & 0 & 1 & 0 & 4 & 0 & 0 \\
\hline Wolf_Grove & D & E & 0 & 1 & 1 & 3 & 0 & 0 \\
\hline Wrightville & A & U & 0 & 0 & 0 & 0 & 0 & 0 \\
\hline Wrightville & B & U & 0 & 0 & 0 & 0 & 0 & 7 \\
\hline Wrightville & C & U & 0 & 0 & 0 & 0 & 0 & 2 \\
\hline Wrightville & D & U & 0 & 0 & 0 & 0 & 0 & 4 \\
\hline Wychwood & A & S & 0 & 0 & 0 & 0 & 0 & 0 \\
\hline Wychwood & B & S & 0 & 0 & 0 & 0 & 0 & 0 \\
\hline Wychwood & C & S & 0 & 0 & 0 & 1 & 0 & 0 \\
\hline Wychwood & D & S & 0 & 0 & 0 & 0 & 0 & 0 \\
\hline
\end{tabular}




\begin{tabular}{|c|c|c|c|c|c|c|c|c|}
\hline SITE & STATION & CATEGORY & RTHU & RUGR & RWBL & SCTA & SORA & SOSP \\
\hline Achbar & $\mathrm{A}$ & SN & 0 & 0 & 0 & 0 & 0 & 0 \\
\hline Achbar & $\overline{\mathrm{B}}$ & $\overline{\mathrm{SN}}$ & 0 & 0 & 0 & 0 & 0 & 0 \\
\hline Achbar & $\overline{\mathrm{C}}$ & $\mathrm{SN}$ & 0 & $\overline{0}$ & 0 & 0 & 0 & $\overline{0}$ \\
\hline Achbar & $\bar{D}$ & SN & 0 & 0 & 0 & 0 & 0 & 0 \\
\hline Bridlewood & A & $\mathrm{UN}$ & 0 & 0 & 0 & 0 & 0 & 0 \\
\hline Bridlewood & $\mathrm{B}$ & UN & 2 & 0 & 0 & 0 & 0 & 0 \\
\hline Bridlewood & $\overline{\mathrm{C}}$ & UN & 0 & 0 & 0 & 1 & 0 & 0 \\
\hline Bridlewood & $\mathrm{D}$ & UN & 0 & 0 & 1 & 0 & 0 & 1 \\
\hline Carp_Hills & $\overline{\mathrm{A}}$ & $\mathrm{F}$ & 1 & 0 & 0 & 1 & 0 & 0 \\
\hline Carp_Hills & $\bar{B}$ & $\bar{F}$ & 0 & 0 & 0 & 1 & 0 & 0 \\
\hline Carp_Hills & $\mathrm{C}$ & $\mathrm{F}$ & 0 & 0 & 0 & 1 & 0 & 0 \\
\hline Carp_Hills & $\mathrm{D}$ & $\bar{F}$ & 0 & 0 & 0 & 1 & 1 & 0 \\
\hline Chapel_Hill & $\mathrm{A}$ & UN & 0 & 0 & 0 & 0 & 0 & 0 \\
\hline Chapel_Hill & $\mathrm{B}$ & UN & 0 & 0 & 0 & 0 & 0 & $\overline{0}$ \\
\hline Chapel_Hill & $\overline{\mathrm{C}}$ & UN & 0 & 0 & 0 & 0 & 0 & $\overline{0}$ \\
\hline Chapel_Hill & $\overline{\mathrm{D}}$ & UN & 0 & 0 & 0 & 0 & 0 & 0 \\
\hline Chelsea & $\overline{\mathrm{A}}$ & $\mathrm{SN}$ & 0 & 0 & 0 & 0 & 0 & 0 \\
\hline Chelsea & $\mathrm{B}$ & $\overline{\mathrm{SN}}$ & 0 & 0 & 0 & 0 & 0 & 0 \\
\hline Chelsea & $\mathrm{C}$ & SN & 0 & 0 & 0 & 0 & 0 & 0 \\
\hline Chelsea & $\mathrm{D}$ & SN & 0 & 0 & 0 & 0 & 0 & $\overline{0}$ \\
\hline Chemin_Scholle & $\bar{A}$ & $\overline{\mathrm{EN}}$ & 0 & 0 & 0 & 0 & 0 & $\overline{0}$ \\
\hline Chemin_Scholle & $\overline{\mathrm{B}}$ & $\overline{\mathrm{EN}}$ & 0 & 0 & 0 & 0 & 0 & $\overline{0}$ \\
\hline Chemin_Scholle & $\mathrm{C}$ & EN & 0 & 0 & 0 & 0 & 0 & 0 \\
\hline Chemin_Scholle & $\bar{D}$ & $\overline{\mathrm{EN}}$ & 0 & 0 & 0 & 0 & 0 & 0 \\
\hline Cote_d'Azur & $\bar{A}$ & $\mathrm{~S}$ & 0 & 0 & 0 & 0 & 0 & 4 \\
\hline Cote_d'Azur & $\mathrm{B}$ & $S$ & 0 & 0 & 0 & 0 & 0 & 2 \\
\hline Cote_d'Azur & $\mathrm{C}$ & $S$ & 0 & 0 & 0 & 0 & 0 & 2 \\
\hline Cote_d'Azur & $\bar{D}$ & $\mathrm{~S}$ & 0 & 0 & 0 & 0 & 0 & 1 \\
\hline Highway_Seven & A & $\bar{E}$ & 0 & 0 & 0 & 0 & 0 & 1 \\
\hline Highway_Seven & B & $\mathrm{E}$ & 0 & 0 & 0 & 0 & 0 & 1 \\
\hline Highway_Seven & $\mathrm{C}$ & $\mathrm{E}$ & 0 & 0 & 0 & 0 & 0 & 0 \\
\hline Highway_Seven & $\overline{\mathrm{D}}$ & $\bar{E}$ & 0 & 0 & 0 & 0 & 0 & 0 \\
\hline Hull & A & $\mathrm{U}$ & 0 & 0 & 0 & 0 & 0 & $\overline{0}$ \\
\hline Hull & $\mathrm{B}$ & $\mathrm{U}$ & 0 & 0 & 0 & 0 & 0 & 0 \\
\hline Hull & $\mathrm{C}$ & $\bar{U}$ & 0 & 0 & 0 & 0 & 0 & 0 \\
\hline Hull & $\mathrm{D}$ & $\mathrm{U}$ & 0 & 0 & 0 & 0 & 0 & 0 \\
\hline Lac_a_la_Perdrix & A & EN & 0 & 0 & 0 & 1 & 0 & 0 \\
\hline Lac_a_la_Perdrix & $\mathrm{B}$ & $\overline{\mathrm{EN}}$ & 0 & 0 & 0 & 1 & 0 & 0 \\
\hline Lac_a_la_Perdrix & $\mathrm{C}$ & EN & 0 & 0 & 0 & 1 & 0 & 0 \\
\hline Lac_a_la_Perdrix & $\bar{D}$ & $\overline{\mathrm{EN}}$ & 0 & 0 & 0 & 0 & 0 & 0 \\
\hline Lac_Philippe & $\bar{A}$ & $\mathrm{~F}$ & 0 & 0 & 0 & 0 & 0 & 0 \\
\hline Lac_Philippe & $\mathrm{B}$ & $\mathrm{F}$ & 0 & 0 & 0 & 0 & 0 & 0 \\
\hline Lac_Philippe & $\mathrm{C}$ & $F$ & 2 & 0 & 0 & 0 & 0 & 0 \\
\hline Lac_Philippe & $\bar{D}$ & $\bar{F}$ & 0 & 0 & 0 & 0 & 0 & 0 \\
\hline
\end{tabular}




\begin{tabular}{|c|c|c|c|c|c|c|c|c|}
\hline Manoir_des_Trembles & $\bar{A}$ & $\overline{\mathrm{UN}}$ & 0 & 0 & 0 & 0 & 0 & 0 \\
\hline Manoir des Trembles & $\mathrm{B}$ & UN & 0 & 0 & 0 & 0 & 0 & 0 \\
\hline Manoir_des_Trembles & $\mathrm{C}$ & UN & 0 & 0 & $\overline{0}$ & 0 & 0 & 0 \\
\hline Manoir_des_Trembles & $\overline{\mathrm{D}}$ & UN & 0 & 0 & 0 & 0 & 0 & 0 \\
\hline Marathon & $\bar{A}$ & $E$ & 0 & 0 & 0 & 0 & $\overline{0}$ & $\overline{0}$ \\
\hline Marathon & $\mathrm{B}$ & $\bar{E}$ & 0 & 0 & 0 & 1 & 0 & 0 \\
\hline Marathon & $\mathrm{C}$ & $E$ & 0 & 0 & 2 & 0 & 0 & 0 \\
\hline Marathon & $\mathrm{D}$ & $E$ & 0 & 0 & 0 & 0 & 0 & 1 \\
\hline Marier & A & $\mathrm{U}$ & 0 & 0 & 0 & 0 & 0 & 1 \\
\hline Marier & $\overline{\mathrm{B}}$ & $\bar{U}$ & 0 & 0 & 0 & 0 & 0 & 0 \\
\hline Marier & $\bar{C}$ & $\bar{U}$ & 0 & 0 & 0 & 0 & 0 & 3 \\
\hline Marier & $\mathrm{D}$ & $\mathrm{U}$ & 0 & 0 & 0 & 0 & 0 & 2 \\
\hline Marlborough & $\mathrm{A}$ & $\mathrm{F}$ & 0 & 0 & 0 & 0 & 0 & 0 \\
\hline Marlborough & B & $\mathbf{F}$ & 0 & 1 & 0 & 0 & 0 & 0 \\
\hline Marlborough & $\mathrm{C}$ & $\mathrm{F}$ & 0 & 0 & 0 & 0 & 0 & 0 \\
\hline Marlborough & $\overline{\mathrm{D}}$ & $\mathrm{F}$ & 0 & 1 & 2 & 0 & 0 & 0 \\
\hline Merivale & A & $\overline{\mathrm{SN}}$ & 0 & 0 & 0 & 0 & 0 & 0 \\
\hline Merivale & B & SN & 0 & 0 & 0 & 0 & 0 & 0 \\
\hline Merivale & $\mathrm{C}$ & SN & 0 & 0 & 0 & 0 & 0 & 0 \\
\hline Merivale & $\mathrm{D}$ & $\mathrm{SN}$ & 0 & 0 & 0 & 0 & 0 & 0 \\
\hline Parc_Champlain & A & $\mathbf{S}$ & 0 & 0 & 0 & 0 & 0 & 1 \\
\hline Parc_Champlain & B & $\mathrm{S}$ & 0 & 0 & 0 & 0 & $\mathbf{0}$ & 2 \\
\hline Parc_Champlain & $\bar{C}$ & $\mathrm{~S}$ & 0 & 0 & 0 & 0 & 0 & 3 \\
\hline Parc_Champlain & $\mathrm{D}$ & $\mathbf{S}$ & 0 & 0 & 0 & 0 & 0 & 2 \\
\hline Pelissier & $\mathrm{A}$ & EN & 0 & 0 & 0 & 0 & 0 & 0 \\
\hline Pelissier & B & $\overline{E N}$ & 0 & 0 & 0 & 0 & 0 & 0 \\
\hline Pelissier & $\mathrm{C}$ & EN & 0 & 0 & 0 & 0 & 0 & 0 \\
\hline Pelissier & $\mathrm{D}$ & EN & 0 & 0 & 0 & 1 & 0 & $\overline{0}$ \\
\hline PineGlen_Annex & $\bar{A}$ & $\mathrm{~S}$ & 0 & 0 & 0 & 0 & 0 & 0 \\
\hline PineGlen_Annex & B & $\mathrm{S}$ & 0 & 0 & 4 & 0 & 0 & 1 \\
\hline PineGlen_Annex & $\mathrm{C}$ & $\mathrm{S}$ & 0 & 0 & 0 & 0 & 0 & 1 \\
\hline PineGlen_Annex & $\mathrm{D}$ & $\mathrm{S}$ & 0 & 0 & 0 & 0 & 0 & 2 \\
\hline Q_Four & A & $\mathrm{E}$ & 0 & 0 & 0 & 0 & 0 & 0 \\
\hline Q_Four & B & $E$ & 0 & 0 & 0 & 0 & 0 & 0 \\
\hline Q_Four & $\mathrm{C}$ & $\bar{E}$ & 0 & 0 & 0 & 1 & 0 & $\overline{0}$ \\
\hline Q_Four & $\mathrm{D}$ & $E$ & 0 & 0 & 0 & 0 & 0 & 0 \\
\hline Sandy_Hill & $\mathrm{A}$ & $\mathrm{U}$ & 0 & 0 & 0 & 0 & 0 & 0 \\
\hline Sandy_Hill & B & $\mathrm{U}$ & 0 & 0 & 0 & 0 & 0 & 1 \\
\hline Sandy_Hill & $\mathrm{C}$ & $\mathrm{U}$ & 0 & 0 & 0 & 0 & 0 & 0 \\
\hline Sandy_Hill & $\mathrm{D}$ & $\mathrm{U}$ & 0 & 0 & 0 & 0 & 0 & $\overline{0}$ \\
\hline Vallee_Meech & $\mathrm{A}$ & $F$ & 0 & 0 & 0 & 0 & 0 & 0 \\
\hline Vallee_Meech & B & $\bar{F}$ & 0 & 0 & 0 & 1 & 0 & 0 \\
\hline Vallee_Meech & $\bar{C}$ & $F$ & 0 & 0 & 0 & 1 & 0 & $\overline{0}$ \\
\hline Vallee_Meech & D & $F$ & 0 & 0 & 0 & 0 & 0 & 0 \\
\hline Wolf_Grove & $\overline{\mathrm{A}}$ & $\mathrm{E}$ & 0 & 0 & 0 & 0 & 0 & $\overline{0}$ \\
\hline
\end{tabular}




\begin{tabular}{|l|l|l|r|r|r|r|r|r|}
\hline Wolf_Grove & B & E & 0 & 0 & 0 & 0 & 0 & 0 \\
\hline Wolf_Grove & C & E & 0 & 0 & 0 & 0 & 0 & 0 \\
\hline Wolf_Grove & D & E & 0 & 0 & 0 & 0 & 0 & 0 \\
\hline Wrightville & A & U & 0 & 0 & 0 & 0 & 0 & 0 \\
\hline Wrightville & B & U & 0 & 0 & 0 & 0 & 0 & 0 \\
\hline Wrightville & C & U & 0 & 0 & 0 & 0 & 0 & 0 \\
\hline Wrightville & D & U & 0 & 0 & 0 & 0 & 0 & 0 \\
\hline Wychwood & A & S & 0 & 0 & 0 & 0 & 0 & 3 \\
\hline Wychwood & B & S & 0 & 0 & 0 & 0 & 0 & 2 \\
\hline Wychwood & C & S & 0 & 0 & 0 & 0 & 0 & 1 \\
\hline Wychwood & $\mathrm{D}$ & $\mathrm{S}$ & 0 & 0 & 0 & 0 & 0 & 2 \\
\hline
\end{tabular}




\begin{tabular}{|c|c|c|c|c|c|c|c|c|}
\hline SITE & STATION & CATEGORY & SWSP & SWTH & VEER & WAVI & WBNU & WIFL \\
\hline Achbar & $\mathrm{A}$ & SN & 0 & 0 & 0 & 0 & 0 & 0 \\
\hline Achbar & $\overline{\mathrm{B}}$ & SN & 0 & 0 & 0 & 0 & 0 & $\overline{0}$ \\
\hline Achbar & $\bar{C}$ & $\overline{\mathrm{SN}}$ & 0 & 0 & 0 & 0 & 0 & $\overline{0}$ \\
\hline Achbar & $\bar{D}$ & $\overline{\mathrm{SN}}$ & 0 & 0 & 1 & 0 & 0 & 0 \\
\hline Bridlewood & $\bar{A}$ & $\overline{\mathrm{UN}}$ & 0 & 0 & 0 & 0 & 0 & 0 \\
\hline Bridlewood & $\bar{B}$ & UN & 0 & 0 & 1 & 0 & 1 & 0 \\
\hline Bridlewood & $\mathrm{C}$ & UN & 0 & 0 & 0 & 0 & 0 & 0 \\
\hline Bridlewood & $\mathrm{D}$ & $\overline{\mathrm{UN}}$ & 0 & 0 & 0 & 0 & 0 & 0 \\
\hline Carp_Hills & $\bar{A}$ & $\mathbf{F}$ & 0 & 0 & 1 & 0 & 0 & $\overline{0}$ \\
\hline Carp_Hills & $\bar{B}$ & $\bar{F}$ & 0 & 0 & 1 & 0 & 0 & $\overline{0}$ \\
\hline Carp_Hills & $\mathrm{C}$ & $\mathbf{F}$ & 0 & 0 & 1 & 0 & 0 & 0 \\
\hline Carp_Hills & $\overline{\mathrm{D}}$ & $\mathbf{F}$ & 0 & 0 & 1 & 0 & 0 & 0 \\
\hline Chapel_Hill & $\bar{A}$ & UN & 0 & 0 & 1 & 0 & 1 & 0 \\
\hline Chapel_Hill & B & UN & 0 & 0 & 0 & 0 & 0 & 0 \\
\hline Chapel_Hill & $\mathrm{C}$ & $\mathrm{UN}$ & 0 & $\overline{0}$ & 0 & 0 & 0 & $\overline{0}$ \\
\hline Chapel_Hill & $\bar{D}$ & $\overline{\mathrm{UN}}$ & 0 & 0 & 2 & 0 & 0 & $\overline{0}$ \\
\hline Chelsea & $\overline{\mathrm{A}}$ & $\overline{\mathrm{SN}}$ & 0 & 0 & 3 & 0 & 0 & 0 \\
\hline Chelsea & $\bar{B}$ & $\overline{\mathrm{SN}}$ & 0 & 0 & 1 & 0 & 0 & 0 \\
\hline Chelsea & $\mathrm{C}$ & SN & 0 & 0 & 1 & 0 & 0 & 0 \\
\hline Chelsea & $\mathrm{D}$ & SN & 0 & $\overline{0}$ & 2 & 0 & 0 & 0 \\
\hline Chemin_Scholle & $\bar{A}$ & $\overline{\mathrm{EN}}$ & 0 & 0 & 1 & 0 & 0 & 0 \\
\hline Chemin_Scholle & $\bar{B}$ & $\overline{\mathrm{EN}}$ & 0 & 0 & 0 & 0 & 0 & $\overline{0}$ \\
\hline Chemin_Scholle & $\mathrm{C}$ & $\overline{\mathrm{EN}}$ & 0 & 0 & 1 & 0 & 0 & 0 \\
\hline Chemin_Scholle & $\overline{\mathrm{D}}$ & $\overline{\text { EN }}$ & 0 & 0 & 0 & 0 & 0 & 0 \\
\hline Cote_d'Azur & $\bar{A}$ & $S$ & 0 & 0 & 0 & 0 & 0 & $\overline{0}$ \\
\hline Cote_d'Azur & B & $S$ & 0 & 0 & 0 & 0 & 0 & 0 \\
\hline Cote_d'Azur & $\mathrm{C}$ & $S$ & 0 & 0 & 0 & 0 & 0 & $\overline{0}$ \\
\hline Cote_d'Azur & $\bar{D}$ & $\mathrm{~S}$ & 0 & 0 & 0 & 0 & 0 & $\overline{0}$ \\
\hline Highway_Seven & A & $E$ & 0 & 0 & 1 & 0 & 1 & $\overline{0}$ \\
\hline Highway_Seven & $\mathrm{B}$ & $E$ & 0 & 0 & 0 & 0 & 2 & 0 \\
\hline Highway_Seven & $\mathrm{C}$ & $\mathrm{E}$ & 0 & 0 & 0 & 0 & 0 & 0 \\
\hline Highway_Seven & $\bar{D}$ & $\mathrm{E}$ & 0 & 0 & 0 & 0 & 0 & 0 \\
\hline Hull & $\mathrm{A}$ & $\mathrm{U}$ & 0 & 0 & 0 & 0 & 0 & 0 \\
\hline Hull & $\mathrm{B}$ & $\mathbf{U}$ & 0 & 0 & 0 & 0 & 0 & 0 \\
\hline Hull & $\mathrm{C}$ & $\mathrm{U}$ & 0 & 0 & 0 & 0 & 0 & 0 \\
\hline Hull & $\overline{\mathrm{D}}$ & $\mathrm{U}$ & 0 & 0 & 0 & 0 & 0 & 0 \\
\hline Lac_a_la_Perdrix & $\mathrm{A}$ & $\overline{\mathrm{EN}}$ & 0 & 0 & 1 & 0 & 0 & 0 \\
\hline Lac_a_la_Perdrix & B & EN & 0 & 0 & 1 & 0 & 0 & 0 \\
\hline Lac_a_la_Perdrix & $\mathrm{C}$ & EN & 0 & 0 & 0 & 0 & 0 & 0 \\
\hline Lac_a_la_Perdrix & $\mathrm{D}$ & EN & 0 & 0 & 0 & 0 & 0 & 0 \\
\hline Lac_Philippe & $\bar{A}$ & $\bar{F}$ & 0 & 1 & 1 & 0 & 0 & $\overline{0}$ \\
\hline Lac_Philippe & B & $F$ & 0 & 0 & 0 & 0 & 0 & 0 \\
\hline Lac_Philippe & $\mathrm{C}$ & $F$ & 0 & 0 & 1 & 0 & 0 & 0 \\
\hline Lac_Philippe & $\mathrm{D}$ & $\mathbf{F}$ & 0 & 0 & 1 & 0 & 0 & 0 \\
\hline
\end{tabular}




\begin{tabular}{|c|c|c|c|c|c|c|c|c|}
\hline Manoir_des_Trembles & $\mathrm{A}$ & $\mathrm{UN}$ & 0 & 0 & 0 & 0 & 1 & 0 \\
\hline Manoir_des_Trembles & $\bar{B}$ & UN & 0 & 0 & 1 & 0 & 1 & 0 \\
\hline Manoir_des_Trembles & $\mathrm{C}$ & $\overline{\mathrm{UN}}$ & 0 & 0 & 1 & 0 & 1 & $\overline{0}$ \\
\hline Manoir_des_Trembles & $\mathrm{D}$ & UN & 0 & 0 & 0 & 0 & 1 & $\overline{0}$ \\
\hline Marathon & $\overline{\mathrm{A}}$ & $\bar{E}$ & 0 & 0 & 1 & 0 & 0 & $\overline{0}$ \\
\hline Marathon & $\bar{B}$ & $E$ & 0 & 0 & 1 & 0 & 0 & $\overline{0}$ \\
\hline Marathon & $\mathrm{C}$ & $E$ & 5 & 0 & 3 & 0 & 0 & 0 \\
\hline Marathon & $\bar{D}$ & $\bar{E}$ & 0 & 0 & 1 & 0 & 0 & $\overline{0}$ \\
\hline Marier & $\bar{A}$ & $\mathrm{U}$ & 0 & 0 & 0 & 0 & 0 & 0 \\
\hline Marier & $\bar{B}$ & $\bar{U}$ & 0 & 0 & 0 & 0 & 0 & 0 \\
\hline Marier & $\mathrm{C}$ & $\bar{U}$ & 0 & 0 & 0 & 0 & 0 & $\overline{0}$ \\
\hline Marier & $\mathrm{D}$ & $\mathrm{U}$ & 0 & 0 & 0 & 0 & 0 & 0 \\
\hline Marlborough & $\mathrm{A}$ & $\mathrm{F}$ & 0 & 0 & 0 & 0 & 0 & 0 \\
\hline Marlborough & B & $\mathrm{F}$ & 0 & 0 & 0 & 0 & 0 & 0 \\
\hline Marlborough & $\mathrm{C}$ & $\mathrm{F}$ & 0 & 0 & 0 & 0 & 0 & 0 \\
\hline Marlborough & $\mathrm{D}$ & $\mathrm{F}$ & 1 & 0 & 0 & 0 & 0 & $\overline{0}$ \\
\hline Merivale & $\bar{A}$ & $\overline{\mathrm{SN}}$ & 0 & 0 & 1 & 0 & $\overline{0}$ & 1 \\
\hline Merivale & B & SN & 0 & 0 & 0 & 0 & 0 & $\overline{0}$ \\
\hline Merivale & $\mathrm{C}$ & $\overline{\mathrm{SN}}$ & 0 & 0 & 1 & 0 & 2 & $\overline{0}$ \\
\hline Merivale & $\mathrm{D}$ & $\mathrm{SN}$ & 0 & 0 & 0 & 0 & $\overline{0}$ & 0 \\
\hline Parc_Champlain & A & $\mathrm{S}$ & 0 & 0 & 0 & 0 & 0 & 0 \\
\hline Parc_Champlain & B & $\mathrm{S}$ & 0 & 0 & 0 & 0 & 0 & $\overline{0}$ \\
\hline Parc_Champlain & $\mathrm{C}$ & $\mathrm{S}$ & 0 & 0 & 0 & 0 & 0 & $\overline{0}$ \\
\hline Parc_Champlain & $\bar{D}$ & $\bar{S}$ & 0 & 0 & 0 & 0 & 0 & $\overline{0}$ \\
\hline Pelissier & $\mathrm{A}$ & EN & 0 & 0 & 0 & 0 & 0 & 0 \\
\hline Pelissier & B & $\overline{\mathrm{EN}}$ & 0 & 0 & 0 & 0 & 0 & 0 \\
\hline Pelissier & $\mathrm{C}$ & EN & 0 & 0 & 1 & 0 & 0 & 0 \\
\hline Pelissier & $\mathrm{D}$ & EN & 0 & 0 & 0 & 0 & 0 & 0 \\
\hline PineGlen_Annex & $\bar{A}$ & $\bar{S}$ & 0 & 0 & $\overline{0}$ & 2 & 1 & $\overline{0}$ \\
\hline PineGlen_Annex & B & $\mathrm{S}$ & 0 & 0 & 0 & 0 & 0 & 0 \\
\hline PineGlen_Annex & $\mathrm{C}$ & $\mathrm{S}$ & 0 & 0 & 0 & 0 & 1 & $\overline{0}$ \\
\hline PineGlen_Annex & $\bar{D}$ & $\mathrm{~S}$ & 0 & 0 & 0 & 0 & 1 & 0 \\
\hline Q_Four & A & $\mathrm{E}$ & 0 & 0 & 2 & 0 & 0 & 0 \\
\hline Q_Four & B & $\mathrm{E}$ & 0 & 0 & 1 & 0 & 0 & $\overline{0}$ \\
\hline Q_Four & $\mathrm{C}$ & $\mathrm{E}$ & 0 & 0 & 0 & 0 & 0 & 0 \\
\hline Q_Four & $\bar{D}$ & $\bar{E}$ & 0 & 0 & 0 & 0 & 0 & $\overline{0}$ \\
\hline Sandy_Hill & $\bar{A}$ & $\overline{\mathrm{U}}$ & 0 & 0 & 0 & 0 & 1 & $\overline{0}$ \\
\hline Sandy_Hill & $\mathrm{B}$ & $\overline{\mathrm{U}}$ & 0 & 0 & 0 & $\overline{0}$ & 0 & 0 \\
\hline Sandy_Hill & $\mathrm{C}$ & $\mathrm{U}$ & 0 & 0 & 0 & 0 & 0 & 0 \\
\hline Sandy_Hill & $\mathrm{D}$ & $\bar{U}$ & 0 & 0 & 0 & 0 & 0 & 0 \\
\hline Vallee_Meech & A & $\mathrm{F}$ & 0 & 0 & 1 & 0 & 0 & $\overline{0}$ \\
\hline Vallee_Meech & $\bar{B}$ & $F$ & 0 & 0 & 2 & 0 & 0 & $\overline{0}$ \\
\hline Vallee_Meech & $\mathrm{C}$ & $\bar{F}$ & 0 & 0 & 2 & 0 & 0 & $\overline{0}$ \\
\hline Vallee_Meech & $\bar{D}$ & $\mathrm{~F}$ & 0 & 0 & 1 & 0 & 0 & 0 \\
\hline Wolf_Grove & $\bar{A}$ & $\mathrm{E}$ & 0 & 0 & 0 & 0 & 0 & 0 \\
\hline
\end{tabular}




\begin{tabular}{|l|l|l|r|r|r|r|r|r|}
\hline Wolf_Grove & B & E & 1 & 0 & 0 & 0 & 0 & 0 \\
\hline Wolf_Grove & C & E & 0 & 0 & 0 & 0 & 0 & 0 \\
\hline Wolf_Grove & $\mathrm{D}$ & $\mathrm{E}$ & 0 & 0 & 0 & 0 & 0 & 0 \\
\hline Wrightville & $\mathrm{A}$ & $\mathrm{U}$ & 0 & 0 & 0 & 0 & 0 & 0 \\
\hline Wrightville & $\mathrm{B}$ & $\mathrm{U}$ & 0 & 0 & 0 & 0 & 0 & 0 \\
\hline Wrightville & $\mathrm{C}$ & $\mathrm{U}$ & 0 & 0 & 0 & 0 & 0 & 0 \\
\hline Wrightville & $\mathrm{D}$ & $\mathrm{U}$ & 0 & 0 & 0 & 0 & 0 & 0 \\
\hline Wychwood & $\mathrm{A}$ & $\mathrm{S}$ & 0 & 0 & 0 & 0 & 0 & 0 \\
\hline Wychwood & $\mathrm{B}$ & $\mathrm{S}$ & 0 & 0 & 0 & 0 & 1 & 0 \\
\hline Wychwood & $\mathrm{C}$ & $\mathrm{S}$ & 0 & 0 & 0 & 0 & 0 & 0 \\
\hline Wychwood & $\mathrm{D}$ & $\mathrm{S}$ & 0 & 0 & 0 & 0 & 0 & 0 \\
\hline
\end{tabular}




\begin{tabular}{|c|c|c|c|c|c|c|c|c|}
\hline $\begin{array}{l}\text { SITE } \\
\end{array}$ & STATION & CATEGORY & WIWA & WIWR & WODU & WOTH & WTSP & $\overline{Y B C U}$ \\
\hline Achbar & $\mathrm{A}$ & SN & 0 & 0 & 0 & 1 & 0 & 0 \\
\hline Achbar & $\overline{\mathrm{B}}$ & $\overline{\mathrm{SN}}$ & 0 & 0 & 0 & 0 & 0 & 0 \\
\hline Achbar & $\mathrm{C}$ & SN & 0 & 0 & 0 & 0 & 0 & 0 \\
\hline Achbar & $\bar{D}$ & $\overline{\mathrm{SN}}$ & 0 & 0 & 0 & 0 & 0 & 0 \\
\hline Bridlewood & $\mathrm{A}$ & UN & 0 & 0 & 0 & 0 & 0 & 0 \\
\hline Bridlewood & $\bar{B}$ & UN & 0 & 0 & 0 & 0 & 0 & 0 \\
\hline Bridlewood & $\mathrm{C}$ & UN & 0 & 0 & 0 & 0 & 0 & 0 \\
\hline Bridlewood & $\bar{D}$ & UN & 0 & 0 & 0 & 0 & 0 & 0 \\
\hline Carp_Hills & $\bar{A}$ & $F$ & 0 & 0 & 0 & 0 & 1 & 0 \\
\hline Carp_Hills & $\mathrm{B}$ & $F$ & 0 & 0 & 0 & 0 & 1 & 0 \\
\hline Carp_Hills & $\mathrm{C}$ & $F$ & 0 & 0 & 0 & 0 & $\overline{0}$ & 0 \\
\hline Carp_Hills & $\bar{D}$ & $F$ & 0 & 0 & 0 & 0 & 1 & 1 \\
\hline Chapel_Hill & $\bar{A}$ & $\overline{\mathrm{UN}}$ & 0 & 0 & 0 & 0 & 1 & 0 \\
\hline Chapel_Hill & $\bar{B}$ & UN & 0 & 0 & 0 & 0 & 0 & 0 \\
\hline Chapel_Hill & $\mathrm{C}$ & UN & 0 & 0 & 0 & 0 & 0 & $\overline{0}$ \\
\hline Chapel_Hill & $\bar{D}$ & UN & 0 & 0 & 0 & 0 & 0 & 0 \\
\hline Chelsea & $\bar{A}$ & SN & 0 & 1 & 0 & 0 & 0 & 0 \\
\hline Chelsea & $\mathrm{B}$ & SN & 0 & 1 & 0 & 1 & 0 & 0 \\
\hline Chelsea & $\mathrm{C}$ & SN & 0 & 1 & 0 & 0 & 0 & 0 \\
\hline Chelsea & $\bar{D}$ & SN & 0 & 1 & 0 & 0 & 0 & 0 \\
\hline Chemin_Scholle & $\bar{A}$ & EN & 0 & 0 & 0 & 0 & 1 & 0 \\
\hline Chemin_Scholle & $\mathrm{B}$ & $\overline{\mathrm{EN}}$ & 0 & 0 & 0 & 0 & 0 & 0 \\
\hline Chemin_Scholle & $\mathrm{C}$ & $\overline{\mathrm{EN}}$ & 0 & 1 & 0 & 0 & 0 & 0 \\
\hline Chemin_Scholle & $\bar{D}$ & EN & 0 & 1 & 0 & 0 & 0 & 0 \\
\hline Cote_d'Azur & A & $\mathrm{S}$ & 0 & 0 & 0 & 0 & 0 & 0 \\
\hline Cote_d'Azur & $\mathrm{B}$ & $\mathrm{S}$ & 0 & 0 & 0 & 0 & 0 & 0 \\
\hline Cote_d'Azur & $\mathrm{C}$ & $\mathrm{S}$ & 0 & 0 & 0 & 0 & 1 & 0 \\
\hline Cote_d'Azur & $\bar{D}$ & $S$ & 0 & 0 & 0 & 0 & 0 & 0 \\
\hline Highway_Seven & $\bar{A}$ & $\mathrm{E}$ & 0 & 0 & 0 & 0 & 3 & 0 \\
\hline Highway_Seven & $\mathrm{B}$ & $\mathrm{E}$ & 0 & 0 & 0 & 0 & 2 & 0 \\
\hline Highway_Seven & $\mathrm{C}$ & $\mathrm{E}$ & 0 & 0 & 0 & 0 & 1 & 0 \\
\hline Highway_Seven & $\bar{D}$ & $\mathrm{E}$ & 0 & 0 & 0 & 0 & 1 & 0 \\
\hline Hull & A & $\mathrm{U}$ & 0 & 0 & 0 & 0 & 0 & 0 \\
\hline Hull & $\mathrm{B}$ & $\overline{\mathrm{U}}$ & 0 & 0 & 0 & 0 & 0 & 0 \\
\hline Hull & $\mathrm{C}$ & $\mathrm{U}$ & 0 & 0 & 0 & 0 & 0 & 0 \\
\hline Hull & $\mathrm{D}$ & $\mathrm{U}$ & 0 & 0 & 0 & 0 & 0 & 0 \\
\hline Lac_a_la_Perdrix & A & EN & 0 & 0 & 0 & 1 & 0 & 0 \\
\hline Lac_a_la_Perdrix & $\mathrm{B}$ & EN & 2 & 0 & 0 & 0 & 0 & 0 \\
\hline Lac_a_la_Perdrix & $\mathrm{C}$ & EN & 0 & 0 & 0 & 0 & 0 & 0 \\
\hline Lac_a_la_Perdrix & $\bar{D}$ & EN & 0 & 0 & 0 & 0 & 0 & 0 \\
\hline Lac_Philippe & A & $\mathrm{F}$ & 0 & 2 & 0 & 0 & 0 & 0 \\
\hline Lac_Philippe & $\mathrm{B}$ & $\mathrm{F}$ & 0 & 1 & 0 & 0 & 0 & 0 \\
\hline Lac_Philippe & $\mathrm{C}$ & $\bar{F}$ & 0 & 1 & 0 & 0 & 0 & 0 \\
\hline Lac_Philippe & $\mathrm{D}$ & $\bar{F}$ & 0 & 0 & 0 & 0 & 0 & 0 \\
\hline
\end{tabular}




\begin{tabular}{|c|c|c|c|c|c|c|c|c|}
\hline Manoir_des_Trembles & A & UN & 0 & 1 & 0 & 2 & 0 & $\overline{0}$ \\
\hline Manoir_des_Trembles & $\mathrm{B}$ & UN & 0 & 0 & 0 & 1 & 0 & 0 \\
\hline Manoir_des_Trembles & $\mathrm{C}$ & UN & 0 & 0 & 0 & 1 & 0 & 0 \\
\hline Manoir_des_Trembles & $\overline{\mathrm{D}}$ & UN & 0 & 0 & 0 & 1 & 0 & 0 \\
\hline Marathon & $\overline{\mathrm{A}}$ & $\bar{E}$ & 0 & 1 & 0 & 1 & 2 & 0 \\
\hline Marathon & B & $\mathrm{E}$ & 0 & 2 & 0 & 1 & 1 & $\overline{0}$ \\
\hline Marathon & $\mathrm{C}$ & $\mathrm{E}$ & 0 & 2 & 0 & 0 & 1 & $\overline{0}$ \\
\hline Marathon & $\mathrm{D}$ & $\bar{E}$ & 0 & 1 & 0 & 1 & 0 & 0 \\
\hline Marier & $\mathrm{A}$ & $\mathrm{U}$ & 0 & 0 & 0 & 0 & 0 & 0 \\
\hline Marier & $\bar{B}$ & $\overline{\mathrm{U}}$ & 0 & 0 & 0 & 0 & 0 & 0 \\
\hline Marier & $\mathrm{C}$ & $\overline{\mathrm{U}}$ & 0 & 0 & 0 & 0 & 0 & $\overline{0}$ \\
\hline Marier & $\mathrm{D}$ & $\bar{U}$ & 0 & 0 & 0 & 0 & 0 & $\overline{0}$ \\
\hline Marlborough & $\mathrm{A}$ & $\bar{F}$ & 0 & 1 & 0 & 1 & 0 & 0 \\
\hline Marlborough & B & $\mathrm{F}$ & 0 & 1 & 0 & 0 & 0 & $\overline{0}$ \\
\hline Marlborough & $\bar{C}$ & $F$ & 0 & 2 & 0 & 0 & 1 & $\overline{0}$ \\
\hline Marlborough & $\mathrm{D}$ & $\bar{F}$ & 0 & 0 & 0 & 0 & 1 & 0 \\
\hline Merivale & $\bar{A}$ & SN & 0 & 2 & 0 & 0 & 0 & 0 \\
\hline Merivale & B & $\overline{\mathrm{SN}}$ & 0 & 0 & 0 & 1 & 0 & 0 \\
\hline Merivale & $\mathrm{C}$ & SN & 0 & 1 & 0 & 0 & 1 & $\overline{0}$ \\
\hline Merivale & $\mathrm{D}$ & SN & 0 & 1 & 0 & 0 & 0 & $\overline{0}$ \\
\hline Parc_Champlain & $\mathrm{A}$ & $\mathrm{S}$ & 0 & 0 & 1 & 0 & 0 & 0 \\
\hline Parc_Champlain & $\bar{B}$ & $\mathrm{~S}$ & 0 & 0 & 0 & 0 & 0 & 0 \\
\hline Parc_Champlain & $\mathrm{C}$ & $\mathrm{S}$ & 0 & 0 & 0 & 0 & 0 & 0 \\
\hline Parc_Champlain & $\mathrm{D}$ & $\mathrm{S}$ & 0 & 0 & 0 & 0 & 0 & 0 \\
\hline Pelissier & $\mathrm{A}$ & EN & 0 & 0 & 0 & 0 & 0 & 0 \\
\hline Pelissier & $\mathrm{B}$ & EN & 0 & 0 & 0 & 0 & 0 & 0 \\
\hline Pelissier & $\mathrm{C}$ & EN & 0 & 1 & 0 & 0 & 0 & $\overline{0}$ \\
\hline Pelissier & $\bar{D}$ & EN & 0 & 0 & 0 & 0 & 1 & $\overline{0}$ \\
\hline PineGlen_Annex & $\bar{A}$ & $\mathrm{~S}$ & 0 & 0 & 0 & 0 & 0 & 0 \\
\hline PineGlen_Annex & $\mathrm{B}$ & $\mathrm{S}$ & 0 & 0 & 0 & 0 & 0 & 0 \\
\hline PineGlen_Annex & $\mathrm{C}$ & $\mathrm{S}$ & 0 & 0 & 0 & 0 & 0 & 0 \\
\hline PineGlen_Annex & $\mathrm{D}$ & $\mathrm{S}$ & 0 & 0 & 0 & 0 & 0 & 0 \\
\hline Q_Four & $\bar{A}$ & $\mathrm{E}$ & 0 & 1 & 0 & 0 & 0 & 0 \\
\hline Q_Four & $\mathrm{B}$ & $E$ & 0 & 1 & 0 & 1 & 1 & 0 \\
\hline Q_Four & $\mathrm{C}$ & $\mathrm{E}$ & 0 & 1 & 0 & 1 & 1 & 0 \\
\hline Q_Four & $\mathrm{D}$ & $E$ & 0 & 1 & 0 & 1 & 1 & 0 \\
\hline Sandy_Hill & A & $\mathrm{U}$ & 0 & 0 & 0 & 0 & 0 & 0 \\
\hline Sandy_Hill & B & $\bar{U}$ & 0 & 0 & 0 & 0 & 0 & 0 \\
\hline Sandy_Hill & $\mathrm{C}$ & $\mathrm{U}$ & 0 & 0 & 0 & 0 & 0 & 0 \\
\hline Sandy_Hill & $\mathrm{D}$ & $\bar{U}$ & 0 & 0 & 0 & 0 & 0 & $\overline{0}$ \\
\hline Vallee_Meech & $\mathrm{A}$ & $F$ & 0 & 0 & 0 & 0 & 0 & 0 \\
\hline Vallee_Meech & B & $\mathrm{F}$ & 0 & 0 & 0 & 0 & 0 & 0 \\
\hline Vallee_Meech & $\mathrm{C}$ & $F$ & 0 & 0 & 0 & 0 & 0 & 0 \\
\hline Vallee_Meech & $\mathrm{D}$ & $\mathrm{F}$ & 0 & 0 & 0 & 0 & 0 & 0 \\
\hline Wolf_Grove & $\mathrm{A}$ & $E$ & 0 & 0 & 0 & 0 & 0 & 0 \\
\hline
\end{tabular}




\begin{tabular}{|l|l|l|r|r|r|r|r|r|}
\hline Wolf_Grove & B & E & 0 & 0 & 0 & 0 & 0 & 0 \\
\hline Wolf_Grove & C & E & 0 & 0 & 0 & 0 & 0 & 0 \\
\hline Wolf_Grove & D & E & 0 & 0 & 0 & 0 & 0 & 0 \\
\hline Wrightville & A & U & 0 & 0 & 0 & 0 & 0 & 0 \\
\hline Wrightville & B & U & 0 & 0 & 0 & 0 & 0 & 0 \\
\hline Wrightville & C & U & 0 & 0 & 0 & 0 & 0 & 0 \\
\hline Wrightville & D & U & 0 & 0 & 0 & 0 & 0 & 0 \\
\hline Wychwood & A & S & 0 & 0 & 0 & 0 & 0 & 0 \\
\hline Wychwood & B & S & 0 & 0 & 0 & 0 & 0 & 0 \\
\hline Wychwood & C & S & 0 & 0 & 1 & 0 & 0 & 0 \\
\hline Wychwood & D & S & 0 & 0 & 0 & 0 & 0 & 0 \\
\hline
\end{tabular}




\begin{tabular}{|c|c|c|c|c|c|c|}
\hline$\overline{\text { SITE }}$ & STATION & CATEGORY & YBSA & YEWA & YRWA & YTVI \\
\hline Achbar & $\mathrm{A}$ & SN & 0 & 0 & 0 & 0 \\
\hline Achbar & $\overline{\mathrm{B}}$ & $\overline{\mathrm{SN}}$ & 0 & 0 & 0 & 0 \\
\hline Achbar & $\overline{\mathrm{C}}$ & $\overline{\mathrm{SN}}$ & 0 & 0 & 0 & 0 \\
\hline Achbar & $\overline{\mathrm{D}}$ & $\overline{\mathrm{SN}}$ & 0 & 0 & 0 & 0 \\
\hline Bridlewood & $\bar{A}$ & $\overline{\mathrm{UN}}$ & 0 & 0 & 0 & 0 \\
\hline Bridlewood & B & UN & I & 0 & 0 & 0 \\
\hline Bridlewood & $\mathrm{C}$ & $\overline{\mathrm{UN}}$ & 1 & $\mathbf{0}$ & 0 & 0 \\
\hline Bridlewood & $\overline{\mathrm{D}}$ & $\overline{\mathrm{UN}}$ & 0 & 0 & 0 & 0 \\
\hline Carp_Hills & $\bar{A}$ & $\bar{F}$ & 2 & 0 & 0 & 0 \\
\hline Carp_Hills & $\bar{B}$ & $\mathrm{~F}$ & 2 & 0 & 0 & 0 \\
\hline Carp_Hills & $\mathrm{C}$ & $\bar{F}$ & 2 & 0 & 0 & 0 \\
\hline Carp_Hills & $\mathrm{D}$ & $\mathrm{F}$ & 1 & 1 & 0 & 0 \\
\hline Chapel_Hill & $\bar{A}$ & UN & 1 & 0 & 0 & 0 \\
\hline Chapel_Hill & B & UN & 1 & 0 & 0 & 0 \\
\hline Chapel_Hill & $\bar{C}$ & $\mathrm{UN}$ & 0 & 0 & 0 & 0 \\
\hline Chapel_Hill & $\bar{D}$ & UN & 1 & 0 & 0 & 0 \\
\hline Chelsea & A & $\overline{\mathrm{SN}}$ & 1 & 0 & 0 & 0 \\
\hline Chelsea & $\bar{B}$ & SN & 0 & 0 & 0 & 1 \\
\hline Chelsea & $\mathrm{C}$ & SN & 1 & 0 & 0 & 0 \\
\hline Chelsea & $\overline{\mathrm{D}}$ & $\overline{\mathrm{SN}}$ & 1 & 0 & 0 & 0 \\
\hline Chemin Scholle & $\bar{A}$ & EN & 0 & 0 & 0 & 0 \\
\hline Chemin_Scholle & B & $\overline{\mathrm{EN}}$ & 0 & 0 & 0 & 0 \\
\hline Chemin_Scholle & $\mathrm{C}$ & EN & 1 & 0 & 0 & 0 \\
\hline Chemin_Scholle & $\mathrm{D}$ & EN & 1 & 0 & 0 & 0 \\
\hline Cote_d'Azur & A & $\mathbf{S}$ & 0 & 0 & 0 & 0 \\
\hline Cote_d'Azur & $\bar{B}$ & $\bar{S}$ & 0 & 0 & 0 & 0 \\
\hline Cote_d'Azur & $\mathrm{C}$ & $\mathrm{S}$ & 0 & 0 & 0 & 0 \\
\hline Cote_d'Azur & $\mathrm{D}$ & $S$ & 0 & 0 & 0 & 0 \\
\hline Highway_Seven & $\overline{\mathrm{A}}$ & $\bar{E}$ & 1 & 0 & 0 & 0 \\
\hline Highway_Seven & B & $E$ & 1 & 0 & 0 & 0 \\
\hline Highway_Seven & $\bar{C}$ & $\mathrm{E}$ & 0 & 0 & 0 & 0 \\
\hline Highway_Seven & $\mathrm{D}$ & $E$ & 1 & 0 & 0 & 0 \\
\hline Hull & A & $\mathrm{U}$ & 0 & 0 & 0 & 0 \\
\hline Hull & $\overline{\mathrm{B}}$ & $\overline{\mathrm{U}}$ & 0 & 0 & 0 & 0 \\
\hline Hull & $\mathrm{C}$ & $\mathrm{U}$ & 0 & 0 & 0 & 0 \\
\hline Hull & $\mathrm{D}$ & $\mathrm{U}$ & 0 & 0 & 0 & 0 \\
\hline Lac_a_la_Perdrix & A & EN & 0 & 0 & 0 & 0 \\
\hline Lac_a_la_Perdrix & $\bar{B}$ & EN & 0 & 0 & 0 & 0 \\
\hline Lac_a_la_Perdrix & $\bar{C}$ & $\overline{\mathrm{EN}}$ & 0 & 0 & 0 & 0 \\
\hline Lac_a_la_Perdrix & $\mathrm{D}$ & $\overline{\mathrm{EN}}$ & 0 & 0 & 0 & 0 \\
\hline Lac_Philippe & A & $\mathrm{F}$ & 1 & 0 & 0 & 0 \\
\hline Lac_Philippe & B & $\mathrm{F}$ & 1 & 0 & 0 & 0 \\
\hline Lac_Philippe & $\bar{C}$ & $F$ & 1 & 0 & 0 & 0 \\
\hline Lac_Philippe & $\overline{\mathrm{D}}$ & $F$ & 1 & 0 & 0 & $\overline{1}$ \\
\hline
\end{tabular}




\begin{tabular}{|c|c|c|c|c|c|c|}
\hline Manoir_des_Trembles & $\bar{A}$ & $\mathrm{UN}$ & 1 & 0 & 0 & 0 \\
\hline Manoir_des_Trembles & $\bar{B}$ & UN & 2 & 0 & 0 & 0 \\
\hline Manoir_des_Trembles & $\mathrm{C}$ & $\overline{\mathrm{UN}}$ & 1 & 0 & 0 & 0 \\
\hline Manoir_des_Trembles & $\overline{\mathrm{D}}$ & $\overline{\mathrm{UN}}$ & 0 & 0 & 0 & $\overline{0}$ \\
\hline Marathon & A & $\mathrm{E}$ & 1 & 0 & 1 & 0 \\
\hline Marathon & $\mathrm{B}$ & $\mathrm{E}$ & 2 & 0 & 0 & 0 \\
\hline Marathon & $\mathrm{C}$ & E & 0 & 0 & 0 & 0 \\
\hline Marathon & $\mathrm{D}$ & $\mathrm{E}$ & 0 & 0 & 0 & 0 \\
\hline Marier & $\bar{A}$ & $\bar{U}$ & 0 & 0 & 0 & $\overline{0}$ \\
\hline Marier & $\overline{\mathrm{B}}$ & $\bar{U}$ & 0 & 0 & 0 & 0 \\
\hline Marier & $\mathrm{C}$ & $\bar{U}$ & 0 & 0 & 0 & 0 \\
\hline Marier & $\overline{\mathrm{D}}$ & $\overline{\mathrm{U}}$ & 0 & 0 & 0 & 0 \\
\hline Marlborough & $\overline{\mathrm{A}}$ & $\mathrm{F}$ & 0 & 0 & 0 & 0 \\
\hline Marlborough & $\mathrm{B}$ & $F$ & 0 & 0 & 0 & 0 \\
\hline Marlborough & $\bar{C}$ & $\bar{F}$ & 1 & 0 & 1 & $\overline{0}$ \\
\hline Marlborough & $\overline{\mathrm{D}}$ & $F$ & 0 & 0 & 1 & 0 \\
\hline Merivale & $\bar{A}$ & SN & 0 & 0 & 0 & $\overline{0}$ \\
\hline Merivale & $\bar{B}$ & $\overline{\mathrm{SN}}$ & 0 & 0 & 0 & 0 \\
\hline Merivale & $\mathrm{C}$ & SN & 0 & 0 & 0 & 0 \\
\hline Merivale & $\overline{\mathrm{D}}$ & $\mathrm{SN}$ & 0 & 0 & 0 & $\overline{0}$ \\
\hline Parc_Champlain & $\overline{\mathrm{A}}$ & $\bar{S}$ & 0 & 0 & 0 & $\overline{0}$ \\
\hline Parc_Champlain & $\bar{B}$ & $\bar{S}$ & 0 & 0 & 0 & $\overline{0}$ \\
\hline Parc_Champlain & $\mathrm{C}$ & $S$ & 0 & 0 & 0 & 0 \\
\hline Parc_Champlain & $\mathrm{D}$ & $S$ & 0 & 0 & 0 & 0 \\
\hline Pelissier & $\mathrm{A}$ & EN & 0 & 0 & 1 & 0 \\
\hline Pelissier & $\bar{B}$ & $\overline{\mathrm{EN}}$ & 0 & 0 & 0 & 0 \\
\hline Pelissier & $\bar{C}$ & $\overline{\mathrm{EN}}$ & 0 & 0 & 0 & $\overline{0}$ \\
\hline Pelissier & $\overline{\mathrm{D}}$ & $\overline{\mathrm{EN}}$ & 0 & 0 & 0 & $\overline{0}$ \\
\hline PineGlen_Annex & $\overline{\mathrm{A}}$ & $S$ & 0 & 0 & 0 & $\overline{0}$ \\
\hline PineGlen_Annex & $\overline{\mathrm{B}}$ & $\mathrm{S}$ & $\begin{array}{ll}0 \\
0\end{array}$ & 0 & 0 & 0 \\
\hline PineGlen_Annex & $\mathrm{C}$ & $\mathbf{S}$ & 0 & 0 & 0 & $\overline{0}$ \\
\hline PineGlen_Annex & $\bar{D}$ & $\bar{S}$ & 0 & 0 & 0 & $\overline{0}$ \\
\hline Q_Four & $\mathrm{A}$ & $\mathrm{E}$ & 0 & 0 & 1 & 0 \\
\hline Q_Four & B & $\bar{E}$ & 0 & 0 & 0 & 0 \\
\hline Q_Four & $\mathrm{C}$ & $\bar{E}$ & 2 & 0 & 0 & $\overline{0}$ \\
\hline Q_Four & $\overline{\mathrm{D}}$ & $\mathrm{E}$ & 1 & 0 & 0 & 0 \\
\hline Sandy_Hill & $\bar{A}$ & $\mathrm{U}$ & 0 & 0 & 0 & 0 \\
\hline Sandy_Hill & $\overline{\mathrm{B}}$ & $\bar{U}$ & 0 & 0 & 0 & 0 \\
\hline Sandy_Hill & $\mathrm{C}$ & $\bar{U}$ & 0 & 0 & 0 & $\overline{0}$ \\
\hline Sandy_Hill & $\mathrm{D}$ & $\bar{U}$ & 0 & 0 & 0 & $\overline{0}$ \\
\hline Vallee_Meech & A & $\mathrm{F}$ & 1 & 0 & 0 & 0 \\
\hline Vallee_Meech & $\overline{\mathrm{B}}$ & $F$ & 0 & 0 & 0 & 0 \\
\hline Vallee_Meech & C & $F$ & 0 & 0 & 0 & 0 \\
\hline Vallee_Meech & $\bar{D}$ & $F$ & 1 & 0 & 0 & $\overline{0}$ \\
\hline Wolf_Grove & $\overline{\mathrm{A}}$ & $\bar{E}$ & 1 & 0 & 0 & $\overline{0}$ \\
\hline
\end{tabular}




\begin{tabular}{|l|l|l|r|r|r|r|}
\hline Wolf_Grove & B & E & 1 & 0 & 0 & 0 \\
\hline Wolf_Grove & C & E & 0 & 0 & 0 & 0 \\
\hline Wolf_Grove & D & E & 0 & 0 & 0 & 0 \\
\hline Wrightville & A & U & 0 & 0 & 0 & 0 \\
\hline Wrightville & B & U & 0 & 0 & 0 & 0 \\
\hline Wrightville & C & U & 0 & 0 & 0 & 0 \\
\hline Wrightville & D & U & 0 & 0 & 0 & 0 \\
\hline Wychwood & A & S & 0 & 0 & 0 & 0 \\
\hline Wychwood & B & S & 0 & 0 & 0 & 0 \\
\hline Wychwood & C & S & 0 & 0 & 0 & 0 \\
\hline Wychwood & D & S & 0 & 0 & 0 & 0 \\
\hline
\end{tabular}

${ }^{\mathrm{e}} \mathrm{F}=$ Forested, $\mathrm{E}=$ Exurban, $\mathrm{S}=$ Suburban, $\mathrm{U}=$ Urban, $\mathrm{EN}=$ Exurban Neighbor, $\mathrm{SN}=$ Suburban Neighbor, UN = Urban Neighbor.

${ }^{\mathrm{f}} \mathrm{AMCR}=$ American Crow Corvus brachyrhynchos, $\mathrm{AMGO}=$ American Goldfinch Carduelis tristis, $\mathrm{AMRE}=$ American Redstart Setophaga ruticilla, $\mathrm{AMRO}=$ American Robin Turdus migratorius, $\mathrm{BAOR}=$ Baltimore Oriole Icterus galbula, $\mathrm{BBCU}=\mathrm{Black}-$ billed Cuckoo Coccyzus erythropthalmus, $\mathrm{BCCH}=$ Black-capped Chickadee Poecile atricapilla, $\mathrm{BHCO}=$ Brown-headed Cowbird Molothrus ater, $\mathrm{BHVI}=$ Blue-headed Vireo Vireo solitarius, $\mathrm{BLBW}=$ Blackburnian Warbler Dendroica fusca, $\mathrm{BLJA}=\mathrm{Blue}$ Jay Cyanocitta cristata, $\mathrm{BRCR}=$ Brown Creeper Certhia americana, $\mathrm{BTBW}=\mathrm{Black}-$ throated Blue Warbler Dendroica caerulescens, BTGW = Black-throated Green Warbler Dendroica virens, $\mathrm{BWWA}=\mathrm{Black}-\mathrm{and}-\mathrm{White}$ Warbler Mniotilta varia, $\mathrm{CAGO}=\mathrm{Canada}$ Goose Branta canadensis, CAWA = Canada Warbler Wilsonia canadensis, CEWA = Cedar Waxwing Bombycilla cedrorum, CHSP = Chipping Sparrow Spizella passerina $\mathrm{CHSW}=$ Chimney Swift Chaetura pelagica, $\mathrm{COGR}=$ Common Grackle Quiscalus quiscula, $\mathrm{COLO}=$ Common Loon Gavia immer, $\mathrm{CORA}=$ Common Raven Corvus corax, $\mathrm{COSN}=$ Wilson's Snipe Gallinago delicata, $\mathrm{COYE}=$ Common Yellowthroat 
Geothlypis trichas, DOWO = Downy Woodpecker Picoides pubescens, EAPH = Eastern Phoebe Sayornis phoebe, EAWP = Eastern Wood-Pewee Contopus virens, EUST = European Starling Sturnus vulgaris, GCFL = Great Crested Flycatcher Myiarchus crinitus, GCKI = Golden-crowned Kinglet Regulus satrapa, HAWO = Hairy Woodpecker Picoides villosus, $\mathrm{HETH}=$ Hermit Thrush Catharus guttatus, HOFI = House Finch Carpodacus mexicanus, HOSP = House Sparrow Passer domesticus, KILL $=$ Killdeer Charadrius vociferus, $\mathrm{LEBI}=$ Least Bittern Ixobrychus exilis, $\mathrm{LEFL}=$ Least Flycatcher Empidonax minimus, MALL = Mallard Anas platyrhynchos, $\mathrm{MODO}=$ Mourning Dove Zenaida macroura, MOWA = Mourning Warbler Oporornis philadelphia, NAWA $=$ Nashville Warbler Vermivora ruficapilla, $\mathrm{NOCA}=$ Northern Cardinal Cardinalis cardinalis, NOFL $=$ Northern Flicker Colaptes auratus, NOWA $=$ Northern Waterthrush Seiurus noveboracensis, OVEN = Ovenbird Seiurus aurocapillus, PIWA = Pine Warbler Dendroica pinus, PIWO = Pileated Woodpecker Dryocopus pileatus, $\mathrm{PUFI}=$ Purple Finch Carpodacus purpureus, $\mathrm{RBGR}=$ Rose-breasted Grosbeak Pheucticus ludovicianus, RBNU = Red-breasted Nuthatch Sitta canadensis, REVI = Redeyed Vireo Vireo olivaceus, RHWO = Red-headed Woodpecker Melanerpes erythrocephalus, $\mathrm{RODO}=$ Rock Pigeon Columba livia, $\mathrm{RTHU}=$ Ruby-throated Hummingbird Archilochus colubris, RUGR = Ruffed Grouse Bonasa umbellus, RWBL = Red-winged Blackbird Agelaius phoeniceus, $\mathrm{SCTA}=$ Scarlet Tanager Piranga olivacea, SORA $=$ Sora Porzana carolina, SOSP $=$ Song Sparrow Melospiza melodia, SWSP $=$ Swamp Sparrow Melospiza georgiana, SWTH = Swainson's Thrush Catharus ustulatus, VEER $=$ Veery Catharus fuscescens, WAVI $=$ Warbling Vireo Vireo gilvus, WBNU $=$ 
White-breasted Nuthatch Sitta carolinensis, WIFL = Willow Flycatcher Empidonax traillii, WIWA = Wilson's Warbler Wilsonia pusilla, WIWR $=$ Winter Wren Troglodytes troglodytes, WODU = Wood Duck Aix sponsa, WOTH = Wood Thrush Hylocichla mustelina, WTSP $=$ White-throated Sparrow Zonotrichia albicollis,, BCU $=$ Yellowbilled Cuckoo Coccyzus americanus, YBSA = Yellow-bellied Sapsucker Sphyrapicus varius, YEWA = Yellow Warbler Dendroica petechia, YRWA = Yellow-rumped Warbler Dendroica coronata, YTVI = Yellow-throated Vireo Vireo flavifrons. 

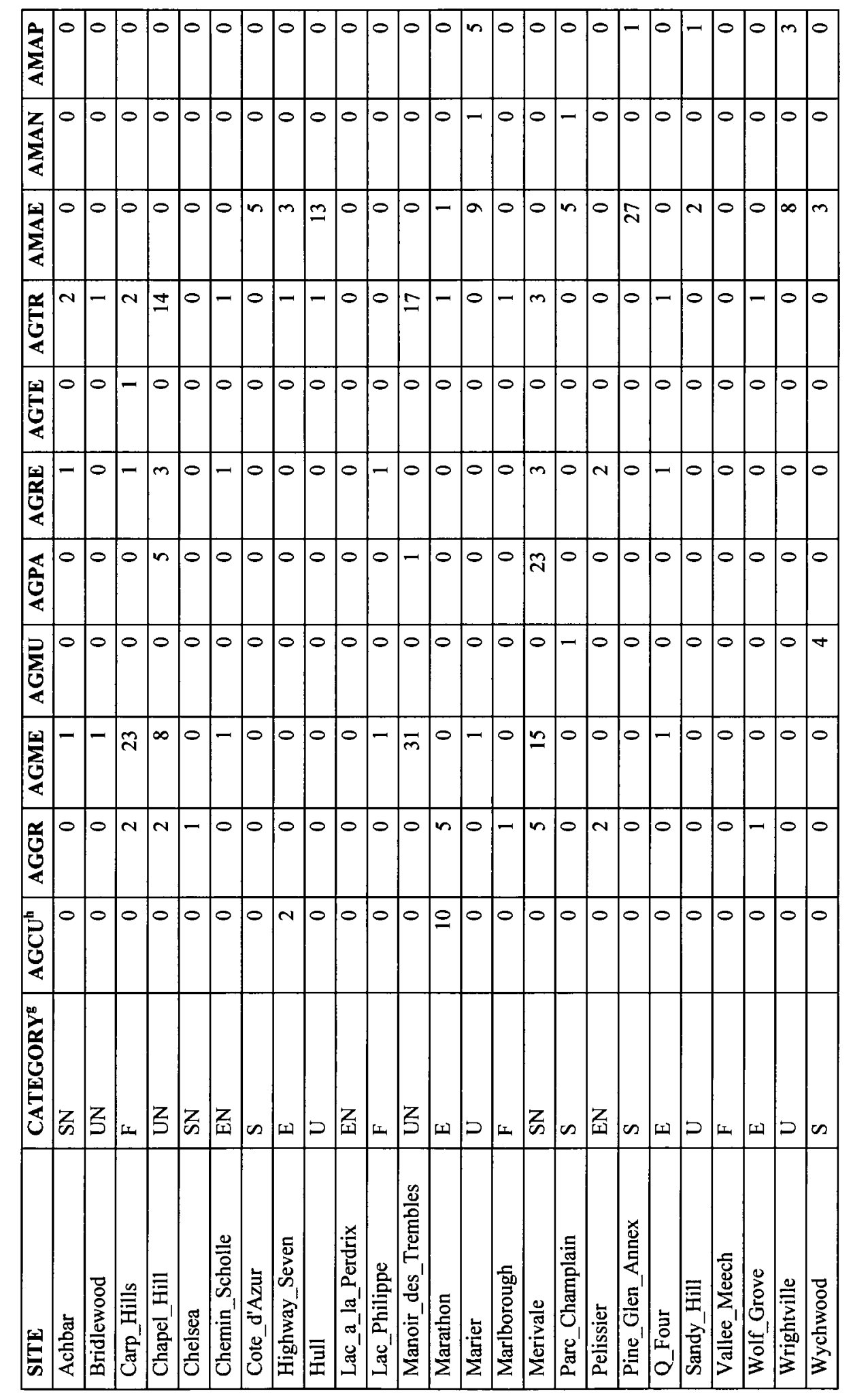


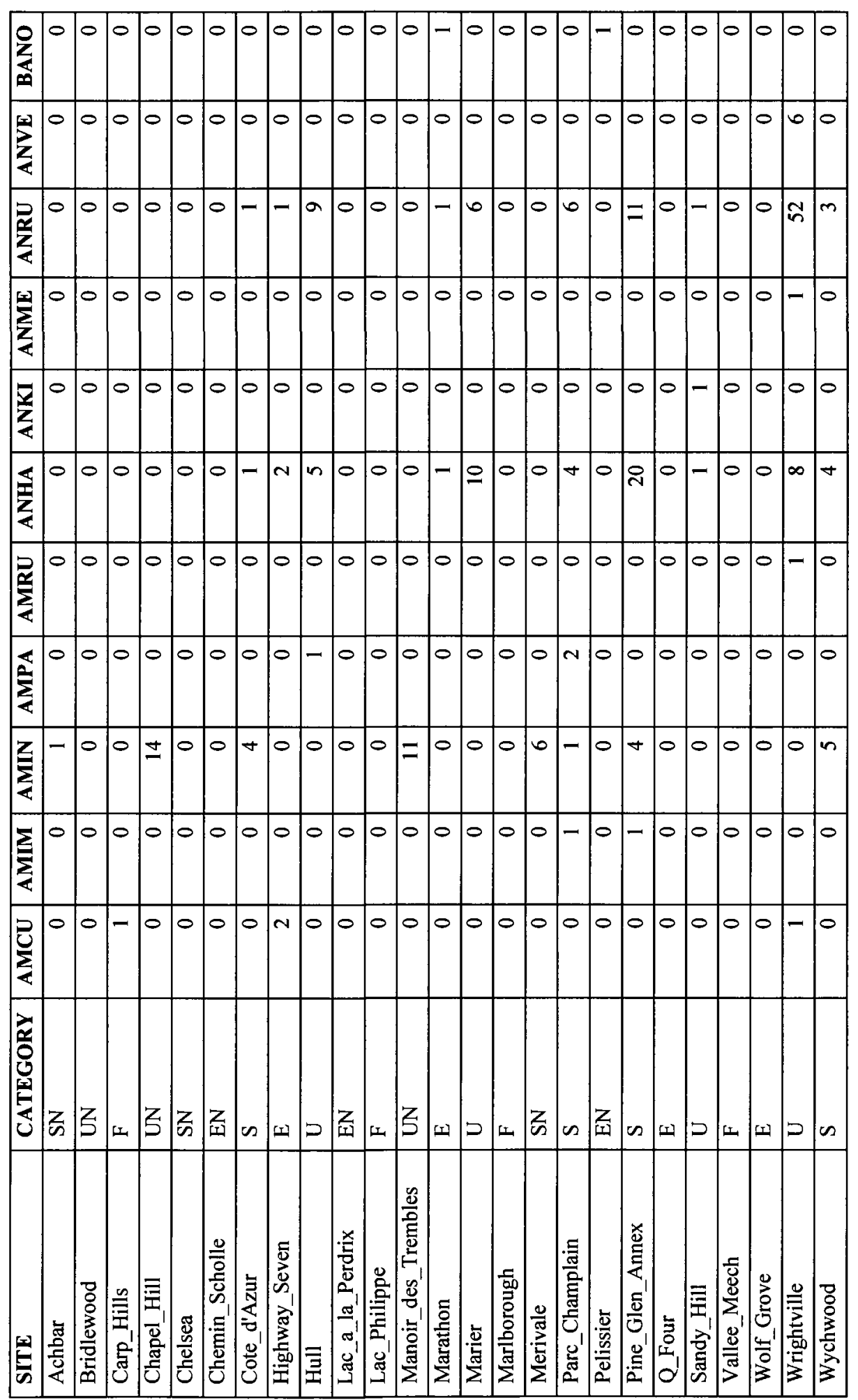



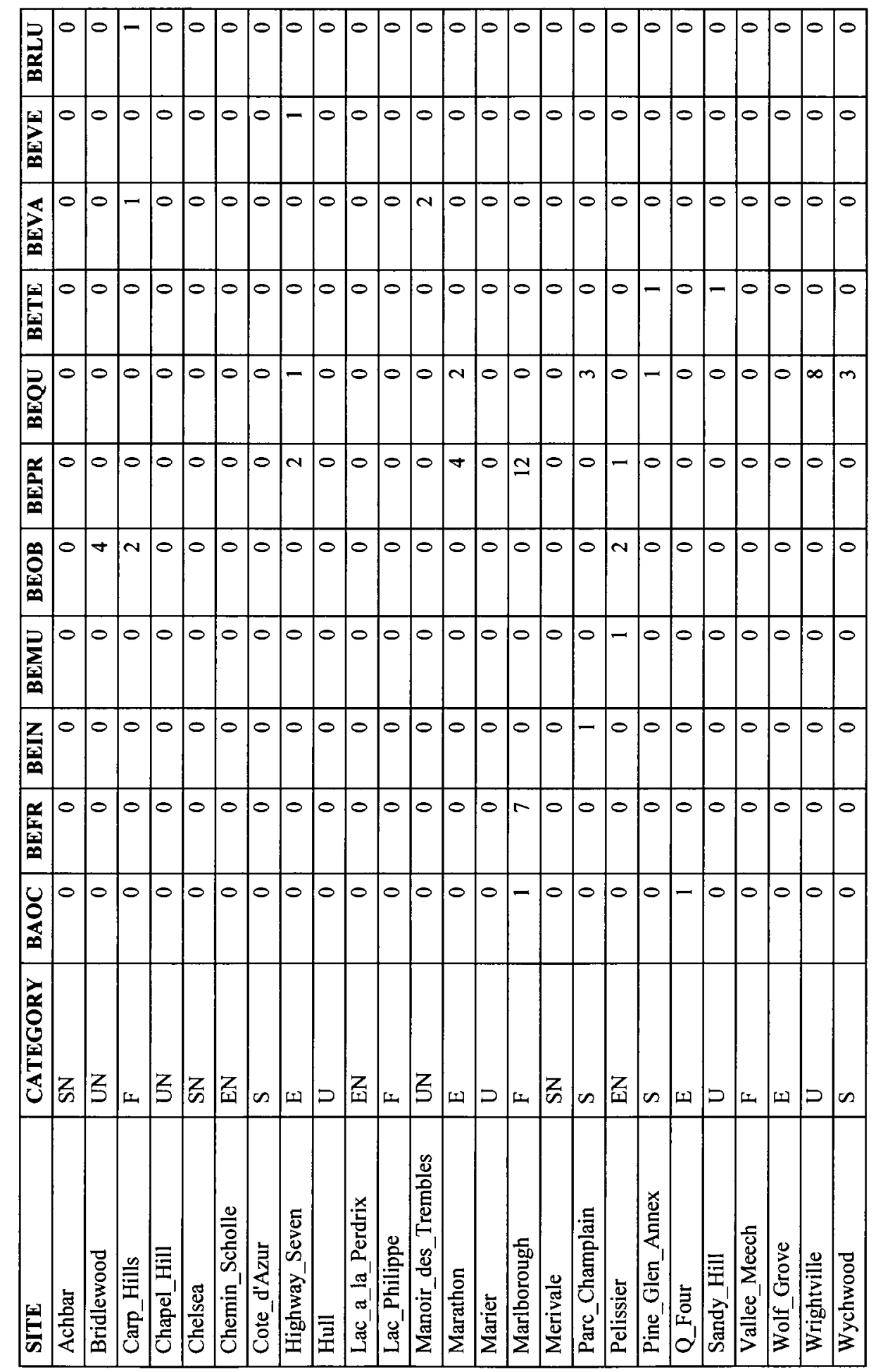
$\frac{N}{n}$

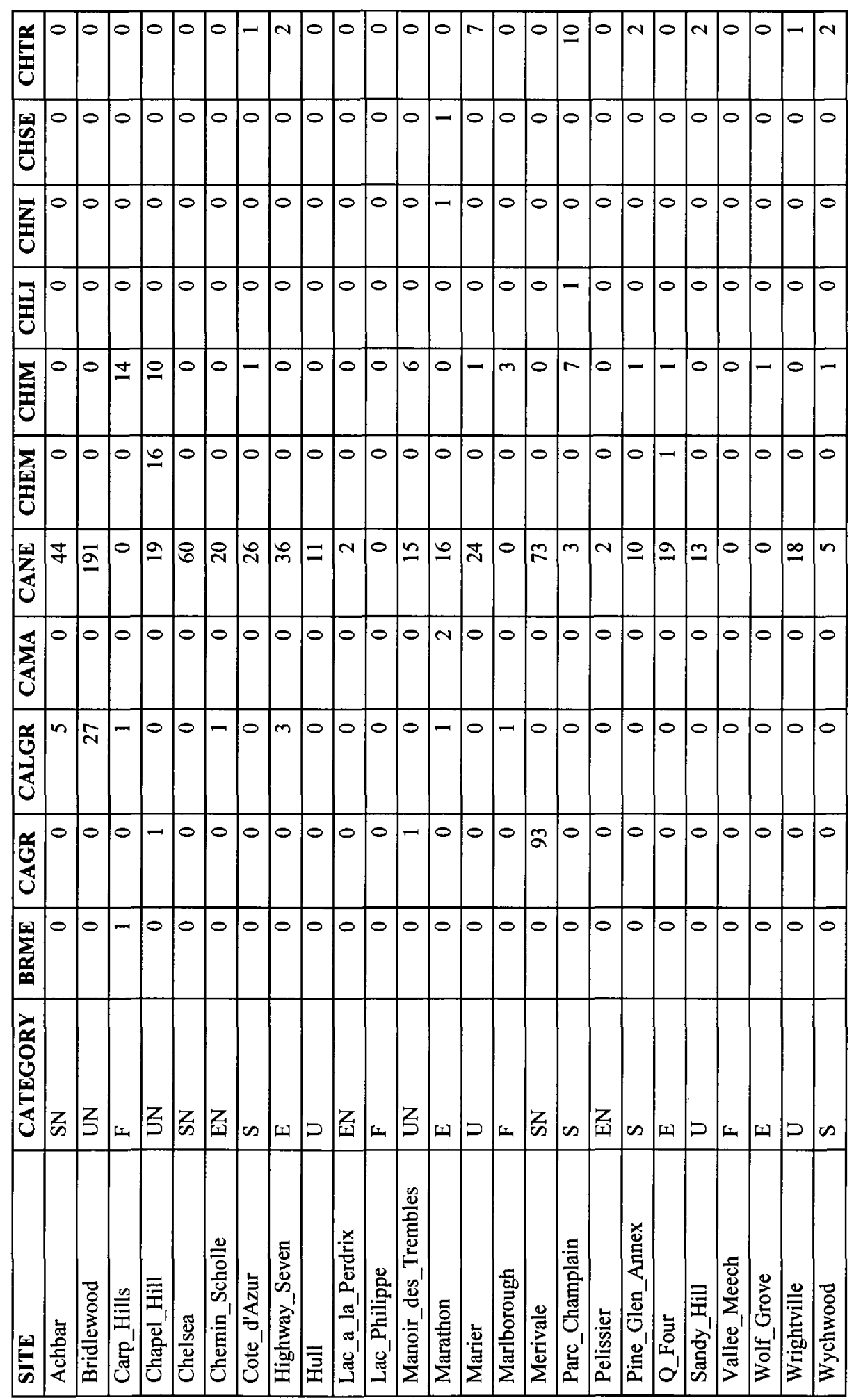




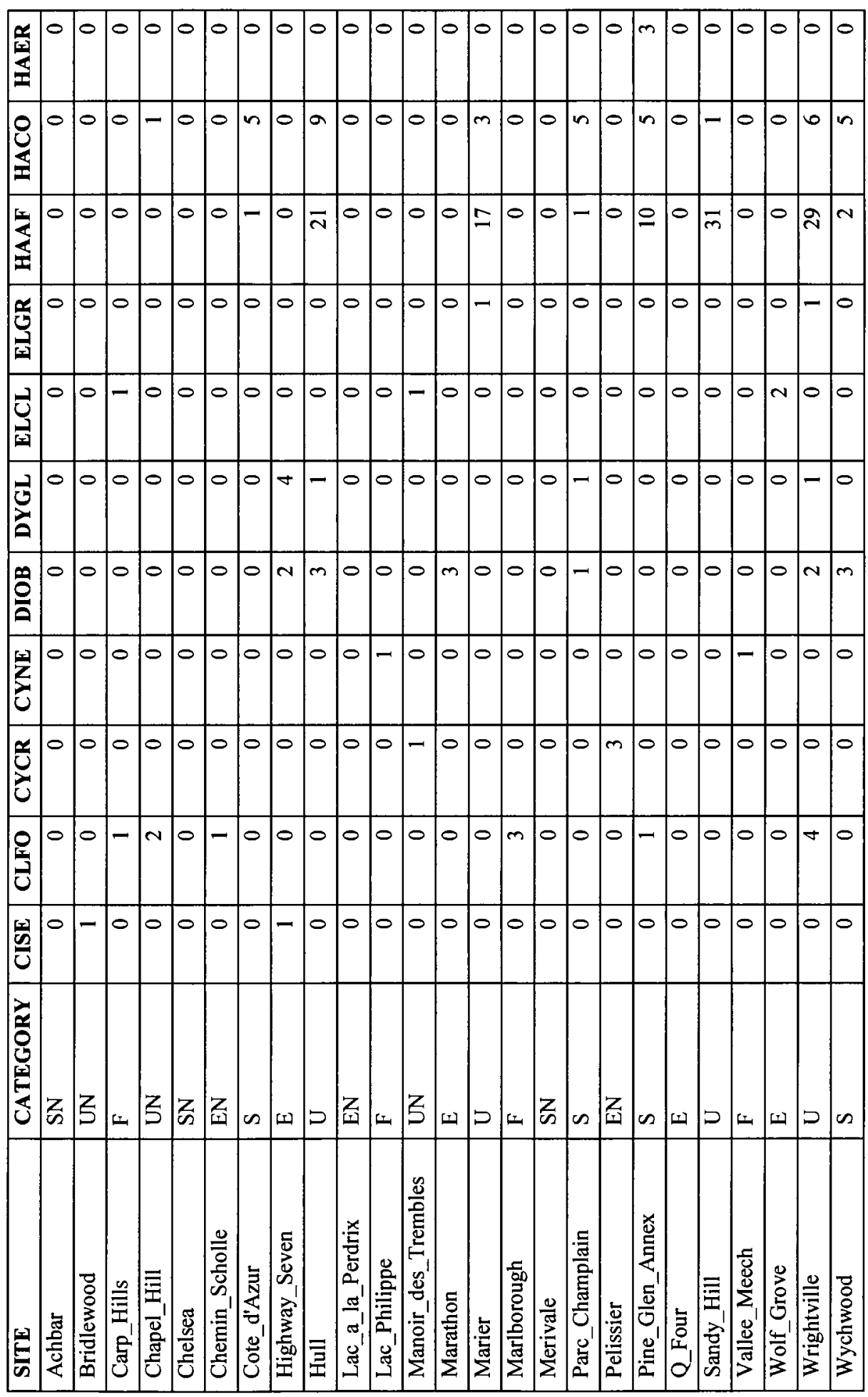


$\frac{a}{m}$

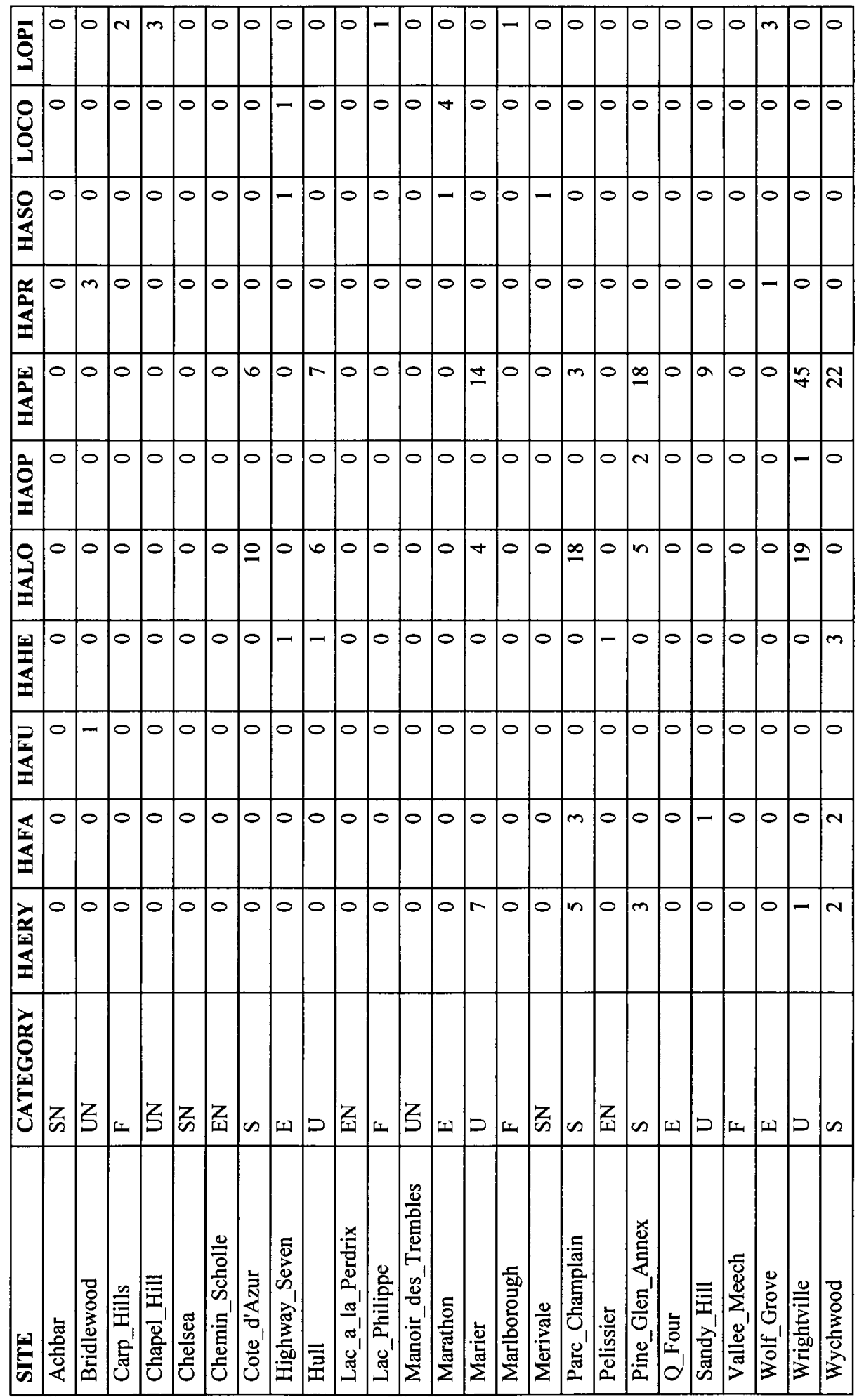


్ㅡㅁ

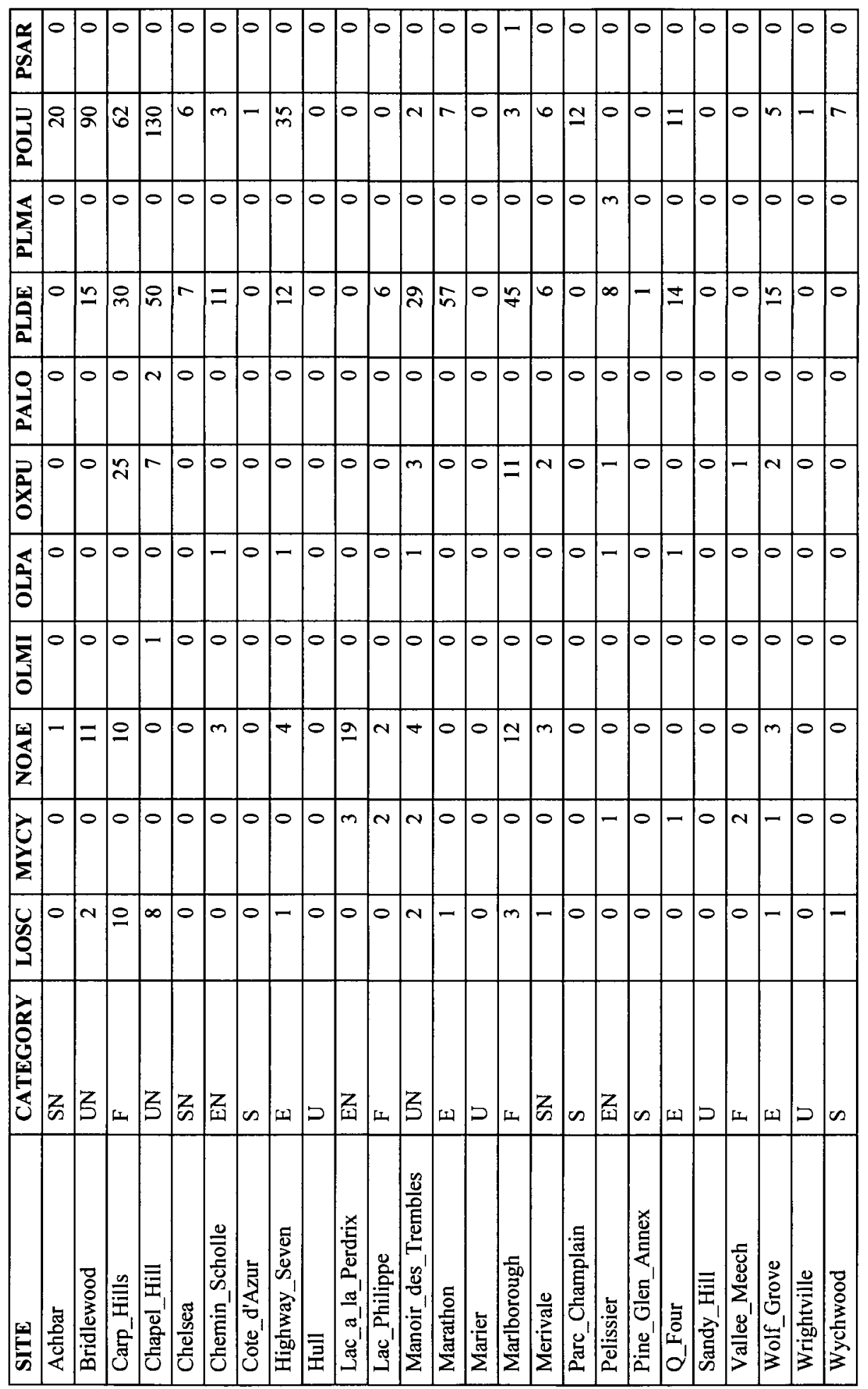




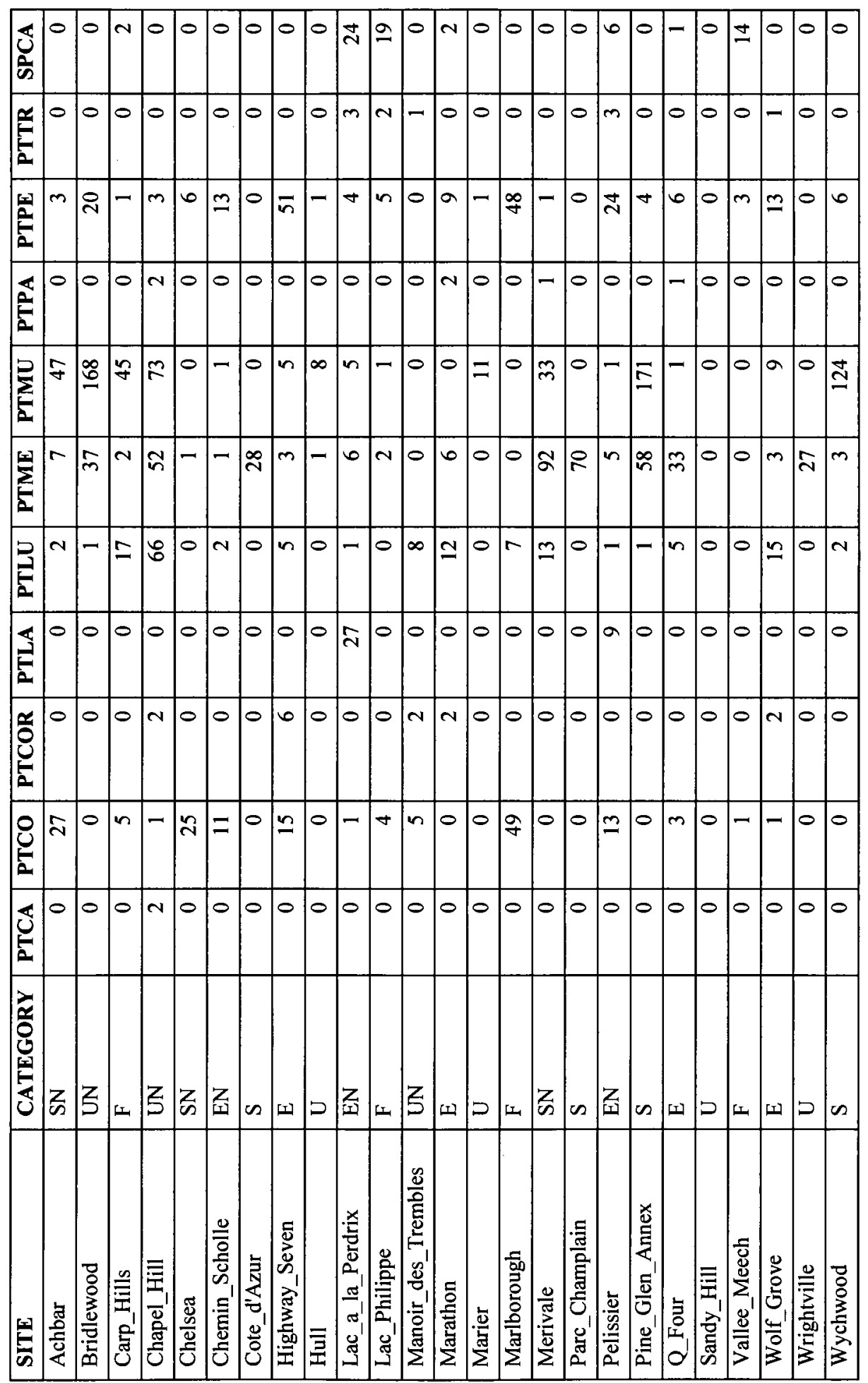


స్ల

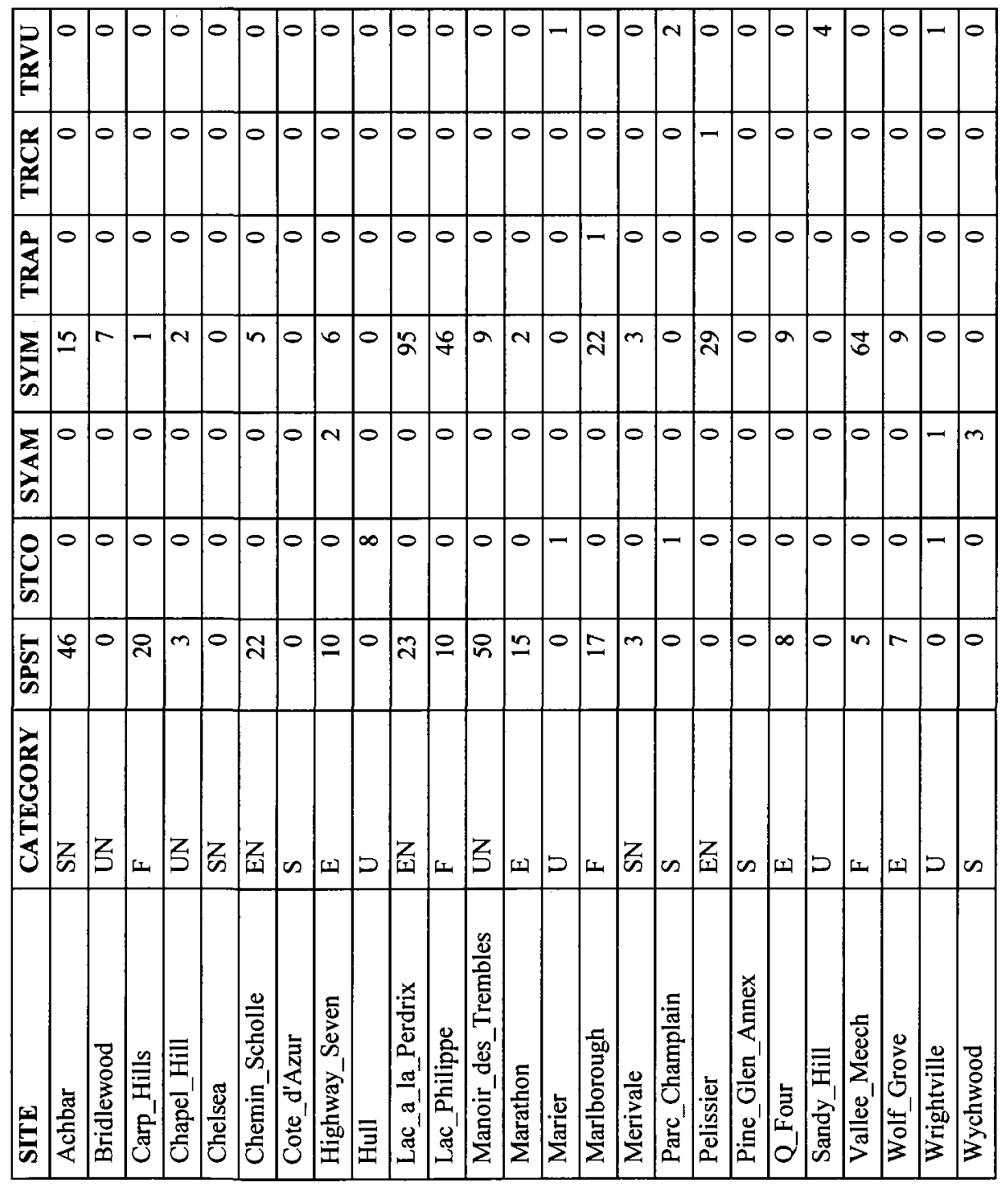




\begin{tabular}{|c|c|c|c|c|c|c|c|c|}
\hline SITE & STATION & CATEGORY $^{g}$ & $\mathbf{A G C U}^{\mathrm{h}}$ & AGGR & AGME & AGMU & AGPA & AGRE \\
\hline Achbar & A & $\mathrm{SN}$ & 0 & 0 & 0 & 0 & 0 & 0 \\
\hline Achbar & $\mathrm{B}$ & $\mathrm{SN}$ & 0 & 0 & 0 & 0 & 0 & 0 \\
\hline Achbar & $\mathrm{C}$ & SN & 0 & 0 & 0 & 0 & 0 & 0 \\
\hline Achbar & $\mathrm{D}$ & $\mathrm{SN}$ & 0 & 0 & 0 & 0 & 0 & 0 \\
\hline Achbar & $\mathrm{E}$ & $\mathrm{SN}$ & 0 & 0 & 0 & 0 & 0 & 1 \\
\hline Achbar & $\mathrm{F}$ & SN & 0 & 0 & 1 & 0 & 0 & 0 \\
\hline Achbar & $\mathrm{H}$ & $\overline{\mathrm{SN}}$ & 0 & 0 & 0 & 0 & 0 & 0 \\
\hline Achbar & I & SN & 0 & 0 & 0 & 0 & 0 & 0 \\
\hline Bridlewood & $\mathrm{A}$ & UN & 0 & 0 & 0 & 0 & 0 & 0 \\
\hline Bridlewood & $\mathrm{B}$ & $\mathrm{UN}$ & 0 & 0 & 0 & 0 & 0 & 0 \\
\hline Bridlewood & $\mathrm{C}$ & $\mathrm{UN}$ & 0 & 0 & 0 & 0 & 0 & 0 \\
\hline Bridlewood & $\mathrm{D}$ & UN & 0 & 0 & 0 & 0 & 0 & 0 \\
\hline Bridlewood & $E$ & UN & 0 & 0 & 0 & 0 & 0 & 0 \\
\hline Bridlewood & $\mathrm{F}$ & UN & 0 & 0 & 1 & 0 & 0 & 0 \\
\hline Bridlewood & $\mathrm{H}$ & UN & 0 & 0 & 0 & 0 & $\overline{0}$ & 0 \\
\hline Bridlewood & I & $\overline{\mathrm{UN}}$ & 0 & 0 & 0 & 0 & $\overline{0}$ & $\overline{0}$ \\
\hline Carp_Hills & $\mathrm{A}$ & $\mathrm{F}$ & 0 & 0 & $\overline{0}$ & 0 & 0 & 0 \\
\hline Carp_Hills & B & $\mathrm{F}$ & 0 & 1 & 1 & 0 & 0 & 0 \\
\hline Carp_Hills & $\mathrm{C}$ & $\mathrm{F}$ & 0 & 0 & 1 & 0 & 0 & 0 \\
\hline Carp_Hills & $\mathrm{D}$ & $\bar{F}$ & 0 & 0 & 0 & 0 & 0 & 0 \\
\hline Carp_Hills & $\mathrm{E}$ & $\mathrm{F}$ & 0 & 0 & 2 & 0 & 0 & 0 \\
\hline Carp_Hills & $\mathrm{F}$ & $\mathrm{F}$ & 0 & 0 & 19 & 0 & 0 & 0 \\
\hline Carp_Hills & $\mathrm{H}$ & $\mathrm{F}$ & 0 & 0 & 0 & 0 & 0 & 1 \\
\hline Carp_Hills & I & $\mathrm{F}$ & 0 & 1 & 0 & 0 & 0 & 0 \\
\hline Chapel_Hill & A & UN & 0 & 0 & 0 & 0 & 0 & 0 \\
\hline Chapel_Hill & B & UN & 0 & 0 & 0 & 0 & 1 & 3 \\
\hline Chapel_Hill & $\mathrm{C}$ & UN & 0 & 0 & 0 & 0 & 0 & 0 \\
\hline Chapel_Hill & $\mathrm{D}$ & UN & 0 & 0 & 0 & 0 & 0 & $\overline{0}$ \\
\hline Chapel_Hill & $\mathrm{E}$ & UN & 0 & 1 & 4 & 0 & 3 & $\overline{0}$ \\
\hline Chapel_Hill & $\mathrm{F}$ & UN & 0 & 0 & 0 & 0 & 0 & 0 \\
\hline Chapel_Hill & $\mathrm{H}$ & UN & 0 & 0 & 0 & 0 & 0 & 0 \\
\hline Chapel_Hill & I & UN & 0 & 1 & 4 & 0 & 1 & 0 \\
\hline Chelsea & $\mathrm{A}$ & $\overline{\mathrm{SN}}$ & 0 & 0 & 0 & 0 & 0 & 0 \\
\hline Chelsea & B & $\overline{\mathrm{SN}}$ & 0 & 0 & 0 & 0 & 0 & 0 \\
\hline Chelsea & $\mathrm{C}$ & $\mathrm{SN}$ & 0 & 1 & 0 & 0 & 0 & 0 \\
\hline Chelsea & $\mathrm{D}$ & SN & 0 & 0 & 0 & 0 & 0 & 0 \\
\hline Chelsea & $\mathrm{E}$ & SN & 0 & 0 & 0 & 0 & 0 & 0 \\
\hline Chelsea & $\mathrm{F}$ & SN & 0 & 0 & 0 & 0 & 0 & 0 \\
\hline Chelsea & $\mathrm{H}$ & $\mathrm{SN}$ & 0 & 0 & 0 & 0 & 0 & 0 \\
\hline Chelsea & I & $\overline{\mathrm{SN}}$ & 0 & 0 & 0 & 0 & 0 & 0 \\
\hline Chemin_Scholle & $\mathrm{A}$ & EN & 0 & 0 & 0 & 0 & 0 & 0 \\
\hline
\end{tabular}




\begin{tabular}{|c|c|c|c|c|c|c|c|c|}
\hline Chemin_Scholle & B & EN & 0 & 0 & 0 & 0 & 0 & 0 \\
\hline Chemin_Scholle & $\mathrm{C}$ & EN & 0 & 0 & 0 & 0 & 0 & 0 \\
\hline Chemin_Scholle & $\mathrm{D}$ & $\mathrm{EN}$ & 0 & 0 & 0 & 0 & 0 & 0 \\
\hline Chemin_Scholle & $\mathrm{E}$ & EN & 0 & 0 & 0 & 0 & 0 & 0 \\
\hline Chemin_Scholle & $\mathrm{F}$ & EN & 0 & 0 & 1 & 0 & 0 & 1 \\
\hline Chemin_Scholle & $\overline{\mathrm{H}}$ & EN & 0 & 0 & 0 & 0 & 0 & 0 \\
\hline Chemin_Scholle & I & EN & 0 & 0 & 0 & 0 & 0 & 0 \\
\hline Cote_d'Azur & A & $\mathrm{S}$ & 0 & 0 & 0 & 0 & 0 & 0 \\
\hline Cote_d'Azur & B & $\mathbf{S}$ & 0 & 0 & 0 & 0 & 0 & 0 \\
\hline Cote_d'Azur & $\mathrm{C}$ & $\mathbf{S}$ & 0 & 0 & 0 & 0 & 0 & 0 \\
\hline Cote_d'Azur & $\bar{D}$ & $\mathbf{S}$ & 0 & 0 & 0 & 0 & 0 & 0 \\
\hline Cote_d'Azur & $\mathrm{E}$ & $\mathbf{S}$ & 0 & 0 & 0 & 0 & 0 & 0 \\
\hline Cote_d'Azur & $\bar{F}$ & $\mathrm{~S}$ & 0 & 0 & 0 & 0 & 0 & 0 \\
\hline Cote_d'Azur & $\mathrm{H}$ & $\mathrm{S}$ & 0 & 0 & 0 & 0 & 0 & $\overline{0}$ \\
\hline Cote_d'Azur & I & $\mathrm{S}$ & 0 & 0 & 0 & 0 & 0 & 0 \\
\hline Highway_Seven & $\bar{A}$ & $\mathrm{E}$ & 0 & 0 & 0 & 0 & 0 & 0 \\
\hline Highway_Seven & $\bar{B}$ & $\bar{E}$ & 0 & 0 & 0 & 0 & $\overline{0}$ & $\overline{0}$ \\
\hline Highway_Seven & $\mathrm{C}$ & $\mathrm{E}$ & 0 & 0 & 0 & 0 & 0 & 0 \\
\hline Highway_Seven & $\bar{D}$ & $\mathrm{E}$ & 0 & 0 & 0 & 0 & 0 & 0 \\
\hline Highway_Seven & $\mathrm{E}$ & $E$ & 2 & 0 & 0 & 0 & 0 & 0 \\
\hline Highway_Seven & $\mathrm{F}$ & $\mathrm{E}$ & 0 & 0 & 0 & 0 & 0 & 0 \\
\hline Highway_Seven & $\mathrm{H}$ & $\bar{E}$ & 0 & 0 & 0 & 0 & 0 & 0 \\
\hline Highway_Seven & I & $\bar{E}$ & 0 & 0 & 0 & 0 & 0 & 0 \\
\hline Hull & $\bar{A}$ & $\bar{U}$ & 0 & 0 & 0 & 0 & 0 & $\overline{0}$ \\
\hline Hull & $\mathrm{B}$ & $\mathrm{U}$ & 0 & 0 & 0 & 0 & 0 & $\overline{0}$ \\
\hline Hull & $\mathrm{C}$ & $\bar{U}$ & 0 & 0 & 0 & 0 & 0 & 0 \\
\hline Hull & $\mathrm{D}$ & $\mathrm{U}$ & 0 & 0 & 0 & 0 & 0 & 0 \\
\hline Hull & $\mathrm{E}$ & $\mathrm{U}$ & 0 & 0 & 0 & 0 & 0 & 0 \\
\hline Hull & $\mathrm{F}$ & $\mathrm{U}$ & 0 & 0 & 0 & 0 & 0 & 0 \\
\hline Hull & $\mathrm{H}$ & $\mathrm{U}$ & 0 & 0 & 0 & 0 & 0 & 0 \\
\hline Hull & I & $\mathrm{U}$ & 0 & 0 & 0 & 0 & 0 & 0 \\
\hline Lac_a_la_Perdrix & $\mathrm{A}$ & EN & 0 & 0 & 0 & 0 & 0 & 0 \\
\hline Lac_a_la_Perdrix & $\overrightarrow{\mathrm{B}}$ & $\mathrm{EN}$ & 0 & 0 & 0 & 0 & 0 & 0 \\
\hline Lac_a_la_Perdrix & $\mathrm{C}$ & EN & 0 & 0 & 0 & 0 & 0 & 0 \\
\hline Lac_a_la_Perdrix & $\mathrm{D}$ & EN & 0 & 0 & 0 & 0 & 0 & 0 \\
\hline Lac_a_la_Perdrix & $\mathrm{E}$ & EN & 0 & 0 & 0 & 0 & 0 & 0 \\
\hline Lac_a_la_Perdrix & $\mathrm{F}$ & EN & 0 & 0 & 0 & 0 & 0 & 0 \\
\hline Lac_a_la_Perdrix & $\mathrm{H}$ & EN & 0 & 0 & 0 & 0 & 0 & 0 \\
\hline Lac_a_la_Perdrix & I & EN & 0 & 0 & 0 & 0 & 0 & 0 \\
\hline Lac_Philippe & $\bar{A}$ & $\bar{F}$ & 0 & 0 & 0 & 0 & 0 & $\overline{0}$ \\
\hline Lac_Philippe & $\mathrm{B}$ & $\mathrm{F}$ & 0 & 0 & 0 & 0 & 0 & 0 \\
\hline Lac_Philippe & $\mathrm{C}$ & $\mathrm{F}$ & 0 & 0 & 0 & 0 & 0 & 0 \\
\hline
\end{tabular}




\begin{tabular}{|c|c|c|c|c|c|c|c|c|}
\hline Lac_Philippe & $\mathrm{D}$ & $\bar{F}$ & 0 & 0 & 0 & 0 & 0 & 0 \\
\hline Lac_Philippe & $E$ & $\mathrm{~F}$ & 0 & 0 & 0 & 0 & 0 & 0 \\
\hline Lac_Philippe & $\bar{F}$ & $\mathrm{~F}$ & 0 & 0 & 0 & 0 & 0 & 1 \\
\hline Lac_Philippe & $\mathrm{H}$ & $\mathrm{F}$ & 0 & 0 & 1 & 0 & 0 & 0 \\
\hline Lac_Philippe & $\mathrm{I}$ & $\mathrm{F}$ & 0 & 0 & 0 & 0 & 0 & 0 \\
\hline Manoir_des_Trembles & $\mathrm{A}$ & UN & 0 & 0 & 0 & 0 & 0 & 0 \\
\hline Manoir_des_Trembles & $\mathrm{B}$ & UN & 0 & 0 & 0 & 0 & 0 & 0 \\
\hline Manoir_des_Trembles & $\mathrm{C}$ & UN & 0 & 0 & 24 & 0 & 1 & 0 \\
\hline Manoir_des_Trembles & $\mathrm{D}$ & $\mathrm{UN}$ & 0 & 0 & 2 & 0 & 0 & 0 \\
\hline Manoir_des_Trembles & $\mathrm{E}$ & UN & 0 & 0 & 5 & 0 & 0 & 0 \\
\hline Manoir_des_Trembles & $\mathrm{F}$ & $\mathrm{UN}$ & 0 & 0 & 0 & 0 & 0 & 0 \\
\hline Manoir_des_Trembles & $\mathrm{H}$ & UN & 0 & 0 & 0 & 0 & 0 & 0 \\
\hline Manoir_des_Trembles & I & UN & 0 & 0 & 0 & 0 & 0 & 0 \\
\hline Marathon & $\bar{A}$ & $\mathrm{E}$ & 0 & 0 & 0 & 0 & 0 & 0 \\
\hline Marathon & $\mathrm{B}$ & $\mathrm{E}$ & 0 & 0 & 0 & 0 & 0 & 0 \\
\hline Marathon & $\mathrm{C}$ & $\mathrm{E}$ & 0 & 3 & 0 & 0 & 0 & 0 \\
\hline Marathon & $\mathrm{D}$ & $\mathrm{E}$ & 0 & 0 & 0 & 0 & 0 & 0 \\
\hline Marathon & $E$ & $\mathrm{E}$ & 0 & 0 & 0 & 0 & 0 & 0 \\
\hline Marathon & $\mathrm{F}$ & $\mathrm{E}$ & 0 & 0 & 0 & 0 & 0 & 0 \\
\hline Marathon & $\mathrm{H}$ & $\bar{E}$ & 0 & 0 & 0 & 0 & 0 & 0 \\
\hline Marathon & I & $\bar{E}$ & 0 & 2 & 0 & 0 & 0 & 0 \\
\hline Marier & $\mathrm{A}$ & $\mathrm{U}$ & 0 & 0 & 0 & 0 & 0 & 0 \\
\hline Marier & $\mathrm{B}$ & $\mathrm{U}$ & 0 & 0 & 0 & 0 & 0 & 0 \\
\hline Marier & $\mathrm{C}$ & $\mathrm{U}$ & 0 & 0 & 0 & 0 & 0 & 0 \\
\hline Marier & $\bar{D}$ & $\bar{U}$ & 0 & 0 & 0 & 0 & 0 & 0 \\
\hline Marier & $\mathrm{E}$ & $\mathrm{U}$ & 0 & 0 & 0 & 0 & 0 & 0 \\
\hline Marier & $\mathrm{F}$ & $\bar{U}$ & 0 & 0 & 1 & 0 & 0 & 0 \\
\hline Marier & $\mathrm{H}$ & $\mathrm{U}$ & 0 & 0 & 0 & 0 & 0 & 0 \\
\hline Marier & I & $U$ & 0 & 0 & 0 & 0 & 0 & 0 \\
\hline Marlborough & $\mathrm{A}$ & $\mathbf{F}$ & 0 & 0 & 0 & 0 & 0 & 0 \\
\hline Marlborough & B & $\mathbf{F}$ & 0 & 0 & 0 & 0 & 0 & $\overline{0}$ \\
\hline Marlborough & $\mathrm{C}$ & $\mathbf{F}$ & 0 & 0 & 0 & 0 & 0 & 0 \\
\hline Marlborough & $\mathrm{D}$ & $\mathbf{F}$ & 0 & 0 & 0 & 0 & 0 & 0 \\
\hline Marlborough & $E$ & $\mathbf{F}$ & 0 & 0 & 0 & 0 & 0 & 0 \\
\hline Marlborough & $\mathrm{F}$ & $\mathbf{F}$ & 0 & 1 & 0 & 0 & 0 & 0 \\
\hline Marlborough & $\mathrm{H}$ & $\mathbf{F}$ & 0 & 0 & 0 & 0 & 0 & 0 \\
\hline Marlborough & I & $\mathbf{F}$ & 0 & 0 & 0 & 0 & 0 & 0 \\
\hline Merivale & $\mathrm{A}$ & $\mathrm{SN}$ & 0 & 0 & 0 & 0 & 0 & 0 \\
\hline Merivale & B & $\mathrm{SN}$ & 0 & 0 & 0 & 0 & 0 & 0 \\
\hline Merivale & $\mathrm{C}$ & $\overline{\mathrm{SN}}$ & 0 & 0 & 15 & 0 & 1 & 1 \\
\hline Merivale & $\mathrm{D}$ & SN & 0 & 0 & 0 & 0 & 0 & $\overline{0}$ \\
\hline Merivale & $\mathrm{E}$ & $\mathrm{SN}$ & 0 & 0 & 0 & 0 & 4 & $\overline{0}$ \\
\hline
\end{tabular}




\begin{tabular}{|c|c|c|c|c|c|c|c|c|}
\hline Merivale & $F$ & SN & 0 & 0 & 0 & 0 & 0 & 0 \\
\hline Merivale & $\mathrm{H}$ & $\mathrm{SN}$ & 0 & 5 & 0 & 0 & 17 & 1 \\
\hline Merivale & I & $\overline{\mathrm{SN}}$ & 0 & 0 & 0 & 0 & 1 & 1 \\
\hline Parc_Champlain & $\overline{\mathrm{A}}$ & $S$ & 0 & 0 & $\overline{0}$ & 0 & 0 & $\overline{0}$ \\
\hline Parc_Champlain & B & $\mathrm{S}$ & 0 & 0 & 0 & 0 & $\overline{0}$ & 0 \\
\hline Parc_Champlain & $\mathrm{C}$ & $\bar{S}$ & 0 & 0 & 0 & 0 & 0 & $\overline{0}$ \\
\hline Parc_Champlain & $\mathrm{D}$ & $\bar{S}$ & 0 & 0 & 0 & 0 & 0 & $\overline{0}$ \\
\hline Parc_Champlain & $\bar{E}$ & $\bar{S}$ & 0 & 0 & 0 & 0 & 0 & $\overline{0}$ \\
\hline Parc_Champlain & $\bar{F}$ & $S$ & 0 & 0 & $\overline{0}$ & 1 & 0 & $\overline{0}$ \\
\hline Parc_Champlain & $\overline{\mathrm{H}}$ & $S$ & 0 & 0 & 0 & 0 & 0 & $\overline{0}$ \\
\hline Parc_Champlain & I & $\mathrm{S}$ & 0 & 0 & 0 & 0 & 0 & $\overline{0}$ \\
\hline Pelissier & $\bar{A}$ & $\overline{\mathrm{EN}}$ & 0 & 0 & 0 & 0 & 0 & $\overline{0}$ \\
\hline Pelissier & B & $\overline{\mathrm{EN}}$ & 0 & 0 & 0 & 0 & 0 & $\overline{0}$ \\
\hline Pelissier & $\mathrm{C}$ & $\overline{\mathrm{EN}}$ & 0 & 2 & 0 & 0 & 0 & $\overline{2}$ \\
\hline Pelissier & D & $\mathrm{EN}$ & 0 & 0 & 0 & 0 & 0 & $\overline{0}$ \\
\hline Pelissier & $\mathrm{E}$ & $\mathrm{EN}$ & 0 & 0 & 0 & 0 & 0 & $\overline{0}$ \\
\hline Pelissier & $F$ & EN & 0 & 0 & 0 & 0 & 0 & $\overline{0}$ \\
\hline Pelissier & $\mathrm{H}$ & EN & 0 & 0 & 0 & 0 & 0 & 0 \\
\hline Pelissier & I & $\overline{\mathrm{EN}}$ & 0 & 0 & 0 & 0 & 0 & $\overline{0}$ \\
\hline PineGlen_Annex & $\bar{A}$ & $S$ & 0 & 0 & 0 & 0 & 0 & $\overline{0}$ \\
\hline PineGlen_Annex & $\bar{B}$ & $S$ & 0 & $\overline{0}$ & 0 & 0 & 0 & $\overline{0}$ \\
\hline PineGlen_Annex & $\mathrm{C}$ & $\bar{S}$ & 0 & 0 & 0 & 0 & 0 & 0 \\
\hline PineGlen_Annex & $\bar{D}$ & $\mathrm{~S}$ & 0 & 0 & 0 & 0 & 0 & 0 \\
\hline PineGlen_Annex & $E$ & $S$ & 0 & 0 & 0 & 0 & 0 & $\overline{0}$ \\
\hline PineGlen_Annex & $\mathrm{F}$ & $S$ & 0 & 0 & 0 & 0 & 0 & 0 \\
\hline PineGlen_Annex & $\mathrm{H}$ & $\mathrm{S}$ & 0 & 0 & 0 & 0 & 0 & 0 \\
\hline PineGlen_Annex & I & $S$ & 0 & 0 & 0 & 0 & 0 & 0 \\
\hline Q_Four & A & $\overline{\mathrm{E}}$ & 0 & 0 & 0 & $\overline{0}$ & 0 & 0 \\
\hline Q_Four & $\bar{B}$ & $\mathrm{E}$ & 0 & 0 & 0 & 0 & 0 & 0 \\
\hline Q_Four & $\mathrm{C}$ & $\mathrm{E}$ & 0 & 0 & 0 & $\overline{0}$ & 0 & 1 \\
\hline Q_Four & $\mathrm{D}$ & $\mathrm{E}$ & 0 & 0 & 0 & 0 & 0 & 0 \\
\hline Q_Four & $\bar{E}$ & $E$ & 0 & 0 & 0 & 0 & 0 & 0 \\
\hline Q_Four & $F$ & $\mathrm{E}$ & 0 & 0 & 1 & 0 & 0 & 0 \\
\hline Q_Four & $\mathrm{H}$ & $\mathrm{E}$ & 0 & 0 & 0 & 0 & 0 & 0 \\
\hline Q_Four & I & $\bar{E}$ & 0 & 0 & 0 & 0 & 0 & 0 \\
\hline Sandy_Hill & $\bar{A}$ & $\overline{\mathrm{U}}$ & 0 & 0 & 0 & 0 & 0 & 0 \\
\hline Sandy_Hill & $\bar{B}$ & $\overline{\mathrm{U}}$ & 0 & 0 & 0 & 0 & 0 & 0 \\
\hline Sandy_Hill & $\mathrm{C}$ & $\mathrm{U}$ & 0 & 0 & 0 & 0 & 0 & 0 \\
\hline Sandy_Hill & $\bar{D}$ & $\overrightarrow{\mathrm{U}}$ & 0 & 0 & 0 & 0 & 0 & 0 \\
\hline Sandy_Hill & $E$ & $\overline{\mathrm{U}}$ & 0 & 0 & 0 & 0 & 0 & 0 \\
\hline Sandy_Hill & $\bar{F}$ & $\bar{U}$ & 0 & 0 & 0 & 0 & 0 & 0 \\
\hline Sandy_Hill & $\mathrm{H}$ & $\overline{\mathrm{U}}$ & 0 & 0 & 0 & 0 & 0 & 0 \\
\hline
\end{tabular}




\begin{tabular}{|c|c|c|c|c|c|c|c|c|}
\hline Sandy_Hill & I & $\mathrm{U}$ & 0 & 0 & 0 & 0 & 0 & 0 \\
\hline Vallee_Meech & $\mathrm{A}$ & $\mathrm{F}$ & 0 & 0 & 0 & 0 & 0 & 0 \\
\hline Vallee_Meech & $\mathrm{B}$ & $\bar{F}$ & 0 & 0 & 0 & 0 & 0 & 0 \\
\hline Vallee_Meech & $\mathrm{C}$ & $\mathrm{F}$ & 0 & 0 & 0 & 0 & 0 & 0 \\
\hline Vallee_Meech & $\mathrm{D}$ & $\bar{F}$ & 0 & 0 & 0 & 0 & 0 & 0 \\
\hline Vallee_Meech & $\mathrm{E}$ & $\bar{F}$ & 0 & 0 & 0 & 0 & 0 & 0 \\
\hline Vallee_Meech & $\mathrm{F}$ & F & 0 & 0 & 0 & 0 & 0 & 0 \\
\hline Vallee_Meech & $\mathrm{H}$ & $\bar{F}$ & 0 & 0 & 0 & 0 & 0 & 0 \\
\hline Vallee_Meech & I & $\bar{F}$ & 0 & 0 & 0 & 0 & 0 & 0 \\
\hline Wolf_Grove & $\mathrm{A}$ & $\mathrm{E}$ & 0 & 1 & 0 & 0 & 0 & 0 \\
\hline Wolf_Grove & $\mathrm{B}$ & $\bar{E}$ & 0 & 0 & 0 & 0 & 0 & 0 \\
\hline Wolf_Grove & $\mathrm{C}$ & $\bar{E}$ & 0 & 0 & 0 & 0 & 0 & 0 \\
\hline Wolf_Grove & $\mathrm{D}$ & $\bar{E}$ & 0 & $\overline{0}$ & 0 & 0 & 0 & 0 \\
\hline Wolf_Grove & $E$ & $E$ & 0 & 0 & 0 & 0 & 0 & 0 \\
\hline Wolf_Grove & $\mathrm{F}$ & $\mathrm{E}$ & 0 & 0 & 0 & 0 & 0 & 0 \\
\hline Wolf_Grove & $\mathrm{H}$ & $E$ & 0 & 0 & 0 & 0 & 0 & 0 \\
\hline Wolf_Grove & I & $E$ & 0 & 0 & 0 & 0 & 0 & 0 \\
\hline Wrightville & $\bar{A}$ & $\bar{U}$ & 0 & 0 & 0 & 0 & 0 & 0 \\
\hline Wrightville & $\bar{B}$ & $\overline{\mathrm{U}}$ & 0 & 0 & 0 & 0 & 0 & 0 \\
\hline Wrightville & $\mathrm{C}$ & $\bar{U}$ & 0 & 0 & 0 & 0 & 0 & 0 \\
\hline Wrightville & $\mathrm{D}$ & $\mathrm{U}$ & 0 & 0 & 0 & 0 & 0 & 0 \\
\hline Wrightville & $E$ & $\mathrm{U}$ & 0 & 0 & 0 & 0 & 0 & 0 \\
\hline Wrightville & $F$ & $\mathrm{U}$ & 0 & 0 & 0 & 0 & 0 & 0 \\
\hline Wrightville & $\mathrm{H}$ & $\bar{U}$ & 0 & 0 & 0 & 0 & 0 & 0 \\
\hline Wrightville & I & $\bar{U}$ & 0 & 0 & 0 & 0 & 0 & 0 \\
\hline Wychwood & $\mathrm{A}$ & $\mathrm{S}$ & 0 & 0 & 0 & 0 & 0 & 0 \\
\hline Wychwood & B & $\mathrm{S}$ & 0 & 0 & 0 & 0 & 0 & 0 \\
\hline Wychwood & $\mathrm{C}$ & $\mathrm{S}$ & 0 & 0 & 0 & 4 & 0 & 0 \\
\hline Wychwood & $\mathrm{D}$ & $\mathrm{S}$ & 0 & 0 & 0 & 0 & 0 & 0 \\
\hline Wychwood & $E$ & $S$ & 0 & 0 & 0 & 0 & 0 & 0 \\
\hline Wychwood & $\mathrm{F}$ & $\mathrm{S}$ & 0 & 0 & 0 & 0 & 0 & 0 \\
\hline Wychwood & $\overline{\mathrm{H}}$ & $\bar{S}$ & 0 & 0 & 0 & 0 & 0 & 0 \\
\hline Wychwood & I & $\bar{S}$ & 0 & 0 & 0 & 0 & 0 & 0 \\
\hline
\end{tabular}




\begin{tabular}{|c|c|c|c|c|c|c|c|c|}
\hline SITE & STATION & CATEGORY & AGTE & AGTR & AMAE & AMAN & AMAP & $\overline{A M C U}$ \\
\hline Achbar & $\mathrm{A}$ & $\mathrm{SN}$ & 0 & 0 & 0 & 0 & 0 & 0 \\
\hline Achbar & B & $\overline{\mathrm{SN}}$ & 0 & 0 & 0 & 0 & 0 & $\overline{0}$ \\
\hline Achbar & $\bar{C}$ & $\overline{\mathrm{SN}}$ & 0 & 0 & 0 & 0 & 0 & 0 \\
\hline Achbar & $\bar{D}$ & $\mathrm{SN}$ & 0 & 0 & 0 & 0 & 0 & 0 \\
\hline Achbar & $E$ & $\overline{\mathrm{SN}}$ & 0 & 2 & 0 & 0 & 0 & 0 \\
\hline Achbar & $\mathrm{F}$ & SN & 0 & 0 & 0 & 0 & 0 & 0 \\
\hline Achbar & $\mathrm{H}$ & $\mathrm{SN}$ & 0 & 0 & 0 & 0 & 0 & 0 \\
\hline Achbar & I & $\mathrm{SN}$ & 0 & 0 & 0 & 0 & 0 & 0 \\
\hline Bridlewood & $\bar{A}$ & $\mathrm{UN}$ & 0 & 0 & 0 & 0 & 0 & 0 \\
\hline Bridlewood & $\mathrm{B}$ & $\overline{\mathrm{UN}}$ & 0 & 0 & 0 & 0 & 0 & 0 \\
\hline Bridlewood & $\mathrm{C}$ & $\overline{U N}$ & 0 & 0 & 0 & 0 & 0 & 0 \\
\hline Bridlewood & $\bar{D}$ & $\overline{\mathrm{UN}}$ & 0 & 0 & 0 & 0 & 0 & $\overline{0}$ \\
\hline Bridlewood & $E$ & $\overline{\mathrm{UN}}$ & 0 & 0 & 0 & 0 & 0 & 0 \\
\hline Bridlewood & $\mathrm{F}$ & $\overline{\mathrm{UN}}$ & 0 & 1 & 0 & 0 & 0 & 0 \\
\hline Bridlewood & $\mathrm{H}$ & $\overline{\mathrm{UN}}$ & 0 & 0 & 0 & 0 & 0 & $\overline{0}$ \\
\hline Bridlewood & I & $\mathrm{UN}$ & 0 & 0 & 0 & 0 & 0 & 0 \\
\hline Carp_Hills & A & $F$ & 0 & 1 & 0 & 0 & 0 & 0 \\
\hline Carp_Hills & $\mathrm{B}$ & $F$ & 0 & 1 & 0 & 0 & 0 & 0 \\
\hline Carp_Hills & $\overline{\mathrm{C}}$ & $F$ & 0 & 0 & 0 & 0 & 0 & 0 \\
\hline Carp_Hills & $\bar{D}$ & $\bar{F}$ & 0 & 0 & 0 & 0 & 0 & 1 \\
\hline Carp_Hills & $\mathrm{E}$ & $\bar{F}$ & 1 & 0 & 0 & 0 & 0 & 0 \\
\hline Carp_Hills & $\bar{F}$ & $F$ & 0 & 0 & 0 & 0 & 0 & 0 \\
\hline Carp_Hills & $\mathrm{H}$ & $F$ & 0 & 0 & 0 & 0 & 0 & 0 \\
\hline Carp_Hills & I & $\bar{F}$ & 0 & 0 & 0 & 0 & 0 & 0 \\
\hline Chapel_Hill & $\mathrm{A}$ & $\overline{U N}$ & 0 & 0 & 0 & 0 & 0 & 0 \\
\hline Chapel_Hill & B & $\overline{\mathrm{UN}}$ & 0 & 0 & 0 & 0 & 0 & 0 \\
\hline Chapel_Hill & $\mathrm{C}$ & $\overline{\mathrm{UN}}$ & 0 & 0 & 0 & 0 & 0 & $\overline{0}$ \\
\hline Chapel_Hill & $\bar{D}$ & $\overline{\mathrm{UN}}$ & 0 & 0 & 0 & 0 & 0 & 0 \\
\hline Chapel_Hill & $\bar{E}$ & $\overline{\mathrm{UN}}$ & 0 & 5 & 0 & 0 & 0 & 0 \\
\hline Chapel_Hill & $\bar{F}$ & $\overline{\mathrm{UN}}$ & 0 & 0 & 0 & 0 & 0 & 0 \\
\hline Chapel_Hill & $\mathrm{H}$ & $\overline{\mathrm{UN}}$ & 0 & 0 & 0 & 0 & 0 & 0 \\
\hline Chapel_Hill & I & UN & 0 & 9 & 0 & 0 & 0 & 0 \\
\hline Chelsea & $\bar{A}$ & $\mathrm{SN}$ & 0 & 0 & 0 & 0 & 0 & 0 \\
\hline Chelsea & $\bar{B}$ & $\mathrm{SN}$ & 0 & 0 & 0 & 0 & 0 & 0 \\
\hline Chelsea & $\mathrm{C}$ & SN & 0 & 0 & 0 & 0 & 0 & 0 \\
\hline Chelsea & $\bar{D}$ & $\mathrm{SN}$ & 0 & 0 & 0 & 0 & 0 & 0 \\
\hline Chelsea & $\mathrm{E}$ & $\overline{\mathrm{SN}}$ & 0 & 0 & 0 & 0 & 0 & 0 \\
\hline Chelsea & $\mathrm{F}$ & $\mathrm{SN}$ & 0 & 0 & 0 & 0 & 0 & 0 \\
\hline Chelsea & $\mathrm{H}$ & $\mathrm{SN}$ & 0 & 0 & 0 & 0 & 0 & 0 \\
\hline Chelsea & I & SN & 0 & 0 & 0 & 0 & 0 & 0 \\
\hline
\end{tabular}




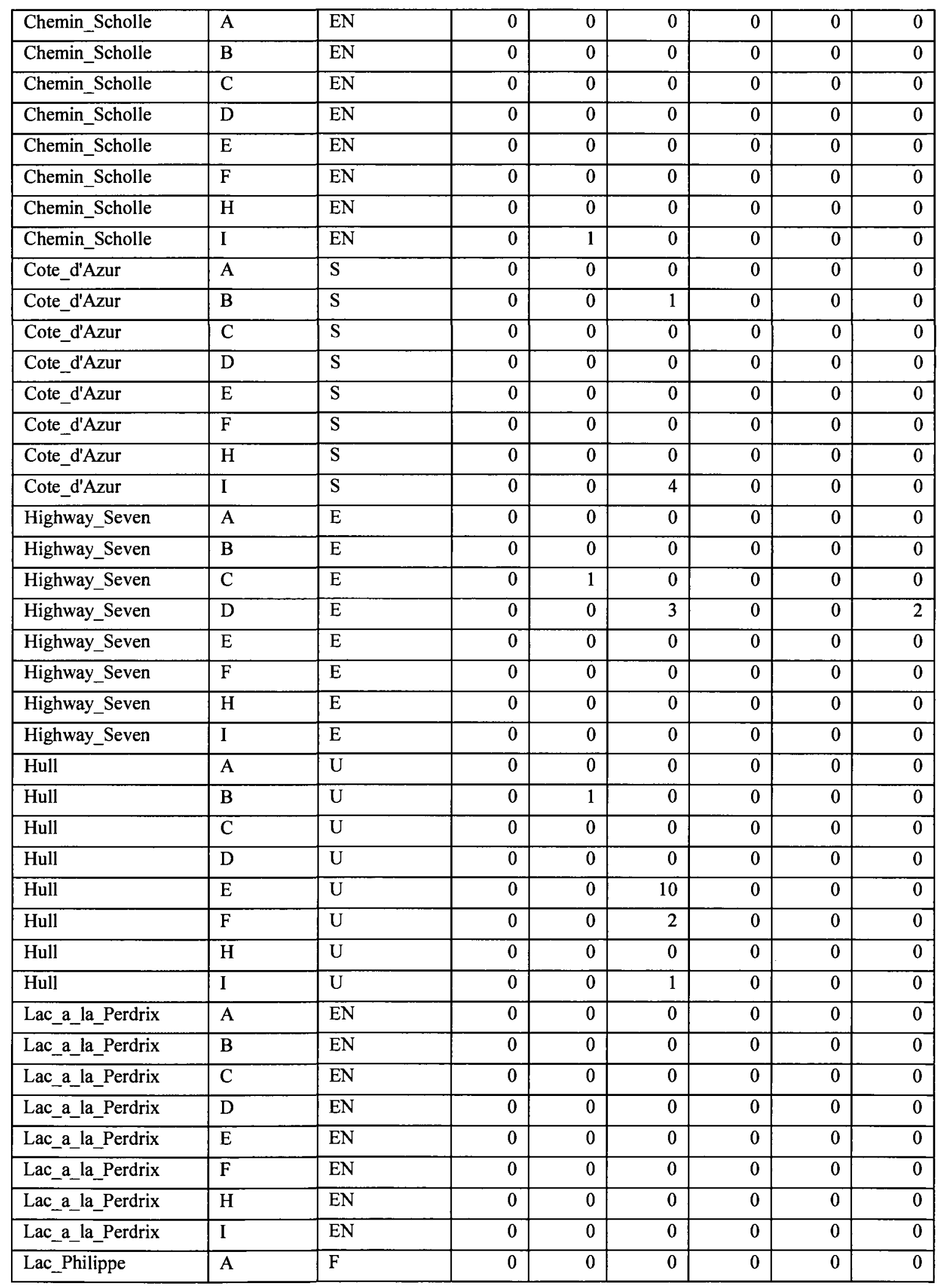




\begin{tabular}{|c|c|c|c|c|c|c|c|c|}
\hline Lac_Philippe & B & $\mathrm{F}$ & 0 & 0 & 0 & 0 & 0 & 0 \\
\hline Lac_Philippe & $\mathrm{C}$ & $\mathrm{F}$ & 0 & 0 & 0 & 0 & 0 & 0 \\
\hline Lac_Philippe & $\bar{D}$ & $\mathrm{~F}$ & 0 & 0 & 0 & 0 & 0 & 0 \\
\hline Lac_Philippe & $\mathbf{E}$ & $\mathrm{F}$ & 0 & 0 & 0 & 0 & 0 & 0 \\
\hline Lac_Philippe & $F$ & $\mathrm{~F}$ & 0 & 0 & 0 & 0 & 0 & 0 \\
\hline Lac_Philippe & $\mathbf{H}$ & $\mathrm{F}$ & 0 & 0 & 0 & 0 & 0 & 0 \\
\hline Lac_Philippe & $\mathbf{I}$ & $\mathrm{F}$ & 0 & 0 & 0 & 0 & 0 & 0 \\
\hline Manoir_des_Trembles & $\bar{A}$ & UN & 0 & 0 & 0 & 0 & 0 & 0 \\
\hline Manoir_des_Trembles & B & UN & 0 & 0 & 0 & 0 & 0 & 0 \\
\hline Manoir_des_Trembles & $\mathrm{C}$ & UN & 0 & 12 & 0 & 0 & 0 & 0 \\
\hline Manoir_des_Trembles & $\mathrm{D}$ & UN & 0 & 1 & 0 & 0 & 0 & $\overline{0}$ \\
\hline Manoir_des_Trembles & $\mathbf{E}$ & UN & 0 & 4 & 0 & 0 & 0 & 0 \\
\hline Manoir_des_Trembles & $F$ & $\overline{\mathrm{UN}}$ & 0 & 0 & 0 & 0 & 0 & 0 \\
\hline Manoir_des_Trembles & $\mathbf{H}$ & UN & 0 & 0 & 0 & 0 & 0 & 0 \\
\hline Manoir_des_Trembles & $\bar{I}$ & UN & 0 & 0 & 0 & 0 & 0 & $\overline{0}$ \\
\hline Marathon & $\mathrm{A}$ & $\mathrm{E}$ & 0 & 0 & 0 & 0 & 0 & $\overline{0}$ \\
\hline Marathon & B & $\bar{E}$ & 0 & 0 & 0 & 0 & 0 & 0 \\
\hline Marathon & $\mathrm{C}$ & $\mathrm{E}$ & 0 & 0 & 0 & 0 & 0 & 0 \\
\hline Marathon & $\mathrm{D}$ & $\mathrm{E}$ & 0 & 0 & 0 & 0 & 0 & 0 \\
\hline Marathon & $\mathbf{E}$ & $\mathrm{E}$ & 0 & 0 & 0 & 0 & 0 & 0 \\
\hline Marathon & $\mathrm{F}$ & $\mathrm{E}$ & 0 & 0 & 0 & 0 & 0 & 0 \\
\hline Marathon & $\mathbf{H}$ & $\mathrm{E}$ & 0 & 1 & 0 & 0 & 0 & $\overline{0}$ \\
\hline Marathon & $\mathbf{I}$ & $\mathrm{E}$ & 0 & 0 & 0 & 0 & 0 & 0 \\
\hline Marier & $\mathrm{A}$ & $\overline{\mathrm{U}}$ & 0 & 0 & 0 & 0 & 4 & $\overline{0}$ \\
\hline Marier & B & $\mathrm{U}$ & 0 & 0 & 7 & 1 & 0 & 0 \\
\hline Marier & $\mathrm{C}$ & $\mathrm{U}$ & 0 & 0 & 0 & 0 & 0 & 0 \\
\hline Marier & $\mathrm{D}$ & $\overline{\mathrm{U}}$ & 0 & 0 & 2 & 0 & 1 & 0 \\
\hline Marier & $\mathrm{E}$ & $\mathrm{U}$ & 0 & 0 & 0 & 0 & 0 & 0 \\
\hline Marier & $\mathrm{F}$ & $\mathrm{U}$ & 0 & 0 & 0 & 0 & 0 & 0 \\
\hline Marier & $\mathrm{H}$ & $\mathrm{U}$ & 0 & 0 & 0 & 0 & 0 & 0 \\
\hline Marier & I & $\overline{\mathrm{U}}$ & 0 & 0 & 0 & 0 & 0 & 0 \\
\hline Marlborough & $\bar{A}$ & $\mathrm{~F}$ & 0 & 0 & 0 & 0 & 0 & 0 \\
\hline Marlborough & B & $\bar{F}$ & 0 & 0 & 0 & 0 & 0 & 0 \\
\hline Marlborough & $\mathrm{C}$ & $\mathrm{F}$ & 0 & 0 & 0 & 0 & 0 & 0 \\
\hline Marlborough & $\mathrm{D}$ & $\mathrm{F}$ & 0 & 0 & 0 & 0 & 0 & 0 \\
\hline Marlborough & $\mathrm{E}$ & $\bar{F}$ & 0 & 0 & 0 & 0 & 0 & 0 \\
\hline Marlborough & $\mathrm{F}$ & $\bar{F}$ & 0 & 1 & 0 & 0 & 0 & 0 \\
\hline Marlborough & $\mathrm{H}$ & $\bar{F}$ & 0 & 0 & 0 & 0 & 0 & 0 \\
\hline Marlborough & $\mathrm{I}$ & $\bar{F}$ & 0 & 0 & 0 & 0 & 0 & 0 \\
\hline Merivale & A & SN & 0 & 0 & 0 & 0 & 0 & 0 \\
\hline Merivale & B & SN & 0 & 0 & 0 & 0 & 0 & 0 \\
\hline
\end{tabular}




\begin{tabular}{|c|c|c|c|c|c|c|c|c|}
\hline Merivale & $\mathrm{C}$ & SN & 0 & 0 & 0 & 0 & 0 & 0 \\
\hline Merivale & $\mathrm{D}$ & SN & 0 & 0 & 0 & 0 & 0 & 0 \\
\hline Merivale & $E$ & SN & 0 & 0 & 0 & 0 & 0 & 0 \\
\hline Merivale & $\mathbf{F}$ & $\overline{\mathrm{SN}}$ & 0 & 3 & 0 & 0 & 0 & 0 \\
\hline Merivale & $\mathrm{H}$ & $\overline{\mathrm{SN}}$ & 0 & 0 & 0 & 0 & 0 & 0 \\
\hline Merivale & I & $\mathrm{SN}$ & 0 & 0 & 0 & 0 & 0 & 0 \\
\hline Parc_Champlain & $\mathrm{A}$ & $\mathbf{S}$ & 0 & 0 & 4 & 0 & 0 & 0 \\
\hline Parc_Champlain & B & $\mathrm{S}$ & 0 & 0 & 0 & 0 & 0 & 0 \\
\hline Parc_Champlain & $\mathrm{C}$ & $\mathbf{S}$ & 0 & 0 & 0 & 0 & 0 & 0 \\
\hline Parc_Champlain & $\mathrm{D}$ & $\mathbf{S}$ & 0 & 0 & I & 0 & 0 & 0 \\
\hline Parc_Champlain & $\mathrm{E}$ & $\mathbf{S}$ & 0 & 0 & 0 & 0 & 0 & $\overline{0}$ \\
\hline Parc_Champlain & $\overline{\mathrm{F}}$ & $\mathbf{S}$ & 0 & 0 & 0 & 0 & 0 & 0 \\
\hline Parc_Champlain & $\mathrm{H}$ & $\mathbf{S}$ & 0 & 0 & 0 & 1 & 0 & 0 \\
\hline Parc_Champlain & I & $\mathbf{S}$ & 0 & 0 & 0 & 0 & 0 & 0 \\
\hline Pelissier & $\mathrm{A}$ & EN & 0 & 0 & 0 & 0 & 0 & 0 \\
\hline Pelissier & $\mathrm{B}$ & EN & 0 & 0 & 0 & 0 & 0 & $\overline{0}$ \\
\hline Pelissier & $\mathrm{C}$ & EN & 0 & 0 & 0 & 0 & 0 & 0 \\
\hline Pelissier & $\mathrm{D}$ & EN & 0 & 0 & 0 & 0 & 0 & 0 \\
\hline Pelissier & $E$ & EN & 0 & 0 & 0 & 0 & 0 & 0 \\
\hline Pelissier & $\mathrm{F}$ & EN & 0 & 0 & 0 & 0 & 0 & 0 \\
\hline Pelissier & $\mathrm{H}$ & EN & 0 & 0 & 0 & 0 & 0 & 0 \\
\hline Pelissier & I & EN & 0 & 0 & 0 & 0 & 0 & 0 \\
\hline PineGlen_Annex & A & $\mathrm{S}$ & 0 & 0 & 0 & 0 & 0 & 0 \\
\hline PineGlen_Annex & $\mathrm{B}$ & $\mathbf{S}$ & 0 & 0 & 0 & 0 & 0 & 0 \\
\hline PineGlen_Annex & $\mathrm{C}$ & $\mathbf{S}$ & 0 & 0 & 19 & 0 & 0 & 0 \\
\hline PineGlen_Annex & $\mathrm{D}$ & $\bar{S}$ & 0 & 0 & 0 & 0 & 0 & 0 \\
\hline PineGlen_Annex & $E$ & $\mathbf{S}$ & 0 & 0 & 4 & 0 & 0 & 0 \\
\hline PineGlen_Annex & $F$ & $\mathbf{S}$ & 0 & 0 & 0 & 0 & 0 & 0 \\
\hline PineGlen_Annex & $\mathrm{H}$ & $\mathrm{S}$ & 0 & 0 & 0 & 0 & 0 & 0 \\
\hline PineGlen_Annex & I & $\mathrm{S}$ & 0 & 0 & 4 & 0 & 1 & 0 \\
\hline Q_Four & A & $\mathrm{E}$ & 0 & 0 & 0 & 0 & 0 & 0 \\
\hline Q_Four & $\mathrm{B}$ & $\mathrm{E}$ & 0 & 0 & 0 & 0 & 0 & 0 \\
\hline Q_Four & $\mathrm{C}$ & $\mathrm{E}$ & 0 & 0 & 0 & 0 & 0 & 0 \\
\hline Q_Four & $\mathrm{D}$ & $E$ & 0 & 0 & 0 & 0 & 0 & $\overline{0}$ \\
\hline Q_Four & $E$ & $\mathrm{E}$ & 0 & 0 & 0 & 0 & 0 & 0 \\
\hline Q_Four & $\mathrm{F}$ & $E$ & 0 & 0 & 0 & 0 & 0 & 0 \\
\hline Q_Four & $\mathrm{H}$ & $E$ & 0 & 1 & 0 & 0 & 0 & 0 \\
\hline Q_Four & I & $\mathrm{E}$ & 0 & 0 & 0 & 0 & 0 & 0 \\
\hline Sandy_Hill & A & $\mathrm{U}$ & 0 & 0 & 1 & 0 & 0 & 0 \\
\hline Sandy_Hill & B & $\mathrm{U}$ & 0 & 0 & 0 & 0 & 1 & $\overline{0}$ \\
\hline Sandy_Hill & $\mathrm{C}$ & $\mathrm{U}$ & 0 & 0 & 1 & 0 & 0 & 0 \\
\hline
\end{tabular}




\begin{tabular}{|c|c|c|c|c|c|c|c|c|}
\hline Sandy_Hill & $\mathrm{D}$ & $\mathrm{U}$ & 0 & 0 & 0 & 0 & 0 & 0 \\
\hline Sandy_Hill & $\mathbf{E}$ & $\mathrm{U}$ & 0 & 0 & 0 & 0 & 0 & 0 \\
\hline Sandy_Hill & $\mathbf{F}$ & $\bar{U}$ & 0 & 0 & 0 & 0 & 0 & 0 \\
\hline Sandy_Hill & $\mathrm{H}$ & $\mathrm{U}$ & 0 & 0 & 0 & 0 & 0 & 0 \\
\hline Sandy_Hill & I & $\bar{U}$ & 0 & 0 & 0 & 0 & 0 & 0 \\
\hline Vallee_Meech & A & $F$ & 0 & 0 & 0 & 0 & 0 & 0 \\
\hline Vallee_Meech & B & $F$ & 0 & 0 & 0 & 0 & 0 & 0 \\
\hline Vallee_Meech & $\mathrm{C}$ & $F$ & 0 & 0 & 0 & 0 & $\overline{0}$ & 0 \\
\hline Vallee_Meech & $\mathrm{D}$ & $F$ & 0 & 0 & 0 & 0 & 0 & 0 \\
\hline Vallee_Meech & $\mathbf{E}$ & $\bar{F}$ & 0 & 0 & 0 & 0 & 0 & 0 \\
\hline Vallee_Meech & $\mathbf{F}$ & $\mathrm{F}$ & 0 & 0 & 0 & 0 & 0 & 0 \\
\hline Vallee_Meech & $\mathrm{H}$ & $\bar{F}$ & 0 & 0 & 0 & 0 & 0 & 0 \\
\hline Vallee_Meech & I & $\bar{F}$ & 0 & 0 & 0 & 0 & 0 & 0 \\
\hline Wolf_Grove & $\mathrm{A}$ & $E$ & 0 & 0 & 0 & 0 & 0 & 0 \\
\hline Wolf_Grove & B & $E$ & $\overline{0}$ & 0 & 0 & 0 & 0 & $\overline{0}$ \\
\hline Wolf_Grove & $\mathrm{C}$ & $\bar{E}$ & 0 & 0 & 0 & 0 & 0 & $\overline{0}$ \\
\hline Wolf_Grove & $\mathrm{D}$ & $\mathrm{E}$ & 0 & 0 & 0 & 0 & 0 & 0 \\
\hline Wolf_Grove & $\mathbf{E}$ & $E$ & 0 & 0 & 0 & 0 & 0 & 0 \\
\hline Wolf_Grove & $F$ & $E$ & 0 & 1 & 0 & 0 & 0 & 0 \\
\hline Wolf_Grove & $\mathrm{H}$ & $\mathrm{E}$ & 0 & 0 & 0 & 0 & 0 & 0 \\
\hline Wolf_Grove & I & $\mathrm{E}$ & 0 & 0 & 0 & 0 & 0 & 0 \\
\hline Wrightville & A & $\bar{U}$ & 0 & 0 & 7 & 0 & 2 & 0 \\
\hline Wrightville & $\mathbf{B}$ & $\overline{\mathrm{U}}$ & 0 & 0 & 0 & 0 & 0 & 1 \\
\hline Wrightville & $\mathrm{C}$ & $\bar{U}$ & 0 & 0 & 0 & 0 & 0 & 0 \\
\hline Wrightville & $\bar{D}$ & $\mathrm{U}$ & 0 & 0 & 0 & 0 & 1 & $\overline{0}$ \\
\hline Wrightville & $\bar{E}$ & $\mathrm{U}$ & 0 & 0 & 1 & 0 & 0 & 0 \\
\hline Wrightville & $\mathbf{F}$ & $\mathrm{U}$ & 0 & 0 & 0 & 0 & 0 & 0 \\
\hline Wrightville & $\mathrm{H}$ & $\bar{U}$ & 0 & 0 & 0 & 0 & 0 & 0 \\
\hline Wrightville & I & $\mathrm{U}$ & 0 & 0 & 0 & 0 & 0 & 0 \\
\hline Wychwood & A & $\mathrm{S}$ & 0 & 0 & 0 & 0 & 0 & 0 \\
\hline Wychwood & B & $\mathrm{S}$ & 0 & 0 & 1 & 0 & 0 & 0 \\
\hline Wychwood & $\mathrm{C}$ & $\mathrm{S}$ & 0 & 0 & 0 & 0 & 0 & 0 \\
\hline Wychwood & $\mathrm{D}$ & $\mathrm{S}$ & 0 & 0 & 0 & 0 & 0 & 0 \\
\hline Wychwood & $\mathbf{E}$ & $\mathrm{S}$ & 0 & 0 & 0 & 0 & 0 & 0 \\
\hline Wychwood & $\mathbf{F}$ & $\mathrm{S}$ & 0 & 0 & 1 & 0 & 0 & 0 \\
\hline Wychwood & $\mathrm{H}$ & $\mathbf{S}$ & 0 & 0 & 0 & 0 & 0 & 0 \\
\hline Wychwood & $\mathrm{I}$ & $\mathbf{S}$ & 0 & 0 & 0 & 0 & 0 & 0 \\
\hline
\end{tabular}




\begin{tabular}{|c|c|c|c|c|c|c|c|c|}
\hline SITE & STATION & CATEGORY & AMIM & $\overline{\text { AMIN }}$ & AMPA & AMRU & ANHA & ANKI \\
\hline Achbar & $\mathrm{A}$ & $\mathrm{SN}$ & 0 & 0 & 0 & 0 & 0 & 0 \\
\hline Achbar & $\mathrm{B}$ & SN & 0 & 0 & 0 & 0 & 0 & 0 \\
\hline Achbar & $\mathrm{C}$ & $\mathrm{SN}$ & 0 & 0 & 0 & 0 & 0 & 0 \\
\hline Achbar & $\bar{D}$ & $\mathrm{SN}$ & 0 & 0 & 0 & 0 & 0 & 0 \\
\hline Achbar & $\mathrm{E}$ & $\mathrm{SN}$ & 0 & 1 & 0 & 0 & 0 & 0 \\
\hline Achbar & $\bar{F}$ & $\mathrm{SN}$ & 0 & 0 & 0 & 0 & 0 & 0 \\
\hline Achbar & $\mathrm{H}$ & $\mathrm{SN}$ & 0 & 0 & 0 & 0 & 0 & 0 \\
\hline Achbar & $\bar{I}$ & SN & 0 & 0 & 0 & 0 & 0 & 0 \\
\hline Bridlewood & $\mathrm{A}$ & UN & 0 & 0 & 0 & 0 & 0 & 0 \\
\hline Bridlewood & $\mathrm{B}$ & $\overline{\mathrm{UN}}$ & 0 & 0 & 0 & 0 & 0 & 0 \\
\hline Bridlewood & $\mathrm{C}$ & UN & 0 & 0 & 0 & 0 & 0 & 0 \\
\hline Bridlewood & $\mathrm{D}$ & $\overline{\mathrm{UN}}$ & 0 & 0 & 0 & 0 & 0 & 0 \\
\hline Bridlewood & $\mathrm{E}$ & UN & 0 & 0 & 0 & 0 & 0 & 0 \\
\hline Bridlewood & $\mathrm{F}$ & $\mathrm{UN}$ & 0 & 0 & 0 & 0 & 0 & 0 \\
\hline Bridlewood & $\mathrm{H}$ & $\mathrm{UN}$ & 0 & 0 & 0 & 0 & 0 & 0 \\
\hline Bridlewood & $\bar{I}$ & $\mathrm{UN}$ & 0 & 0 & 0 & 0 & 0 & 0 \\
\hline Carp_Hills & $\mathrm{A}$ & $\mathrm{F}$ & 0 & 0 & 0 & 0 & 0 & 0 \\
\hline Carp_Hills & $\mathrm{B}$ & $\mathrm{F}$ & 0 & 0 & 0 & 0 & 0 & 0 \\
\hline Carp_Hills & $\mathrm{C}$ & $\mathrm{F}$ & 0 & 0 & 0 & 0 & 0 & 0 \\
\hline Carp_Hills & $\mathrm{D}$ & $\mathrm{F}$ & 0 & 0 & 0 & 0 & 0 & 0 \\
\hline Carp_Hills & $E$ & $\mathrm{~F}$ & 0 & 0 & 0 & 0 & 0 & 0 \\
\hline Carp_Hills & $\mathrm{F}$ & $\bar{F}$ & 0 & 0 & 0 & 0 & 0 & 0 \\
\hline Carp_Hills & $\mathrm{H}$ & $\mathrm{F}$ & 0 & 0 & 0 & 0 & 0 & 0 \\
\hline Carp_Hills & I & $\mathrm{F}$ & $\overline{0}$ & 0 & 0 & 0 & 0 & 0 \\
\hline Chapel_Hill & $\mathrm{A}$ & $\mathrm{UN}$ & 0 & 0 & 0 & $\overline{0}$ & 0 & 0 \\
\hline Chapel_Hill & $\mathrm{B}$ & UN & 0 & 7 & 0 & 0 & 0 & 0 \\
\hline Chapel_Hill & $\bar{C}$ & $\mathrm{UN}$ & 0 & 1 & 0 & 0 & 0 & 0 \\
\hline Chapel_Hill & $\mathrm{D}$ & $\mathrm{UN}$ & 0 & 2 & 0 & 0 & 0 & 0 \\
\hline Chapel_Hill & $\mathrm{E}$ & $\mathrm{UN}$ & 0 & 0 & 0 & 0 & 0 & 0 \\
\hline Chapel_Hill & $\mathrm{F}$ & $\mathrm{UN}$ & 0 & 0 & 0 & 0 & 0 & 0 \\
\hline Chapel_Hill & $\mathrm{H}$ & UN & 0 & 4 & 0 & 0 & 0 & 0 \\
\hline Chapel_Hill & I & UN & 0 & 0 & 0 & 0 & 0 & 0 \\
\hline Chelsea & $\mathrm{A}$ & $\mathrm{SN}$ & 0 & 0 & 0 & 0 & 0 & 0 \\
\hline Chelsea & $\mathrm{B}$ & $\mathrm{SN}$ & 0 & 0 & 0 & 0 & 0 & 0 \\
\hline Chelsea & $\mathrm{C}$ & $\mathrm{SN}$ & 0 & 0 & 0 & 0 & 0 & 0 \\
\hline Chelsea & $\mathrm{D}$ & $\mathrm{SN}$ & 0 & 0 & 0 & 0 & 0 & 0 \\
\hline Chelsea & $E$ & $\overline{\mathrm{SN}}$ & 0 & 0 & 0 & 0 & 0 & 0 \\
\hline Chelsea & $\mathbf{F}$ & $\mathrm{SN}$ & 0 & 0 & 0 & 0 & 0 & 0 \\
\hline
\end{tabular}




\begin{tabular}{|c|c|c|c|c|c|c|c|c|}
\hline Chelsea & $\mathrm{H}$ & $\mathrm{SN}$ & 0 & 0 & 0 & 0 & 0 & 0 \\
\hline Chelsea & I & SN & 0 & 0 & 0 & 0 & 0 & $\overline{0}$ \\
\hline Chemin_Scholle & $\bar{A}$ & $\overline{\mathrm{EN}}$ & 0 & 0 & 0 & 0 & 0 & 0 \\
\hline Chemin_Scholle & $\mathrm{B}$ & $\overline{\mathrm{EN}}$ & 0 & 0 & 0 & 0 & 0 & 0 \\
\hline Chemin_Scholle & $\mathrm{C}$ & EN & 0 & 0 & 0 & 0 & 0 & 0 \\
\hline Chemin_Scholle & D & EN & 0 & 0 & 0 & 0 & 0 & 0 \\
\hline Chemin_Scholle & $\mathrm{E}$ & EN & 0 & 0 & 0 & 0 & 0 & 0 \\
\hline Chemin_Scholle & $F$ & $\overline{E N}$ & 0 & 0 & 0 & 0 & 0 & 0 \\
\hline Chemin_Scholle & $\overline{\mathrm{H}}$ & EN & 0 & 0 & 0 & 0 & 0 & 0 \\
\hline Chemin_Scholle & I & EN & 0 & 0 & 0 & 0 & 0 & 0 \\
\hline Cote_d'Azur & $\bar{A}$ & $\mathrm{~S}$ & 0 & 0 & 0 & 0 & 0 & 0 \\
\hline Cote_d'Azur & B & $\mathrm{S}$ & 0 & 0 & 0 & 0 & 1 & 0 \\
\hline Cote_d'Azur & $\mathrm{C}$ & $\bar{S}$ & 0 & 0 & 0 & 0 & 0 & $\overline{0}$ \\
\hline Cote_d'Azur & $\mathrm{D}$ & $\mathrm{S}$ & 0 & 0 & 0 & 0 & 0 & $\overline{0}$ \\
\hline Cote_d'Azur & $\bar{E}$ & $\mathrm{~S}$ & 0 & 0 & 0 & 0 & 0 & $\overline{0}$ \\
\hline Cote_d'Azur & $F$ & $\mathrm{~S}$ & 0 & 4 & 0 & 0 & 0 & 0 \\
\hline Cote_d'Azur & $\mathrm{H}$ & $\bar{S}$ & 0 & 0 & 0 & 0 & 0 & 0 \\
\hline Cote_d'Azur & $\bar{I}$ & $\mathrm{~S}$ & 0 & 0 & 0 & 0 & 0 & 0 \\
\hline Highway_Seven & $\bar{A}$ & $\bar{E}$ & 0 & 0 & 0 & 0 & 0 & $\overline{0}$ \\
\hline Highway_Seven & B & $E$ & 0 & 0 & 0 & 0 & 0 & $\overline{0}$ \\
\hline Highway_Seven & $\mathrm{C}$ & $\bar{E}$ & 0 & 0 & 0 & 0 & 0 & $\overline{0}$ \\
\hline Highway_Seven & $\mathrm{D}$ & $\mathrm{E}$ & 0 & 0 & 0 & 0 & 0 & $\overline{0}$ \\
\hline Highway_Seven & $\bar{E}$ & $\bar{E}$ & 0 & 0 & 0 & 0 & 2 & $\overline{0}$ \\
\hline Highway_Seven & $F$ & $\mathrm{E}$ & 0 & 0 & 0 & 0 & 0 & 0 \\
\hline Highway_Seven & $\mathrm{H}$ & $E$ & 0 & 0 & 0 & 0 & 0 & $\overline{0}$ \\
\hline Highway_Seven & I & $\mathrm{E}$ & 0 & 0 & 0 & 0 & 0 & 0 \\
\hline Hull & $\bar{A}$ & $\overline{\mathrm{U}}$ & 0 & 0 & 0 & 0 & 0 & 0 \\
\hline Hull & B & $\mathrm{U}$ & 0 & 0 & 0 & 0 & 0 & 0 \\
\hline Hull & $\bar{C}$ & $\mathrm{U}$ & 0 & 0 & 0 & 0 & 1 & $\overline{0}$ \\
\hline Hull & $\mathrm{D}$ & $\overline{\mathrm{U}}$ & 0 & 0 & 0 & 0 & 0 & 0 \\
\hline Hull & $\bar{E}$ & $\bar{U}$ & 0 & 0 & 1 & 0 & 0 & 0 \\
\hline Hull & $F$ & $\bar{U}$ & 0 & 0 & 0 & 0 & 2 & 0 \\
\hline Hull & $\mathrm{H}$ & $\mathrm{U}$ & 0 & 0 & 0 & 0 & 0 & 0 \\
\hline Hull & I & $\mathrm{U}$ & 0 & 0 & 0 & 0 & 2 & $\overline{0}$ \\
\hline Lac_a_la_Perdrix & A & EN & 0 & 0 & 0 & 0 & 0 & 0 \\
\hline Lac_a_la_Perdrix & B & EN & 0 & 0 & 0 & 0 & 0 & 0 \\
\hline Lac_a_la_Perdrix & $\mathrm{C}$ & EN & 0 & 0 & 0 & 0 & 0 & $\overline{0}$ \\
\hline Lac_a_la_Perdrix & $\mathrm{D}$ & EN & 0 & 0 & 0 & 0 & 0 & $\overline{0}$ \\
\hline Lac_a_la_Perdrix & $\bar{E}$ & $\overline{\mathrm{EN}}$ & 0 & 0 & 0 & 0 & 0 & 0 \\
\hline
\end{tabular}




\begin{tabular}{|c|c|c|c|c|c|c|c|c|}
\hline Lac_a_la_Perdrix & $F$ & EN & 0 & 0 & 0 & 0 & 0 & 0 \\
\hline Lac_a_la_Perdrix & $\mathrm{H}$ & EN & 0 & 0 & 0 & 0 & 0 & 0 \\
\hline Lac_a_la_Perdrix & I & $\mathrm{EN}$ & 0 & 0 & 0 & 0 & 0 & 0 \\
\hline Lac_Philippe & $\bar{A}$ & $\mathrm{~F}$ & 0 & 0 & 0 & 0 & 0 & 0 \\
\hline Lac_Philippe & B & $\mathrm{F}$ & 0 & 0 & 0 & 0 & 0 & 0 \\
\hline Lac_Philippe & $\mathrm{C}$ & $\mathrm{F}$ & 0 & 0 & 0 & 0 & 0 & 0 \\
\hline Lac_Philippe & $\mathrm{D}$ & $\mathrm{F}$ & 0 & 0 & 0 & 0 & 0 & 0 \\
\hline Lac_Philippe & $\mathrm{E}$ & $\mathrm{F}$ & 0 & 0 & 0 & 0 & 0 & 0 \\
\hline Lac_Philippe & $\bar{F}$ & $\mathrm{~F}$ & 0 & 0 & 0 & 0 & 0 & 0 \\
\hline Lac_Philippe & $\mathrm{H}$ & $\mathrm{F}$ & 0 & 0 & 0 & 0 & 0 & 0 \\
\hline Lac_Philippe & $\bar{I}$ & $F$ & 0 & 0 & 0 & 0 & 0 & 0 \\
\hline Manoir_des_Trembles & $\mathrm{A}$ & $\mathrm{UN}$ & 0 & 0 & 0 & 0 & 0 & 0 \\
\hline Manoir_des_Trembles & B & $\mathrm{UN}$ & 0 & 3 & 0 & 0 & 0 & 0 \\
\hline Manoir_des_Trembles & $\mathrm{C}$ & UN & 0 & 1 & 0 & 0 & 0 & 0 \\
\hline Manoir_des_Trembles & $\overline{\mathrm{D}}$ & $\mathrm{UN}$ & 0 & 0 & 0 & 0 & 0 & 0 \\
\hline Manoir_des_Trembles & $\mathrm{E}$ & UN & 0 & 1 & 0 & 0 & 0 & 0 \\
\hline Manoir_des_Trembles & $\mathbf{F}$ & UN & 0 & 1 & 0 & 0 & 0 & 0 \\
\hline Manoir_des_Trembles & $\mathrm{H}$ & UN & 0 & 5 & 0 & 0 & 0 & 0 \\
\hline Manoir_des_Trembles & I & UN & 0 & 0 & 0 & 0 & 0 & 0 \\
\hline Marathon & $\mathrm{A}$ & $E$ & 0 & 0 & 0 & 0 & 0 & 0 \\
\hline Marathon & B & $E$ & 0 & 0 & 0 & 0 & 0 & $\overline{0}$ \\
\hline Marathon & $\bar{C}$ & $E$ & 0 & 0 & 0 & 0 & 0 & 0 \\
\hline Marathon & $\mathrm{D}$ & $E$ & 0 & 0 & 0 & $\overline{0}$ & 0 & $\overline{0}$ \\
\hline Marathon & $E$ & $E$ & 0 & 0 & 0 & 0 & 0 & 0 \\
\hline Marathon & $\mathbf{F}$ & $E$ & 0 & 0 & 0 & $\overline{0}$ & 0 & 0 \\
\hline Marathon & $\mathrm{H}$ & $\mathrm{E}$ & 0 & 0 & 0 & 0 & 0 & 0 \\
\hline Marathon & I & $E$ & 0 & 0 & 0 & 0 & 0 & 0 \\
\hline Marier & $\mathrm{A}$ & $\mathrm{U}$ & 0 & 0 & 0 & 0 & 1 & 0 \\
\hline Marier & B & $\mathrm{U}$ & 0 & 0 & 0 & 0 & 6 & $\overline{0}$ \\
\hline Marier & $\mathrm{C}$ & $\mathrm{U}$ & 0 & 0 & 0 & 0 & 0 & 0 \\
\hline Marier & $\mathrm{D}$ & $\mathrm{U}$ & 0 & 0 & 0 & 0 & 0 & 0 \\
\hline Marier & $E$ & $\bar{U}$ & 0 & 0 & 0 & 0 & 0 & 0 \\
\hline Marier & $F$ & $\mathrm{U}$ & 0 & 0 & 0 & 0 & 3 & 0 \\
\hline Marier & $\mathrm{H}$ & $\bar{U}$ & 0 & 0 & 0 & 0 & 0 & 0 \\
\hline Marier & $\bar{I}$ & $\mathrm{U}$ & 0 & 0 & 0 & 0 & 0 & 0 \\
\hline Marlborough & $\mathrm{A}$ & $\mathrm{F}$ & 0 & 0 & 0 & 0 & 0 & 0 \\
\hline Marlborough & B & $\mathrm{F}$ & 0 & 0 & 0 & 0 & 0 & 0 \\
\hline Marlborough & $\mathrm{C}$ & $F$ & 0 & 0 & 0 & 0 & 0 & 0 \\
\hline Marlborough & $\mathrm{D}$ & $F$ & 0 & 0 & 0 & 0 & 0 & 0 \\
\hline
\end{tabular}




\begin{tabular}{|c|c|c|c|c|c|c|c|c|}
\hline Marlborough & $E$ & $\mathbf{F}$ & 0 & 0 & 0 & 0 & 0 & 0 \\
\hline Marlborough & $F$ & $\mathbf{F}$ & 0 & 0 & 0 & 0 & 0 & 0 \\
\hline Marlborough & $\mathrm{H}$ & $\mathbf{F}$ & 0 & 0 & 0 & 0 & 0 & 0 \\
\hline Marlborough & I & $\mathbf{F}$ & 0 & 0 & 0 & 0 & 0 & 0 \\
\hline Merivale & A & SN & 0 & 4 & 0 & 0 & 0 & 0 \\
\hline Merivale & B & $\mathrm{SN}$ & 0 & 0 & 0 & 0 & 0 & 0 \\
\hline Merivale & $\mathrm{C}$ & SN & 0 & 0 & 0 & 0 & 0 & 0 \\
\hline Merivale & $\mathrm{D}$ & $\mathrm{SN}$ & 0 & 0 & 0 & 0 & 0 & 0 \\
\hline Merivale & $\mathrm{E}$ & SN & 0 & 0 & 0 & 0 & 0 & 0 \\
\hline Merivale & $F$ & SN & 0 & 2 & 0 & 0 & 0 & 0 \\
\hline Merivale & $\mathrm{H}$ & SN & 0 & 0 & 0 & 0 & 0 & 0 \\
\hline Merivale & I & $\mathrm{SN}$ & 0 & 0 & 0 & 0 & 0 & 0 \\
\hline Parc_Champlain & $\mathrm{A}$ & $\mathrm{S}$ & 0 & 0 & 0 & 0 & 0 & 0 \\
\hline Parc_Champlain & B & $\mathrm{S}$ & 0 & 0 & 2 & 0 & 0 & 0 \\
\hline Parc_Champlain & $\mathrm{C}$ & $\mathbf{S}$ & 0 & 0 & 0 & 0 & 0 & 0 \\
\hline Parc_Champlain & $\mathrm{D}$ & $\mathrm{S}$ & 0 & 1 & 0 & 0 & 0 & 0 \\
\hline Parc_Champlain & $\mathrm{E}$ & $\mathbf{S}$ & 0 & 0 & 0 & 0 & 0 & 0 \\
\hline Parc_Champlain & $\mathbf{F}$ & $\mathbf{S}$ & 0 & 0 & 0 & 0 & 0 & 0 \\
\hline Parc_Champlain & $\mathbf{H}$ & $\mathbf{S}$ & 1 & 0 & 0 & 0 & 4 & 0 \\
\hline Parc_Champlain & I & $\mathrm{S}$ & 0 & 0 & 0 & 0 & 0 & 0 \\
\hline Pelissier & $\mathrm{A}$ & EN & 0 & 0 & 0 & 0 & 0 & 0 \\
\hline Pelissier & B & EN & 0 & 0 & 0 & 0 & 0 & 0 \\
\hline Pelissier & $\mathrm{C}$ & EN & 0 & 0 & 0 & 0 & 0 & 0 \\
\hline Pelissier & $\mathrm{D}$ & EN & 0 & 0 & 0 & 0 & 0 & 0 \\
\hline Pelissier & $E$ & EN & 0 & 0 & 0 & 0 & 0 & 0 \\
\hline Pelissier & $\mathrm{F}$ & EN & 0 & 0 & 0 & 0 & 0 & 0 \\
\hline Pelissier & $\mathrm{H}$ & EN & 0 & 0 & 0 & 0 & 0 & 0 \\
\hline Pelissier & $\mathrm{I}$ & EN & 0 & 0 & 0 & 0 & 0 & 0 \\
\hline PineGlen_Annex & A & $\mathrm{S}$ & 0 & 1 & 0 & 0 & 0 & 0 \\
\hline PineGlen_Annex & B & $\mathrm{S}$ & 0 & 0 & 0 & 0 & 1 & 0 \\
\hline PineGlen_Annex & $\mathrm{C}$ & $\mathrm{S}$ & 0 & 0 & 0 & 0 & 7 & 0 \\
\hline PineGlen_Annex & $\mathrm{D}$ & $\mathrm{S}$ & 0 & 0 & 0 & 0 & 0 & 0 \\
\hline PineGlen_Annex & $E$ & $\mathrm{~S}$ & 0 & 0 & 0 & 0 & 7 & 0 \\
\hline PineGlen_Annex & $\mathbf{F}$ & $\mathrm{S}$ & 0 & 1 & 0 & 0 & 0 & 0 \\
\hline PineGlen_Annex & $\mathrm{H}$ & $\mathrm{S}$ & 0 & 0 & 0 & 0 & 4 & 0 \\
\hline PineGlen_Annex & $\bar{I}$ & $\mathrm{~S}$ & 1 & 2 & 0 & 0 & 0 & 0 \\
\hline Q_Four & A & $E$ & 0 & 0 & 0 & 0 & 0 & 0 \\
\hline Q_Four & B & $\mathrm{E}$ & 0 & 0 & 0 & 0 & 0 & 0 \\
\hline Q Four & $\mathrm{C}$ & $\mathrm{E}$ & 0 & 0 & 0 & 0 & 0 & 0 \\
\hline
\end{tabular}




\begin{tabular}{|c|c|c|c|c|c|c|c|c|}
\hline Q_Four & $\bar{D}$ & $\mathrm{E}$ & 0 & 0 & 0 & 0 & 0 & 0 \\
\hline Q_Four & $E$ & $E$ & 0 & 0 & 0 & 0 & 0 & 0 \\
\hline Q Four & $\mathrm{F}$ & $\mathrm{E}$ & 0 & 0 & 0 & 0 & 0 & 0 \\
\hline Q_Four & $\mathrm{H}$ & $\mathrm{E}$ & 0 & 0 & 0 & 0 & 0 & 0 \\
\hline Q_Four & $I$ & $E$ & 0 & 0 & 0 & 0 & 0 & $\overline{0}$ \\
\hline Sandy_Hill & $\mathrm{A}$ & $\bar{U}$ & 0 & 0 & 0 & 0 & 0 & 0 \\
\hline Sandy_Hill & $\bar{B}$ & $\mathrm{U}$ & 0 & 0 & 0 & 0 & 0 & $\overline{0}$ \\
\hline Sandy_Hill & $\mathrm{C}$ & $\mathrm{U}$ & 0 & 0 & 0 & 0 & 0 & 0 \\
\hline Sandy_Hill & $\bar{D}$ & $\mathrm{U}$ & 0 & 0 & 0 & 0 & 0 & 0 \\
\hline Sandy_Hill & $\mathrm{E}$ & $\mathrm{U}$ & 0 & 0 & 0 & 0 & 0 & 0 \\
\hline Sandy_Hill & $\mathrm{F}$ & $\mathrm{U}$ & 0 & 0 & 0 & 0 & 0 & 0 \\
\hline Sandy_Hill & $\mathrm{H}$ & $\mathrm{U}$ & 0 & 0 & 0 & 0 & 0 & 1 \\
\hline Sandy_Hill & $I$ & $\mathrm{U}$ & 0 & 0 & 0 & 0 & 0 & 0 \\
\hline Vallee_Meech & $\mathrm{A}$ & $\bar{F}$ & 0 & 0 & 0 & 0 & 0 & 0 \\
\hline Vallee_Meech & $\bar{B}$ & $\mathrm{~F}$ & 0 & 0 & 0 & 0 & 0 & 0 \\
\hline Vallee_Meech & $\mathrm{C}$ & $\mathrm{F}$ & 0 & 0 & 0 & 0 & 0 & 0 \\
\hline Vallee_Meech & $\bar{D}$ & $\mathrm{~F}$ & 0 & 0 & 0 & 0 & 0 & 0 \\
\hline Vallee_Meech & $\mathrm{E}$ & $\mathrm{F}$ & 0 & 0 & 0 & 0 & 0 & 0 \\
\hline Vallee_Meech & $\bar{F}$ & $F$ & 0 & 0 & 0 & 0 & 0 & 0 \\
\hline Vallee_Meech & $\mathrm{H}$ & $\mathrm{F}$ & 0 & 0 & 0 & 0 & 0 & 0 \\
\hline Vallee_Meech & I & $\mathrm{F}$ & 0 & 0 & 0 & 0 & 0 & 0 \\
\hline Wolf_Grove & $\mathrm{A}$ & $\bar{E}$ & 0 & 0 & 0 & 0 & 0 & 0 \\
\hline Wolf_Grove & $\bar{B}$ & $\mathrm{E}$ & 0 & 0 & 0 & 0 & 0 & 0 \\
\hline Wolf_Grove & $\mathrm{C}$ & $\mathrm{E}$ & 0 & 0 & 0 & 0 & 0 & 0 \\
\hline Wolf_Grove & $\bar{D}$ & $\mathrm{E}$ & 0 & 0 & 0 & 0 & 0 & 0 \\
\hline Wolf_Grove & $\mathrm{E}$ & $\mathrm{E}$ & 0 & 0 & 0 & 0 & 0 & 0 \\
\hline Wolf_Grove & $\mathrm{F}$ & $\mathbf{E}$ & 0 & 0 & 0 & 0 & 0 & 0 \\
\hline Wolf_Grove & $\mathrm{H}$ & $\bar{E}$ & 0 & 0 & 0 & 0 & 0 & 0 \\
\hline Wolf_Grove & $\bar{I}$ & $\mathrm{E}$ & 0 & 0 & 0 & 0 & 0 & 0 \\
\hline Wrightville & $\mathrm{A}$ & $\mathrm{U}$ & 0 & 0 & 0 & 1 & 4 & 0 \\
\hline Wrightville & $\mathrm{B}$ & $\bar{U}$ & 0 & 0 & 0 & 0 & 0 & 0 \\
\hline Wrightville & $\mathrm{C}$ & $\overline{\mathrm{U}}$ & 0 & 0 & 0 & 0 & 1 & 0 \\
\hline Wrightville & $\mathrm{D}$ & $\bar{U}$ & 0 & 0 & 0 & 0 & 0 & 0 \\
\hline Wrightville & $\mathrm{E}$ & $\mathrm{U}$ & 0 & 0 & 0 & 0 & 0 & 0 \\
\hline Wrightville & $\mathrm{F}$ & $\mathrm{U}$ & 0 & 0 & 0 & 0 & 0 & $\overline{0}$ \\
\hline Wrightville & $\mathrm{H}$ & $\mathrm{U}$ & 0 & 0 & 0 & 0 & 0 & 0 \\
\hline Wrightville & I & $\mathrm{U}$ & 0 & 0 & 0 & 0 & 3 & 0 \\
\hline Wychwood & $\bar{A}$ & $\mathbf{S}$ & 0 & 0 & 0 & 0 & 2 & 0 \\
\hline Wychwood & $\mathrm{B}$ & $\mathrm{S}$ & 0 & 1 & 0 & 0 & 0 & 0 \\
\hline
\end{tabular}




\begin{tabular}{|l|l|l|r|r|r|r|r|r|}
\hline Wychwood & C & S & 0 & 2 & 0 & 0 & 0 & 0 \\
\hline Wychwood & D & S & 0 & 2 & 0 & 0 & 0 & 0 \\
\hline Wychwood & E & S & 0 & 0 & 0 & 0 & 0 & 0 \\
\hline Wychwood & F & S & 0 & 0 & 0 & 0 & 0 & 0 \\
\hline Wychwood & H & S & 0 & 0 & 0 & 0 & 1 & 0 \\
\hline Wychwood & I & S & 0 & 0 & 0 & 0 & 1 & 0 \\
\hline
\end{tabular}




\begin{tabular}{|c|c|c|c|c|c|c|c|c|}
\hline SITE & STATION & CATEGORY & ANME & $\overline{\text { ANRU }}$ & ANVE & BANO & BAOC & BEFR \\
\hline Achbar & $\mathrm{A}$ & $\mathrm{SN}$ & 0 & 0 & 0 & 0 & 0 & 0 \\
\hline Achbar & B & $\mathrm{SN}$ & 0 & 0 & 0 & 0 & 0 & 0 \\
\hline Achbar & $\mathrm{C}$ & $\mathrm{SN}$ & 0 & 0 & 0 & 0 & 0 & 0 \\
\hline Achbar & $\bar{D}$ & $\overline{\mathrm{SN}}$ & 0 & 0 & 0 & 0 & 0 & 0 \\
\hline Achbar & $E$ & $\mathrm{SN}$ & 0 & 0 & 0 & 0 & 0 & 0 \\
\hline Achbar & $\mathrm{F}$ & $\mathrm{SN}$ & 0 & 0 & 0 & 0 & 0 & 0 \\
\hline Achbar & $\mathrm{H}$ & $\overline{\mathrm{SN}}$ & 0 & 0 & 0 & 0 & 0 & 0 \\
\hline Achbar & I & $\mathrm{SN}$ & 0 & 0 & 0 & 0 & 0 & 0 \\
\hline Bridlewood & A & $\mathrm{UN}$ & 0 & 0 & 0 & 0 & 0 & 0 \\
\hline Bridlewood & $\overline{\mathrm{B}}$ & $\mathrm{UN}$ & 0 & 0 & 0 & 0 & 0 & 0 \\
\hline Bridlewood & $\mathrm{C}$ & $\mathrm{UN}$ & 0 & 0 & 0 & 0 & 0 & 0 \\
\hline Bridlewood & D & $\mathrm{UN}$ & 0 & 0 & 0 & 0 & 0 & $\overline{0}$ \\
\hline Bridlewood & $\mathrm{E}$ & $\mathrm{UN}$ & 0 & 0 & 0 & 0 & 0 & 0 \\
\hline Bridlewood & $\bar{F}$ & $\mathrm{UN}$ & 0 & 0 & 0 & 0 & 0 & 0 \\
\hline Bridlewood & $\mathrm{H}$ & $\mathrm{UN}$ & 0 & 0 & 0 & 0 & 0 & 0 \\
\hline Bridlewood & I & $\mathrm{UN}$ & 0 & 0 & 0 & 0 & 0 & 0 \\
\hline Carp_Hills & A & $\mathbf{F}$ & 0 & 0 & 0 & 0 & 0 & 0 \\
\hline Carp_Hills & B & $\mathbf{F}$ & 0 & 0 & 0 & 0 & 0 & 0 \\
\hline Carp_Hills & $\mathrm{C}$ & $\mathbf{F}$ & 0 & 0 & 0 & 0 & 0 & 0 \\
\hline Carp_Hills & $\overline{\mathrm{D}}$ & $\bar{F}$ & 0 & 0 & 0 & 0 & 0 & $\overline{0}$ \\
\hline Carp_Hills & $E$ & $\bar{F}$ & 0 & 0 & 0 & 0 & $\overline{0}$ & 0 \\
\hline Carp_Hills & $\mathrm{F}$ & $F$ & 0 & 0 & 0 & 0 & $\overline{0}$ & 0 \\
\hline Carp_Hills & $\mathrm{H}$ & $\mathbf{F}$ & 0 & 0 & 0 & 0 & 0 & 0 \\
\hline Carp_Hills & I & $\mathbf{F}$ & 0 & 0 & 0 & 0 & 0 & 0 \\
\hline Chapel_Hill & $\mathrm{A}$ & $\mathrm{UN}$ & 0 & 0 & 0 & 0 & 0 & 0 \\
\hline Chapel_Hill & B & $\mathrm{UN}$ & 0 & 0 & 0 & 0 & 0 & $\overline{0}$ \\
\hline Chapel_Hill & $\mathrm{C}$ & $\mathrm{UN}$ & 0 & 0 & 0 & 0 & 0 & 0 \\
\hline Chapel_Hill & $\mathrm{D}$ & $\mathrm{UN}$ & 0 & 0 & 0 & 0 & 0 & 0 \\
\hline Chapel_Hill & $\mathrm{E}$ & $\mathrm{UN}$ & 0 & 0 & 0 & 0 & 0 & 0 \\
\hline Chapel_Hill & $\bar{F}$ & $\overline{\mathrm{UN}}$ & 0 & 0 & $\overline{0}$ & 0 & 0 & $\overline{0}$ \\
\hline Chapel_Hill & $\mathrm{H}$ & UN & 0 & 0 & 0 & 0 & 0 & 0 \\
\hline Chapel_Hill & I & UN & 0 & 0 & 0 & 0 & 0 & 0 \\
\hline Chelsea & $\mathrm{A}$ & $\mathrm{SN}$ & 0 & 0 & 0 & 0 & 0 & 0 \\
\hline Chelsea & B & $\mathrm{SN}$ & 0 & 0 & 0 & 0 & 0 & 0 \\
\hline Chelsea & $\mathrm{C}$ & $\mathrm{SN}$ & 0 & 0 & 0 & 0 & 0 & 0 \\
\hline Chelsea & $\mathrm{D}$ & $\mathrm{SN}$ & 0 & 0 & 0 & 0 & 0 & 0 \\
\hline Chelsea & $\mathrm{E}$ & $\mathrm{SN}$ & 0 & 0 & 0 & 0 & 0 & 0 \\
\hline Chelsea & $\mathrm{F}$ & $\mathrm{SN}$ & 0 & 0 & 0 & 0 & 0 & 0 \\
\hline Chelsea & $\mathrm{H}$ & $\mathrm{SN}$ & 0 & 0 & 0 & 0 & 0 & 0 \\
\hline Chelsea & I & $\mathrm{SN}$ & 0 & 0 & 0 & 0 & 0 & 0 \\
\hline
\end{tabular}




\begin{tabular}{|c|c|c|c|c|c|c|c|c|}
\hline Chemin_Scholle & $\mathrm{A}$ & EN & 0 & 0 & 0 & 0 & 0 & 0 \\
\hline Chemin_Scholle & $\overline{\mathrm{B}}$ & EN & 0 & 0 & 0 & 0 & 0 & 0 \\
\hline Chemin_Scholle & $\mathrm{C}$ & EN & 0 & 0 & 0 & 0 & 0 & 0 \\
\hline Chemin_Scholle & $\mathrm{D}$ & EN & 0 & 0 & 0 & 0 & 0 & 0 \\
\hline Chemin_Scholle & $E$ & EN & 0 & 0 & 0 & 0 & 0 & 0 \\
\hline Chemin_Scholle & $\mathrm{F}$ & EN & 0 & 0 & 0 & 0 & 0 & 0 \\
\hline Chemin_Scholle & $\mathrm{H}$ & EN & 0 & 0 & 0 & 0 & 0 & 0 \\
\hline Chemin_Scholle & I & EN & 0 & 0 & 0 & 0 & 0 & 0 \\
\hline Cote_d'Azur & $\bar{A}$ & $\mathrm{~S}$ & 0 & 0 & 0 & 0 & 0 & 0 \\
\hline Cote_d'Azur & $\bar{B}$ & $\mathrm{~S}$ & 0 & 0 & 0 & 0 & 0 & 0 \\
\hline Cote_d'Azur & $\mathrm{C}$ & $\overline{\mathrm{S}}$ & 0 & 1 & 0 & 0 & 0 & 0 \\
\hline Cote_d'Azur & $\mathrm{D}$ & $\mathrm{S}$ & 0 & 0 & 0 & 0 & 0 & $\overline{0}$ \\
\hline Cote_d'Azur & $\mathrm{E}$ & $\bar{S}$ & 0 & 0 & 0 & 0 & 0 & 0 \\
\hline Cote_d'Azur & $\mathrm{F}$ & $\mathrm{S}$ & 0 & 0 & 0 & 0 & 0 & 0 \\
\hline Cote d'Azur & $\mathrm{H}$ & $\mathrm{S}$ & 0 & 0 & 0 & 0 & 0 & 0 \\
\hline Cote_d'Azur & I & $\mathrm{S}$ & 0 & 0 & 0 & 0 & 0 & 0 \\
\hline Highway_Seven & $\bar{A}$ & $E$ & 0 & 0 & 0 & 0 & 0 & 0 \\
\hline Highway_Seven & B & $\mathrm{E}$ & 0 & 0 & 0 & 0 & 0 & 0 \\
\hline Highway_Seven & $\mathrm{C}$ & $\mathrm{E}$ & 0 & 0 & 0 & 0 & 0 & 0 \\
\hline Highway_Seven & $\mathrm{D}$ & $\mathrm{E}$ & 0 & 0 & 0 & 0 & 0 & 0 \\
\hline Highway_Seven & $\mathrm{E}$ & $E$ & 0 & 0 & 0 & 0 & 0 & 0 \\
\hline Highway_Seven & $\mathrm{F}$ & $\mathrm{E}$ & 0 & 0 & 0 & 0 & 0 & 0 \\
\hline Highway_Seven & $\mathrm{H}$ & $\mathrm{E}$ & 0 & 1 & 0 & 0 & 0 & 0 \\
\hline Highway_Seven & $\bar{I}$ & $\mathrm{E}$ & 0 & 0 & 0 & 0 & 0 & 0 \\
\hline Hull & $\mathrm{A}$ & $\mathrm{U}$ & 0 & 0 & 0 & 0 & 0 & 0 \\
\hline Hull & B & $\mathrm{U}$ & 0 & 0 & 0 & 0 & 0 & 0 \\
\hline Hull & $\mathrm{C}$ & $\mathrm{U}$ & 0 & 0 & 0 & 0 & 0 & 0 \\
\hline Hull & $\mathrm{D}$ & $\bar{U}$ & 0 & 0 & 0 & 0 & 0 & 0 \\
\hline Hull & $\mathrm{E}$ & $\mathrm{U}$ & 0 & 9 & 0 & 0 & 0 & 0 \\
\hline Hull & $\bar{F}$ & $\mathrm{U}$ & 0 & 0 & 0 & 0 & 0 & 0 \\
\hline Hull & $\mathrm{H}$ & $\mathrm{U}$ & 0 & 0 & 0 & 0 & 0 & 0 \\
\hline Hull & $\bar{I}$ & $\mathrm{U}$ & 0 & 0 & 0 & 0 & 0 & 0 \\
\hline Lac_a_la_Perdrix & $\bar{A}$ & EN & 0 & 0 & 0 & 0 & 0 & 0 \\
\hline Lac_a_la_Perdrix & B & EN & 0 & 0 & 0 & 0 & 0 & 0 \\
\hline Lac_a_la_Perdrix & $\mathrm{C}$ & EN & 0 & 0 & 0 & 0 & 0 & 0 \\
\hline Lac_a_la_Perdrix & $\mathrm{D}$ & $\mathrm{EN}$ & 0 & 0 & 0 & 0 & 0 & 0 \\
\hline Lac_a_la_Perdrix & $\mathbf{E}$ & $\overline{\mathrm{EN}}$ & 0 & 0 & 0 & 0 & 0 & 0 \\
\hline Lac_a_la_Perdrix & $\mathrm{F}$ & EN & 0 & 0 & 0 & 0 & 0 & 0 \\
\hline Lac_a_la_Perdrix & $\mathrm{H}$ & EN & 0 & 0 & 0 & 0 & 0 & 0 \\
\hline Lac_a_la_Perdrix & I & $\overline{\mathrm{EN}}$ & 0 & 0 & 0 & 0 & 0 & $\overline{0}$ \\
\hline Lac_Philippe & $\mathrm{A}$ & $\mathrm{F}$ & 0 & 0 & 0 & 0 & 0 & 0 \\
\hline
\end{tabular}




\begin{tabular}{|c|c|c|c|c|c|c|c|c|}
\hline Lac_Philippe & $\mathrm{B}$ & $\mathbf{F}$ & 0 & 0 & 0 & 0 & 0 & $\overline{0}$ \\
\hline Lac_Philippe & $\mathrm{C}$ & $\bar{F}$ & 0 & 0 & 0 & 0 & 0 & 0 \\
\hline Lac_Philippe & $\mathrm{D}$ & $\mathrm{F}$ & 0 & 0 & 0 & 0 & 0 & 0 \\
\hline Lac_Philippe & $\mathrm{E}$ & $\mathrm{F}$ & 0 & 0 & 0 & 0 & 0 & 0 \\
\hline Lac Philippe & $\mathrm{F}$ & $\mathbf{F}$ & 0 & 0 & 0 & 0 & 0 & 0 \\
\hline Lac_Philippe & $\mathrm{H}$ & $\mathrm{F}$ & 0 & 0 & 0 & 0 & 0 & 0 \\
\hline Lac_Philippe & $\bar{I}$ & $\mathbf{F}$ & 0 & 0 & 0 & 0 & 0 & $\overline{0}$ \\
\hline Manoir_des_Trembles & $\mathrm{A}$ & $\overline{\mathrm{UN}}$ & 0 & 0 & 0 & 0 & 0 & 0 \\
\hline Manoir_des_Trembles & B & UN & 0 & 0 & 0 & 0 & 0 & 0 \\
\hline Manoir_des_Trembles & $\mathrm{C}$ & UN & 0 & 0 & 0 & 0 & 0 & 0 \\
\hline Manoir_des_Trembles & $\mathrm{D}$ & UN & 0 & 0 & 0 & 0 & 0 & 0 \\
\hline Manoir_des_Trembles & $\mathrm{E}$ & UN & 0 & 0 & 0 & 0 & 0 & 0 \\
\hline Manoir_des_Trembles & $\mathrm{F}$ & $\mathbf{U N}$ & 0 & 0 & 0 & 0 & 0 & 0 \\
\hline Manoir_des_Trembles & $\mathrm{H}$ & $\mathbf{U N}$ & 0 & 0 & 0 & 0 & 0 & 0 \\
\hline Manoir_des_Trembles & $\bar{I}$ & UN & 0 & 0 & 0 & 0 & 0 & 0 \\
\hline Marathon & $\mathrm{A}$ & $\mathrm{E}$ & 0 & 0 & 0 & 0 & 0 & 0 \\
\hline Marathon & $\mathrm{B}$ & $\mathrm{E}$ & 0 & 0 & 0 & 0 & 0 & 0 \\
\hline Marathon & $\mathrm{C}$ & $E$ & 0 & 0 & 0 & 0 & 0 & 0 \\
\hline Marathon & $\mathrm{D}$ & $\mathrm{E}$ & 0 & 0 & 0 & 0 & 0 & 0 \\
\hline Marathon & $\mathrm{E}$ & $\mathrm{E}$ & 0 & 0 & 0 & 1 & 0 & 0 \\
\hline Marathon & $\mathrm{F}$ & $\mathrm{E}$ & 0 & 0 & 0 & 0 & 0 & 0 \\
\hline Marathon & $\mathrm{H}$ & $E$ & 0 & 0 & 0 & 0 & 0 & $\overline{0}$ \\
\hline Marathon & I & $E$ & 0 & 0 & 0 & 0 & 0 & 0 \\
\hline Marier & A & $\mathrm{U}$ & 0 & 1 & 0 & 0 & 0 & 0 \\
\hline Marier & $\mathrm{B}$ & $\bar{U}$ & 0 & 0 & 0 & 0 & 0 & 0 \\
\hline Marier & $\mathrm{C}$ & $\mathrm{U}$ & 0 & 0 & 0 & 0 & 0 & 0 \\
\hline Marier & $\mathrm{D}$ & $\mathrm{U}$ & 0 & 1 & 0 & 0 & 0 & 0 \\
\hline Marier & $\mathrm{E}$ & $\mathrm{U}$ & 0 & 2 & 0 & 0 & 0 & 0 \\
\hline Marier & $\bar{F}$ & $\bar{U}$ & 0 & 0 & 0 & 0 & 0 & 0 \\
\hline Marier & $\mathrm{H}$ & $\mathrm{U}$ & 0 & 0 & 0 & 0 & 0 & 0 \\
\hline Marier & I & $\mathrm{U}$ & 0 & 0 & 0 & 0 & 0 & 0 \\
\hline Marlborough & $\mathrm{A}$ & $\mathrm{F}$ & 0 & 0 & 0 & 0 & 0 & 0 \\
\hline Marlborough & $\mathrm{B}$ & $\mathrm{F}$ & 0 & 0 & 0 & 0 & 0 & 0 \\
\hline Marlborough & $\mathrm{C}$ & $\bar{F}$ & 0 & 0 & 0 & 0 & 0 & 0 \\
\hline Marlborough & $\bar{D}$ & $\bar{F}$ & 0 & 0 & 0 & 0 & 0 & 0 \\
\hline Marlborough & $\mathrm{E}$ & $\bar{F}$ & 0 & 0 & 0 & 0 & 0 & 0 \\
\hline Marlborough & $\mathbf{F}$ & $F$ & 0 & 0 & 0 & 0 & 0 & 7 \\
\hline Marlborough & $\mathrm{H}$ & $\mathrm{F}$ & 0 & 0 & 0 & 0 & 1 & 0 \\
\hline Marlborough & I & $F$ & 0 & 0 & 0 & 0 & 0 & 0 \\
\hline Merivale & $\mathrm{A}$ & $\mathrm{SN}$ & 0 & 0 & 0 & 0 & 0 & 0 \\
\hline Merivale & B & $\overline{\mathrm{SN}}$ & 0 & 0 & 0 & 0 & 0 & $\overline{0}$ \\
\hline
\end{tabular}




\begin{tabular}{|c|c|c|c|c|c|c|c|c|}
\hline Merivale & $\mathrm{C}$ & SN & 0 & 0 & 0 & 0 & 0 & 0 \\
\hline Merivale & $\mathrm{D}$ & $\mathrm{SN}$ & 0 & 0 & 0 & 0 & 0 & 0 \\
\hline Merivale & $\bar{E}$ & $\overline{\mathrm{SN}}$ & 0 & 0 & 0 & 0 & 0 & 0 \\
\hline Merivale & $\mathrm{F}$ & $\mathrm{SN}$ & 0 & 0 & 0 & 0 & 0 & 0 \\
\hline Merivale & $\mathrm{H}$ & $\mathrm{SN}$ & 0 & 0 & 0 & 0 & 0 & 0 \\
\hline Merivale & 1 & $\mathrm{SN}$ & 0 & 0 & 0 & 0 & 0 & 0 \\
\hline Parc_Champlain & A & $\mathrm{S}$ & 0 & 5 & 0 & 0 & 0 & 0 \\
\hline Parc_Champlain & B & $\mathbf{S}$ & 0 & 1 & 0 & 0 & 0 & 0 \\
\hline Parc_Champlain & $\mathrm{C}$ & $\overline{\mathrm{S}}$ & 0 & 0 & 0 & 0 & 0 & 0 \\
\hline Parc_Champlain & $\bar{D}$ & $\mathrm{~S}$ & 0 & 0 & 0 & 0 & 0 & 0 \\
\hline Parc_Champlain & $\mathrm{E}$ & $\mathrm{S}$ & 0 & 0 & 0 & 0 & 0 & 0 \\
\hline Parc_Champlain & $\mathrm{F}$ & $\mathrm{S}$ & 0 & 0 & 0 & 0 & 0 & 0 \\
\hline Parc_Champlain & $\mathrm{H}$ & $\mathrm{S}$ & 0 & 0 & 0 & 0 & 0 & 0 \\
\hline Pare_Champlain & 1 & $\mathrm{~S}$ & 0 & 0 & 0 & 0 & 0 & 0 \\
\hline Pelissier & A & EN & 0 & 0 & 0 & 0 & 0 & 0 \\
\hline Pelissier & $\mathbf{B}$ & EN & 0 & 0 & 0 & 0 & 0 & 0 \\
\hline Pelissier & $\mathrm{C}$ & EN & 0 & 0 & 0 & 1 & 0 & 0 \\
\hline Pelissier & $\mathrm{D}$ & EN & $\overline{0}$ & 0 & 0 & 0 & 0 & 0 \\
\hline Pelissier & $\mathrm{E}$ & EN & 0 & 0 & 0 & 0 & 0 & 0 \\
\hline Pelissier & $\mathrm{F}$ & EN & 0 & 0 & 0 & 0 & 0 & 0 \\
\hline Pelissier & $\mathbf{H}$ & EN & 0 & 0 & 0 & 0 & 0 & 0 \\
\hline Pelissier & I & EN & 0 & 0 & 0 & 0 & 0 & 0 \\
\hline PineGlen_Annex & A & $\mathrm{S}$ & 0 & 2 & 0 & 0 & 0 & 0 \\
\hline PineGlen_Annex & B & $\mathrm{S}$ & 0 & 1 & 0 & 0 & 0 & 0 \\
\hline PineGlen_Annex & $\mathrm{C}$ & $\mathbf{S}$ & 0 & 0 & 0 & 0 & 0 & 0 \\
\hline PineGlen_Annex & $\mathrm{D}$ & $\bar{S}$ & 0 & 0 & 0 & 0 & 0 & 0 \\
\hline PineGlen_Annex & $\mathrm{E}$ & $S$ & 0 & 7 & 0 & 0 & 0 & 0 \\
\hline PineGlen_Annex & $\mathrm{F}$ & $\mathrm{S}$ & 0 & 1 & 0 & 0 & 0 & 0 \\
\hline PineGlen_Annex & $\mathrm{H}$ & $\mathrm{S}$ & 0 & 0 & 0 & 0 & 0 & 0 \\
\hline PineGlen_Annex & $\mathrm{I}$ & $\mathrm{S}$ & 0 & 0 & 0 & 0 & 0 & 0 \\
\hline Q_Four & $\bar{A}$ & $\mathrm{E}$ & 0 & 0 & 0 & 0 & 0 & 0 \\
\hline Q_Four & B & $E$ & 0 & 0 & 0 & 0 & 0 & 0 \\
\hline Q_Four & $\mathrm{C}$ & $\bar{E}$ & 0 & 0 & 0 & 0 & 0 & 0 \\
\hline Q_Four & $\mathrm{D}$ & $\mathrm{E}$ & 0 & 0 & 0 & 0 & 0 & 0 \\
\hline Q_Four & $E$ & $\mathrm{E}$ & 0 & 0 & 0 & 0 & 1 & 0 \\
\hline Q_Four & $F$ & $\mathrm{E}$ & 0 & 0 & 0 & 0 & 0 & 0 \\
\hline Q_Four & $\mathrm{H}$ & $\bar{E}$ & 0 & 0 & 0 & 0 & 0 & 0 \\
\hline Q_Four & I & $\bar{E}$ & 0 & 0 & 0 & 0 & 0 & 0 \\
\hline Sandy_Hill & $\bar{A}$ & $\overline{\mathrm{U}}$ & 0 & 0 & 0 & 0 & 0 & 0 \\
\hline Sandy_Hill & B & $\mathrm{U}$ & 0 & 0 & 0 & 0 & 0 & 0 \\
\hline Sandy_Hill & $\mathrm{C}$ & $\bar{U}$ & 0 & 1 & 0 & 0 & 0 & 0 \\
\hline
\end{tabular}




\begin{tabular}{|c|c|c|c|c|c|c|c|c|}
\hline Sandy_Hill & $\bar{D}$ & $\mathrm{U}$ & 0 & 0 & 0 & 0 & 0 & 0 \\
\hline Sandy_Hill & $E$ & $\bar{U}$ & 0 & 0 & 0 & 0 & 0 & 0 \\
\hline Sandy_Hill & $F$ & $\mathrm{U}$ & 0 & 0 & 0 & 0 & 0 & 0 \\
\hline Sandy_Hill & $\overline{\mathrm{H}}$ & $\mathrm{U}$ & 0 & 0 & 0 & 0 & 0 & 0 \\
\hline Sandy_Hill & I & $\mathrm{U}$ & 0 & 0 & 0 & 0 & 0 & 0 \\
\hline Vallee_Meech & $\mathrm{A}$ & $\mathrm{F}$ & 0 & 0 & 0 & 0 & 0 & 0 \\
\hline Vallee_Meech & B & $\bar{F}$ & 0 & 0 & 0 & 0 & 0 & 0 \\
\hline Vallee_Meech & $\mathrm{C}$ & $\mathrm{F}$ & 0 & 0 & 0 & 0 & 0 & 0 \\
\hline Vallee_Meech & $\mathrm{D}$ & $F$ & 0 & 0 & 0 & 0 & 0 & 0 \\
\hline Vallee_Meech & $\mathrm{E}$ & $F$ & 0 & 0 & 0 & 0 & 0 & 0 \\
\hline Vallee_Meech & $\mathrm{F}$ & $\mathrm{F}$ & 0 & 0 & 0 & 0 & 0 & 0 \\
\hline Vallee_Meech & $\mathrm{H}$ & $F$ & 0 & 0 & 0 & 0 & 0 & 0 \\
\hline Vallee_Meech & I & $\mathrm{F}$ & 0 & 0 & 0 & 0 & 0 & 0 \\
\hline Wolf_Grove & $\mathrm{A}$ & $\mathrm{E}$ & 0 & 0 & 0 & 0 & 0 & 0 \\
\hline Wolf_Grove & B & $\bar{E}$ & 0 & 0 & 0 & 0 & 0 & 0 \\
\hline Wolf_Grove & $\mathrm{C}$ & $E$ & 0 & 0 & 0 & 0 & 0 & 0 \\
\hline Wolf_Grove & $\bar{D}$ & $\mathrm{E}$ & 0 & 0 & 0 & 0 & 0 & 0 \\
\hline Wolf_Grove & $E$ & $E$ & 0 & 0 & 0 & 0 & 0 & 0 \\
\hline Wolf_Grove & $\mathrm{F}$ & $\mathrm{E}$ & 0 & 0 & 0 & 0 & 0 & 0 \\
\hline Wolf_Grove & $\mathrm{H}$ & $E$ & 0 & 0 & 0 & 0 & 0 & 0 \\
\hline Wolf_Grove & I & $\mathrm{E}$ & 0 & 0 & 0 & 0 & 0 & 0 \\
\hline Wrightville & A & $\mathrm{U}$ & 0 & 0 & 0 & 0 & 0 & 0 \\
\hline Wrightville & B & $\mathrm{U}$ & 0 & 0 & 6 & 0 & 0 & 0 \\
\hline Wrightville & $\mathrm{C}$ & $\mathrm{U}$ & 0 & 0 & 0 & 0 & 0 & 0 \\
\hline Wrightville & $\mathrm{D}$ & $\overline{\mathrm{U}}$ & 1 & 49 & 0 & 0 & 0 & 0 \\
\hline Wrightville & $E$ & $\bar{U}$ & 0 & 1 & 0 & 0 & 0 & 0 \\
\hline Wrightville & $\mathrm{F}$ & $\mathrm{U}$ & 0 & 0 & 0 & 0 & 0 & 0 \\
\hline Wrightville & $\mathrm{H}$ & $\mathrm{U}$ & 0 & 1 & 0 & 0 & 0 & 0 \\
\hline Wrightville & I & $\mathrm{U}$ & 0 & 1 & 0 & 0 & 0 & 0 \\
\hline Wychwood & $\bar{A}$ & $\mathrm{~S}$ & 0 & 0 & 0 & 0 & 0 & 0 \\
\hline Wychwood & $\bar{B}$ & $\mathrm{~S}$ & 0 & 0 & 0 & 0 & 0 & 0 \\
\hline Wychwood & $\mathrm{C}$ & $\mathbf{S}$ & 0 & 0 & 0 & 0 & 0 & 0 \\
\hline Wychwood & $\mathrm{D}$ & $\mathrm{S}$ & 0 & 0 & $\overline{0}$ & 0 & 0 & 0 \\
\hline Wychwood & $E$ & $\mathrm{~S}$ & 0 & 0 & 0 & 0 & 0 & 0 \\
\hline Wychwood & $F$ & $\mathrm{~S}$ & 0 & 0 & 0 & 0 & 0 & 0 \\
\hline Wychwood & $\mathrm{H}$ & $\mathrm{S}$ & 0 & 0 & 0 & 0 & 0 & 0 \\
\hline Wychwood & I & $S$ & 0 & 0 & 0 & 0 & 0 & 0 \\
\hline
\end{tabular}




\begin{tabular}{|c|c|c|c|c|c|c|c|c|}
\hline SITE & STATION & CATEGORY & BEIN & BEMU & BEOB & BEPR & BEQU & BETE \\
\hline Achbar & A & SN & 0 & 0 & 0 & 0 & 0 & 0 \\
\hline Achbar & $\bar{B}$ & $\overline{\mathrm{SN}}$ & 0 & 0 & 0 & 0 & 0 & 0 \\
\hline Achbar & $\mathrm{C}$ & $\mathrm{SN}$ & 0 & 0 & 0 & 0 & 0 & 0 \\
\hline Achbar & $\mathrm{D}$ & SN & 0 & 0 & 0 & 0 & 0 & $\overline{0}$ \\
\hline Achbar & $E$ & SN & 0 & $\overline{0}$ & 0 & 0 & $\overline{0}$ & $\overline{0}$ \\
\hline Achbar & $\bar{F}$ & SN & 0 & 0 & 0 & 0 & 0 & $\overline{0}$ \\
\hline Achbar & $\mathrm{H}$ & $\overline{\mathrm{SN}}$ & 0 & 0 & 0 & 0 & 0 & 0 \\
\hline Achbar & I & $\mathrm{SN}$ & 0 & 0 & 0 & 0 & 0 & $\overline{0}$ \\
\hline Bridlewood & $\mathrm{A}$ & UN & 0 & 0 & 0 & 0 & 0 & 0 \\
\hline Bridlewood & $\mathrm{B}$ & UN & 0 & 0 & 0 & 0 & 0 & $\overline{0}$ \\
\hline Bridlewood & $\bar{C}$ & $\mathrm{UN}$ & 0 & 0 & 0 & 0 & 0 & $\overline{0}$ \\
\hline Bridlewood & $\mathrm{D}$ & $\mathrm{UN}$ & 0 & 0 & 0 & 0 & 0 & 0 \\
\hline Bridlewood & $\bar{E}$ & UN & 0 & 0 & 0 & 0 & 0 & 0 \\
\hline Bridlewood & $\mathrm{F}$ & UN & 0 & 0 & 3 & 0 & 0 & $\overline{0}$ \\
\hline Bridlewood & $\mathrm{H}$ & UN & 0 & 0 & 1 & 0 & 0 & 0 \\
\hline Bridlewood & I & UN & 0 & 0 & 0 & 0 & 0 & $\overline{0}$ \\
\hline Carp_Hills & A & $\mathrm{F}$ & 0 & 0 & 0 & 0 & 0 & 0 \\
\hline Carp_Hills & $\bar{B}$ & $F$ & 0 & 0 & 0 & 0 & 0 & $\overline{0}$ \\
\hline Carp_Hills & $\mathrm{C}$ & $F$ & 0 & 0 & 0 & 0 & 0 & $\overline{0}$ \\
\hline Carp_Hills & $\mathrm{D}$ & $\mathrm{F}$ & 0 & 0 & 0 & 0 & 0 & 0 \\
\hline Carp_Hills & $\mathrm{E}$ & $\mathrm{F}$ & 0 & 0 & 1 & 0 & 0 & 0 \\
\hline Carp_Hills & $F$ & $F$ & 0 & 0 & 0 & 0 & 0 & $\overline{0}$ \\
\hline Carp_Hills & $\mathrm{H}$ & $\mathrm{F}$ & 0 & 0 & 0 & 0 & 0 & 0 \\
\hline Carp_Hills & $I$ & $\mathrm{~F}$ & 0 & 0 & 1 & 0 & 0 & $\overline{0}$ \\
\hline Chapel_Hill & A & UN & 0 & 0 & 0 & 0 & 0 & 0 \\
\hline Chapel_Hill & $\mathrm{B}$ & UN & 0 & 0 & 0 & 0 & 0 & $\overline{0}$ \\
\hline Chapel_Hill & $\mathrm{C}$ & UN & 0 & 0 & 0 & 0 & 0 & 0 \\
\hline Chapel_Hill & $\overline{\mathrm{D}}$ & UN & 0 & 0 & 0 & 0 & 0 & 0 \\
\hline Chapel_Hill & $\bar{E}$ & UN & 0 & 0 & 0 & 0 & 0 & 0 \\
\hline Chapel_Hill & $\mathrm{F}$ & UN & 0 & 0 & 0 & 0 & 0 & 0 \\
\hline Chapel_Hill & $\overline{\mathrm{H}}$ & $\overline{\mathrm{UN}}$ & 0 & 0 & 0 & 0 & 0 & 0 \\
\hline Chapel_Hill & I & $\overline{\mathrm{UN}}$ & 0 & 0 & 0 & 0 & 0 & $\overline{0}$ \\
\hline Chelsea & $\bar{A}$ & $\mathrm{SN}$ & 0 & 0 & 0 & 0 & 0 & 0 \\
\hline Chelsea & B & $\mathrm{SN}$ & 0 & 0 & 0 & 0 & 0 & 0 \\
\hline Chelsea & $\mathrm{C}$ & $\mathrm{SN}$ & 0 & 0 & 0 & 0 & 0 & 0 \\
\hline Chelsea & $\bar{D}$ & SN & 0 & 0 & 0 & 0 & 0 & 0 \\
\hline Chelsea & $\bar{E}$ & $\overline{\mathrm{SN}}$ & 0 & 0 & 0 & 0 & 0 & 0 \\
\hline Chelsea & $\mathrm{F}$ & SN & 0 & 0 & 0 & 0 & $\mathbf{0}$ & 0 \\
\hline Chelsea & $\overline{\mathrm{H}}$ & $\mathrm{SN}$ & 0 & 0 & 0 & 0 & 0 & 0 \\
\hline Chelsea & I & $\overline{\mathrm{SN}}$ & 0 & 0 & 0 & 0 & 0 & $\overline{0}$ \\
\hline Chemin_Scholle & $\mathrm{A}$ & EN & 0 & 0 & 0 & 0 & 0 & 0 \\
\hline Chemin_Scholle & $\mathrm{B}$ & EN & 0 & 0 & 0 & 0 & 0 & 0 \\
\hline Chemin_Scholle & $\mathrm{C}$ & EN & 0 & 0 & 0 & 0 & 0 & 0 \\
\hline Chemin_Scholle & $\bar{D}$ & EN & 0 & 0 & 0 & 0 & 0 & 0 \\
\hline
\end{tabular}




\begin{tabular}{|c|c|c|c|c|c|c|c|c|}
\hline Chemin_Scholle & $\bar{E}$ & EN & 0 & 0 & 0 & 0 & 0 & $\overline{0}$ \\
\hline Chemin_Scholle & F & EN & 0 & 0 & 0 & 0 & 0 & 0 \\
\hline Chemin_Scholle & $\overline{\mathrm{H}}$ & EN & 0 & 0 & 0 & 0 & 0 & $\overline{0}$ \\
\hline Chemin_Scholle & I & EN & 0 & 0 & 0 & 0 & 0 & $\overline{0}$ \\
\hline Cote_d'Azur & $\mathrm{A}$ & $\bar{S}$ & 0 & 0 & 0 & $\overline{0}$ & 0 & 0 \\
\hline Cote_d'Azur & B & $\mathrm{S}$ & 0 & $\mathbf{0}$ & 0 & 0 & 0 & 0 \\
\hline Cote d'Azur & $\mathrm{C}$ & $\mathbf{S}$ & 0 & 0 & 0 & 0 & 0 & $\overline{0}$ \\
\hline Cote_d'Azur & $\bar{D}$ & $\bar{S}$ & 0 & 0 & 0 & 0 & 0 & $\overline{0}$ \\
\hline Cote_d'Azur & $\bar{E}$ & $\mathbf{S}$ & 0 & 0 & 0 & 0 & 0 & 0 \\
\hline Cote_d'Azur & $\mathrm{F}$ & $\mathrm{S}$ & 0 & 0 & 0 & 0 & 0 & 0 \\
\hline Cote d'Azur & $\mathrm{H}$ & $\mathrm{S}$ & 0 & 0 & 0 & 0 & 0 & $\overline{0}$ \\
\hline Cote_d'Azur & I & $\mathbf{S}$ & 0 & 0 & 0 & 0 & 0 & $\overline{0}$ \\
\hline Highway_Seven & A & $\mathrm{E}$ & 0 & 0 & 0 & 2 & 0 & 0 \\
\hline Highway_Seven & B & $\mathrm{E}$ & 0 & 0 & $\mathbf{0}$ & 0 & 0 & 0 \\
\hline Highway_Seven & $\mathrm{C}$ & $E$ & $\overline{0}$ & 0 & 0 & 0 & 0 & $\overline{0}$ \\
\hline Highway_Seven & $\mathrm{D}$ & $\mathrm{E}$ & 0 & 0 & 0 & 0 & 0 & 0 \\
\hline Highway_Seven & $\mathrm{E}$ & $\mathrm{E}$ & 0 & 0 & 0 & 0 & 0 & $\overline{0}$ \\
\hline Highway_Seven & $\mathrm{F}$ & $\mathrm{E}$ & 0 & 0 & 0 & 0 & 0 & 0 \\
\hline Highway_Seven & $\mathrm{H}$ & $E$ & 0 & 0 & 0 & 0 & 1 & $\overline{0}$ \\
\hline Highway_Seven & I & $\bar{E}$ & 0 & 0 & 0 & 0 & 0 & $\overline{0}$ \\
\hline Hull & $\bar{A}$ & $\overline{\mathrm{U}}$ & 0 & 0 & 0 & 0 & 0 & $\overline{0}$ \\
\hline Hull & B & $\bar{U}$ & 0 & 0 & 0 & 0 & 0 & $\overline{0}$ \\
\hline Hull & $\mathrm{C}$ & $\overline{\mathrm{U}}$ & 0 & 0 & 0 & 0 & 0 & $\overline{0}$ \\
\hline Hull & $\mathrm{D}$ & $\overline{\mathrm{U}}$ & 0 & 0 & 0 & 0 & 0 & 0 \\
\hline Hull & $\mathrm{E}$ & $\overline{\mathrm{U}}$ & 0 & 0 & 0 & 0 & 0 & $\overline{0}$ \\
\hline Hull & $F$ & $\bar{U}$ & 0 & 0 & 0 & 0 & 0 & $\overline{0}$ \\
\hline Hull & $\mathrm{H}$ & $\overline{\mathrm{U}}$ & 0 & 0 & 0 & 0 & 0 & $\overline{0}$ \\
\hline Hull & I & $\overline{\mathrm{U}}$ & 0 & 0 & 0 & 0 & 0 & $\overline{0}$ \\
\hline Lac_a_la_Perdrix & A & EN & 0 & 0 & 0 & 0 & 0 & 0 \\
\hline Lac_a_la_Perdrix & $\mathrm{B}$ & EN & 0 & 0 & 0 & 0 & 0 & 0 \\
\hline Lac_a_la_Perdrix & $\mathrm{C}$ & $\overline{\mathrm{EN}}$ & 0 & 0 & 0 & 0 & 0 & $\overline{0}$ \\
\hline Lac_a_la_Perdrix & $\mathrm{D}$ & $\overline{\mathrm{EN}}$ & 0 & 0 & 0 & 0 & 0 & 0 \\
\hline Lac_a_la_Perdrix & $\bar{E}$ & $\overline{\mathrm{EN}}$ & 0 & 0 & 0 & 0 & 0 & $\overline{0}$ \\
\hline Lac_a_la_Perdrix & $\bar{F}$ & $\overline{\mathrm{EN}}$ & 0 & 0 & 0 & 0 & 0 & $\overline{0}$ \\
\hline Lac_a_la_Perdrix & $\mathrm{H}$ & EN & 0 & 0 & 0 & 0 & 0 & $\overline{0}$ \\
\hline Lac_a_la_Perdrix & I & EN & 0 & 0 & 0 & 0 & 0 & 0 \\
\hline Lac_Philippe & $\bar{A}$ & $\mathrm{~F}$ & 0 & 0 & 0 & 0 & 0 & 0 \\
\hline Lac_Philippe & $\mathrm{B}$ & $\mathrm{F}$ & 0 & 0 & 0 & 0 & 0 & 0 \\
\hline Lac_Philippe & $\mathrm{C}$ & $F$ & 0 & 0 & 0 & 0 & 0 & $\overline{0}$ \\
\hline Lac_Philippe & $\mathrm{D}$ & $\bar{F}$ & 0 & 0 & 0 & 0 & 0 & $\overline{0}$ \\
\hline Lac_Philippe & $\bar{E}$ & $\mathrm{~F}$ & 0 & 0 & 0 & 0 & 0 & $\overline{0}$ \\
\hline Lac_Philippe & $\mathrm{F}$ & $\mathrm{F}$ & 0 & 0 & 0 & 0 & 0 & 0 \\
\hline Lac_Philippe & $\mathrm{H}$ & $\mathrm{F}$ & 0 & 0 & 0 & 0 & 0 & $\overline{0}$ \\
\hline Lac_Philippe & I & $F$ & 0 & 0 & 0 & 0 & 0 & 0 \\
\hline Manoir_des_Trembles & $\overline{\mathrm{A}}$ & $\overline{\mathrm{UN}}$ & 0 & $\overline{0}$ & 0 & 0 & 0 & $\overline{0}$ \\
\hline
\end{tabular}




\begin{tabular}{|c|c|c|c|c|c|c|c|c|}
\hline Manoir_des_Trembles & B & UN & 0 & 0 & 0 & 0 & 0 & 0 \\
\hline Manoir des Trembles & $\mathrm{C}$ & UN & 0 & 0 & 0 & 0 & 0 & 0 \\
\hline Manoir_des_Trembles & $\bar{D}$ & $\overline{\mathrm{UN}}$ & 0 & 0 & 0 & 0 & 0 & $\overline{0}$ \\
\hline Manoir_des_Trembles & $\bar{E}$ & UN & 0 & 0 & 0 & 0 & 0 & 0 \\
\hline Manoir_des_Trembles & $\bar{F}$ & UN & 0 & 0 & 0 & 0 & 0 & 0 \\
\hline Manoir des Trembles & $\overline{\mathrm{H}}$ & UN & 0 & 0 & 0 & 0 & 0 & 0 \\
\hline Manoir_des_Trembles & I & UN & 0 & 0 & 0 & 0 & 0 & 0 \\
\hline Marathon & $\mathrm{A}$ & $\mathrm{E}$ & 0 & 0 & 0 & 0 & 0 & 0 \\
\hline Marathon & $\mathrm{B}$ & $\mathrm{E}$ & 0 & 0 & 0 & 0 & 0 & 0 \\
\hline Marathon & $\mathrm{C}$ & $\overline{\mathrm{E}}$ & 0 & 0 & 0 & 1 & 0 & 0 \\
\hline Marathon & $\bar{D}$ & $\bar{E}$ & 0 & 0 & 0 & 0 & 0 & 0 \\
\hline Marathon & $\mathrm{E}$ & $\bar{E}$ & 0 & 0 & 0 & 0 & 0 & 0 \\
\hline Marathon & $\bar{F}$ & $E$ & 0 & 0 & 0 & 0 & 0 & 0 \\
\hline Marathon & $\mathrm{H}$ & $\bar{E}$ & 0 & 0 & 0 & 2 & 0 & 0 \\
\hline Marathon & I & $\mathbf{E}$ & 0 & 0 & 0 & 1 & 0 & 0 \\
\hline Marier & A & $\bar{U}$ & 0 & 0 & 0 & 0 & 0 & 0 \\
\hline Marier & B & $\mathrm{U}$ & 0 & 0 & 0 & 0 & 0 & 0 \\
\hline Marier & $\overline{\mathrm{C}}$ & $\mathrm{U}$ & 0 & 0 & 0 & 0 & 0 & 0 \\
\hline Marier & $\mathrm{D}$ & $\mathrm{U}$ & 0 & 0 & 0 & 0 & 0 & 0 \\
\hline Marier & $\bar{E}$ & $\mathrm{U}$ & 0 & 0 & 0 & 0 & 0 & 0 \\
\hline Marier & $\bar{F}$ & $\mathrm{U}$ & 0 & 0 & 0 & 0 & 0 & 0 \\
\hline Marier & $\mathrm{H}$ & $\mathrm{U}$ & 0 & 0 & 0 & 0 & 0 & 0 \\
\hline Marier & I & $\mathrm{U}$ & 0 & 0 & 0 & 0 & 0 & 0 \\
\hline Marlborough & $\bar{A}$ & $\mathbf{F}$ & 0 & 0 & 0 & 0 & 0 & 0 \\
\hline Marlborough & B & $F$ & 0 & 0 & 0 & 0 & 0 & 0 \\
\hline Marlborough & $\mathrm{C}$ & $\mathbf{F}$ & 0 & 0 & 0 & 0 & 0 & 0 \\
\hline Marlborough & $\mathrm{D}$ & $\mathbf{F}$ & 0 & 0 & 0 & 0 & 0 & 0 \\
\hline Marlborough & $E$ & $\mathbf{F}$ & 0 & 0 & 0 & 0 & 0 & 0 \\
\hline Marlborough & $F$ & $\mathbf{F}$ & 0 & 0 & 0 & 10 & 0 & 0 \\
\hline Marlborough & $\mathrm{H}$ & $F$ & 0 & 0 & 0 & 0 & 0 & 0 \\
\hline Marlborough & I & $\mathbf{F}$ & 0 & 0 & 0 & 1 & 0 & 0 \\
\hline Merivale & $\bar{A}$ & $\overline{\mathrm{SN}}$ & 0 & 0 & 0 & 0 & 0 & 0 \\
\hline Merivale & B & $\mathrm{SN}$ & 0 & 0 & 0 & 0 & 0 & 0 \\
\hline Merivale & $\bar{C}$ & $\overline{\mathrm{SN}}$ & 0 & 0 & 0 & 0 & 0 & 0 \\
\hline Merivale & $\mathrm{D}$ & $\mathrm{SN}$ & 0 & 0 & 0 & 0 & 0 & 0 \\
\hline Merivale & $\mathrm{E}$ & $\overline{\mathrm{SN}}$ & 0 & 0 & 0 & 0 & 0 & 0 \\
\hline Merivale & $\mathrm{F}$ & $\mathrm{SN}$ & 0 & 0 & 0 & 0 & 0 & 0 \\
\hline Merivale & $\mathrm{H}$ & $\overline{\mathrm{SN}}$ & 0 & 0 & 0 & 0 & 0 & 0 \\
\hline Merivale & $\mathrm{I}$ & $\mathrm{SN}$ & 0 & 0 & 0 & 0 & 0 & 0 \\
\hline Parc_Champlain & A & $\mathrm{S}$ & 0 & 0 & 0 & 0 & 0 & 0 \\
\hline Parc_Champlain & B & $\mathrm{S}$ & 1 & 0 & 0 & 0 & 2 & 0 \\
\hline Parc_Champlain & $\mathrm{C}$ & $\mathrm{S}$ & 0 & 0 & 0 & 0 & 1 & 0 \\
\hline Parc_Champlain & $\mathrm{D}$ & $\mathrm{S}$ & 0 & 0 & 0 & 0 & 0 & 0 \\
\hline Parc_Champlain & $\bar{E}$ & $\mathrm{~S}$ & 0 & 0 & 0 & 0 & 0 & 0 \\
\hline Parc_Champlain & $\mathrm{F}$ & $\mathrm{S}$ & 0 & 0 & 0 & 0 & 0 & 0 \\
\hline
\end{tabular}




\begin{tabular}{|c|c|c|c|c|c|c|c|c|}
\hline Parc_Champlain & $\mathrm{H}$ & $\mathrm{S}$ & 0 & 0 & 0 & 0 & 0 & $\overline{0}$ \\
\hline Parc_Champlain & $\mathrm{II}$ & $\mathrm{S}$ & 0 & 0 & 0 & 0 & 0 & 0 \\
\hline Pelissier & $\bar{A}$ & $\mathrm{EN}$ & 0 & 0 & 0 & 0 & 0 & $\overline{0}$ \\
\hline Pelissier & $\bar{B}$ & $\mathrm{EN}$ & 0 & 0 & 0 & 0 & 0 & $\overline{0}$ \\
\hline Pelissier & $\mathrm{C}$ & $\overline{E N}$ & 0 & 1 & 2 & 1 & 0 & 0 \\
\hline Pelissier & $\bar{D}$ & EN & 0 & 0 & 0 & 0 & 0 & $\overline{0}$ \\
\hline Pelissier & $E$ & $\overline{\mathrm{EN}}$ & 0 & 0 & 0 & 0 & 0 & $\overline{0}$ \\
\hline $\begin{array}{l}\text { Pelissier } \\
\end{array}$ & $\mathrm{F}$ & $\overline{\mathrm{EN}}$ & 0 & 0 & 0 & 0 & 0 & $\overline{0}$ \\
\hline Pelissier & $\overline{\mathrm{H}}$ & $\mathrm{EN}$ & 0 & 0 & 0 & 0 & 0 & 0 \\
\hline Pelissier & I & $\overline{\mathrm{EN}}$ & 0 & 0 & 0 & 0 & 0 & $\overline{0}$ \\
\hline PineGlen_Annex & $\bar{A}$ & $\mathrm{~S}$ & 0 & 0 & 0 & 0 & 0 & 1 \\
\hline PineGlen_Annex & B & $\mathrm{S}$ & 0 & 0 & 0 & 0 & 0 & 0 \\
\hline PineGlen_Annex & $\mathrm{C}$ & $\mathrm{S}$ & 0 & 0 & 0 & 0 & 0 & $\overline{0}$ \\
\hline PineGlen_Annex & $\mathrm{D}$ & $\mathrm{S}$ & 0 & 0 & 0 & 0 & 0 & 0 \\
\hline PineGlen_Annex & $E$ & $\mathrm{~S}$ & 0 & 0 & 0 & 0 & 1 & $\overline{0}$ \\
\hline PineGlen_Annex & $\bar{F}$ & $\mathrm{~S}$ & 0 & 0 & 0 & 0 & 0 & $\overline{0}$ \\
\hline PineGlen_Annex & $\mathrm{H}$ & $\bar{S}$ & 0 & 0 & 0 & 0 & 0 & 0 \\
\hline PineGlen_Annex & I & $S$ & 0 & 0 & 0 & 0 & 0 & $\overline{0}$ \\
\hline Q_Four & A & E & 0 & 0 & 0 & 0 & 0 & 0 \\
\hline Q_Four & B & $\mathrm{E}$ & 0 & 0 & 0 & 0 & 0 & 0 \\
\hline Q_Four & $\mathrm{C}$ & $\mathrm{E}$ & 0 & 0 & 0 & 0 & 0 & 0 \\
\hline Q_Four & $\mathrm{D}$ & $E$ & 0 & 0 & 0 & 0 & 0 & 0 \\
\hline Q_Four & $E$ & $E$ & 0 & 0 & 0 & 0 & 0 & 0 \\
\hline Q_Four & F & $\mathrm{E}$ & 0 & 0 & 0 & 0 & 0 & 0 \\
\hline Q_Four & $\mathrm{H}$ & $E$ & 0 & 0 & 0 & 0 & 0 & 0 \\
\hline Q_Four & $I$ & $\mathrm{E}$ & 0 & 0 & 0 & 0 & 0 & 0 \\
\hline Sandy_Hill & $\bar{A}$ & $\mathrm{U}$ & 0 & 0 & 0 & 0 & 0 & 1 \\
\hline Sandy_Hill & $\mathrm{B}$ & $\overline{\mathrm{U}}$ & 0 & 0 & 0 & 0 & 0 & $\overline{0}$ \\
\hline Sandy_Hill & $\mathrm{C}$ & $\overline{\mathrm{U}}$ & 0 & 0 & 0 & 0 & 0 & 0 \\
\hline Sandy_Hill & $\mathrm{D}$ & $\mathrm{U}$ & 0 & 0 & 0 & 0 & 0 & 0 \\
\hline Sandy_Hill & $\mathrm{E}$ & $\mathrm{U}$ & 0 & 0 & 0 & 0 & 0 & 0 \\
\hline Sandy_Hill & $\mathrm{F}$ & $\mathrm{U}$ & 0 & 0 & 0 & 0 & 0 & 0 \\
\hline Sandy_Hill & $\mathrm{H}$ & $\mathrm{U}$ & 0 & 0 & 0 & 0 & 0 & 0 \\
\hline Sandy_Hill & $I$ & $\mathrm{U}$ & 0 & 0 & 0 & 0 & 0 & 0 \\
\hline Vallee_Meech & $\mathrm{A}$ & $\bar{F}$ & 0 & 0 & 0 & 0 & 0 & 0 \\
\hline Vallee_Meech & $\mathrm{B}$ & $\mathrm{F}$ & 0 & 0 & 0 & 0 & 0 & 0 \\
\hline Vallee_Meech & $\mathrm{C}$ & $F$ & 0 & 0 & 0 & 0 & 0 & 0 \\
\hline Vallee_Meech & $\mathrm{D}$ & $\mathrm{F}$ & 0 & 0 & 0 & 0 & 0 & 0 \\
\hline Vallee_Meech & $\mathrm{E}$ & $\mathrm{F}$ & 0 & 0 & 0 & 0 & 0 & 0 \\
\hline Vallee_Meech & $F$ & $\mathrm{~F}$ & 0 & 0 & 0 & 0 & 0 & 0 \\
\hline Vallee_Meech & $\mathrm{H}$ & $\mathrm{F}$ & 0 & 0 & 0 & 0 & 0 & $\overline{0}$ \\
\hline Vallee_Meech & I & $\mathrm{F}$ & 0 & 0 & 0 & 0 & 0 & 0 \\
\hline Wolf_Grove & $\mathrm{A}$ & $E$ & 0 & 0 & 0 & 0 & 0 & 0 \\
\hline Wolf_Grove & $\mathrm{B}$ & $\mathrm{E}$ & 0 & 0 & 0 & 0 & 0 & 0 \\
\hline Wolf_Grove & $\mathrm{C}$ & $\bar{E}$ & 0 & 0 & 0 & 0 & 0 & 0 \\
\hline
\end{tabular}




\begin{tabular}{|l|l|l|r|r|r|r|r|r|}
\hline Wolf_Grove & D & E & 0 & 0 & 0 & 0 & 0 & 0 \\
\hline Wolf_Grove & E & E & 0 & 0 & 0 & 0 & 0 & 0 \\
\hline Wolf_Grove & F & E & 0 & 0 & 0 & 0 & 0 & 0 \\
\hline Wolf_Grove & H & E & 0 & 0 & 0 & 0 & 0 & 0 \\
\hline Wolf_Grove & I & E & 0 & 0 & 0 & 0 & 0 & 0 \\
\hline Wrightville & A & U & 0 & 0 & 0 & 0 & 0 & 0 \\
\hline Wrightville & B & U & 0 & 0 & 0 & 0 & 0 & 0 \\
\hline Wrightville & C & U & 0 & 0 & 0 & 0 & 0 & 0 \\
\hline Wrightville & D & U & 0 & 0 & 0 & 0 & 0 & 0 \\
\hline Wrightville & E & U & 0 & 0 & 0 & 0 & 0 & 0 \\
\hline Wrightville & F & U & 0 & 0 & 0 & 0 & 0 & 0 \\
\hline Wrightville & H & U & 0 & 0 & 0 & 0 & 6 & 0 \\
\hline Wrightville & I & U & 0 & 0 & 0 & 0 & 0 & 0 \\
\hline Wychwood & A & S & 0 & 0 & 0 & 0 & 0 & 0 \\
\hline Wychwood & B & S & 0 & 0 & 0 & 0 & 2 & 0 \\
\hline Wychwood & C & S & 0 & 0 & 0 & 0 & 0 & 0 \\
\hline Wychwood & D & S & 0 & 0 & 0 & 0 & 0 & 0 \\
\hline Wychwood & E & S & 0 & 0 & 0 & 0 & 0 & 0 \\
\hline Wychwood & F & S & 0 & 0 & 0 & 0 & 0 & 0 \\
\hline Wychwood & H & S & 0 & 0 & 0 & 0 & 1 & 0 \\
\hline Wychwood & I & S & 0 & 0 & 0 & 0 & 0 & 0 \\
\hline
\end{tabular}




\begin{tabular}{|c|c|c|c|c|c|c|c|c|}
\hline SITE & STATION & CATEGORY & BEVA & BEVE & BRLU & BRME & CAGR & CALGR \\
\hline Achbar & A & SN & 0 & 0 & 0 & 0 & 0 & 0 \\
\hline Achbar & B & $\overline{\mathrm{SN}}$ & 0 & 0 & 0 & 0 & 0 & 0 \\
\hline Achbar & $\bar{C}$ & $\overline{\mathrm{SN}}$ & 0 & 0 & 0 & 0 & 0 & 0 \\
\hline Achbar & $\bar{D}$ & $\overline{\mathrm{SN}}$ & 0 & 0 & 0 & 0 & 0 & 4 \\
\hline Achbar & $E$ & $\mathrm{SN}$ & 0 & 0 & 0 & 0 & 0 & 0 \\
\hline Achbar & $F$ & $\mathrm{SN}$ & 0 & 0 & 0 & 0 & 0 & 0 \\
\hline Achbar & $\mathrm{H}$ & SN & 0 & 0 & 0 & 0 & $\overline{0}$ & 0 \\
\hline Achbar & I & SN & 0 & 0 & 0 & 0 & 0 & 1 \\
\hline Bridlewood & A & UN & 0 & 0 & 0 & 0 & 0 & 1 \\
\hline Bridlewood & $\bar{B}$ & $\overline{\mathrm{UN}}$ & 0 & 0 & 0 & 0 & 0 & 0 \\
\hline Bridlewood & $\mathrm{C}$ & UN & 0 & 0 & 0 & 0 & 0 & 10 \\
\hline Bridlewood & $\bar{D}$ & $\overline{\mathrm{UN}}$ & 0 & $\overline{0}$ & 0 & 0 & 0 & 1 \\
\hline Bridlewood & $E$ & UN & 0 & 0 & 0 & 0 & 0 & 0 \\
\hline Bridlewood & $F$ & UN & 0 & 0 & 0 & 0 & 0 & 0 \\
\hline Bridlewood & $\mathrm{H}$ & UN & 0 & 0 & 0 & 0 & 0 & 7 \\
\hline Bridlewood & I & UN & 0 & 0 & 0 & 0 & 0 & 8 \\
\hline Carp_Hills & $\overline{\mathrm{A}}$ & $\mathrm{F}$ & 0 & 0 & 0 & 0 & 0 & 0 \\
\hline Carp_Hills & $\mathrm{B}$ & $F$ & 0 & 0 & 0 & 0 & 0 & 0 \\
\hline Carp_Hills & $\mathrm{C}$ & $\mathrm{F}$ & 0 & 0 & 0 & 0 & 0 & 0 \\
\hline Carp_Hills & $\overline{\mathrm{D}}$ & $F$ & 0 & 0 & 0 & 0 & 0 & 0 \\
\hline Carp_Hills & $E$ & $\mathrm{~F}$ & 0 & 0 & 0 & 0 & 0 & 1 \\
\hline Carp_Hills & $\mathrm{F}$ & $F$ & 0 & 0 & 0 & 0 & 0 & 0 \\
\hline Carp_Hills & $\mathrm{H}$ & $\bar{F}$ & 0 & 0 & 1 & 1 & 0 & 0 \\
\hline Carp_Hills & I & $F$ & 1 & 0 & 0 & 0 & 0 & 0 \\
\hline Chapel_Hill & $\mathrm{A}$ & $\overline{\mathrm{UN}}$ & 0 & 0 & 0 & 0 & 0 & 0 \\
\hline Chapel_Hill & $\bar{B}$ & UN & $\overline{0}$ & 0 & 0 & 0 & 0 & 0 \\
\hline Chapel_Hill & $\mathrm{C}$ & UN & 0 & 0 & 0 & 0 & 0 & 0 \\
\hline Chapel_Hill & $\bar{D}$ & UN & 0 & 0 & 0 & 0 & 0 & 0 \\
\hline Chapel_Hill & $\bar{E}$ & UN & 0 & 0 & 0 & 0 & 0 & 0 \\
\hline Chapel_Hill & $F$ & UN & 0 & 0 & 0 & 0 & 0 & 0 \\
\hline Chapel_Hill & $\mathrm{H}$ & UN & 0 & 0 & 0 & 0 & 0 & 0 \\
\hline Chapel_Hill & I & $\overline{\mathrm{UN}}$ & 0 & 0 & 0 & 0 & 1 & $\overline{0}$ \\
\hline Chelsea & $\bar{A}$ & $\mathrm{SN}$ & 0 & 0 & 0 & 0 & 0 & 0 \\
\hline Chelsea & $\bar{B}$ & SN & 0 & 0 & 0 & 0 & 0 & 0 \\
\hline Chelsea & $\mathrm{C}$ & SN & 0 & 0 & 0 & 0 & 0 & 0 \\
\hline Chelsea & $\mathrm{D}$ & SN & 0 & 0 & 0 & 0 & 0 & 0 \\
\hline Chelsea & $E$ & $\overline{\mathrm{SN}}$ & 0 & 0 & 0 & 0 & 0 & 0 \\
\hline Chelsea & $\mathrm{F}$ & SN & 0 & 0 & 0 & 0 & 0 & $\overline{0}$ \\
\hline Chelsea & $\mathrm{H}$ & SN & 0 & 0 & 0 & 0 & 0 & $\overline{0}$ \\
\hline Chelsea & I & SN & 0 & 0 & 0 & 0 & 0 & 0 \\
\hline Chemin_Scholle & $\bar{A}$ & EN & 0 & 0 & 0 & 0 & 0 & $\overline{0}$ \\
\hline Chemin_Scholle & $\mathrm{B}$ & EN & 0 & 0 & 0 & 0 & 0 & 0 \\
\hline
\end{tabular}




\begin{tabular}{|c|c|c|c|c|c|c|c|c|}
\hline Chemin_Scholle & $\mathrm{C}$ & $\mathrm{EN}$ & 0 & 0 & 0 & 0 & 0 & 0 \\
\hline Chemin_Scholle & $\mathrm{D}$ & $\mathrm{EN}$ & 0 & 0 & 0 & 0 & 0 & 0 \\
\hline Chemin_Scholle & $E$ & EN & 0 & 0 & 0 & 0 & 0 & 0 \\
\hline Chemin_Scholle & $\mathrm{F}$ & $\mathrm{EN}$ & 0 & 0 & 0 & 0 & 0 & $\overline{0}$ \\
\hline Chemin_Scholle & $\overline{\mathrm{H}}$ & EN & 0 & 0 & 0 & 0 & 0 & 1 \\
\hline Chemin_Scholle & I & $\overline{\mathrm{EN}}$ & 0 & 0 & 0 & 0 & 0 & $\overline{0}$ \\
\hline Cote_d'Azur & $\overline{\mathrm{A}}$ & $\bar{S}$ & 0 & 0 & 0 & 0 & 0 & $\overline{0}$ \\
\hline Cote_d'Azur & B & $\bar{S}$ & 0 & 0 & 0 & 0 & 0 & 0 \\
\hline Cote_d'Azur & $\mathrm{C}$ & $\mathrm{S}$ & 0 & 0 & 0 & 0 & 0 & $\overline{0}$ \\
\hline Cote_d'Azur & $\bar{D}$ & $\bar{S}$ & 0 & 0 & 0 & 0 & 0 & $\overline{0}$ \\
\hline Cote_d'Azur & $\bar{E}$ & $\bar{S}$ & 0 & 0 & 0 & 0 & 0 & 0 \\
\hline Cote_d'Azur & $\mathrm{F}$ & $\mathrm{S}$ & 0 & 0 & 0 & 0 & 0 & 0 \\
\hline Cote_d'Azur & $\widetilde{\mathrm{H}}$ & $\bar{S}$ & 0 & 0 & 0 & 0 & 0 & $\overline{0}$ \\
\hline Cote_d'Azur & I & $\mathrm{S}$ & 0 & 0 & 0 & 0 & 0 & $\overline{0}$ \\
\hline Highway_Seven & $\mathrm{A}$ & $\mathrm{E}$ & 0 & 0 & 0 & 0 & 0 & 0 \\
\hline Highway_Seven & B & $E$ & 0 & 0 & 0 & 0 & 0 & $\overline{0}$ \\
\hline Highway_Seven & $\mathrm{C}$ & $\mathrm{E}$ & 0 & 0 & 0 & 0 & 0 & $\overline{0}$ \\
\hline Highway_Seven & $\bar{D}$ & $\bar{E}$ & 0 & 0 & 0 & 0 & 0 & $\overline{0}$ \\
\hline Highway_Seven & $\bar{E}$ & $\bar{E}$ & 0 & 0 & 0 & 0 & 0 & 0 \\
\hline Highway_Seven & $\mathrm{F}$ & $\mathrm{E}$ & 0 & 0 & 0 & 0 & 0 & 1 \\
\hline Highway_Seven & $\mathrm{H}$ & $\bar{E}$ & 0 & 1 & 0 & 0 & 0 & 0 \\
\hline Highway_Seven & $I$ & $\mathrm{E}$ & 0 & 0 & 0 & 0 & 0 & 2 \\
\hline Hull & A & $\mathrm{U}$ & 0 & 0 & 0 & 0 & 0 & 0 \\
\hline Hull & $\bar{B}$ & $\bar{U}$ & 0 & 0 & 0 & 0 & 0 & $\overline{0}$ \\
\hline Hull & $\mathrm{C}$ & $\mathrm{U}$ & 0 & 0 & 0 & 0 & 0 & 0 \\
\hline Hull & $\bar{D}$ & $\bar{U}$ & 0 & 0 & 0 & 0 & 0 & $\overline{0}$ \\
\hline Hull & $\mathrm{E}$ & $\bar{U}$ & 0 & 0 & 0 & 0 & 0 & 0 \\
\hline Hull & $\bar{F}$ & $\bar{U}$ & 0 & 0 & 0 & 0 & 0 & 0 \\
\hline Hull & $\overline{\mathrm{H}}$ & $\mathrm{U}$ & 0 & 0 & 0 & 0 & 0 & 0 \\
\hline Hull & I & $\bar{U}$ & 0 & 0 & 0 & 0 & 0 & 0 \\
\hline Lac_a_la_Perdrix & A & EN & 0 & 0 & 0 & 0 & 0 & $\overline{0}$ \\
\hline Lac_a_la_Perdrix & $\overline{\mathrm{B}}$ & $\overline{\mathrm{EN}}$ & 0 & 0 & 0 & 0 & 0 & $\overline{0}$ \\
\hline Lac_a_la_Perdrix & $\mathrm{C}$ & EN & 0 & 0 & 0 & 0 & 0 & 0 \\
\hline Lac_a_la_Perdrix & $\mathrm{D}$ & EN & 0 & 0 & 0 & 0 & 0 & 0 \\
\hline Lac_a_la_Perdrix & $E$ & $\overline{\text { EN }}$ & 0 & 0 & 0 & 0 & 0 & 0 \\
\hline Lac_a_la_Perdrix & $\bar{F}$ & EN & 0 & 0 & 0 & 0 & 0 & 0 \\
\hline Lac_a_la_Perdrix & $\mathrm{H}$ & EN & 0 & 0 & 0 & 0 & 0 & 0 \\
\hline Lac_a_la_Perdrix & I & $\overline{\text { EN }}$ & 0 & 0 & 0 & 0 & 0 & 0 \\
\hline Lac_Philippe & A & $\mathrm{F}$ & 0 & 0 & 0 & 0 & 0 & 0 \\
\hline Lac_Philippe & $\overline{\mathrm{B}}$ & $\mathrm{F}$ & 0 & 0 & 0 & 0 & 0 & 0 \\
\hline Lac_Philippe & $\mathrm{C}$ & $\mathrm{F}$ & 0 & 0 & 0 & 0 & 0 & 0 \\
\hline Lac_Philippe & $\mathrm{D}$ & $\mathrm{F}$ & 0 & 0 & 0 & 0 & 0 & 0 \\
\hline Lac_Philippe & $\bar{E}$ & $\mathrm{~F}$ & 0 & 0 & 0 & 0 & 0 & 0 \\
\hline
\end{tabular}




\begin{tabular}{|c|c|c|c|c|c|c|c|c|}
\hline Lac_Philippe & $F$ & $F$ & 0 & 0 & 0 & 0 & 0 & 0 \\
\hline Lac_Philippe & $\mathrm{H}$ & $F$ & 0 & 0 & 0 & 0 & 0 & 0 \\
\hline Lac_Philippe & I & $F$ & 0 & 0 & 0 & 0 & 0 & 0 \\
\hline Manoir_des_Trembles & $\mathrm{A}$ & UN & 0 & 0 & 0 & 0 & 0 & 0 \\
\hline Manoir_des_Trembles & $\bar{B}$ & UN & 0 & 0 & 0 & 0 & 0 & 0 \\
\hline Manoir_des_Trembles & $\bar{C}$ & UN & 2 & 0 & 0 & 0 & 1 & 0 \\
\hline Manoir_des_Trembles & $\bar{D}$ & $\overline{\mathrm{UN}}$ & 0 & 0 & 0 & 0 & 0 & 0 \\
\hline Manoir_des_Trembles & $\bar{E}$ & $\mathrm{UN}$ & 0 & 0 & 0 & 0 & 0 & 0 \\
\hline Manoir_des_Trembles & $\bar{F}$ & $\mathrm{UN}$ & 0 & 0 & 0 & 0 & 0 & 0 \\
\hline Manoir_des_Trembles & $\mathrm{H}$ & UN & 0 & 0 & 0 & 0 & 0 & 0 \\
\hline Manoir_des_Trembles & I & $\overline{\mathrm{UN}}$ & 0 & 0 & 0 & 0 & 0 & 0 \\
\hline Marathon & $\bar{A}$ & $\bar{E}$ & 0 & 0 & 0 & 0 & 0 & 0 \\
\hline Marathon & $\bar{B}$ & $\bar{E}$ & 0 & 0 & 0 & 0 & 0 & 1 \\
\hline Marathon & $\mathrm{C}$ & $\mathrm{E}$ & 0 & 0 & 0 & 0 & 0 & 0 \\
\hline Marathon & $\mathrm{D}$ & $E$ & 0 & 0 & 0 & 0 & 0 & 0 \\
\hline Marathon & $\mathrm{E}$ & $\mathrm{E}$ & 0 & 0 & 0 & 0 & 0 & 0 \\
\hline Marathon & $F$ & $\mathrm{E}$ & 0 & 0 & 0 & 0 & 0 & 0 \\
\hline Marathon & $\mathrm{H}$ & $\bar{E}$ & 0 & 0 & 0 & 0 & 0 & 0 \\
\hline Marathon & I & $E$ & 0 & 0 & 0 & 0 & 0 & 0 \\
\hline Marier & $\bar{A}$ & $\bar{U}$ & 0 & 0 & 0 & 0 & 0 & 0 \\
\hline Marier & $\bar{B}$ & $\bar{U}$ & 0 & 0 & 0 & 0 & 0 & 0 \\
\hline Marier & $\mathrm{C}$ & $\mathrm{U}$ & 0 & 0 & 0 & 0 & 0 & 0 \\
\hline Marier & D & $\bar{U}$ & 0 & 0 & 0 & 0 & 0 & 0 \\
\hline Marier & $E$ & $\overline{\mathrm{U}}$ & 0 & 0 & 0 & 0 & 0 & 0 \\
\hline Marier & $F$ & $\bar{U}$ & 0 & 0 & 0 & 0 & 0 & 0 \\
\hline Marier & $\overline{\mathrm{H}}$ & $\overline{\mathrm{U}}$ & 0 & 0 & 0 & 0 & 0 & 0 \\
\hline Marier & I & $\bar{U}$ & 0 & 0 & 0 & 0 & 0 & 0 \\
\hline Marlborough & $\bar{A}$ & $\bar{F}$ & 0 & 0 & 0 & 0 & 0 & 0 \\
\hline Marlborough & $\mathrm{B}$ & $F$ & 0 & 0 & 0 & 0 & 0 & 0 \\
\hline Marlborough & $\bar{C}$ & $F$ & 0 & 0 & 0 & 0 & 0 & 0 \\
\hline Marlborough & $\mathrm{D}$ & $\mathrm{F}$ & 0 & 0 & 0 & 0 & 0 & 0 \\
\hline Marlborough & $\mathrm{E}$ & $\bar{F}$ & 0 & 0 & 0 & 0 & 0 & 0 \\
\hline Marlborough & $F$ & $\bar{F}$ & 0 & 0 & 0 & 0 & 0 & 0 \\
\hline Marlborough & $\mathrm{H}$ & $F$ & 0 & 0 & 0 & 0 & 0 & 0 \\
\hline Marlborough & I & $F$ & 0 & 0 & 0 & 0 & 0 & 1 \\
\hline Merivale & $\mathrm{A}$ & $\mathrm{SN}$ & 0 & 0 & 0 & 0 & 0 & 0 \\
\hline Merivale & B & $\mathrm{SN}$ & 0 & 0 & 0 & 0 & 5 & 0 \\
\hline Merivale & $\mathrm{C}$ & $\overline{\mathrm{SN}}$ & 0 & 0 & 0 & 0 & 23 & 0 \\
\hline Merivale & $\mathrm{D}$ & $\overline{\mathrm{SN}}$ & 0 & 0 & 0 & 0 & 0 & 0 \\
\hline Merivale & $E$ & $\mathrm{SN}$ & 0 & 0 & 0 & 0 & 23 & 0 \\
\hline Merivale & $F$ & $\overline{\mathrm{SN}}$ & 0 & 0 & 0 & 0 & 18 & 0 \\
\hline Merivale & $\mathrm{H}$ & $\overline{\mathrm{SN}}$ & 0 & 0 & 0 & 0 & 16 & 0 \\
\hline Merivale & I & SN & 0 & 0 & 0 & 0 & 1 & 0 \\
\hline
\end{tabular}




\begin{tabular}{|c|c|c|c|c|c|c|c|c|}
\hline Parc_Champlain & A & $\mathrm{S}$ & 0 & 0 & 0 & 0 & 0 & 0 \\
\hline Parc_Champlain & B & $\mathrm{S}$ & 0 & 0 & 0 & 0 & 0 & $\overline{0}$ \\
\hline Parc_Champlain & $\mathrm{C}$ & $\bar{S}$ & 0 & 0 & 0 & 0 & 0 & $\overline{0}$ \\
\hline Parc_Champlain & $\mathrm{D}$ & $\mathrm{S}$ & 0 & 0 & 0 & 0 & 0 & 0 \\
\hline Parc_Champlain & $E$ & $\bar{S}$ & 0 & 0 & 0 & 0 & 0 & 0 \\
\hline Parc_Champlain & $\bar{F}$ & $\bar{S}$ & 0 & 0 & 0 & 0 & 0 & 0 \\
\hline Parc_Champlain & $\overline{\mathrm{H}}$ & $\mathrm{S}$ & 0 & 0 & 0 & 0 & 0 & 0 \\
\hline Parc_Champlain & $\mathrm{I}$ & $\mathrm{S}$ & 0 & $\overline{0}$ & 0 & 0 & 0 & 0 \\
\hline Pelissier & $\overline{\mathrm{A}}$ & $\overline{\mathrm{EN}}$ & 0 & 0 & 0 & 0 & 0 & $\overline{0}$ \\
\hline Pelissier & $\bar{B}$ & $\overline{\mathrm{EN}}$ & 0 & 0 & 0 & 0 & 0 & $\overline{0}$ \\
\hline Pelissier & $\bar{C}$ & $\overline{\mathrm{EN}}$ & 0 & 0 & 0 & 0 & 0 & 0 \\
\hline Pelissier & $\bar{D}$ & $\overline{\mathrm{EN}}$ & 0 & 0 & 0 & 0 & 0 & 0 \\
\hline Pelissier & $\bar{E}$ & $\overline{\mathrm{EN}}$ & 0 & 0 & 0 & 0 & 0 & $\overline{0}$ \\
\hline Pelissier & $\mathbf{F}$ & EN & 0 & 0 & 0 & 0 & 0 & 0 \\
\hline Pelissier & $\mathrm{H}$ & EN & 0 & 0 & 0 & 0 & 0 & 0 \\
\hline Pelissier & $\bar{I}$ & $\overline{\mathrm{EN}}$ & 0 & 0 & 0 & 0 & 0 & $\overline{0}$ \\
\hline PineGlen_Annex & $\bar{A}$ & $\mathrm{~S}$ & 0 & 0 & 0 & 0 & 0 & 0 \\
\hline PineGlen_Annex & B & $\mathrm{S}$ & 0 & 0 & 0 & 0 & 0 & 0 \\
\hline PineGlen_Annex & $\mathrm{C}$ & $\mathrm{S}$ & 0 & 0 & 0 & 0 & 0 & 0 \\
\hline PineGlen_Annex & $\bar{D}$ & $\mathrm{~S}$ & 0 & 0 & 0 & 0 & 0 & 0 \\
\hline PineGlen_Annex & $\bar{E}$ & $\mathrm{~S}$ & 0 & 0 & 0 & 0 & 0 & 0 \\
\hline PineGlen_Annex & $\mathbf{F}$ & $\mathrm{S}$ & 0 & 0 & 0 & 0 & 0 & 0 \\
\hline PineGlen_Annex & $\overline{\mathrm{H}}$ & $\mathrm{S}$ & 0 & 0 & 0 & 0 & 0 & 0 \\
\hline PineGlen_Annex & $\bar{I}$ & $\mathrm{~S}$ & 0 & 0 & 0 & 0 & 0 & 0 \\
\hline Q_Four & $\overline{\mathrm{A}}$ & $\bar{E}$ & 0 & 0 & 0 & 0 & 0 & $\overline{0}$ \\
\hline Q_Four & $\mathrm{B}$ & $\mathrm{E}$ & 0 & 0 & 0 & 0 & 0 & 0 \\
\hline Q_Four & $\mathrm{C}$ & $E$ & 0 & 0 & 0 & 0 & 0 & 0 \\
\hline Q_Four & $\mathrm{D}$ & $\mathbf{E}$ & 0 & 0 & 0 & 0 & 0 & 0 \\
\hline Q_Four & $\mathrm{E}$ & $E$ & 0 & 0 & 0 & 0 & 0 & 0 \\
\hline Q_Four & $F$ & $\mathrm{E}$ & 0 & 0 & 0 & 0 & 0 & 0 \\
\hline Q_Four & $\mathrm{H}$ & $\mathrm{E}$ & 0 & 0 & 0 & 0 & 0 & 0 \\
\hline Q_Four & I & $E$ & 0 & 0 & 0 & 0 & 0 & 0 \\
\hline Sandy_Hill & $\overline{\mathrm{A}}$ & $\mathrm{U}$ & 0 & 0 & 0 & 0 & 0 & $\overline{0}$ \\
\hline Sandy_Hill & $\mathrm{B}$ & $\mathrm{U}$ & 0 & 0 & 0 & 0 & 0 & 0 \\
\hline Sandy_Hill & $\mathrm{C}$ & $\mathrm{U}$ & 0 & 0 & 0 & 0 & 0 & 0 \\
\hline Sandy_Hill & D & $\mathrm{U}$ & 0 & 0 & 0 & 0 & 0 & 0 \\
\hline Sandy_Hill & $\bar{E}$ & $\bar{U}$ & 0 & 0 & 0 & 0 & 0 & 0 \\
\hline Sandy_Hill & $\mathbf{F}$ & $\mathrm{U}$ & 0 & 0 & 0 & 0 & 0 & 0 \\
\hline Sandy_Hill & $\mathrm{H}$ & $\mathrm{U}$ & 0 & 0 & 0 & 0 & 0 & 0 \\
\hline Sandy_Hill & I & $\mathrm{U}$ & 0 & 0 & 0 & 0 & 0 & 0 \\
\hline Vallee_Meech & $\mathrm{A}$ & $\mathrm{F}$ & 0 & 0 & 0 & 0 & 0 & 0 \\
\hline Vallee_Meech & $\mathrm{B}$ & $F$ & 0 & 0 & 0 & 0 & 0 & 0 \\
\hline Vallee_Meech & $\mathrm{C}$ & $F$ & 0 & 0 & 0 & 0 & 0 & 0 \\
\hline
\end{tabular}




\begin{tabular}{|c|c|c|c|c|c|c|c|c|}
\hline Vallee_Meech & $\mathrm{D}$ & $\mathrm{F}$ & 0 & 0 & 0 & 0 & 0 & 0 \\
\hline Vallee_Meech & $\bar{E}$ & $\mathrm{~F}$ & 0 & 0 & 0 & 0 & 0 & 0 \\
\hline Vallee_Meech & $F$ & $\mathrm{~F}$ & 0 & 0 & 0 & 0 & $\overline{0}$ & 0 \\
\hline Vallee_Meech & $\overline{\mathrm{H}}$ & $\mathrm{F}$ & 0 & 0 & 0 & 0 & $\overline{0}$ & 0 \\
\hline Vallee_Meech & I & $\mathrm{F}$ & 0 & 0 & 0 & 0 & 0 & 0 \\
\hline Wolf_Grove & $\mathrm{A}$ & $E$ & 0 & 0 & 0 & 0 & 0 & 0 \\
\hline Wolf_Grove & $\bar{B}$ & $E$ & 0 & 0 & 0 & $\overline{0}$ & 0 & 0 \\
\hline Wolf_Grove & $\bar{C}$ & $E$ & 0 & 0 & 0 & 0 & 0 & 0 \\
\hline Wolf Grove & $\mathrm{D}$ & $E$ & 0 & 0 & 0 & 0 & 0 & 0 \\
\hline Wolf_Grove & $\bar{E}$ & $E$ & 0 & 0 & 0 & 0 & 0 & 0 \\
\hline Wolf_Grove & $F$ & $\mathrm{E}$ & 0 & 0 & 0 & 0 & 0 & 0 \\
\hline Wolf_Grove & $\mathrm{H}$ & $\mathrm{E}$ & 0 & 0 & 0 & 0 & 0 & 0 \\
\hline Wolf_Grove & I & $E$ & 0 & 0 & 0 & 0 & 0 & 0 \\
\hline Wrightville & $\mathrm{A}$ & $\mathrm{U}$ & 0 & 0 & 0 & 0 & 0 & 0 \\
\hline Wrightville & B & $\mathrm{U}$ & 0 & 0 & 0 & 0 & 0 & 0 \\
\hline Wrightville & $\mathrm{C}$ & $\mathrm{U}$ & 0 & 0 & 0 & 0 & 0 & 0 \\
\hline Wrightville & $\mathrm{D}$ & $\mathrm{U}$ & 0 & 0 & 0 & 0 & 0 & 0 \\
\hline Wrightville & $\mathrm{E}$ & $\bar{U}$ & 0 & 0 & 0 & 0 & 0 & 0 \\
\hline Wrightville & $F$ & $\mathrm{U}$ & 0 & 0 & 0 & 0 & 0 & 0 \\
\hline Wrightville & $\mathrm{H}$ & $\bar{U}$ & 0 & 0 & 0 & 0 & 0 & 0 \\
\hline Wrightville & I & $\mathrm{U}$ & 0 & 0 & 0 & 0 & 0 & 0 \\
\hline Wychwood & $\mathrm{A}$ & $\mathrm{S}$ & 0 & 0 & 0 & 0 & 0 & 0 \\
\hline Wychwood & B & $\mathrm{S}$ & 0 & 0 & 0 & 0 & 0 & 0 \\
\hline Wychwood & $\bar{C}$ & $\mathrm{~S}$ & 0 & 0 & 0 & 0 & 0 & 0 \\
\hline Wychwood & $\bar{D}$ & $\mathrm{~S}$ & 0 & 0 & 0 & 0 & 0 & 0 \\
\hline Wychwood & $E$ & $\mathrm{~S}$ & 0 & 0 & 0 & 0 & 0 & 0 \\
\hline Wychwood & $F$ & $\mathrm{~S}$ & 0 & 0 & 0 & 0 & 0 & 0 \\
\hline Wychwood & $\bar{H}$ & $\mathrm{~S}$ & 0 & 0 & 0 & 0 & 0 & 0 \\
\hline Wychwood & $\bar{I}$ & $\mathrm{~S}$ & 0 & 0 & 0 & 0 & $\overline{0}$ & $\overline{0}$ \\
\hline
\end{tabular}




\begin{tabular}{|c|c|c|c|c|c|c|c|c|}
\hline SITE & STATION & CATEGORY & CAMA & CANE & CHEM & CHIM & CHLI & CHNI \\
\hline Achbar & A & SN & 0 & 1 & 0 & 0 & 0 & 0 \\
\hline Achbar & B & $\overline{\mathrm{SN}}$ & 0 & 1 & 0 & 0 & 0 & $\overline{0}$ \\
\hline Achbar & $\mathrm{C}$ & $\overline{\mathrm{SN}}$ & 0 & 5 & 0 & 0 & 0 & 0 \\
\hline Achbar & $\overline{\mathrm{D}}$ & $\overline{\mathrm{SN}}$ & 0 & 10 & 0 & 0 & 0 & $\overline{0}$ \\
\hline Achbar & $\bar{E}$ & $\mathrm{SN}$ & 0 & 5 & 0 & 0 & 0 & 0 \\
\hline Achbar & $\bar{F}$ & $\overline{\mathrm{SN}}$ & 0 & 9 & 0 & 0 & 0 & $\overline{0}$ \\
\hline Achbar & $\mathrm{H}$ & $\mathrm{SN}$ & 0 & 9 & 0 & 0 & 0 & $\overline{0}$ \\
\hline Achbar & I & SN & 0 & 3 & 0 & 0 & 0 & 0 \\
\hline Bridlewood & $\mathrm{A}$ & $\mathrm{UN}$ & 0 & 14 & 0 & 0 & 0 & $\mathbf{0}$ \\
\hline Bridlewood & B & $\mathrm{UN}$ & 0 & 13 & 0 & 0 & 0 & 0 \\
\hline Bridlewood & $\mathrm{C}$ & $\overline{\mathrm{UN}}$ & 0 & 15 & 0 & 0 & 0 & $\overline{0}$ \\
\hline Bridlewood & $\bar{D}$ & UN & 0 & 35 & 0 & 0 & 0 & $\overline{0}$ \\
\hline Bridlewood & $\bar{E}$ & $\overline{\mathrm{UN}}$ & 0 & 29 & 0 & 0 & 0 & $\overline{0}$ \\
\hline Bridlewood & F & UN & 0 & 23 & 0 & 0 & 0 & $\overline{0}$ \\
\hline Bridlewood & $\mathrm{H}$ & $\overline{\mathrm{UN}}$ & 0 & 27 & 0 & 0 & 0 & $\overline{0}$ \\
\hline Bridlewood & I & $\overline{\mathrm{UN}}$ & 0 & 29 & 0 & 0 & 0 & 0 \\
\hline Carp_Hills & A & $\mathrm{F}$ & 0 & 0 & 0 & 1 & 0 & $\overline{0}$ \\
\hline Carp_Hills & B & $F$ & 0 & 0 & 0 & 6 & 0 & 0 \\
\hline Carp_Hills & $\mathrm{C}$ & $\bar{F}$ & 0 & 0 & 0 & 1 & 0 & $\overline{0}$ \\
\hline Carp_Hills & $\bar{D}$ & $\bar{F}$ & 0 & 0 & 0 & 0 & 0 & $\overline{0}$ \\
\hline Carp_Hills & $\mathrm{E}$ & $\mathrm{F}$ & 0 & 0 & 0 & 1 & 0 & $\overline{0}$ \\
\hline Carp_Hills & $\mathrm{F}$ & $\mathrm{F}$ & 0 & 0 & 0 & 3 & 0 & 0 \\
\hline Carp_Hills & $\mathrm{H}$ & $\mathrm{F}$ & 0 & 0 & 0 & 0 & 0 & 0 \\
\hline Carp_Hills & I & $F$ & 0 & 0 & 0 & 2 & 0 & 0 \\
\hline Chapel_Hill & $\bar{A}$ & $\overline{\mathrm{UN}}$ & 0 & 0 & 0 & 0 & 0 & 0 \\
\hline Chapel_Hill & $\mathrm{B}$ & $\mathrm{UN}$ & 0 & 2 & 0 & 0 & 0 & $\overline{0}$ \\
\hline Chapel_Hill & $\mathrm{C}$ & $\overline{\mathrm{UN}}$ & 0 & 5 & 3 & 0 & 0 & $\overline{0}$ \\
\hline Chapel_Hill & $\bar{D}$ & UN & 0 & 6 & 7 & 0 & 0 & 0 \\
\hline Chapel_Hill & $\bar{E}$ & UN & 0 & 0 & 0 & 2 & 0 & 0 \\
\hline Chapel_Hill & F & $\overline{\mathrm{UN}}$ & 0 & 0 & 1 & 1 & 0 & 0 \\
\hline Chapel_Hill & $\mathrm{H}$ & UN & 0 & 5 & 5 & 0 & 0 & 0 \\
\hline Chapel_Hill & I & UN & 0 & 0 & 0 & 7 & 0 & 0 \\
\hline Chelsea & $\overline{\mathrm{A}}$ & SN & 0 & 2 & 0 & 0 & 0 & 0 \\
\hline Chelsea & $\bar{B}$ & SN & 0 & 12 & 0 & 0 & 0 & 0 \\
\hline Chelsea & $\mathrm{C}$ & SN & 0 & 7 & 0 & 0 & 0 & 0 \\
\hline Chelsea & $\overline{\mathrm{D}}$ & SN & 0 & 13 & 0 & 0 & 0 & 0 \\
\hline Chelsea & $\mathrm{E}$ & $\mathrm{SN}$ & 0 & 11 & 0 & 0 & 0 & 0 \\
\hline Chelsea & $\bar{F}$ & $\mathrm{SN}$ & 0 & 0 & 0 & 0 & 0 & 0 \\
\hline Chelsea & $\mathrm{H}$ & $\mathrm{SN}$ & 0 & 11 & 0 & 0 & 0 & 0 \\
\hline Chelsea & $I$ & $\mathrm{SN}$ & 0 & 3 & 0 & 0 & 0 & $\overline{0}$ \\
\hline Chemin_Scholle & $\bar{A}$ & $\overline{\mathrm{EN}}$ & 0 & 2 & 0 & 0 & 0 & 0 \\
\hline
\end{tabular}




\begin{tabular}{|c|c|c|c|c|c|c|c|c|}
\hline Chemin_Scholle & B & EN & 0 & 1 & 0 & 0 & 0 & 0 \\
\hline Chemin_Scholle & $\bar{C}$ & $\overline{E N}$ & 0 & 5 & 0 & 0 & 0 & 0 \\
\hline Chemin_Scholle & $\bar{D}$ & $\overline{\mathrm{EN}}$ & 0 & 1 & 0 & 0 & 0 & 0 \\
\hline Chemin_Scholle & $\mathrm{E}$ & $\overline{\mathrm{EN}}$ & 0 & 2 & 0 & 0 & 0 & 0 \\
\hline Chemin_Scholle & $\mathrm{F}$ & EN & $\overline{0}$ & 7 & 0 & $\overline{0}$ & 0 & $\overline{0}$ \\
\hline Chemin_Scholle & $\mathrm{H}$ & EN & 0 & 1 & 0 & 0 & 0 & 0 \\
\hline Chemin_Scholle & I & $\overline{\text { EN }}$ & 0 & 1 & 0 & 0 & 0 & 0 \\
\hline Cote_d'Azur & $\bar{A}$ & $\mathrm{~S}$ & 0 & 1 & 0 & 0 & 0 & 0 \\
\hline Cote_d'Azur & $\mathrm{B}$ & $\mathbf{S}$ & 0 & 4 & 0 & 0 & 0 & 0 \\
\hline Cote_d'Azur & $\mathrm{C}$ & $\mathrm{S}$ & 0 & 0 & 0 & 0 & 0 & 0 \\
\hline Cote_d'Azur & $\mathrm{D}$ & $\mathrm{S}$ & 0 & 0 & 0 & 1 & 0 & 0 \\
\hline Cote_d'Azur & $\mathrm{E}$ & $\mathrm{S}$ & 0 & 10 & 0 & 0 & 0 & 0 \\
\hline Cote_d'Azur & $\mathrm{F}$ & $\mathrm{S}$ & 0 & 10 & 0 & 0 & 0 & 0 \\
\hline Cote_d'Azur & $\mathrm{H}$ & $\mathrm{S}$ & 0 & 1 & 0 & 0 & 0 & 0 \\
\hline Cote_d'Azur & I & $\mathbf{S}$ & $\overline{0}$ & 0 & 0 & $\overline{0}$ & 0 & 0 \\
\hline Highway_Seven & $\bar{A}$ & $E$ & 0 & 9 & 0 & 0 & 0 & 0 \\
\hline Highway_Seven & $\bar{B}$ & $\bar{E}$ & 0 & 1 & 0 & 0 & 0 & 0 \\
\hline Highway_Seven & $\mathrm{C}$ & $E$ & 0 & 0 & 0 & 0 & 0 & 0 \\
\hline Highway_Seven & D & $\bar{E}$ & 0 & 10 & 0 & 0 & 0 & 0 \\
\hline Highway_Seven & $\mathrm{E}$ & $\bar{E}$ & 0 & 0 & 0 & 0 & 0 & 0 \\
\hline Highway_Seven & $F$ & $E$ & 0 & 14 & 0 & 0 & 0 & 0 \\
\hline Highway_Seven & $\mathrm{H}$ & $E$ & 0 & 0 & 0 & 0 & 0 & 0 \\
\hline Highway_Seven & I & $E$ & 0 & 1 & 0 & 0 & 0 & $\overline{0}$ \\
\hline Hull & $\mathrm{A}$ & $\bar{U}$ & 0 & 0 & 0 & 0 & 0 & 0 \\
\hline Hull & B & $\mathrm{U}$ & 0 & 2 & 0 & 0 & 0 & $\overline{0}$ \\
\hline Hull & $\mathrm{C}$ & $\bar{U}$ & 0 & 1 & 0 & 0 & 0 & $\overline{0}$ \\
\hline Hull & $\mathrm{D}$ & $\mathrm{U}$ & 0 & 0 & 0 & 0 & 0 & $\overline{0}$ \\
\hline Hull & $\bar{E}$ & $\overline{\mathrm{U}}$ & 0 & 0 & 0 & 0 & 0 & $\overline{0}$ \\
\hline Hull & $\mathrm{F}$ & $\bar{U}$ & 0 & 0 & 0 & 0 & 0 & $\overline{0}$ \\
\hline Hull & $\mathrm{H}$ & $\bar{U}$ & 0 & 1 & 0 & 0 & 0 & $\overline{0}$ \\
\hline Hull & I & $\mathrm{U}$ & 0 & 6 & 0 & 0 & 0 & 0 \\
\hline Lac_a_la_Perdrix & A & EN & 0 & 0 & 0 & 0 & 0 & 0 \\
\hline Lac_a_la_Perdrix & B & EN & 0 & 0 & 0 & 0 & 0 & $\overline{0}$ \\
\hline Lac_a_la_Perdrix & $\mathrm{C}$ & EN & 0 & 0 & 0 & 0 & 0 & 0 \\
\hline Lac_a_la_Perdrix & $\mathrm{D}$ & EN & 0 & 2 & 0 & 0 & 0 & 0 \\
\hline Lac_a_la_Perdrix & $\mathrm{E}$ & EN & 0 & 0 & 0 & 0 & 0 & 0 \\
\hline Lac_a_la_Perdrix & $\mathrm{F}$ & EN & 0 & 0 & 0 & 0 & 0 & $\overline{0}$ \\
\hline Lac_a_la_Perdrix & $\mathrm{H}$ & EN & 0 & 0 & 0 & 0 & 0 & 0 \\
\hline Lac_a_la_Perdrix & I & $\overline{E N}$ & 0 & 0 & 0 & 0 & 0 & $\overline{0}$ \\
\hline Lac_Philippe & $\overline{\mathrm{A}}$ & $F$ & 0 & 0 & 0 & 0 & 0 & $\overline{0}$ \\
\hline Lac_Philippe & B & $F$ & 0 & 0 & 0 & $\overline{0}$ & 0 & $\overline{0}$ \\
\hline Lac_Philippe & $\bar{C}$ & $F$ & 0 & 0 & 0 & 0 & 0 & 0 \\
\hline
\end{tabular}




\begin{tabular}{|c|c|c|c|c|c|c|c|c|}
\hline Lac_Philippe & $\bar{D}$ & $\bar{F}$ & 0 & 0 & 0 & 0 & 0 & $\overline{0}$ \\
\hline Lac_Philippe & $\mathrm{E}$ & $\mathrm{F}$ & 0 & 0 & 0 & 0 & 0 & 0 \\
\hline Lac_Philippe & $\mathbf{F}$ & $F$ & 0 & 0 & 0 & 0 & 0 & 0 \\
\hline Lac_Philippe & $\mathrm{H}$ & $\mathrm{F}$ & 0 & 0 & 0 & 0 & 0 & 0 \\
\hline Lac_Philippe & I & $F$ & 0 & 0 & 0 & 0 & 0 & 0 \\
\hline Manoir_des_Trembles & $\mathrm{A}$ & UN & 0 & 1 & 0 & $\overline{0}$ & 0 & 0 \\
\hline Manoir_des_Trembles & B & UN & 0 & 7 & 0 & 0 & 0 & 0 \\
\hline Manoir_des_Trembles & $\mathrm{C}$ & $\overline{\mathrm{UN}}$ & 0 & 0 & 0 & 6 & 0 & $\overline{0}$ \\
\hline Manoir_des_Trembles & $\mathrm{D}$ & UN & 0 & 0 & 0 & 0 & 0 & 0 \\
\hline Manoir_des_Trembles & $E$ & UN & 0 & 0 & 0 & 0 & 0 & 0 \\
\hline Manoir_des_Trembles & $\mathrm{F}$ & UN & 0 & 2 & 0 & 0 & 0 & 0 \\
\hline Manoir_des_Trembles & $\mathrm{H}$ & $\mathrm{UN}$ & 0 & 1 & 0 & 0 & 0 & 0 \\
\hline Manoir_des_Trembles & I & UN & 0 & 4 & 0 & 0 & 0 & 0 \\
\hline Marathon & $\mathrm{A}$ & $E$ & 0 & 2 & 0 & 0 & 0 & $\mathbf{0}$ \\
\hline Marathon & B & $\mathrm{E}$ & 0 & 9 & 0 & 0 & 0 & 0 \\
\hline Marathon & $\mathrm{C}$ & $\mathrm{E}$ & 0 & 0 & 0 & 0 & 0 & 0 \\
\hline Marathon & $\mathrm{D}$ & $\bar{E}$ & 0 & 3 & 0 & 0 & 0 & 0 \\
\hline Marathon & $\mathrm{E}$ & $\mathrm{E}$ & 0 & 1 & 0 & 0 & 0 & 0 \\
\hline Marathon & $\bar{F}$ & $\mathrm{E}$ & 2 & 0 & 0 & 0 & 0 & 0 \\
\hline Marathon & $\mathrm{H}$ & $E$ & 0 & 0 & 0 & 0 & 0 & 0 \\
\hline Marathon & I & $\mathrm{E}$ & 0 & 0 & 0 & 0 & 0 & 1 \\
\hline Marier & $\mathrm{A}$ & $\mathrm{U}$ & 0 & 4 & 0 & 0 & 0 & 0 \\
\hline Marier & B & $\mathrm{U}$ & 0 & 2 & 0 & 0 & 0 & 0 \\
\hline Marier & $\mathrm{C}$ & $\mathrm{U}$ & 0 & 2 & 0 & 0 & 0 & 0 \\
\hline Marier & $\mathrm{D}$ & $\mathrm{U}$ & 0 & 0 & 0 & 0 & 0 & 0 \\
\hline Marier & $\mathbf{E}$ & $\mathrm{U}$ & 0 & 0 & 0 & 0 & 0 & 0 \\
\hline Marier & $\mathbf{F}$ & $\bar{U}$ & 0 & 10 & 0 & 0 & 0 & 0 \\
\hline Marier & $\mathrm{H}$ & $\mathrm{U}$ & 0 & 4 & 0 & 0 & 0 & 0 \\
\hline Marier & I & $\mathrm{U}$ & 0 & 2 & 0 & 1 & 0 & 0 \\
\hline Marlborough & $\mathrm{A}$ & $\mathrm{F}$ & 0 & 0 & 0 & 0 & 0 & 0 \\
\hline Marlborough & B & $\mathrm{F}$ & 0 & 0 & 0 & 0 & 0 & 0 \\
\hline Marlborough & $\mathrm{C}$ & $\bar{F}$ & 0 & 0 & 0 & 0 & 0 & 0 \\
\hline Marlborough & D & $\mathrm{F}$ & $\overline{0}$ & 0 & 0 & 0 & 0 & 0 \\
\hline Marlborough & $\mathbf{E}$ & $\mathrm{F}$ & 0 & 0 & 0 & 0 & 0 & 0 \\
\hline Marlborough & $\mathrm{F}$ & $\mathrm{F}$ & 0 & 0 & 0 & 3 & 0 & 0 \\
\hline Marlborough & $\mathrm{H}$ & $\mathrm{F}$ & 0 & 0 & 0 & 0 & 0 & 0 \\
\hline Marlborough & I & $\mathrm{F}$ & 0 & 0 & 0 & 0 & 0 & 0 \\
\hline Merivale & $\bar{A}$ & $\mathrm{SN}$ & 0 & 6 & 0 & 0 & 0 & 0 \\
\hline Merivale & B & $\mathrm{SN}$ & $\overline{0}$ & 35 & 0 & 0 & 0 & 0 \\
\hline Merivale & $\mathrm{C}$ & $\mathrm{SN}$ & 0 & 1 & 0 & 0 & 0 & 0 \\
\hline Merivale & $\mathrm{D}$ & $\mathrm{SN}$ & 0 & 1 & 0 & 0 & 0 & 0 \\
\hline Merivale & $\bar{E}$ & $\overline{\mathrm{SN}}$ & $\overline{0}$ & 7 & 0 & 0 & $\overline{0}$ & 0 \\
\hline
\end{tabular}




\begin{tabular}{|c|c|c|c|c|c|c|c|c|}
\hline Merivale & $F$ & SN & 0 & 7 & 0 & 0 & 0 & 0 \\
\hline Merivale & $\mathbf{H}$ & $\mathrm{SN}$ & 0 & 3 & 0 & 0 & 0 & 0 \\
\hline Merivale & I & $\mathrm{SN}$ & 0 & 13 & 0 & 0 & 0 & 0 \\
\hline Parc_Champlain & $\mathrm{A}$ & $\mathrm{S}$ & 0 & 0 & 0 & 0 & 0 & 0 \\
\hline Parc_Champlain & $\mathbf{B}$ & $\mathrm{S}$ & 0 & 1 & 0 & 6 & 0 & 0 \\
\hline Parc_Champlain & $\mathrm{C}$ & $\mathrm{S}$ & 0 & 0 & 0 & 0 & 0 & 0 \\
\hline Parc_Champlain & $\mathrm{D}$ & $S$ & 0 & 0 & 0 & 0 & 0 & 0 \\
\hline Parc_Champlain & $\bar{E}$ & $\mathrm{~S}$ & 0 & 0 & 0 & 1 & 0 & 0 \\
\hline Parc_Champlain & $\mathrm{F}$ & $\mathrm{S}$ & 0 & 1 & 0 & 0 & 1 & 0 \\
\hline Parc_Champlain & $\mathrm{H}$ & $\mathrm{S}$ & 0 & 1 & 0 & 0 & 0 & 0 \\
\hline Parc_Champlain & $I$ & $S$ & 0 & 0 & 0 & 0 & 0 & 0 \\
\hline Pelissier & $\mathrm{A}$ & EN & 0 & 0 & 0 & 0 & 0 & 0 \\
\hline Pelissier & $\mathrm{B}$ & EN & 0 & 1 & 0 & 0 & 0 & 0 \\
\hline Pelissier & $\mathrm{C}$ & $\overline{\mathrm{EN}}$ & 0 & 0 & 0 & 0 & 0 & 0 \\
\hline Pelissier & $\mathrm{D}$ & EN & 0 & 0 & 0 & 0 & 0 & 0 \\
\hline Pelissier & $\bar{E}$ & EN & 0 & 0 & 0 & 0 & 0 & 0 \\
\hline Pelissier & $\bar{F}$ & EN & 0 & 0 & 0 & 0 & 0 & 0 \\
\hline Pelissier & $\mathrm{H}$ & EN & 0 & 0 & 0 & 0 & 0 & 0 \\
\hline Pelissier & I & EN & 0 & 1 & 0 & 0 & 0 & 0 \\
\hline PineGlen_Annex & $\mathrm{A}$ & $\mathrm{S}$ & 0 & 3 & 0 & 0 & 0 & 0 \\
\hline PineGlen_Annex & B & $\mathrm{S}$ & 0 & 0 & 0 & 0 & 0 & 0 \\
\hline PineGlen_Annex & $\mathrm{C}$ & $\mathrm{S}$ & 0 & 0 & 0 & 0 & 0 & 0 \\
\hline PineGlen_Annex & $\mathrm{D}$ & $\mathrm{S}$ & 0 & 0 & 0 & 0 & 0 & 0 \\
\hline PineGlen_Annex & $\mathrm{E}$ & $\mathrm{S}$ & 0 & 0 & 0 & 0 & 0 & 0 \\
\hline PineGlen_Annex & $\mathrm{F}$ & $\mathrm{S}$ & 0 & 0 & 0 & 1 & 0 & 0 \\
\hline PineGlen_Annex & $\mathrm{H}$ & $\mathrm{S}$ & 0 & 2 & 0 & 0 & 0 & 0 \\
\hline PineGlen_Annex & I & $\mathrm{S}$ & 0 & 0 & 0 & 0 & 0 & 0 \\
\hline Q_Four & A & $\mathrm{E}$ & 0 & 2 & 0 & $\overline{0}$ & 0 & 0 \\
\hline Q_Four & $\mathrm{B}$ & $\mathrm{E}$ & 0 & 0 & 0 & 0 & 0 & 0 \\
\hline Q_Four & $\mathrm{C}$ & $\mathrm{E}$ & 0 & 11 & 0 & 1 & 0 & 0 \\
\hline Q_Four & $\mathrm{D}$ & $\mathrm{E}$ & 0 & 5 & 0 & 0 & 0 & 0 \\
\hline Q_Four & $\mathrm{E}$ & $\mathrm{E}$ & 0 & 0 & 1 & 0 & 0 & 0 \\
\hline Q_Four & $\mathbf{F}$ & $\mathrm{E}$ & 0 & 0 & 0 & 0 & 0 & 0 \\
\hline Q Four & $\mathrm{H}$ & $\mathrm{E}$ & 0 & 0 & 0 & 0 & 0 & 0 \\
\hline Q_Four & I & $\mathrm{E}$ & 0 & 1 & 0 & 0 & 0 & 0 \\
\hline Sandy_Hill & A & $\mathrm{U}$ & 0 & 0 & 0 & 0 & 0 & 0 \\
\hline Sandy_Hill & B & $\mathrm{U}$ & 0 & 0 & 0 & 0 & 0 & 0 \\
\hline Sandy_Hill & $\mathrm{C}$ & $\mathbf{U}$ & 0 & 0 & 0 & 0 & 0 & 0 \\
\hline Sandy_Hill & D & $\mathrm{U}$ & 0 & 1 & 0 & 0 & 0 & 0 \\
\hline Sandy_Hill & $\mathrm{E}$ & $\mathrm{U}$ & 0 & 0 & 0 & 0 & 0 & 0 \\
\hline Sandy_Hill & $F$ & $\overline{\mathrm{U}}$ & 0 & 3 & 0 & 0 & 0 & 0 \\
\hline Sandy_Hill & $\mathrm{H}$ & $\mathrm{U}$ & 0 & 1 & 0 & 0 & 0 & 0 \\
\hline
\end{tabular}




\begin{tabular}{|c|c|c|c|c|c|c|c|c|}
\hline Sandy_Hill & I & $\overline{\mathrm{U}}$ & 0 & 4 & 0 & 0 & 0 & 0 \\
\hline Vallee_Meech & $\vec{A}$ & $\mathbf{F}$ & 0 & 0 & 0 & 0 & 0 & 0 \\
\hline Vallee_Meech & $\mathrm{B}$ & $\bar{F}$ & 0 & 0 & 0 & 0 & 0 & 0 \\
\hline Vallee_Meech & $\mathrm{C}$ & $\bar{F}$ & 0 & 0 & 0 & 0 & 0 & $\overline{0}$ \\
\hline Vallee_Meech & $\mathrm{D}$ & $\bar{F}$ & 0 & 0 & $\overline{0}$ & 0 & 0 & 0 \\
\hline Vallee_Meech & $E$ & $\bar{F}$ & 0 & 0 & 0 & 0 & 0 & 0 \\
\hline Vallee_Meech & $\mathrm{F}$ & $\mathbf{F}$ & 0 & 0 & 0 & 0 & 0 & 0 \\
\hline Vallee_Meech & $\mathrm{H}$ & $\mathbf{F}$ & 0 & 0 & 0 & 0 & 0 & 0 \\
\hline Vallee_Meech & I & $\overline{\mathbf{F}}$ & 0 & 0 & 0 & 0 & 0 & 0 \\
\hline Wolf_Grove & $A$ & $E$ & 0 & 0 & 0 & 1 & 0 & 0 \\
\hline Wolf_Grove & $\mathrm{B}$ & $\bar{E}$ & 0 & 0 & 0 & 0 & 0 & 0 \\
\hline Wolf_Grove & $\mathrm{C}$ & $E$ & 0 & 0 & 0 & 0 & 0 & 0 \\
\hline Wolf_Grove & $\bar{D}$ & $\bar{E}$ & 0 & 0 & $\overline{0}$ & 0 & 0 & 0 \\
\hline Wolf_Grove & $E$ & $E$ & 0 & 0 & 0 & 0 & 0 & 0 \\
\hline Wolf_Grove & $\mathrm{F}$ & $\mathbf{E}$ & 0 & 0 & 0 & 0 & 0 & 0 \\
\hline Wolf_Grove & $\mathrm{H}$ & $\bar{E}$ & 0 & 0 & 0 & 0 & 0 & 0 \\
\hline Wolf_Grove & $\bar{I}$ & $E$ & 0 & 0 & 0 & 0 & 0 & $\overline{0}$ \\
\hline Wrightville & $A$ & $\mathrm{U}$ & 0 & 0 & 0 & 0 & 0 & 0 \\
\hline Wrightville & $\mathrm{B}$ & $\mathbf{U}$ & 0 & 5 & 0 & 0 & 0 & 0 \\
\hline Wrightville & $\mathrm{C}$ & $\mathbf{U}$ & 0 & 6 & 0 & 0 & 0 & 0 \\
\hline Wrightville & $\mathrm{D}$ & $\mathrm{U}$ & 0 & 0 & 0 & 0 & 0 & 0 \\
\hline Wrightville & $E$ & $\mathrm{U}$ & 0 & 0 & 0 & 0 & 0 & 0 \\
\hline Wrightville & $\bar{F}$ & $\mathrm{U}$ & 0 & 1 & 0 & 0 & 0 & 0 \\
\hline Wrightville & $\mathrm{H}$ & $\mathrm{U}$ & 0 & 0 & 0 & 0 & 0 & 0 \\
\hline Wrightville & I & $\mathbf{U}$ & 0 & 6 & 0 & 0 & 0 & 0 \\
\hline Wychwood & $\bar{A}$ & $\mathrm{~S}$ & 0 & 0 & 0 & 0 & 0 & 0 \\
\hline Wychwood & $\mathrm{B}$ & $\mathrm{S}$ & 0 & 0 & 0 & 0 & 0 & 0 \\
\hline Wychwood & $\mathrm{C}$ & $\mathrm{S}$ & 0 & 1 & 0 & 1 & 0 & 0 \\
\hline Wychwood & $\mathrm{D}$ & $\mathrm{S}$ & 0 & 0 & 0 & 0 & 0 & 0 \\
\hline Wychwood & $E$ & $\mathrm{~S}$ & 0 & 1 & 0 & 0 & 0 & 0 \\
\hline Wychwood & $\mathrm{F}$ & $\mathrm{S}$ & 0 & 0 & 0 & 0 & 0 & 0 \\
\hline Wychwood & $\mathrm{H}$ & $\mathrm{S}$ & 0 & 1 & 0 & 0 & 0 & 0 \\
\hline Wychwood & I & $\mathrm{S}$ & 0 & 2 & 0 & 0 & 0 & 0 \\
\hline
\end{tabular}




\begin{tabular}{|c|c|c|c|c|c|c|c|c|}
\hline SITE & STATION & CATEGORY & CHSE & CHTR & CISE & CLFO & CYCR & CYNE \\
\hline Achbar & $\mathrm{A}$ & SN & 0 & 0 & 0 & 0 & 0 & 0 \\
\hline Achbar & $\mathrm{B}$ & SN & 0 & 0 & 0 & 0 & 0 & 0 \\
\hline Achbar & $\mathrm{C}$ & SN & 0 & 0 & 0 & 0 & 0 & 0 \\
\hline Achbar & $\mathrm{D}$ & SN & 0 & 0 & 0 & 0 & 0 & 0 \\
\hline Achbar & $\mathrm{E}$ & $\mathrm{SN}$ & 0 & 0 & 0 & 0 & 0 & 0 \\
\hline Achbar & $\mathrm{F}$ & $\mathrm{SN}$ & 0 & 0 & 0 & 0 & 0 & 0 \\
\hline Achbar & $\mathbf{H}$ & SN & 0 & 0 & 0 & 0 & 0 & 0 \\
\hline Achbar & I & $\mathrm{SN}$ & 0 & 0 & 0 & 0 & 0 & 0 \\
\hline Bridlewood & $\mathrm{A}$ & $\mathrm{UN}$ & 0 & 0 & 0 & 0 & 0 & 0 \\
\hline Bridlewood & B & $\mathrm{UN}$ & 0 & 0 & 0 & 0 & 0 & 0 \\
\hline Bridlewood & $\mathrm{C}$ & UN & 0 & 0 & 0 & 0 & 0 & 0 \\
\hline Bridlewood & $\mathrm{D}$ & $\overline{\mathrm{UN}}$ & 0 & 0 & 0 & 0 & 0 & 0 \\
\hline Bridlewood & $\mathrm{E}$ & $\mathrm{UN}$ & 0 & 0 & 1 & 0 & 0 & 0 \\
\hline Bridlewood & $\mathrm{F}$ & UN & 0 & 0 & 0 & 0 & 0 & $\overline{0}$ \\
\hline Bridlewood & $\mathbf{H}$ & UN & 0 & 0 & 0 & 0 & 0 & 0 \\
\hline Bridlewood & I & UN & 0 & 0 & 0 & 0 & 0 & 0 \\
\hline Carp_Hills & $\mathrm{A}$ & $F$ & 0 & 0 & 0 & 1 & 0 & 0 \\
\hline Carp_Hills & $\mathrm{B}$ & $\mathrm{F}$ & 0 & 0 & 0 & 0 & 0 & 0 \\
\hline Carp_Hills & $\mathrm{C}$ & $\mathrm{F}$ & 0 & 0 & 0 & 0 & 0 & 0 \\
\hline Carp_Hills & $\mathrm{D}$ & $\mathrm{F}$ & 0 & 0 & 0 & 0 & 0 & 0 \\
\hline Carp_Hills & $\bar{E}$ & $\mathrm{~F}$ & 0 & 0 & 0 & 0 & 0 & 0 \\
\hline Carp_Hills & $\mathrm{F}$ & $\mathrm{F}$ & 0 & 0 & 0 & 0 & 0 & 0 \\
\hline Carp_Hills & $\mathrm{H}$ & $\mathrm{F}$ & 0 & 0 & 0 & 0 & 0 & 0 \\
\hline Carp_Hills & I & $\mathrm{F}$ & 0 & 0 & 0 & 0 & 0 & 0 \\
\hline Chapel_Hill & $\mathrm{A}$ & UN & 0 & 0 & 0 & 0 & 0 & 0 \\
\hline Chapel_Hill & $\mathrm{B}$ & $\mathrm{UN}$ & 0 & 0 & 0 & 0 & 0 & 0 \\
\hline Chapel_Hill & $\mathrm{C}$ & UN & 0 & 0 & 0 & 0 & $\overline{0}$ & 0 \\
\hline Chapel_Hill & $\mathrm{D}$ & $\mathrm{UN}$ & 0 & 0 & 0 & 0 & 0 & 0 \\
\hline Chapel_Hill & $E$ & UN & 0 & 0 & 0 & 1 & 0 & 0 \\
\hline Chapel_Hill & $\mathrm{F}$ & UN & 0 & 0 & 0 & 1 & 0 & 0 \\
\hline Chapel_Hill & $\mathrm{H}$ & $\mathrm{UN}$ & 0 & 0 & 0 & 0 & 0 & 0 \\
\hline Chapel_Hill & $\bar{I}$ & $\mathrm{UN}$ & 0 & 0 & 0 & 0 & 0 & 0 \\
\hline Chelsea & A & SN & 0 & 0 & 0 & 0 & 0 & 0 \\
\hline Chelsea & $\mathrm{B}$ & SN & 0 & 0 & 0 & 0 & 0 & 0 \\
\hline Chelsea & $\mathrm{C}$ & SN & 0 & 0 & 0 & 0 & 0 & 0 \\
\hline Chelsea & $\mathrm{D}$ & SN & 0 & 0 & 0 & 0 & 0 & 0 \\
\hline Chelsea & $E$ & SN & 0 & 0 & 0 & 0 & 0 & $\overline{0}$ \\
\hline Chelsea & $\mathrm{F}$ & SN & 0 & 0 & 0 & 0 & 0 & 0 \\
\hline Chelsea & $\mathrm{H}$ & SN & 0 & 0 & 0 & 0 & 0 & 0 \\
\hline Chelsea & $\bar{I}$ & SN & 0 & 0 & 0 & 0 & 0 & 0 \\
\hline Chemin_Scholle & $\mathrm{A}$ & EN & 0 & 0 & 0 & 0 & 0 & 0 \\
\hline
\end{tabular}




\begin{tabular}{|c|c|c|c|c|c|c|c|c|}
\hline Chemin_Scholle & $\bar{B}$ & EN & 0 & 0 & 0 & 0 & 0 & 0 \\
\hline Chemin_Scholle & $\mathrm{C}$ & $\mathrm{EN}$ & 0 & 0 & 0 & 0 & 0 & 0 \\
\hline Chemin_Scholle & $\bar{D}$ & EN & 0 & $\overline{0}$ & 0 & 0 & $\mathbf{0}$ & $\overline{0}$ \\
\hline Chemin_Scholle & $E$ & EN & 0 & 0 & 0 & 0 & 0 & $\overline{0}$ \\
\hline Chemin_Scholle & $\bar{F}$ & $\overline{E N}$ & 0 & 0 & 0 & 1 & 0 & 0 \\
\hline Chemin_Scholle & $\overline{\mathrm{H}}$ & EN & 0 & 0 & $\overline{0}$ & 0 & $\overline{0}$ & $\overline{0}$ \\
\hline Chemin_Scholle & I & EN & 0 & $\overline{0}$ & $\overline{0}$ & 0 & 0 & 0 \\
\hline Cote_d'Azur & $\mathrm{A}$ & $\mathrm{S}$ & 0 & 0 & 0 & 0 & 0 & 0 \\
\hline Cote_d'Azur & B & $\mathrm{S}$ & 0 & 0 & 0 & 0 & 0 & 0 \\
\hline Cote_d'Azur & $\mathrm{C}$ & $\mathrm{S}$ & 0 & $\overline{0}$ & 0 & 0 & 0 & 0 \\
\hline Cote_d'Azur & $\bar{D}$ & $\bar{S}$ & 0 & 1 & 0 & 0 & 0 & 0 \\
\hline Cote_d'Azur & $\mathrm{E}$ & $\mathrm{S}$ & 0 & 0 & 0 & 0 & 0 & 0 \\
\hline Cote_d'Azur & $\bar{F}$ & $\bar{S}$ & 0 & $\overline{0}$ & 0 & 0 & 0 & 0 \\
\hline Cote_d'Azur & $\mathrm{H}$ & $\mathrm{S}$ & 0 & 0 & 0 & 0 & 0 & 0 \\
\hline Cote_d'Azur & I & $\mathrm{S}$ & 0 & $\overline{0}$ & 0 & 0 & $\mathbf{0}$ & $\overline{0}$ \\
\hline Highway_Seven & A & $E$ & 0 & 0 & 0 & 0 & 0 & 0 \\
\hline Highway_Seven & B & $E$ & 0 & 0 & 0 & 0 & 0 & 0 \\
\hline Highway_Seven & $\mathrm{C}$ & $\bar{E}$ & 0 & 0 & 0 & 0 & 0 & 0 \\
\hline Highway_Seven & $\bar{D}$ & $E$ & 0 & 0 & 0 & 0 & 0 & 0 \\
\hline Highway_Seven & $\mathrm{E}$ & $\overline{\mathrm{E}}$ & 0 & 2 & 0 & 0 & 0 & 0 \\
\hline Highway_Seven & $F$ & $\bar{E}$ & 0 & 0 & 0 & 0 & 0 & 0 \\
\hline Highway_Seven & $\mathrm{H}$ & $E$ & 0 & 0 & 1 & 0 & 0 & 0 \\
\hline Highway_Seven & I & $\mathrm{E}$ & 0 & 0 & $\overline{0}$ & 0 & 0 & 0 \\
\hline Hull & $\mathrm{A}$ & $\mathrm{U}$ & 0 & 0 & 0 & 0 & 0 & 0 \\
\hline Hull & B & $\mathrm{U}$ & 0 & 0 & 0 & 0 & 0 & 0 \\
\hline Hull & $\mathrm{C}$ & $\bar{U}$ & 0 & 0 & 0 & 0 & 0 & 0 \\
\hline Hull & $\bar{D}$ & $\mathrm{U}$ & 0 & 0 & 0 & 0 & 0 & 0 \\
\hline Hull & $E$ & $\mathrm{U}$ & 0 & 0 & 0 & 0 & 0 & 0 \\
\hline Hull & $F$ & $\overline{\mathrm{U}}$ & 0 & 0 & 0 & 0 & 0 & 0 \\
\hline Hull & $\mathrm{H}$ & $\overline{\mathrm{U}}$ & 0 & 0 & 0 & 0 & 0 & 0 \\
\hline Hull & I & $\overline{\mathrm{U}}$ & 0 & 0 & 0 & 0 & 0 & 0 \\
\hline Lac_a_la_Perdrix & $\mathrm{A}$ & EN & 0 & 0 & $\overline{0}$ & 0 & 0 & 0 \\
\hline Lac_a_la_Perdrix & $\mathrm{B}$ & $\overline{\mathrm{EN}}$ & 0 & 0 & 0 & 0 & 0 & 0 \\
\hline Lac_a_la_Perdrix & $\mathrm{C}$ & EN & 0 & 0 & 0 & 0 & 0 & 0 \\
\hline Lac_a_la_Perdrix & D & $\overline{E N}$ & 0 & 0 & 0 & 0 & 0 & 0 \\
\hline Lac_a_la_Perdrix & $E$ & $\overline{E N}$ & 0 & 0 & 0 & 0 & 0 & 0 \\
\hline Lac_a_la_Perdrix & $\mathrm{F}$ & EN & 0 & 0 & 0 & 0 & 0 & 0 \\
\hline Lac_a_la_Perdrix & $\mathrm{H}$ & EN & 0 & 0 & 0 & 0 & 0 & 0 \\
\hline Lac_a_la_Perdrix & I & $\overline{E N}$ & 0 & 0 & $\overline{0}$ & 0 & 0 & 0 \\
\hline Lac_Philippe & $\overline{\mathrm{A}}$ & $\bar{F}$ & 0 & 0 & $\overline{0}$ & 0 & 0 & 0 \\
\hline Lac_Philippe & $\bar{B}$ & $\mathrm{~F}$ & 0 & 0 & 0 & 0 & 0 & 1 \\
\hline Lac_Philippe & $\mathrm{C}$ & $\mathrm{F}$ & 0 & 0 & 0 & 0 & 0 & 0 \\
\hline
\end{tabular}




\begin{tabular}{|c|c|c|c|c|c|c|c|c|}
\hline Lac_Philippe & $\mathrm{D}$ & $\mathrm{F}$ & 0 & 0 & 0 & 0 & 0 & 0 \\
\hline Lac_Philippe & $E$ & $F$ & 0 & 0 & 0 & 0 & 0 & 0 \\
\hline Lac_Philippe & $\mathrm{F}$ & $F$ & 0 & 0 & 0 & 0 & 0 & 0 \\
\hline Lac_Philippe & $\mathrm{H}$ & $\bar{F}$ & 0 & 0 & 0 & 0 & 0 & 0 \\
\hline Lac_Philippe & $\bar{I}$ & $F$ & 0 & 0 & 0 & 0 & 0 & 0 \\
\hline Manoir_des_Trembles & $\mathrm{A}$ & UN & 0 & 0 & 0 & 0 & 0 & 0 \\
\hline Manoir_des_Trembles & $\mathrm{B}$ & $\mathrm{UN}$ & 0 & 0 & 0 & 0 & 0 & 0 \\
\hline Manoir_des_Trembles & $\mathrm{C}$ & UN & 0 & 0 & 0 & 0 & 0 & 0 \\
\hline Manoir_des_Trembles & $\mathrm{D}$ & $\overline{\mathrm{UN}}$ & 0 & 0 & 0 & 0 & 0 & 0 \\
\hline Manoir_des_Trembles & $E$ & UN & 0 & 0 & 0 & 0 & 0 & 0 \\
\hline Manoir_des_Trembles & $\mathrm{F}$ & $\overline{\mathrm{UN}}$ & 0 & 0 & 0 & 0 & 0 & 0 \\
\hline Manoir_des_Trembles & $\mathrm{H}$ & UN & 0 & 0 & 0 & 0 & 1 & 0 \\
\hline Manoir_des_Trembles & I & UN & 0 & 0 & 0 & 0 & 0 & 0 \\
\hline Marathon & $\mathrm{A}$ & $E$ & 0 & 0 & 0 & 0 & 0 & 0 \\
\hline Marathon & $\mathrm{B}$ & $\bar{E}$ & 0 & 0 & 0 & 0 & 0 & 0 \\
\hline Marathon & $\mathrm{C}$ & $\mathrm{E}$ & 0 & 0 & 0 & 0 & 0 & 0 \\
\hline Marathon & $\mathrm{D}$ & $\bar{E}$ & 0 & 0 & 0 & 0 & 0 & 0 \\
\hline Marathon & $\mathrm{E}$ & $\mathrm{E}$ & 0 & 0 & 0 & 0 & 0 & 0 \\
\hline Marathon & $F$ & $E$ & 0 & 0 & 0 & 0 & 0 & 0 \\
\hline Marathon & $\mathrm{H}$ & $\mathrm{E}$ & 0 & 0 & 0 & 0 & 0 & 0 \\
\hline Marathon & $I$ & $E$ & 0 & 0 & 0 & 0 & 0 & 0 \\
\hline Marier & $\mathrm{A}$ & $\mathrm{U}$ & 0 & 0 & 0 & 0 & 0 & 0 \\
\hline Marier & $\bar{B}$ & $\bar{U}$ & 0 & 1 & 0 & 0 & 0 & $\overline{0}$ \\
\hline Marier & $\mathrm{C}$ & $\mathrm{U}$ & 0 & 2 & 0 & 0 & 0 & 0 \\
\hline Marier & $\mathrm{D}$ & $\mathrm{U}$ & 0 & 0 & 0 & 0 & 0 & 0 \\
\hline Marier & $E$ & $\mathrm{U}$ & 0 & 0 & 0 & 0 & 0 & 0 \\
\hline Marier & $\mathrm{F}$ & $\overline{\mathrm{U}}$ & 0 & 0 & 0 & 0 & 0 & 0 \\
\hline Marier & $\mathrm{H}$ & $\mathrm{U}$ & 0 & 0 & 0 & 0 & 0 & 0 \\
\hline Marier & I & $\mathrm{U}$ & 0 & 4 & 0 & 0 & 0 & 0 \\
\hline Marlborough & $\mathrm{A}$ & $\mathrm{F}$ & 0 & 0 & 0 & 0 & 0 & 0 \\
\hline Marlborough & $\mathrm{B}$ & $\bar{F}$ & 0 & 0 & 0 & 0 & 0 & 0 \\
\hline Marlborough & $\mathrm{C}$ & $\mathrm{F}$ & 0 & 0 & 0 & 0 & 0 & 0 \\
\hline Marlborough & $\mathrm{D}$ & $F$ & 0 & 0 & 0 & 0 & 0 & 0 \\
\hline Marlborough & $E$ & $\bar{F}$ & 0 & 0 & 0 & 0 & 0 & 0 \\
\hline Marlborough & $\bar{F}$ & $F$ & 0 & 0 & 0 & 3 & 0 & 0 \\
\hline Marlborough & $\mathrm{H}$ & $\bar{F}$ & 0 & 0 & 0 & 0 & 0 & 0 \\
\hline Marlborough & I & $F$ & 0 & 0 & 0 & 0 & 0 & 0 \\
\hline Merivale & A & SN & 0 & 0 & 0 & 0 & 0 & 0 \\
\hline Merivale & $\mathrm{B}$ & $\mathrm{SN}$ & 0 & 0 & 0 & 0 & 0 & 0 \\
\hline Merivale & $\mathrm{C}$ & $\mathrm{SN}$ & 0 & 0 & 0 & 0 & 0 & $\overline{0}$ \\
\hline Merivale & $\mathrm{D}$ & SN & 0 & 0 & 0 & 0 & 0 & 0 \\
\hline Merivale & $\mathrm{E}$ & SN & 0 & 0 & 0 & 0 & 0 & 0 \\
\hline
\end{tabular}




\begin{tabular}{|c|c|c|c|c|c|c|c|c|}
\hline Merivale & $\bar{F}$ & SN & 0 & 0 & 0 & 0 & 0 & 0 \\
\hline Merivale & $\mathrm{H}$ & $\mathrm{SN}$ & 0 & 0 & 0 & 0 & 0 & 0 \\
\hline Merivale & I & SN & 0 & 0 & 0 & 0 & 0 & 0 \\
\hline Parc_Champlain & $\mathrm{A}$ & $\mathrm{S}$ & 0 & 0 & 0 & 0 & 0 & 0 \\
\hline Parc_Champlain & $\overrightarrow{\mathrm{B}}$ & $\mathrm{S}$ & 0 & 7 & 0 & 0 & 0 & 0 \\
\hline Parc_Champlain & $\mathrm{C}$ & $\mathrm{S}$ & 0 & 0 & 0 & 0 & 0 & 0 \\
\hline Parc_Champlain & $\bar{D}$ & $\mathrm{~S}$ & 0 & 1 & 0 & 0 & 0 & 0 \\
\hline Parc_Champlain & $\mathrm{E}$ & $\mathrm{S}$ & 0 & 1 & 0 & 0 & 0 & 0 \\
\hline Parc_Champlain & $\mathrm{F}$ & $\bar{S}$ & 0 & 1 & 0 & 0 & 0 & 0 \\
\hline Parc_Champlain & $\mathrm{H}$ & $\mathrm{S}$ & 0 & 0 & 0 & 0 & 0 & 0 \\
\hline Parc_Champlain & I & $\mathrm{S}$ & 0 & 0 & 0 & 0 & 0 & 0 \\
\hline Pelissier & $\mathrm{A}$ & EN & 0 & 0 & 0 & 0 & 0 & 0 \\
\hline Pelissier & B & EN & 0 & 0 & 0 & 0 & 0 & 0 \\
\hline Pelissier & $\mathrm{C}$ & EN & 0 & 0 & 0 & 0 & 0 & 0 \\
\hline Pelissier & $\bar{D}$ & $\overline{E N}$ & 0 & 0 & 0 & 0 & 0 & 0 \\
\hline Pelissier & $\mathrm{E}$ & EN & 0 & 0 & 0 & 0 & 2 & 0 \\
\hline Pelissier & $\bar{F}$ & EN & 0 & 0 & 0 & 0 & 0 & 0 \\
\hline Pelissier & $\mathrm{H}$ & EN & 0 & 0 & 0 & 0 & 0 & 0 \\
\hline Pelissier & $\mathrm{I}$ & EN & 0 & 0 & 0 & 0 & 1 & $\overline{0}$ \\
\hline PineGlen_Annex & $\mathrm{A}$ & $\mathrm{S}$ & 0 & 1 & 0 & 0 & 0 & 0 \\
\hline PineGlen_Annex & B & $\bar{S}$ & 0 & 0 & 0 & 1 & 0 & 0 \\
\hline PineGlen_Annex & $\mathrm{C}$ & $\mathrm{S}$ & 0 & 0 & 0 & 0 & 0 & 0 \\
\hline PineGlen_Annex & $\bar{D}$ & $\bar{S}$ & 0 & 1 & 0 & 0 & 0 & 0 \\
\hline PineGlen_Annex & $\mathrm{E}$ & $\mathrm{S}$ & 0 & 0 & 0 & 0 & 0 & 0 \\
\hline PineGlen_Annex & $\mathrm{F}$ & $\mathrm{S}$ & 0 & 0 & 0 & 0 & 0 & 0 \\
\hline PineGlen_Annex & $\mathrm{H}$ & $\mathrm{S}$ & 0 & 0 & 0 & 0 & 0 & 0 \\
\hline PineGlen_Annex & I & $\mathrm{S}$ & 0 & 0 & 0 & 0 & 0 & 0 \\
\hline Q_Four & $\mathrm{A}$ & $\mathrm{E}$ & 0 & 0 & 0 & 0 & 0 & 0 \\
\hline Q_Four & $\mathrm{B}$ & $\mathrm{E}$ & 0 & 0 & 0 & 0 & 0 & 0 \\
\hline Q_Four & $\mathrm{C}$ & $\mathrm{E}$ & 0 & 0 & 0 & 0 & 0 & 0 \\
\hline Q_Four & $\mathrm{D}$ & $\mathrm{E}$ & 0 & 0 & 0 & 0 & 0 & 0 \\
\hline Q_Four & $\mathbf{E}$ & $\mathbf{E}$ & 0 & 0 & 0 & 0 & 0 & 0 \\
\hline Q_Four & $\mathrm{F}$ & $\mathrm{E}$ & 0 & 0 & 0 & 0 & 0 & 0 \\
\hline Q Four & $\mathrm{H}$ & $E$ & 0 & 0 & 0 & 0 & 0 & 0 \\
\hline Q_Four & I & $\mathrm{E}$ & 0 & 0 & 0 & 0 & 0 & 0 \\
\hline Sandy_Hill & $\mathrm{A}$ & $\mathrm{U}$ & 0 & $\overline{0}$ & 0 & 0 & 0 & 0 \\
\hline Sandy_Hill & B & $\mathrm{U}$ & 0 & 0 & 0 & 0 & 0 & 0 \\
\hline Sandy_Hill & $\mathrm{C}$ & $\mathrm{U}$ & 0 & 0 & 0 & 0 & 0 & 0 \\
\hline Sandy_Hill & $\mathrm{D}$ & $\mathrm{U}$ & 0 & 0 & 0 & 0 & 0 & 0 \\
\hline Sandy_Hill & $E$ & $\mathrm{U}$ & 0 & 0 & 0 & 0 & 0 & 0 \\
\hline Sandy_Hill & $\mathrm{F}$ & $\mathrm{U}$ & 0 & 0 & 0 & 0 & 0 & 0 \\
\hline Sandy_Hill & $\mathrm{H}$ & $\mathrm{U}$ & 0 & 2 & 0 & 0 & 0 & 0 \\
\hline
\end{tabular}




\begin{tabular}{|c|c|c|c|c|c|c|c|c|}
\hline Sandy_Hill & $\mathbf{I}$ & $\mathrm{U}$ & 0 & 0 & 0 & 0 & 0 & 0 \\
\hline Vallee_Meech & $\mathrm{A}$ & $\mathrm{F}$ & 0 & 0 & 0 & 0 & 0 & 1 \\
\hline Vallee_Meech & $\mathrm{B}$ & $\bar{F}$ & 0 & 0 & 0 & 0 & 0 & 0 \\
\hline Vallee_Meech & $\mathrm{C}$ & $F$ & 0 & 0 & 0 & 0 & 0 & 0 \\
\hline Vallee_Meech & $\mathrm{D}$ & $F$ & 0 & 0 & 0 & 0 & 0 & 0 \\
\hline Vallee_Meech & $E$ & $F$ & 0 & 0 & 0 & 0 & 0 & 0 \\
\hline Vallee_Meech & $F$ & $\bar{F}$ & 0 & 0 & 0 & 0 & 0 & 0 \\
\hline Vallee_Meech & $\overline{\mathrm{H}}$ & $\mathrm{F}$ & 0 & 0 & 0 & 0 & 0 & 0 \\
\hline Vallee_Meech & I & $F$ & 0 & 0 & 0 & 0 & 0 & 0 \\
\hline Wolf_Grove & $\mathrm{A}$ & $E$ & 0 & 0 & 0 & 0 & 0 & 0 \\
\hline Wolf_Grove & $\mathrm{B}$ & $\mathrm{E}$ & 0 & 0 & 0 & 0 & 0 & 0 \\
\hline Wolf_Grove & $\mathrm{C}$ & $\mathrm{E}$ & 0 & 0 & 0 & 0 & 0 & $\overline{0}$ \\
\hline Wolf_Grove & $\mathrm{D}$ & $\mathrm{E}$ & 0 & 0 & 0 & 0 & 0 & 0 \\
\hline Wolf_Grove & $\mathrm{E}$ & $\mathrm{E}$ & 0 & 0 & 0 & 0 & 0 & 0 \\
\hline Wolf_Grove & $\mathrm{F}$ & $\mathrm{E}$ & 0 & 0 & 0 & 0 & 0 & 0 \\
\hline$\overline{\text { Wolf_Grove }}$ & $\mathrm{H}$ & $\bar{E}$ & 0 & 0 & 0 & 0 & 0 & 0 \\
\hline Wolf_Grove & $\mathbf{I}$ & $\mathrm{E}$ & 0 & 0 & 0 & 0 & 0 & 0 \\
\hline Wrightville & A & $\overline{\mathrm{U}}$ & 0 & 0 & 0 & 0 & 0 & 0 \\
\hline Wrightville & $\mathrm{B}$ & $\overline{\mathrm{U}}$ & 0 & 0 & 0 & 0 & 0 & 0 \\
\hline Wrightville & $\mathrm{C}$ & $\overline{\mathrm{U}}$ & 0 & 0 & 0 & 0 & 0 & 0 \\
\hline Wrightville & $\bar{D}$ & $\overline{\mathrm{U}}$ & 0 & 0 & 0 & 0 & 0 & 0 \\
\hline Wrightville & $\mathrm{E}$ & $\mathrm{U}$ & 0 & 0 & 0 & 0 & 0 & 0 \\
\hline Wrightville & $\mathrm{F}$ & $\overline{\mathrm{U}}$ & 0 & 1 & 0 & 2 & 0 & 0 \\
\hline Wrightville & $\mathrm{H}$ & $\mathrm{U}$ & 0 & 0 & 0 & 2 & 0 & 0 \\
\hline Wrightville & $\mathbf{I}$ & $\overline{\mathrm{U}}$ & 0 & 0 & 0 & 0 & 0 & 0 \\
\hline Wychwood & $\mathrm{A}$ & $\mathrm{S}$ & 0 & 0 & 0 & 0 & 0 & 0 \\
\hline Wychwood & B & $\overline{\mathrm{S}}$ & 0 & 0 & 0 & 0 & 0 & 0 \\
\hline Wychwood & $\mathrm{C}$ & $\mathrm{S}$ & 0 & 0 & 0 & 0 & 0 & 0 \\
\hline Wychwood & $\bar{D}$ & $\bar{S}$ & 0 & 0 & 0 & 0 & 0 & 0 \\
\hline Wychwood & $\mathrm{E}$ & $\mathrm{S}$ & 0 & 1 & 0 & 0 & 0 & 0 \\
\hline Wychwood & $\mathrm{F}$ & $\mathrm{S}$ & 0 & 0 & 0 & 0 & 0 & 0 \\
\hline Wychwood & $\mathrm{H}$ & $\mathrm{S}$ & 0 & 1 & 0 & 0 & 0 & 0 \\
\hline Wychwood & $I$ & $\bar{S}$ & 0 & 0 & 0 & 0 & 0 & $\overline{0}$ \\
\hline
\end{tabular}




\begin{tabular}{|c|c|c|c|c|c|c|c|c|}
\hline SITE & STATION & CATEGORY & DIOB & DYGL & ELCL & ELGR & HAAF & HACO \\
\hline Achbar & $A$ & SN & 0 & 0 & 0 & 0 & 0 & 0 \\
\hline Achbar & B & SN & 0 & 0 & 0 & 0 & 0 & 0 \\
\hline Achbar & $\mathrm{C}$ & $\overline{\mathrm{SN}}$ & 0 & 0 & 0 & $\overline{0}$ & 0 & 0 \\
\hline Achbar & $\mathrm{D}$ & $\overline{\mathrm{SN}}$ & 0 & 0 & 0 & 0 & 0 & 0 \\
\hline Achbar & $\bar{E}$ & $\mathrm{SN}$ & 0 & 0 & 0 & 0 & 0 & 0 \\
\hline Achbar & $\mathrm{F}$ & $\mathrm{SN}$ & 0 & 0 & 0 & 0 & 0 & 0 \\
\hline Achbar & $\mathrm{H}$ & SN & 0 & 0 & 0 & 0 & 0 & 0 \\
\hline Achbar & I & $\mathrm{SN}$ & 0 & 0 & 0 & 0 & 0 & 0 \\
\hline Bridlewood & A & UN & 0 & 0 & 0 & 0 & 0 & 0 \\
\hline Bridlewood & B & $\overline{\mathrm{UN}}$ & 0 & 0 & 0 & 0 & 0 & 0 \\
\hline Bridlewood & $\bar{C}$ & UN & 0 & 0 & 0 & 0 & 0 & 0 \\
\hline Bridlewood & $\mathrm{D}$ & $\mathrm{UN}$ & $\overline{0}$ & 0 & 0 & 0 & 0 & $\overline{0}$ \\
\hline Bridlewood & $\mathrm{E}$ & $\mathrm{UN}$ & 0 & 0 & 0 & 0 & 0 & 0 \\
\hline Bridlewood & $\mathrm{F}$ & $\overline{\mathrm{UN}}$ & 0 & 0 & 0 & 0 & 0 & 0 \\
\hline Bridlewood & $\mathrm{H}$ & UN & 0 & 0 & 0 & 0 & 0 & 0 \\
\hline Bridlewood & I & $\mathrm{UN}$ & 0 & 0 & 0 & 0 & 0 & 0 \\
\hline Carp_Hills & $\bar{A}$ & $\mathrm{~F}$ & 0 & 0 & 0 & 0 & 0 & 0 \\
\hline Carp_Hills & B & $\bar{F}$ & 0 & 0 & 0 & 0 & 0 & 0 \\
\hline Carp_Hills & $\mathrm{C}$ & $F$ & 0 & 0 & 0 & 0 & 0 & 0 \\
\hline Carp_Hills & $\mathrm{D}$ & $F$ & 0 & 0 & 0 & 0 & 0 & 0 \\
\hline Carp_Hills & $\bar{E}$ & $F$ & 0 & 0 & 0 & 0 & 0 & 0 \\
\hline Carp_Hills & $\bar{F}$ & $\mathrm{~F}$ & 0 & 0 & 0 & 0 & 0 & $\overline{0}$ \\
\hline Carp_Hills & $\mathrm{H}$ & $F$ & 0 & 0 & 0 & 0 & 0 & 0 \\
\hline Carp_Hills & I & $\bar{F}$ & 0 & 0 & 1 & 0 & 0 & 0 \\
\hline Chapel_Hill & $\overline{\mathrm{A}}$ & $\overline{\mathrm{UN}}$ & 0 & 0 & 0 & 0 & 0 & 0 \\
\hline Chapel_Hill & B & $\overline{\mathrm{UN}}$ & 0 & 0 & 0 & 0 & 0 & $\overline{0}$ \\
\hline Chapel_Hill & $\bar{C}$ & $\overline{\mathrm{UN}}$ & 0 & 0 & 0 & 0 & 0 & $\overline{0}$ \\
\hline Chapel_Hill & $\bar{D}$ & $\overline{\mathrm{UN}}$ & 0 & 0 & 0 & 0 & 0 & 0 \\
\hline Chapel_Hill & $\mathrm{E}$ & $\mathrm{UN}$ & 0 & 0 & 0 & 0 & 0 & 0 \\
\hline Chapel_Hill & $\mathrm{F}$ & $\overline{\mathrm{UN}}$ & 0 & 0 & 0 & 0 & 0 & $\overline{0}$ \\
\hline Chapel_Hill & $\mathrm{H}$ & $\overline{\mathrm{UN}}$ & 0 & 0 & 0 & 0 & 0 & 1 \\
\hline Chapel_Hill & I & $\overline{\mathrm{UN}}$ & 0 & 0 & 0 & $\overline{0}$ & 0 & $\overline{0}$ \\
\hline Chelsea & $\bar{A}$ & $\mathrm{SN}$ & 0 & 0 & 0 & 0 & 0 & 0 \\
\hline Chelsea & B & $\mathrm{SN}$ & 0 & 0 & 0 & 0 & 0 & 0 \\
\hline Chelsea & $\mathrm{C}$ & $\mathrm{SN}$ & 0 & 0 & 0 & 0 & 0 & 0 \\
\hline Chelsea & $\bar{D}$ & $\mathrm{SN}$ & 0 & 0 & 0 & 0 & 0 & 0 \\
\hline Chelsea & $\bar{E}$ & $\overline{\mathrm{SN}}$ & 0 & 0 & 0 & 0 & 0 & $\overline{0}$ \\
\hline Chelsea & $\mathrm{F}$ & $\mathrm{SN}$ & 0 & 0 & 0 & 0 & 0 & 0 \\
\hline Chelsea & $\overline{\mathrm{H}}$ & SN & 0 & $\overline{0}$ & 0 & 0 & 0 & 0 \\
\hline Chelsea & I & $\mathrm{SN}$ & 0 & 0 & 0 & 0 & 0 & 0 \\
\hline Chemin_Scholle & $\overline{\mathrm{A}}$ & $\overline{E N}$ & 0 & 0 & 0 & 0 & 0 & 0 \\
\hline
\end{tabular}




\begin{tabular}{|c|c|c|c|c|c|c|c|c|}
\hline Chemin_Scholle & $\mathrm{B}$ & EN & 0 & 0 & 0 & 0 & 0 & 0 \\
\hline Chemin_Scholle & $\mathrm{C}$ & EN & 0 & 0 & 0 & 0 & 0 & 0 \\
\hline Chemin_Scholle & $\mathrm{D}$ & EN & 0 & 0 & 0 & 0 & 0 & 0 \\
\hline Chemin_Scholle & $E$ & EN & 0 & 0 & 0 & 0 & 0 & 0 \\
\hline Chemin_Scholle & $\mathrm{F}$ & EN & 0 & 0 & 0 & 0 & 0 & 0 \\
\hline Chemin_Scholle & $\mathrm{H}$ & EN & 0 & 0 & 0 & $\overline{0}$ & 0 & 0 \\
\hline Chemin_Scholle & I & EN & 0 & 0 & 0 & 0 & 0 & 0 \\
\hline Cote_d'Azur & $\mathrm{A}$ & $\mathrm{S}$ & 0 & 0 & 0 & 0 & 0 & 0 \\
\hline Cote_d'Azur & $\mathrm{B}$ & $\mathrm{S}$ & 0 & 0 & 0 & 0 & 0 & 0 \\
\hline Cote_d'Azur & $\mathrm{C}$ & $\bar{S}$ & 0 & 0 & 0 & 0 & 0 & 0 \\
\hline Cote_d'Azur & $\mathrm{D}$ & $\mathrm{S}$ & 0 & 0 & 0 & 0 & 0 & 0 \\
\hline Cote_d'Azur & $\bar{E}$ & $\mathrm{~S}$ & 0 & 0 & 0 & 0 & 0 & $\overline{0}$ \\
\hline Cote_d'Azur & $\bar{F}$ & $\mathrm{~S}$ & 0 & 0 & 0 & 0 & 1 & 5 \\
\hline Cote_d'Azur & $\mathrm{H}$ & $\mathrm{S}$ & 0 & 0 & 0 & 0 & 0 & 0 \\
\hline Cote_d'Azur & I & $\mathrm{S}$ & 0 & 0 & 0 & 0 & 0 & $\overline{0}$ \\
\hline Highway_Seven & $\bar{A}$ & $\mathrm{E}$ & 0 & 0 & 0 & 0 & 0 & $\overline{0}$ \\
\hline Highway_Seven & $\overline{\mathrm{B}}$ & $\mathrm{E}$ & 0 & 0 & 0 & 0 & 0 & 0 \\
\hline Highway_Seven & $\mathrm{C}$ & $\mathrm{E}$ & 0 & 0 & 0 & 0 & 0 & 0 \\
\hline Highway_Seven & D & $\mathrm{E}$ & 0 & 2 & 0 & 0 & 0 & 0 \\
\hline Highway_Seven & $\mathbf{E}$ & $\mathrm{E}$ & 0 & 0 & 0 & 0 & 0 & 0 \\
\hline Highway_Seven & $\mathrm{F}$ & $\mathrm{E}$ & 0 & 0 & 0 & 0 & 0 & 0 \\
\hline Highway_Seven & $\mathrm{H}$ & $E$ & 2 & 2 & 0 & 0 & 0 & 0 \\
\hline Highway_Seven & I & $\mathrm{E}$ & 0 & 0 & 0 & 0 & 0 & 0 \\
\hline Hull & $\mathrm{A}$ & $\mathrm{U}$ & 0 & 0 & 0 & 0 & 0 & $\overline{0}$ \\
\hline Hull & B & $\mathrm{U}$ & 0 & 0 & 0 & 0 & 5 & 0 \\
\hline Hull & $\mathrm{C}$ & $\overline{\mathrm{U}}$ & 0 & 0 & 0 & 0 & 0 & 0 \\
\hline Hull & $\mathrm{D}$ & $\bar{U}$ & 0 & 0 & 0 & 0 & 0 & 0 \\
\hline Hull & $\mathrm{E}$ & $\mathrm{U}$ & 0 & 0 & 0 & 0 & 1 & 2 \\
\hline Hull & $\mathrm{F}$ & $\mathrm{U}$ & 0 & 1 & 0 & 0 & 3 & 2 \\
\hline Hull & $\mathrm{H}$ & $\mathrm{U}$ & 0 & 0 & 0 & 0 & 9 & 5 \\
\hline Hull & $I$ & $\mathrm{U}$ & 3 & 0 & 0 & 0 & 1 & 0 \\
\hline Lac_a_la_Perdrix & $\mathrm{A}$ & EN & 0 & 0 & 0 & 0 & 0 & 0 \\
\hline Lac_a'la_Perdrix & B & EN & 0 & 0 & 0 & 0 & 0 & 0 \\
\hline Lac_a_la_Perdrix & $\mathrm{C}$ & EN & 0 & 0 & 0 & 0 & 0 & 0 \\
\hline Lac_a_la_Perdrix & $\mathrm{D}$ & EN & 0 & 0 & 0 & 0 & 0 & 0 \\
\hline Lac_a_la_Perdrix & $\mathrm{E}$ & EN & 0 & 0 & 0 & 0 & 0 & 0 \\
\hline Lac_a_la_Perdrix & $\bar{F}$ & EN & 0 & 0 & 0 & 0 & 0 & 0 \\
\hline Lac_a_la_Perdrix & $\mathrm{H}$ & EN & 0 & 0 & 0 & 0 & 0 & 0 \\
\hline Lac_a_la_Perdrix & $\mathrm{I}$ & $\mathrm{EN}$ & 0 & 0 & 0 & 0 & 0 & 0 \\
\hline Lac_Philippe & $\mathrm{A}$ & $\mathrm{F}$ & 0 & 0 & 0 & 0 & 0 & 0 \\
\hline Lac_Philippe & B & $\mathrm{F}$ & 0 & 0 & 0 & 0 & 0 & 0 \\
\hline Lac_Philippe & $\mathrm{C}$ & $\mathrm{F}$ & 0 & 0 & 0 & 0 & 0 & 0 \\
\hline
\end{tabular}




\begin{tabular}{|c|c|c|c|c|c|c|c|c|}
\hline Lac_Philippe & $\mathrm{D}$ & $\mathrm{F}$ & 0 & 0 & 0 & 0 & 0 & 0 \\
\hline Lac_Philippe & $E$ & $\bar{F}$ & 0 & 0 & 0 & 0 & 0 & 0 \\
\hline Lac_Philippe & $F$ & $\mathrm{~F}$ & 0 & 0 & 0 & 0 & 0 & 0 \\
\hline Lac_Philippe & $\mathrm{H}$ & $\mathrm{F}$ & 0 & 0 & 0 & 0 & 0 & 0 \\
\hline Lac_Philippe & I & $\mathrm{F}$ & 0 & 0 & 0 & 0 & 0 & 0 \\
\hline Manoir_des_Trembles & $\bar{A}$ & UN & 0 & 0 & $\overline{0}$ & 0 & 0 & 0 \\
\hline Manoir_des_Trembles & $\overline{\mathrm{B}}$ & UN & 0 & 0 & 0 & 0 & 0 & 0 \\
\hline Manoir_des_Trembles & $\mathrm{C}$ & UN & 0 & 0 & 1 & 0 & 0 & 0 \\
\hline Manoir_des_Trembles & $\mathrm{D}$ & UN & 0 & 0 & 0 & 0 & 0 & 0 \\
\hline Manoir_des_Trembles & $\mathrm{E}$ & UN & 0 & 0 & 0 & 0 & 0 & 0 \\
\hline Manoir_des_Trembles & $F$ & UN & 0 & 0 & 0 & 0 & 0 & 0 \\
\hline Manoir_des_Trembles & $\mathrm{H}$ & UN & 0 & 0 & 0 & 0 & 0 & 0 \\
\hline Manoir_des_Trembles & I & $\mathrm{UN}$ & 0 & 0 & 0 & 0 & 0 & 0 \\
\hline Marathon & $\mathrm{A}$ & $\bar{E}$ & 0 & 0 & 0 & 0 & 0 & 0 \\
\hline Marathon & B & $E$ & 0 & 0 & 0 & 0 & 0 & 0 \\
\hline Marathon & $\mathrm{C}$ & $E$ & 0 & 0 & 0 & 0 & 0 & 0 \\
\hline Marathon & $\mathrm{D}$ & $E$ & 3 & 0 & 0 & 0 & 0 & 0 \\
\hline Marathon & $E$ & $E$ & 0 & 0 & 0 & 0 & 0 & 0 \\
\hline Marathon & $F$ & $E$ & 0 & 0 & 0 & 0 & 0 & 0 \\
\hline Marathon & $\mathrm{H}$ & $E$ & 0 & 0 & 0 & 0 & 0 & 0 \\
\hline Marathon & $\mathrm{I}$ & $\bar{E}$ & 0 & 0 & 0 & 0 & 0 & $\overline{0}$ \\
\hline Marier & $\bar{A}$ & $\overline{\mathrm{U}}$ & 0 & 0 & 0 & 1 & 4 & 0 \\
\hline Marier & B & $\mathrm{U}$ & 0 & 0 & 0 & 0 & 2 & 0 \\
\hline Marier & $\mathrm{C}$ & $\bar{U}$ & 0 & 0 & 0 & 0 & 2 & 0 \\
\hline Marier & $\mathrm{D}$ & $\mathrm{U}$ & 0 & 0 & 0 & 0 & 1 & 0 \\
\hline Marier & $E$ & $\mathrm{U}$ & 0 & 0 & 0 & 0 & 2 & 0 \\
\hline Marier & $\mathrm{F}$ & $\mathrm{U}$ & 0 & 0 & 0 & 0 & 3 & 1 \\
\hline Marier & $\mathrm{H}$ & $\mathrm{U}$ & 0 & 0 & 0 & 0 & 0 & 2 \\
\hline Marier & I & $\mathrm{U}$ & 0 & 0 & 0 & 0 & 2 & 0 \\
\hline Marlborough & A & $F$ & 0 & 0 & 0 & 0 & 0 & 0 \\
\hline Marlborough & B & $F$ & 0 & 0 & 0 & 0 & 0 & 0 \\
\hline Marlborough & $\mathrm{C}$ & $\mathrm{F}$ & 0 & 0 & 0 & 0 & 0 & 0 \\
\hline Marlborough & $\mathrm{D}$ & $\mathrm{F}$ & 0 & 0 & 0 & 0 & 0 & 0 \\
\hline Marlborough & $E$ & $F$ & 0 & 0 & 0 & 0 & 0 & 0 \\
\hline Marlborough & $F$ & $F$ & 0 & 0 & 0 & 0 & 0 & 0 \\
\hline Marlborough & $\mathrm{H}$ & $F$ & 0 & 0 & 0 & 0 & 0 & 0 \\
\hline Marlborough & I & $\mathrm{F}$ & 0 & 0 & 0 & 0 & 0 & 0 \\
\hline Merivale & $\mathrm{A}$ & $\mathrm{SN}$ & 0 & 0 & 0 & 0 & 0 & 0 \\
\hline Merivale & $\mathrm{B}$ & $\mathrm{SN}$ & 0 & 0 & 0 & 0 & 0 & $\overline{0}$ \\
\hline Merivale & $\mathrm{C}$ & $\mathrm{SN}$ & 0 & 0 & 0 & 0 & 0 & 0 \\
\hline Merivale & $\mathrm{D}$ & $\mathrm{SN}$ & 0 & 0 & 0 & 0 & 0 & 0 \\
\hline Merivale & $E$ & $\mathrm{SN}$ & 0 & 0 & 0 & 0 & 0 & 0 \\
\hline
\end{tabular}




\begin{tabular}{|c|c|c|c|c|c|c|c|c|}
\hline Merivale & $\bar{F}$ & SN & 0 & 0 & 0 & 0 & 0 & 0 \\
\hline Merivale & $\mathrm{H}$ & $\overline{\mathrm{SN}}$ & 0 & 0 & 0 & 0 & 0 & 0 \\
\hline Merivale & I & SN & 0 & 0 & 0 & 0 & 0 & 0 \\
\hline Parc_Champlain & A & $\mathrm{S}$ & 0 & 0 & 0 & 0 & 0 & 1 \\
\hline Parc_Champlain & B & $\mathbf{S}$ & 0 & 0 & 0 & 0 & 0 & 0 \\
\hline Parc_Champlain & $\mathrm{C}$ & $\mathrm{S}$ & 0 & 0 & 0 & 0 & 0 & 0 \\
\hline Parc_Champlain & $\mathrm{D}$ & $\mathrm{S}$ & 0 & 0 & 0 & 0 & 0 & 1 \\
\hline Parc_Champlain & $\mathrm{E}$ & $\mathrm{S}$ & 1 & 0 & 0 & 0 & 0 & 0 \\
\hline Parc_Champlain & $\mathbf{F}$ & $\mathrm{S}$ & 0 & 0 & $\overline{0}$ & 0 & 0 & 2 \\
\hline Parc_Champlain & $\mathrm{H}$ & $\mathrm{S}$ & 0 & 1 & 0 & 0 & 0 & 1 \\
\hline Parc_Champlain & I & $\mathrm{S}$ & 0 & 0 & 0 & 0 & 0 & 0 \\
\hline Pelissier & $\bar{A}$ & $\overline{\mathrm{EN}}$ & 0 & 0 & 0 & 0 & 0 & 0 \\
\hline Pelissier & B & $\mathrm{EN}$ & 0 & 0 & 0 & 0 & 0 & 0 \\
\hline Pelissier & $\mathrm{C}$ & EN & 0 & 0 & 0 & 0 & 0 & 0 \\
\hline Pelissier & $\mathrm{D}$ & EN & 0 & 0 & 0 & 0 & 0 & 0 \\
\hline Pelissier & $\bar{E}$ & $\mathrm{EN}$ & 0 & 0 & 0 & 0 & 0 & 0 \\
\hline Pelissier & $\mathbf{F}$ & EN & 0 & 0 & 0 & 0 & 0 & 0 \\
\hline Pelissier & $\mathrm{H}$ & EN & 0 & 0 & 0 & 0 & 0 & 0 \\
\hline Pelissier & I & EN & 0 & 0 & 0 & 0 & 0 & 0 \\
\hline PineGlen_Annex & $\mathrm{A}$ & $\mathrm{S}$ & 0 & 0 & 0 & 0 & 0 & 0 \\
\hline PineGlen_Annex & $\mathrm{B}$ & $\mathrm{S}$ & 0 & 0 & 0 & 0 & 0 & 0 \\
\hline PineGlen_Annex & $\mathrm{C}$ & $\mathrm{S}$ & 0 & 0 & 0 & 0 & 3 & 0 \\
\hline PineGlen_Annex & $\mathrm{D}$ & $\mathrm{S}$ & 0 & 0 & 0 & 0 & 0 & 0 \\
\hline PineGlen_Annex & $\mathrm{E}$ & $\mathrm{S}$ & 0 & 0 & 0 & 0 & 0 & 1 \\
\hline PineGlen_Annex & $\mathbf{F}$ & $\mathrm{S}$ & 0 & 0 & 0 & 0 & 3 & 0 \\
\hline PineGlen_Annex & $\mathrm{H}$ & $\mathbf{S}$ & 0 & 0 & 0 & 0 & 1 & 0 \\
\hline PineGlen_Annex & I & $\mathbf{S}$ & 0 & 0 & 0 & 0 & 3 & 4 \\
\hline Q_Four & $\mathrm{A}$ & $\mathrm{E}$ & 0 & 0 & 0 & 0 & 0 & 0 \\
\hline Q_Four & B & $\mathrm{E}$ & 0 & 0 & 0 & 0 & 0 & $\overline{0}$ \\
\hline Q_Four & $\mathrm{C}$ & $\mathrm{E}$ & 0 & 0 & 0 & 0 & 0 & 0 \\
\hline Q_Four & $\mathrm{D}$ & $\mathrm{E}$ & 0 & 0 & 0 & 0 & 0 & 0 \\
\hline Q_Four & $\mathrm{E}$ & $\mathrm{E}$ & 0 & 0 & 0 & 0 & 0 & 0 \\
\hline Q_Four & $\mathrm{F}$ & $\mathrm{E}$ & 0 & 0 & 0 & 0 & 0 & 0 \\
\hline Q_Four & $\mathrm{H}$ & $E$ & 0 & 0 & 0 & 0 & 0 & 0 \\
\hline Q_Four & I & $E$ & 0 & 0 & 0 & 0 & 0 & 0 \\
\hline Sandy_Hill & $\mathrm{A}$ & $\mathrm{U}$ & 0 & 0 & 0 & 0 & 1 & 0 \\
\hline Sandy_Hill & $\mathrm{B}$ & $\mathrm{U}$ & 0 & 0 & 0 & 0 & 8 & 1 \\
\hline Sandy_Hill & $\mathrm{C}$ & $\mathrm{U}$ & 0 & $\overline{0}$ & 0 & 0 & 12 & 0 \\
\hline Sandy_Hill & $\mathrm{D}$ & $\mathrm{U}$ & 0 & 0 & 0 & 0 & 6 & 0 \\
\hline Sandy_Hill & $\mathrm{E}$ & $\bar{U}$ & 0 & 0 & 0 & 0 & 1 & 0 \\
\hline Sandy_Hill & $\mathrm{F}$ & $\overline{\mathrm{U}}$ & 0 & $\overline{0}$ & 0 & 0 & 2 & 0 \\
\hline Sandy_Hill & $\mathrm{H}$ & $\overline{\mathrm{U}}$ & 0 & 0 & 0 & 0 & 0 & 0 \\
\hline
\end{tabular}




\begin{tabular}{|c|c|c|c|c|c|c|c|c|}
\hline Sandy_Hill & I & $\mathrm{U}$ & 0 & 0 & 0 & 0 & 1 & 0 \\
\hline Vallee_Meech & $\mathrm{A}$ & $F$ & 0 & 0 & 0 & 0 & 0 & 0 \\
\hline Vallee_Meech & $\mathrm{B}$ & $F$ & 0 & 0 & 0 & 0 & 0 & 0 \\
\hline Vallee_Meech & $\mathrm{C}$ & $F$ & 0 & 0 & 0 & 0 & 0 & 0 \\
\hline Vallee_Meech & $\mathrm{D}$ & $F$ & 0 & 0 & 0 & 0 & 0 & 0 \\
\hline Vallee_Meech & $\mathrm{E}$ & $F$ & 0 & 0 & 0 & 0 & 0 & 0 \\
\hline Vallee_Meech & $\mathrm{F}$ & $F$ & 0 & 0 & 0 & 0 & 0 & 0 \\
\hline Vallee_Meech & $\mathrm{H}$ & $F$ & 0 & 0 & 0 & 0 & 0 & 0 \\
\hline Vallee_Meech & I & $\mathrm{F}$ & 0 & 0 & 0 & 0 & 0 & 0 \\
\hline Wolf_Grove & $\bar{A}$ & $E$ & 0 & 0 & 2 & 0 & 0 & 0 \\
\hline Wolf_Grove & $\mathrm{B}$ & $\mathrm{E}$ & 0 & 0 & 0 & 0 & 0 & 0 \\
\hline Wolf_Grove & $\mathrm{C}$ & $\bar{E}$ & 0 & $\overline{0}$ & 0 & 0 & 0 & 0 \\
\hline Wolf_Grove & $\bar{D}$ & $\mathrm{E}$ & 0 & 0 & 0 & 0 & 0 & $\overline{0}$ \\
\hline Wolf_Grove & $\mathrm{E}$ & $E$ & 0 & 0 & 0 & 0 & 0 & 0 \\
\hline Wolf_Grove & $F$ & $E$ & 0 & 0 & 0 & 0 & 0 & 0 \\
\hline Wolf_Grove & $\mathrm{H}$ & $\mathrm{E}$ & 0 & 0 & 0 & 0 & 0 & $\overline{0}$ \\
\hline Wolf_Grove & I & $\mathrm{E}$ & 0 & 0 & 0 & 0 & 0 & 0 \\
\hline Wrightville & $\mathrm{A}$ & $\mathrm{U}$ & 2 & 0 & 0 & 0 & 9 & 6 \\
\hline Wrightville & $\mathrm{B}$ & $\mathrm{U}$ & 0 & 0 & 0 & 0 & 1 & 0 \\
\hline Wrightville & $\mathrm{C}$ & $\mathrm{U}$ & 0 & 1 & 0 & 0 & 0 & 0 \\
\hline Wrightville & $\mathrm{D}$ & $\mathrm{U}$ & 0 & 0 & 0 & 0 & 16 & 0 \\
\hline Wrightville & $E$ & $\mathrm{U}$ & 0 & 0 & 0 & 0 & 1 & 0 \\
\hline Wrightville & $\mathrm{F}$ & $\mathrm{U}$ & 0 & 0 & 0 & 1 & 0 & 0 \\
\hline Wrightville & $\mathrm{H}$ & $\mathrm{U}$ & 0 & 0 & 0 & 0 & 1 & 0 \\
\hline Wrightville & I & $\mathrm{U}$ & 0 & 0 & 0 & 0 & 1 & 0 \\
\hline Wychwood & $\mathrm{A}$ & $\mathrm{S}$ & 0 & 0 & 0 & 0 & 0 & 0 \\
\hline Wychwood & B & $\mathrm{S}$ & 0 & 0 & 0 & 0 & 1 & 2 \\
\hline Wychwood & $\mathrm{C}$ & $\mathrm{S}$ & 1 & 0 & 0 & 0 & 0 & 0 \\
\hline Wychwood & $\mathrm{D}$ & $\mathrm{S}$ & 0 & 0 & 0 & 0 & 0 & 0 \\
\hline Wychwood & $\mathrm{E}$ & $\mathrm{S}$ & 0 & 0 & 0 & 0 & 0 & 0 \\
\hline Wychwood & $\mathrm{F}$ & $\mathrm{S}$ & 0 & 0 & 0 & 0 & 0 & 0 \\
\hline Wychwood & $\mathbf{H}$ & $\mathrm{S}$ & 0 & 0 & 0 & 0 & 0 & 3 \\
\hline Wychwood & I & $\mathrm{S}$ & 2 & 0 & 0 & 0 & 0 & 0 \\
\hline
\end{tabular}




\begin{tabular}{|c|c|c|c|c|c|c|c|c|}
\hline SITE & STATION & CATEGORY & HAER & HAERY & HAFA & HAFU & HAHE & HALO \\
\hline Achbar & A & SN & 0 & 0 & 0 & 0 & 0 & 0 \\
\hline Achbar & B & $\mathrm{SN}$ & 0 & 0 & 0 & 0 & 0 & 0 \\
\hline Achbar & $\mathrm{C}$ & $\mathrm{SN}$ & 0 & 0 & 0 & 0 & 0 & 0 \\
\hline Achbar & $\mathrm{D}$ & $\mathrm{SN}$ & 0 & 0 & 0 & 0 & 0 & 0 \\
\hline Achbar & $\mathrm{E}$ & $\mathrm{SN}$ & 0 & 0 & 0 & 0 & 0 & 0 \\
\hline Achbar & $\mathrm{F}$ & SN & 0 & 0 & 0 & 0 & 0 & 0 \\
\hline Achbar & $\mathrm{H}$ & SN & 0 & 0 & 0 & 0 & 0 & 0 \\
\hline Achbar & $\bar{I}$ & $\mathrm{SN}$ & 0 & 0 & 0 & 0 & 0 & 0 \\
\hline Bridlewood & A & $\overline{\mathrm{UN}}$ & 0 & 0 & 0 & 0 & 0 & 0 \\
\hline Bridlewood & $\mathrm{B}$ & $\mathrm{UN}$ & 0 & 0 & 0 & 0 & 0 & 0 \\
\hline Bridlewood & $\mathrm{C}$ & $\mathrm{UN}$ & 0 & 0 & 0 & 0 & 0 & 0 \\
\hline Bridlewood & $\mathrm{D}$ & $\mathrm{UN}$ & 0 & 0 & 0 & 1 & 0 & 0 \\
\hline Bridlewood & $E$ & $\overline{\mathrm{UN}}$ & 0 & 0 & 0 & 0 & 0 & 0 \\
\hline Bridlewood & $\mathrm{F}$ & $\mathrm{UN}$ & 0 & 0 & 0 & 0 & 0 & 0 \\
\hline Bridlewood & $\mathrm{H}$ & $\overline{U N}$ & 0 & 0 & 0 & 0 & 0 & 0 \\
\hline Bridlewood & I & UN & 0 & 0 & 0 & 0 & 0 & 0 \\
\hline Carp_Hills & $A$ & $\mathrm{~F}$ & 0 & 0 & 0 & 0 & 0 & 0 \\
\hline Carp_Hills & $\mathrm{B}$ & $\mathrm{F}$ & 0 & 0 & 0 & 0 & 0 & 0 \\
\hline Carp_Hills & $\mathrm{C}$ & $\mathrm{F}$ & 0 & 0 & 0 & 0 & 0 & 0 \\
\hline Carp_Hills & $\mathrm{D}$ & $\mathrm{F}$ & 0 & 0 & 0 & 0 & 0 & 0 \\
\hline Carp_Hills & $\mathrm{E}$ & $\mathrm{F}$ & 0 & 0 & 0 & 0 & 0 & 0 \\
\hline Carp_Hills & $\bar{F}$ & $\bar{F}$ & 0 & 0 & 0 & 0 & 0 & 0 \\
\hline Carp_Hills & $\mathrm{H}$ & $\mathrm{F}$ & 0 & 0 & 0 & 0 & 0 & 0 \\
\hline Carp_Hills & I & $F$ & 0 & 0 & 0 & 0 & 0 & 0 \\
\hline Chapel_Hill & A & UN & 0 & 0 & 0 & 0 & 0 & 0 \\
\hline Chapel_Hill & B & UN & 0 & 0 & 0 & 0 & 0 & 0 \\
\hline Chapel_Hill & $\mathrm{C}$ & $\mathrm{UN}$ & 0 & 0 & 0 & 0 & 0 & 0 \\
\hline Chapel_Hill & $\mathrm{D}$ & UN & 0 & 0 & 0 & 0 & 0 & 0 \\
\hline Chapel_Hill & $\mathrm{E}$ & $\mathrm{UN}$ & 0 & 0 & 0 & 0 & 0 & 0 \\
\hline Chapel_Hill & $\mathbf{F}$ & UN & 0 & 0 & 0 & 0 & 0 & 0 \\
\hline Chapel_Hill & $\mathrm{H}$ & $\overline{\mathrm{UN}}$ & 0 & 0 & 0 & 0 & 0 & 0 \\
\hline Chapel_Hill & I & UN & 0 & 0 & 0 & 0 & 0 & 0 \\
\hline Chelsea & $\mathrm{A}$ & SN & 0 & 0 & 0 & 0 & 0 & 0 \\
\hline Chelsea & $\mathrm{B}$ & $\mathrm{SN}$ & 0 & 0 & 0 & 0 & 0 & 0 \\
\hline Chelsea & $\mathrm{C}$ & $\mathrm{SN}$ & 0 & 0 & 0 & 0 & 0 & 0 \\
\hline Chelsea & $\mathrm{D}$ & $\mathrm{SN}$ & 0 & 0 & 0 & 0 & 0 & 0 \\
\hline Chelsea & $\mathrm{E}$ & SN & 0 & 0 & 0 & 0 & 0 & 0 \\
\hline Chelsea & $\mathbf{F}$ & SN & 0 & 0 & 0 & 0 & 0 & 0 \\
\hline Chelsea & $\mathrm{H}$ & SN & 0 & 0 & 0 & 0 & 0 & 0 \\
\hline Chelsea & I & SN & 0 & 0 & 0 & 0 & 0 & 0 \\
\hline Chemin_Scholle & $\mathrm{A}$ & $\mathrm{EN}$ & 0 & 0 & 0 & 0 & 0 & 0 \\
\hline
\end{tabular}




\begin{tabular}{|c|c|c|c|c|c|c|c|c|}
\hline Chemin_Scholle & B & EN & 0 & 0 & 0 & 0 & 0 & 0 \\
\hline Chemin_Scholle & $\mathrm{C}$ & EN & 0 & 0 & 0 & 0 & 0 & $\overline{0}$ \\
\hline Chemin_Scholle & $\mathrm{D}$ & EN & 0 & 0 & 0 & 0 & 0 & 0 \\
\hline Chemin_Scholle & $E$ & EN & 0 & 0 & 0 & 0 & 0 & 0 \\
\hline Chemin_Scholle & F & EN & 0 & 0 & 0 & 0 & 0 & 0 \\
\hline Chemin_Scholle & $\mathrm{H}$ & EN & 0 & 0 & 0 & 0 & 0 & 0 \\
\hline Chemin_Scholle & I & EN & 0 & 0 & 0 & 0 & 0 & 0 \\
\hline Cote_d'Azur & $\mathrm{A}$ & $\mathrm{S}$ & 0 & 0 & 0 & 0 & 0 & 0 \\
\hline Cote_d'Azur & $\overline{\mathrm{B}}$ & $\bar{S}$ & 0 & 0 & 0 & 0 & 0 & 0 \\
\hline Cote_d'Azur & $\mathrm{C}$ & $\mathbf{S}$ & 0 & 0 & 0 & 0 & 0 & 0 \\
\hline Cote_d'Azur & $\mathrm{D}$ & $\mathrm{S}$ & 0 & 0 & 0 & 0 & 0 & 2 \\
\hline Cote_d'Azur & $\bar{E}$ & $\mathrm{~S}$ & 0 & 0 & 0 & 0 & 0 & 0 \\
\hline Cote_d'Azur & $\mathrm{F}$ & $\mathrm{S}$ & 0 & 0 & 0 & 0 & 0 & 7 \\
\hline Cote_d'Azur & $\mathrm{H}$ & $\mathrm{S}$ & 0 & 0 & 0 & 0 & 0 & 0 \\
\hline Cote_d'Azur & I & $\mathrm{S}$ & 0 & 0 & 0 & 0 & 0 & 1 \\
\hline Highway_Seven & $\mathrm{A}$ & $\mathrm{E}$ & 0 & 0 & 0 & 0 & 0 & 0 \\
\hline Highway_Seven & $\mathrm{B}$ & $\bar{E}$ & 0 & 0 & 0 & $\overline{0}$ & 0 & $\overline{0}$ \\
\hline Highway_Seven & $\mathrm{C}$ & $\mathrm{E}$ & 0 & 0 & 0 & 0 & 0 & 0 \\
\hline Highway_Seven & $\mathrm{D}$ & $\mathrm{E}$ & 0 & 0 & 0 & 0 & 0 & 0 \\
\hline Highway_Seven & $\mathrm{E}$ & $\bar{E}$ & 0 & 0 & 0 & 0 & 0 & 0 \\
\hline Highway_Seven & $\mathrm{F}$ & $E$ & 0 & 0 & 0 & 0 & 0 & 0 \\
\hline Highway_Seven & $\mathrm{H}$ & $\bar{E}$ & 0 & 0 & 0 & 0 & 1 & $\overline{0}$ \\
\hline Highway_Seven & $\mathrm{I}$ & $E$ & 0 & 0 & 0 & 0 & 0 & 0 \\
\hline Hull & $\mathrm{A}$ & $\mathrm{U}$ & 0 & 0 & 0 & 0 & 0 & 0 \\
\hline Hull & $\mathrm{B}$ & $\mathrm{U}$ & 0 & 0 & 0 & 0 & 0 & 0 \\
\hline Hull & $\overline{\mathrm{C}}$ & $\bar{U}$ & 0 & 0 & 0 & 0 & 0 & $\overline{0}$ \\
\hline Hull & $\mathrm{D}$ & $\mathrm{U}$ & 0 & 0 & 0 & 0 & 0 & 0 \\
\hline Hull & $\mathrm{E}$ & $\mathbf{U}$ & 0 & 0 & 0 & 0 & 0 & 2 \\
\hline Hull & $\mathrm{F}$ & $\mathrm{U}$ & 0 & 0 & 0 & 0 & 0 & 0 \\
\hline Hull & $\mathrm{H}$ & $\mathrm{U}$ & 0 & 0 & 0 & 0 & 1 & 4 \\
\hline Hull & I & $\bar{U}$ & 0 & 0 & 0 & 0 & 0 & 0 \\
\hline Lac_a_la_Perdrix & $\mathrm{A}$ & EN & 0 & 0 & 0 & 0 & 0 & 0 \\
\hline Lac_a_la_Perdrix & $\mathrm{B}$ & EN & 0 & 0 & 0 & 0 & 0 & 0 \\
\hline Lac_a_la_Perdrix & $\mathrm{C}$ & EN & 0 & 0 & 0 & 0 & 0 & 0 \\
\hline Lac_a_la_Perdrix & $\mathrm{D}$ & EN & 0 & 0 & 0 & 0 & 0 & 0 \\
\hline Lac_a_la_Perdrix & $\mathrm{E}$ & EN & 0 & 0 & 0 & 0 & 0 & 0 \\
\hline Lac_a_la_Perdrix & $\mathbf{F}$ & EN & 0 & 0 & 0 & 0 & 0 & 0 \\
\hline Lac_a_la_Perdrix & $\mathrm{H}$ & EN & 0 & 0 & 0 & 0 & 0 & 0 \\
\hline Lac_a_la_Perdrix & I & $\overline{E N}$ & 0 & 0 & 0 & 0 & 0 & 0 \\
\hline Lac_Philippe & A & $\mathbf{F}$ & 0 & 0 & 0 & 0 & 0 & 0 \\
\hline Lac_Philippe & $\mathrm{B}$ & $\mathbf{F}$ & 0 & 0 & 0 & 0 & 0 & 0 \\
\hline Lac_Philippe & $\mathrm{C}$ & $\mathbf{F}$ & 0 & 0 & 0 & 0 & 0 & $\overline{0}$ \\
\hline
\end{tabular}




\begin{tabular}{|c|c|c|c|c|c|c|c|c|}
\hline Lac_Philippe & $\mathrm{D}$ & $\mathrm{F}$ & 0 & 0 & 0 & 0 & 0 & 0 \\
\hline Lac_Philippe & $\mathrm{E}$ & $\mathrm{F}$ & 0 & 0 & 0 & 0 & 0 & 0 \\
\hline Lac_Philippe & $\mathrm{F}$ & $\mathrm{F}$ & 0 & 0 & 0 & 0 & 0 & 0 \\
\hline Lac_Philippe & $\mathrm{H}$ & $\bar{F}$ & 0 & 0 & 0 & 0 & 0 & 0 \\
\hline Lac_Philippe & I & $\mathrm{F}$ & 0 & 0 & 0 & 0 & 0 & 0 \\
\hline Manoir_des_Trembles & $\mathrm{A}$ & UN & 0 & 0 & 0 & 0 & 0 & $\overline{0}$ \\
\hline Manoir_des_Trembles & $\mathrm{B}$ & UN & 0 & 0 & 0 & 0 & 0 & 0 \\
\hline Manoir_des_Trembles & $\mathrm{C}$ & UN & 0 & 0 & 0 & 0 & 0 & $\overline{0}$ \\
\hline Manoir_des_Trembles & $\mathrm{D}$ & UN & 0 & 0 & 0 & 0 & 0 & 0 \\
\hline Manoir_des_Trembles & $\mathrm{E}$ & UN & 0 & 0 & 0 & 0 & 0 & 0 \\
\hline Manoir_des_Trembles & $\mathrm{F}$ & UN & 0 & 0 & 0 & 0 & 0 & 0 \\
\hline Manoir_des_Trembles & $\mathrm{H}$ & UN & 0 & 0 & 0 & 0 & 0 & $\overline{0}$ \\
\hline Manoir_des_Trembles & I & UN & 0 & 0 & 0 & 0 & 0 & 0 \\
\hline Marathon & $\mathrm{A}$ & $E$ & 0 & 0 & 0 & 0 & 0 & 0 \\
\hline Marathon & $\mathrm{B}$ & $E$ & 0 & 0 & 0 & 0 & 0 & 0 \\
\hline Marathon & $\mathrm{C}$ & $E$ & 0 & 0 & 0 & 0 & 0 & 0 \\
\hline Marathon & $\mathrm{D}$ & $\bar{E}$ & 0 & 0 & 0 & 0 & 0 & 0 \\
\hline Marathon & $\mathrm{E}$ & $\bar{E}$ & 0 & 0 & 0 & 0 & 0 & $\overline{0}$ \\
\hline Marathon & $\mathrm{F}$ & $\mathrm{E}$ & 0 & 0 & 0 & 0 & 0 & 0 \\
\hline Marathon & $\mathrm{H}$ & $\mathrm{E}$ & 0 & 0 & 0 & 0 & 0 & 0 \\
\hline Marathon & I & $\mathrm{E}$ & 0 & 0 & 0 & 0 & 0 & 0 \\
\hline Marier & $\mathrm{A}$ & $\mathrm{U}$ & 0 & 1 & 0 & 0 & 0 & $\overline{0}$ \\
\hline Marier & B & $\mathrm{U}$ & 0 & 0 & 0 & 0 & 0 & 0 \\
\hline Marier & $\mathrm{C}$ & $\mathrm{U}$ & 0 & 5 & 0 & 0 & 0 & 2 \\
\hline Marier & $\mathrm{D}$ & $\mathrm{U}$ & 0 & 0 & 0 & 0 & 0 & 0 \\
\hline Marier & $\mathrm{E}$ & $\mathrm{U}$ & 0 & 0 & 0 & 0 & 0 & 0 \\
\hline Marier & $\bar{F}$ & $\overline{\mathrm{U}}$ & 0 & 0 & 0 & 0 & 0 & $\overline{0}$ \\
\hline Marier & $\mathrm{H}$ & $\mathrm{U}$ & 0 & 1 & 0 & 0 & 0 & 2 \\
\hline Marier & I & $\mathrm{U}$ & 0 & 0 & 0 & 0 & 0 & $\overline{0}$ \\
\hline Marlborough & A & $\mathrm{F}$ & 0 & $\overline{0}$ & 0 & 0 & 0 & 0 \\
\hline Marlborough & $\mathrm{B}$ & $\mathrm{F}$ & 0 & 0 & 0 & 0 & 0 & 0 \\
\hline Marlborough & $\mathrm{C}$ & $\bar{F}$ & 0 & 0 & 0 & 0 & 0 & 0 \\
\hline Marlborough & $\mathrm{D}$ & $\mathrm{F}$ & 0 & 0 & 0 & 0 & 0 & 0 \\
\hline Marlborough & $E$ & $\mathrm{~F}$ & 0 & 0 & 0 & 0 & 0 & 0 \\
\hline Marlborough & $\bar{F}$ & $\bar{F}$ & 0 & 0 & 0 & 0 & 0 & $\overline{0}$ \\
\hline Marlborough & $\mathrm{H}$ & $\mathrm{F}$ & 0 & 0 & 0 & 0 & 0 & 0 \\
\hline Marlborough & I & $\bar{F}$ & 0 & 0 & 0 & 0 & 0 & $\overline{0}$ \\
\hline Merivale & $\mathrm{A}$ & $\mathrm{SN}$ & 0 & 0 & 0 & 0 & 0 & 0 \\
\hline Merivale & $\bar{B}$ & $\mathrm{SN}$ & 0 & 0 & 0 & 0 & 0 & $\overline{0}$ \\
\hline Merivale & $\mathrm{C}$ & $\mathrm{SN}$ & 0 & 0 & 0 & 0 & 0 & 0 \\
\hline Merivale & $\mathrm{D}$ & $\mathrm{SN}$ & 0 & 0 & 0 & 0 & 0 & $\overline{0}$ \\
\hline Merivale & $\mathbf{E}$ & $\mathrm{SN}$ & 0 & 0 & 0 & 0 & 0 & 0 \\
\hline
\end{tabular}




\begin{tabular}{|c|c|c|c|c|c|c|c|c|}
\hline Merivale & $\bar{F}$ & $\overline{\mathrm{SN}}$ & 0 & 0 & 0 & 0 & 0 & 0 \\
\hline Merivale & $\mathrm{H}$ & SN & 0 & 0 & 0 & 0 & 0 & 0 \\
\hline Merivale & I & SN & 0 & 0 & 0 & 0 & 0 & 0 \\
\hline Parc_Champlain & $\bar{A}$ & $\mathrm{~S}$ & 0 & 0 & 0 & 0 & 0 & 1 \\
\hline Parc_Champlain & $\bar{B}$ & $\mathrm{~S}$ & 0 & 0 & 0 & 0 & 0 & 0 \\
\hline Parc_Champlain & $\mathrm{C}$ & $\mathrm{S}$ & 0 & 0 & 0 & 0 & 0 & 0 \\
\hline Parc_Champlain & $\mathrm{D}$ & $\mathrm{S}$ & 0 & 3 & 1 & 0 & 0 & 5 \\
\hline Parc_Champlain & $\mathrm{E}$ & $\mathrm{S}$ & 0 & 0 & 1 & 0 & 0 & 0 \\
\hline Parc_Champlain & $\bar{F}$ & $\mathrm{~S}$ & 0 & 2 & 1 & 0 & 0 & 7 \\
\hline Parc_Champlain & $\mathrm{H}$ & $\bar{S}$ & 0 & 0 & 0 & 0 & 0 & 5 \\
\hline Parc_Champlain & $\bar{I}$ & $\bar{S}$ & 0 & 0 & 0 & 0 & 0 & $\overline{0}$ \\
\hline Pelissier & $\overline{\mathrm{A}}$ & EN & 0 & 0 & 0 & 0 & 0 & $\overline{0}$ \\
\hline Pelissier & B & EN & 0 & 0 & 0 & 0 & 0 & 0 \\
\hline Pelissier & $\mathrm{C}$ & EN & 0 & 0 & 0 & 0 & 0 & 0 \\
\hline Pelissier & $\mathrm{D}$ & EN & 0 & 0 & 0 & 0 & 0 & $\overline{0}$ \\
\hline Pelissier & $\mathrm{E}$ & EN & 0 & 0 & 0 & 0 & 1 & 0 \\
\hline Pelissier & $\mathrm{F}$ & EN & 0 & 0 & 0 & 0 & 0 & $\overline{0}$ \\
\hline Pelissier & $\mathrm{H}$ & $\overline{\text { EN }}$ & 0 & 0 & 0 & 0 & 0 & $\overline{0}$ \\
\hline Pelissier & I & EN & 0 & 0 & 0 & 0 & 0 & $\overline{0}$ \\
\hline PineGlen_Annex & A & $\mathbf{S}$ & 1 & 0 & 0 & 0 & 0 & 0 \\
\hline PineGlen_Annex & B & $\mathrm{S}$ & 0 & 0 & 0 & 0 & 0 & 0 \\
\hline PineGlen_Annex & $\mathrm{C}$ & $\mathrm{S}$ & 0 & 0 & 0 & 0 & 0 & $\overline{0}$ \\
\hline PineGlen_Annex & $\mathrm{D}$ & $\mathrm{S}$ & 0 & 0 & 0 & 0 & 0 & $\overline{0}$ \\
\hline PineGlen_Annex & $\bar{E}$ & $\mathrm{~S}$ & 2 & 0 & 0 & 0 & 0 & 1 \\
\hline PineGlen_Annex & $\mathrm{F}$ & $\mathrm{S}$ & 0 & 1 & 0 & 0 & 0 & $\overline{0}$ \\
\hline PineGlen_Annex & $\mathrm{H}$ & $\overline{\mathrm{S}}$ & 0 & 0 & 0 & 0 & 0 & 1 \\
\hline PineGlen_Annex & I & $\bar{S}$ & 0 & 2 & 0 & 0 & 0 & 3 \\
\hline Q_Four & A & $\mathrm{E}$ & 0 & 0 & 0 & 0 & 0 & $\overline{0}$ \\
\hline Q_Four & B & $\mathrm{E}$ & 0 & 0 & 0 & 0 & 0 & $\overline{0}$ \\
\hline Q Four & $\bar{C}$ & $\mathrm{E}$ & 0 & 0 & 0 & 0 & 0 & $\overline{0}$ \\
\hline Q_Four & $\mathrm{D}$ & $\mathrm{E}$ & 0 & 0 & 0 & 0 & 0 & 0 \\
\hline Q_Four & $E$ & $\mathrm{E}$ & 0 & 0 & 0 & 0 & 0 & 0 \\
\hline Q_Four & F & $\mathrm{E}$ & 0 & 0 & 0 & 0 & 0 & $\overline{0}$ \\
\hline Q_Four & $\mathrm{H}$ & $\bar{E}$ & $\overline{0}$ & 0 & 0 & 0 & 0 & $\overline{0}$ \\
\hline Q_Four & I & $\bar{E}$ & 0 & 0 & 0 & 0 & 0 & $\overline{0}$ \\
\hline Sandy_Hill & $\bar{A}$ & $\mathrm{U}$ & 0 & 0 & 0 & 0 & 0 & 0 \\
\hline Sandy_Hill & B & $\bar{U}$ & 0 & 0 & 0 & 0 & 0 & $\overline{0}$ \\
\hline Sandy_Hill & $\mathrm{C}$ & $\bar{U}$ & 0 & 0 & 0 & 0 & 0 & 0 \\
\hline Sandy_Hill & $\bar{D}$ & $\overline{\mathrm{U}}$ & 0 & 0 & 1 & 0 & 0 & 0 \\
\hline Sandy_Hill & $\bar{E}$ & $\mathrm{U}$ & 0 & 0 & 0 & 0 & 0 & 0 \\
\hline Sandy_Hill & $\bar{F}$ & $\mathrm{U}$ & 0 & 0 & 0 & 0 & 0 & $\overline{0}$ \\
\hline Sandy_Hill & $\mathrm{H}$ & $\overline{\mathrm{U}}$ & 0 & 0 & 0 & 0 & 0 & 0 \\
\hline
\end{tabular}




\begin{tabular}{|c|c|c|c|c|c|c|c|c|}
\hline Sandy_Hill & I & $\overline{\mathrm{U}}$ & 0 & 0 & 0 & 0 & 0 & 0 \\
\hline Vallee_Meech & $\mathrm{A}$ & $F$ & 0 & 0 & 0 & 0 & 0 & 0 \\
\hline Vallee_Meech & B & $\mathrm{F}$ & 0 & 0 & 0 & 0 & 0 & 0 \\
\hline Vallee_Meech & $\mathrm{C}$ & $\bar{F}$ & 0 & 0 & 0 & 0 & 0 & 0 \\
\hline Vallee_Meech & $\mathrm{D}$ & $\mathrm{F}$ & 0 & 0 & 0 & 0 & 0 & 0 \\
\hline Vallee_Meech & $\mathbf{E}$ & $\mathbf{F}$ & 0 & 0 & 0 & 0 & 0 & 0 \\
\hline Vallee_Meech & $\mathbf{F}$ & $F$ & 0 & 0 & 0 & 0 & 0 & 0 \\
\hline Vallee_Meech & $\mathbf{H}$ & $\mathrm{F}$ & 0 & 0 & 0 & 0 & 0 & 0 \\
\hline Vallee_Meech & I & $\bar{F}$ & 0 & 0 & 0 & 0 & 0 & $\overline{0}$ \\
\hline Wolf_Grove & $\mathrm{A}$ & $\mathrm{E}$ & 0 & 0 & 0 & 0 & 0 & 0 \\
\hline Wolf_Grove & B & $\mathrm{E}$ & 0 & 0 & 0 & 0 & 0 & 0 \\
\hline Wolf_Grove & $\mathrm{C}$ & $\mathrm{E}$ & 0 & 0 & 0 & 0 & 0 & 0 \\
\hline Wolf_Grove & $\mathrm{D}$ & $\mathrm{E}$ & 0 & 0 & 0 & 0 & 0 & 0 \\
\hline Wolf_Grove & $\overline{\mathbf{E}}$ & $\mathrm{E}$ & 0 & 0 & 0 & 0 & 0 & 0 \\
\hline Wolf_Grove & $\mathbf{F}$ & $\mathrm{E}$ & 0 & 0 & 0 & 0 & 0 & 0 \\
\hline Wolf_Grove & $\mathrm{H}$ & $\mathrm{E}$ & 0 & 0 & 0 & 0 & 0 & 0 \\
\hline Wolf_Grove & I & $\bar{E}$ & 0 & 0 & 0 & 0 & 0 & 0 \\
\hline Wrightville & $\mathrm{A}$ & $\mathrm{U}$ & 0 & 1 & 0 & 0 & 0 & 18 \\
\hline Wrightville & B & $\mathrm{U}$ & 0 & 0 & 0 & 0 & 0 & 0 \\
\hline Wrightville & $\mathrm{C}$ & $\overline{\mathrm{U}}$ & 0 & 0 & 0 & 0 & 0 & 0 \\
\hline Wrightville & $\mathrm{D}$ & $\bar{U}$ & 0 & 0 & 0 & 0 & 0 & 1 \\
\hline Wrightville & $\mathbf{E}$ & $\bar{U}$ & 0 & 0 & 0 & 0 & 0 & 0 \\
\hline Wrightville & $\mathbf{F}$ & $\mathrm{U}$ & 0 & 0 & 0 & 0 & 0 & 0 \\
\hline Wrightville & $\mathbf{H}$ & $\overline{\mathrm{U}}$ & 0 & 0 & 0 & 0 & 0 & 0 \\
\hline Wrightville & I & $\bar{U}$ & 0 & 0 & 0 & 0 & 0 & 0 \\
\hline Wychwood & $\bar{A}$ & $\mathrm{~S}$ & 0 & 0 & 0 & 0 & 0 & 0 \\
\hline Wychwood & $\mathrm{B}$ & $\mathrm{S}$ & 0 & 0 & 1 & 0 & 0 & 0 \\
\hline Wychwood & $\mathrm{C}$ & $\mathrm{S}$ & 0 & 0 & 0 & 0 & 0 & 0 \\
\hline Wychwood & $\mathrm{D}$ & $\mathrm{S}$ & 0 & 1 & 1 & 0 & 1 & 0 \\
\hline Wychwood & $\mathrm{E}$ & $\mathrm{S}$ & 0 & 0 & 0 & 0 & 0 & 0 \\
\hline Wychwood & $\bar{F}$ & $\bar{S}$ & 0 & 0 & 0 & 0 & 1 & 0 \\
\hline Wychwood & $\mathrm{H}$ & $\mathrm{S}$ & 0 & 1 & 0 & 0 & 0 & 0 \\
\hline Wychwood & I & $\mathrm{S}$ & 0 & 0 & 0 & 0 & 1 & 0 \\
\hline
\end{tabular}




\begin{tabular}{|c|c|c|c|c|c|c|c|c|}
\hline SITE & STATION & CATEGORY & HAOP & HAPE & HAPR & HASO & LOCO & LOPI \\
\hline Achbar & $\bar{A}$ & SN & 0 & 0 & 0 & 0 & 0 & 0 \\
\hline Achbar & B & SN & 0 & 0 & 0 & 0 & 0 & 0 \\
\hline Achbar & $\mathrm{C}$ & SN & 0 & 0 & 0 & 0 & 0 & 0 \\
\hline Achbar & $\bar{D}$ & SN & 0 & 0 & 0 & 0 & 0 & 0 \\
\hline Achbar & $\bar{E}$ & $\mathrm{SN}$ & 0 & 0 & 0 & 0 & 0 & 0 \\
\hline Achbar & $\mathbf{F}$ & $\mathrm{SN}$ & 0 & 0 & 0 & 0 & 0 & 0 \\
\hline Achbar & $\mathrm{H}$ & SN & 0 & 0 & 0 & 0 & 0 & 0 \\
\hline Achbar & I & SN & 0 & 0 & 0 & 0 & 0 & 0 \\
\hline Bridlewood & $\overline{\mathrm{A}}$ & UN & 0 & 0 & 0 & 0 & 0 & 0 \\
\hline Bridlewood & B & $\overline{\mathrm{UN}}$ & 0 & 0 & 0 & 0 & 0 & 0 \\
\hline Bridlewood & $\mathrm{C}$ & UN & 0 & 0 & 3 & 0 & 0 & 0 \\
\hline Bridlewood & $\bar{D}$ & UN & 0 & 0 & 0 & 0 & 0 & 0 \\
\hline Bridlewood & $\bar{E}$ & UN & 0 & 0 & 0 & 0 & 0 & 0 \\
\hline Bridlewood & $\mathbf{F}$ & UN & 0 & 0 & 0 & 0 & 0 & 0 \\
\hline Bridlewood & $\mathrm{H}$ & $\overline{\mathrm{UN}}$ & 0 & 0 & 0 & 0 & 0 & 0 \\
\hline Bridlewood & I & UN & 0 & 0 & $\overline{0}$ & 0 & 0 & 0 \\
\hline Carp_Hills & $\bar{A}$ & $F$ & 0 & 0 & 0 & 0 & 0 & 0 \\
\hline Carp_Hills & $\bar{B}$ & $\mathrm{~F}$ & 0 & 0 & 0 & 0 & 0 & 1 \\
\hline Carp_Hills & $\bar{C}$ & $\bar{F}$ & $\overline{0}$ & 0 & 0 & 0 & 0 & 0 \\
\hline Carp_Hills & $\mathrm{D}$ & F & 0 & 0 & 0 & 0 & 0 & 0 \\
\hline Carp_Hills & $\bar{E}$ & $F$ & 0 & 0 & 0 & 0 & 0 & 1 \\
\hline Carp_Hills & $\bar{F}$ & $\mathrm{~F}$ & 0 & 0 & 0 & 0 & 0 & 0 \\
\hline Carp_Hills & $\mathrm{H}$ & $F$ & 0 & 0 & 0 & 0 & 0 & 0 \\
\hline Carp_Hills & I & $F$ & 0 & 0 & 0 & 0 & 0 & 0 \\
\hline Chapel_Hill & $\bar{A}$ & $\overline{\mathrm{UN}}$ & 0 & 0 & 0 & 0 & 0 & 2 \\
\hline Chapel_Hill & B & $\mathrm{UN}$ & 0 & 0 & 0 & 0 & 0 & 0 \\
\hline Chapel_Hill & $\mathrm{C}$ & UN & 0 & 0 & 0 & 0 & 0 & 0 \\
\hline Chapel_Hill & $\bar{D}$ & UN & 0 & 0 & 0 & 0 & 0 & 0 \\
\hline Chapel_Hill & $\mathrm{E}$ & $\overline{U N}$ & 0 & 0 & 0 & 0 & 0 & 1 \\
\hline Chapel_Hill & $\mathbf{F}$ & $\overline{\mathrm{UN}}$ & 0 & 0 & 0 & 0 & 0 & 0 \\
\hline Chapel_Hill & $\mathrm{H}$ & UN & 0 & 0 & 0 & 0 & 0 & 0 \\
\hline Chapel_Hill & $\mathrm{I}$ & UN & 0 & 0 & 0 & 0 & 0 & 0 \\
\hline Chelsea & $\overline{\mathrm{A}}$ & $\overline{\mathrm{SN}}$ & 0 & 0 & 0 & 0 & 0 & 0 \\
\hline Chelsea & $\bar{B}$ & SN & 0 & 0 & 0 & 0 & 0 & 0 \\
\hline Chelsea & $\mathrm{C}$ & $\overline{\mathrm{SN}}$ & 0 & 0 & 0 & 0 & 0 & 0 \\
\hline Chelsea & $\mathrm{D}$ & SN & 0 & 0 & 0 & 0 & 0 & 0 \\
\hline Chelsea & $\mathrm{E}$ & $\overline{\text { SN }}$ & 0 & 0 & 0 & 0 & 0 & 0 \\
\hline Chelsea & $F$ & SN & 0 & 0 & 0 & 0 & 0 & 0 \\
\hline Chelsea & $\mathrm{H}$ & $\mathrm{SN}$ & 0 & 0 & 0 & 0 & 0 & 0 \\
\hline Chelsea & I & SN & 0 & 0 & 0 & 0 & 0 & 0 \\
\hline
\end{tabular}




\begin{tabular}{|c|c|c|c|c|c|c|c|c|}
\hline Chemin_Scholle & $\mathrm{A}$ & EN & 0 & 0 & 0 & 0 & 0 & 0 \\
\hline Chemin_Scholle & $\mathrm{B}$ & $\overline{\mathrm{EN}}$ & 0 & 0 & 0 & 0 & 0 & 0 \\
\hline Chemin_Scholle & $\mathrm{C}$ & EN & 0 & 0 & 0 & 0 & 0 & 0 \\
\hline Chemin_Scholle & $\bar{D}$ & $\mathrm{EN}$ & 0 & 0 & 0 & 0 & 0 & 0 \\
\hline Chemin_Scholle & $E$ & EN & 0 & 0 & 0 & 0 & 0 & 0 \\
\hline Chemin_Scholle & $\mathrm{F}$ & EN & 0 & 0 & 0 & 0 & 0 & 0 \\
\hline Chemin_Scholle & $\mathrm{H}$ & EN & 0 & 0 & 0 & 0 & 0 & 0 \\
\hline Chemin_Scholle & I & $\overline{\mathrm{EN}}$ & 0 & 0 & 0 & 0 & 0 & 0 \\
\hline Cote_d'Azur & A & $\mathbf{S}$ & 0 & 1 & 0 & 0 & 0 & 0 \\
\hline Cote_d'Azur & B & $\mathbf{S}$ & 0 & 1 & 0 & 0 & 0 & 0 \\
\hline Cote_d'Azur & $\mathrm{C}$ & $\mathbf{S}$ & 0 & 1 & 0 & 0 & 0 & 0 \\
\hline Cote_d'Azur & $\mathrm{D}$ & $\mathrm{S}$ & 0 & 1 & 0 & 0 & 0 & 0 \\
\hline Cote_d'Azur & $\bar{E}$ & $\mathrm{~S}$ & 0 & 1 & 0 & 0 & 0 & 0 \\
\hline Cote_d'Azur & $F$ & $\mathrm{~S}$ & 0 & 1 & 0 & 0 & 0 & 0 \\
\hline Cote_d'Azur & $\mathrm{H}$ & $\mathrm{S}$ & 0 & $\overline{0}$ & 0 & 0 & 0 & 0 \\
\hline Cote_d'Azur & I & $\mathrm{S}$ & 0 & 0 & 0 & 0 & 0 & 0 \\
\hline Highway_Seven & $\mathrm{A}$ & $\mathrm{E}$ & 0 & 0 & 0 & 0 & 0 & 0 \\
\hline Highway_Seven & $\mathrm{B}$ & $\mathrm{E}$ & 0 & 0 & 0 & 0 & 0 & 0 \\
\hline Highway_Seven & $\mathrm{C}$ & $\mathrm{E}$ & 0 & 0 & 0 & 0 & 0 & 0 \\
\hline Highway_Seven & $\overline{\mathrm{D}}$ & $\bar{E}$ & 0 & 0 & 0 & 0 & $\overline{0}$ & 0 \\
\hline Highway_Seven & $\bar{E}$ & $\bar{E}$ & 0 & 0 & 0 & 0 & 1 & 0 \\
\hline Highway_Seven & $\mathrm{F}$ & $\mathrm{E}$ & 0 & 0 & 0 & 0 & 0 & 0 \\
\hline Highway_Seven & $\mathrm{H}$ & $\mathrm{E}$ & 0 & 0 & 0 & 1 & 0 & 0 \\
\hline Highway_Seven & I & $\mathrm{E}$ & 0 & 0 & 0 & 0 & 0 & 0 \\
\hline Hull & A & $\mathrm{U}$ & 0 & 0 & 0 & 0 & 0 & 0 \\
\hline Hull & B & $\bar{U}$ & 0 & 0 & 0 & 0 & 0 & 0 \\
\hline Hull & $\mathrm{C}$ & $\mathrm{U}$ & 0 & 0 & 0 & 0 & 0 & 0 \\
\hline Hull & $\bar{D}$ & $\mathrm{U}$ & 0 & 0 & 0 & 0 & 0 & 0 \\
\hline Hull & $\bar{E}$ & $\mathrm{U}$ & 0 & 2 & 0 & 0 & 0 & 0 \\
\hline Hull & $\bar{F}$ & $\mathrm{U}$ & 0 & 1 & 0 & 0 & 0 & 0 \\
\hline Hull & $\mathrm{H}$ & $\mathrm{U}$ & 0 & 2 & 0 & 0 & 0 & 0 \\
\hline Hull & I & $\mathrm{U}$ & 0 & 2 & 0 & 0 & 0 & 0 \\
\hline Lac_a_la_Perdrix & $\mathrm{A}$ & $\overline{E N}$ & 0 & 0 & 0 & 0 & 0 & 0 \\
\hline Lac_a_la_Perdrix & B & EN & 0 & 0 & 0 & 0 & 0 & 0 \\
\hline Lac_a_la_Perdrix & $\mathrm{C}$ & $\mathrm{EN}$ & 0 & 0 & 0 & 0 & 0 & 0 \\
\hline Lac_a_la_Perdrix & $\bar{D}$ & $\mathrm{EN}$ & 0 & 0 & 0 & 0 & 0 & 0 \\
\hline Lac_a_la_Perdrix & $\mathrm{E}$ & $\mathrm{EN}$ & 0 & 0 & $\overline{0}$ & 0 & 0 & 0 \\
\hline Lac_a_la_Perdrix & $\mathbf{F}$ & $\mathrm{EN}$ & 0 & 0 & $\overline{0}$ & 0 & 0 & 0 \\
\hline Lac_a_la_Perdrix & $\mathrm{H}$ & $\overline{\mathrm{EN}}$ & 0 & 0 & 0 & 0 & 0 & 0 \\
\hline Lac_a_la_Perdrix & I & $\mathrm{EN}$ & 0 & 0 & 0 & 0 & 0 & 0 \\
\hline Lac_Philippe & $\mathrm{A}$ & $\mathbf{F}$ & 0 & 0 & 0 & 0 & 0 & 0 \\
\hline
\end{tabular}




\begin{tabular}{|c|c|c|c|c|c|c|c|c|}
\hline Lac_Philippe & B & $\mathbf{F}$ & 0 & 0 & 0 & 0 & 0 & 0 \\
\hline Lac_Philippe & $\mathrm{C}$ & $\bar{F}$ & 0 & $\overline{0}$ & 0 & 0 & 0 & 0 \\
\hline Lac_Philippe & $\overline{\mathrm{D}}$ & $F$ & 0 & 0 & 0 & 0 & $\overline{0}$ & 0 \\
\hline Lac_Philippe & $\mathrm{E}$ & $\bar{F}$ & 0 & 0 & 0 & 0 & 0 & 0 \\
\hline Lac_Philippe & $\bar{F}$ & $\bar{F}$ & 0 & 0 & 0 & 0 & 0 & 0 \\
\hline Lac_Philippe & $\mathrm{H}$ & F & 0 & 0 & 0 & 0 & 0 & 1 \\
\hline Lac_Philippe & I & $\mathbf{F}$ & 0 & 0 & 0 & 0 & 0 & 0 \\
\hline Manoir_des_Trembles & $\bar{A}$ & $\mathrm{UN}$ & 0 & 0 & 0 & 0 & 0 & 0 \\
\hline Manoir_des_Trembles & $\bar{B}$ & $\overline{\mathrm{UN}}$ & 0 & 0 & 0 & 0 & 0 & 0 \\
\hline Manoir_des_Trembles & $\bar{C}$ & $\mathrm{UN}$ & 0 & 0 & 0 & 0 & 0 & 0 \\
\hline Manoir_des_Trembles & $\mathrm{D}$ & $\overline{\mathrm{UN}}$ & 0 & 0 & 0 & 0 & 0 & 0 \\
\hline Manoir_des_Trembles & $\bar{E}$ & $\overline{\mathrm{UN}}$ & 0 & 0 & 0 & 0 & 0 & 0 \\
\hline Manoir_des_Trembles & $\mathrm{F}$ & $\overline{\mathrm{UN}}$ & 0 & 0 & 0 & 0 & 0 & 0 \\
\hline Manoir_des_Trembles & $\mathrm{H}$ & $\overline{\mathrm{UN}}$ & 0 & 0 & 0 & 0 & 0 & 0 \\
\hline Manoir_des_Trembles & $\mathrm{I}$ & $\mathrm{UN}$ & 0 & 0 & 0 & 0 & 0 & 0 \\
\hline Marathon & $\bar{A}$ & $\mathrm{E}$ & 0 & 0 & 0 & 0 & 0 & 0 \\
\hline Marathon & B & $\mathbf{E}$ & 0 & 0 & 0 & 0 & 0 & 0 \\
\hline Marathon & $\mathrm{C}$ & $\bar{E}$ & 0 & 0 & 0 & 0 & 2 & 0 \\
\hline Marathon & $\bar{D}$ & $\bar{E}$ & 0 & 0 & 0 & I & 0 & 0 \\
\hline Marathon & $\mathrm{E}$ & $\overline{\mathrm{E}}$ & 0 & 0 & 0 & 0 & 0 & 0 \\
\hline Marathon & $\bar{F}$ & $\bar{E}$ & 0 & 0 & 0 & 0 & 2 & 0 \\
\hline Marathon & $\mathrm{H}$ & $\bar{E}$ & 0 & 0 & 0 & 0 & 0 & 0 \\
\hline Marathon & I & $\bar{E}$ & 0 & 0 & 0 & 0 & 0 & 0 \\
\hline Marier & $\bar{A}$ & $\mathrm{U}$ & 0 & 3 & 0 & 0 & 0 & 0 \\
\hline Marier & B & $\mathrm{U}$ & 0 & 1 & 0 & 0 & 0 & 0 \\
\hline Marier & $\mathrm{C}$ & $\bar{U}$ & 0 & 1 & 0 & 0 & 0 & 0 \\
\hline Marier & $\bar{D}$ & $\bar{U}$ & 0 & 3 & 0 & 0 & 0 & 0 \\
\hline Marier & $\bar{E}$ & $\bar{U}$ & 0 & 2 & 0 & 0 & 0 & 0 \\
\hline Marier & $\bar{F}$ & $\bar{U}$ & $\overline{0}$ & 0 & 0 & 0 & 0 & 0 \\
\hline Marier & $\mathrm{H}$ & $\mathrm{U}$ & 0 & 3 & 0 & 0 & 0 & 0 \\
\hline Marier & I & $\bar{U}$ & 0 & 1 & 0 & 0 & 0 & 0 \\
\hline Marlborough & $\bar{A}$ & $\mathrm{~F}$ & 0 & 0 & 0 & 0 & 0 & 0 \\
\hline Marlborough & B & $F$ & 0 & 0 & 0 & 0 & 0 & 0 \\
\hline Marlborough & $\mathrm{C}$ & $F$ & 0 & 0 & 0 & 0 & 0 & 0 \\
\hline Marlborough & $\bar{D}$ & $\bar{F}$ & 0 & 0 & 0 & 0 & 0 & 0 \\
\hline Marlborough & $\bar{E}$ & $\bar{F}$ & 0 & 0 & 0 & 0 & 0 & $\overline{0}$ \\
\hline Marlborough & $\mathrm{F}$ & $F$ & $\overline{0}$ & 0 & 0 & 0 & 0 & 1 \\
\hline Marlborough & $\mathrm{H}$ & $\mathrm{F}$ & 0 & 0 & 0 & 0 & 0 & 0 \\
\hline Marlborough & I & $F$ & 0 & 0 & 0 & 0 & 0 & 0 \\
\hline Merivale & A & SN & 0 & 0 & 0 & 0 & 0 & 0 \\
\hline Merivale & B & $\overline{\mathrm{SN}}$ & 0 & 0 & 0 & 0 & 0 & 0 \\
\hline
\end{tabular}




\begin{tabular}{|c|c|c|c|c|c|c|c|c|}
\hline Merivale & $\mathrm{C}$ & $\overline{\mathrm{SN}}$ & 0 & 0 & 0 & 0 & 0 & 0 \\
\hline Merivale & D & SN & 0 & 0 & 0 & 0 & 0 & 0 \\
\hline Merivale & $E$ & SN & 0 & 0 & 0 & 0 & 0 & 0 \\
\hline Merivale & $\mathrm{F}$ & SN & 0 & 0 & 0 & 1 & 0 & 0 \\
\hline Merivale & $\mathrm{H}$ & SN & 0 & 0 & 0 & 0 & 0 & 0 \\
\hline Merivale & I & $\overline{\mathrm{SN}}$ & 0 & 0 & 0 & 0 & 0 & $\overline{0}$ \\
\hline Parc_Champlain & $\mathrm{A}$ & $\mathrm{S}$ & 0 & 0 & 0 & 0 & 0 & $\overline{0}$ \\
\hline Parc_Champlain & $\mathrm{B}$ & $\mathrm{S}$ & 0 & 0 & 0 & 0 & 0 & 0 \\
\hline Parc_Champlain & $\mathrm{C}$ & $\mathrm{S}$ & 0 & 0 & 0 & 0 & 0 & 0 \\
\hline Parc_Champlain & $\mathrm{D}$ & $\mathrm{S}$ & 0 & 1 & 0 & 0 & 0 & 0 \\
\hline Parc_Champlain & $\bar{E}$ & $\mathrm{~S}$ & 0 & 0 & 0 & 0 & 0 & 0 \\
\hline Parc_Champlain & $F$ & $\mathrm{~S}$ & 0 & 1 & 0 & 0 & 0 & 0 \\
\hline Parc_Champlain & $\mathrm{H}$ & $\mathrm{S}$ & 0 & 0 & 0 & 0 & 0 & $\overline{0}$ \\
\hline Parc_Champlain & I & $\mathrm{S}$ & 0 & 1 & 0 & 0 & 0 & 0 \\
\hline Pelissier & A & $\mathrm{EN}$ & 0 & 0 & 0 & 0 & 0 & 0 \\
\hline Pelissier & $\mathrm{B}$ & $\overline{\mathrm{EN}}$ & 0 & 0 & 0 & 0 & 0 & 0 \\
\hline Pelissier & $\mathrm{C}$ & $\overline{\mathrm{EN}}$ & 0 & 0 & 0 & 0 & 0 & 0 \\
\hline Pelissier & $\mathrm{D}$ & $\overline{E N}$ & 0 & 0 & 0 & 0 & 0 & $\overline{0}$ \\
\hline Pelissier & $E$ & $\overline{\mathrm{EN}}$ & 0 & 0 & 0 & 0 & 0 & 0 \\
\hline Pelissier & $\mathrm{F}$ & EN & 0 & 0 & 0 & 0 & 0 & 0 \\
\hline Pelissier & $\mathrm{H}$ & $\overline{E N}$ & 0 & 0 & 0 & 0 & 0 & 0 \\
\hline Pelissier & I & $\overline{E N}$ & 0 & 0 & 0 & 0 & 0 & 0 \\
\hline PineGlen_Annex & $\bar{A}$ & $\mathrm{~S}$ & 0 & 0 & 0 & 0 & 0 & 0 \\
\hline PineGlen_Annex & $\mathrm{B}$ & $\mathrm{S}$ & 0 & 0 & 0 & 0 & 0 & 0 \\
\hline PineGlen_Annex & $\mathrm{C}$ & $\mathrm{S}$ & 0 & 0 & 0 & 0 & 0 & 0 \\
\hline PineGlen_Annex & $\mathrm{D}$ & $\mathrm{S}$ & 0 & 0 & 0 & 0 & 0 & 0 \\
\hline PineGlen_Annex & $E$ & $\mathrm{~S}$ & 1 & 18 & 0 & 0 & 0 & 0 \\
\hline PineGlen_Annex & $F$ & $\mathrm{~S}$ & 0 & 0 & 0 & 0 & 0 & 0 \\
\hline PineGlen_Annex & $\mathrm{H}$ & $\mathrm{S}$ & 0 & 0 & 0 & 0 & 0 & 0 \\
\hline PineGlen_Annex & I & $\mathrm{S}$ & 1 & 0 & 0 & 0 & 0 & 0 \\
\hline Q_Four & $\bar{A}$ & $\mathrm{E}$ & 0 & 0 & 0 & 0 & 0 & 0 \\
\hline Q_Four & $\mathrm{B}$ & $\mathrm{E}$ & 0 & 0 & 0 & 0 & 0 & 0 \\
\hline Q_Four & $\mathrm{C}$ & $\mathrm{E}$ & 0 & 0 & 0 & 0 & 0 & 0 \\
\hline Q_Four & $\mathrm{D}$ & $\mathrm{E}$ & 0 & 0 & 0 & 0 & 0 & 0 \\
\hline Q_Four & $E$ & $\mathrm{E}$ & 0 & 0 & 0 & 0 & 0 & 0 \\
\hline Q_Four & $F$ & $\mathrm{E}$ & 0 & 0 & 0 & 0 & 0 & 0 \\
\hline Q_Four & $\mathrm{H}$ & 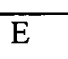 & 0 & 0 & 0 & 0 & 0 & 0 \\
\hline Q_Four & $\mathrm{I}$ & $\mathrm{E}$ & 0 & 0 & 0 & 0 & 0 & 0 \\
\hline Sandy_Hill & $\mathrm{A}$ & $\mathrm{U}$ & 0 & 1 & 0 & 0 & 0 & 0 \\
\hline Sandy_Hill & B & $\overline{\mathrm{U}}$ & 0 & 7 & 0 & 0 & 0 & 0 \\
\hline Sandy_Hill & $\mathrm{C}$ & $\overline{\mathrm{U}}$ & 0 & 1 & 0 & 0 & 0 & 0 \\
\hline
\end{tabular}




\begin{tabular}{|c|c|c|c|c|c|c|c|c|}
\hline Sandy_Hill & $\mathrm{D}$ & $\mathrm{U}$ & 0 & 0 & 0 & 0 & 0 & 0 \\
\hline Sandy_Hill & $\bar{E}$ & $\mathrm{U}$ & 0 & 0 & 0 & 0 & 0 & 0 \\
\hline Sandy_Hill & $\bar{F}$ & $\mathrm{U}$ & 0 & 0 & 0 & 0 & 0 & 0 \\
\hline Sandy_Hill & $\overline{\mathrm{H}}$ & $\bar{U}$ & 0 & 0 & 0 & 0 & 0 & 0 \\
\hline Sandy_Hill & $\bar{I}$ & $\mathrm{U}$ & 0 & 0 & 0 & 0 & 0 & 0 \\
\hline Vallee_Meech & $\bar{A}$ & $F$ & 0 & 0 & 0 & 0 & 0 & 0 \\
\hline Vallee_Meech & B & $F$ & 0 & 0 & 0 & 0 & 0 & 0 \\
\hline Vallee_Meech & $\mathrm{C}$ & $F$ & 0 & 0 & 0 & 0 & 0 & 0 \\
\hline Vallee_Meech & $\mathrm{D}$ & $F$ & 0 & 0 & 0 & 0 & 0 & 0 \\
\hline Vallee_Meech & $\bar{E}$ & $F$ & 0 & 0 & 0 & 0 & 0 & 0 \\
\hline Vallee_Meech & $\bar{F}$ & $F$ & 0 & 0 & 0 & 0 & 0 & 0 \\
\hline Vallee_Meech & $\overline{\mathrm{H}}$ & $F$ & 0 & 0 & 0 & 0 & 0 & 0 \\
\hline Vallee_Meech & I & $F$ & 0 & 0 & 0 & 0 & $\overline{0}$ & 0 \\
\hline Wolf_Grove & A & $\bar{E}$ & 0 & 0 & 0 & 0 & 0 & 3 \\
\hline Wolf_Grove & B & $\bar{E}$ & 0 & 0 & 0 & 0 & 0 & 0 \\
\hline Wolf_Grove & $\bar{C}$ & $\bar{E}$ & 0 & 0 & 0 & 0 & 0 & 0 \\
\hline Wolf_Grove & $\mathrm{D}$ & $\mathrm{E}$ & 0 & 0 & 0 & 0 & 0 & 0 \\
\hline Wolf_Grove & $\bar{E}$ & $\mathrm{E}$ & 0 & 0 & 0 & 0 & 0 & 0 \\
\hline Wolf_Grove & F & $\mathrm{E}$ & 0 & 0 & 1 & 0 & 0 & 0 \\
\hline Wolf_Grove & $\overline{\mathrm{H}}$ & $\bar{E}$ & 0 & 0 & 0 & 0 & 0 & 0 \\
\hline Wolf_Grove & I & $\bar{E}$ & 0 & 0 & 0 & 0 & 0 & 0 \\
\hline Wrightville & A & $\mathrm{U}$ & 1 & 24 & 0 & 0 & 0 & 0 \\
\hline Wrightville & B & $\mathrm{U}$ & 0 & 0 & 0 & 0 & 0 & 0 \\
\hline Wrightville & $\mathrm{C}$ & $\mathrm{U}$ & 0 & 1 & 0 & 0 & 0 & 0 \\
\hline Wrightville & $\mathrm{D}$ & $\mathrm{U}$ & 0 & 12 & 0 & 0 & 0 & 0 \\
\hline Wrightville & $\bar{E}$ & $\mathrm{U}$ & 0 & 1 & 0 & 0 & 0 & 0 \\
\hline Wrightville & $\bar{F}$ & $\mathrm{U}$ & 0 & 0 & 0 & 0 & 0 & 0 \\
\hline Wrightville & $\mathrm{H}$ & $\overline{\mathrm{U}}$ & 0 & 3 & 0 & 0 & 0 & 0 \\
\hline Wrightville & I & $\bar{U}$ & 0 & 4 & 0 & 0 & 0 & 0 \\
\hline Wychwood & A & $\mathrm{S}$ & 0 & 1 & 0 & 0 & 0 & 0 \\
\hline Wychwood & B & $\mathrm{S}$ & 0 & 5 & 0 & 0 & 0 & 0 \\
\hline Wychwood & $\bar{C}$ & $\mathrm{~S}$ & 0 & 0 & 0 & 0 & 0 & 0 \\
\hline Wychwood & $\overline{\mathrm{D}}$ & $\mathrm{S}$ & 0 & 3 & 0 & 0 & 0 & 0 \\
\hline Wychwood & $\bar{E}$ & $\mathrm{~S}$ & 0 & 1 & 0 & 0 & 0 & 0 \\
\hline Wychwood & $\mathbf{F}$ & $S$ & 0 & 7 & 0 & 0 & 0 & 0 \\
\hline Wychwood & $\mathrm{H}$ & $\mathrm{S}$ & 0 & 4 & 0 & 0 & 0 & 0 \\
\hline Wychwood & I & $\mathrm{S}$ & 0 & 1 & 0 & 0 & 0 & 0 \\
\hline
\end{tabular}




\begin{tabular}{|c|c|c|c|c|c|c|c|c|}
\hline$\overline{\text { SITE }}$ & STATION & CATEGORY & LOSC & MYCY & NOAE & OLMI & OLPA & $\overline{\text { OXPU }}$ \\
\hline Achbar & $\bar{A}$ & $\mathrm{SN}$ & 0 & 0 & 0 & 0 & 0 & 0 \\
\hline Achbar & B & SN & 0 & 0 & 0 & 0 & 0 & 0 \\
\hline Achbar & $\mathrm{C}$ & $\overline{\mathrm{SN}}$ & 0 & 0 & 0 & 0 & 0 & 0 \\
\hline Achbar & $\bar{D}$ & $\overline{\mathrm{SN}}$ & 0 & 0 & 0 & 0 & 0 & 0 \\
\hline Achbar & $\bar{E}$ & $\mathrm{SN}$ & 0 & 0 & 0 & 0 & 0 & 0 \\
\hline Achbar & $\bar{F}$ & $\overline{\mathrm{SN}}$ & 0 & 0 & 0 & 0 & 0 & 0 \\
\hline Achbar & $\overline{\mathrm{H}}$ & $\mathrm{SN}$ & 0 & 0 & 0 & 0 & 0 & 0 \\
\hline Achbar & I & SN & 0 & 0 & $\overline{0}$ & 0 & 0 & 0 \\
\hline Bridlewood & $\overline{\mathrm{A}}$ & UN & 0 & 0 & 0 & 0 & 0 & 0 \\
\hline Bridlewood & B & $\overline{\text { UN }}$ & 0 & 0 & 8 & 0 & 0 & 0 \\
\hline Bridlewood & $\mathrm{C}$ & UN & 1 & 0 & 0 & 0 & 0 & 0 \\
\hline Bridlewood & $\bar{D}$ & UN & 1 & 0 & 0 & 0 & $\overline{0}$ & $\overline{0}$ \\
\hline Bridlewood & $\bar{E}$ & UN & 0 & 0 & 0 & 0 & 0 & 0 \\
\hline Bridlewood & $F$ & $\overline{\mathrm{UN}}$ & 0 & 0 & 1 & 0 & 0 & 0 \\
\hline Bridlewood & $\mathrm{H}$ & UN & 0 & 0 & 0 & 0 & 0 & 0 \\
\hline Bridlewood & I & UN & 0 & 0 & 2 & 0 & 0 & 0 \\
\hline Carp_Hills & $\bar{A}$ & $\mathrm{~F}$ & 1 & 0 & 8 & 0 & 0 & 1 \\
\hline Carp_Hills & B & $\mathrm{F}$ & 4 & 0 & 0 & 0 & 0 & 14 \\
\hline Carp_Hills & $\mathrm{C}$ & $F$ & 0 & 0 & 2 & 0 & 0 & 2 \\
\hline Carp_Hills & $\mathrm{D}$ & $F$ & 0 & 0 & 0 & 0 & 0 & 0 \\
\hline Carp_Hills & $E$ & $F$ & 2 & 0 & 0 & 0 & 0 & 4 \\
\hline Carp_Hills & $F$ & $F$ & 1 & 0 & 0 & 0 & 0 & 4 \\
\hline Carp_Hills & $\mathrm{H}$ & $F$ & 1 & 0 & 0 & 0 & 0 & 0 \\
\hline Carp_Hills & I & $\mathrm{F}$ & 1 & 0 & 0 & 0 & 0 & 0 \\
\hline Chapel_Hill & $\bar{A}$ & UN & 1 & 0 & 0 & 0 & 0 & 0 \\
\hline Chapel_Hill & B & UN & 0 & 0 & 0 & 0 & 0 & 1 \\
\hline Chapel_Hill & $\mathrm{C}$ & UN & 0 & 0 & 0 & 0 & 0 & 0 \\
\hline Chapel_Hill & $\bar{D}$ & UN & 0 & 0 & 0 & 0 & 0 & 0 \\
\hline Chapel_Hill & $E$ & UN & 0 & 0 & 0 & 0 & 0 & 6 \\
\hline Chapel_Hill & $F$ & UN & 0 & 0 & 0 & 0 & 0 & 0 \\
\hline Chapel_Hill & $\mathrm{H}$ & UN & 0 & 0 & 0 & 0 & 0 & 0 \\
\hline Chapel_Hill & I & UN & 7 & 0 & 0 & 1 & 0 & 0 \\
\hline Chelsea & $\bar{A}$ & SN & 0 & 0 & 0 & 0 & 0 & 0 \\
\hline Chelsea & B & SN & 0 & 0 & 0 & 0 & 0 & 0 \\
\hline Chelsea & $\mathrm{C}$ & SN & 0 & 0 & 0 & 0 & 0 & 0 \\
\hline Chelsea & $\mathrm{D}$ & SN & 0 & 0 & 0 & 0 & 0 & 0 \\
\hline Chelsea & $E$ & SN & 0 & 0 & 0 & 0 & 0 & 0 \\
\hline Chelsea & $F$ & SN & 0 & 0 & 0 & 0 & 0 & 0 \\
\hline Chelsea & $\mathrm{H}$ & SN & 0 & 0 & 0 & 0 & 0 & 0 \\
\hline Chelsea & I & SN & 0 & 0 & 0 & 0 & 0 & 0 \\
\hline
\end{tabular}




\begin{tabular}{|c|c|c|c|c|c|c|c|c|}
\hline Chemin_Scholle & $\mathrm{A}$ & EN & 0 & 0 & 0 & 0 & 0 & 0 \\
\hline Chemin_Scholle & B & EN & 0 & 0 & 0 & 0 & 0 & 0 \\
\hline Chemin_Scholle & $\mathrm{C}$ & EN & 0 & 0 & 0 & 0 & 0 & 0 \\
\hline Chemin_Scholle & $\mathrm{D}$ & EN & 0 & 0 & 0 & 0 & 0 & 0 \\
\hline Chemin_Scholle & $\mathbf{E}$ & EN & 0 & 0 & 0 & 0 & 0 & 0 \\
\hline Chemin_Scholle & $\bar{F}$ & EN & 0 & 0 & 1 & 0 & 0 & 0 \\
\hline Chemin_Scholle & $\mathrm{H}$ & EN & 0 & 0 & 1 & 0 & 1 & 0 \\
\hline Chemin_Scholle & I & EN & 0 & 0 & 1 & 0 & 0 & 0 \\
\hline Cote_d'Azur & $\bar{A}$ & $\bar{S}$ & 0 & 0 & 0 & 0 & 0 & 0 \\
\hline Cote_d'Azur & $\mathrm{B}$ & $\mathrm{S}$ & 0 & 0 & 0 & 0 & 0 & 0 \\
\hline Cote_d'Azur & $\mathrm{C}$ & $\mathrm{S}$ & 0 & 0 & 0 & 0 & 0 & 0 \\
\hline Cote_d'Azur & $\mathrm{D}$ & $\mathrm{S}$ & 0 & 0 & 0 & 0 & 0 & 0 \\
\hline Cote_d'Azur & $\mathrm{E}$ & $\bar{S}$ & 0 & 0 & 0 & 0 & 0 & 0 \\
\hline Cote_d'Azur & $\bar{F}$ & $\mathrm{~S}$ & 0 & 0 & 0 & 0 & 0 & 0 \\
\hline Cote_d'Azur & $\mathrm{H}$ & $\mathrm{S}$ & 0 & 0 & 0 & 0 & 0 & 0 \\
\hline Cote_d'Azur & I & $\mathrm{S}$ & 0 & 0 & 0 & 0 & 0 & 0 \\
\hline Highway_Seven & $\mathrm{A}$ & $\mathrm{E}$ & 0 & 0 & 3 & 0 & 0 & 0 \\
\hline Highway_Seven & $\mathrm{B}$ & $\bar{E}$ & 0 & 0 & 0 & 0 & 0 & 0 \\
\hline Highway_Seven & $\mathrm{C}$ & $\mathbf{E}$ & 0 & 0 & 0 & 0 & 1 & 0 \\
\hline Highway_Seven & $\mathrm{D}$ & $\mathbf{E}$ & 0 & 0 & 0 & 0 & 0 & 0 \\
\hline Highway_Seven & $\mathbf{E}$ & $\mathrm{E}$ & 1 & 0 & 0 & 0 & 0 & 0 \\
\hline Highway_Seven & $\mathbf{F}$ & $\mathrm{E}$ & 0 & 0 & 1 & 0 & 0 & 0 \\
\hline Highway_Seven & $\mathrm{H}$ & $\mathrm{E}$ & 0 & 0 & 0 & 0 & 0 & 0 \\
\hline Highway_Seven & I & $\mathbf{E}$ & 0 & 0 & 0 & 0 & 0 & 0 \\
\hline Hull & $\mathrm{A}$ & $\overline{\mathrm{U}}$ & 0 & 0 & 0 & 0 & 0 & 0 \\
\hline Hull & B & $\mathrm{U}$ & 0 & 0 & 0 & 0 & 0 & 0 \\
\hline Hull & $\mathrm{C}$ & $\mathrm{U}$ & 0 & 0 & 0 & 0 & 0 & 0 \\
\hline Hull & D & $\bar{U}$ & 0 & 0 & 0 & 0 & 0 & 0 \\
\hline Hull & $\mathbf{E}$ & $\overline{\mathrm{U}}$ & 0 & 0 & 0 & 0 & 0 & 0 \\
\hline Hull & $\mathbf{F}$ & $\overline{\mathrm{U}}$ & 0 & 0 & 0 & 0 & 0 & 0 \\
\hline Hull & $\mathrm{H}$ & $\mathrm{U}$ & 0 & 0 & 0 & 0 & 0 & 0 \\
\hline Hull & I & $\mathrm{U}$ & 0 & 0 & 0 & 0 & 0 & 0 \\
\hline Lac_a_la_Perdrix & A & $\mathrm{EN}$ & 0 & 0 & 1 & 0 & 0 & 0 \\
\hline Lac_a_la_Perdrix & $\bar{B}$ & EN & 0 & 0 & 0 & 0 & 0 & $\overline{0}$ \\
\hline Lac_a_la_Perdrix & $\mathrm{C}$ & EN & 0 & 0 & 0 & 0 & 0 & 0 \\
\hline Lac_a_la_Perdrix & $\mathrm{D}$ & EN & 0 & 0 & 0 & 0 & 0 & 0 \\
\hline Lac_a_la_Perdrix & $\mathbf{E}$ & EN & 0 & 2 & 0 & 0 & 0 & 0 \\
\hline Lac_a_la_Perdrix & $\mathrm{F}$ & $\mathrm{EN}$ & 0 & 0 & 0 & 0 & 0 & 0 \\
\hline Lac_a_la_Perdrix & $\mathrm{H}$ & EN & 0 & 1 & 14 & 0 & 0 & 0 \\
\hline Lac_a_la_Perdrix & I & EN & 0 & 0 & 4 & 0 & 0 & 0 \\
\hline Lac_Philippe & $\mathrm{A}$ & $\bar{F}$ & 0 & 0 & 0 & 0 & 0 & 0 \\
\hline
\end{tabular}




\begin{tabular}{|c|c|c|c|c|c|c|c|c|}
\hline Lac_Philippe & B & $\bar{F}$ & 0 & 1 & 0 & 0 & 0 & 0 \\
\hline Lac_Philippe & $\mathrm{C}$ & $F$ & 0 & 0 & 0 & 0 & 0 & 0 \\
\hline Lac_Philippe & $\bar{D}$ & $F$ & 0 & 1 & 1 & 0 & 0 & 0 \\
\hline Lac_Philippe & $\bar{E}$ & $F$ & 0 & 0 & 0 & 0 & 0 & 0 \\
\hline Lac_Philippe & $F$ & $F$ & 0 & 0 & 1 & 0 & 0 & 0 \\
\hline Lac_Philippe & $\mathbf{H}$ & $F$ & 0 & 0 & 0 & 0 & 0 & 0 \\
\hline Lac_Philippe & I & F & 0 & 0 & 0 & 0 & 0 & 0 \\
\hline Manoir_des_Trembles & A & $\mathrm{UN}$ & 0 & 0 & 0 & 0 & 0 & 0 \\
\hline Manoir_des_Trembles & B & $\overline{\mathrm{UN}}$ & 0 & 0 & 0 & 0 & 0 & 1 \\
\hline Manoir_des_Trembles & $\mathrm{C}$ & UN & 2 & 0 & 0 & 0 & 0 & 0 \\
\hline Manoir_des_Trembles & D & $\mathrm{UN}$ & 0 & 1 & 0 & 0 & 0 & 0 \\
\hline Manoir_des_Trembles & $\bar{E}$ & UN & 0 & 0 & 2 & 0 & 0 & $\overline{0}$ \\
\hline Manoir_des_Trembles & $F$ & UN & 0 & 0 & 1 & 0 & 0 & 1 \\
\hline Manoir_des_Trembles & $\mathrm{H}$ & UN & 0 & 1 & 1 & 0 & 0 & 0 \\
\hline Manoir_des_Trembles & I & $\mathrm{UN}$ & 0 & 0 & 0 & 0 & 1 & 1 \\
\hline Marathon & $\mathrm{A}$ & $\bar{E}$ & 0 & 0 & 0 & 0 & 0 & 0 \\
\hline Marathon & B & $\bar{E}$ & 0 & 0 & 0 & 0 & 0 & 0 \\
\hline Marathon & $\mathrm{C}$ & $\mathrm{E}$ & 1 & 0 & 0 & 0 & 0 & $\overline{0}$ \\
\hline Marathon & D & $\mathbf{E}$ & 0 & 0 & 0 & 0 & 0 & 0 \\
\hline Marathon & $\mathbf{E}$ & $\bar{E}$ & 0 & 0 & 0 & 0 & 0 & $\overline{0}$ \\
\hline Marathon & $\mathbf{F}$ & $\mathbf{E}$ & 0 & 0 & 0 & 0 & 0 & 0 \\
\hline Marathon & $\mathrm{H}$ & $\bar{E}$ & 0 & 0 & 0 & 0 & 0 & 0 \\
\hline Marathon & I & $\bar{E}$ & 0 & 0 & 0 & 0 & 0 & 0 \\
\hline Marier & $\bar{A}$ & $\bar{U}$ & 0 & 0 & 0 & 0 & 0 & 0 \\
\hline Marier & $\mathrm{B}$ & $\mathrm{U}$ & 0 & 0 & 0 & 0 & 0 & 0 \\
\hline Marier & $\mathrm{C}$ & $\bar{U}$ & 0 & 0 & 0 & 0 & 0 & 0 \\
\hline Marier & D & $\bar{U}$ & 0 & 0 & 0 & 0 & 0 & 0 \\
\hline Marier & $\mathrm{E}$ & $\overline{\mathrm{U}}$ & 0 & 0 & 0 & 0 & 0 & 0 \\
\hline Marier & $F$ & $\bar{U}$ & 0 & 0 & 0 & 0 & 0 & 0 \\
\hline Marier & $\mathrm{H}$ & $\bar{U}$ & 0 & 0 & 0 & 0 & 0 & 0 \\
\hline Marier & I & $\bar{U}$ & 0 & 0 & 0 & 0 & 0 & 0 \\
\hline Marlborough & $\mathrm{A}$ & $F$ & 0 & 0 & 4 & 0 & 0 & 1 \\
\hline Marlborough & B & $F$ & 0 & 0 & 1 & 0 & 0 & 0 \\
\hline Marlborough & $\mathrm{C}$ & $F$ & 0 & 0 & 1 & 0 & 0 & 0 \\
\hline Marlborough & D & $F$ & 2 & 0 & 2 & 0 & 0 & 0 \\
\hline Marlborough & $E$ & $F$ & 0 & 0 & 0 & 0 & 0 & 0 \\
\hline Marlborough & $F$ & $F$ & 0 & 0 & 1 & 0 & 0 & 10 \\
\hline Marlborough & $\mathrm{H}$ & $F$ & 1 & 0 & 2 & 0 & 0 & 0 \\
\hline Marlborough & I & $F$ & 0 & 0 & 1 & 0 & 0 & 0 \\
\hline Merivale & $\bar{A}$ & $\overline{\mathrm{SN}}$ & 0 & 0 & 0 & 0 & 0 & 0 \\
\hline Merivale & $\bar{B}$ & $\overline{\mathrm{SN}}$ & 0 & 0 & 2 & 0 & 0 & $\overline{0}$ \\
\hline
\end{tabular}




\begin{tabular}{|c|c|c|c|c|c|c|c|c|}
\hline Merivale & $\mathrm{C}$ & $\mathrm{SN}$ & 0 & 0 & 0 & 0 & 0 & 0 \\
\hline Merivale & $\bar{D}$ & SN & 0 & 0 & 0 & 0 & 0 & 0 \\
\hline Merivale & $\bar{E}$ & SN & 0 & 0 & 0 & 0 & 0 & 0 \\
\hline Merivale & $\overrightarrow{\mathrm{F}}$ & SN & 0 & 0 & 1 & 0 & 0 & 0 \\
\hline Merivale & $\mathrm{H}$ & SN & 1 & 0 & 0 & 0 & 0 & 2 \\
\hline Merivale & I & SN & 0 & 0 & 0 & 0 & 0 & 0 \\
\hline Parc_Champlain & $\bar{A}$ & $\bar{S}$ & 0 & 0 & 0 & 0 & 0 & 0 \\
\hline Parc_Champlain & B & $\mathrm{S}$ & 0 & 0 & 0 & 0 & 0 & 0 \\
\hline Parc_Champlain & $\mathrm{C}$ & $\bar{S}$ & 0 & 0 & 0 & 0 & 0 & 0 \\
\hline Parc_Champlain & $\bar{D}$ & $\mathrm{~S}$ & 0 & 0 & 0 & 0 & 0 & 0 \\
\hline Parc_Champlain & $E$ & $\mathrm{~S}$ & 0 & 0 & 0 & 0 & 0 & 0 \\
\hline Parc_Champlain & $\mathrm{F}$ & $\mathrm{S}$ & 0 & 0 & 0 & 0 & 0 & 0 \\
\hline Parc_Champlain & $\mathrm{H}$ & $\bar{S}$ & 0 & 0 & 0 & 0 & 0 & 0 \\
\hline Parc_Champlain & $\mathbf{I}$ & $\mathrm{S}$ & 0 & 0 & 0 & 0 & 0 & 0 \\
\hline Pelissier & $\bar{A}$ & $\overline{\mathrm{EN}}$ & 0 & 0 & 0 & 0 & 1 & 0 \\
\hline Pelissier & $\overline{\mathrm{B}}$ & $\overline{E N}$ & 0 & 0 & 0 & 0 & 0 & $\overline{0}$ \\
\hline Pelissier & $\bar{C}$ & $\overline{E N}$ & 0 & 0 & 0 & 0 & 0 & 0 \\
\hline Pelissier & $\bar{D}$ & $\overline{\mathrm{EN}}$ & 0 & 0 & 0 & 0 & 0 & 1 \\
\hline Pelissier & $\bar{E}$ & $\overline{\mathrm{EN}}$ & 0 & 1 & 0 & 0 & 0 & $\overline{0}$ \\
\hline Pelissier & $\mathrm{F}$ & $\overline{\mathrm{EN}}$ & 0 & 0 & 0 & 0 & 0 & 0 \\
\hline Pelissier & $\mathrm{H}$ & $\overline{E N}$ & 0 & 0 & 0 & 0 & 0 & 0 \\
\hline Pelissier & I & $\overline{E N}$ & 0 & 0 & 0 & 0 & 0 & 0 \\
\hline PineGlen_Annex & $\bar{A}$ & $\mathrm{~S}$ & 0 & 0 & 0 & 0 & 0 & 0 \\
\hline PineGlen_Annex & $\bar{B}$ & $\bar{S}$ & 0 & 0 & 0 & 0 & 0 & $\overline{0}$ \\
\hline PineGlen_Annex & $\mathrm{C}$ & $\mathrm{S}$ & 0 & 0 & 0 & 0 & 0 & 0 \\
\hline PineGlen_Annex & $\bar{D}$ & $\mathrm{~S}$ & 0 & 0 & 0 & 0 & 0 & $\overline{0}$ \\
\hline PineGlen_Annex & $\bar{E}$ & $\mathrm{~S}$ & 0 & 0 & 0 & 0 & $\overline{0}$ & 0 \\
\hline PineGlen_Annex & $\mathrm{F}$ & $\mathrm{S}$ & 0 & 0 & 0 & 0 & 0 & 0 \\
\hline PineGlen_Annex & $\mathrm{H}$ & $\mathrm{S}$ & 0 & 0 & 0 & 0 & 0 & 0 \\
\hline PineGlen_Annex & I & $\mathrm{S}$ & 0 & 0 & 0 & 0 & 0 & $\overline{0}$ \\
\hline Q_Four & $\mathrm{A}$ & $\mathrm{E}$ & 0 & 0 & 0 & 0 & 0 & 0 \\
\hline Q_Four & B & $\mathrm{E}$ & 0 & 0 & 0 & 0 & 0 & $\overline{0}$ \\
\hline Q_Four & $\mathrm{C}$ & $\mathrm{E}$ & 0 & 1 & 0 & 0 & 0 & 0 \\
\hline Q_Four & D & $E$ & 0 & 0 & 0 & 0 & 0 & 0 \\
\hline Q_Four & $E$ & $E$ & 0 & 0 & 0 & 0 & 1 & 0 \\
\hline$\overline{\text { Q_Four }}$ & $\mathrm{F}$ & $\bar{E}$ & 0 & 0 & 0 & 0 & 0 & 0 \\
\hline Q_Four & $\mathrm{H}$ & $E$ & 0 & 0 & 0 & 0 & 0 & 0 \\
\hline Q_Four & I & $\bar{E}$ & 0 & 0 & 0 & 0 & 0 & $\overline{0}$ \\
\hline Sandy_Hill & $\bar{A}$ & $\mathrm{U}$ & 0 & 0 & 0 & 0 & 0 & 0 \\
\hline Sandy_Hill & B & $\overline{\mathrm{U}}$ & 0 & 0 & 0 & 0 & 0 & 0 \\
\hline Sandy_Hill & $\mathrm{C}$ & $\mathrm{U}$ & 0 & 0 & 0 & 0 & 0 & 0 \\
\hline
\end{tabular}




\begin{tabular}{|c|c|c|c|c|c|c|c|c|}
\hline Sandy_Hill & $\mathrm{D}$ & $\overline{\mathrm{U}}$ & 0 & 0 & 0 & 0 & 0 & 0 \\
\hline Sandy_Hill & $E$ & $\mathrm{U}$ & 0 & 0 & 0 & 0 & 0 & 0 \\
\hline Sandy_Hill & $F$ & $\mathrm{U}$ & 0 & 0 & 0 & 0 & 0 & 0 \\
\hline Sandy_Hill & $\mathrm{H}$ & $\overline{\mathrm{U}}$ & 0 & 0 & 0 & 0 & 0 & 0 \\
\hline Sandy_Hill & $\bar{I}$ & $\mathrm{U}$ & 0 & 0 & 0 & 0 & 0 & 0 \\
\hline Vallee_Meech & $\bar{A}$ & $F$ & 0 & 0 & 0 & 0 & 0 & 0 \\
\hline Vallee_Meech & B & $\mathrm{F}$ & 0 & 0 & 0 & 0 & 0 & 0 \\
\hline Vallee_Meech & $\mathrm{C}$ & $F$ & 0 & 0 & 0 & 0 & 0 & 0 \\
\hline Vallee_Meech & $\bar{D}$ & $\mathrm{~F}$ & 0 & 0 & 0 & 0 & 0 & 0 \\
\hline Vallee_Meech & $\bar{E}$ & $F$ & 0 & 0 & 0 & 0 & 0 & 0 \\
\hline Vallee_Meech & $\bar{F}$ & $\mathrm{~F}$ & 0 & 1 & 0 & 0 & 0 & 0 \\
\hline Vallee_Meech & $\mathrm{H}$ & $\mathrm{F}$ & 0 & 0 & 0 & 0 & 0 & 1 \\
\hline Vallee_Meech & $\mathbf{I}$ & $F$ & 0 & 1 & 0 & 0 & 0 & 0 \\
\hline Wolf_Grove & $\mathrm{A}$ & $\mathrm{E}$ & 1 & 0 & 0 & 0 & 0 & 2 \\
\hline Wolf_Grove & B & $\mathrm{E}$ & 0 & 0 & 0 & 0 & 0 & 0 \\
\hline Wolf_Grove & $\mathrm{C}$ & $\mathrm{E}$ & 0 & 0 & 2 & 0 & 0 & $\overline{0}$ \\
\hline Wolf_Grove & $\mathrm{D}$ & $\bar{E}$ & 0 & 0 & 0 & 0 & 0 & 0 \\
\hline Wolf_Grove & $\mathbf{E}$ & $\mathrm{E}$ & 0 & 0 & 0 & 0 & 0 & 0 \\
\hline Wolf_Grove & $\mathbf{F}$ & $\bar{E}$ & 0 & 0 & 0 & 0 & 0 & 0 \\
\hline Wolf_Grove & $\mathrm{H}$ & $\mathrm{E}$ & 0 & 1 & 0 & 0 & 0 & 0 \\
\hline Wolf_Grove & I & $\mathrm{E}$ & 0 & 0 & 1 & 0 & 0 & 0 \\
\hline Wrightville & $\bar{A}$ & $\mathrm{U}$ & 0 & 0 & 0 & 0 & 0 & 0 \\
\hline Wrightville & $\mathrm{B}$ & $\mathrm{U}$ & 0 & 0 & 0 & 0 & 0 & 0 \\
\hline Wrightville & $\mathrm{C}$ & $\mathrm{U}$ & 0 & 0 & 0 & 0 & 0 & 0 \\
\hline Wrightville & $\mathrm{D}$ & $\mathrm{U}$ & 0 & 0 & 0 & 0 & 0 & 0 \\
\hline Wrightville & $\mathrm{E}$ & $\mathrm{U}$ & 0 & 0 & 0 & 0 & 0 & 0 \\
\hline Wrightville & $\mathrm{F}$ & $\mathrm{U}$ & 0 & 0 & 0 & 0 & 0 & 0 \\
\hline Wrightville & $\mathrm{H}$ & $\mathrm{U}$ & 0 & 0 & 0 & 0 & 0 & 0 \\
\hline Wrightville & I & $\mathrm{U}$ & 0 & 0 & 0 & 0 & 0 & 0 \\
\hline Wychwood & $\mathrm{A}$ & $\mathrm{S}$ & 0 & 0 & 0 & 0 & 0 & 0 \\
\hline Wychwood & $\mathrm{B}$ & $\mathrm{S}$ & 0 & 0 & 0 & 0 & 0 & 0 \\
\hline Wychwood & $\mathrm{C}$ & $\mathrm{S}$ & 1 & 0 & 0 & 0 & 0 & 0 \\
\hline Wychwood & $\mathrm{D}$ & $\mathrm{S}$ & 0 & 0 & 0 & 0 & 0 & 0 \\
\hline Wychwood & $\mathrm{E}$ & $\mathrm{S}$ & 0 & 0 & 0 & 0 & 0 & 0 \\
\hline Wychwood & $\mathrm{F}$ & $\mathrm{S}$ & 0 & 0 & 0 & 0 & 0 & 0 \\
\hline Wychwood & $\mathrm{H}$ & $\mathrm{S}$ & 0 & 0 & 0 & 0 & 0 & 0 \\
\hline Wychwood & I & $\mathrm{S}$ & 0 & 0 & 0 & 0 & 0 & 0 \\
\hline
\end{tabular}




\begin{tabular}{|c|c|c|c|c|c|c|c|c|}
\hline SITE & STATION & CATEGORY & PALO & PLDE & PLMA & POLU & PSAR & PTCA \\
\hline Achbar & $\mathrm{A}$ & SN & 0 & 0 & 0 & 0 & 0 & 0 \\
\hline Achbar & B & SN & 0 & 0 & 0 & 0 & 0 & 0 \\
\hline Achbar & $\mathrm{C}$ & SN & 0 & 0 & 0 & 0 & 0 & 0 \\
\hline Achbar & D & SN & 0 & 0 & 0 & 4 & 0 & 0 \\
\hline Achbar & $\mathbf{E}$ & $\overline{\mathrm{SN}}$ & 0 & 0 & 0 & 16 & 0 & 0 \\
\hline Achbar & $\mathbf{F}$ & $\mathrm{SN}$ & 0 & 0 & 0 & 0 & 0 & 0 \\
\hline Achbar & $\mathrm{H}$ & SN & 0 & 0 & 0 & 0 & 0 & 0 \\
\hline Achbar & I & SN & 0 & 0 & 0 & 0 & 0 & 0 \\
\hline Bridlewood & $\mathrm{A}$ & $\mathrm{UN}$ & 0 & 2 & 0 & 1 & 0 & 0 \\
\hline Bridlewood & B & UN & 0 & 6 & 0 & 3 & 0 & 0 \\
\hline Bridlewood & $\mathrm{C}$ & $\mathrm{UN}$ & 0 & 0 & 0 & 0 & 0 & $\overline{0}$ \\
\hline Bridlewood & $\mathrm{D}$ & $\mathrm{UN}$ & 0 & 1 & 0 & 0 & 0 & 0 \\
\hline Bridlewood & $\mathrm{E}$ & $\overline{\mathrm{UN}}$ & 0 & 2 & 0 & 47 & 0 & 0 \\
\hline Bridlewood & $\mathrm{F}$ & $\mathrm{UN}$ & 0 & 4 & 0 & 22 & 0 & 0 \\
\hline Bridlewood & $\mathrm{H}$ & $\mathrm{UN}$ & 0 & 0 & 0 & 1 & 0 & 0 \\
\hline Bridlewood & I & $\mathrm{UN}$ & 0 & 0 & 0 & 8 & 0 & 0 \\
\hline Carp_Hills & $\mathrm{A}$ & $\mathrm{F}$ & 0 & 0 & 0 & 1 & 0 & 0 \\
\hline Carp_Hills & B & $\mathrm{F}$ & 0 & 11 & 0 & 7 & 0 & 0 \\
\hline Carp_Hills & $\mathrm{C}$ & $\mathrm{F}$ & 0 & 0 & 0 & 3 & 0 & 0 \\
\hline Carp_Hills & $\mathrm{D}$ & $\mathrm{F}$ & 0 & 0 & 0 & 0 & 0 & 0 \\
\hline Carp_Hills & $\mathbf{E}$ & $\mathrm{F}$ & 0 & 4 & 0 & 14 & 0 & 0 \\
\hline Carp_Hills & $\bar{F}$ & $\bar{F}$ & 0 & 14 & 0 & 32 & 0 & 0 \\
\hline Carp_Hills & $\mathrm{H}$ & $\mathbf{F}$ & 0 & 0 & 0 & 4 & 0 & 0 \\
\hline Carp_Hills & I & $\mathbf{F}$ & 0 & 1 & 0 & 1 & 0 & 0 \\
\hline Chapel_Hill & $\mathrm{A}$ & $\overline{\mathrm{UN}}$ & 0 & 7 & 0 & 61 & 0 & 0 \\
\hline Chapel_Hill & B & $\mathrm{UN}$ & 0 & 1 & 0 & 7 & 0 & 0 \\
\hline Chapel_Hill & $\mathrm{C}$ & $\mathrm{UN}$ & 0 & 0 & 0 & 1 & 0 & 0 \\
\hline Chapel_Hill & $\mathrm{D}$ & $\mathrm{UN}$ & 0 & 0 & 0 & 28 & 0 & 0 \\
\hline Chapel_Hill & $\mathbf{E}$ & $\overline{\mathrm{UN}}$ & 0 & 33 & 0 & 20 & 0 & 0 \\
\hline Chapel_Hill & $\mathbf{F}$ & $\mathrm{UN}$ & 2 & 2 & 0 & 11 & 0 & 0 \\
\hline Chapel_Hill & $\mathrm{H}$ & $\mathrm{UN}$ & 0 & 0 & 0 & 1 & 0 & 0 \\
\hline Chapel_Hill & I & $\mathrm{UN}$ & 0 & 6 & 0 & 1 & 0 & 2 \\
\hline Chelsea & $\mathrm{A}$ & SN & 0 & 0 & 0 & 0 & 0 & 0 \\
\hline Chelsea & B & SN & 0 & 0 & 0 & 1 & 0 & 0 \\
\hline Chelsea & $\mathrm{C}$ & SN & 0 & 0 & 0 & 0 & 0 & 0 \\
\hline Chelsea & $\mathrm{D}$ & SN & 0 & 6 & 0 & 0 & 0 & 0 \\
\hline Chelsea & $\mathbf{E}$ & SN & 0 & 0 & 0 & 3 & 0 & 0 \\
\hline Chelsea & $F$ & $\overline{\mathrm{SN}}$ & 0 & 1 & 0 & $\overline{0}$ & 0 & 0 \\
\hline
\end{tabular}




\begin{tabular}{|c|c|c|c|c|c|c|c|c|}
\hline Chelsea & $\mathrm{H}$ & $\mathrm{SN}$ & 0 & 0 & 0 & 2 & 0 & 0 \\
\hline Chelsea & 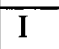 & $\mathrm{SN}$ & $\overline{0}$ & 0 & 0 & 0 & 0 & 0 \\
\hline Chemin Scholle & $\overline{\mathrm{A}}$ & EN & 0 & 0 & 0 & 1 & 0 & 0 \\
\hline Chemin Scholle & B & $\overline{\mathrm{EN}}$ & 0 & 2 & 0 & 0 & 0 & 0 \\
\hline Chemin Scholle & $\bar{C}$ & EN & 0 & 0 & 0 & 0 & 0 & 0 \\
\hline Chemin Scholle & $\mathrm{D}$ & EN & 0 & 0 & 0 & 0 & 0 & 0 \\
\hline Chemin_Scholle & $\bar{E}$ & EN & 0 & 2 & 0 & 1 & 0 & $\overline{0}$ \\
\hline Chemin_Scholle & $\bar{F}$ & EN & 0 & 6 & 0 & 1 & 0 & 0 \\
\hline Chemin_Scholle & $\mathrm{H}$ & EN & 0 & 0 & 0 & 0 & 0 & 0 \\
\hline Chemin_Scholle & $I$ & EN & $\overline{0}$ & 1 & 0 & 0 & 0 & 0 \\
\hline Cote_d'Azur & $\bar{A}$ & $\mathrm{~S}$ & 0 & 0 & 0 & 0 & 0 & $\overline{0}$ \\
\hline Cote_d'Azur & $\mathrm{B}$ & $\mathrm{S}$ & 0 & 0 & 0 & 0 & 0 & 0 \\
\hline Cote_d'Azur & $\mathrm{C}$ & $\mathrm{S}$ & 0 & 0 & 0 & 0 & 0 & 0 \\
\hline Cote_d'Azur & $\mathrm{D}$ & $\mathrm{S}$ & 0 & 0 & 0 & 0 & 0 & 0 \\
\hline Cote_d'Azur & $\mathrm{E}$ & $\mathrm{S}$ & $\mathbf{0}$ & 0 & 0 & 0 & $\mathbf{0}$ & 0 \\
\hline Cote_d'Azur & $\mathrm{F}$ & $\mathrm{S}$ & 0 & 0 & 0 & 0 & 0 & 0 \\
\hline Cote_d'Azur & $\overline{\mathrm{H}}$ & $\mathrm{S}$ & 0 & 0 & 0 & 1 & 0 & 0 \\
\hline Cote_d'Azur & 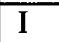 & $\mathrm{S}$ & 0 & 0 & 0 & 0 & 0 & 0 \\
\hline Highway_Seven & $\mathrm{A}$ & $\mathrm{E}$ & 0 & 7 & 0 & 8 & 0 & 0 \\
\hline Highway_Seven & $\mathrm{B}$ & $\bar{E}$ & 0 & 0 & 0 & 2 & 0 & 0 \\
\hline Highway_Seven & $\bar{C}$ & $\mathrm{E}$ & 0 & 1 & 0 & 4 & 0 & 0 \\
\hline Highway_Seven & $\mathrm{D}$ & $\mathrm{E}$ & 0 & 0 & 0 & 15 & 0 & 0 \\
\hline Highway_Seven & $\bar{E}$ & $\mathrm{E}$ & 0 & 0 & 0 & 2 & 0 & 0 \\
\hline Highway_Seven & $\mathrm{F}$ & $\bar{E}$ & $\overline{0}$ & 3 & 0 & 0 & 0 & 0 \\
\hline Highway_Seven & $\mathrm{H}$ & $\mathrm{E}$ & 0 & 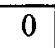 & 0 & 3 & 0 & 0 \\
\hline Highway_Seven & I & $\mathrm{E}$ & 0 & 1 & 0 & 0 & 0 & 0 \\
\hline Hull & $\overline{\mathrm{A}}$ & $\bar{U}$ & 0 & 0 & 0 & $\overline{0}$ & 0 & 0 \\
\hline Hull & $\bar{B}$ & $\overline{\mathrm{U}}$ & 0 & 0 & $\overline{0}$ & 0 & 0 & 0 \\
\hline Hull & $\mathrm{C}$ & $\bar{U}$ & 0 & 0 & 0 & 0 & 0 & 0 \\
\hline Hull & $\mathrm{D}$ & $\bar{U}$ & 0 & 0 & 0 & 0 & 0 & 0 \\
\hline Hull & $\bar{E}$ & $\mathrm{U}$ & 0 & 0 & 0 & 0 & 0 & 0 \\
\hline Hull & $\mathrm{F}$ & $\overline{\mathrm{U}}$ & 0 & 0 & 0 & 0 & 0 & 0 \\
\hline Hull & $\mathrm{H}$ & $\mathrm{U}$ & 0 & 0 & 0 & 0 & 0 & 0 \\
\hline Hull & I & $\mathrm{U}$ & 0 & 0 & 0 & 0 & 0 & 0 \\
\hline Lac_a_la_Perdrix & $\mathrm{A}$ & $\overline{\mathrm{EN}}$ & 0 & 0 & 0 & 0 & 0 & 0 \\
\hline Lac_a_la_Perdrix & B & EN & 0 & 0 & 0 & $\mathbf{0}$ & 0 & 0 \\
\hline Lac_a_la_Perdrix & $\mathrm{C}$ & EN & 0 & 0 & 0 & 0 & 0 & 0 \\
\hline Lac_a_la_Perdrix & $\mathrm{D}$ & EN & 0 & 0 & 0 & 0 & 0 & 0 \\
\hline Lac_a_la_Perdrix & $\bar{E}$ & EN & 0 & 0 & 0 & 0 & 0 & $\overline{0}$ \\
\hline
\end{tabular}




\begin{tabular}{|c|c|c|c|c|c|c|c|c|}
\hline Lac_a_la_Perdrix & $\mathrm{F}$ & EN & 0 & 0 & 0 & 0 & 0 & 0 \\
\hline Lac_a_la_Perdrix & $\mathrm{H}$ & EN & 0 & 0 & 0 & 0 & 0 & 0 \\
\hline Lac_a_la_Perdrix & $\bar{I}$ & EN & 0 & 0 & 0 & 0 & 0 & 0 \\
\hline Lac_Philippe & A & $\mathbf{F}$ & 0 & 0 & 0 & 0 & 0 & 0 \\
\hline Lac_Philippe & $\mathrm{B}$ & $\bar{F}$ & 0 & 0 & 0 & 0 & 0 & 0 \\
\hline Lac_Philippe & $\mathrm{C}$ & $F$ & 0 & 0 & 0 & 0 & 0 & 0 \\
\hline Lac_Philippe & $\mathrm{D}$ & $\mathbf{F}$ & 0 & 0 & 0 & 0 & 0 & 0 \\
\hline Lac_Philippe & $\mathrm{E}$ & $F$ & 0 & 0 & 0 & 0 & 0 & 0 \\
\hline Lac_Philippe & $\bar{F}$ & $\mathrm{~F}$ & 0 & 0 & 0 & 0 & 0 & 0 \\
\hline Lac_Philippe & $\mathrm{H}$ & $\mathrm{F}$ & 0 & 6 & 0 & 0 & 0 & 0 \\
\hline Lac_Philippe & $\bar{I}$ & $\mathrm{~F}$ & 0 & 0 & 0 & 0 & 0 & 0 \\
\hline Manoir_des_Trembles & $\mathrm{A}$ & UN & 0 & 1 & 0 & 0 & 0 & $\overline{0}$ \\
\hline Manoir_des_Trembles & $\mathrm{B}$ & UN & 0 & 3 & 0 & 0 & 0 & 0 \\
\hline Manoir_des_Trembles & $\mathrm{C}$ & UN & 0 & 14 & 0 & 0 & 0 & 0 \\
\hline Manoir_des_Trembles & $\mathrm{D}$ & UN & 0 & 6 & 0 & 0 & 0 & 0 \\
\hline Manoir_des_Trembles & $E$ & UN & 0 & 1 & 0 & 0 & 0 & 0 \\
\hline Manoir_des_Trembles & $\mathrm{F}$ & UN & 0 & 1 & 0 & 1 & 0 & 0 \\
\hline Manoir_des_Trembles & $\mathrm{H}$ & UN & 0 & 1 & 0 & 0 & 0 & 0 \\
\hline Manoir_des_Trembles & I & $\mathbf{U N}$ & 0 & 2 & 0 & 1 & 0 & 0 \\
\hline Marathon & $A$ & $\mathbf{E}$ & 0 & 0 & 0 & 0 & 0 & 0 \\
\hline Marathon & $\mathrm{B}$ & $E$ & 0 & 11 & 0 & 0 & 0 & 0 \\
\hline Marathon & $\mathrm{C}$ & $E$ & 0 & 31 & 0 & 1 & 0 & $\overline{0}$ \\
\hline Marathon & $\mathrm{D}$ & $\mathbf{E}$ & 0 & 0 & 0 & 0 & 0 & 0 \\
\hline Marathon & $E$ & $E$ & 0 & 7 & 0 & 1 & 0 & 0 \\
\hline Marathon & $F$ & $\mathbf{E}$ & 0 & 0 & 0 & 0 & 0 & $\overline{0}$ \\
\hline Marathon & $\mathrm{H}$ & $\mathbf{E}$ & 0 & $\overline{8}$ & 0 & 4 & 0 & 0 \\
\hline Marathon & $\bar{I}$ & $E$ & 0 & 0 & 0 & 1 & 0 & 0 \\
\hline Marier & $\mathrm{A}$ & $\mathbf{U}$ & 0 & 0 & 0 & 0 & 0 & $\overline{0}$ \\
\hline Marier & B & $\mathbf{U}$ & 0 & 0 & 0 & 0 & 0 & $\overline{0}$ \\
\hline Marier & $\mathrm{C}$ & $\mathbf{U}$ & 0 & 0 & 0 & 0 & 0 & 0 \\
\hline Marier & $\mathrm{D}$ & $\mathbf{U}$ & 0 & 0 & 0 & 0 & 0 & 0 \\
\hline Marier & $\mathrm{E}$ & $\mathbf{U}$ & 0 & 0 & 0 & 0 & 0 & 0 \\
\hline Marier & $\mathrm{F}$ & $\mathbf{U}$ & 0 & 0 & 0 & 0 & 0 & 0 \\
\hline Marier & $\mathrm{H}$ & $\mathbf{U}$ & 0 & 0 & 0 & 0 & 0 & 0 \\
\hline Marier & $\bar{I}$ & $\mathbf{U}$ & 0 & 0 & 0 & 0 & 0 & 0 \\
\hline Marlborough & $\mathrm{A}$ & $F$ & 0 & 5 & 0 & 0 & 0 & 0 \\
\hline Marlborough & B & $\mathbf{F}$ & 0 & 1 & 0 & $\overline{0}$ & 0 & $\overline{0}$ \\
\hline Marlborough & $\mathrm{C}$ & $\mathbf{F}$ & 0 & 2 & 0 & 0 & 0 & 0 \\
\hline Marlborough & D & $\mathbf{F}$ & 0 & 16 & 0 & 2 & 0 & 0 \\
\hline
\end{tabular}




\begin{tabular}{|c|c|c|c|c|c|c|c|c|}
\hline Marlborough & $\mathrm{E}$ & $F$ & 0 & 2 & 0 & 0 & 0 & 0 \\
\hline Marlborough & $F$ & $\mathrm{~F}$ & 0 & 12 & 0 & 1 & 1 & 0 \\
\hline Marlborough & $\mathbf{H}$ & $\mathrm{F}$ & 0 & 3 & 0 & 0 & 0 & 0 \\
\hline Marlborough & I & $\mathrm{F}$ & 0 & 3 & 0 & 0 & 0 & 0 \\
\hline Merivale & $\mathrm{A}$ & SN & 0 & 0 & 0 & 2 & 0 & 0 \\
\hline Merivale & B & $\mathrm{SN}$ & 0 & 0 & 0 & 0 & 0 & 0 \\
\hline Merivale & $\mathrm{C}$ & SN & 0 & 5 & 0 & 1 & 0 & 0 \\
\hline Merivale & $\mathbf{D}$ & SN & 0 & 0 & 0 & 1 & 0 & 0 \\
\hline Merivale & $E$ & $\mathrm{SN}$ & 0 & 1 & 0 & 2 & 0 & 0 \\
\hline Merivale & $\bar{F}$ & SN & 0 & 0 & 0 & 0 & 0 & 0 \\
\hline Merivale & $\mathrm{H}$ & $\mathrm{SN}$ & 0 & 0 & 0 & 0 & 0 & 0 \\
\hline Merivale & I & SN & 0 & 0 & 0 & 0 & 0 & 0 \\
\hline Parc_Champlain & A & $\mathrm{S}$ & 0 & 0 & 0 & 0 & 0 & 0 \\
\hline Parc_Champlain & B & $\mathrm{S}$ & 0 & 0 & 0 & 1 & 0 & 0 \\
\hline Parc_Champlain & $\mathrm{C}$ & $\mathrm{S}$ & 0 & 0 & 0 & 5 & 0 & 0 \\
\hline Parc_Champlain & D & $\mathrm{S}$ & 0 & 0 & 0 & 0 & 0 & 0 \\
\hline Parc_Champlain & $E$ & $\mathrm{~S}$ & 0 & 0 & 0 & 4 & 0 & 0 \\
\hline Parc_Champlain & $F$ & $\mathrm{~S}$ & 0 & 0 & 0 & 0 & 0 & 0 \\
\hline Parc_Champlain & $\mathbf{H}$ & $\mathrm{S}$ & 0 & 0 & 0 & 2 & 0 & 0 \\
\hline Parc_Champlain & I & $\mathrm{S}$ & 0 & 0 & 0 & 0 & 0 & 0 \\
\hline Pelissier & A & $\mathrm{EN}$ & 0 & 1 & 0 & 0 & 0 & 0 \\
\hline Pelissier & $\mathrm{B}$ & $\mathrm{EN}$ & 0 & 0 & 0 & 0 & 0 & 0 \\
\hline Pelissier & $\mathrm{C}$ & $\mathrm{EN}$ & 0 & 4 & 0 & 0 & 0 & 0 \\
\hline Pelissier & $\mathrm{D}$ & $\mathrm{EN}$ & 0 & 3 & 3 & 0 & 0 & 0 \\
\hline Pelissier & $\mathrm{E}$ & EN & 0 & 0 & 0 & 0 & 0 & 0 \\
\hline Pelissier & $\mathbf{F}$ & EN & 0 & 0 & 0 & 0 & 0 & $\overline{0}$ \\
\hline Pelissier & $\mathbf{H}$ & $\mathrm{EN}$ & 0 & 0 & 0 & 0 & 0 & 0 \\
\hline Pelissier & I & EN & 0 & 0 & 0 & 0 & 0 & 0 \\
\hline PineGlen_Annex & $\mathrm{A}$ & $\mathrm{S}$ & 0 & 0 & 0 & 0 & 0 & 0 \\
\hline PineGlen_Annex & B & $\mathrm{S}$ & 0 & 0 & 0 & 0 & 0 & 0 \\
\hline PineGlen_Annex & $\mathrm{C}$ & $\mathrm{S}$ & 0 & 0 & 0 & 0 & 0 & 0 \\
\hline PineGlen_Annex & $\mathrm{D}$ & $\mathrm{S}$ & 0 & 0 & 0 & 0 & 0 & 0 \\
\hline PineGlen_Annex & $E$ & $\mathrm{~S}$ & 0 & 0 & 0 & 0 & 0 & 0 \\
\hline PineGlen_Annex & $\mathbf{F}$ & $\mathrm{S}$ & 0 & 0 & 0 & 0 & 0 & 0 \\
\hline PineGlen_Annex & $\mathbf{H}$ & $\mathrm{S}$ & 0 & 1 & 0 & 0 & 0 & 0 \\
\hline PineGlen_Annex & $\mathrm{I}$ & $\mathrm{S}$ & 0 & 0 & 0 & 0 & 0 & 0 \\
\hline Q_Four & $\mathrm{A}$ & $E$ & 0 & 0 & 0 & 0 & 0 & 0 \\
\hline Q_Four & $\bar{B}$ & $\mathrm{E}$ & 0 & 0 & 0 & 0 & 0 & 0 \\
\hline Q_Four & $\mathrm{C}$ & $\mathrm{E}$ & 0 & 6 & 0 & 0 & 0 & 0 \\
\hline
\end{tabular}




\begin{tabular}{|c|c|c|c|c|c|c|c|c|}
\hline Q_Four & $\bar{D}$ & $\bar{E}$ & 0 & 0 & 0 & 1 & 0 & 0 \\
\hline Q_Four & $\mathrm{E}$ & $\bar{E}$ & 0 & 0 & 0 & 10 & 0 & 0 \\
\hline Q_Four & $F$ & $E$ & 0 & 2 & 0 & 0 & 0 & 0 \\
\hline Q_Four & $\mathrm{H}$ & $\mathrm{E}$ & 0 & 3 & 0 & 0 & 0 & 0 \\
\hline Q_Four & I & $\bar{E}$ & 0 & 3 & 0 & 0 & 0 & 0 \\
\hline Sandy_Hill & $\overline{\mathrm{A}}$ & $\overline{\mathrm{U}}$ & 0 & 0 & 0 & 0 & 0 & 0 \\
\hline Sandy_Hill & $\overline{\mathrm{B}}$ & $\overline{\mathrm{U}}$ & 0 & 0 & 0 & 0 & 0 & 0 \\
\hline Sandy_Hill & $\bar{C}$ & $\bar{U}$ & 0 & 0 & 0 & 0 & 0 & 0 \\
\hline Sandy_Hill & $\mathrm{D}$ & $\bar{U}$ & 0 & 0 & 0 & 0 & 0 & 0 \\
\hline Sandy_Hill & $\bar{E}$ & $\overline{\mathrm{U}}$ & 0 & 0 & 0 & 0 & 0 & 0 \\
\hline Sandy_Hill & $F$ & $\mathrm{U}$ & 0 & 0 & 0 & 0 & 0 & 0 \\
\hline Sandy_Hill & $\mathrm{H}$ & $\overline{\mathrm{U}}$ & 0 & 0 & 0 & 0 & 0 & 0 \\
\hline Sandy_Hill & I & $\mathrm{U}$ & 0 & 0 & 0 & 0 & 0 & 0 \\
\hline Vallee_Meech & $\overline{\mathrm{A}}$ & $\bar{F}$ & 0 & 0 & 0 & 0 & 0 & 0 \\
\hline Vallee_Meech & B & $\bar{F}$ & 0 & 0 & 0 & 0 & 0 & 0 \\
\hline Vallee_Meech & $\mathrm{C}$ & $F$ & 0 & 0 & 0 & 0 & 0 & 0 \\
\hline Vallee_Meech & D & $\bar{F}$ & 0 & 0 & 0 & 0 & 0 & 0 \\
\hline Vallee_Meech & $\bar{E}$ & $F$ & 0 & 0 & 0 & 0 & 0 & 0 \\
\hline Vallee_Meech & $F$ & F & 0 & 0 & 0 & 0 & 0 & 0 \\
\hline Vallee_Meech & $\mathrm{H}$ & $\bar{F}$ & 0 & 0 & 0 & 0 & 0 & 0 \\
\hline Vallee_Meech & I & $\bar{F}$ & 0 & 0 & $\overline{0}$ & 0 & $\overline{0}$ & 0 \\
\hline Wolf_Grove & $\bar{A}$ & $\mathrm{E}$ & 0 & 7 & 0 & 0 & 0 & 0 \\
\hline Wolf_Grove & B & $\mathrm{E}$ & 0 & 0 & 0 & 0 & 0 & 0 \\
\hline Wolf_Grove & $\bar{C}$ & $\bar{E}$ & 0 & 0 & 0 & 0 & 0 & 0 \\
\hline Wolf_Grove & $\bar{D}$ & $\bar{E}$ & 0 & 0 & 0 & 2 & 0 & $\overline{0}$ \\
\hline Wolf_Grove & $E$ & $E$ & 0 & 0 & 0 & 0 & 0 & 0 \\
\hline Wolf_Grove & $F$ & $\mathrm{E}$ & 0 & 8 & 0 & 3 & 0 & 0 \\
\hline Wolf_Grove & $\mathrm{H}$ & $E$ & 0 & 0 & 0 & 0 & 0 & 0 \\
\hline Wolf_Grove & I & $\bar{E}$ & 0 & 0 & 0 & 0 & 0 & 0 \\
\hline Wrightville & $\bar{A}$ & $\mathrm{U}$ & 0 & 0 & 0 & 0 & 0 & 0 \\
\hline Wrightville & B & $\mathbf{U}$ & 0 & 0 & 0 & 0 & 0 & 0 \\
\hline Wrightville & $\bar{C}$ & $\overline{\mathrm{U}}$ & 0 & 0 & 0 & $\overline{0}$ & 0 & 0 \\
\hline Wrightville & $\bar{D}$ & $\bar{U}$ & 0 & 0 & 0 & 0 & 0 & 0 \\
\hline Wrightville & $\bar{E}$ & $\bar{U}$ & 0 & 0 & 0 & 0 & 0 & 0 \\
\hline Wrightville & $\bar{F}$ & $\mathrm{U}$ & 0 & 0 & 0 & 0 & 0 & 0 \\
\hline Wrightville & $\mathrm{H}$ & $\bar{U}$ & 0 & 0 & 0 & 1 & 0 & $\overline{0}$ \\
\hline Wrightville & I & $\bar{U}$ & 0 & 0 & 0 & 0 & 0 & 0 \\
\hline Wychwood & $\mathrm{A}$ & $\mathrm{S}$ & 0 & 0 & 0 & 0 & 0 & 0 \\
\hline Wychwood & $\bar{B}$ & $\mathrm{~S}$ & 0 & 0 & 0 & 3 & 0 & 0 \\
\hline
\end{tabular}




\begin{tabular}{|l|l|l|r|r|r|r|r|r|}
\hline Wychwood & C & S & 0 & 0 & 0 & 2 & 0 & 0 \\
\hline Wychwood & D & S & 0 & 0 & 0 & 0 & 0 & 0 \\
\hline Wychwood & E & S & 0 & 0 & 0 & 0 & 0 & 0 \\
\hline Wychwood & F & S & 0 & 0 & 0 & 0 & 0 & 0 \\
\hline Wychwood & H & S & 0 & 0 & 0 & 0 & 0 & 0 \\
\hline Wychwood & I & S & 0 & 0 & 0 & 2 & 0 & 0 \\
\hline
\end{tabular}




\begin{tabular}{|c|c|c|c|c|c|c|c|c|}
\hline SITE & STATION & CATEGORY & PTCO & PTCOR & PTLA & PTLU & PTME & PTMU \\
\hline Achbar & A & SN & 2 & 0 & 0 & 0 & 0 & 18 \\
\hline Achbar & $\mathrm{B}$ & $\mathrm{SN}$ & 10 & 0 & 0 & 0 & 1 & 0 \\
\hline Achbar & $\mathrm{C}$ & $\mathrm{SN}$ & 0 & 0 & 0 & 0 & 1 & 5 \\
\hline Achbar & $\mathrm{D}$ & SN & 0 & 0 & 0 & 0 & 4 & 5 \\
\hline Achbar & $E$ & $\mathrm{SN}$ & 11 & 0 & 0 & 2 & 0 & 0 \\
\hline Achbar & $\mathrm{F}$ & $\mathrm{SN}$ & 2 & 0 & 0 & 0 & 1 & 15 \\
\hline Achbar & $\mathrm{H}$ & $\mathrm{SN}$ & 1 & 0 & 0 & 0 & 0 & 4 \\
\hline Achbar & I & $\mathrm{SN}$ & 1 & 0 & 0 & 0 & 0 & 0 \\
\hline Bridlewood & A & $\mathbf{U N}$ & 0 & 0 & 0 & 0 & 0 & 2 \\
\hline Bridlewood & B & $\mathbf{U N}$ & 0 & 0 & 0 & 0 & 5 & 23 \\
\hline Bridlewood & $\mathrm{C}$ & $\mathbf{U N}$ & 0 & 0 & 0 & 0 & 0 & 50 \\
\hline Bridlewood & $\mathrm{D}$ & $\mathrm{UN}$ & 0 & 0 & 0 & 0 & 15 & 10 \\
\hline Bridlewood & $E$ & $\mathbf{U N}$ & 0 & 0 & 0 & 0 & 9 & 26 \\
\hline Bridlewood & $F$ & $\mathrm{UN}$ & 0 & 0 & 0 & 0 & 3 & 2 \\
\hline Bridlewood & $\mathrm{H}$ & $\mathrm{UN}$ & 0 & 0 & 0 & 0 & 1 & 8 \\
\hline Bridlewood & I & $\mathbf{U N}$ & 0 & 0 & 0 & 1 & 4 & 46 \\
\hline Carp_Hills & A & $\mathbf{F}$ & 0 & 0 & 0 & 0 & 0 & 14 \\
\hline Carp_Hills & $\mathrm{B}$ & $\mathbf{F}$ & 5 & 0 & 0 & 4 & 0 & 0 \\
\hline Carp_Hills & $\mathrm{C}$ & $\mathbf{F}$ & 0 & 0 & 0 & 0 & 1 & 3 \\
\hline Carp_Hills & $\mathrm{D}$ & $\mathbf{F}$ & 0 & 0 & 0 & 0 & 0 & 0 \\
\hline Carp_Hills & $\mathrm{E}$ & $\mathbf{F}$ & 0 & 0 & 0 & 2 & 0 & 0 \\
\hline Carp_Hills & $\mathrm{F}$ & $\mathbf{F}$ & 0 & 0 & 0 & 9 & 1 & 0 \\
\hline Carp_Hills & $\overline{\mathrm{H}}$ & $\bar{F}$ & 0 & 0 & 0 & 0 & 0 & 27 \\
\hline Carp_Hills & $\mathrm{I}$ & $\mathbf{F}$ & 0 & 0 & 0 & 2 & 0 & 0 \\
\hline Chapel_Hill & $\mathrm{A}$ & $\mathbf{U N}$ & 0 & 0 & 0 & 8 & 13 & 0 \\
\hline Chapel_Hill & $\mathrm{B}$ & $\mathbf{U N}$ & 0 & 0 & 0 & 0 & 7 & 5 \\
\hline Chapel_Hill & $\mathrm{C}$ & $\mathrm{UN}$ & 0 & 0 & 0 & 0 & 0 & 7 \\
\hline Chapel_Hill & $\mathrm{D}$ & $\mathrm{UN}$ & 0 & 0 & 0 & 0 & 0 & 48 \\
\hline Chapel_Hill & $E$ & $\mathrm{UN}$ & 0 & 0 & 0 & 24 & 22 & 0 \\
\hline Chapel_Hill & $F$ & $\mathrm{UN}$ & 1 & 0 & 0 & 4 & 10 & 1 \\
\hline Chapel_Hill & $\mathrm{H}$ & $\mathrm{UN}$ & 0 & 0 & 0 & 2 & 0 & 12 \\
\hline Chapel_Hill & I & $\mathbf{U N}$ & 0 & 2 & $\overline{0}$ & 28 & 0 & 0 \\
\hline Chelsea & A & SN & 6 & 0 & 0 & 0 & 0 & 0 \\
\hline Chelsea & $\mathrm{B}$ & SN & 0 & 0 & 0 & 0 & 0 & 0 \\
\hline Chelsea & $\mathrm{C}$ & $\mathrm{SN}$ & 1 & 0 & 0 & 0 & 0 & 0 \\
\hline Chelsea & $\mathrm{D}$ & $\mathrm{SN}$ & 8 & 0 & 0 & 0 & 1 & 0 \\
\hline Chelsea & $\mathrm{E}$ & $\mathrm{SN}$ & 1 & 0 & 0 & 0 & 0 & 0 \\
\hline
\end{tabular}




\begin{tabular}{|c|c|c|c|c|c|c|c|c|}
\hline Chelsea & $\mathrm{F}$ & $\mathrm{SN}$ & 1 & 0 & 0 & 0 & 0 & 0 \\
\hline Chelsea & $\mathrm{H}$ & $\mathrm{SN}$ & 3 & 0 & 0 & 0 & 0 & 0 \\
\hline Chelsea & $\bar{I}$ & $\mathrm{SN}$ & 5 & 0 & 0 & 0 & 0 & 0 \\
\hline Chemin_Scholle & $\mathrm{A}$ & EN & 0 & 0 & 0 & 0 & 0 & 0 \\
\hline Chemin_Scholle & $\mathbf{B}$ & $\mathrm{EN}$ & 3 & 0 & 0 & 0 & 1 & 0 \\
\hline Chemin_Scholle & $\mathrm{C}$ & $\mathrm{EN}$ & 1 & 0 & 0 & 0 & 0 & 0 \\
\hline Chemin_Scholle & $\mathrm{D}$ & EN & 1 & 0 & 0 & 1 & 0 & 0 \\
\hline Chemin_Scholle & $E$ & EN & 4 & 0 & 0 & 1 & 0 & 0 \\
\hline Chemin_Scholle & $\mathrm{F}$ & EN & 2 & 0 & 0 & 0 & 0 & 1 \\
\hline Chemin_Scholle & $\mathrm{H}$ & EN & 0 & 0 & 0 & 0 & 0 & 0 \\
\hline Chemin_Scholle & I & $\mathrm{EN}$ & 0 & 0 & 0 & 0 & 0 & $\overline{0}$ \\
\hline Cote_d'Azur & $\overline{\mathrm{A}}$ & $\mathrm{S}$ & 0 & 0 & 0 & 0 & 0 & 0 \\
\hline Cote_d'Azur & B & $\mathbf{S}$ & 0 & 0 & 0 & 0 & 4 & 0 \\
\hline Cote_d'Azur & $\mathrm{C}$ & $\mathrm{S}$ & 0 & 0 & 0 & 0 & 12 & 0 \\
\hline Cote_d'Azur & $\mathrm{D}$ & $\mathrm{S}$ & 0 & 0 & 0 & 0 & 1 & 0 \\
\hline Cote_d'Azur & $\mathrm{E}$ & $\mathrm{S}$ & 0 & 0 & 0 & 0 & 10 & 0 \\
\hline Cote_d'Azur & $\mathrm{F}$ & $S$ & 0 & 0 & 0 & 0 & 1 & 0 \\
\hline Cote_d'Azur & $\mathrm{H}$ & $\mathrm{S}$ & 0 & 0 & 0 & 0 & 0 & 0 \\
\hline Cote_d'Azur & I & $\mathrm{S}$ & 0 & 0 & 0 & 0 & 0 & 0 \\
\hline Highway_Seven & A & $\mathrm{E}$ & 11 & 0 & 0 & 0 & 0 & 0 \\
\hline Highway_Seven & B & $\mathrm{E}$ & 0 & 0 & 0 & 1 & 2 & 1 \\
\hline Highway_Seven & $\mathrm{C}$ & $\mathrm{E}$ & 1 & 1 & 0 & 1 & 0 & 0 \\
\hline Highway_Seven & $\mathrm{D}$ & $\mathrm{E}$ & 0 & 0 & 0 & 0 & 0 & 1 \\
\hline Highway_Seven & $\mathrm{E}$ & $\mathrm{E}$ & 0 & 5 & 0 & 3 & 0 & 0 \\
\hline Highway_Seven & $\mathrm{F}$ & $E$ & 1 & 0 & 0 & 0 & 0 & 3 \\
\hline Highway_Seven & $\mathrm{H}$ & $\mathrm{E}$ & 0 & 0 & 0 & 0 & 0 & 0 \\
\hline Highway_Seven & $\mathrm{I}$ & $E$ & 2 & 0 & 0 & 0 & 1 & 0 \\
\hline Hull & A & $\mathrm{U}$ & 0 & 0 & 0 & 0 & 0 & 0 \\
\hline Hull & B & $\mathrm{U}$ & 0 & 0 & 0 & 0 & 0 & 0 \\
\hline Hull & $\mathrm{C}$ & $\mathrm{U}$ & 0 & 0 & 0 & 0 & 1 & 0 \\
\hline Hull & $\mathrm{D}$ & $\mathrm{U}$ & 0 & 0 & 0 & 0 & 0 & 0 \\
\hline Hull & $\mathrm{E}$ & $\mathrm{U}$ & 0 & 0 & 0 & 0 & 0 & 7 \\
\hline Hull & $\mathrm{F}$ & $\mathrm{U}$ & 0 & 0 & 0 & 0 & 0 & 0 \\
\hline Hull & $\mathrm{H}$ & $\mathrm{U}$ & 0 & 0 & 0 & 0 & 0 & 0 \\
\hline Hull & I & $\mathrm{U}$ & 0 & 0 & 0 & 0 & 0 & 1 \\
\hline Lac_a_la_Perdrix & A & EN & 0 & 0 & 0 & 0 & 0 & 2 \\
\hline Lac_a_la_Perdrix & B & EN & 0 & 0 & 1 & 0 & 0 & 0 \\
\hline Lac a la Perdrix & $\mathrm{C}$ & EN & 0 & 0 & 4 & 0 & 0 & 0 \\
\hline
\end{tabular}




\begin{tabular}{|c|c|c|c|c|c|c|c|c|}
\hline Lac_a_la_Perdrix & $\mathrm{D}$ & EN & 1 & 0 & 3 & 0 & 3 & 2 \\
\hline Lac_a_la_Perdrix & $\mathrm{E}$ & EN & 0 & 0 & 8 & 0 & 1 & 0 \\
\hline Lac_a_la_Perdrix & $\mathrm{F}$ & EN & 0 & 0 & 2 & 0 & 0 & 0 \\
\hline Lac_a_la_Perdrix & $\mathrm{H}$ & EN & 0 & 0 & 2 & 0 & 0 & 0 \\
\hline Lac_a_la_Perdrix & I & EN & 0 & 0 & 7 & 1 & 2 & 1 \\
\hline Lac_Philippe & $\mathrm{A}$ & $\bar{F}$ & 0 & 0 & 0 & 0 & 0 & 0 \\
\hline Lac_Philippe & $\mathrm{B}$ & $\bar{F}$ & 0 & 0 & 0 & 0 & 0 & 0 \\
\hline Lac_Philippe & $\mathrm{C}$ & $\mathrm{F}$ & 0 & 0 & 0 & 0 & 0 & $\overline{0}$ \\
\hline Lac_Philippe & $\mathrm{D}$ & $\mathrm{F}$ & 1 & 0 & 0 & 0 & 1 & 0 \\
\hline Lac_Philippe & $\mathrm{E}$ & $\bar{F}$ & 0 & 0 & 0 & 0 & 0 & 0 \\
\hline Lac_Philippe & $\mathrm{F}$ & F & 2 & 0 & 0 & 0 & 1 & 1 \\
\hline Lac_Philippe & $\mathrm{H}$ & F & 1 & 0 & 0 & 0 & 0 & 0 \\
\hline Lac_Philippe & I & $\bar{F}$ & 0 & 0 & 0 & 0 & 0 & 0 \\
\hline Manoir_des_Trembles & $\bar{A}$ & $\overline{\mathrm{UN}}$ & 0 & 0 & 0 & 0 & 0 & $\overline{0}$ \\
\hline Manoir_des_Trembles & $\mathrm{B}$ & $\overline{U N}$ & 0 & 0 & 0 & 0 & 0 & $\overline{0}$ \\
\hline Manoir_des_Trembles & $\mathrm{C}$ & $\mathrm{UN}$ & 0 & 1 & 0 & 6 & 0 & $\overline{0}$ \\
\hline Manoir_des Trembles & $\overrightarrow{\mathrm{D}}$ & UN & 4 & 0 & 0 & 0 & 0 & 0 \\
\hline Manoir_des_Trembles & $E$ & UN & 0 & 1 & 0 & 2 & 0 & 0 \\
\hline Manoir_des_Trembles & $\mathrm{F}$ & UN & 1 & 0 & 0 & 0 & 0 & 0 \\
\hline Manoir_des_Trembles & $\mathrm{H}$ & UN & 0 & 0 & 0 & 0 & 0 & $\overline{0}$ \\
\hline Manoir_des_Trembles & $\bar{I}$ & UN & 0 & 0 & 0 & 0 & 0 & 0 \\
\hline Marathon & $\mathrm{A}$ & $\mathrm{E}$ & 0 & 0 & 0 & 0 & 0 & 0 \\
\hline Marathon & B & $\mathrm{E}$ & 0 & 0 & 0 & 0 & 3 & 0 \\
\hline Marathon & $\mathrm{C}$ & $\mathrm{E}$ & 0 & 1 & 0 & 9 & 0 & 0 \\
\hline Marathon & $\mathrm{D}$ & $\mathrm{E}$ & 0 & 0 & 0 & 0 & 2 & 0 \\
\hline Marathon & $\mathrm{E}$ & $\mathrm{E}$ & 0 & 0 & 0 & 0 & 0 & 0 \\
\hline Marathon & $\mathrm{F}$ & $\bar{E}$ & 0 & 0 & 0 & 0 & 0 & 0 \\
\hline Marathon & $\mathrm{H}$ & $\mathrm{E}$ & 0 & 0 & 0 & 2 & 1 & 0 \\
\hline Marathon & I & $\mathrm{E}$ & 0 & 1 & 0 & 1 & 0 & 0 \\
\hline Marier & $\mathrm{A}$ & $\mathbf{U}$ & 0 & 0 & 0 & 0 & 0 & 0 \\
\hline Marier & $\mathrm{B}$ & $\mathrm{U}$ & 0 & 0 & 0 & 0 & 0 & 0 \\
\hline Marier & $\mathrm{C}$ & $\mathrm{U}$ & 0 & 0 & 0 & 0 & 0 & 2 \\
\hline Marier & $\mathrm{D}$ & $\mathrm{U}$ & 0 & 0 & 0 & 0 & 0 & 0 \\
\hline Marier & $E$ & $\bar{U}$ & $\overline{0}$ & 0 & 0 & 0 & 0 & 0 \\
\hline Marier & $\bar{F}$ & $\mathrm{U}$ & 0 & 0 & 0 & 0 & 0 & 0 \\
\hline Marier & $\mathrm{H}$ & $\mathrm{U}$ & 0 & 0 & 0 & 0 & 0 & 3 \\
\hline Marier & I & $\mathbf{U}$ & 0 & 0 & 0 & 0 & 0 & 6 \\
\hline Marlborough & $\mathrm{A}$ & $\mathbf{F}$ & 0 & 0 & 0 & 0 & 0 & 0 \\
\hline
\end{tabular}




\begin{tabular}{|c|c|c|c|c|c|c|c|c|}
\hline Marlborough & $\mathbf{B}$ & $\mathrm{F}$ & 10 & 0 & 0 & 0 & 0 & 0 \\
\hline Marlborough & $\mathrm{C}$ & $\mathrm{F}$ & 5 & 0 & 0 & 0 & 0 & 0 \\
\hline Marlborough & $\mathrm{D}$ & $F$ & 14 & 0 & 0 & 0 & 0 & 0 \\
\hline Marlborough & $E$ & $\bar{F}$ & 2 & 0 & 0 & 0 & 0 & 0 \\
\hline Marlborough & $F$ & $F$ & 2 & 0 & 0 & 7 & 0 & 0 \\
\hline Marlborough & $\mathrm{H}$ & $\mathrm{F}$ & 10 & 0 & 0 & 0 & 0 & 0 \\
\hline Marlborough & I & $\mathrm{F}$ & 6 & 0 & 0 & 0 & 0 & 0 \\
\hline Merivale & $\mathrm{A}$ & SN & 0 & 0 & 0 & 0 & 20 & 11 \\
\hline Merivale & B & $\mathrm{SN}$ & 0 & 0 & 0 & 1 & 9 & 6 \\
\hline Merivale & $\mathrm{C}$ & $\mathrm{SN}$ & 0 & 0 & 0 & 5 & 48 & 0 \\
\hline Merivale & $\mathrm{D}$ & $\mathrm{SN}$ & 0 & 0 & 0 & 0 & 2 & 0 \\
\hline Merivale & $\mathbf{E}$ & SN & 0 & 0 & 0 & 0 & 6 & 0 \\
\hline Merivale & $\mathrm{F}$ & SN & 0 & 0 & 0 & 4 & 1 & 1 \\
\hline Merivale & $\mathrm{H}$ & SN & 0 & 0 & 0 & 0 & 1 & 1 \\
\hline Merivale & I & $\mathrm{SN}$ & 0 & 0 & 0 & 1 & 5 & 14 \\
\hline Parc_Champlain & A & $\mathbf{S}$ & 0 & 0 & 0 & 0 & 11 & 0 \\
\hline Parc_Champlain & $\mathbf{B}$ & $\mathrm{S}$ & 0 & 0 & 0 & 0 & 2 & 0 \\
\hline Parc_Champlain & $\mathrm{C}$ & $\mathrm{S}$ & 0 & 0 & 0 & 0 & 3 & 0 \\
\hline Parc_Champlain & $\mathrm{D}$ & $\mathbf{S}$ & 0 & 0 & 0 & 0 & 6 & 0 \\
\hline Parc_Champlain & $E$ & $\mathbf{S}$ & 0 & 0 & 0 & 0 & 0 & 0 \\
\hline Parc_Champlain & $\mathrm{F}$ & $\mathrm{S}$ & 0 & 0 & 0 & 0 & 33 & 0 \\
\hline Parc_Champlain & $\mathrm{H}$ & $\mathrm{S}$ & 0 & 0 & 0 & 0 & 10 & 0 \\
\hline Parc_Champlain & I & $\mathrm{S}$ & 0 & 0 & 0 & 0 & 5 & 0 \\
\hline Pelissier & $\mathrm{A}$ & EN & 1 & 0 & 3 & 0 & 1 & 0 \\
\hline Pelissier & $\mathbf{B}$ & EN & 2 & 0 & 0 & 0 & 0 & 0 \\
\hline Pelissier & $\mathrm{C}$ & EN & 1 & 0 & 0 & 0 & 0 & 1 \\
\hline Pelissier & $\mathrm{D}$ & EN & 0 & 0 & 0 & 1 & 0 & 0 \\
\hline Pelissier & $\mathbf{E}$ & EN & 1 & 0 & 0 & 0 & 1 & 0 \\
\hline Pelissier & $F$ & EN & 8 & 0 & 6 & 0 & 2 & 0 \\
\hline Pelissier & $\mathrm{H}$ & EN & 0 & 0 & 0 & 0 & 1 & 0 \\
\hline Pelissier & $\mathbf{I}$ & EN & 0 & 0 & 0 & 0 & 0 & 0 \\
\hline PineGlen_Annex & $\mathrm{A}$ & $\mathrm{S}$ & 0 & 0 & 0 & 0 & 1 & 7 \\
\hline PineGlen_Annex & $\mathbf{B}$ & $\mathbf{S}$ & 0 & 0 & 0 & 0 & 0 & 0 \\
\hline PineGlen_Annex & $\mathrm{C}$ & $\mathbf{S}$ & 0 & 0 & 0 & 0 & 18 & 0 \\
\hline PineGlen_Annex & $\mathrm{D}$ & $\mathrm{S}$ & 0 & 0 & 0 & 0 & 26 & 0 \\
\hline PineGlen_Annex & $\mathrm{E}$ & $\mathbf{S}$ & 0 & 0 & 0 & 0 & 0 & 0 \\
\hline PineGlen_Annex & $\mathrm{F}$ & $\mathrm{S}$ & 0 & 0 & 0 & 0 & 1 & 0 \\
\hline PineGlen_Annex & $\mathrm{H}$ & $\mathrm{S}$ & 0 & 0 & 0 & 1 & 10 & 164 \\
\hline
\end{tabular}




\begin{tabular}{|c|c|c|c|c|c|c|c|c|}
\hline PineGlen_Annex & I & $\mathrm{S}$ & 0 & 0 & 0 & 0 & 2 & 0 \\
\hline Q_Four & $\bar{A}$ & $E$ & 0 & 0 & 0 & 0 & 10 & 0 \\
\hline Q_Four & $\mathrm{B}$ & $E$ & 0 & 0 & 0 & 0 & 0 & 0 \\
\hline Q_Four & $\mathrm{C}$ & $E$ & 1 & 0 & 0 & 0 & 6 & 0 \\
\hline Q_Four & D & $\bar{E}$ & 0 & 0 & 0 & 0 & 6 & 0 \\
\hline Q_Four & $E$ & $E$ & 1 & 0 & 0 & 3 & 0 & 0 \\
\hline Q Four & $\mathrm{F}$ & $E$ & 0 & 0 & 0 & 2 & 2 & 0 \\
\hline Q_Four & $\mathrm{H}$ & $\mathrm{E}$ & 1 & 0 & 0 & 0 & 2 & 0 \\
\hline Q_Four & I & $\mathrm{E}$ & 0 & 0 & 0 & 0 & 7 & 1 \\
\hline Sandy_Hill & $\mathrm{A}$ & $\mathrm{U}$ & 0 & 0 & 0 & 0 & 0 & 0 \\
\hline Sandy_Hill & $\mathrm{B}$ & $\bar{U}$ & 0 & 0 & 0 & 0 & 0 & 0 \\
\hline Sandy_Hill & $\mathrm{C}$ & $\bar{U}$ & 0 & 0 & 0 & 0 & 0 & 0 \\
\hline Sandy_Hill & $\mathrm{D}$ & $\mathrm{U}$ & 0 & 0 & 0 & 0 & 0 & 0 \\
\hline Sandy_Hill & $E$ & $\bar{U}$ & 0 & 0 & 0 & 0 & 0 & 0 \\
\hline Sandy_Hill & $\mathrm{F}$ & $\bar{U}$ & 0 & 0 & 0 & 0 & 0 & 0 \\
\hline Sandy_Hill & $\mathrm{H}$ & $\bar{U}$ & 0 & 0 & 0 & 0 & 0 & 0 \\
\hline Sandy_Hill & I & $\bar{U}$ & 0 & 0 & 0 & 0 & 0 & 0 \\
\hline Vallee_Meech & $\mathrm{A}$ & $\mathrm{F}$ & 0 & 0 & 0 & 0 & 0 & 0 \\
\hline Vallee_Meech & B & $\bar{F}$ & 0 & 0 & 0 & 0 & 0 & 0 \\
\hline Vallee_Meech & C & $\mathrm{F}$ & 0 & 0 & 0 & 0 & 0 & 0 \\
\hline Vallee_Meech & $\bar{D}$ & $\mathrm{~F}$ & 1 & 0 & 0 & 0 & 0 & 0 \\
\hline Vallee_Meech & $\bar{E}$ & $\bar{F}$ & 0 & 0 & 0 & 0 & 0 & 0 \\
\hline Vallee_Meech & $\bar{F}$ & $\bar{F}$ & 0 & 0 & 0 & 0 & 0 & $\overline{0}$ \\
\hline Vallee_Meech & $\mathrm{H}$ & $\mathrm{F}$ & 0 & 0 & 0 & 0 & 0 & 0 \\
\hline Vallee_Meech & I & $F$ & 0 & 0 & 0 & 0 & 0 & 0 \\
\hline Wolf_Grove & A & $E$ & 1 & 1 & 0 & 12 & 0 & 0 \\
\hline Wolf_Grove & B & $E$ & 0 & 0 & 0 & 0 & 0 & 0 \\
\hline Wolf_Grove & $\mathrm{C}$ & $E$ & 0 & 0 & 0 & 0 & 0 & 0 \\
\hline Wolf_Grove & D & $\bar{E}$ & 0 & 0 & 0 & 1 & 2 & 7 \\
\hline Wolf_Grove & $E$ & $E$ & 0 & 0 & 0 & 0 & 0 & 1 \\
\hline Wolf_Grove & $\mathrm{F}$ & $\bar{E}$ & 0 & 1 & 0 & 2 & 0 & 1 \\
\hline Wolf_Grove & $\mathrm{H}$ & $E$ & 0 & 0 & 0 & 0 & 1 & 0 \\
\hline Wolf_Grove & I & $E$ & 0 & 0 & 0 & 0 & 0 & 0 \\
\hline Wrightville & A & $\mathrm{U}$ & 0 & 0 & 0 & 0 & 2 & 0 \\
\hline Wrightville & B & $\mathrm{U}$ & 0 & 0 & 0 & 0 & 0 & 0 \\
\hline Wrightville & $\mathrm{C}$ & $\bar{U}$ & 0 & 0 & 0 & 0 & 9 & 0 \\
\hline Wrightville & D & $\mathrm{U}$ & 0 & 0 & 0 & 0 & 1 & 0 \\
\hline Wrightville & $E$ & $\mathrm{U}$ & 0 & 0 & 0 & 0 & 1 & 0 \\
\hline
\end{tabular}




\begin{tabular}{|l|l|l|r|r|r|r|r|r|}
\hline Wrightville & F & U & 0 & 0 & 0 & 0 & 0 & 0 \\
\hline Wrightville & H & U & 0 & 0 & 0 & 0 & 0 & 0 \\
\hline Wrightville & I & U & 0 & 0 & 0 & 0 & 14 & 0 \\
\hline Wychwood & A & S & 0 & 0 & 0 & 0 & 1 & 4 \\
\hline Wychwood & B & S & 0 & 0 & 0 & 0 & 0 & 2 \\
\hline Wychwood & C & S & 0 & 0 & 0 & 2 & 0 & 71 \\
\hline Wychwood & D & S & 0 & 0 & 0 & 0 & 0 & 5 \\
\hline Wychwood & E & S & 0 & 0 & 0 & 0 & 0 & 32 \\
\hline Wychwood & F & S & 0 & 0 & 0 & 0 & 0 & 2 \\
\hline Wychwood & H & S & 0 & 0 & 0 & 0 & 1 & 0 \\
\hline Wychwood & I & S & 0 & 0 & 0 & 0 & 1 & $\mathbf{8}$ \\
\hline
\end{tabular}




\begin{tabular}{|c|c|c|c|c|c|c|c|c|}
\hline SITE & STATION & CATEGORY & PTPA & PTPE & PTTR & SPCA & SPST & STCO \\
\hline Achbar & $\mathrm{A}$ & $\overline{\mathrm{SN}}$ & 0 & 3 & 0 & 0 & 2 & 0 \\
\hline Achbar & $\bar{B}$ & $\mathrm{SN}$ & 0 & 0 & 0 & 0 & 14 & $\overline{0}$ \\
\hline Achbar & $\mathrm{C}$ & $\overline{\mathrm{SN}}$ & 0 & 0 & 0 & 0 & 2 & $\overline{0}$ \\
\hline Achbar & $\bar{D}$ & SN & 0 & 0 & 0 & 0 & 2 & 0 \\
\hline Achbar & $E$ & SN & 0 & 0 & $\overline{0}$ & 0 & 8 & 0 \\
\hline Achbar & $\bar{F}$ & SN & 0 & 0 & 0 & 0 & 1 & 0 \\
\hline Achbar & $\mathrm{H}$ & $\mathrm{SN}$ & 0 & 0 & 0 & 0 & 11 & 0 \\
\hline Achbar & I & SN & 0 & 0 & 0 & 0 & 6 & 0 \\
\hline Bridlewood & $\mathrm{A}$ & UN & 0 & 11 & 0 & 0 & 0 & 0 \\
\hline Bridlewood & $\bar{B}$ & UN & 0 & 3 & 0 & 0 & 0 & $\overline{0}$ \\
\hline Bridlewood & $\mathrm{C}$ & UN & 0 & 2 & 0 & 0 & 0 & $\overline{0}$ \\
\hline Bridlewood & $\bar{D}$ & UN & 0 & 1 & 0 & 0 & 0 & 0 \\
\hline Bridlewood & $\bar{E}$ & $\overline{\mathrm{UN}}$ & 0 & 0 & 0 & 0 & 0 & $\overline{0}$ \\
\hline Bridlewood & $F$ & UN & 0 & 2 & 0 & 0 & 0 & 0 \\
\hline Bridlewood & $\mathrm{H}$ & UN & 0 & 0 & 0 & 0 & 0 & 0 \\
\hline Bridlewood & I & UN & 0 & I & 0 & 0 & 0 & $\overline{0}$ \\
\hline Carp_Hills & $\bar{A}$ & $F$ & 0 & 0 & 0 & 0 & 2 & 0 \\
\hline Carp_Hills & $\bar{B}$ & $\bar{F}$ & 0 & 0 & 0 & 0 & 4 & $\overline{0}$ \\
\hline Carp_Hills & $\mathrm{C}$ & $F$ & 0 & 0 & 0 & 0 & 8 & 0 \\
\hline Carp_Hills & D & $F$ & 0 & 0 & 0 & 0 & 1 & $\overline{0}$ \\
\hline Carp_Hills & $\mathrm{E}$ & $\bar{F}$ & 0 & 0 & 0 & 2 & 2 & $\overline{0}$ \\
\hline Carp_Hills & $\bar{F}$ & $F$ & 0 & 0 & 0 & 0 & 0 & $\overline{0}$ \\
\hline Carp_Hills & $\mathrm{H}$ & $\bar{F}$ & 0 & 0 & 0 & 0 & 2 & $\overline{0}$ \\
\hline Carp_Hills & I & $\mathrm{F}$ & 0 & 0 & 0 & 0 & 0 & 0 \\
\hline Chapel_Hill & $\bar{A}$ & $\overline{\mathrm{UN}}$ & 0 & 1 & 0 & 0 & 0 & $\overline{0}$ \\
\hline Chapel_Hill & $\bar{B}$ & UN & 0 & 0 & 0 & 0 & 1 & 0 \\
\hline Chapel_Hill & $\mathrm{C}$ & UN & 0 & 1 & 0 & 0 & 1 & $\overline{0}$ \\
\hline Chapel_Hill & $\bar{D}$ & UN & 0 & 1 & 0 & 0 & 1 & 0 \\
\hline Chapel_Hill & $\bar{E}$ & $\overline{\mathrm{UN}}$ & 0 & 0 & 0 & 0 & 0 & $\overline{0}$ \\
\hline Chapel_Hill & $\mathrm{F}$ & $\mathrm{UN}$ & 1 & 0 & 0 & 0 & 0 & 0 \\
\hline Chapel_Hill & $\mathrm{H}$ & $\overline{\mathrm{UN}}$ & 0 & 0 & 0 & 0 & 0 & $\overline{0}$ \\
\hline Chapel_Hill & I & $\mathrm{UN}$ & 1 & 0 & 0 & 0 & 0 & 0 \\
\hline Chelsea & $\bar{A}$ & $\mathrm{SN}$ & 0 & 2 & 0 & 0 & 0 & $\overline{0}$ \\
\hline Chelsea & B & $\mathrm{SN}$ & 0 & 0 & 0 & 0 & 0 & 0 \\
\hline Chelsea & $\mathrm{C}$ & $\mathrm{SN}$ & 0 & 0 & 0 & 0 & 0 & $\overline{0}$ \\
\hline Chelsea & $\bar{D}$ & $\overline{\mathrm{SN}}$ & 0 & 1 & 0 & 0 & 0 & 0 \\
\hline Chelsea & $\overline{\mathrm{E}}$ & $\overline{\mathrm{SN}}$ & 0 & 0 & 0 & 0 & 0 & $\overline{0}$ \\
\hline Chelsea & $\bar{F}$ & $\mathrm{SN}$ & 0 & 0 & 0 & 0 & 0 & 0 \\
\hline Chelsea & $\mathrm{H}$ & $\mathrm{SN}$ & 0 & 3 & 0 & 0 & 0 & 0 \\
\hline Chelsea & I & $\overline{\mathrm{SN}}$ & 0 & 0 & $\overline{0}$ & 0 & 0 & 0 \\
\hline
\end{tabular}




\begin{tabular}{|c|c|c|c|c|c|c|c|c|}
\hline Chemin_Scholle & A & EN & 0 & 1 & 0 & 0 & 3 & 0 \\
\hline Chemin_Scholle & $\mathrm{B}$ & EN & 0 & 3 & 0 & 0 & 2 & 0 \\
\hline Chemin_Scholle & $\mathrm{C}$ & EN & 0 & 0 & 0 & 0 & 2 & 0 \\
\hline Chemin_Scholle & $\mathrm{D}$ & EN & 0 & 2 & 0 & 0 & 3 & 0 \\
\hline Chemin_Scholle & $\mathrm{E}$ & EN & 0 & 0 & 0 & 0 & 5 & $\overline{0}$ \\
\hline Chemin_Scholle & $\mathrm{F}$ & EN & 0 & 4 & 0 & 0 & 0 & 0 \\
\hline Chemin_Scholle & $\mathrm{H}$ & EN & 0 & 1 & 0 & 0 & 4 & 0 \\
\hline Chemin_Scholle & $\mathrm{I}$ & EN & 0 & 0 & 0 & 0 & 3 & $\overline{0}$ \\
\hline Cote_d'Azur & $\bar{A}$ & $\mathrm{~S}$ & 0 & 0 & 0 & 0 & 0 & 0 \\
\hline Cote_d'Azur & $\mathrm{B}$ & $\mathrm{S}$ & 0 & 0 & 0 & 0 & 0 & 0 \\
\hline Cote_d'Azur & $\mathrm{C}$ & $\mathrm{S}$ & 0 & 0 & 0 & 0 & 0 & 0 \\
\hline Cote_d'Azur & $\mathrm{D}$ & $\mathrm{S}$ & 0 & 0 & 0 & 0 & 0 & 0 \\
\hline Cote_d'Azur & $E$ & $\mathrm{~S}$ & 0 & 0 & 0 & 0 & 0 & 0 \\
\hline Cote_d'Azur & $\mathrm{F}$ & $\mathrm{S}$ & 0 & 0 & 0 & 0 & 0 & $\overline{0}$ \\
\hline Cote_d'Azur & $\mathrm{H}$ & $\mathrm{S}$ & 0 & 0 & 0 & 0 & 0 & $\overline{0}$ \\
\hline Cote_d'Azur & $\bar{I}$ & $\mathrm{~S}$ & 0 & 0 & 0 & 0 & 0 & 0 \\
\hline Highway_Seven & $\mathrm{A}$ & $\mathrm{E}$ & 0 & 15 & 0 & 0 & 8 & 0 \\
\hline Highway_Seven & $\overline{\mathrm{B}}$ & $E$ & 0 & 0 & 0 & 0 & 0 & $\overline{0}$ \\
\hline Highway_Seven & $\mathrm{C}$ & $E$ & 0 & 2 & 0 & 0 & 1 & 0 \\
\hline Highway_Seven & $\mathrm{D}$ & $\mathrm{E}$ & 0 & 0 & 0 & 0 & 0 & 0 \\
\hline Highway_Seven & $\bar{E}$ & $E$ & 0 & 0 & 0 & 0 & 0 & 0 \\
\hline Highway_Seven & $\mathrm{F}$ & $E$ & 0 & 2 & 0 & 0 & 0 & 0 \\
\hline Highway_Seven & $\mathrm{H}$ & $E$ & 0 & 0 & 0 & 0 & 0 & 0 \\
\hline Highway_Seven & I & $E$ & 0 & 32 & 0 & 0 & 1 & 0 \\
\hline Hull & $\mathrm{A}$ & $\mathbf{U}$ & 0 & 0 & 0 & 0 & 0 & 0 \\
\hline Hull & $\mathrm{B}$ & $\bar{U}$ & 0 & 0 & 0 & 0 & 0 & 0 \\
\hline Hull & $\mathrm{C}$ & $\bar{U}$ & 0 & 1 & 0 & 0 & 0 & 0 \\
\hline Hull & $\mathrm{D}$ & $\mathrm{U}$ & 0 & 0 & 0 & 0 & 0 & 0 \\
\hline Hull & $E$ & $\mathrm{U}$ & 0 & 0 & 0 & 0 & 0 & 2 \\
\hline Hull & $F$ & $\mathrm{U}$ & 0 & 0 & 0 & 0 & 0 & 6 \\
\hline Hull & $\mathrm{H}$ & $\mathrm{U}$ & 0 & 0 & 0 & 0 & 0 & 0 \\
\hline Hull & I & $\mathbf{U}$ & 0 & 0 & 0 & 0 & 0 & 0 \\
\hline Lac_a_la_Perdrix & $\mathrm{A}$ & EN & 0 & 0 & 0 & 3 & 0 & 0 \\
\hline Lac_a_la_Perdrix & $\mathrm{B}$ & EN & 0 & 0 & 0 & 2 & 4 & 0 \\
\hline Lac_a_la_Perdrix & $\mathrm{C}$ & EN & 0 & 0 & 0 & 0 & 7 & 0 \\
\hline Lac_a_la_Perdrix & $\mathrm{D}$ & $\overline{E N}$ & 0 & 1 & 0 & 0 & 6 & 0 \\
\hline Lac_a_la_Perdrix & $E$ & EN & 0 & 1 & 1 & 12 & 1 & 0 \\
\hline Lac_a_la_Perdrix & $F$ & $\overline{\mathrm{EN}}$ & 0 & 1 & 1 & 1 & 1 & 0 \\
\hline Lac_a_la_Perdrix & $\mathrm{H}$ & EN & 0 & 1 & 0 & 3 & 3 & 0 \\
\hline Lac_a_la_Perdrix & $\bar{I}$ & EN & 0 & 0 & 1 & 3 & 1 & 0 \\
\hline Lac_Philippe & $\bar{A}$ & $F$ & 0 & 0 & 0 & 1 & 3 & 0 \\
\hline
\end{tabular}




\begin{tabular}{|c|c|c|c|c|c|c|c|c|}
\hline Lac_Philippe & B & $\mathrm{F}$ & 0 & 0 & 0 & 2 & 0 & 0 \\
\hline Lac_Philippe & $\mathrm{C}$ & $\mathrm{F}$ & 0 & 0 & 0 & 4 & 0 & 0 \\
\hline Lac_Philippe & $\mathrm{D}$ & $\bar{F}$ & 0 & 1 & 0 & 4 & 2 & $\overline{0}$ \\
\hline Lac_Philippe & $E$ & $\mathrm{~F}$ & 0 & 0 & 1 & 1 & 1 & 0 \\
\hline Lac_Philippe & $F$ & $F$ & 0 & 1 & 0 & 5 & 3 & 0 \\
\hline Lac_Philippe & $\mathrm{H}$ & $\mathrm{F}$ & 0 & 0 & 0 & 0 & 1 & $\overline{0}$ \\
\hline Lac_Philippe & I & $\mathrm{F}$ & 0 & 3 & 1 & 2 & 0 & 0 \\
\hline Manoir_des_Trembles & $\mathrm{A}$ & UN & 0 & 0 & 0 & 0 & 8 & 0 \\
\hline Manoir_des_Trembles & $\bar{B}$ & $\overline{\mathrm{UN}}$ & 0 & 0 & 0 & 0 & 2 & 0 \\
\hline Manoir_des_Trembles & $\mathrm{C}$ & UN & 0 & 0 & 0 & 0 & 0 & 0 \\
\hline Manoir_des_Trembles & $\mathrm{D}$ & UN & 0 & 0 & 0 & 0 & 6 & 0 \\
\hline Manoir_des_Trembles & $\mathrm{E}$ & UN & 0 & 0 & 0 & 0 & 10 & $\overline{0}$ \\
\hline Manoir_des_Trembles & $\mathrm{F}$ & UN & 0 & 0 & 1 & 0 & 12 & 0 \\
\hline Manoir_des_Trembles & $\mathrm{H}$ & UN & 0 & 0 & $\overline{0}$ & 0 & 1 & 0 \\
\hline Manoir_des_Trembles & I & $\mathrm{UN}$ & 0 & 0 & 0 & 0 & 10 & $\overline{0}$ \\
\hline Marathon & $\mathrm{A}$ & $\mathrm{E}$ & 0 & 1 & 0 & 0 & 2 & 0 \\
\hline Marathon & $\bar{B}$ & $\mathrm{E}$ & 0 & 2 & 0 & 2 & 5 & 0 \\
\hline Marathon & $\mathrm{C}$ & $\mathrm{E}$ & 1 & 0 & 0 & 0 & 2 & 0 \\
\hline Marathon & $\mathrm{D}$ & $\mathrm{E}$ & 0 & 0 & 0 & 0 & 0 & 0 \\
\hline Marathon & $\mathrm{E}$ & $\mathrm{E}$ & 0 & 2 & 0 & 0 & 4 & 0 \\
\hline Marathon & $F$ & $E$ & 0 & 0 & 0 & 0 & 0 & 0 \\
\hline Marathon & $\mathrm{H}$ & $E$ & 0 & 4 & 0 & 0 & 1 & 0 \\
\hline Marathon & I & $\mathrm{E}$ & 1 & 0 & 0 & 0 & 1 & 0 \\
\hline Marier & $\mathrm{A}$ & $\mathrm{U}$ & 0 & 0 & 0 & 0 & 0 & $\overline{0}$ \\
\hline Marier & B & $\mathrm{U}$ & 0 & 0 & 0 & 0 & 0 & $\overline{0}$ \\
\hline Marier & $\mathrm{C}$ & $\bar{U}$ & 0 & 0 & 0 & 0 & 0 & 0 \\
\hline Marier & $\mathrm{D}$ & $\mathrm{U}$ & 0 & 0 & 0 & 0 & 0 & 1 \\
\hline Marier & $\bar{E}$ & $\mathrm{U}$ & 0 & 0 & 0 & 0 & 0 & 0 \\
\hline Marier & $\mathrm{F}$ & $\mathrm{U}$ & 0 & 0 & 0 & 0 & 0 & 0 \\
\hline Marier & $\mathrm{H}$ & $\mathrm{U}$ & 0 & 0 & 0 & 0 & 0 & 0 \\
\hline Marier & $\mathrm{I}$ & $\mathrm{U}$ & 0 & 1 & 0 & 0 & 0 & 0 \\
\hline Marlborough & $\mathrm{A}$ & $\mathrm{F}$ & 0 & 7 & 0 & 0 & 1 & 0 \\
\hline Marlborough & $\mathbf{B}$ & $F$ & 0 & 4 & 0 & 0 & 1 & 0 \\
\hline Marlborough & $\mathrm{C}$ & $F$ & 0 & 0 & 0 & 0 & 2 & 0 \\
\hline Marlborough & $\mathrm{D}$ & $\mathrm{F}$ & 0 & 12 & 0 & 0 & 7 & 0 \\
\hline Marlborough & $E$ & $\mathrm{~F}$ & 0 & 4 & 0 & 0 & 0 & 0 \\
\hline Marlborough & $\mathrm{F}$ & $\mathrm{F}$ & 0 & 0 & 0 & 0 & 2 & $\overline{0}$ \\
\hline Marlborough & $\mathrm{H}$ & $\mathrm{F}$ & 0 & 12 & 0 & 0 & 3 & 0 \\
\hline Marlborough & I & $\mathrm{F}$ & 0 & 8 & 0 & 0 & 0 & 0 \\
\hline Merivale & $\mathrm{A}$ & $\mathrm{SN}$ & 0 & 0 & 0 & 0 & 1 & 0 \\
\hline Merivale & B & $\mathrm{SN}$ & 0 & 1 & 0 & 0 & 0 & 0 \\
\hline
\end{tabular}




\begin{tabular}{|c|c|c|c|c|c|c|c|c|}
\hline Merivale & $\bar{C}$ & SN & 1 & 0 & 0 & 0 & 0 & 0 \\
\hline Merivale & $\bar{D}$ & SN & 0 & 0 & 0 & 0 & 2 & 0 \\
\hline Merivale & E & $\overline{\mathrm{SN}}$ & 0 & 0 & 0 & 0 & 0 & 0 \\
\hline Merivale & $\mathbf{F}$ & SN & 0 & 0 & 0 & 0 & 0 & 0 \\
\hline Merivale & $\overline{\mathrm{H}}$ & $\mathrm{SN}$ & 0 & 0 & 0 & 0 & 0 & 0 \\
\hline Merivale & I & SN & 0 & 0 & 0 & 0 & 0 & 0 \\
\hline Parc_Champlain & A & $\mathrm{S}$ & 0 & 0 & 0 & 0 & 0 & 1 \\
\hline Parc_Champlain & $\bar{B}$ & $\mathrm{~S}$ & 0 & 0 & 0 & 0 & 0 & 0 \\
\hline Parc_Champlain & $\bar{C}$ & $\mathrm{~S}$ & 0 & 0 & 0 & 0 & 0 & 0 \\
\hline Parc_Champlain & $\bar{D}$ & $\mathrm{~s}$ & 0 & 0 & 0 & $\overline{0}$ & 0 & 0 \\
\hline Parc_Champlain & $\bar{E}$ & $\mathrm{~S}$ & 0 & 0 & 0 & 0 & 0 & 0 \\
\hline Parc_Champlain & $\mathbf{F}$ & $\mathrm{S}$ & 0 & 0 & 0 & 0 & 0 & 0 \\
\hline Parc_Champlain & $\mathrm{H}$ & $\mathrm{S}$ & 0 & 0 & 0 & 0 & 0 & 0 \\
\hline Parc_Champlain & I & $\bar{S}$ & 0 & 0 & 0 & 0 & 0 & 0 \\
\hline Pelissier & A & EN & 0 & 5 & 0 & 1 & 0 & 0 \\
\hline Pelissier & $\bar{B}$ & EN & 0 & 1 & 0 & 1 & 0 & 0 \\
\hline Pelissier & $\mathrm{C}$ & EN & 0 & 0 & 0 & 0 & 0 & 0 \\
\hline Pelissier & $\bar{D}$ & $\overline{\mathrm{EN}}$ & 0 & 5 & 0 & 0 & 0 & 0 \\
\hline Pelissier & $\bar{E}$ & $\overline{\mathrm{EN}}$ & 0 & 4 & 1 & 0 & 0 & 0 \\
\hline Pelissier & $F$ & EN & 0 & 4 & 0 & 2 & 0 & 0 \\
\hline Pelissier & $\overline{\mathrm{H}}$ & EN & 0 & 3 & 0 & 1 & 0 & 0 \\
\hline Pelissier & I & $\overline{E N}$ & 0 & 2 & 2 & 1 & 0 & 0 \\
\hline PineGlen_Annex & $\overline{\mathrm{A}}$ & $\mathrm{S}$ & 0 & 1 & 0 & 0 & 0 & 0 \\
\hline PineGlen_Annex & $\bar{B}$ & $\mathrm{~S}$ & 0 & 0 & 0 & 0 & 0 & 0 \\
\hline PineGlen_Annex & $\overline{\mathrm{C}}$ & $\mathrm{S}$ & 0 & 0 & 0 & 0 & 0 & 0 \\
\hline PineGlen_Annex & $\overline{\mathrm{D}}$ & $\mathrm{S}$ & 0 & 0 & 0 & 0 & 0 & 0 \\
\hline PineGlen_Annex & $\bar{E}$ & $\mathrm{~S}$ & 0 & 0 & 0 & 0 & 0 & 0 \\
\hline PineGlen_Annex & $F$ & $\mathrm{~S}$ & 0 & 0 & 0 & 0 & 0 & 0 \\
\hline PineGlen_Annex & $\overline{\mathrm{H}}$ & $\mathrm{S}$ & 0 & 3 & 0 & 0 & 0 & 0 \\
\hline PineGlen_Annex & $I$ & $\mathrm{~S}$ & 0 & 0 & 0 & 0 & 0 & 0 \\
\hline Q_Four & $\bar{A}$ & $\bar{E}$ & 0 & 0 & 0 & 0 & 1 & 0 \\
\hline Q_Four & $\bar{B}$ & $E$ & 0 & 0 & 0 & 0 & 0 & 0 \\
\hline Q_Four & $\mathrm{C}$ & $\mathrm{E}$ & 0 & 1 & 0 & 0 & 1 & 0 \\
\hline Q_Four & D & $E$ & 0 & 0 & 0 & 0 & 0 & 0 \\
\hline Q_Four & $\mathrm{E}$ & $\mathrm{E}$ & 0 & 0 & 0 & 0 & 0 & 0 \\
\hline$\overline{\text { Q_Four }}$ & $\mathrm{F}$ & $\bar{E}$ & 0 & 1 & 0 & 0 & 3 & 0 \\
\hline Q_Four & $\mathbf{H}$ & $E$ & 0 & 4 & 0 & 0 & 2 & 0 \\
\hline Q_Four & I & $\bar{E}$ & 0 & 0 & 0 & 1 & 1 & 0 \\
\hline Sandy_Hill & $\bar{A}$ & $\bar{U}$ & 0 & 0 & 0 & 0 & 0 & $\overline{0}$ \\
\hline Sandy_Hill & B & $\mathrm{U}$ & 0 & 0 & 0 & 0 & 0 & 0 \\
\hline Sandy_Hill & $\mathrm{C}$ & $\mathrm{U}$ & 0 & 0 & 0 & 0 & 0 & 0 \\
\hline
\end{tabular}




\begin{tabular}{|c|c|c|c|c|c|c|c|c|}
\hline Sandy_Hill & $\bar{D}$ & $\overline{\mathrm{U}}$ & 0 & 0 & 0 & 0 & 0 & 0 \\
\hline Sandy_Hill & $\bar{E}$ & $\overline{\mathrm{U}}$ & $\overline{0}$ & 0 & 0 & $\overline{0}$ & 0 & 0 \\
\hline Sandy_Hill & $F$ & $\mathrm{U}$ & 0 & 0 & 0 & 0 & 0 & 0 \\
\hline Sandy_Hill & $\overline{\mathrm{H}}$ & $\mathrm{U}$ & 0 & 0 & 0 & 0 & 0 & 0 \\
\hline Sandy_Hill & I & $\mathrm{U}$ & 0 & 0 & 0 & 0 & 0 & 0 \\
\hline Vallee_Meech & $\bar{A}$ & $\bar{F}$ & 0 & 1 & 0 & 2 & 1 & 0 \\
\hline Vallee_Meech & B & $\bar{F}$ & 0 & 0 & 0 & 1 & 0 & 0 \\
\hline Vallee_Meech & $\mathrm{C}$ & $\mathrm{F}$ & 0 & 0 & 0 & 1 & 0 & 0 \\
\hline Vallee_Meech & D & $\mathrm{F}$ & 0 & 0 & 0 & 4 & 3 & 0 \\
\hline Vallee_Meech & $E$ & $F$ & 0 & 0 & 0 & 3 & 0 & 0 \\
\hline Vallee_Meech & $F$ & $\mathrm{~F}$ & 0 & 1 & 0 & 1 & 0 & 0 \\
\hline Vallee_Meech & $\mathrm{H}$ & $\mathrm{F}$ & 0 & 1 & 0 & 0 & 1 & 0 \\
\hline Vallee_Meech & I & $\mathrm{F}$ & 0 & 0 & 0 & 2 & 0 & 0 \\
\hline Wolf_Grove & $\bar{A}$ & $\bar{E}$ & 0 & 1 & 0 & 0 & 2 & 0 \\
\hline Wolf_Grove & B & $\mathrm{E}$ & 0 & 0 & 0 & 0 & 0 & 0 \\
\hline Wolf_Grove & $\mathrm{C}$ & $\mathrm{E}$ & 0 & 1 & 0 & 0 & 2 & 0 \\
\hline Wolf_Grove & $\bar{D}$ & $E$ & 0 & 0 & 0 & 0 & 1 & 0 \\
\hline Wolf_Grove & $\mathrm{E}$ & $\mathrm{E}$ & 0 & 3 & 0 & 0 & 0 & 0 \\
\hline Wolf_Grove & $F$ & $\bar{E}$ & 0 & 0 & 0 & 0 & 1 & 0 \\
\hline Wolf_Grove & $\overline{\mathrm{H}}$ & $\mathrm{E}$ & 0 & 2 & 1 & 0 & 1 & 0 \\
\hline Wolf_Grove & I & $E$ & 0 & 6 & 0 & 0 & 0 & 0 \\
\hline Wrightville & A & $\mathrm{U}$ & 0 & 0 & 0 & 0 & 0 & 0 \\
\hline Wrightville & B & $\mathrm{U}$ & 0 & 0 & 0 & 0 & 0 & 0 \\
\hline Wrightville & $\mathrm{C}$ & $\bar{U}$ & 0 & 0 & 0 & 0 & 0 & 1 \\
\hline Wrightville & $\mathrm{D}$ & $\mathrm{U}$ & 0 & 0 & 0 & 0 & 0 & 0 \\
\hline Wrightville & $\bar{E}$ & $\bar{U}$ & 0 & 0 & 0 & 0 & 0 & 0 \\
\hline Wrightville & $\bar{F}$ & $\overline{\mathrm{U}}$ & 0 & 0 & 0 & 0 & 0 & 0 \\
\hline Wrightville & $\mathrm{H}$ & $\bar{U}$ & 0 & 0 & 0 & 0 & 0 & 0 \\
\hline Wrightville & I & $\mathrm{U}$ & 0 & 0 & 0 & 0 & 0 & 0 \\
\hline Wychwood & A & $\mathrm{S}$ & 0 & 0 & 0 & 0 & 0 & 0 \\
\hline Wychwood & B & $S$ & 0 & 0 & 0 & 0 & 0 & 0 \\
\hline Wychwood & $\mathrm{C}$ & $S$ & 0 & 6 & 0 & 0 & 0 & 0 \\
\hline Wychwood & D & $S$ & 0 & 0 & 0 & 0 & 0 & 0 \\
\hline Wychwood & $\mathrm{E}$ & $\mathrm{S}$ & 0 & 0 & 0 & 0 & 0 & 0 \\
\hline Wychwood & $\bar{F}$ & $\mathrm{~S}$ & 0 & 0 & 0 & 0 & 0 & 0 \\
\hline Wychwood & $\mathrm{H}$ & $\mathrm{S}$ & 0 & 0 & 0 & 0 & 0 & 0 \\
\hline Wychwood & I & $\mathrm{S}$ & 0 & 0 & 0 & 0 & 0 & 0 \\
\hline
\end{tabular}




\begin{tabular}{|c|c|c|c|c|c|c|c|}
\hline SITE & STATION & CATEGORY & SYAM & SYIM & TRAP & TRCR & TRVU \\
\hline Achbar & $\mathrm{A}$ & SN & 0 & 0 & 0 & 0 & 0 \\
\hline Achbar & B & $\overline{\mathrm{SN}}$ & $\overline{0}$ & 7 & 0 & 0 & $\overline{0}$ \\
\hline Achbar & $\mathrm{C}$ & SN & 0 & 1 & 0 & 0 & $\overline{0}$ \\
\hline Achbar & $\mathrm{D}$ & SN & 0 & 0 & 0 & 0 & 0 \\
\hline Achbar & $\bar{E}$ & SN & $\overline{0}$ & 1 & $\overline{0}$ & 0 & $\overline{0}$ \\
\hline Achbar & $F$ & SN & 0 & 0 & $\overline{0}$ & 0 & $\overline{0}$ \\
\hline Achbar & $\overline{\mathrm{H}}$ & $\overline{\mathrm{SN}}$ & 0 & 4 & 0 & 0 & 0 \\
\hline Achbar & I & SN & 0 & 2 & 0 & 0 & 0 \\
\hline Bridlewood & $\mathrm{A}$ & UN & 0 & 0 & 0 & 0 & $\overline{0}$ \\
\hline Bridlewood & $\bar{B}$ & UN & 0 & 4 & 0 & 0 & $\overline{0}$ \\
\hline Bridlewood & $\bar{C}$ & UN & 0 & 2 & 0 & 0 & $\overline{0}$ \\
\hline Bridlewood & $\bar{D}$ & UN & 0 & 0 & 0 & 0 & 0 \\
\hline Bridlewood & $E$ & UN & 0 & 1 & 0 & 0 & 0 \\
\hline Bridlewood & $F$ & UN & 0 & 0 & 0 & 0 & 0 \\
\hline Bridlewood & $\mathrm{H}$ & UN & 0 & 0 & 0 & 0 & $\overline{0}$ \\
\hline Bridlewood & I & UN & 0 & 0 & 0 & 0 & $\mathbf{0}$ \\
\hline Carp_Hills & $\bar{A}$ & $\bar{F}$ & 0 & 0 & $\overline{0}$ & 0 & $\overline{0}$ \\
\hline Carp_Hills & B & $\overline{\mathrm{F}}$ & 0 & 0 & 0 & 0 & $\overline{0}$ \\
\hline Carp_Hills & $\mathrm{C}$ & $F$ & 0 & 0 & 0 & 0 & $\overline{0}$ \\
\hline Carp_Hills & $\bar{D}$ & $F$ & 0 & 1 & 0 & 0 & $\overline{0}$ \\
\hline Carp_Hills & $E$ & $F$ & 0 & 0 & 0 & 0 & $\overline{0}$ \\
\hline Carp_Hills & $\bar{F}$ & $\bar{F}$ & 0 & 0 & 0 & 0 & $\overline{0}$ \\
\hline Carp_Hills & $\overline{\mathrm{H}}$ & $F$ & 0 & 0 & 0 & 0 & $\overline{0}$ \\
\hline Carp_Hills & I & $F$ & 0 & 0 & 0 & 0 & $\overline{0}$ \\
\hline Chapel_Hill & $\bar{A}$ & UN & 0 & 0 & 0 & 0 & $\overline{0}$ \\
\hline Chapel_Hill & B & UN & 0 & 0 & 0 & 0 & 0 \\
\hline Chapel_Hill & $\mathrm{C}$ & UN & 0 & 0 & 0 & 0 & $\overline{0}$ \\
\hline Chapel_Hill & $\overline{\mathrm{D}}$ & UN & 0 & 0 & 0 & 0 & $\overline{0}$ \\
\hline Chapel_Hill & $E$ & UN & 0 & 0 & 0 & 0 & $\overline{0}$ \\
\hline Chapel_Hill & $F$ & $\mathrm{UN}$ & 0 & 0 & 0 & 0 & 0 \\
\hline Chapel_Hill & $\mathrm{H}$ & UN & 0 & 2 & 0 & 0 & $\overline{0}$ \\
\hline Chapel_Hill & I & UN & 0 & 0 & 0 & 0 & $\overline{0}$ \\
\hline Chelsea & $\bar{A}$ & $\overline{\mathrm{SN}}$ & 0 & 0 & 0 & 0 & $\overline{0}$ \\
\hline Chelsea & $\bar{B}$ & SN & $\overline{0}$ & 0 & 0 & 0 & $\overline{0}$ \\
\hline Chelsea & $\mathrm{C}$ & SN & 0 & 0 & 0 & 0 & $\overline{0}$ \\
\hline Chelsea & $\mathrm{D}$ & SN & 0 & 0 & 0 & 0 & $\overline{0}$ \\
\hline Chelsea & $E$ & SN & 0 & 0 & 0 & 0 & $\overline{0}$ \\
\hline Chelsea & $\bar{F}$ & SN & 0 & 0 & 0 & 0 & $\overline{0}$ \\
\hline Chelsea & $\overline{\mathrm{H}}$ & SN & 0 & 0 & 0 & 0 & $\overline{0}$ \\
\hline Chelsea & I & SN & 0 & 0 & 0 & 0 & $\overline{0}$ \\
\hline Chemin_Scholle & $\bar{A}$ & $\overline{E N}$ & 0 & 0 & 0 & 0 & $\overline{0}$ \\
\hline Chemin_Scholle & B & EN & 0 & 0 & 0 & 0 & $\overline{0}$ \\
\hline Chemin_Scholle & $\overline{\mathrm{C}}$ & EN & 0 & 2 & 0 & 0 & 0 \\
\hline Chemin_Scholle & $\bar{D}$ & EN & 0 & 1 & 0 & 0 & $\overline{0}$ \\
\hline
\end{tabular}




\begin{tabular}{|c|c|c|c|c|c|c|c|}
\hline Chemin_Scholle & $\mathrm{E}$ & EN & 0 & 1 & 0 & 0 & 0 \\
\hline Chemin_Scholle & $\mathrm{F}$ & EN & 0 & 0 & 0 & 0 & 0 \\
\hline Chemin_Scholle & $\mathrm{H}$ & EN & 0 & 0 & 0 & 0 & 0 \\
\hline Chemin_Scholle & I & EN & 0 & 1 & 0 & 0 & 0 \\
\hline Cote_d'Azur & $\bar{A}$ & $\mathrm{~S}$ & 0 & 0 & 0 & 0 & $\overline{0}$ \\
\hline Cote_d'Azur & $\mathrm{B}$ & $\bar{S}$ & 0 & 0 & 0 & 0 & 0 \\
\hline Cote_d'Azur & $\bar{C}$ & $S$ & 0 & 0 & 0 & 0 & 0 \\
\hline Cote_d'Azur & $\bar{D}$ & $\mathrm{~S}$ & 0 & 0 & 0 & 0 & 0 \\
\hline Cote_d'Azur & $\bar{E}$ & $\mathrm{~S}$ & 0 & 0 & 0 & 0 & 0 \\
\hline Cote_d'Azur & $\mathrm{F}$ & $\mathrm{S}$ & 0 & 0 & 0 & 0 & 0 \\
\hline Cote_d'Azur & $\mathrm{H}$ & $\mathrm{S}$ & 0 & 0 & 0 & 0 & 0 \\
\hline Cote_d'Azur & I & $\mathrm{S}$ & 0 & 0 & 0 & 0 & 0 \\
\hline Highway_Seven & $\bar{A}$ & $\bar{E}$ & 0 & 1 & 0 & 0 & 0 \\
\hline Highway_Seven & B & $\bar{E}$ & 0 & 0 & 0 & 0 & 0 \\
\hline Highway_Seven & $\bar{C}$ & $\bar{E}$ & 0 & 4 & 0 & 0 & 0 \\
\hline Highway_Seven & $\mathrm{D}$ & $E$ & 0 & 0 & 0 & 0 & 0 \\
\hline Highway_Seven & $\bar{E}$ & $\mathrm{E}$ & 0 & 0 & 0 & 0 & 0 \\
\hline Highway_Seven & $\mathrm{F}$ & $\mathrm{E}$ & 0 & 0 & 0 & 0 & 0 \\
\hline Highway_Seven & $\mathrm{H}$ & $\mathrm{E}$ & 1 & 0 & 0 & 0 & 0 \\
\hline Highway_Seven & $\bar{I}$ & $\bar{E}$ & 0 & 1 & 0 & 0 & 0 \\
\hline Hull & $\bar{A}$ & $\mathrm{U}$ & 0 & 0 & 0 & 0 & 0 \\
\hline Hull & B & $\bar{U}$ & 0 & 0 & 0 & 0 & 0 \\
\hline Hull & $\mathrm{C}$ & $\overline{\mathrm{U}}$ & 0 & 0 & 0 & 0 & 0 \\
\hline Hull & $\mathrm{D}$ & $\mathrm{U}$ & 0 & 0 & 0 & 0 & 0 \\
\hline Hull & $\mathrm{E}$ & U & 0 & 0 & 0 & 0 & 0 \\
\hline Hull & $\mathrm{F}$ & $\mathrm{U}$ & 0 & 0 & 0 & 0 & 0 \\
\hline Hull & $\mathrm{H}$ & $\bar{U}$ & 0 & 0 & 0 & 0 & 0 \\
\hline Hull & I & $\mathrm{U}$ & 0 & 0 & 0 & 0 & 0 \\
\hline Lac_a_la_Perdrix & $\mathrm{A}$ & EN & 0 & 9 & 0 & 0 & 0 \\
\hline Lac_a_la_Perdrix & $\bar{B}$ & $\overline{\text { EN }}$ & 0 & 6 & 0 & 0 & 0 \\
\hline Lac_a_la_Perdrix & $\mathrm{C}$ & EN & 0 & 6 & 0 & 0 & 0 \\
\hline Lac_a_la_Perdrix & $\mathrm{D}$ & EN & 0 & 1 & 0 & 0 & 0 \\
\hline Lac_a_la_Perdrix & $\mathrm{E}$ & EN & 0 & 15 & 0 & 0 & 0 \\
\hline Lac_a_la_Perdrix & $\mathrm{F}$ & EN & 0 & 28 & 0 & 0 & 0 \\
\hline Lac_a_la_Perdrix & $\mathrm{H}$ & EN & 0 & 14 & 0 & 0 & 0 \\
\hline Lac_a_la_Perdrix & $\mathrm{I}$ & EN & 0 & 16 & 0 & 0 & 0 \\
\hline Lac_Philippe & $\mathrm{A}$ & $\mathbf{F}$ & 0 & 4 & 0 & 0 & 0 \\
\hline Lac_Philippe & $\mathrm{B}$ & $F$ & 0 & 8 & 0 & 0 & 0 \\
\hline Lac_Philippe & $\mathrm{C}$ & $\mathrm{F}$ & 0 & 1 & 0 & 0 & 0 \\
\hline Lac_Philippe & $\bar{D}$ & $\mathrm{~F}$ & 0 & 6 & 0 & 0 & 0 \\
\hline Lac_Philippe & $\mathrm{E}$ & $F$ & 0 & 2 & 0 & 0 & 0 \\
\hline Lac_Philippe & $\mathbf{F}$ & $F$ & 0 & I9 & 0 & 0 & 0 \\
\hline Lac_Philippe & $\mathrm{H}$ & $\mathrm{F}$ & 0 & 0 & 0 & 0 & 0 \\
\hline Lac_Philippe & I & $\mathrm{F}$ & 0 & 6 & 0 & 0 & 0 \\
\hline Manoir_des_Trembles & $\bar{A}$ & UN & 0 & 0 & 0 & 0 & 0 \\
\hline
\end{tabular}




\begin{tabular}{|c|c|c|c|c|c|c|c|}
\hline Manoir_des_Trembles & B & $\overline{\mathrm{UN}}$ & 0 & 2 & 0 & 0 & 0 \\
\hline Manoir_des_Trembles & $\mathrm{C}$ & UN & 0 & 0 & 0 & 0 & 0 \\
\hline Manoir_des_Trembles & $\mathrm{D}$ & UN & 0 & 1 & 0 & 0 & 0 \\
\hline Manoir_des_Trembles & $\mathrm{E}$ & UN & 0 & 0 & 0 & 0 & 0 \\
\hline Manoir_des_Trembles & $\mathbf{F}$ & $\mathrm{UN}$ & 0 & 1 & $\mathbf{0}$ & 0 & 0 \\
\hline Manoir_des_Trembles & $\mathrm{H}$ & $\mathrm{UN}$ & 0 & 4 & 0 & 0 & 0 \\
\hline Manoir_des_Trembles & $\mathrm{I}$ & $\overline{\mathrm{UN}}$ & 0 & 1 & $\overline{0}$ & 0 & $\overline{0}$ \\
\hline Marathon & $\mathrm{A}$ & $E$ & 0 & 2 & 0 & 0 & 0 \\
\hline Marathon & $\mathrm{B}$ & $\mathbf{E}$ & 0 & 0 & 0 & 0 & 0 \\
\hline Marathon & $\mathrm{C}$ & $\mathrm{E}$ & 0 & 0 & 0 & 0 & 0 \\
\hline Marathon & $\mathrm{D}$ & $\mathrm{E}$ & 0 & 0 & 0 & 0 & 0 \\
\hline Marathon & $E$ & $\mathbf{E}$ & 0 & 0 & 0 & 0 & 0 \\
\hline Marathon & $\mathrm{F}$ & $\mathbf{E}$ & 0 & 0 & 0 & 0 & $\overline{0}$ \\
\hline Marathon & $\mathrm{H}$ & $\bar{E}$ & 0 & 0 & 0 & 0 & 0 \\
\hline Marathon & I & $\mathrm{E}$ & 0 & 0 & 0 & 0 & 0 \\
\hline Marier & $\mathrm{A}$ & $\mathrm{U}$ & 0 & 0 & 0 & 0 & 0 \\
\hline Marier & $\mathrm{B}$ & $\mathrm{U}$ & 0 & 0 & 0 & 0 & 0 \\
\hline Marier & $\mathrm{C}$ & $\bar{U}$ & 0 & 0 & 0 & 0 & 0 \\
\hline Marier & $\mathrm{D}$ & $\mathrm{U}$ & 0 & 0 & 0 & 0 & 0 \\
\hline Marier & $\mathrm{E}$ & $\mathrm{U}$ & 0 & 0 & 0 & 0 & 0 \\
\hline Marier & $F$ & $\mathrm{U}$ & 0 & 0 & 0 & 0 & 0 \\
\hline Marier & $\mathrm{H}$ & $\mathrm{U}$ & 0 & 0 & 0 & 0 & 1 \\
\hline Marier & I & $\bar{U}$ & 0 & 0 & 0 & 0 & 0 \\
\hline Marlborough & A & $\mathbf{F}$ & 0 & 4 & 0 & 0 & 0 \\
\hline Marlborough & $\mathrm{B}$ & $\mathbf{F}$ & 0 & 3 & 0 & 0 & 0 \\
\hline Marlborough & $\mathrm{C}$ & $\mathbf{F}$ & 0 & 2 & 0 & 0 & 0 \\
\hline Marlborough & $\mathrm{D}$ & $F$ & 0 & 1 & 0 & 0 & 0 \\
\hline Marlborough & $\mathrm{E}$ & F & 0 & 0 & 1 & 0 & 0 \\
\hline Marlborough & $\mathrm{F}$ & $F$ & 0 & 0 & 0 & 0 & 0 \\
\hline Marlborough & $\mathrm{H}$ & $\mathbf{F}$ & 0 & 10 & 0 & 0 & 0 \\
\hline Marlborough & I & $F$ & 0 & 2 & 0 & 0 & 0 \\
\hline Merivale & $\mathrm{A}$ & $\mathrm{SN}$ & 0 & 0 & 0 & 0 & 0 \\
\hline Merivale & $\mathrm{B}$ & $\mathrm{SN}$ & 0 & 2 & 0 & 0 & 0 \\
\hline Merivale & $\mathrm{C}$ & $\overline{\mathrm{SN}}$ & 0 & 0 & 0 & 0 & 0 \\
\hline Merivale & $\mathrm{D}$ & SN & 0 & 0 & 0 & 0 & 0 \\
\hline Merivale & $\mathrm{E}$ & $\mathrm{SN}$ & 0 & 0 & 0 & 0 & 0 \\
\hline Merivale & $F$ & $\mathrm{SN}$ & 0 & 0 & 0 & 0 & 0 \\
\hline Merivale & $\mathrm{H}$ & $\mathrm{SN}$ & 0 & 0 & 0 & 0 & 0 \\
\hline Merivale & $\mathrm{I}$ & $\mathrm{SN}$ & 0 & 1 & 0 & 0 & 0 \\
\hline Parc_Champlain & A & $\mathrm{S}$ & 0 & 0 & 0 & 0 & 0 \\
\hline Parc_Champlain & B & $\mathrm{S}$ & 0 & 0 & 0 & 0 & 0 \\
\hline Parc_Champlain & $\mathrm{C}$ & $\bar{S}$ & 0 & 0 & 0 & 0 & 0 \\
\hline Parc_Champlain & $\bar{D}$ & $\mathrm{~S}$ & 0 & 0 & 0 & 0 & 2 \\
\hline Parc Champlain & $\mathrm{E}$ & $\mathrm{S}$ & 0 & 0 & 0 & 0 & 0 \\
\hline Parc_Champlain & $\mathrm{F}$ & $\mathrm{S}$ & 0 & 0 & 0 & 0 & 0 \\
\hline
\end{tabular}




\begin{tabular}{|c|c|c|c|c|c|c|c|}
\hline Parc_Champlain & $\overline{\mathrm{H}}$ & $\mathrm{S}$ & 0 & 0 & 0 & 0 & 0 \\
\hline Parc_Champlain & I & $\mathrm{S}$ & 0 & 0 & 0 & 0 & $\overline{0}$ \\
\hline Pelissier & $\bar{A}$ & EN & 0 & 14 & 0 & 0 & 0 \\
\hline Pelissier & B & EN & 0 & 3 & 0 & 0 & 0 \\
\hline Pelissier & $\bar{C}$ & $\overline{\mathrm{EN}}$ & 0 & 0 & 0 & 0 & $\overline{0}$ \\
\hline Pelissier & $\mathrm{D}$ & EN & 0 & $\mathbf{0}$ & 0 & 1 & 0 \\
\hline $\begin{array}{l}\text { Pelissier } \\
\end{array}$ & $E$ & EN & 0 & 1 & 0 & $\overline{0}$ & $\overline{0}$ \\
\hline Pelissier & $\bar{F}$ & $\overline{E N}$ & 0 & 2 & 0 & 0 & $\overline{0}$ \\
\hline Pelissier & $\mathrm{H}$ & EN & 0 & 4 & 0 & 0 & 0 \\
\hline $\begin{array}{l}\text { Pelissier } \\
\end{array}$ & I & EN & 0 & 5 & 0 & 0 & 0 \\
\hline PineGlen_Annex & A & $\mathrm{S}$ & 0 & $\mathbf{0}$ & 0 & 0 & 0 \\
\hline PineGlen_Annex & B & $\mathrm{S}$ & 0 & $\mathbf{0}$ & 0 & 0 & 0 \\
\hline PineGlen_Annex & $\mathrm{C}$ & $\mathrm{S}$ & 0 & $\overline{0}$ & 0 & 0 & $\overline{0}$ \\
\hline PineGlen_Annex & $\overline{\mathrm{D}}$ & $\mathrm{S}$ & 0 & $\overline{0}$ & 0 & 0 & 0 \\
\hline PineGlen_Annex & $\mathrm{E}$ & $\mathrm{S}$ & 0 & 0 & 0 & 0 & 0 \\
\hline PineGlen_Annex & $F$ & $\mathrm{~S}$ & 0 & 0 & 0 & 0 & 0 \\
\hline PineGlen_Annex & $\mathrm{H}$ & $\bar{S}$ & 0 & 0 & 0 & 0 & 0 \\
\hline PineGlen_Annex & I & $\mathrm{S}$ & 0 & 0 & 0 & 0 & 0 \\
\hline Q_Four & A & $\mathrm{E}$ & 0 & 4 & 0 & 0 & 0 \\
\hline Q_Four & $\bar{B}$ & $\bar{E}$ & 0 & $\overline{1}$ & 0 & 0 & 0 \\
\hline Q_Four & $\mathrm{C}$ & $E$ & 0 & 1 & 0 & 0 & 0 \\
\hline Q_Four & $\bar{D}$ & $\mathrm{E}$ & 0 & 0 & 0 & 0 & 0 \\
\hline Q_Four & $\mathrm{E}$ & $\bar{E}$ & 0 & 0 & 0 & 0 & 0 \\
\hline Q_Four & $\mathbf{F}$ & $\mathrm{E}$ & 0 & 0 & 0 & 0 & 0 \\
\hline Q_Four & $\mathrm{H}$ & $\bar{E}$ & 0 & 3 & 0 & 0 & 0 \\
\hline Q_Four & I & $E$ & 0 & 0 & 0 & 0 & 0 \\
\hline Sandy_Hill & $\bar{A}$ & $\overline{\mathrm{U}}$ & 0 & 0 & 0 & 0 & 0 \\
\hline Sandy_Hill & B & $\overline{\mathrm{U}}$ & 0 & 0 & 0 & 0 & 0 \\
\hline Sandy_Hill & $\mathrm{C}$ & $\mathrm{U}$ & 0 & 0 & 0 & 0 & 0 \\
\hline Sandy_Hill & $\mathrm{D}$ & $\mathrm{U}$ & 0 & 0 & 0 & 0 & 0 \\
\hline Sandy_Hill & $\mathrm{E}$ & $\mathrm{U}$ & 0 & 0 & 0 & 0 & 0 \\
\hline Sandy_Hill & $F$ & $\mathrm{U}$ & 0 & 0 & $\overline{0}$ & 0 & 0 \\
\hline Sandy_Hill & $\overline{\mathrm{H}}$ & $\bar{U}$ & 0 & 0 & 0 & 0 & 0 \\
\hline Sandy_Hill & I & $\overline{\mathrm{U}}$ & 0 & 0 & 0 & 0 & 4 \\
\hline Vallee_Meech & $\mathrm{A}$ & $F$ & 0 & 9 & 0 & 0 & 0 \\
\hline Vallee_Meech & B & $\bar{F}$ & $\overline{0}$ & 3 & 0 & 0 & 0 \\
\hline Vallee_Meech & $\mathrm{C}$ & $\bar{F}$ & 0 & 4 & 0 & 0 & 0 \\
\hline Vallee_Meech & $\mathrm{D}$ & $\bar{F}$ & $\overline{0}$ & 6 & 0 & 0 & 0 \\
\hline Vallee_Meech & $\bar{E}$ & $F$ & 0 & 8 & 0 & 0 & $\overline{0}$ \\
\hline Vallee_Meech & $\bar{F}$ & $\mathrm{~F}$ & 0 & 19 & 0 & 0 & $\overline{0}$ \\
\hline Vallee_Meech & $\overline{\mathrm{H}}$ & F & 0 & 3 & 0 & 0 & 0 \\
\hline Vallee_Meech & I & $\mathrm{F}$ & 0 & 12 & 0 & 0 & 0 \\
\hline Wolf_Grove & $\bar{A}$ & $\mathrm{E}$ & 0 & 0 & 0 & 0 & 0 \\
\hline Wolf_Grove & $\mathrm{B}$ & $\bar{E}$ & 0 & 0 & 0 & 0 & $\overline{0}$ \\
\hline Wolf_Grove & $\mathrm{C}$ & $\bar{E}$ & 0 & 2 & 0 & 0 & 0 \\
\hline
\end{tabular}




\begin{tabular}{|c|c|c|c|c|c|c|c|}
\hline Wolf_Grove & $\bar{D}$ & $\bar{E}$ & 0 & 0 & 0 & 0 & $\overline{0}$ \\
\hline Wolf_Grove & $E$ & $\mathrm{E}$ & 0 & 0 & 0 & 0 & 0 \\
\hline Wolf_Grove & $\bar{F}$ & $\bar{E}$ & 0 & 0 & 0 & 0 & $\overline{0}$ \\
\hline Wolf_Grove & $\mathrm{H}$ & $\bar{E}$ & 0 & 7 & 0 & 0 & $\overline{0}$ \\
\hline Wolf_Grove & I & $\bar{E}$ & 0 & 0 & 0 & 0 & $\overline{0}$ \\
\hline Wrightville & $\mathrm{A}$ & $\overline{\mathrm{U}}$ & 0 & 0 & 0 & 0 & 0 \\
\hline Wrightville & B & $\bar{U}$ & 0 & 0 & 0 & 0 & 0 \\
\hline Wrightville & $\mathrm{C}$ & $\overline{\mathrm{U}}$ & 0 & 0 & 0 & 0 & 1 \\
\hline Wrightville & $\overline{\mathrm{D}}$ & $\mathrm{U}$ & 0 & 0 & 0 & 0 & 0 \\
\hline Wrightville & $\mathrm{E}$ & $\overline{\mathrm{U}}$ & 0 & 0 & 0 & 0 & 0 \\
\hline Wrightville & $F$ & $\mathrm{U}$ & 0 & 0 & 0 & 0 & 0 \\
\hline Wrightville & $\mathrm{H}$ & $\mathrm{U}$ & 1 & 0 & 0 & 0 & 0 \\
\hline Wrightville & I & $\overline{\mathrm{U}}$ & 0 & 0 & 0 & 0 & $\overline{0}$ \\
\hline Wychwood & $\mathrm{A}$ & $S$ & 2 & 0 & $\overline{0}$ & $\overline{0}$ & 0 \\
\hline Wychwood & $\mathrm{B}$ & $\mathrm{S}$ & 0 & 0 & 0 & 0 & 0 \\
\hline Wychwood & $\mathrm{C}$ & $\bar{S}$ & 0 & 0 & 0 & 0 & 0 \\
\hline Wychwood & $\mathrm{D}$ & $\mathrm{S}$ & 0 & 0 & 0 & 0 & 0 \\
\hline Wychwood & $\bar{E}$ & $S$ & 0 & 0 & 0 & 0 & $\overline{0}$ \\
\hline Wychwood & $\mathrm{F}$ & $S$ & 0 & 0 & 0 & 0 & 0 \\
\hline Wychwood & $\mathrm{H}$ & $\mathrm{S}$ & 0 & 0 & 0 & 0 & 0 \\
\hline Wychwood & I & $S$ & 1 & 0 & 0 & 0 & 0 \\
\hline
\end{tabular}

${ }^{\mathrm{g}} \mathrm{F}=$ Forested, $\mathrm{E}=$ Exurban, $\mathrm{S}=$ Suburban, $\mathrm{U}=$ Urban, $\mathrm{EN}=$ Exurban Neighbor, $\mathrm{SN}=$ Suburban Neighbor, $\mathrm{UN}=$ Urban Neighbor.

${ }^{\mathrm{h}} \mathrm{AGCU}=$ Agonum cupripenne, $\mathrm{AGGR}=$ Agonum gratiosum, $\mathrm{AGME}=$ Agonum melanarium, $\mathrm{AGMU}=$ Agonum muelleri, $\mathrm{AGPA}=$ Agonum palustre, $\mathrm{AGRE}=$ Agonum retractum, $\mathrm{AGTE}=$ Agonum tenue, $\mathrm{AGTR}=$ Agonum trigeminum, $\mathrm{AMAE}=$ Amara aenea, $\mathrm{AMAN}=$ Amara angustata, $\mathrm{AMAP}=$ Amara apricaria, $\mathrm{AMCU}=$ Amara cupreolata, $\mathrm{AMIM}=$ Amara impuncticollis, $\mathrm{AMIN}=$ Amphasia interstitialis, $\mathrm{AMPA}=$ Amara patruelis, $\mathrm{AMRU}=$ Amara rubric, $\mathrm{ANHA}=$ Anisodactylus harrisii, $\mathrm{ANKI}=$ Anisodactylus kirbyi, $\mathrm{ANME}=$ Anisodactylus merula, $\mathrm{ANRU}=$ Anisodactylus rusticus, ANVE $=$ Anisodactylus verticalis, $\mathrm{BANO}=$ Badister notatus, $\mathrm{BAOC}=$ Badister ocularis, $\mathrm{BEFR}=$ Bembidion frontale, $\mathrm{BEIN}=$ Bembidion inaequale, $\mathrm{BEMU}=$ Bembidion 
muscicola, $\mathrm{BEOB}=$ Bembidion obtusum, $\mathrm{BEPR}=$ Bembidion praticola, $\mathrm{BEQU}=$ Bembidion quadrimaculatum oppositum, $\mathrm{BETE}=$ Bembidion tetracolum, $\mathrm{BEVA}=$ Bembidion variegatum, $\mathrm{BEVE}=$ Bembidion versicolor, $\mathrm{BRLU}=$ Bradycellus lugubris, BRME $=$ Brachinus medius, $\mathrm{CAGR}=$ Carabus granulatus, $\mathrm{CALGR}=$ Calathus gregarius, $\mathrm{CAMA}=$ Carabus maeander, $\mathrm{CANE}=$ Carabus nemoralis, $\mathrm{CHEM}=$ Chlaenius emarginatus, $\mathrm{CHIM}=$ Chlaenius impunctifrons, $\mathrm{CHLI}=$ Chlaenius lithophilus, $\mathrm{CHNI}=$ Chlaenius niger, $\mathrm{CHSE}=$ Chlaenius sericeus, $\mathrm{CHTR}=$ Chlaenius tricolor, $\mathrm{CISE}=$ Cicindela sexguttata, $\mathrm{CLFO}=$ Clivina fossor, $\mathrm{CYCR}=$ Cymindis cribricollis, $\mathrm{CYNE}=$ Cymindis neglectus, $\mathrm{DIOB}=$ Diplocheila obtusa, $\mathrm{DYGL}=$ Dyschirius globulosus, ELCL = Elaphrus clairvillei, ELGR = Elaphropus granarius, $\mathrm{HAAF}=$ Harpalus affinis, $\mathrm{HACO}=$ Harpalus compare, $\mathrm{HAER}=$ Harpalus eraticus, HAERY $=$ Harpalus erythropus, $\mathrm{HAFA}=$ Harpalus faunus, $\mathrm{HAFU}=$ Harpalus fulvilabris, $\mathrm{HAHE}=$ Harpalus herbivagus, $\mathrm{HALO}=$ Harpalus longicollis, $\mathrm{HAOP}=$ Harpalus opacipennis, $\mathrm{HAPE}=$ Harpalus pensylvanicus, $\mathrm{HAPR}=$ Harpalus providens, HASO $=$ Harpalus somnulentus, $\mathrm{LOCO}=$ Loxandrus commutabilis, LOPI $=$ Loricera pilicornis, $\mathrm{LOSC}=$ Lophoglossus scrutator, $\mathrm{MYCY}=$ Myas cyanescens, $\mathrm{NOAE}=$ Notiophilus aeneus,, $\mathrm{OLMI}=$ Olisthopus micans, $\mathrm{OLPA}=$ Olisthopus parmatus, $\mathrm{OXPU}=$ Oxypselaphus pusillus, $\mathrm{PALO}=$ Patrobus longicornis, $\mathrm{PLDE}=$ Platynus decentis, $\mathrm{PLMA}$ $=$ Platynus mannerheimi, POLU $=$ Poecilus lucublandus lucublandus, $\mathrm{PSAR}=$ Pseudamara arenaria, $\mathrm{PTCA}=$ Pterostichus caudicalis, $\mathrm{PTCO}=$ Pterostichus coracinus, $\mathrm{PTCOR}=$ Pterostichus corvinus, $\mathrm{PTLA}=$ Pterostichus lachrymosus, $\mathrm{PTLU}=$ Pterostichus luctuosus, $\mathrm{PTME}=$ Pterostichus melanarius, $\mathrm{PTMU}=$ Pterostichus mutus, 
PTPA $=$ Pterostichus patruelis, $\mathrm{PTPE}=$ Pterostichus pensylvanicus, $\mathrm{PTTR}=$ Pterostichus tristis, $\mathrm{SPCA}=$ Sphaeroderus canadensis canadensis, $\mathrm{SPST}=$ Sphaeroderus stenostomus lecontei, $\mathrm{STCO}=$ Stenolophus conjunctus, $\mathrm{SYAM}=$ Syntomus americanus, $\mathrm{SYIM}=$ Synuchus impunctatus, $\mathrm{TRAP}=$ Trechus apicalis, $\mathrm{TRCR}=$ Trechus crassiscapus, TRVU = Trichotichnus vulpeculus. 
Appendix 8. Scatterplots of breeding bird and carabid beetle variables describing community structure.

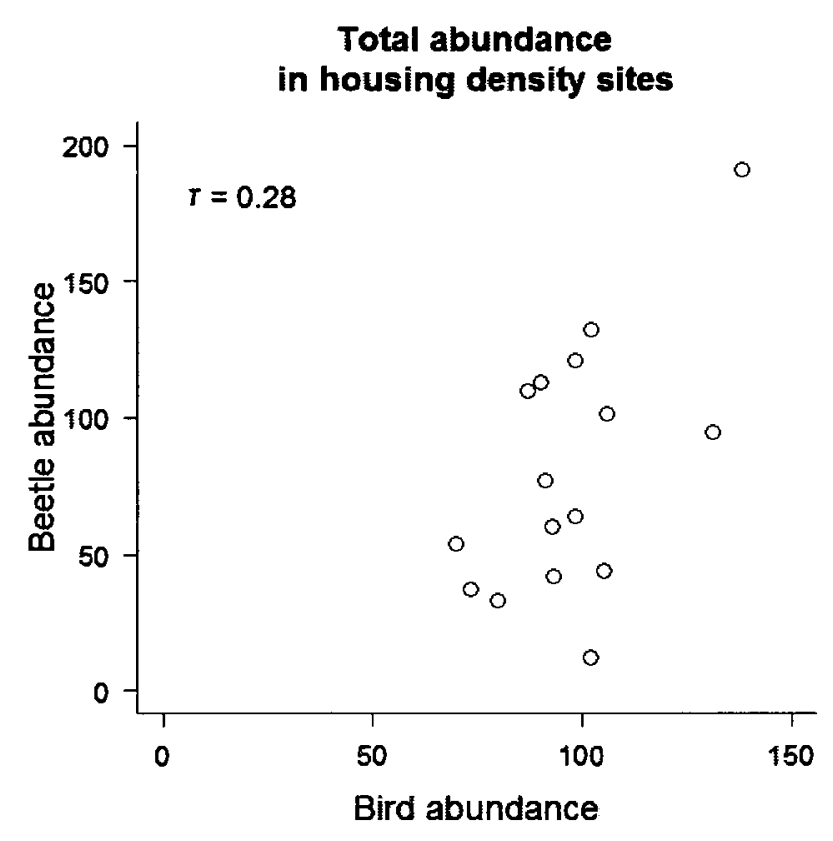


Introduced abundance

in housing density sites
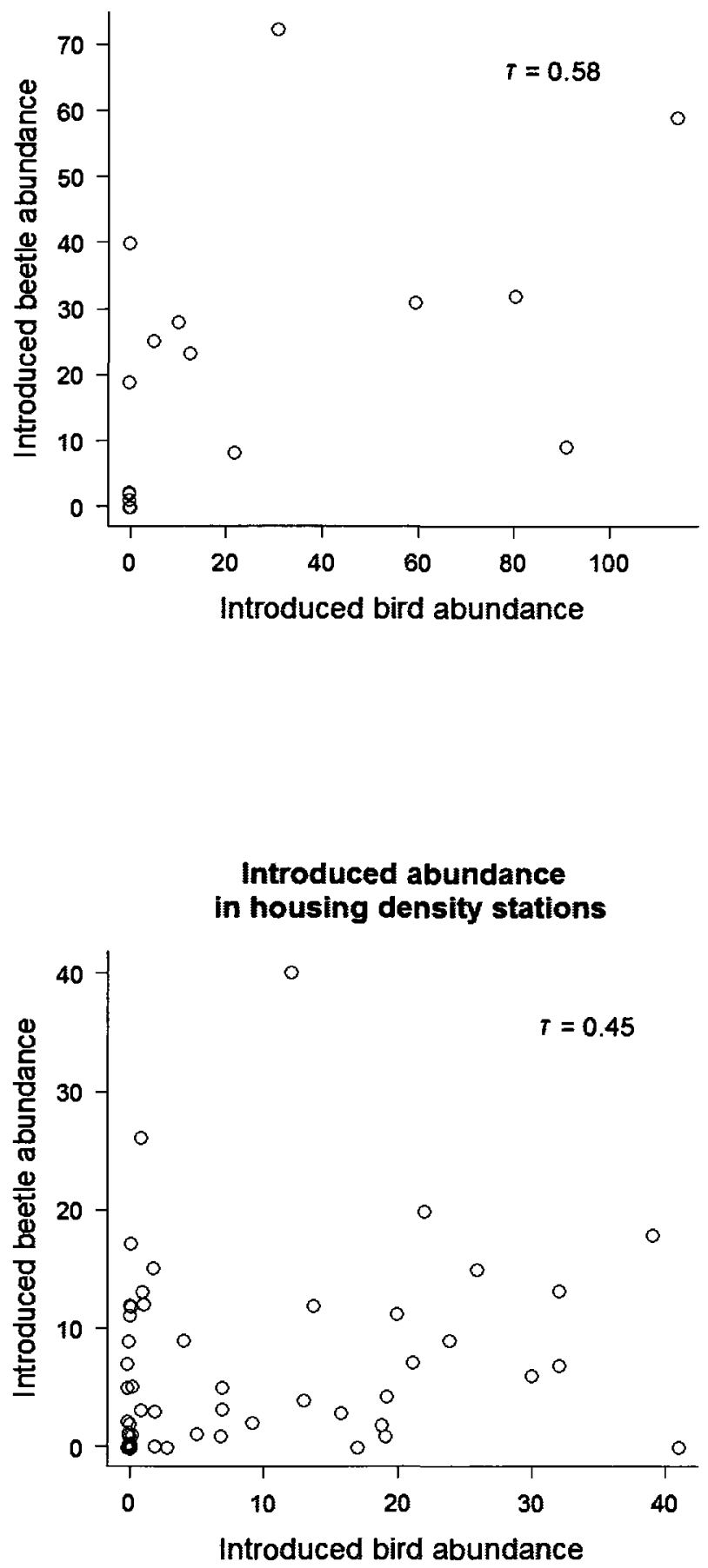
Forest species abundance

in housing density sites

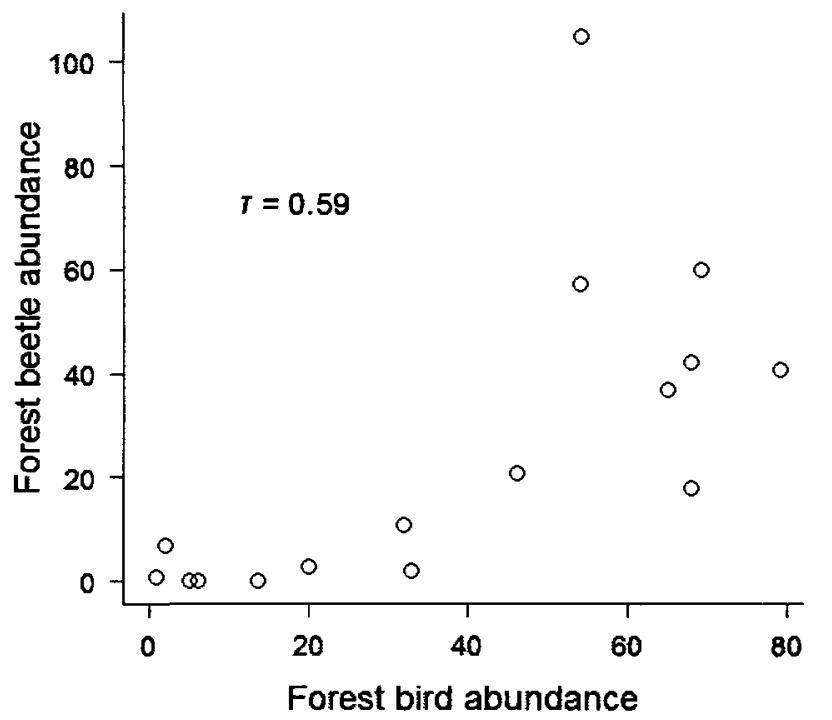

Forest species abundance

in housing density stations

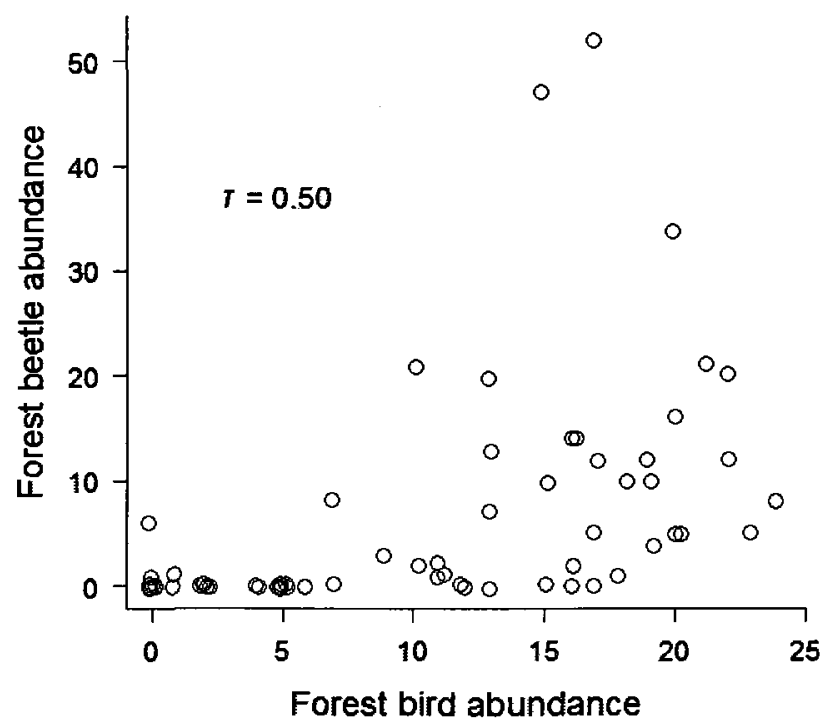




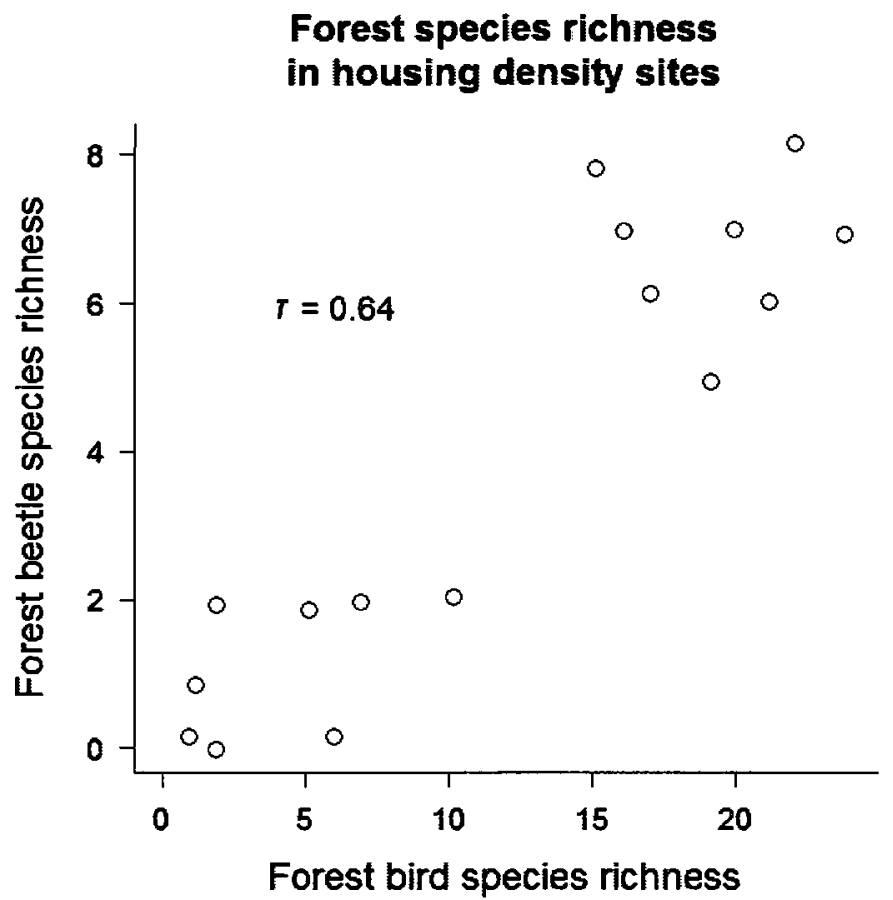

Forest species richness in housing density stations

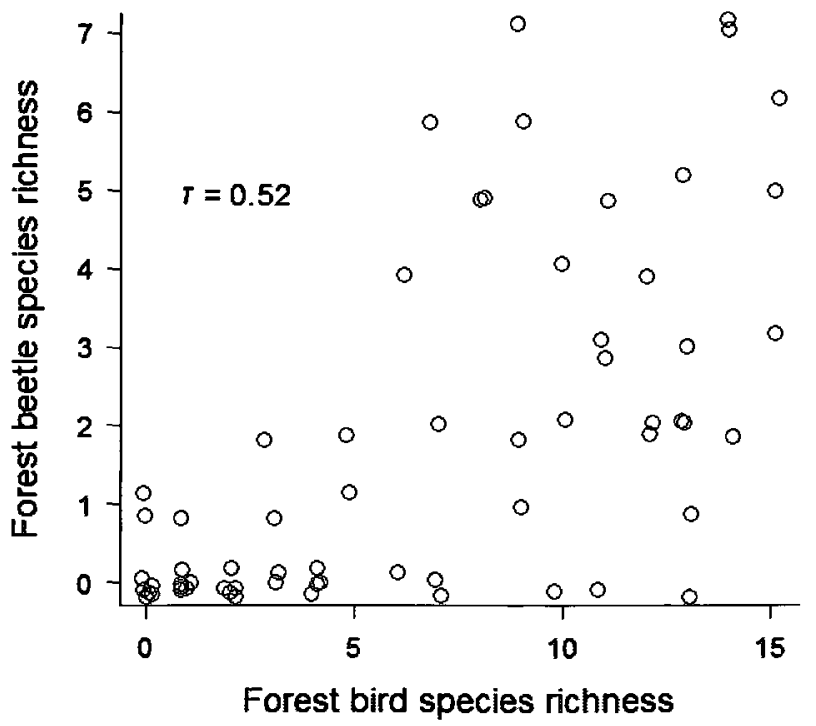


Standardized forest richness

in housing density sites

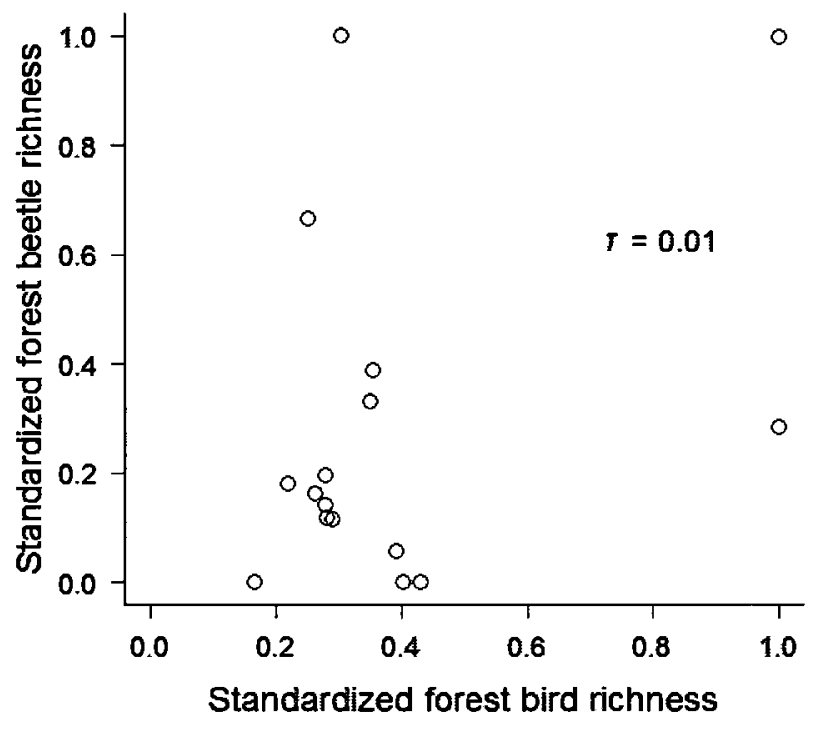

Standardized forest richness

in housing density stations

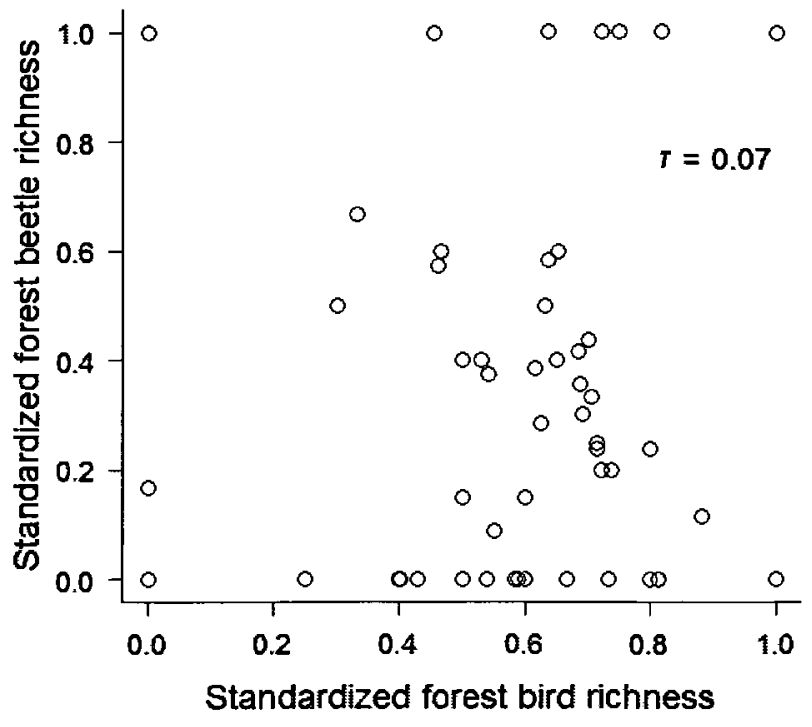


Open-habitat abundance

in housing density sites

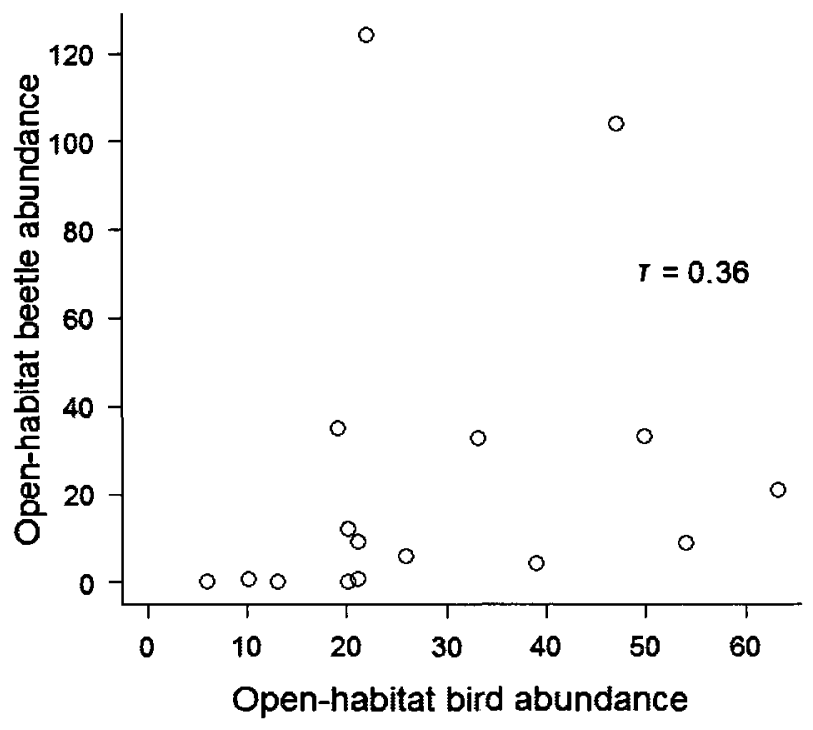

Open-habitat abundance

in housing density stations

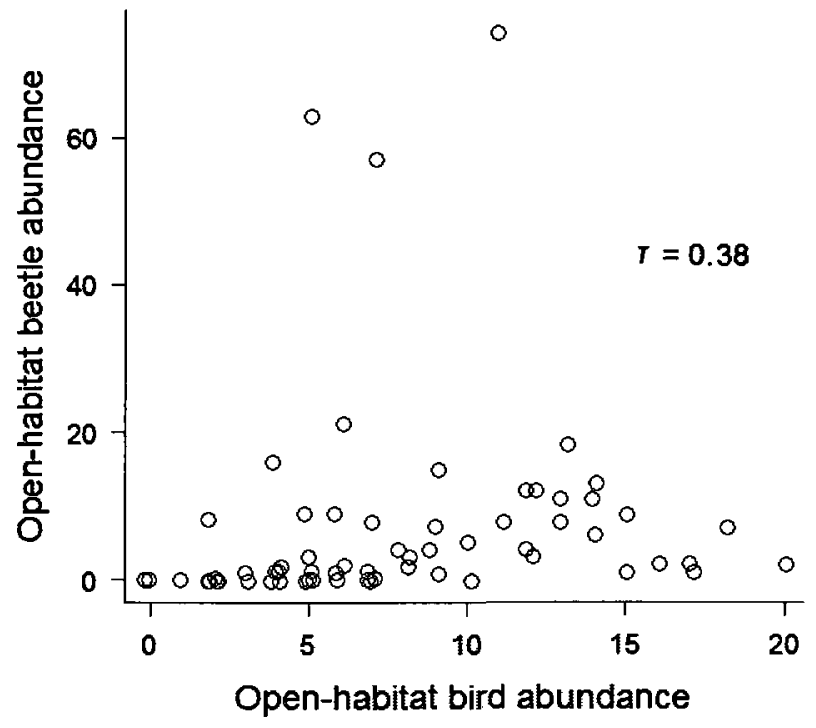


Open-habitat species richness

in housing density sites

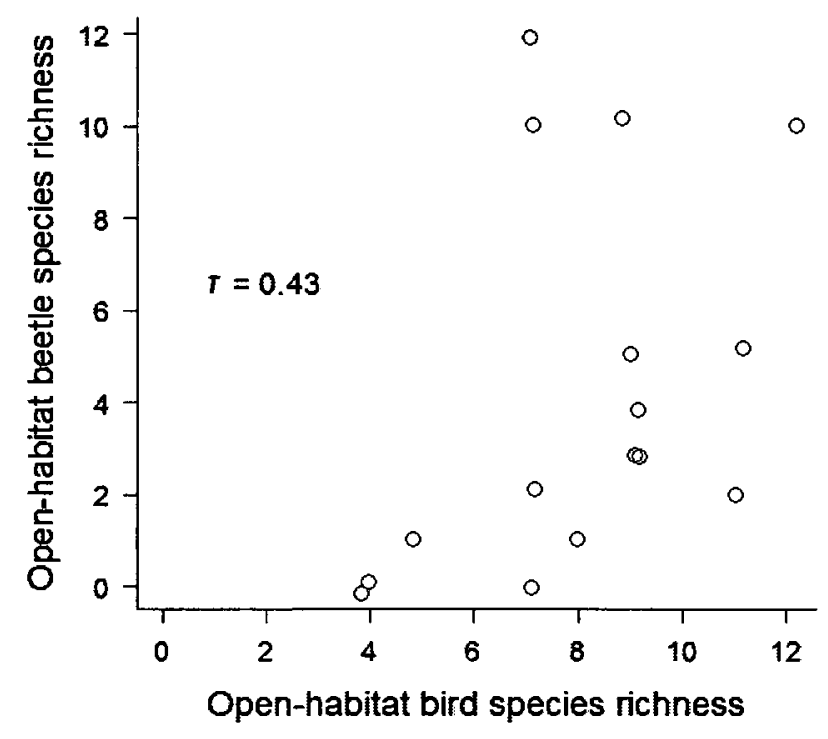

Open-habitat specles richness

in housing density stations

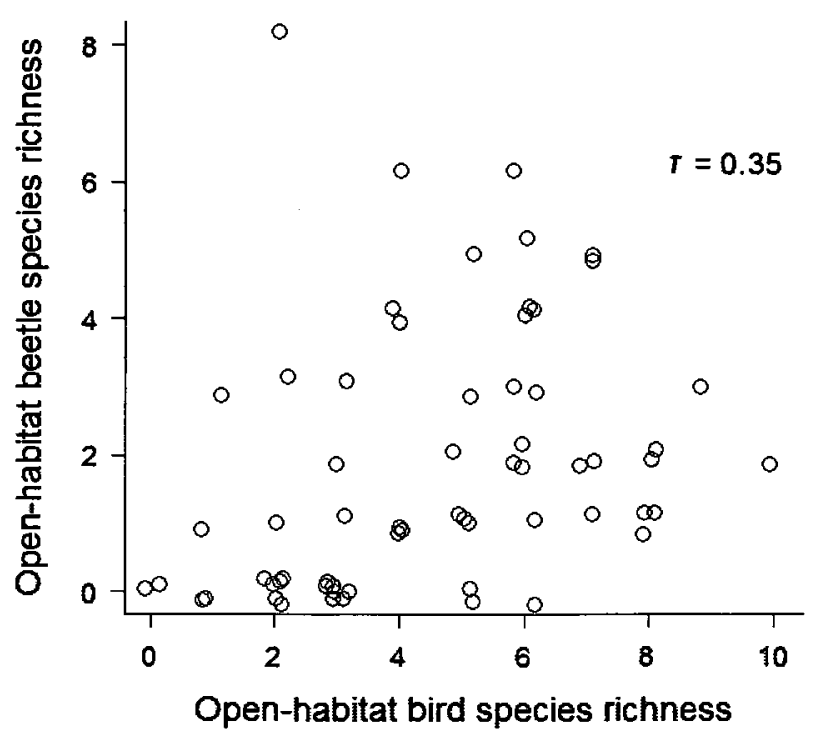


Standardized open-habitat richness

in housing density sites

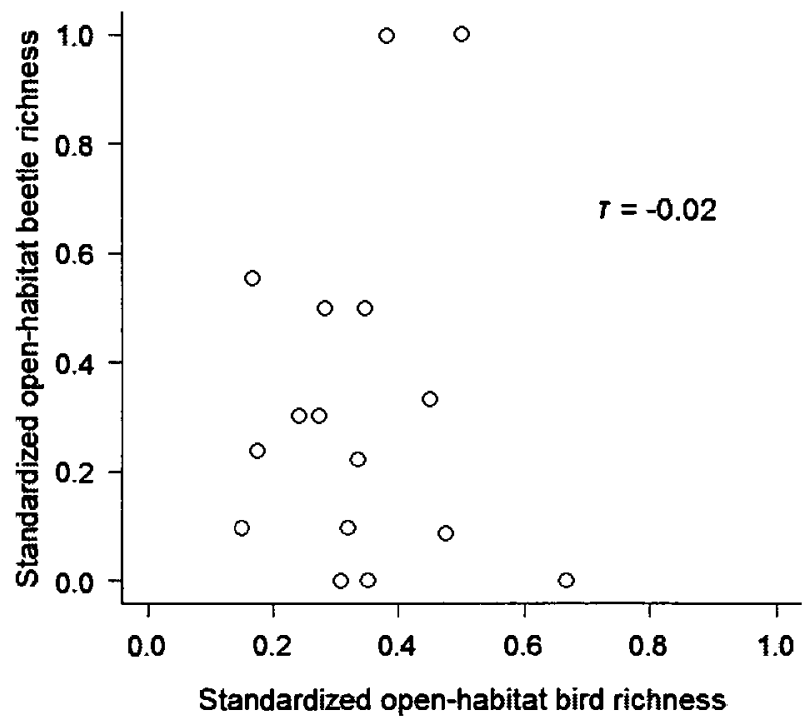

Standardized open-habitat richness

in housing density stations

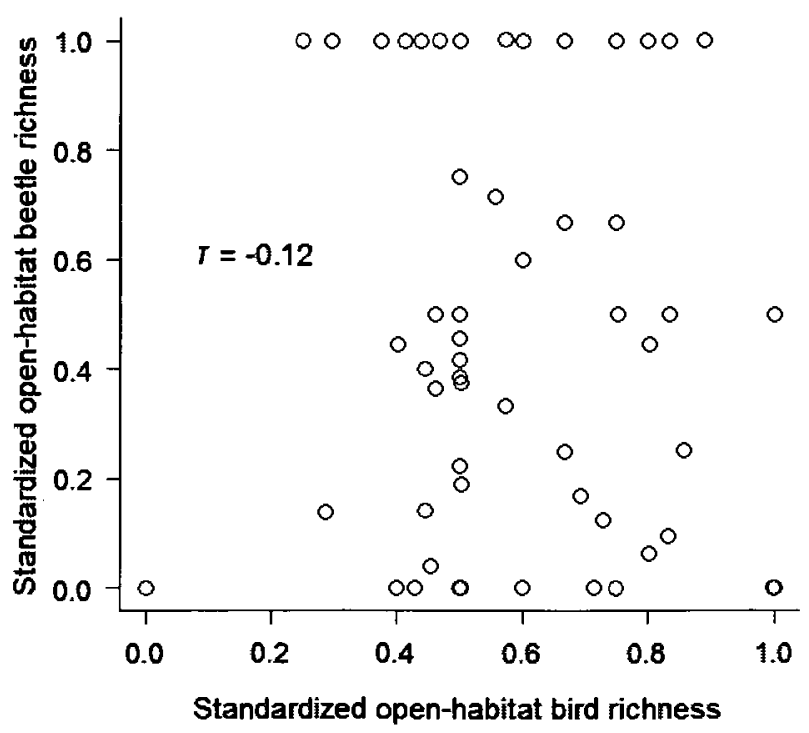



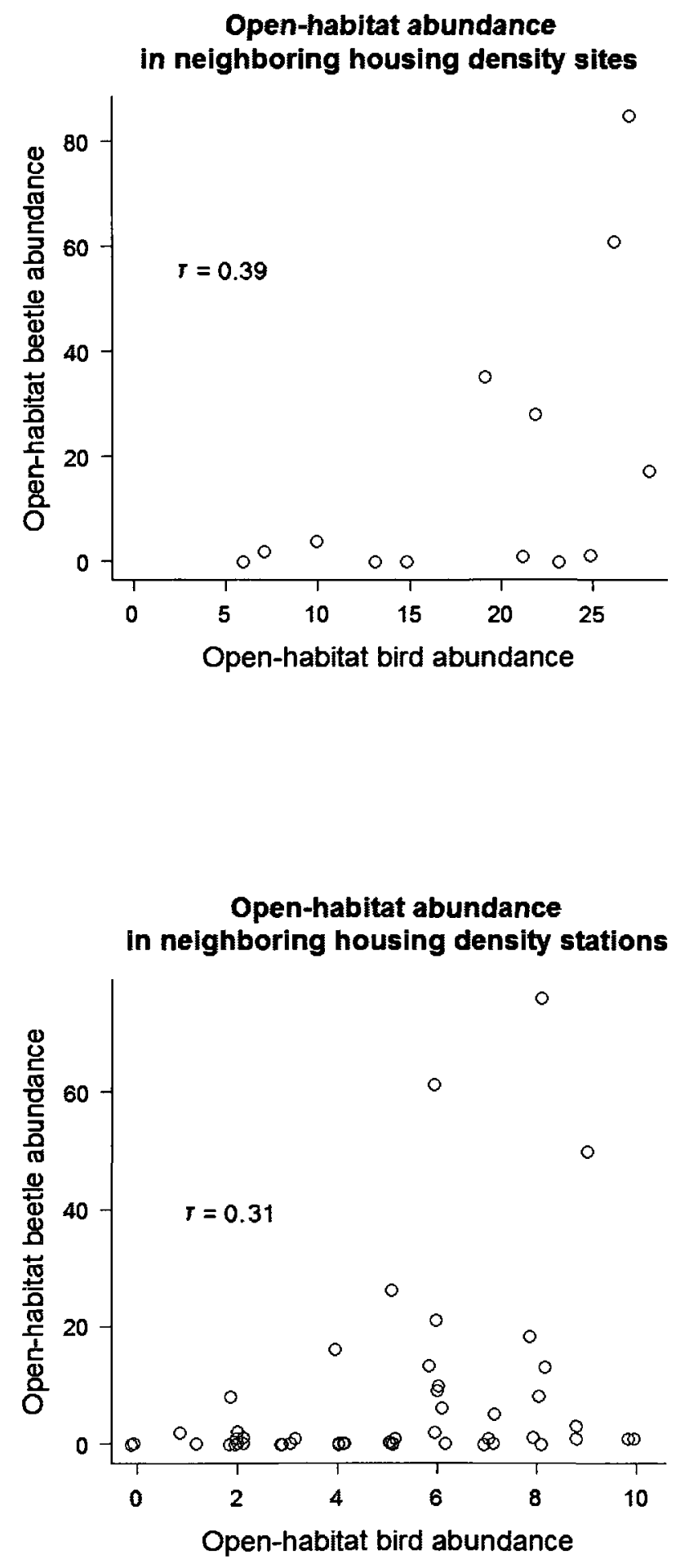

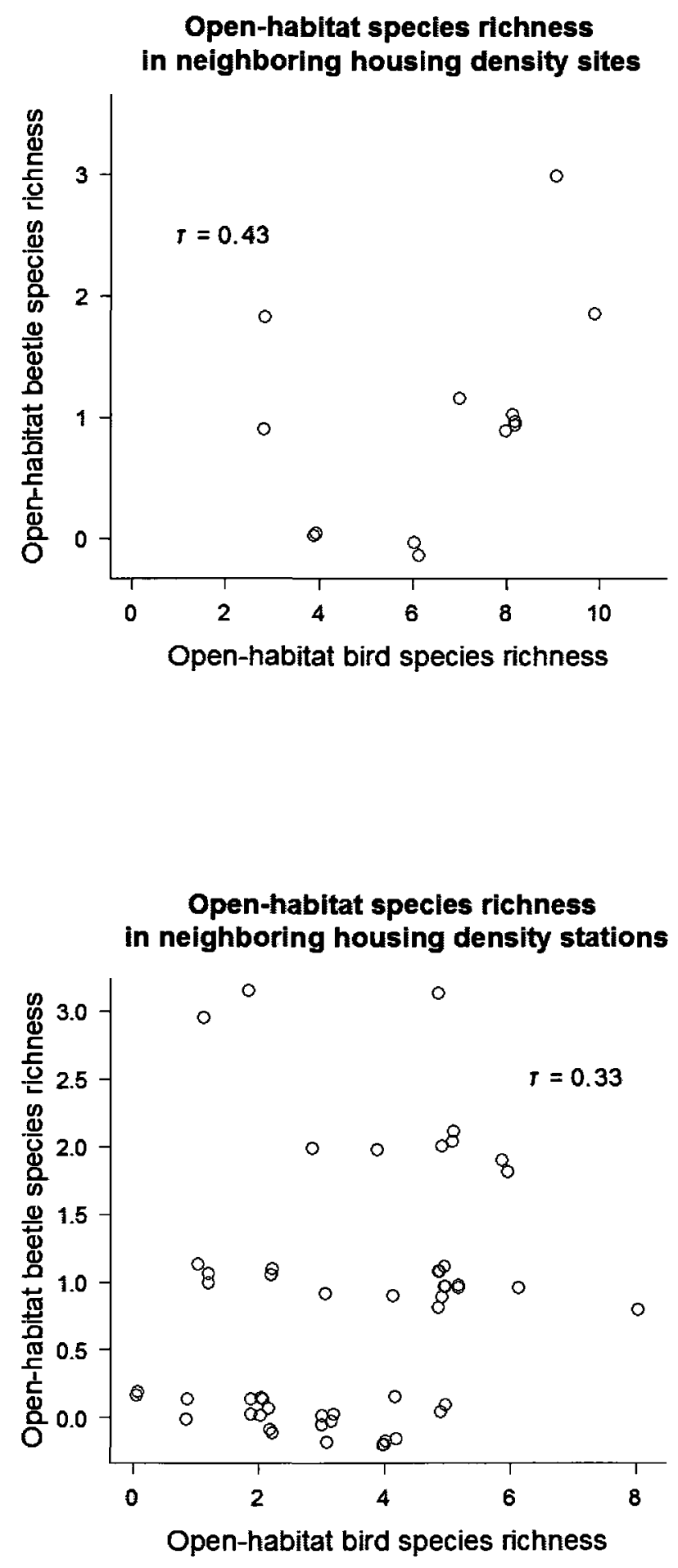
Standardized open-habitat richness

in neighboring housing density sites

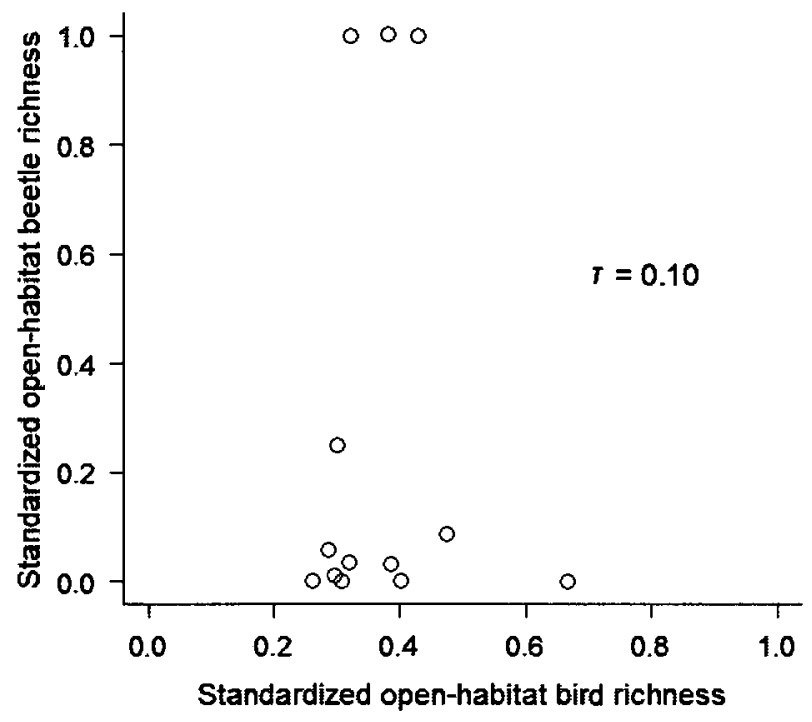

Standardized open-habitat richness in neighboring housing density stations

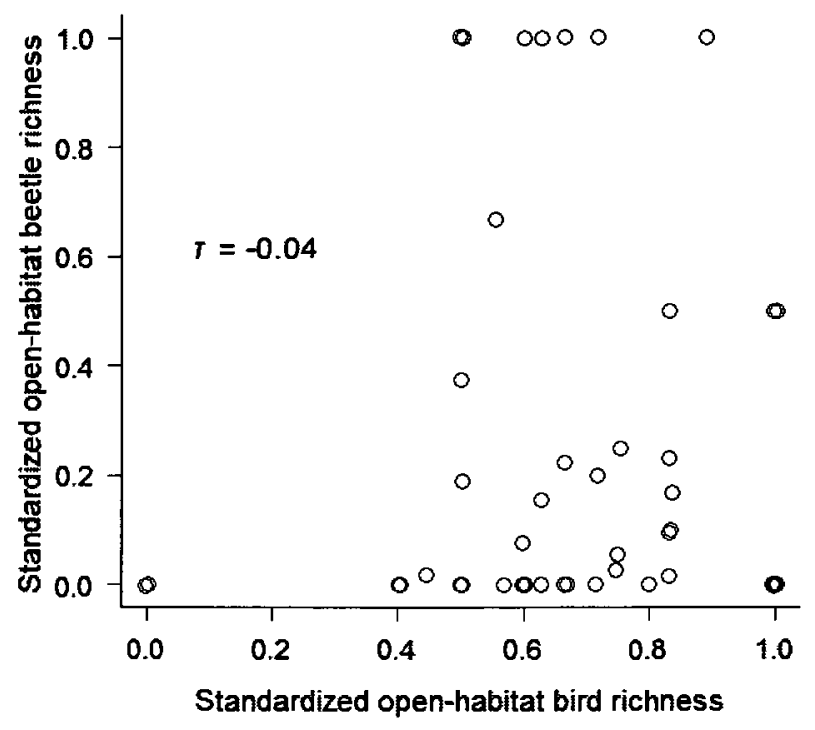


Appendix 9. The locations of Suburban Neighbor ( $\boldsymbol{\square})$ and Urban Neighbor $(\checkmark)$ sites in the study area. Exurban Neighbor sites are represented by the symbol $\Delta$ and Forested sites are represented by the symbol $\bullet$. Dark gray lines indicate roads. Forest cover is in light gray.

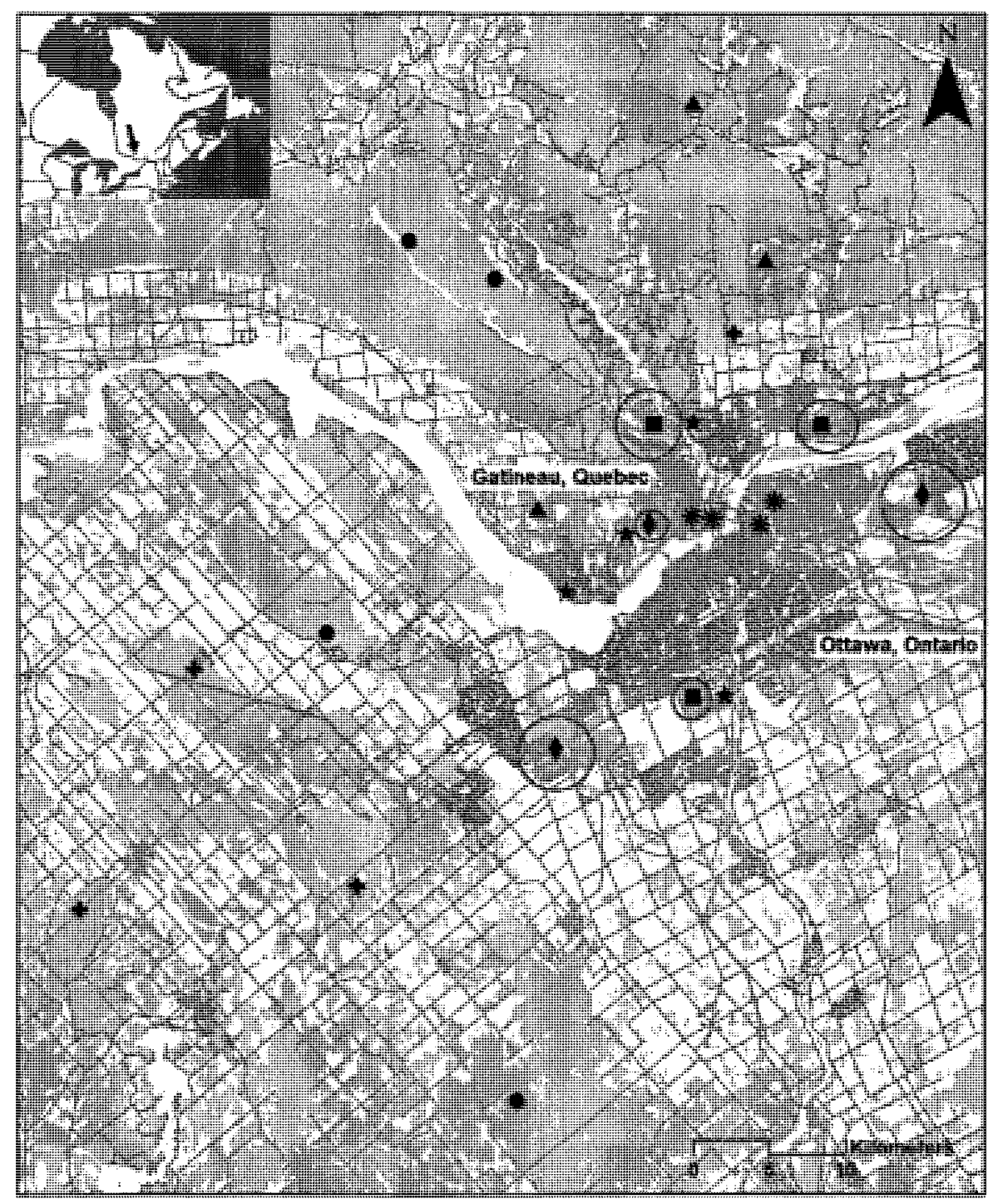

